TESE DE DOUTORADO EM ENGENHARIA DE SISTEMAS ELETRÔNICOS E DE AUTOMAÇÃO

\title{
PROPOSTA DE MODELO NÃO-PARAMÉTRICO PARA QUANTIFICAÇÃO DE REGIMES DE FLUIDIZAÇÃO
}

David de Almeida Fiorillo

\section{UNIVERSIDADE DE BRASÍLIA}


Página iii 
UNIVERSIDADE DE BRASÍLIA

Faculdade de Tecnologia

Departamento de Engenharia Elétrica

\section{PROPOSTA DE MODELO NÃO-PARAMÉTRICO PARA QUANTIFICAÇÃO DE REGIMES DE FLUIDIZAÇÃO}

David de Almeida Fiorillo

Tese submetida ao Departamento de Engenharia Elétrica da Universidade de Brasília como requisito para obtenção do grau de Doutor em Sistemas Eletrônicos e Automação.

ORIENTADOR: GEOVANY ARAÚJO BORGES

CO-ORIETADORA: ALINE SOUZA DE PAULA

TESE DE DOUTORADO EM ENGENHARIA DE SISTEMAS ELETRÔNICOS E DE AUTOMAÇÃO

PUBLICAÇÃO: PPGEAENE.TD - 115/2017

BRASÍLIA/DF: ABRIL - 2017 
UNIVERSIDADE DE BRASÍLIA

FACULDADE DE TECNOLOGIA

DEPARTAMENTO DE ENGENHARIA ELÉTRICA

\section{PROPOSTA DE MODELO NÃO-PARAMÉTRICO PARA QUANTIFICAÇÃO DE REGIMES DE FLUIDIZAÇÃO}

\section{DAVID DE ALMEIDA FIORILLO}

TESE DE DOUTORADO SUBMETIDA AO DEPARTAMENTO DE ENGENHARIA ELÉTRICA DA FACULDADE DE TECNOLOGIA DA UNIVERSIDADE DE BRASÍLIA, COMO PARTE DOS REQUISITOS NECESSÁRIOS PARA A OBTENÇÃO DO GRAU DE DOUTOR.

APROVADA POR:

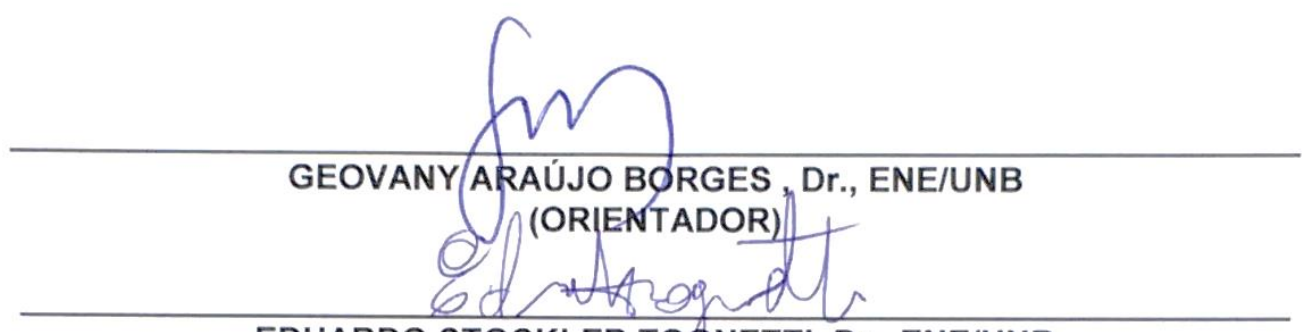

EDUARDO STOCKLER TOGNETTI, Dr., ENE/UNB

(EXAMINADOR INTERNO)

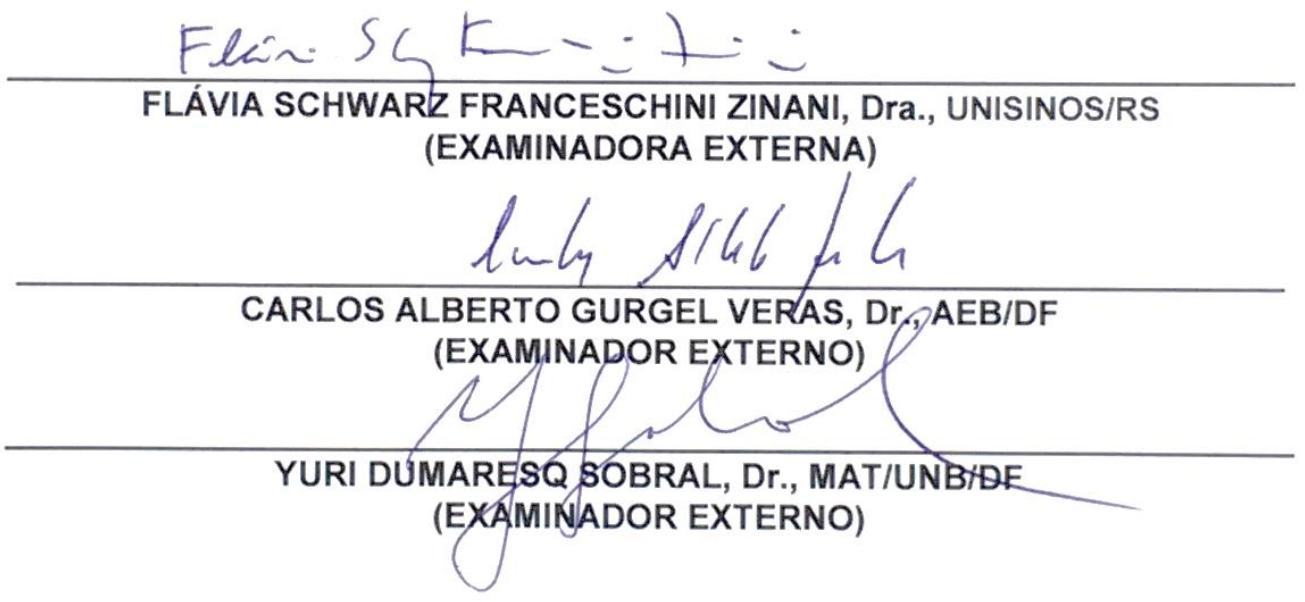




\section{FICHA CATALOGRÁFICA}

\begin{tabular}{|c|c|}
\hline \multicolumn{2}{|c|}{ FIORILLO, DAVID DE ALMEIDA } \\
\hline \multicolumn{2}{|c|}{$\begin{array}{l}\text { Proposta de modelo não-paramétrico para quantificação de regimes de fluidização [Distrito Federal] } \\
2017 .\end{array}$} \\
\hline \multicolumn{2}{|c|}{$\begin{array}{l}\text { xxi, 184p., } 210 \text { x } 297 \text { mm (ENE/FT/UnB, Doutor, Tese de Doutorado - Universidade de Brasília. } \\
\text { Faculdade de Tecnologia. }\end{array}$} \\
\hline \multicolumn{2}{|c|}{ Departamento de Engenharia Elétrica } \\
\hline 1. Interação fluido-partícula & 2. Fluidização \\
\hline 3. Fluido-dinâmica & 4. Quantificação de regimes de fluidização \\
\hline I. ENE/FT/UnB & II. Título (série) \\
\hline
\end{tabular}

\section{REFERÊNCIA BIBLIOGRÁFICA}

FIORILLO., D. A. (2017). Proposta de modelo não-paramétrico para quantificação de regimes de fluidização. Tese de Doutorado em Engenharia de Sistemas Eletrônicos e de Automação, Publicação PPGEAENE.TD-115/2017, Departamento de Engenharia Elétrica, Universidade de Brasília, Brasília, DF, $184 p$.

\section{CESSÃO DE DIREITOS}

AUTOR: David de Almeida Fiorillo.

TÍTULO: Proposta de modelo não-paramétrico para quantificação de regimes de fluidização.

GRAU: Doutor

ANO: 2017

É concedida à Universidade de Brasília permissão para reproduzir cópias desta tese de doutorado e para emprestar ou vender tais cópias somente para propósitos acadêmicos e científicos. O autor reserva outros direitos de publicação e nenhuma parte dessa tese de doutorado pode ser reproduzida sem autorização por escrito do autor.

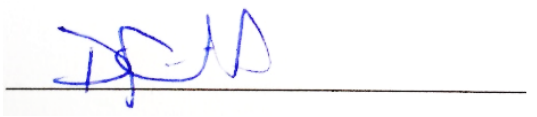

David de Almeida Fiorillo

CLN 408, Bloco E, Ap 109, Asa Norte

70.856-550 Brasília - DF - Brasil. 
Dedico a minha família à qual tenho a sorte de fazer parte; sem ela, esse trabalho não seria possível. 


\section{AGRADECIMENTOS}

A Deus e a todas as experiências vividas, responsáveis por me conduziram ao término deste trabalho.

A Elizabeth e Tadeu Fiorillo, pais que me apoiaram com todo o amor que há nessa vida. A Clarice Fiorillo, irmã querida que tanto me ensina.

A Mariana Zardo pela eterna amizade e apoio em iniciar o doutorado. Aos compadres e amigos queridos Flaini e Anatália pela força e fé depositados para conclusão deste trabalho.

A Carlos Alberto Gurgel Veras pelo incentivo em fazer o doutorado na Unb.

A Sérgio Leite por ter proporcionado a participação no projeto FINEP que construiu e operou o primeiro gaseificador de leito fluidizado circulante do Brasil em escala semi-industrial, localizado no município de Linhas - ES, e primeiras discussões que motivaram a elaboração desta tese.

A Patrick Rousset pela amizade, discussões que favoreceram a compreensão do processo de gaseificação e por ter aumentado a rede de conhecimento no assunto.

A Flavia Zinani pelas valiosas discussões sobre programação do MFIX e representatividade dos modelos numéricos de escoamento.

A William Lane (thank you) por ter tirado inúmeras dúvidas quanto a modelagem e implementações MFIX.

A Paulo Strobel por contribuir nas discussões sobre operação de simulação numérica.

A Aline de Paula pelo fantástico direcionamento na escrita e nos estudos de sistemas não-lineares.

Aos amigos queridos do laboratório de robótica e automação (LARA/UNB), Claudia Ochoa, Miguel Gutierrez, Leo Broche, Mileny Ximenes, Roberto Baptista, Marienne Naváez, Luis Figueiredo (obrigadão pela revisão do artigo!), Mariana Bernardes, Hugo Tadashi, Henrique Menegaz, e outros, que conviveram comigo e puderam me ouvir e transmitir seus conhecimentos. A todos, meu muito obrigado.

A Rubiana Martins por permitir que a simulação fosse feita em sua casa, num período em que a UNB sofria com a indisponibilidade de energia elétrica. Muito obrigado, salvou!

A Thiara Massariol, guerreira que encarou de frente fortes adversidades da vida, mantendo seu foco nos estudos e na família. Agradeço por toda sua ajuda, pois sem ela, esta tese não alcaçaria resultados experimentais.

A Lucas Silveira do LFFT/UCL, quem acreditou e apoiou o projeto e construção da primeira unidade laboratorial de leito fluidizado do estado do Espírito Santo para pesquisa e desenvolvimentos em eficiência energética.

Ao professor Yuri Dumaresq pelas valiosas discussões e rigor do tratamento matemático da simulação numérica. Ao professor Renato Borges por emprestar um cluster de desempenho compatível com a simulação aqui realizada. Ao departamento de engenharia elétrica da UNB pelo acesso aos principais acervos do mundo na área pesquisada. A Adriana Reis, por resolver todos os trâmites burocráticos.

A CAPES pelo suporte financeiro.

Ao orientador Geovany Borges

Página vi 
"A mente é o pensador, o intelecto é o chefe e as lembranças são como livros numa biblioteca no meu mundo interior. Quando o chefe não dá ao pensador algo positivo para pensar a respeito, a mente vai até a biblioteca e pega qualquer livro de memórias para guiar seu pensamento. Mas quando o intelecto desempenha um papel firme e adorável - como um bom chefe - a mente se mantém nos trilhos e apenas os melhores livros saem da biblioteca. Hoje, dê a sua mente pensamentos positivos e elevados para pensar."

Brahma Kumaris

Página viii 


\section{Página ix}




\section{RESUMO}

Este trabalho apresenta uma investigação da aplicação de invariantes do caos, em diferentes regiões de uma coluna de leito fluidizado experimental fria, capazes de quantificar os regimes de fluidização, enfatizando a identificação do regime rápido. $\mathrm{O}$ trabalho foi divido em duas etapas, o projeto de bancada e estudo de regiões característica de uma coluna de fluidização, a partir de simulação numérica, e análise não-linear a partir de séries temporais de pressão estática de coluna LFC (leito fluidizado circulante) experimental. A fase de projeto auxiliado por simulação numérica reuniu teorias e fundamentos da fluidodinâmica computacional, através do modelo TFM (Two Fluid Model), para compreensão do escoamento multifásicos numa coluna de leito fluidizado circulante (LFC) e estudo de mapeamento de suas regiões características em diversos regimes de fluidização. A fase experimental consistiu na montagem de bancada e ensaios preliminares para atenuação de ruído para observação de séries temporais do sinal de flutuação de pressão estática nas regiões características. Na etapa de ensaios, três tipos de partículas foram utilizados (vidro $355 \mu \mathrm{m}$, areia 1,0 $\mathrm{mm}$ e areia 1,2 $\mathrm{mm}$ ), quando submetidas a condições operacionais específicas (fluxos do ar de entrada), desenvolveram os regimes de fluidização investigados (expandido, borbulhante, turbulento e rápido). A definição dos regimes de fluidização de referência é baseado na descrição da literatura e corrigido através da transparência da coluna LFC experimental. A análise não-linear, que consistiu na avaliação da evolução de invariantes do caos como a dimensão de correlação, entropia de Kolmogorov e o coeficiente de Hurst, de séries temporais de pressões estáticas, coletadas a partir de três regiões distintas de uma coluna de fluidização, submetidas a diferentes regimes e tipo de partículas.

A metodologia proposta, permitiu investigar a evolução de indicadores baseados nas invariantes caóticas para quantificação dos estados de fluidização de referência. A principal contribuição desta análise, residiu numa nova abordagem de modelo não-paramétrico (tabela) baseada nas invariantes caóticas entre as regiões de uma coluna LFC. A proposta avalia a similaridade caótica, entre as regiões características de uma coluna LFC para quantificação dos regimes e consequente classificação. Esta técnica, associado a instrumentação rápida de medição de pressão estática, poderia ser usado para controlar regimes de fluidização de sistemas fluidizados como gaseificadores de leito fluidizado, melhorando seu desempenho na conversão de sólidos e gás combustível.

O estudo concluiu que as invariantes do caos foram sensíveis aos regimes de fluidização e pouco dependeram das características das partículas. Apesar desta técnica não ter sido testada em colunas escalonadas, de acordo com a teoria, é possível inferir que as invariantes permanecerão sensíveis aos regimes de fluidização, e pouco sensível a mudança geométrica de uma coluna escalonada.

Os principais impactos são redução da complexidade operacional para o controle de sistemas fluidizados contínuos, a quantificação do grau de turbulência global da coluna, redução da variabilidade dos produtos dos sistemas fluidizados, e incremento da repetibilidade do processo de leito fluidizado, uma vez que os regimes podem ser quantificados.

Título: Proposta de modelo não-paramétrico para quantificação de regimes de fluidização

Autor: David de Almeida Fiorillo

Orientador: Geovany Araújo Borges

Co-orientador: Aline Souza de Paula

Palavras-Chave: interação fluido-partícula, fluidização, fluido-dinâmica, quantificação de regimes de fluidização, sistema não-linear espaço-temporal. 


\begin{abstract}
This work presents an investigation of the application of chaotic invariants in different regions of an isothermal experimental fluidized bed column, capable of quantifying the fluidization regimes, emphasizing the identification of the fast regime. The work was divided in two stages, the bench design and study of regions characteristic of a fluidization column, from numerical simulation, and non-linear analysis from time series of static pressure of experimental CFB (circulating fluidized bed) column. The numerical simulation-assisted design phase brought together theories and fundamentals of computational fluid dynamics through the Two Fluid Model (TFM) model, to understand the multiphase flow in a circulating fluidized bed (CFB) and mapping study of its characteristic regions in several fluidization regimes. The experimental phase consisted of the assembly of bench and preliminary tests for noise attenuation for observation of time series of the signal of static pressure fluctuation in the characteristic regions. In the test stage, three types of particles were used ( $355 \mu \mathrm{m}$ glass, $1.0 \mathrm{~mm}$ sand and $1.2 \mathrm{~mm}$ sand), when subjected to specific operating conditions (incoming air flows), they developed the investigated fluidization regimes (expanded, bubbling, turbulent, and fast). The definition of the reference fluidization regimes is based on the literature description and corrected through the transparency of the experimental LFC column. The nonlinear analysis, which consisted in the evaluation of the evolution of chaos invariants such as the correlation dimension, Kolmogorov entropy and the Hurst exponent, of time series of static pressures, collected from three distinct regions of a fluidization column, subjected to different regimes and type of particles.
\end{abstract}

The proposed methodology allowed to investigate the evolution of indicators based on the chaotic invariants for quantification of reference fluidization states. The main contribution of this analysis resided in a new non-parametric (table) model based on the chaotic invariants between the regions of an LFC column. The proposal evaluates the chaotic similarity between the characteristic regions of an LFC column for quantification of the regimes and consequent classification. This technique, coupled with rapid static pressure measurement instrumentation, could be used to control fluidization regimes of fluidized systems as fluidized bed gasifiers, improving their performance in the conversion of solids and fuel gas.

The study concluded that chaotic invariants were sensitive to fluidization regimes and did not depend on particle characteristics. Although this technique has not been tested in staggered columns, according to the theory, it is possible to infer that the invariants will remain sensitive to the fluidization regimes, and little sensitivity to the geometric change of a stepped column.

The main impacts are reducing the operational complexity for the control of continuous fluidized systems, quantifying the overall column turbulence, reducing the variability of the products of the fluidized systems, and increasing the repeatability of the fluidized bed process, since the regimes can be quantified.

Title: Non-parametric model proposal for quantification of fluidization regimes

Author: David de Almeida Fiorillo

Advisor: Geovany Araújo Borges

Co-advisor: Aline Souza de Paula

Keywords: fluid-particle interaction, fluidization, fluid-dynamic, quantifying of flow regime, nonlinear space-time system. 


\section{SUMÁRIO}

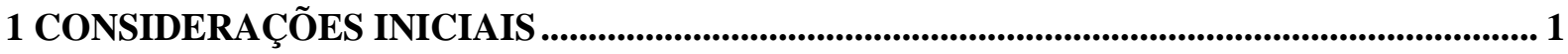

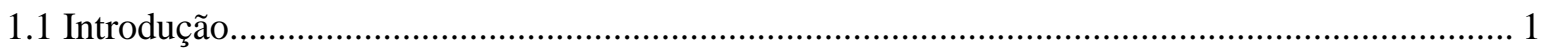

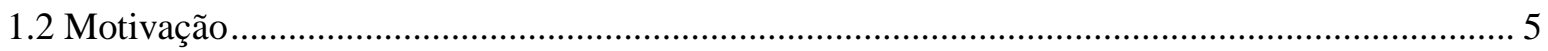

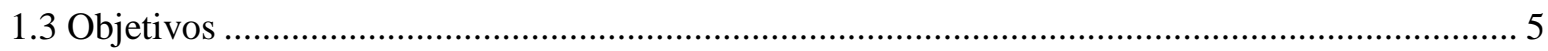

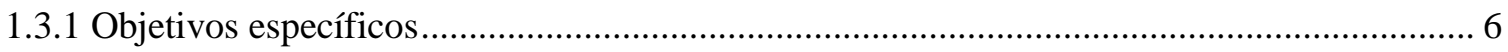

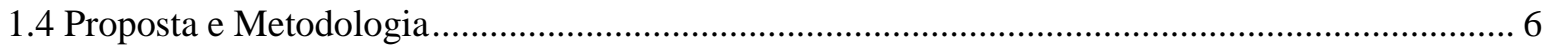

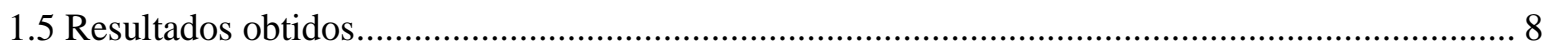

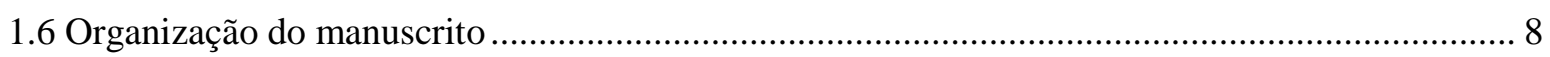

2 CONCEITOS, FUNDAMENTOS E ESTADO DA ARTE .................................................... 10

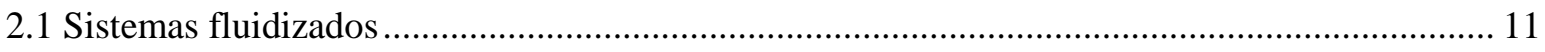

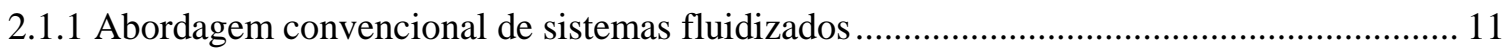

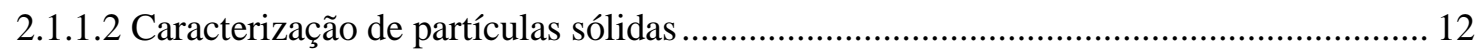

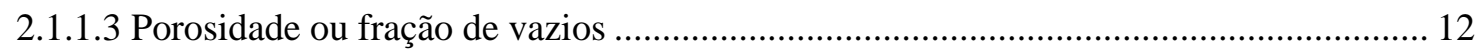

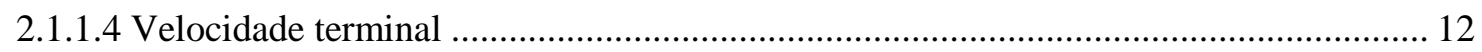

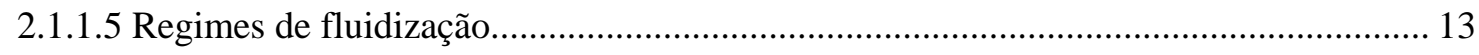

2.1.1.6 Classificação de partículas segundo resposta à fluidização........................................ 16

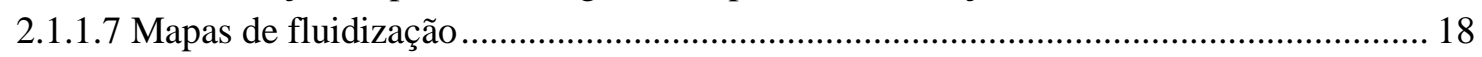

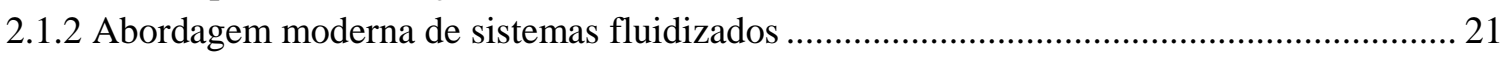

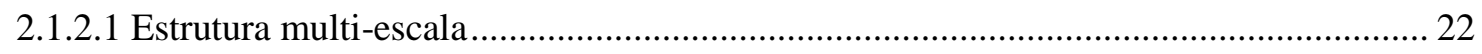

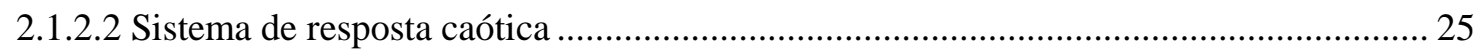

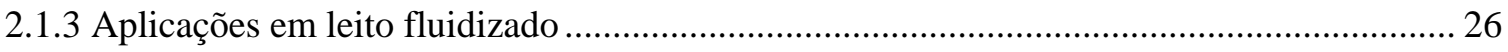

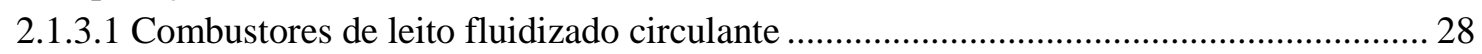

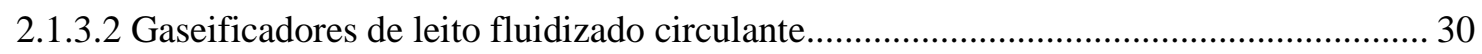

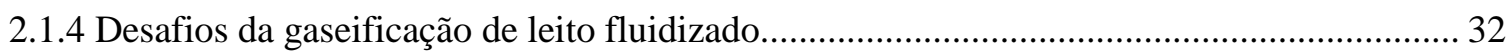

2.1.4.1 Problema de ajuste de regime rápido em coluna LFC opaca.......................................... 34

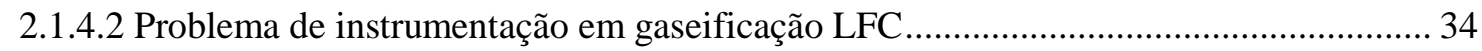

2.1.4.3 Problema de quantificação de regimes em LFC .......................................................... 38

2.2 Fluidodinâmica computacional em colunas de fluidização........................................................ 39

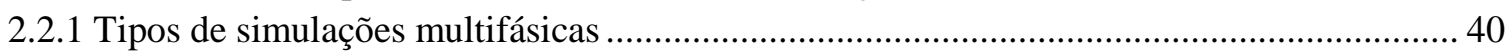

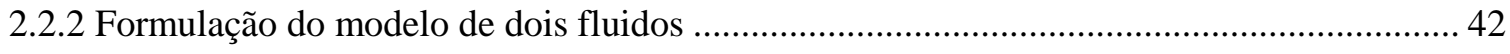

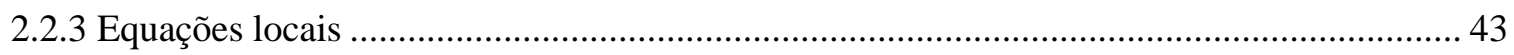

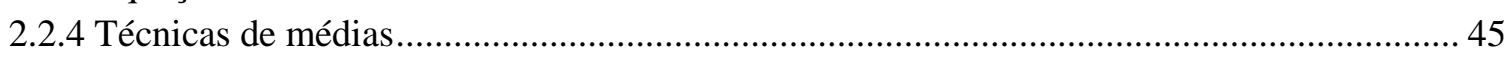

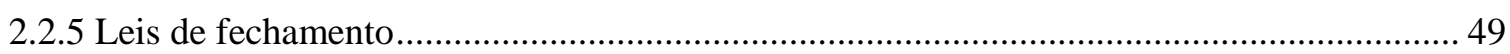

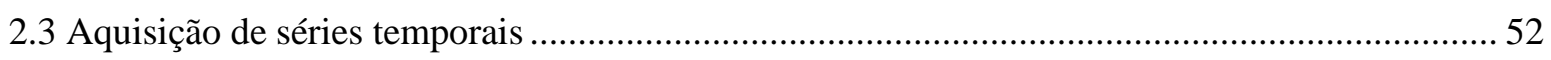

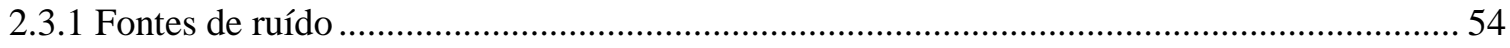

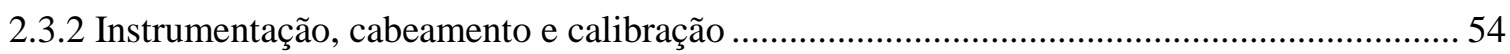

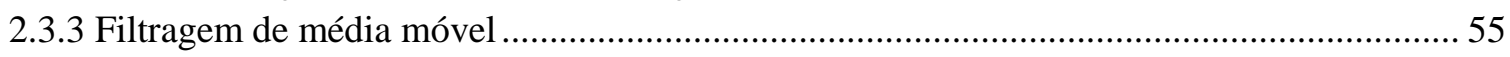

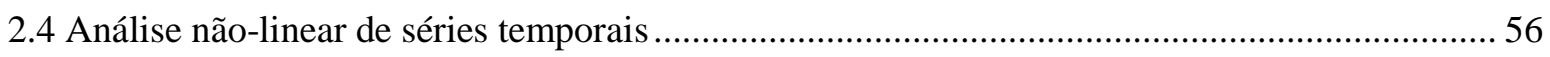

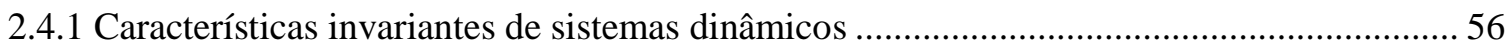

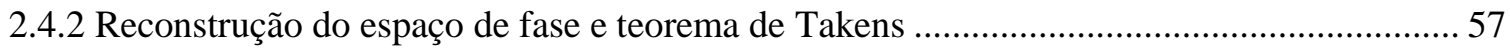

2.4.3.1 Método de reconstrução do espaço de fase ……........................................................... 57

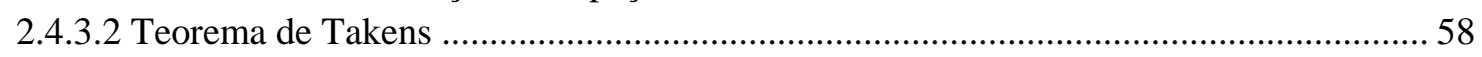

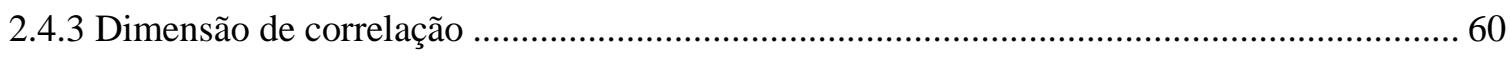

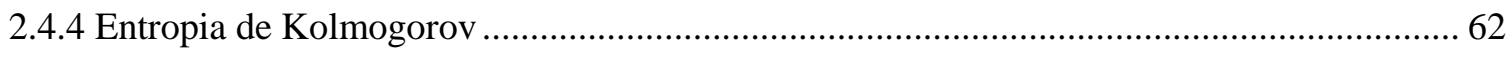

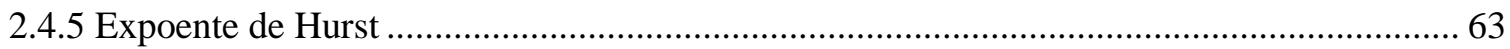




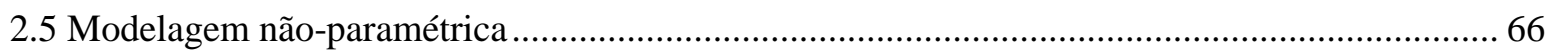

3 PROPOSTA E PROJETO DE BANCADA …...................................................................................... 67

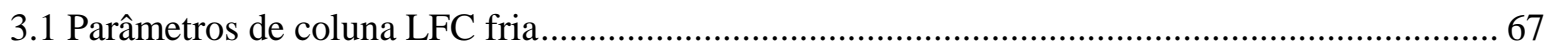

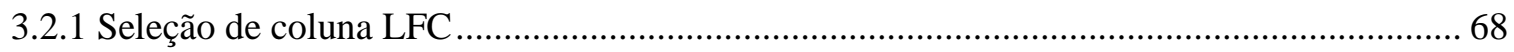

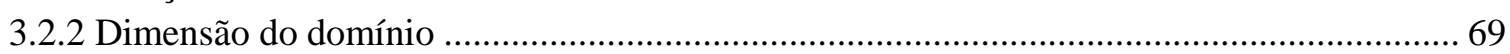

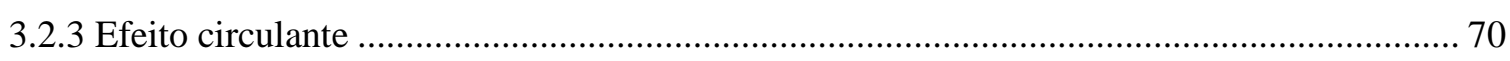

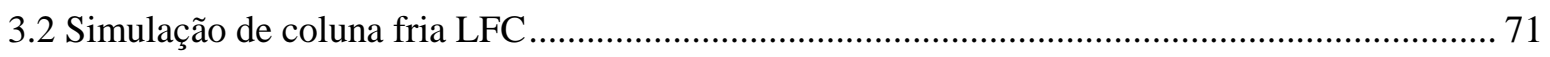

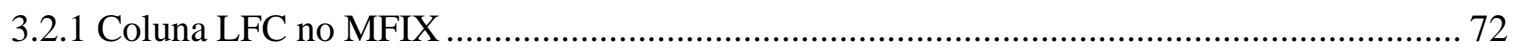

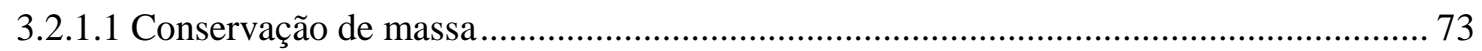

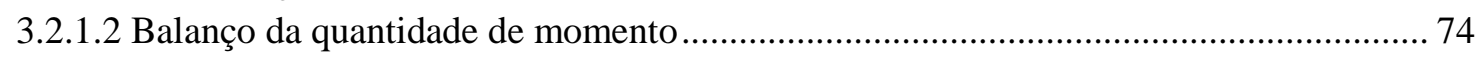

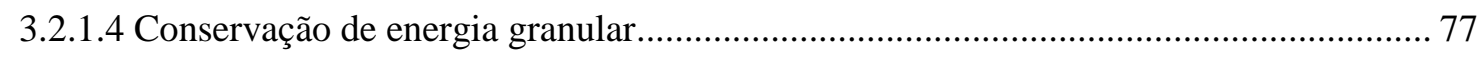

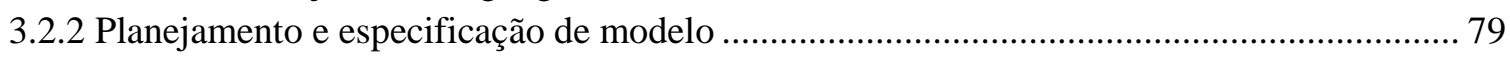

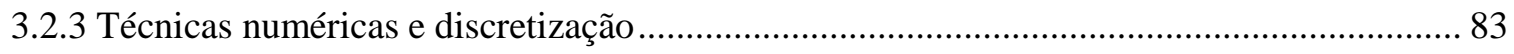

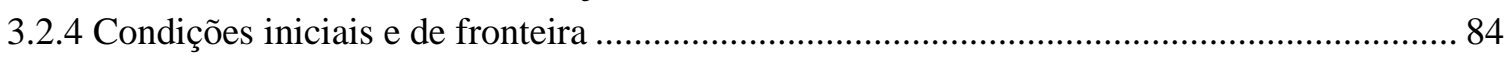

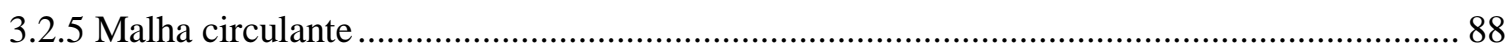

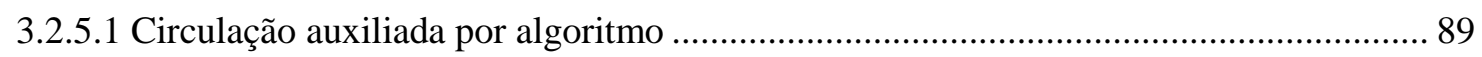

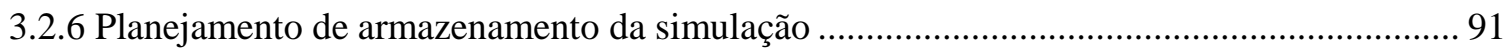

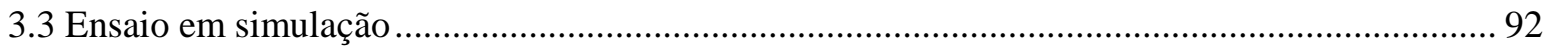

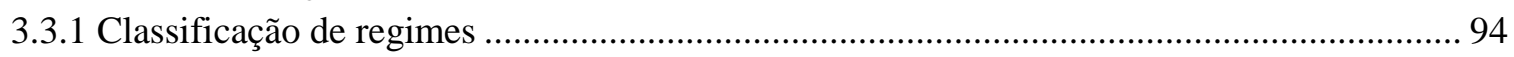

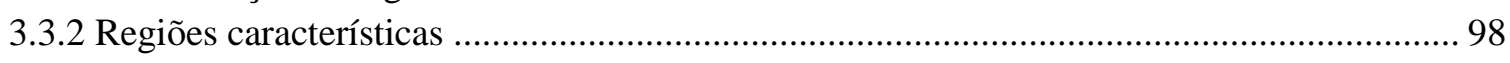

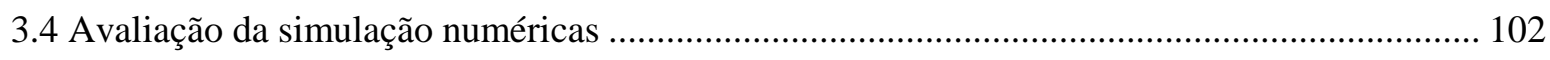

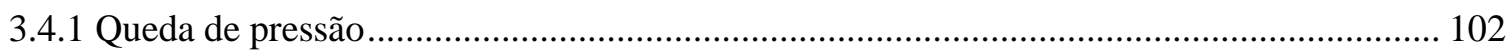

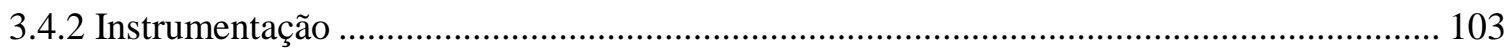

4 MÉTODO DE QUANTIFICAÇÃO DE REGIMES DE FLUIDIZAÇÃO ................................ 105

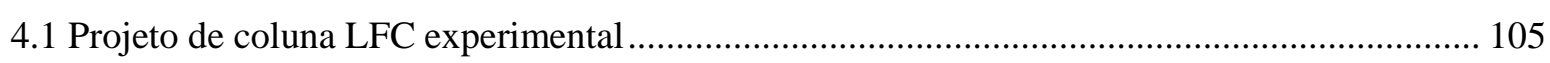

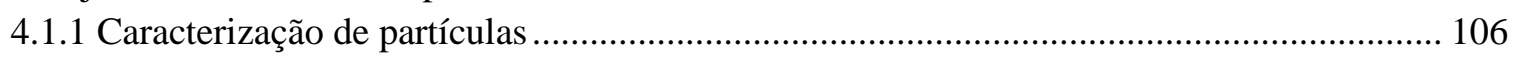

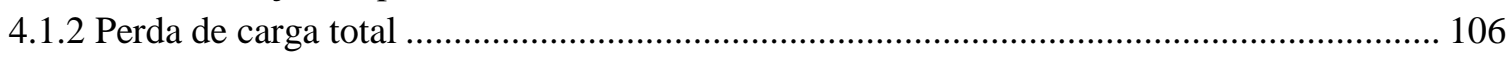

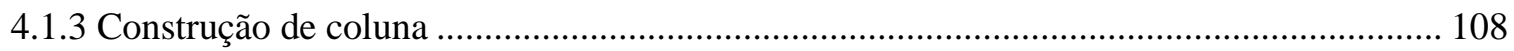

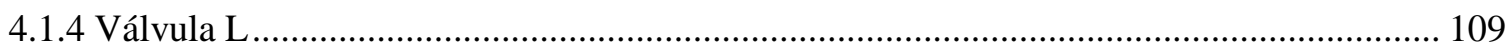

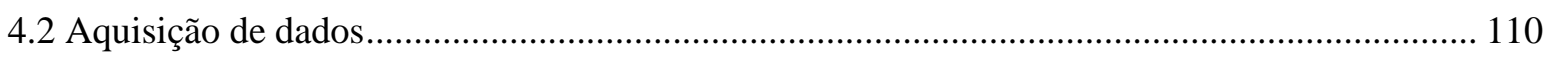

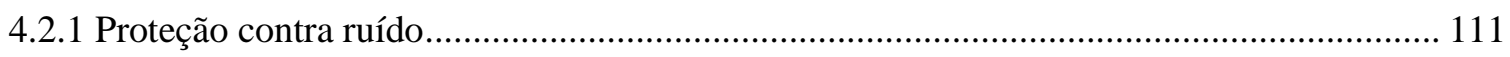

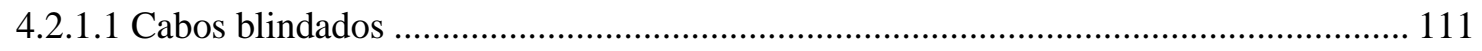

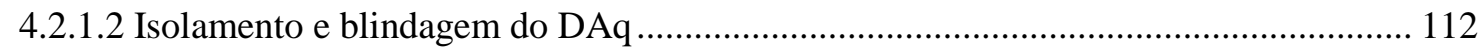

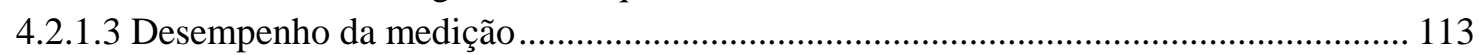

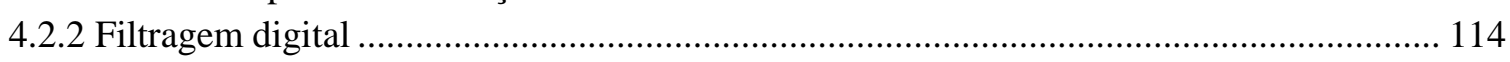

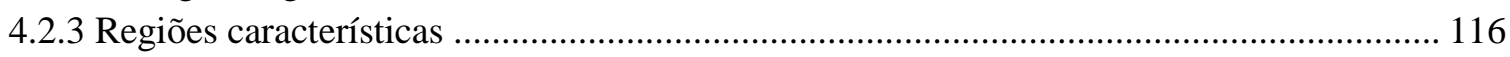

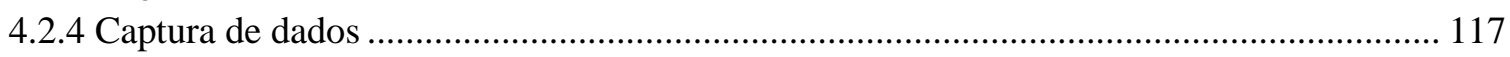

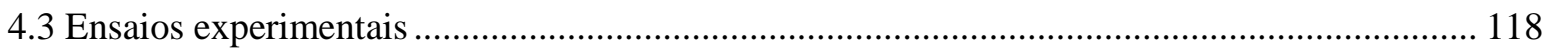

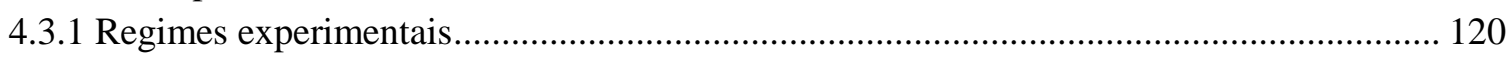

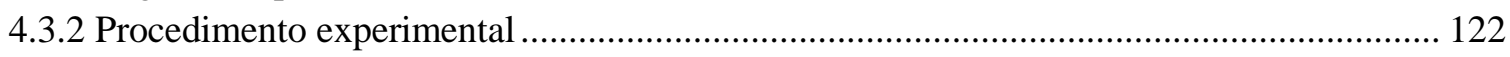

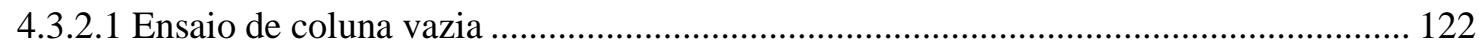

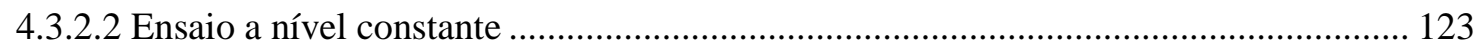

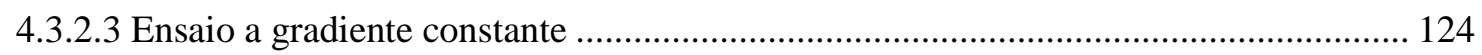

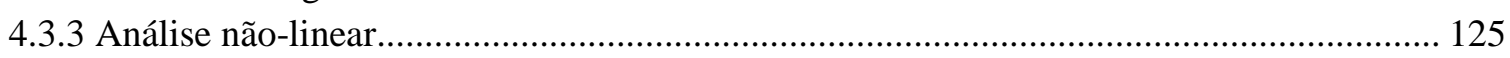

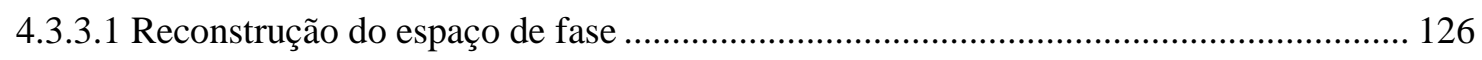

4.3.3.2 Dimensão de correlação e entropia de Kolmogorov ………………............................. 127

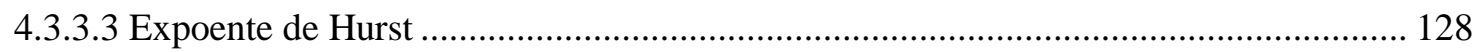




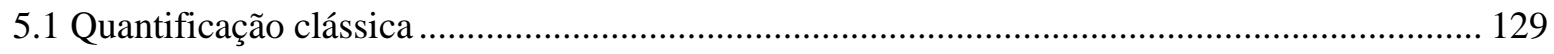

5.1.1 Vidro $355 \mu \mathrm{m}$

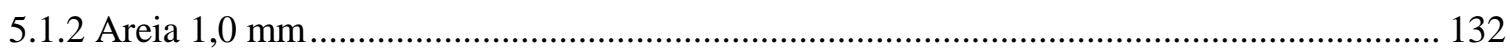

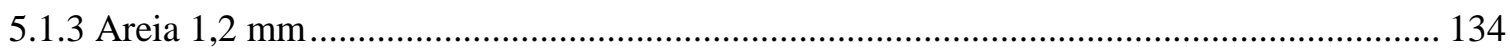

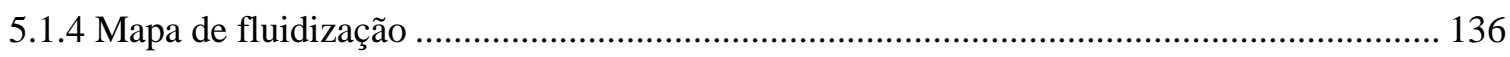

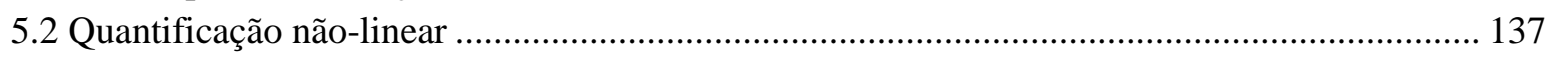

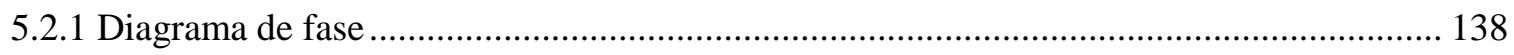

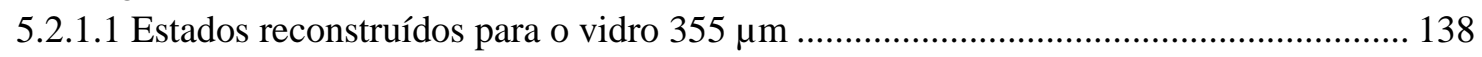

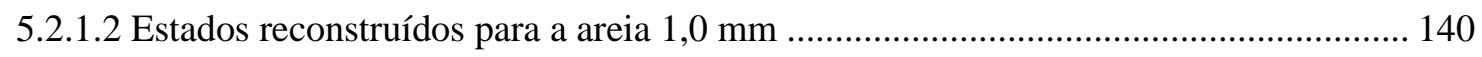

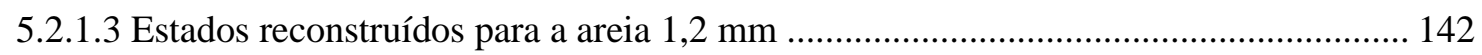

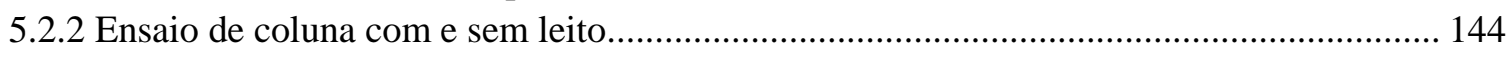

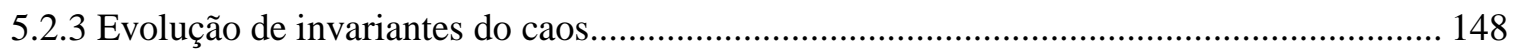

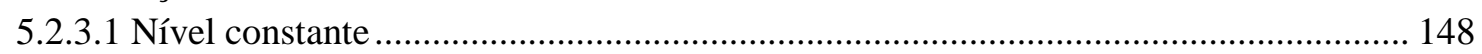

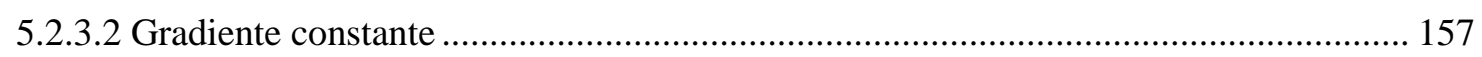

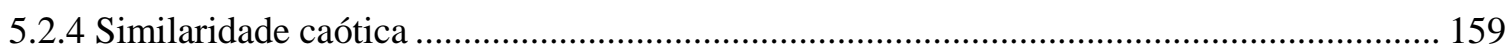

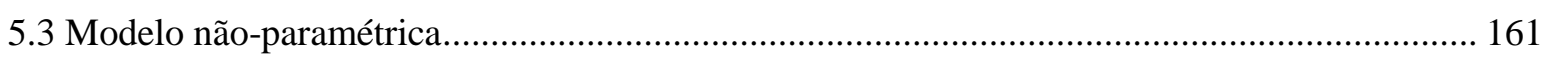

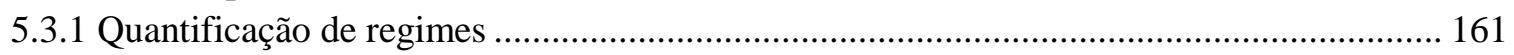

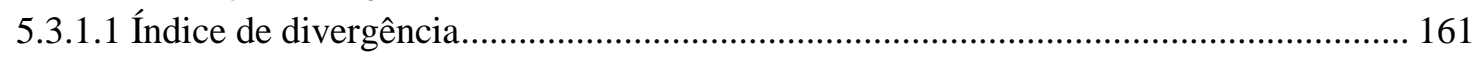

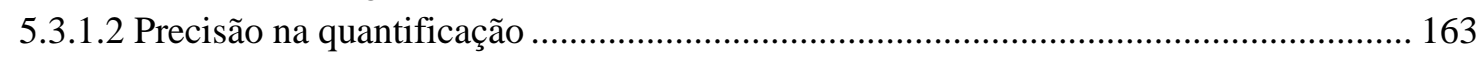

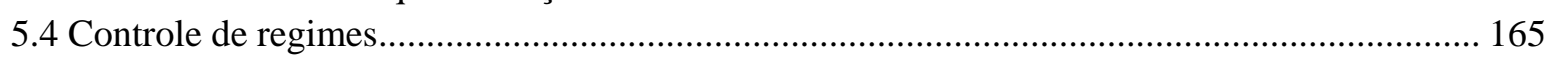

5.4.1 Controlador automático de regimes de fluidização ........................................................... 166

6 CONCLUSÃO

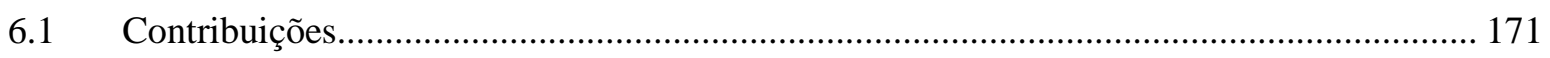

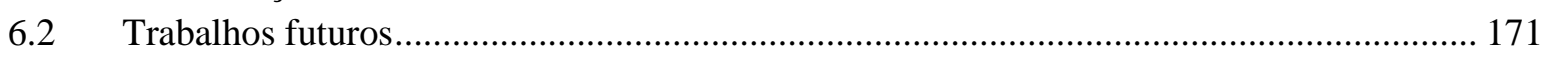

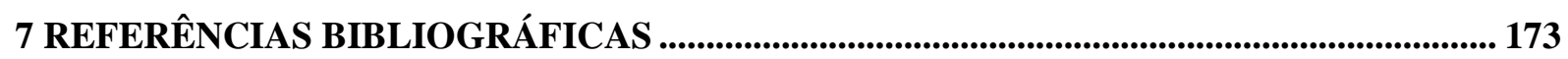




\section{LISTA DE FIGURAS}

Figura 1 - Quantidade de emissão de $\mathrm{CO}_{2}$ equivalente devido a exploração dos recursos energéticos disponíveis renováveis e não-renováveis. Adaptado de [11] ........................................................... 3 Figura 2 - Curva característica de queda de pressão de regimes de fluidização. Adaptado de [59]...... 14 Figura 3 - Curva característica de porosidade global da coluna dos regimes de fluidização. Adaptado de [22]. 15

Figura 4 - Classificação de partículas sólidas proposta por Geldart. Adaptado de [61]....................... 16 Figura 5 - Mapeamento da sequência de estados de fluidização e suas transições, para cada tipo de partícula na classificação de Geldart, face ao aumento da velocidade do gás de entrada. Adaptado de [62]. 18

Figura 6 - Perfis qualitativos da fração de sólidos numa coluna de fluidização. Adaptado de [62]..... 19 Figura 7 - Diagrama Porosidade vs. Velocidade de leito fluidizado. Mudanças na velocidade do gás de entrada alteram o regime de fluxo para um sistema gás-sólido com partículas FCC. Adaptado de [18].

Figura 8 - Mapa de regimes de fluidização adimensionalizado de Grace. Adaptado de [20]

Figura 9 - Estruturas espaço-temporais multi-níveis e multi-escalas em engenharia. Adaptado de [67]

Figura 10 - Mapa de regime de fluidização para partícula FCC, a partir de simulação numérica com restrições de métodos multi-escala. Adaptado de [23].

Figura 11 - Visão geral dos principais processos termoquímicos para conversão de biomassa em energia

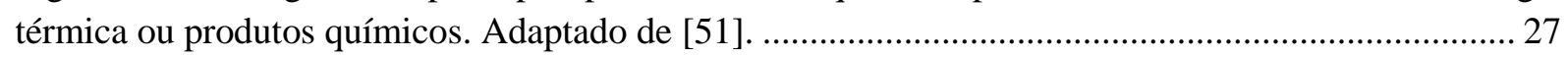

Figura 12 - Potências térmicas características para diferentes gaseificadores. Adaptado de [42]......... 31 Figura 13 - Estatística mundial do número de gaseificadores, pelo tipo de combustível. Adaptado de

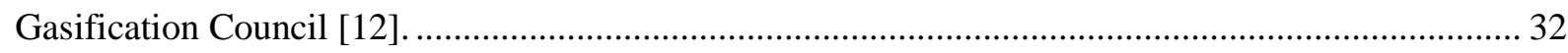

Figura 14 - Infógrafo do problema da coluna opaca de gaseificação em leito fluidizado circulante. ... 34 Figura 15 - Flutuações de dados de um gaseificador de leito fluidizado circulante real, com diâmetro interno de coluna de $0,8 \mathrm{~m}$ e altura de $12 \mathrm{~m}$, operando em leito fluidizado e taxa de amostragem de $1 \mathrm{~s}$.

Figura 16 - Flutuações de pressão estática, na base, de um gaseificador de leito fluidizado circulante real, com diâmetro interno de coluna de $0,8 \mathrm{~m}$ e altura de $12 \mathrm{~m}$, operando em leito borbulhante e taxa de amostragem de $1 \mathrm{~s}$.

Figura 17 - Problema dos múltiplos padrões de escoamento gás-sólidos que conduzem a mesma diferença de pressão, se a distância, $\mathrm{L}$, não for devidamente dimensionada.......................................... 38

Figura 18 - Representação de simulações dos métodos numéricos de fluxo multifásico no mesmo domínio (volume de controle ou tamanho da geometria). Adaptado de [114]...................................... 42

Figura 19 - Volume de controle fixado contendo duas fases. Adaptador de [112] . ............................... 43

Figura 20 - Cadeia de medição e aquisição de dados baseado em microcomputador. Adaptado de [131].

.

Figura 21 - Conexões de cabeamento blindado. Adaptado de [131] [133] ........................................... 55

Figura 22 - Estudo de atraso para coordenadas de atraso de tempo. Adaptado de [140] ...................... 59

Figura 23 - Reconstrução de paisagem montanhosa a partir de iteração coordenada de triângulos.

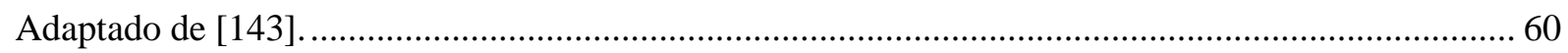

Figura 24 - Trajetórias no espaço de fase e sequências de caixas associadas. Adaptador de [144]..... 62 Figura 25 - As moléculas, representadas pelos pontos pretos, colidem aleatoriamente entre si e com a partícula (amarelo), tecendo uma trajetória (linha vermelha) que caracteriza o movimento Browniano. Adaptado de [148]. 64

Figura 26 - Quantificação da rugosidade de série temporal a partir do expoente de Hurst. Adaptado de [149]. .. 65 
Figura 27 - Fluxograma para seleção de coluna de fluidização LFC fria em escala laboratorial.......... 68

Figura 28 - Classificação de partículas e aplicação de correlações para estimativa do TDH. .............. 69

Figura 29 - Comparativo entre simulações TFM 2D, 3D e experimental para coluna LFC fria de mesmas

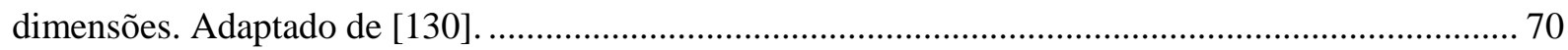

Figura 30 - Sistema de leito fluidizado circulante operando em regime rápido. Adaptador de [53].... 71

Figura 31 - Fluxos granulares de cisalhamento lento e rápido. Adaptado de [168] .............................. 76

Figura 32 - Trecho do código com o controle de parâmetros de execução aplicados na simulação de

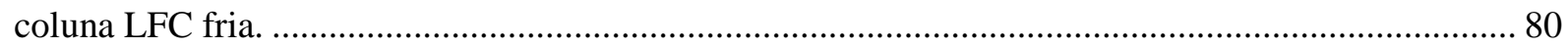

Figura 33 - Trecho do código com os parâmetros físicos da simulação de coluna LFC fria................. 80

Figura 34 - Malha ortogonal cartesiana de $4 \mathrm{~mm}$ aplicada em domínio de coluna LFC. Perspectiva da

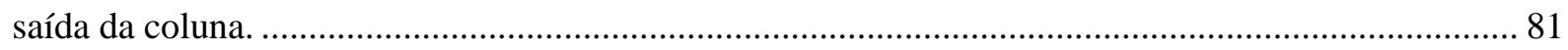

Figura 35 - Trecho do código com os parâmetros geométricos para simulação de coluna LFC fria.... 82 Figura 36 - Trecho do código com as especificação de parâmetros da fase gás da simulação multifásica.

Figura 37 - Trecho do código com as especificações de parâmetros da fase sólida da simulação

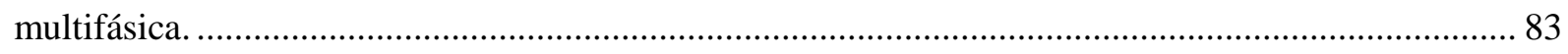

Figura 38 - Trecho do código com os parâmetros numéricos para simulação de coluna LFC fria. ..... 84 Figura 39 - Trecho do código com as condições iniciais de leito para a coluna LFC. …...................... 85

Figura 40 - Trecho do código com as condições iniciais de bordo livre para a coluna LFC................ 85 Figura 41 - Trecho do código com as condições de contorno para o distribuidor da coluna LFC fria. 86 Figura 42 - Trecho do código com as condições de contorno para a saída lateral da coluna LFC fria. 86 Figura 43 - Trecho do código com as condições de contorno para a entrada lateral da coluna LFC fria.

Figura 44 - Trecho do código com as condições de contorno no topo da coluna LFC fria e condições de

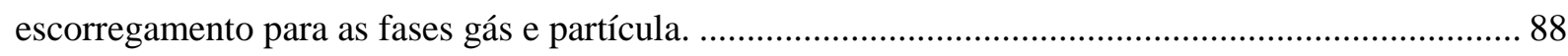

Figura 45 - Aproximação numérica implementada para o efeito circulante. ........................................ 89 Figura 46 - Fluxograma de execução da simulação para uso de funções definidas pelo usuário. Adaptado de [169]

Figura 47 - Função definida pelo usuário para devolver o material arrastado para fora, de volta para a

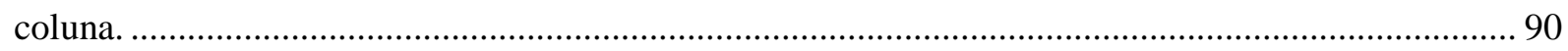

Figura 48 - Efeito circulante auxiliado por algoritmo mantém o inventário de massa constante......... 91

Figura 49 - Parâmetros de controle de saída de dados. ...................................................................... 92

Figura 50 - Parâmetros de controle de paralelismo de soluções das equações....................................... 92

Figura 51 - Metodologia de ensaios de simulação 3D em coluna fria de leito fluidizado circulante.... 93

Figura 52 - Comparativo entre reconstruções de valores médios temporais dos campos de velocidade de

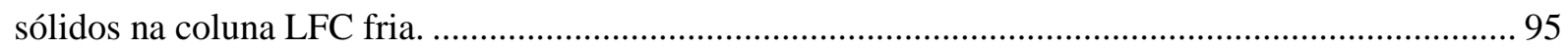

Figura 53 - Perfis radiais em três regiões (base, meio e topo) do regime borbulhante. ......................... 96

Figura 54 - Perfis radiais em três regiões (base, meio e topo) do regime turbulento. ............................. 96

Figura 55 - Perfis radiais em três regiões (base, meio e topo) do regime rápido. .................................. 97

Figura 56 - Perfis radiais em três regiões (base, meio e topo) do regime transporte.............................. 97

Figura 57 - Estudo de flutuações de pressão estáticas características ao longo da coluna LFC............ 99 Figura 58 - Perfil do expoente de Hurst ao longo da coluna LFC para diferentes regimes de fluidização.

Figura 59 - Perfil da dimensão de correlação ao longo da coluna LFC para diferentes regimes de

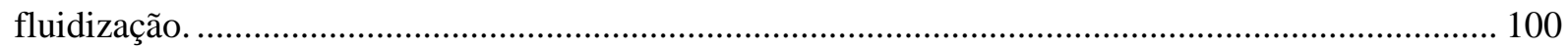

Figura 60 - Perfil da entropia de Kolmogorov ao longo da coluna LFC para diferentes regimes de fluidização. 101

Figura 61 - Pressão diferencial na coluna LFC face as velocidades de entrada do ar que desenvolveram os regimes de fluidização estudados. 102 
Figura 62 - Desvio padrão do sinal de pressão estática na base da coluna LFC, face as velocidades de entradas de ar que desenvolveram os regimes de fluidização estudados........................................... 103

Figura 63 - Série temporal do sinal de pressão estática na base de uma coluna LFC numérica. ......... 103 Figura 64 - Metodologia adotada para o cálculo de perda de carga total de coluna LFC experimental. 108

Figura 65 - Comparativo entre coluna LFC numérica e bancada experimental de leito fluidizado

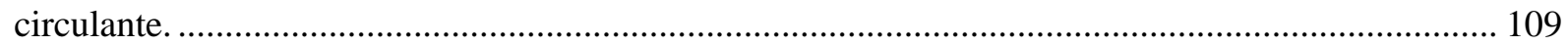

Figura 66 - Montagem de malha circulante, destacando a selagem mecânica a partir da válvula L... 110 Figura 67 - Tomadas de pressão e posicionamento dos medidores de pressão estática da coluna LFC

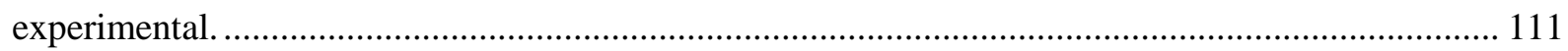
Figura 68 - Esquema de ligações elétricas completo, destacando as fontes de ruído irradiada e conduzida. 113

Figura 69 - Desempenho da imunidade de uma aquisição de dados experimental. ............................ 114 Figura 70 - O sinal protegido e filtrado digitalmente permite evidenciar flutuações da interação fluidopartícula. 115

Figura 71 - Regiões características para observação local da flutuação pressão estática ao longo de uma coluna LFC. 116

Figura 72 - Comparativo dos comportamentos das pressões estáticas médias e desvios padrão de pressão diferencial entre colunas LFC experimental e simulada.

Figura 73 - Aplicação para aquisição de dados desenvolvida em Labveiw para observação de flutuação de pressão estática em três regiões (base, meio e topo) ao longo da coluna LFC............................... 118 Figura 74 - Proposta de metodologia experimental para quantificação de regimes de fluidização em

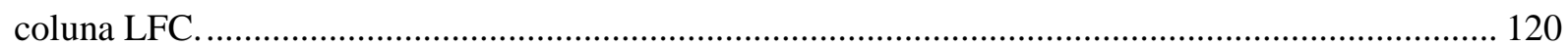
Figura 75 - Definição dos regimes de fluidização experimental usados para nova proposta de quantificação. 121

Figura 76 - Estudo de informação mútua de série temporal de flutuação de pressão estática na tomada P5 (90 cm da base), indicando um atraso de 11 períodos, considerando o critério do primeiro mínimo.

Figura 77 - Tela de configuração do software RRCHAOS para estimativa das invariantes dimensão de correlação e entropia de Kolmogorov. 127

Figura 78 - Comportamento na base $(9 \mathrm{~cm}$ da base) dos sinais de desvio padrão $(\sigma 1)$, pressão estática (P1) e diferencial (P1-P3) numa coluna LFC com leito de partículas de vidro $355 \mu \mathrm{m}$, submetidos a diferentes regimes de fluidização. 130 Figura 79 - Comportamento no meio ( $45 \mathrm{~cm}$ da base) dos sinais de desvio padrão $(\sigma 3)$, pressão estática (P3) e diferencial (P3-P5) numa coluna LFC com leito de partículas de vidro $355 \mu \mathrm{m}$, submetidos a diferentes regimes de fluidização. 131 Figura 80 - Comportamento no topo ( $90 \mathrm{~cm}$ da base) dos sinais de desvio padrão $(\sigma 5)$, pressão estática (P5) e diferencial (P1-P5) numa coluna LFC com leito de partículas de vidro $355 \mu \mathrm{m}$, submetidos a diferentes regimes de fluidização.

Figura 81 - Comportamento na base ( $9 \mathrm{~cm}$ da base) dos sinais de desvio padrão $(\sigma 1)$, pressão estática (P1) e diferencial (P1-P3) numa coluna LFC com leito de partículas de areia 1,0 mm, submetidos a diferentes regimes de fluidização. 133

Figura 82 - Comportamento no meio ( $45 \mathrm{~cm}$ da base) dos sinais de desvio padrão $(\sigma 3)$, pressão estática (P3) e diferencial (P3-P5) numa coluna LFC com leito de partículas de areia 1,0 mm, submetidos a diferentes regimes de fluidização. 133 Figura 83 - Comportamento no topo $(90 \mathrm{~cm}$ da base) dos sinais de desvio padrão $(\sigma 5)$, pressão estática (P5) e diferencial (P1-P5) numa coluna LFC com leito de partículas de areia 1,0 mm, submetidos a diferentes regimes de fluidização. 134 
Figura 84 - Comportamento na base ( $9 \mathrm{~cm}$ da base) dos sinais de desvio padrão $(\sigma 1)$, pressão estática (P1) e diferencial (P1-P3) numa coluna LFC com leito de partículas de areia 1,2 mm, submetidos a diferentes regimes de fluidização. 135 Figura 85 - Comportamento no meio ( $45 \mathrm{~cm}$ da base) dos sinais de desvio padrão $(\sigma 3)$, pressão estática (P3) e diferencial (P3-P5) numa coluna LFC com leito de partículas de areia 1,2 mm, submetidos a diferentes regimes de fluidização. 135

Figura 86 - Comportamento no topo $(90 \mathrm{~cm}$ da base) dos sinais de desvio padrão $(\sigma 5)$, pressão estática (P5) e diferencial (P1-P5) numa coluna LFC com leito de partículas de areia 1,2 mm, submetidos a diferentes regimes de fluidização. 136 Figura 87 - Quantificação clássica de regimes de fluidização através do uso de mapa de regimes de Grace. 137

Figura 88 - Evolução das trajetórias dos estados de fluidização na base da coluna LFC para o vidro 355

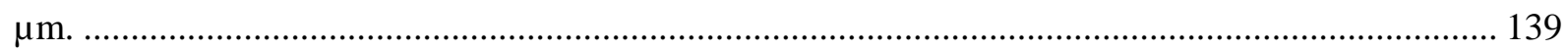
Figura 89 - Evolução das trajetórias dos estados de fluidização no meio da coluna LFC para o vidro 355

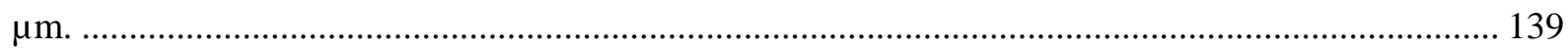
Figura 90 - Evolução das trajetórias dos estados de fluidização no topo da coluna LFC para o vidro 355 $\mu \mathrm{m}$. 140

Figura 91 - Evolução das trajetórias dos estados de fluidização na base da coluna LFC para a areia 1,0 $\mathrm{mm}$ 141

Figura 92 - Evolução das trajetórias dos estados de fluidização no meio da coluna LFC para a areia 1,0

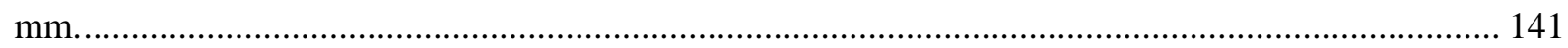

Figura 93 - Evolução das trajetórias dos estados de fluidização no topo da coluna LFC para a areia 1,0 $\mathrm{mm}$. 142

Figura 94 - Evolução das trajetórias dos estados de fluidização na base da coluna LFC para a areia 1,2

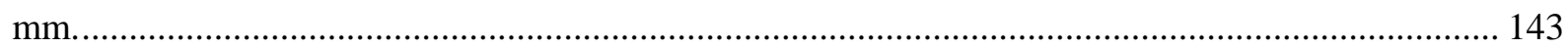

Figura 95 - Evolução das trajetórias dos estados de fluidização no meio da coluna LFC para a areia 1,2

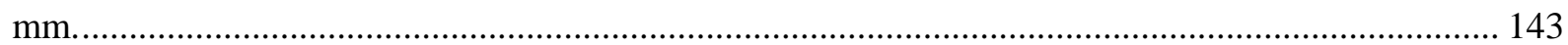

Figura 96 - Evolução das trajetórias dos estados de fluidização no topo da coluna LFC para a areia 1,2

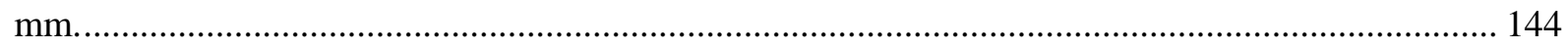

Figura 97 - Comparativo entre os perfis de entropia de coluna vazia e cheia de leito de partícula de vidro $355 \mu \mathrm{m}$. 145

Figura 98 - Comparativo entre os perfis de entropia de coluna vazia e cheia de leito de partícula de areia $1,0 \mathrm{~mm}$. 146

Figura 99 - Comparativo entre os perfis de entropia de coluna vazia e cheia de leito de partícula de areia $1,2 \mathrm{~mm}$. 147

Figura 100 - Comportamento da evolução do expoente de Hurst, dimensão de correlação e entropia de Kolmogorov, na base, em diferentes regimes, para leito de $8 \mathrm{~cm}$ de partículas de vidro $355 \mu \mathrm{m} . \ldots . .148$ Figura 101 - Comportamento da evolução do expoente de Hurst, dimensão de correlação e entropia de Kolmogorov, no meio, em diferentes regimes, para leito de $8 \mathrm{~cm}$ de partículas de vidro $355 \mu \mathrm{m} . . . .149$ Figura 102 - Comportamento da evolução do expoente de Hurst, dimensão de correlação e entropia de Kolmogorov, no topo, em diferentes regimes, para leito de $8 \mathrm{~cm}$ de partículas de vidro $355 \mu \mathrm{m} . \ldots . .150$ Figura 103 - Comportamento da evolução do expoente de Hurst, dimensão de correlação e entropia de Kolmogorov, na base, em diferentes regimes, para leito de $8 \mathrm{~cm}$ de partículas de areia $1,0 \mathrm{~mm}$....... 151 Figura 104 - Comportamento da evolução do expoente de Hurst, dimensão de correlação e entropia de Kolmogorov, no meio, em diferentes regimes, para leito de $8 \mathrm{~cm}$ de partículas de areia 1,0 mm..... 152 Figura 105 - Comportamento da evolução do expoente de Hurst, dimensão de correlação e entropia de Kolmogorov, no topo, em diferentes regimes, para leito de $8 \mathrm{~cm}$ de partículas de areia 1,0 mm....... 153 Figura 106 - Comportamento da evolução do expoente de Hurst, dimensão de correlação e entropia de Kolmogorov, na base, em diferentes regimes, para leito de $8 \mathrm{~cm}$ de partículas de areia 1,2 $\mathrm{mm} . \ldots . .154$ 
Figura 107 - Comportamento da evolução do expoente de Hurst, dimensão de correlação e entropia de Kolmogorov, no meio, em diferentes regimes, para leito de $8 \mathrm{~cm}$ de partículas de areia 1,2 mm..... 155 Figura 108 - Comportamento da evolução do expoente de Hurst, dimensão de correlação e entropia de Kolmogorov, no topo, em diferentes regimes, para leito de $8 \mathrm{~cm}$ de partículas de areia $1,2 \mathrm{~mm} . \ldots . .156$ Figura 109 - Perfis axiais do comportamento da entropia de Kolmogorov para as partículas investigadas, na coluna LFC.

Figura 110 - Comportamento da evolução da entropia de Kolmogorov na coluna LFC, em diferentes

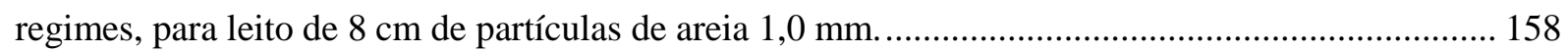

Figura 111 - Perfis axiais do comportamento da entropia de Kolmogorov para as partículas de areia 1,0 $\mathrm{mm}$, na coluna LFC. 158

Figura 112 - Comportamento do índice de similaridade caótica, considerando a hipótese do regime de transporte. 160 Figura 113 - Curvas características do sinal de divergência de cada ensaio para partículas de vidro 355 $\mu \mathrm{m}$. 161

Figura 114 - Curvas características do sinal de divergência de cada ensaio para partículas de areia 1,0 $\mathrm{mm}$ 162

Figura 115 - Curvas características do sinal de divergência de cada ensaio para partículas de areia 1,0

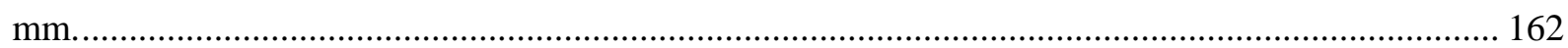

Figura 116 - Perfil axial do expoente de Hurst para um leito de vidro $355 \mu \mathrm{m}$ em coluna LFC. ....... 163

Figura 117 - Perfil axial do expoente de Hurst para um leito de areia 1,0 mm em coluna LFC......... 163

Figura 118 - Perfil axial do expoente de Hurst para um leito de areia 1,2 mm em coluna LFC......... 164 Figura 119 - Fluxograma de proposta para controle de regime de fluidização aplicado a gaseificadores. 166

Figura 120 - Estratégia de controle cascata para implementação de controle de regime de leito fluidizado circulante. 167 


\section{LISTA DE TABELAS}

Tabela 1 - Principais reações durante um processo de gaseificação de biomassa [44].

Tabela 2 - Técnicas de medição e parâmetros de processo de leito fluidizado aplicável para escalas de bancada (B), piloto (P) e testes em escalas comerciais (C). Adaptador de [53].

Tabela 3 - Fontes de sinais comuns e configurações de entrada recomendadas. Adaptado de [131] [132].

Tabela 4 - Parâmetros físicos e condições iniciais para o modelo TFM de leito fluidizado circulante. 94 Tabela 5 - Medições da massa específica e porosidade de leito empacotado para o vidro $355 \mu \mathrm{m}$, areia $1,0 \mathrm{~mm}$ e areia $1,2 \mathrm{~mm}$.

Tabela 6 - Rotação do ventilador que desempenha cada regime de fluidização para cada tipo de partícula com $8 \mathrm{~cm}$ de leito.

Tabela 7 - Lista de eventos de ensaio de coluna LFC vazia, identificando os instantes de mudança de rotação.

Tabela 8 - Lista de eventos de ensaio a nível constante, identificando os momentos e tipos de ajustes para manter o inventário constante.

Tabela 9 - Lista de eventos de ensaio de gradiente de pressão constante, identificando os momentos, configurações do nível de leito e ajustes para manter o inventário constante.

Tabela 10 - Caracterização local média dos regimes de fluidização através das invariantes do caos como expoente de Hurst, entropia de Kolmogorov e dimensão de correlação, para areia de 1,0 mm. 128 Tabela 11 - Caracterização local média usando o expoente de Hurst e índice do caos para as partículas de vidro e areia em cada regime. 160

Tabela 12 - Modelo não-paramétrico para classificação dos regimes de fluidização a partir dos índices do caos. 164 


\section{NOMENCLATURA}

$d_{p} \quad$ Diâmetro de partícula [m]

$x_{i} \quad$ Fração em peso do tamanho da partícula [-]

$\phi_{p} \quad$ Esfericidade de partículas [-]

$\varepsilon \quad$ Fração de vazios de leitos porosos [-]

$U \quad$ Velocidade do fluido $[\mathrm{m} / \mathrm{s}]$

$U_{r} \quad$ Velocidade relativa $[\mathrm{m} / \mathrm{s}]$

$U_{t} \quad$ Velocidade terminal $[\mathrm{m} / \mathrm{s}]$

$\rho_{p} \quad$ Massa específica da partícula $\left[\mathrm{kg} / \mathrm{m}^{3}\right]$

$\rho_{f} \quad$ Massa específica do fluido $\left[\mathrm{kg} / \mathrm{m}^{3}\right]$

$C_{D} \quad$ Coeficiente de arrasto [-]

Ar Número de Arquimedes [-]

$\mu \quad$ viscosidade dinâmica $[\mathrm{kg} / \mathrm{ms}]$

$U_{t}^{*} \quad$ Velocidade adimensional [-]

$\Delta P \quad$ Pressão diferencial $[\mathrm{Pa}$

$R e_{p} \quad$ Número de Reynolds para partícula [-]

$G_{s} \quad$ Fluxo mássico de sólidos $\left[\mathrm{kg} / \mathrm{m}^{2} \mathrm{~s}\right]$

$R_{A / C} \quad$ Razão ar/combustível [-]

$V \quad$ Volume $\left[\mathrm{m}^{3}\right]$

$A \quad$ Área $\left[\mathrm{m}^{2}\right]$

LFC Leito fluidizado circulante

$\mathrm{MW}_{\text {th }} \quad$ Megawatt térmico 


\section{CONSIDERAÇÕES INICIAIS}

Como transformar/usar recursos energéticos renováveis de forma sustentável? Do que se trata este trabalho e quais seriam seus impactos? Como esta tese foi organizada para definir e tratar o problema? Este capítulo apresenta considerações gerais relacionadas à contextualização do assunto, motivação e objetivos do trabalho.

\subsection{Introdução}

Avaliações recentes confirmam antigas inquietações relacionadas com o aquecimento global, formação de chuva ácida, qualidade do ar, gestão de recursos não-renováveis e etc. Cada um destes temas está relacionado com a forma como usamos a energia, culminando numa reavaliação global do uso de combustíveis fósseis [1]. Aproximadamente $72 \%$ da energia elétrica global é gerada a partir de processos de combustão. A geração elétrica por combustão é razoavelmente eficiente e bem conhecida, com alta disponibilidade (termelétricas) e de baixo custo, mas altamente emissora [2]. Reduzir as emissões sem desacelerar o crescimento, é uma tarefa desafiadora.

A operação de combustores de leito fluidizado tornou-se amplamente útil, durante a última década, principalmente devido às suas vantagens ambientais (controle direto através de aditivos) e sua capacidade de queimar diferentes tipos de combustíveis. O leito fluidizado tornou a geração de calor mais simples por que permitiu o controle das emissões, através de aditivos, retirando lavadores de gases (wet scrubber) do processo global. A necessidade de operar combustores de leito fluidizado circulante com controle de temperatura reside na manutenção de limites de temperatura, na compensação automática de distúrbios, provocados, principalmente, pela heterogeneidade do combustível. A operação automatizada, permite o fornecimento contínuo de calor aos consumidores. O controle de temperatura de combustores de leito fluidizado pode ser modelado pelo balanço líquido de transferência de calor, numa coluna de combustão. A temperatura interna da coluna depende basicamente do fator de ar (imposto pela relação de ar e combustível), taxa de recirculação e do coeficiente de convecção que é fortemente influenciado pelo regime de fluidização [3]. Como as colunas de leito fluidizado são opacas, para evitar a perda de calor, operadores não são capazes ajustar visualmente o regime de uma coluna, sendo necessários outros métodos.

Apesar do grande avanço do leito fluidizado, a caminho do domínio do processo de combustão cada vez mais limpo, o propósito do combustor está limitado a produção de calor próximo a fonte de combustível, devido as dificuldades e custo elevado do transporte de sólidos. Essa limitação pode ser superada através de mudanças no projeto do reator e na redução do fator de ar (F.A. ou razão de equivalência) unitário (no combustor) para 0,2-0,3. A operação do reator com baixa razão de equivalência favorece a combustão parcial, resultando em gases que ainda podem ser queimados. A processo de conversão termoquímico, em condições de mistura rica em combustível com F.A. entre 0,2-0,3 é chamado de gaseificação [4]. As aplicações do processo de gaseificação impactam na conversão de resíduos sólidos carbonáceos em gás combustível. Diferente dos combustores de leito fluidizado que fornecem calor os gaseificadores de leito fluidizado precisam de reter calor para o favorecimento das reações termoquímicas. Um reator de gaseificação também sofre com os efeitos de defluidização ou aglomeração de partículas do leito, o qual degrada a qualidade da fluidização corrente [5]. Outra diferença entre gaseificadores e combustores, é que a permanência da composição do gás de saída em gaseificadores são mais sensíveis são mais sensíveis a manutenção das variáveis como fator de ar, temperatura do reator e ao regime de fluidização (grau de contato fluido-partícula) do que combustores [6]. 
A gaseificação é um processo capaz de substituir o fornecimento de combustíveis fósseis por combustíveis de biomassa nos estados sólido (carvão vegetal), líquido (bioóleo) e gasoso (gás de gaseificação e gás síntese). A biomassa tornou-se uma citação valiosa em diversos artigos e levantamentos governamentais, devido a sua abundância, redução de seu preço, principalmente em países em desenvolvimento como os do Mercosul, e por cumprir requisitos de conversão em processos de gaseificação (composição em massa de carbono, hidrogênio, oxigênio, nitrogênio e enxofre favoráveis). As razões práticas em decidir pela gaseificação consistem: no aumento dos preços de combustíveis fósseis e recursos importados, nas dificuldades de gestão sustentável de resíduos carbonáceos e na conformidade de emissões com mecanismos limpos atuais.

Conta a história, que sábios chineses iluminaram alguns templos com gás de solo, usando tubulação de bambu no ano 900 [7]. Mas, segundo registro, foi um padre inglês de Croften, John Clayton, o primeiro a encontrar uma forma a produzir gás inflamável a partir da destilação seca do carvão no século XVII [7]. A partir destes conhecimentos, iniciara a primeira companhia de gás de carvão de Londres, em 1812, para iluminação pública [7].

A gaseificação, é um processo da rota termoquímica que transforma materiais carbonáceos, geralmente sólidos, numa mistura combustível de gases, chamada gás de gaseificação (geralmente baixo Poder Calorífico Inferior, PCI). Ambas reações de combustão completa e parcial são ativadas pela temperatura (termoquímica) e distinguem-se pelas condições sub e sobrestequiométricas da gaseificação, resultando em cinzas e gases que ainda podem ser queimados [4]. A ideia de produzir combustível gasoso limpo, através da gaseificação, a partir de qualquer resíduo sólido carbonáceo é atraente, pois potencializa o fechamento de um ciclo sustentável para estes resíduos [8]. O beneficiamento/limpeza do gás através de processos de remoção de particulados e voláteis (alcatrão e outros), como lavadores de gás (borbulhadores, wet scrubber), filtros (dolomita calcinada) e craqueamento térmico, estão em constante desenvolvimento, mas já apresentam soluções comerciais disponíveis [9] [10].

Nas regiões de baixa disponibilidade de combustível fóssil, as plantas de gaseificação (mais comuns em leito fixo) foram modificadas para operar com biomassa. Nos anos trinta, com os primeiros sinais de viabilidade na exploração de derivados do petróleo de alto poder calorífico em larga escala, resultaram na desativação das plantas de gaseificação juntamente com suas pesquisas [7].

O ressurgimento de muitas atividades de desenvolvimento e implantação de gaseificadores ocorreu devido à escassez de combustíveis líquidos na Europa, no início da Segunda Guerra Mundial. Apesar de avanços na gaseificação no período da Segunda Guerra, após seu fim, o fornecimento de combustíveis fósseis foi renovado e houve uma rápida reconversão para derivados do petróleo. Com o petróleo barato, a gaseificação foi abandonada nos países industrializados, sendo usada como soluções para casos isolados [7].

A escassez de recursos pode conduzir a crises quando não há políticas mitigadoras e soluções alternativas numa gestão. Tendências aos conceitos sustentáveis e avanços nas técnicas de gestão de recursos naturais permitiram avaliar os reais impactos às mudanças nas políticas energéticas. A Figura 1 apresenta um mapeamento de recursos e seus potenciais de emissão, evidenciando como estudos de eficiência energética de processos de conversão termoquímica (seta vermelha) poderiam motivar a exploração dos recursos renováveis aumentando a capacidade energética e reduzindo as emissões e custos. 


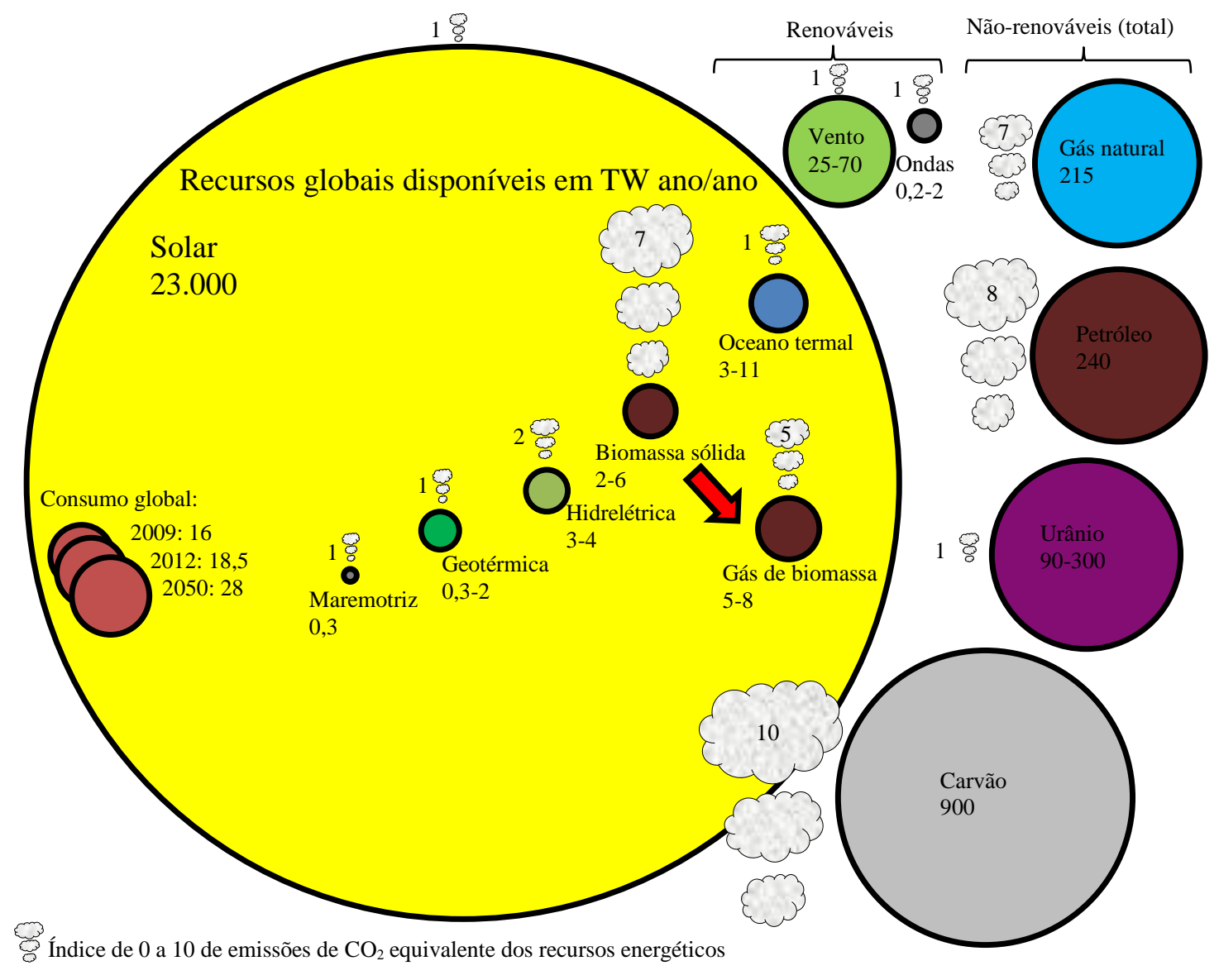

Figura 1 - Quantidade de emissão de $\mathrm{CO}_{2}$ equivalente devido a exploração dos recursos energéticos disponíveis renováveis e não-renováveis. Adaptado de [11].

O processo de gaseificação encontra-se em constante desenvolvimento no mundo pelo potencial de converter grandes volumes e tipos de resíduos sólidos (desde fósseis a lixo) em gás combustível limpo. Há em torno de 680 unidades comerciais de gaseificação existentes no mundo, um indicativo de sua complexidade operacional [12]. Dentre os diversos tipos de gaseificadores, os de leito fluidizado circulante (LFC) são os que apresentam maior potencial para a conversão de grandes volumes de sólidos por operarem em regime de fluidização rápido, garantindo maior grau de interação fluido-partícula do que outros regimes. Contudo, ainda apresenta problemas, como o de manter controlada a composição de seu gás de saída (baixa disponibilidade), para ser considerado como processo de geração de energia de alta disponibilidade. Seus principais problemas estão relacionados a alta complexidade operacional e alta variabilidade na composição do gás produzido.

Atualmente, a operação contínua de gaseificadores é alcançada através da implementação de malhas de controle de temperatura e do fator de ar (F.A. ou E.R Equivalence Ratio), $F A=\left(R_{A / C}\right)_{\text {real }} /\left(R_{A / C}\right)_{\text {esteq }}$ $\left(R_{A / C}\right.$ é a razão ar/combustível). Outros fatores, como a falta de controle da taxa de circulação e do regime de fluidização podem explicar a persistência da variabilidade da composição final do gás de saída [6].

Além das condições de gaseificação (temperatura, pressão, composição do material, etc) o grau de contato entre o material carbonáceos o e agente gaseificante (geralmente ar) é decisiva para aumentar a taxa da conversão de carbono. Fan et al. [13] demonstraram que taxa de conversão de carbono, a eficiência de gaseificação e o poder calorífico inferior são maiores em gaseificadores de leito fluidizado 
circulante (mais complexos de operar) do que em leitos borbulhantes (menos complexos de operar). Portanto, a quantificação/identificação do regime de fluidização corrente pode proporcionar contribuições na melhoria na eficiência da conversão termoquímica de carbono e a constância da composição do gás de saída.

O problema da quantificação/identificação dos regimes de fluidização vem sendo tratado por cientistas do mundo todo. A evolução do tratamento do problema foi marcada em três etapas:

- Metodologia de mapeamento de regimes de fluidização baseado em variáveis de escala macroscópica como: o diâmetro, gradiente de pressão; velocidade e massa específica da partícula; viscosidade, velocidade e massa específica do agente fluidizante; e porosidade [14] [15] [16] [17] [18] [19] [20]. Contudo, essa metodologia falha na previsão de regimes de fluidização, quando a coluna é escalona [21]

- Metodologia de mapeamento de regimes de fluidização baseado em variáveis de escalas micro, meso e macroscópicas auxiliada por modelos numéricos [22] [23] [24] [25]. A consideração de diferentes escalas para a formação de regimes de fluidização permitiu aos modelos numéricos aumentar a precisão de suas previsões de intervalos de velocidades do gás de entrada que formam os regimes para diversos tipos de partícula e escalonamento de coluna. Contudo, o monitoramento e medições contínuas de variáveis de escala micro e meso (como o uso de técnicas de raio $\mathrm{X}$ rápido) ainda são onerosas e podem tornar a implementação de controle regime inviável.

- Metodologia de mapeamento de regimes de fluidização baseado na análise não-linear de sinais de variáveis macroscópicas considerando a resposta caótica de leitos fluidizados [26] [27] [28] [29] [30] [31] [32] [33] [34] [35]. Esses trabalhos tentam quantificar sinais de concentração e pressão diferencial, em diferentes regimes de fluidização, através da evolução de invariantes do caos como a dimensão de correlação, entropia de Kolmogorov, expoente de Lyapunov, expoente de Hurst, etc. A vantagem do uso de invariantes é que, de acordo com a teoria, preservam o comportamento face ao escalonamento da coluna de fluidização. Apesar do grande potencial que as ferramentas de análise não-linear ao comportamento caótico trazem, não foram encontradas metodologias que permitam o monitoramento e controle de regimes de fluidização em leito fluidizado.

Este trabalho contribui para sequência de estudos pertinentes ao mapeamento de regimes de fluidização explorando a evolução das invariantes do caos. Diferente dos trabalhos pesquisados, o sinal aqui utilizado, para avaliar propriedades invariantes da interação fluidizado-partícula local, em diferentes posições da coluna, é a flutuação da pressão estática. Sinais de pressão diferencial combinam flutuações de diferentes regiões podendo mascarar propriedades singulares destas regiões, quando analisadas separadamente. Outra razão, é baixo custo, facilidade de instalação e compatibilização às colunas industriais quentes. Esta metodologia leva em conta o problema espaço-temporal intrínsecos de sistemas de leito fluidizado circulante. Portanto, realiza estudos de regiões características para efetuar medições capazes quantificar e distinguir regimes de fluidização. Diferentes de outros trabalhos que usam apenas uma medida, este associa três medições ao longo de uma coluna LFC para propor um quantificador baseado na entropia de Kolmogorov.

O estudo do controle de regime (quantificação da interação fluido-partícula numa coluna) pode contribuir com o aumento da eficiência global de processos de gaseificação, através de operação de controle automático de regime de fluidização. 


\subsection{Motivação}

A motivação para realização deste trabalho nasceu em 2010, de uma pesquisa de campo, quando o autor participou do projeto e construção da primeira unidade semi-industrial brasileira de gaseificação em leito fluidizado circulante de biomassa lotada na cidade de São Mateus no Espírito Santo (ES), Brasil. $\mathrm{Na}$ época, a proposta o projeto era de converter biomassa de cana de açúcar em gás de gaseificação para geração elétrica em ciclo Rankine. A unidade construída possui uma coluna de gaseificação de $0,8 \mathrm{~m}$ de diâmetro interno, $12 \mathrm{~m}$ de altura e capacidade de produção de $1 \mathrm{MW}_{\text {th }}$ (potência térmica). Seu plano de ensaios operacionais previu a gaseificação LFC de carvão (diâmetro de partícula, $\mathrm{dp}=2,0 \mathrm{~mm}$ ) com alto teor de cinzas misturado com fibras de bagaço de cana seca (até $100 \mathrm{~mm}$ de comprimento). A razão de misturar foi de facilitar sua fluidez do bagaço dentro do alimentador, facilitando o controle de injeção de material na coluna de gaseificação.

Diferente de colunas laboratoriais transparentes de fluidização fria, as colunas industriais quentes de gaseificação, são opacas devido a sua proteção térmica (refratário). A temperatura desta unidade de gaseificação de leito fluidizado circulante varia entre $800-950^{\circ} \mathrm{C}$, e a forma atual de controlar seu regime de fluidização é cruzando-se informações do fluxo de injeção do agente gaseificante e da queda de pressão na coluna, com mapas de regimes de fluidização [36], para encontrar estimar o regime de fluidização corrente. Contudo, através de visores de fluxo industriais de janela circular aparafusada, foi possível confirmar a imprecisão deste método, que classificou uma coluna de gaseificação (carvão 2 $\mathrm{mm}$ ) como regime rápido, enquanto o regime corrente foi o turbulento. Além disso, foi observado aumento da imprecisão quando partículas maiores, como carvão $3 \mathrm{~mm}$, e misturas entre carvão e palha de bagaço de cana foram usadas.

Através da instrumentação de medição de vazão de ar e medição do nível do silo de alimentação foi possível monitorar as razões entre combustível e agente gaseificante, permitindo bom controle da temperatura e do fator de ar corrente. Contudo, essas duas variáveis não são suficientes para manter a composição do gás de saída constante, visto que, a conversão de sólido em gás do leito muda seu peso e consequentemente seu regime, provocando diferentes taxas de conversão de carbono. Após a partida desta unidade de gaseificação de leito fluidizado circulante, há a perda do rastreamento do regime de fluidização rápido devido a redução do inventário de massa (leito que circula) ocasionada pela conversão termoquímica do leito de sólidos.

A redução da complexidade operacional de sistemas de gaseificação LFC, através de sua automatização, pode impactar numa nova geração para sustentabilidade energética. Com avanço em pesquisas, estes sistemas serão capazes converter qualquer tipo de resíduo carbonáceos em energia limpa. O primeiro grande impacto será a conversão do resíduo sólido urbano (lixo), resíduos de estações de tratamento e a liberação de áreas dos aterros sanitários. Este processo promoverá a descentralização da geração energética, reduzindo os riscos de sobrecarga iminente de sistemas centralizados. A produção abundante de gás e derivados do gás de gaseificação, reduzirá a dependência dos combustíveis fósseis (carvão e petróleo). Por fim, o livre comércio de países inseridos em grandes blocos econômicos e atividades comerciais entre eles, gerarão uma nova economia: a dos resíduos.

\subsection{Objetivos}

O objetivo central desta tese é a proposta de uma nova abordagem para quantificação e identificação dos regimes de fluidização em leito fluidizado circulante frio, utilizando análises não-lineares. Este trabalho considera a possibilidade de aplicações de implementação de sistemas automatizados capazes de controlar regimes de fluidização, em colunas escalonadas, no modo regulatório (num determinado regime permanente). 


\subsubsection{Objetivos específicos}

Para alcançar os objetivos gerais, pretende-se avaliar a fluidodinâmica caótica em um reator de leito fluidizado circulante frio, tendo como objetivos específicos:

- Revisão teórica de:

○ Fundamentos modernos da fluidodinâmica em leito fluidizados circulantes;

- Fundamentos da fluidodinâmica computacional aplicado a leitos fluidizados circulantes frio;

- Fundamentos da teoria do caos para avaliação de invariantes a partir de série temporais.

- Estudo de:

- Especificação do tamanho das séries temporais para estimação da dimensão de correlação e entropia de Kolmogorov com incertezas abaixo de 1\% (RRCHAOS);

- Elaboração de índices de caos baseados nas razões das invariantes locais para investigar a quantificação dos regimes de fluidização de diferentes partículas.

- Simulação numérica de bancada experimental:

- Implementação do modelo multifásico TFM (two fluid model) 3D para estudo de fluidização de leito fluidizado circulante frio (MFIX).

- Estudo de queda de pressão em diferentes alturas de leito para especificação de potência de sistema de injeção do agente fluidizante.

- Verificação do problema espaço-temporal numa coluna de fluidização através das invariantes locais entre três regiões axiais e da sensibilidade das invariantes do caos nos diferentes regimes de fluidização.

- Análise Experimental:

- Projeto e construção de planta instrumentada, de escala laboratorial, de leito fluidizado circulante fria.

- Estudo de isolamento e bloqueio de ruído em sensores pressão estática e sistema de aquisição de dados para medição da interação fluido-partícula.

- Avaliação do problema espaço-temporal numa coluna de fluidização através das invariantes locais entre três regiões axiais.

- Avaliação da sensibilidade das invariantes caóticas a mudança dos três tipos de partículas, para os diferentes regimes de fluidização.

\subsection{Proposta e Metodologia}

A dinâmica, condições operacionais e escalas industriais da conversão termoquímica de um gaseificador de leito fluidizado circulante exige altos investimentos para ser reproduzida em universidades brasileiras. Gaseificadores reais trabalham com altas temperaturas $\left(700-950^{\circ} \mathrm{C}\right)$, medições de queda de pressão na coluna, medições fluxos de entrada (agente gaseificante e combustível) e através destas informações, operadores tentam manter o regime de fluidização controlado. Grandes fabricantes como Foster Wheeler, ICM, MSW Power Corporation, entre outras, desenvolvem e operam gaseificadores sem o controle direto de regimes de fluidização. Soluções caras de instrumentação, como uso raio X rápido, podem ser usadas para auxiliar um operador quanto a indicação do regime de fluidização, onerando ainda mais o processo. Contudo, através de análises não-lineares de séries temporais de sinais de pressão é possível reconstruir a dinâmica do comportamento do leito fluidizado e avaliar suas propriedades invariantes locais, em diferentes pontos de medição, para cada regime de fluidização. A partir da proposta de quantificar/identificar regimes de fluidização em gaseificadores reais com base em 
análises não-lineares de séries temporais de pressão, é possível usar instrumentação convencional (barata).

Para garantir a representatividade do problema de quantificação/identificação de regimes em gaseificadores reais, este trabalho propõe:

- Quantificação dos regimes através de séries temporais de pressão estática, mantendo a instrumentação convencional dos fabricantes atuais;

- Uso de quantificadores não-lineares baseados em invariantes do caos para garantir que efeitos de escalonamento não influencie os resultados de quantificação de regimes;

- Realização de ensaios de leito fluidizado circulante em temperatura ambiente como referência ao pior caso para captura da interação fluido-partícula, visto que em gaseificadores reais, a viscosidade do gás aumenta com a temperatura, aumentando a sensibilidade desta captura. Mesmo assim, é necessário verificar a influência da temperatura para o método proposto.

Portanto, esta investigação baseia-se no projeto e construção de uma coluna de fluidização fria, em escala laboratorial e com malha circulante, para ensaios de quatro regimes de fluidização - expandido, borbulhante, turbulento e rápido. A inserção de três tomadas de pressão, ao longo da coluna, permite estudar o problema espaço-temporal de sistemas fluidizados, assim como a caracterização de regiões da coluna, para efetuar medições de pressão estática. As séries temporais são quantificadas, localmente, por estimadores de invariantes do caos, e a evolução do comportamento simultâneo, de todas as tomadas de pressão, são investigados.

O trabalho é dividido em duas etapas, uma envolvendo simulação numérica e outra, envolvendo a construção e ensaios experimentais de escala laboratorial. Na primeira etapa, implementa-se uma modelagem numérica TFM para auxiliar o projeto de bancada experimental e verificação de alguns parâmetros do caos nos diferentes regimes de fluidização, em três regiões da coluna, a partir das séries temporais de pressão estática. Na segunda etapa, constrói-se uma coluna LFC, com as mesmas dimensões do modelo numérico, para estudar a evolução de parâmetros do caos nos diferentes regimes de fluidização, em três regiões da coluna e com três tipos de partículas, a partir das séries temporais de pressão estática. A análise de caos, a partir de séries temporais inclui a reconstrução de atratores, determinação da dimensão de correlação, da entropia de Kolmogorov e do expoente de Hurst. As análises no domínio do tempo deste trabalho são apresentadas em termos de média e desvio padrão.

A partir do aparato experimental realiza-se uma investigação do comportamento dinâmico, através da análise não-linear local de séries temporais de pressão estática de três pontos axialmente distribuído no domínio, e propõe-se um índice baseado nas invariantes caos, capaz de quantificar o regime corrente de uma coluna de fluidização transparente. A metodologia aplicada considera o problema espaço-temporal de sistemas fluidizados, avaliando a evolução da entropia de Kolmogorov (imprevisibilidade ou grau de desordem do sinal avaliado) nas regiões de base, meio e topo de uma coluna de fluidização para os regimes expandido, borbulhante, turbulento e rápido. O expoente de Hurst pode melhorar a precisão no julgamento entre os regimes expandido e borbulhante. Através de uma planta de leito fluidizado circulante fria, instrumentada na base, no meio e no topo são ensaiados três tipos de partículas - vidro de $355 \mu \mathrm{m}$, areia 1,0 $\mathrm{mm}$ e areia 1,2 $\mathrm{mm}$ - operando nos quatro regimes. Baseado na razão entre entropias de Kolmogorov de diferentes regiões da coluna, este trabalho avalia a evolução das similaridades caóticas dessas regiões para quantificar cada regime de fluidização.

O presente trabalho investiga experimentalmente, através da análise não-linear local de séries temporais de pressão estática, de três pontos axialmente distribuído no domínio, e propõe um índice baseado nas invariantes caos, capaz de quantificar o regime corrente de uma coluna de fluidização transparente (confirmação visual dos regimes). A metodologia aplicada, considera o problema espaço-temporal de 
sistemas fluidizados, avaliando a evolução da entropia de Kolmogorov (imprevisibilidade ou grau de desordem do sinal avaliado) nas regiões de base, meio e topo de uma coluna de fluidização para os regimes expandido, borbulhante, turbulento e rápido. O expoente de Hurst pode melhorar a precisão no julgamento entre os regimes expandido e borbulhante. Através de uma planta de leito fluidizado circulante fria, instrumentada na base, no meio e no topo são ensaiados três tipos de partículas - vidro de $355 \mu \mathrm{m}$, areia $1,0 \mathrm{~mm}$ e areia $1,2 \mathrm{~mm}$ - operando nos quatro regimes. Baseado na razão entre entropias de Kolmogorov de diferentes regiões da coluna, este trabalho avalia a evolução das similaridades caóticas dessas regiões para quantificar cada regime de fluidização.

\subsection{Resultados obtidos}

Os resultados indicam a presença de duas regiões características numa coluna de fluidização - a razão entre base-meio, que reduz a medida que o fluxo de ar ou a energia dos regimes aumentam; a razão meio-topo, que aumenta à medida que o fluxo de ar ou energia dos regimes aumentam. A principal contribuição, reside na construção do índice de divergência, definido como a diferença entre a similaridade base-meio e a meio-topo. Para divergências nulas de todos os ensaios, a invariante do expoente de Hurst foi capaz de distinguir entre os regimes expandido e borbulhante. O regime turbulento foi observado para divergências maiores do que zero e menores do que a máxima. Já o regime rápido apresenta o máximo sinal de divergência.

O estudo concluiu que as invariantes do caos foram sensíveis aos regimes de fluidização e pouco dependeram das características das partículas. Apesar desta técnica não ter sido testada em colunas escalonadas, a partir da teoria de análise de séries temporais por invariantes caóticas, é possível inferir que as invariantes permanecerão sensíveis aos regimes de fluidização, e pouco sensível a mudança geométrica de uma coluna escalonada [37].

O método proposto demonstra potencial para ser aplicado em controle de processos contínuos de leito fluidizado como limpeza, mistura, recobrimento, granulação, secagem, pirólise, gaseificação e combustão, para manutenção dos regimes de fluidização desejados face as mudanças de inventário de massa. Os principais impactos são redução da complexidade operacional, facilitada agora pela implementação de malha de controle de regime, aumentando a eficiência das reações, reduzindo a variabilidade dos gases de saída e incrementando a repetibilidade do processo.

\subsection{Organização do manuscrito}

Esta tese é dividida em seis capítulos. Segue abaixo, uma breve descrição de seus conteúdos.

O capítulo 1, apresenta uma contextualização acerca da gaseificação, seus impactos e problemas. Além disso, apresenta-se também a motivação da pesquisa sobre o tema, os objetivos e a metodologia.

O capítulo 2, a revisão bibliográfica, apresenta conceitos modernos da fluidodinâmicos em leito fluidizado circulante, uma revisão nos fundamentos da fluidodinâmica computacional para implementação de simulação numérica de uma coluna de leito fluidizado circulante e breve introdução à Teoria do Caos aplicado a análise não linear de séries temporais. Em seguida, descreve a fundamentação matemática das técnicas de análises não lineares para reconstrução de atratores e estimação de invariantes do caos como dimensão de correlação, entropia de Kolmogorov e expoente de Hust. Também são apresentados alguns resultados de trabalhos semelhantes ao exposto aqui.

O capítulo 3, apresenta uma modelagem numérica capaz de prever condições operacionais para ensaios reais. O capítulo apresenta as equações governantes de escoamento multifásico pelo modelo de dois 
fluidos (TFM), implementadas no código MFIX (Multiphase Flow with Interphase eXchange). Neste capítulo foram discutidas as condições iniciais, de contorno e parâmetros numéricos capaz reproduzir perdas de cargas numa de fluidização, em diferentes regimes, auxiliando o projeto de uma bancada experimental.

O capítulo 4, apresenta a metodologia experimental, definida com capítulo anterior, para investigação da quantificação dos regimes de fluidização. Descreve cuidados para o bloqueio e isolamento de ruídos, para captura da interação fluido-partícula local. Neste capítulo, são descritos e especificados os materiais usados na condução destas práticas.

O capítulo 5, resultados, avalia as invariantes locais do caos em diferentes regiões axiais da coluna de fluidização, a partir de séries temporais numéricas e experimentais. Em seguida, os resultados desta análise foram comparados e discutidos. O capítulo apresenta o desempenho do sistema de aquisição de sinais e proposta de nova abordagem para quantificação de regime de fluidização em leito fluidizado circulante, a partir do índice de similaridade, para controle de processos.

O capítulo 6, considerações finais, apresenta as conclusões alcançadas, as contribuições da tese e sugestões para trabalhos futuros que contribuam para o controle dos gaseificadores de leito fluidizado circulante. 


\section{CONCEITOS, FUNDAMENTOS E ESTADO DA ARTE}

Este capítulo reúne os conceitos, fundamentos e estado da arte utilizados no desenvolvimento da proposta desta tese. $O$ conteúdo bibliográfico será exposto em duas partes: a descrição qualitativa, abordando recentes observações quanto ao comportamento do escoamento gás-sólidos em leitos fluidizados, e a descrição quantitativa, evidenciando teorias $e$ o equacionamento matemático aplicados a esses sistemas.

As publicações na área de sistemas fluidizados, tem experimentado constantes mudanças quanto a sua compreensão/caracterização e procedimentos para escalonamento de coluna. $\mathrm{O}$ sucesso do escalonamento de reatores de leito fluidizado (LF) não é garantido se for aplicada a abordagem de engenharia de fluidização convencional de números adimensionais. A consideração da hidrodinâmica caótica em sistemas fluidizados, desde a década de 1990, tem aumentado a quantidade publicações quanto a novas possibilidades de caracterização, escalonamento de coluna e controle de regimes de fluidização [38] [39] [28] [30] [23] [40] [41] [33] [42] [43] [44] [45] [25] [46] [47] [48] [49] [50] [51] [52].

$\mathrm{Na}$ abordagem convencional, os regimes de fluidização são caracterizados pela perda de carga, entre dois pontos espacialmente distribuídos, e a velocidade que o a agente fluidizante (caso geral de sistemas fluidizados) atravessa o leito. A perda de carga distingui bem leitos empacotados (partículas empilhadas naturalmente) de leitos fluidizados (até a mínima fluidização), porque expandem, linearmente (homogêneo), até o estado de mínima fluidização, ou regime de fluidização particulada. Após a expansão máxima, o leito move-se, desempenhando diversos padrões ou regimes de fluidização heterogêneo, como a fluidização borbulhante, turbulenta, rápida e de transporte pneumático, conhecido como regime de fluidização agregativa, e a perda de carga não apresenta valores diferenças consideráveis para distinguir os regimes. Portanto, a perda de carga é insuficiente para caracterizar todos os regimes de fluidização.

O comportamento caótico pode ocorrer em sistemas dinâmicos descritos por equações não-lineares. O caos mostra-se através de movimentos irregulares, que nunca se repete exatamente. Outra característica é quanto a previsão limitada do comportamento futuro, a partir de observações anteriores. Diferentes de sistemas de resposta estocástica, os sistemas com resposta caótica são previsíveis (a curto prazo) porque as trajetórias dinâmicas reais visitam apenas uma pequena parte do espaço de fase, chamada atrator ou região de atração.

O sucesso da aplicação de modelos fluidodinâmicos, usando métodos de discretização (particionamento do domínio) em duas ou três dimensões, para projeto de sistemas fluidizados reais, tem aumentado o número de artigos científicos, substancialmente, nos últimos anos. O uso de simulações numéricas transientes, em sistemas fluidizados, pode auxiliar no projeto mecânico (estudo de geometria de coluna e perda de carga para dimensionamento de equipamentos), de instrumentação (seleção de variáveis de processo e suas correspondentes resolução e faixa de operação do instrumento) e operacional (seleção de condições operacionais e estudo de algoritmos de controle de processos), considerando as abordagens convencional e de resposta caótica.

Em análise não-linear de resposta caótica, um atrator representando a evolução da dinâmica do sistema no espaço de estado pode ser reconstruído a partir de série de medidas de uma variável característica. Este trabalho, trabalha com a flutuação de pressão estática medida em pontos distribuídos ao longo de 
uma coluna de fluidização. Os atratores da variável selecionada, podem ser caracterizados por invariantes tais como a dimensão de correlação (mede a complexidade do sinal de pressão estática), a entropia de Kolmogorov (a taxa de perda de informação baseado no sinal de pressão estática) e o expoente de Hurst (mede a rugosidade da série caótica em que valores entre 0,5 e 1, respectivamente, representa uma série rugosa e suave). Se possível, a caracterização por invariantes do caos, dos regimes de fluidização, pode contribuir com novas técnicas para controle automatizados de plantas de gaseificação de leito fluidizado circulante (LFC).

Para sistemas fluidizados reais, uma avaliação de possíveis fontes de ruído de medição deve ser realizada, pois pode afetar a análise do caos. A análise do caos tem o potencial para fornecer sinais instantâneos da quantificação de regimes de fluidização de uma coluna, permitindo a implementação de algoritmos de controle de processos. O estudo de controle de processos em sistemas fluidizados pode contribuir com sua continuidade operacional, bem com a redução da variabilidade da composição do gás de saída, considerando gaseificadores de leito fluidizado circulante (LFC).

\subsection{Sistemas fluidizados}

Sistemas fluidizados, em geral, possuem vantagem natural de terem altas taxas de transferência de massa e calor. Desde a década de 80, a tecnologia de sistemas fluidizados está comercialmente presente em aplicações de limpeza, mistura, recobrimento, granulação, secagem, pirólise, gaseificação, combustão, entre outros. Cada uma destas aplicações, deve operar em diferentes regimes de fluidização, de forma a maximizar a transferência de calor, massa, favorecendo as condições para determinadas reações químicas (como em pirólise, gaseificação e combustão).

A abordagem convencional é relevante, principalmente, para compor as equações de fechamento, presentes na modelagem multifásica de sistemas fluidizados.

A abordagem moderna, complementa a abordagem anterior com mecanismos de formação de regimes, reconhecendo a complexidade a estrutura multi-escala e o comportamento caótico de sistemas fluidizados.

\subsubsection{Abordagem convencional de sistemas fluidizados}

A abordagem convencional é caracterizada pela elaboração de mapas de fluidização baseado em variáveis macroscópicas e métodos de adimensionalização destas variáveis, para o monitoramento e controle dos regimes. Para formulação dos mapas são necessárias definições de características das partículas como diâmetros, massa específica, fração de vazios ou porosidade, velocidade terminal, regimes de fluidização e classificação das partículas segundo resposta à fluidização. O cruzamento das informações das partículas, com características do agente fluidizante e da geometria da coluna, permitem o mapeamento dos diferentes tipos de regimes de fluidização [53].

Os mapas de fluidização adimensionalizados através de variáveis macroscópicas são eficazes para registrar as transições de regimes na própria coluna que o gerou. Quando a coluna é escalonada, estes mapas subespecificam a previsão do regime de fluidização, pois alguns não consideram os fluxos mássicos arrastados e não levam em conta fatores de micro e meso-escala. 


\subsubsection{Caracterização de partículas sólidas}

Em fluidização, a caracterização de partículas inclui parâmetros de tamanho, massa específica, porosidade interna e forma. Devido a heterogeneidade das partículas, existem diferentes formas e técnicas para caracterizar seu diâmetro. A literatura reúne diversas formas para definição do diâmetro de uma amostra de partículas - como diâmetro cilíndrico, esférico, superficial, volumétrico, volumétrico-superficial, de queda livre, de arrasto, do perímetro, diâmetro de Sieve, de Stokes, de área projetada, de Feret, de Martin - sendo o diâmetro médio de tamanhos misturados, conforme a Equação 1 , um dos mais usados devido as facilidades de medição ( $x_{i}$ fração em peso do tamanho da partícula $\left.d_{p i}\right)[54]$.

$$
\overline{d_{p}}=\frac{1}{\sum \frac{x_{i}}{d_{p i}}}
$$

Equação 1

Partículas sólidas naturais podem ocorrer em que qualquer forma. Dentre uma variedade de técnicas para caracterizar a forma da partícula, em sua maioria tem como base: o volume, a superfície, a área projetada e perímetro projetado [54]. Há várias técnicas para caracterizar a forma da partícula como: o grau de esfericidade, circularidade, fator de forma de Heywood, esfericidade e circularidade de trabalho, entre outros. Proposto por Wadell [55] uma medida da esfericidade operacional para uma partícula definido conforme a Equação 2, é usual devido a sua facilidade de medição. A esfericidade operacional de diversas partículas pode ser consultada facilmente através de tabelas.

$$
\phi_{p}=\left(\frac{\text { Volume da partícula }}{\text { Volume da menor esfera circunscrita na partícula }}\right)^{1 / 3}
$$

Equação 2

\subsubsection{Porosidade ou fração de vazios}

Devido ao empilhamento de um leito partículas, regulares ou não, existem zonas de ausência de sólidos, chamadas de "vazios". A porosidade, $\varepsilon$, é definida como a razão entre o volume de "vazios", ou ausência de partículas, pelo volume total ocupado pelo leito de partículas sólidas, conforme a Equação 3.

$$
\varepsilon=\frac{\text { Volume ocupado pela ausência de partículas }}{\text { Volume ocupado pelo leito de partículas }}
$$

Equação 3

Experimentalmente, através de proveta, bequer, balança de precisão, líquido com massa específica baixo é possível encontrar os volumes da Equação 3, conforme [56].

\subsubsection{Velocidade terminal}

Para uma partícula movendo-se num fluido, a força atuante sobre a superfície desta, depende apenas do fluxo do fluido em sua vizinhança. O caso de uma única partícula irregular, que se move com uma velocidade constante e relativa, $U_{r}$, a um fluido newtoniano, na condição de queda, pode ser definida pela Equação 4. 


$$
U_{r}=U_{t}=\sqrt{\frac{4}{3} \frac{d_{p}\left(\rho_{p}-\rho_{f}\right) g}{\rho_{f} C_{D}}}
$$

Haider e Levenspiel [57] propuseram um método aproximado para avaliação direta da velocidade terminal, considerando partículas irregulares, através da definição de um diâmetro de partícula, $d_{p}^{*}$, e velocidade, $U^{*}$, adimensionais, dados pela Equação 5 .

$$
\begin{aligned}
& A r=\frac{d_{p}^{3} \rho_{f}\left(\rho_{p}-\rho_{f}\right) g}{\mu^{2}} \\
& (R e)_{p}=\frac{U_{r} d_{p} \rho_{f}}{\mu} \\
& d_{p}^{*}=d_{p}\left[\frac{\rho_{f}\left(\rho_{p}-\rho_{f}\right) g}{\mu^{2}}\right]^{1 / 3}=A r^{1 / 3} \\
& U^{*}=u^{*}=U\left[\frac{\rho_{f}^{2}}{\mu\left(\rho_{p}-\rho_{f}\right) g}\right]^{1 / 3}=\frac{(R e)_{p}}{A r^{1 / 3}} \\
& U_{t}^{*}=\left[\frac{18}{\left(d_{p}^{*}\right)^{2}}+\frac{2,335-1,744 \phi}{\left(d_{p}^{*}\right)^{0,5}}\right]^{-1}, 0,5<\phi<1 \\
& U_{t}^{*}=\left[\frac{18}{\left(d_{p}^{*}\right)^{2}}+\frac{0,591}{\left(d_{p}^{*}\right)^{0,5}}\right]^{-1}, \phi=1
\end{aligned}
$$

\subsubsection{Regimes de fluidização}

A caracterização dos regimes de fluidização iniciaram de estudos empíricos ligados a curva de queda de pressão de uma coluna de fluidização. A partir da Lei de Darcy, as correlações de Blake, Bronwnell e Kats, Carman e Kozeny permtiram a complementação da correlação de Ergun, que estipula o gradiente de pressão, $\Delta P / L$, num leito de partículas para os casos laminares e turbulentos pode ser dado pela Equação 6 [58].

$$
\frac{\Delta P}{L} \frac{g d_{p} \phi}{2 \rho_{f} U^{2}} \frac{\varepsilon^{3}}{(1-\varepsilon)}=75 \frac{(1-\varepsilon)}{\phi(R e)_{p}}+0,875
$$

Equação 6

A partir do trabalho de Ergun, outros cientistas como Gibilaro et al. [59] propuseram modificações nos expoentes da equação de Ergun para melhores ajustes no gradiente de pressão.

A curva característica da queda de pressão de um leito fluidizado de partículas finas em função do aumento da velocidade do ar de entrada, é representado pela Figura 2. O comportamento dos regimes de fluidização em função do gradiente de pressão não são facilmente distinguíveis. Este método diferencia bem um leito fixo de um fluidizado (borbulhante, turbulento, rápido e transporte).

No regime de leito expandido o gás flui através dos interstícios de um leito de partículas. O leito se expande suave e homogeneamente (vide destaque no regime expandido da Figura 2), a superfície do leito é bem definida e o movimento de partículas ocorre em pequena escala. A velocidade de operação (ar de entrada, $U$ ) se encontra entre a $U_{m f}$ e a velocidade de mínimo borbulhamento $\left(U_{m b}\right)$. 
No regime borbulhante, formam-se vazios (bolhas, conforme destaque do regime borbulhante da Figura 2) próximo ao distribuidor, que coalescem e crescem. As bolhas sobem até a superfície e estouram. $\mathrm{O}$ tamanho das bolhas se aproxima do tamanho da seção transversal da coluna. A superfície superior se eleva e colapsa com frequência regular. A velocidade de operação está entre $U_{m b}$ e a velocidade de transição turbulenta $\left(U_{c}\right)$

No regime de fluidização turbulenta, a flutuação de pressão gradualmente decresce até o regime turbulento ser alcançado. As instabilidades podem provocar aumento na movimentação de vazios (bolhas ou golfos, conforme destaque do regime turbulento da Figura 2). Pequenos vazios de gás e agrupamentos acentuados de partículas fazem movimento de sobe e desce, no caso de colunas verticais. A lâmina ou superfície superior do leito torna-se difícil de distinguir. A velocidade de operação está entre $U_{c}$ e fim da velocidade turbulenta $\left(U_{k}\right)$

No regime rápido, o leito fica sem uma superfície bem definida e as partículas são transportadas em forma de agrupamentos devem ser substituídas através da circulação interna (conforme destaque do regime rápido da Figura 2) e circulação externa, através de uma malha circulante. Este regime é caracterizado pela formação de um escoamento núcleo-anelar, em que a região central da coluna, possui movimento ascendente de fase diluída (pobre de partículas), enquanto, a região anular (borda da coluna), apresenta um movimento descendente de fase densa.

No transporte pneumático, não há leito bem definido, todas as partículas alimentadas são transportadas para o topo da coluna como uma fase diluída [54].

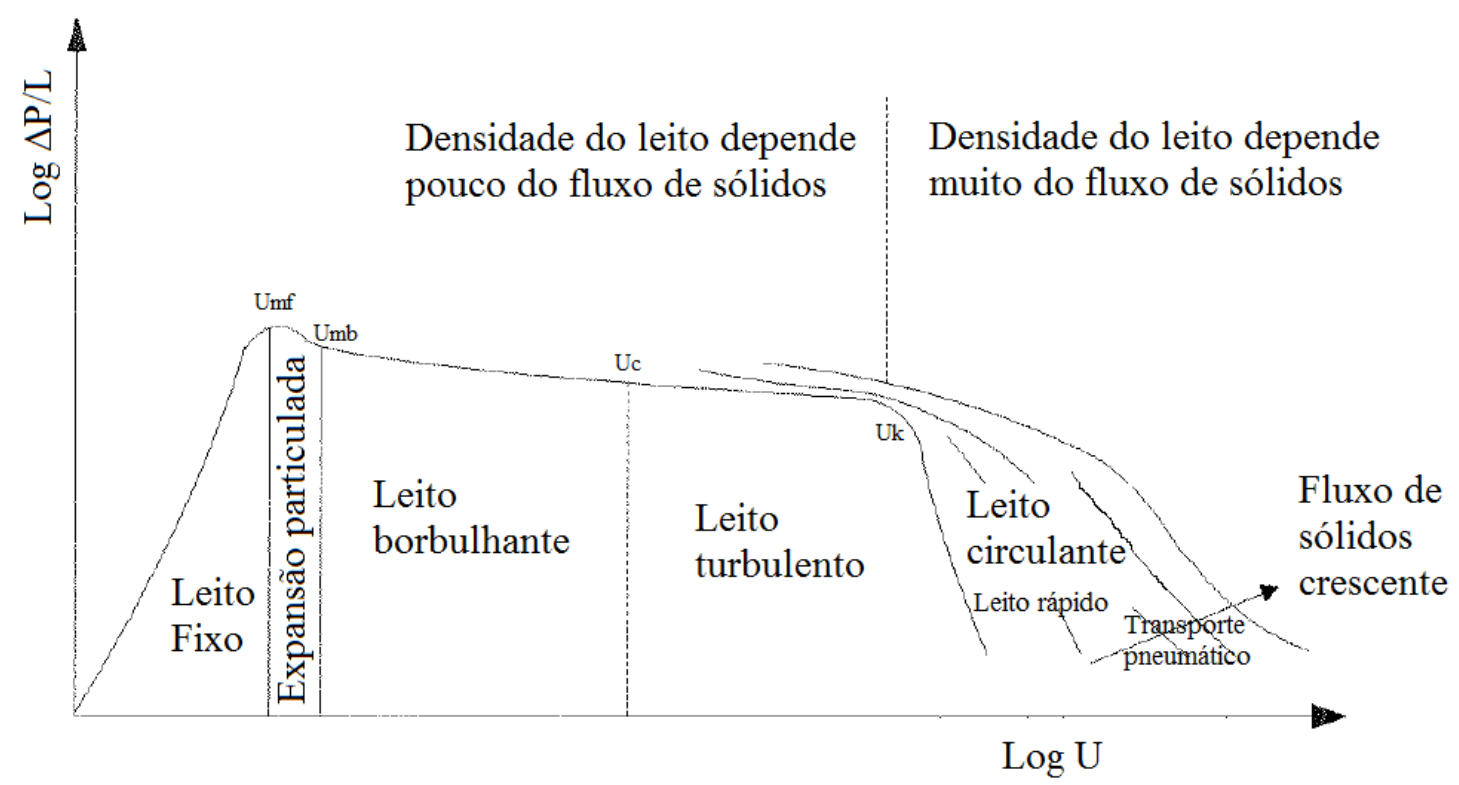

Figura 2 - Curva característica de queda de pressão de regimes de fluidização. Adaptado de [60].

Sob o ponto de vista da fração de vazios ou porosidade global da coluna de fluidização G/S, o início do processo ocorre na velocidade de mínima fluidização, $U_{m f}$, para partículas grossas e na velocidade mínima borbulhante, $U_{m b}$, para pós finos, conforme a Figura 3. Durante a fluidização, o sistema fluidopartícula adquire uma estrutura de duas fases, que consiste de uma fase discreta rica de bolhas diluídas e uma fase densa contínua de emulsão rica em sólidos. A porosidade na fase bolha diluída está próximo à unidade, enquanto a porosidade na fase densa permanece mais ou menos constante e perto da porosidade de mínima fluidização, $\varepsilon_{m f}$. 
Para as partículas sólidas com superfícies mais lisas e diferentes tamanho, especialmente com a incorporação de pós finos, a fluidização G/S é menos agregativa (heterogênea) e mais particulada (homogênea). As bolhas são pequenas e mais numerosas e com velocidades de gás mais elevadas. É possível alterar a forma de bolhas, especialmente com a reciclagem dos sólidos a partir da parte superior para a parte inferior do leito fluidizado. Tal recirculação pode produzir uma nova estrutura de escoamento de duas fases com fios (strands) ou agrupamentos (clusters) de sólidos como uma fase descontínua, dispersa numa fase contínua diluída. A este escoamento bifásico com estruturas agrupadas em velocidades elevadas, só é possível operar nos chamados leitos fluidizados circulante (reciclagem), que são geralmente caracterizados pela presença simultânea de uma região diluída no topo e uma região densa no fundo da coluna [22].

Com o aumento da velocidade do gás, o sistema agregativo engloba assim uma série de fenômenos: fluidização borbulhante, turbulenta e rápida, para então culminar no transporte diluído a uma velocidade $U_{p t}$ (velocidade de afogamento ou choking) correspondente à saturação da capacidade de transporte, $K^{*}$, conforme mostra a Figura 3. Em $U_{p t}$, a fluidização rápida forma duas regiões, consistindo de uma região diluída no topo coexistindo com uma região densa na parte inferior. Essa reversão súbita é caracterizada por uma mudança descontínua na porosidade e estrutura do leito. No transporte diluído, um sistema G/S demonstra a natureza pseudo-homogêneo. Por fim, em velocidades de gás ainda mais elevada, a idealizada homogeneidade torna-se evidente quando partículas começam a se comportar de forma discreta [22].

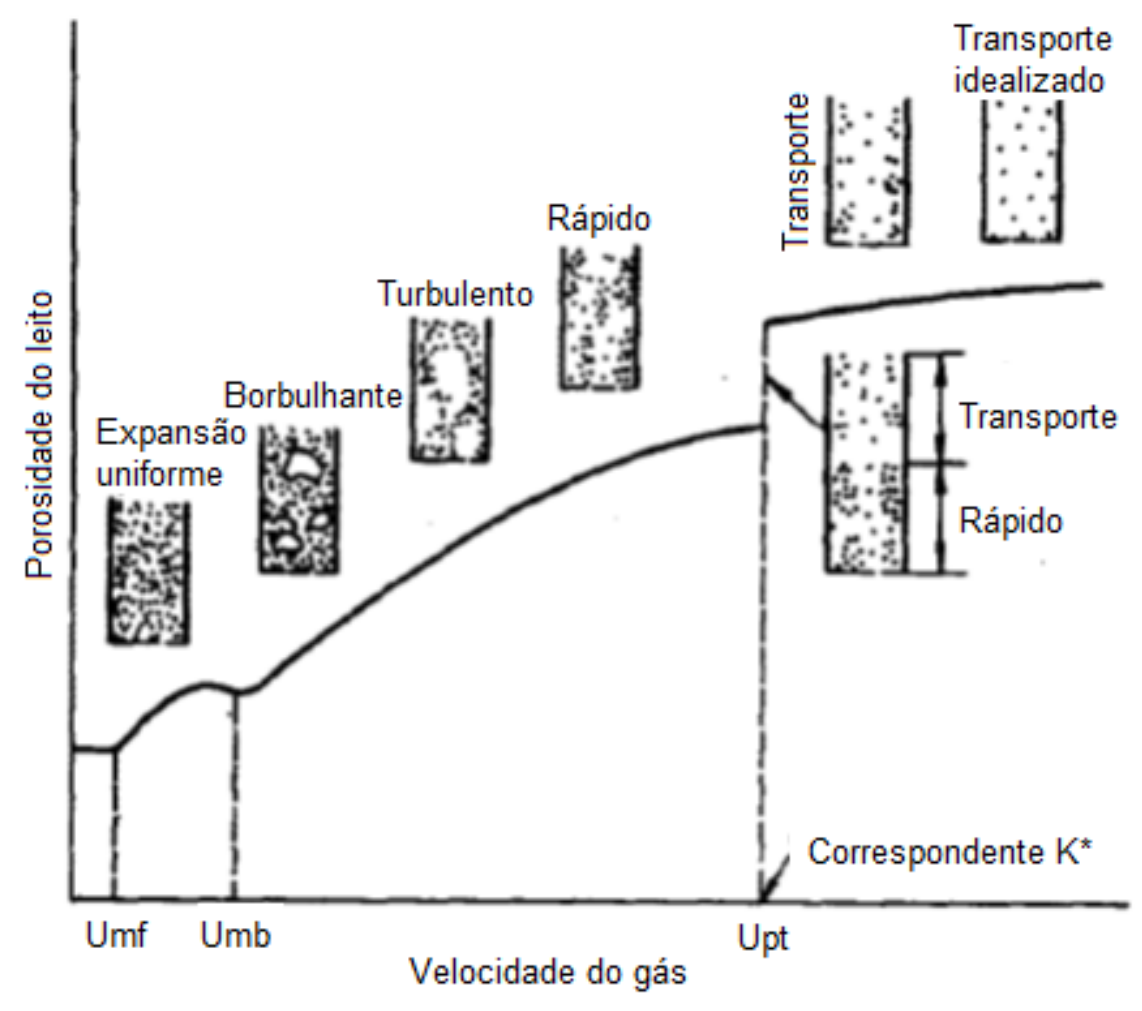

Figura 3 - Curva característica de porosidade global da coluna dos regimes de fluidização. Adaptado de [22].

Apesar do perfil de porosidade global da coluna permitir a caracterização de regimes de fluidização, sua medição direta tem avançado no incremento da precisão, através do uso de técnicas sensores de impedâncias [61] e raio X rápido [25]. Contudo, essas aplicações ainda são restritas para leitos frios 
(temperatura ambiente) de escala laboratoriais, necessitando de novas técnicas compatíveis com aplicações para leitos quentes, como secagem, pirólise, combustão e gaseificação (> $\left.100^{\circ} \mathrm{C}\right)$.

\subsubsection{Classificação de partículas segundo resposta à fluidização}

Através de observações cuidadosas do comportamento de partículas ao processo de fluidização, desde pós até partículas maiores, Geldart [62] encontrou quatro diferentes grupos e as organizou, segundo a diferença entre massa específica da partícula (sólido granular) e o agente fluidizante (geralmente gás) em função do diâmetro, conforme a Figura 4.

O grupo C da classificação de Geldart [62], são pós finos e coesivos. A fluidização é dificultada devido a forças entre as partículas dominarem face a as forças exercidas pelo gás. O comportamento típico deste tipo de pó, é a formação de canal preferenciais (processo de canalização) onde o leito de partículas não chega a fluidizar [63], conforma Figura 4. A Farinha e amido são exemplos típicos.

O grupo A da classificação de Geldart [62], são partículas aeráveis, com baixo diâmetro e/ou baixa massa específica $\left(<\sim 1.400 \mathrm{~kg} / \mathrm{m}^{3}\right)$. Estes fluidizam facilmente, sofrendo a expansão do leito em baixas velocidades do gás de entrada e o estado de borbulhamento pode ser facilmente controlado em altas velocidades. Exemplos deste tipo são as partículas usadas como fluidos de craqueamento catalítico (FCC) [63], conforme a Figura 4.

O grupo B, da classificação de Geldart [62] são partículas parecidas com areia e massa específica entre $1.400<\rho_{s}<4.000 \mathrm{~kg} / \mathrm{m}^{3}$. Estes sólidos fluidizam bem e no regime borbulhante produzem bolhas rápidas e grandes [63], conforme a Figura 4.

O grupo D da classificação de Gerdart [62], são de partículas jorráveis, de grandes dimensões e massas específicas. Leitos de grandes profundidades são difíceis de fluidizar. Este tipo de partícula se comporta de forma estranha, provocando grandes explosões de bolhas ou formação de canais preferenciais (canalização), caso o distribuidor não seja uniforme [63], conforme a Figura 4. Exemplos deste tipo de partícula são grãos alimentícios (café, ervilha, etc.) e alguns minérios cozidos.

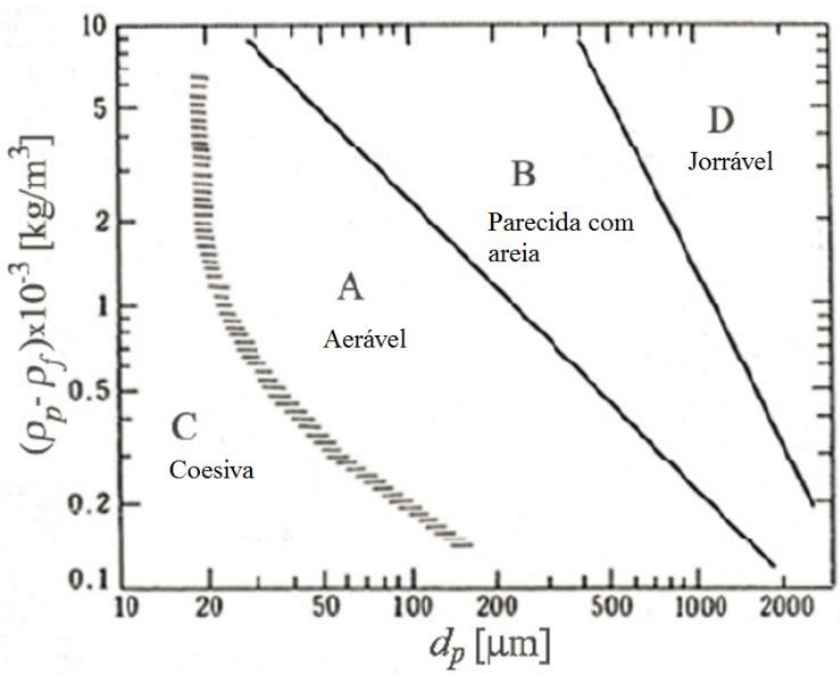

Figura 4 - Classificação de partículas sólidas proposta por Geldart. Adaptado de [62]. 
Outros autores como Miyauchi et al. [64] identificaram, dentro das regiões classificadas por Geldart, sub-regiões para cada especificação de partícula, como areias, grãos, pós metálicos, entre outros.

A classificação dos tipos de partículas conduz ao mapeamento dos estados de fluidização, considerando colunas com malha circulante, devido ao arrasto excessivo imposto pelos regimes turbulento, rápido e transporte pneumático (vide Figura 5).

A sequência dos regimes de fluidização para partículas do grupo C, da Figura 5, indicam a dificuldade, destas partículas, em fluidizar nos regimes expandido e borbulhante. Tal fato, está atribuído as forças de coesão interpartículas responsáveis um comportamento pistonado ou formação de golfos, característicos da fluidização turbulenta. Aumentado ainda mais a velocidade do gás de entrada é possível alcançar os regimes de fluidização rápido e de transporte pneumático.

A sequência das características de fluidização para partículas do grupo A, conforme a Figura 5, são presenças de expansão de leito e formação de bolhas. Neste tipo de partícula, ficam evidentes as velocidades de transição entre regimes. No regime expandido é verificada a expansão da altura do leito, a partir da velocidade de mínima fluidização, $U_{m f}$. Com o aumento da velocidade do gás de entrada, aparecem as primeiras bolhas, marcando o início do regime borbulhante e na velocidade de mínimo borbulhamento, $U_{m b}$, enquanto os graus de intensidade de bolhas estão em função do $U_{m b}$. Aumentando da velocidade do gás de entrada, as bolhas eclodem, dando lugar a golfos e ejeção de materiais para fora da coluna. O movimento alternativo (sobe e desce) de porções do leito podem ser caracterizados pelo espectro de Fourier de pressão estática. $\mathrm{O}$ aumento ainda maior da velocidade do gás de entrada promove o regime rápido, caracterizado pelo escoamento núcleo-anelar, em que o arrasto de sólidos, desde da base até o topo da coluna, ocorre de forma diluída e ascendente pela parte central, e seu retorno, do topo para base, de forma densa e descendente pela parte anelar, também chamado de circulação interna. $\mathrm{O}$ último regime é o transporte pneumático, caracterizado pela ausência de circulação interna onde o arrasto ascendente pode ocorrer de forma diluída ou densa.

A sequência das características de fluidização para partículas do grupo B, conforme a Figura 5 , a presença das bolhas ocorre próximo a velocidade de mínima fluidização, ou seja, quando $U_{m f} \approx U_{m b}$. A faixa de operação do regime expandido é estreita (ou nula) fazendo com que o leito de partículas do grupo B iniciem o regime borbulhante. A intensidade das bolhas pode variar linearmente com o excesso de velocidade o gás a partir da velocidade mínima de borbulhamento, $U-U_{m b}$. Os regimes turbulento, rápido e de transporte são semelhantes as partículas do grupo A. Como o grupo B são partículas mais pesadas, o alto consumo energético, geralmente, inviabiliza sua operação em transporte pneumático.

A sequência das características de fluidização para partículas do grupo D, conforme a Figura 5, a expansão do leito é nula e as bolhas coalescem (fundem) rapidamente. Isto significa que partículas do grupo $\mathrm{D}$, tendem a não apresentar regimes expandidos e comportamento borbulhante regular, saltando diretamente para o regime turbulento. Como este grupo trata de partícula muito pesada, o alto consumo energético, geralmente, inviabiliza a operação em regimes rápidos e de transporte. Outro fator impeditivo para a operação em regimes rápido e de transporte é o alto grau de colisões que esses regimes proporcionam, podendo danificar essas partículas, geralmente, grãos alimentícios. 


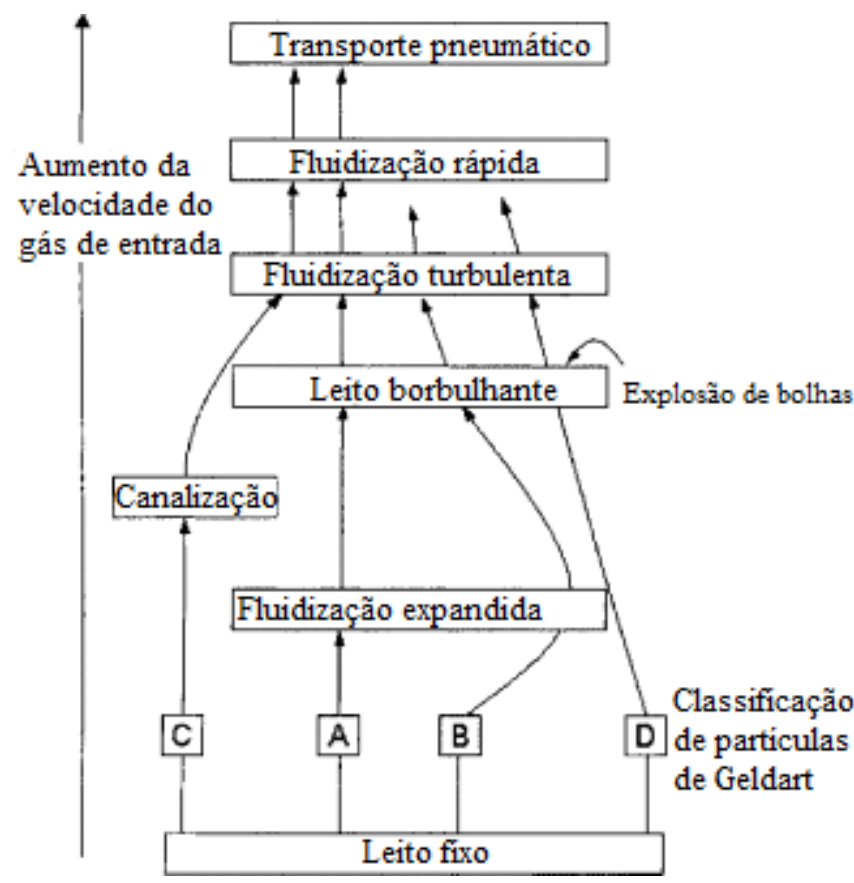

Figura 5 - Mapeamento da sequência de estados de fluidização e suas transições, para cada tipo de partícula na classificação de Geldart, face ao aumento da velocidade do gás de entrada. Adaptado de [63].

Portanto, a principal diferença entre os regimes fluidização na diversidade de classificação de Geldart é a faixa operacional do regime de fluidização que a velocidade de gás de entrada pode promover. Partículas do grupo C possuem faixas operacionais dos regimes expandido e borbulhante nulas, enquanto partículas do grupo $\mathrm{D}$, podem possuir estreitas faixas de operacionais para o regime borbulhante.

A classificação do comportamento das partículas em diferentes regimes, motivou a proposição de diferentes tipos de mapas de fluidização com o propósito de tentar auxiliar no escalonamento de reatores e colunas de leito fluidizado.

\subsubsection{Mapas de fluidização}

O comportamento dinâmico de sistemas fluido-partículas pode ser parcialmente caracterizado por variáveis macroscópicas como o diâmetro e classificação de partículas, o fluxo de sólidos, a queda de pressão e o fluxo de fluido contido no sistema. A relação entre essas variáveis pode ser usada para identificar/classificar regimes de fluidização numa determinada escala do sistema. Ou seja, experimentos em escala laboratorial não podem ser usados como referência para projeto de sistemas de escalas maiores.

Com a intenção de incrementar os projetos de escalonamento de colunas de fluidização e condições operacionais para controle de regimes, muitos cientistas investiram em abordagem adimensionalizadas de mapas de fluidização. Conforme Zenz [14], propôs um diagrama de fase para sistemas gás-sólidos em escoamento vertical cujo são gradiente de pressão e taxa de sólidos, capaz de, qualitativamente, apresentar características dos regimes de escoamento. Em seguida, Reh [15] propôs um mapa para sistemas de contato gás-sólido, ou diagrama de Reh, para traçar uma visão global do fenômeno de fluidização mais parâmetros macroscópicos como: velocidade do gás de entrada, viscosidade cinemática 
do gás, diâmetro médio das partículas, massa específica do gás e do sólido. O cruzamento destas informações gerou os parâmetros K (ordenada) e M (abscissa) num gráfico que destaca regiões limites para operação de regimes de fluidização. Yerushalmi et al. [16], propuseram a caracterização relacionando a velocidade de escorregamento e a fração de sólidos. Outros diagramas relevantes para a mapeamento dos regimes de fluidização pode ser citado em Broedermann [17], Kwauk et al. [19], Squires et al. [65].

Os perfis da fração de sólidos seriam quantificadores razoáveis de regimes de fluidização, conforme a Figura 6, nos variados sistemas fluidizados, se sua medição não fosse tão imprecisa. Atualmente, muitos pesquisadores e fabricantes estão testando sistemas, baseados em técnicas de imageamento de raio $\mathrm{X}$ rápido para estimação precisa da fração sólidos [25]. Contudo, além de caras estas técnicas ainda não trabalham bem em condições operacionais extremas, como em combustão e gaseificação, e com proteções técnicas (refratários).

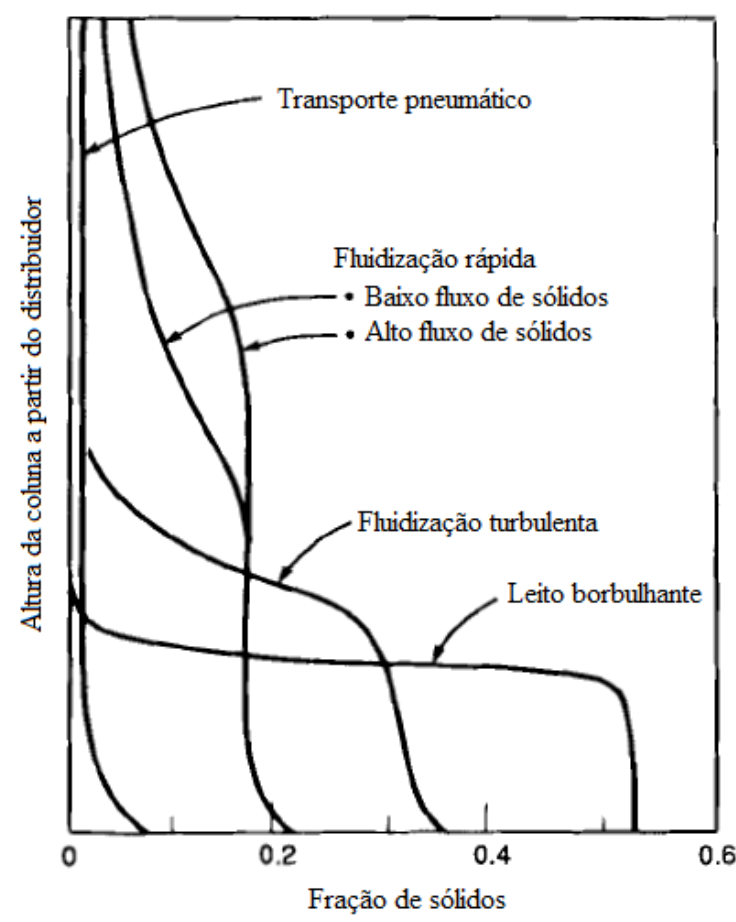

Figura 6 - Perfis qualitativos da fração de sólidos numa coluna de fluidização. Adaptado de [63].

Na Figura 7, o diagrama de porosidade vs. velocidade do ar de entrada, segundo Avidan et al. [18], embora estes valores representam um sistema de gás-sólido particular, a progressão das alterações pode ser aplicada a outros sistemas de gás-sólido. Portanto, o uso do diagrama noutros sistemas gás-sólidos inclui o escalonamento da unidade. Desprezando método de medição da porosidade e assumindo que o valor traçado na Figura 7 seja a média de dois pontos, posicionado na base e outra no topo, as diferentes inclinações representam diferentes regimes, neste método. Para a partícula FCC, este método apresentou bons resultados para identificação das velocidades de transições entre regimes, através da mudança da alteração do coeficiente angular das retas. No No regime turbulento, a Figura 7 apresenta o limiar da ejeção de partículas da coluna. Isto significa que para velocidade acima deste valor, é necessária uma malha circulante para manter o inventário de massa constante. 
Para os regimes rápido e transporte, é necessário conhecer o fluxo que o agente fluidizante é capaz de arrastar, considerando as características geométricas da coluna, e as propriedades da partícula. Contudo, conforme Mousa et al. [21] e outros cientistas, mapa de fluidização, como o da Figura 7, falha ao ser usado para escalonamento de colunas de fluidização, pois as inclinações deste são válidas apenas para a partícula FCC.

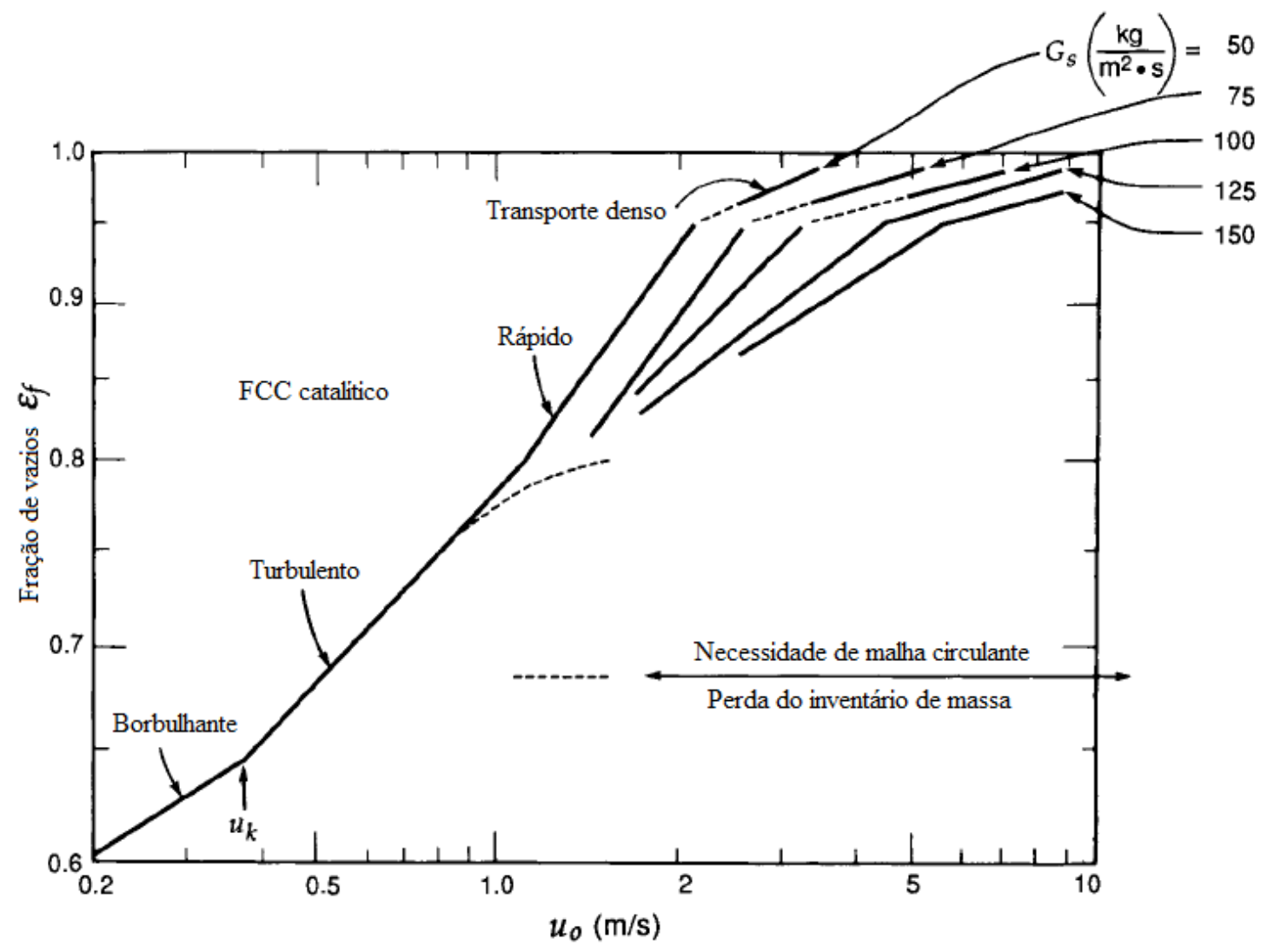

Figura 7 - Diagrama Porosidade vs. Velocidade de leito fluidizado. Mudanças na velocidade do gás de entrada alteram o regime de fluxo para um sistema gás-sólido com partículas FCC. Adaptado de [18].

Para solucionar as especificidades das condições de fluidização, que cada tipo de partícula oferece, Grace [20] formulou um mapeamento dos regimes de fluidização, considerando o tipo de partícula de Geldart e características macroscópicas como a fração de vazio, $\varepsilon$, e como função $f\left(\rho_{f}, g, \rho_{p}-\right.$ $\left.\rho_{f}, \mu, d_{p}, U\right)$, onde $\rho_{f}$ é a massa específica do fluido, $\rho_{p}$ é a massa específica da partícula, $\mu$ a viscosidade do fluido, $d_{p}$ é o diâmetro da partícula, $U$ é a velocidade de entrada de ar e $g$ é a gravidade local. O cruzamento destas variáveis é necessário para o processo de adimensionalização da velocidade, $u^{*}$, e do diâmetro da partícula, $d_{p}^{*}$, conforme a Equação 5. Este mapa, permite a generalização para diversos tipos de partículas, mas, em teoria, não para outras escalas de colunas. Segundo Mousa et al. [21], o mapa de Grace falha, pois não considera o efeito do fluxo de massa num regime corrente, não obteve dados suficiente para validação e desprezou efeitos em micro e meso escala que regem os regimes de fluidização.

Mais tarde, outros cientistas [66] incrementaram o mapa de fluidização de Grace com mais precisão, considerando outros fatores como a fluxo de sólidos. Contudo, mesmo os mapas mais precisos ainda falham no processo de escalonamento. Além disso, os dados usados na construção dos mapas de 
fluidização são baseadas em medições indiretas e necessita de ambientes laboratoriais controlados e/ou instrumentação cara para alcançar níveis de precisão razoáveis.
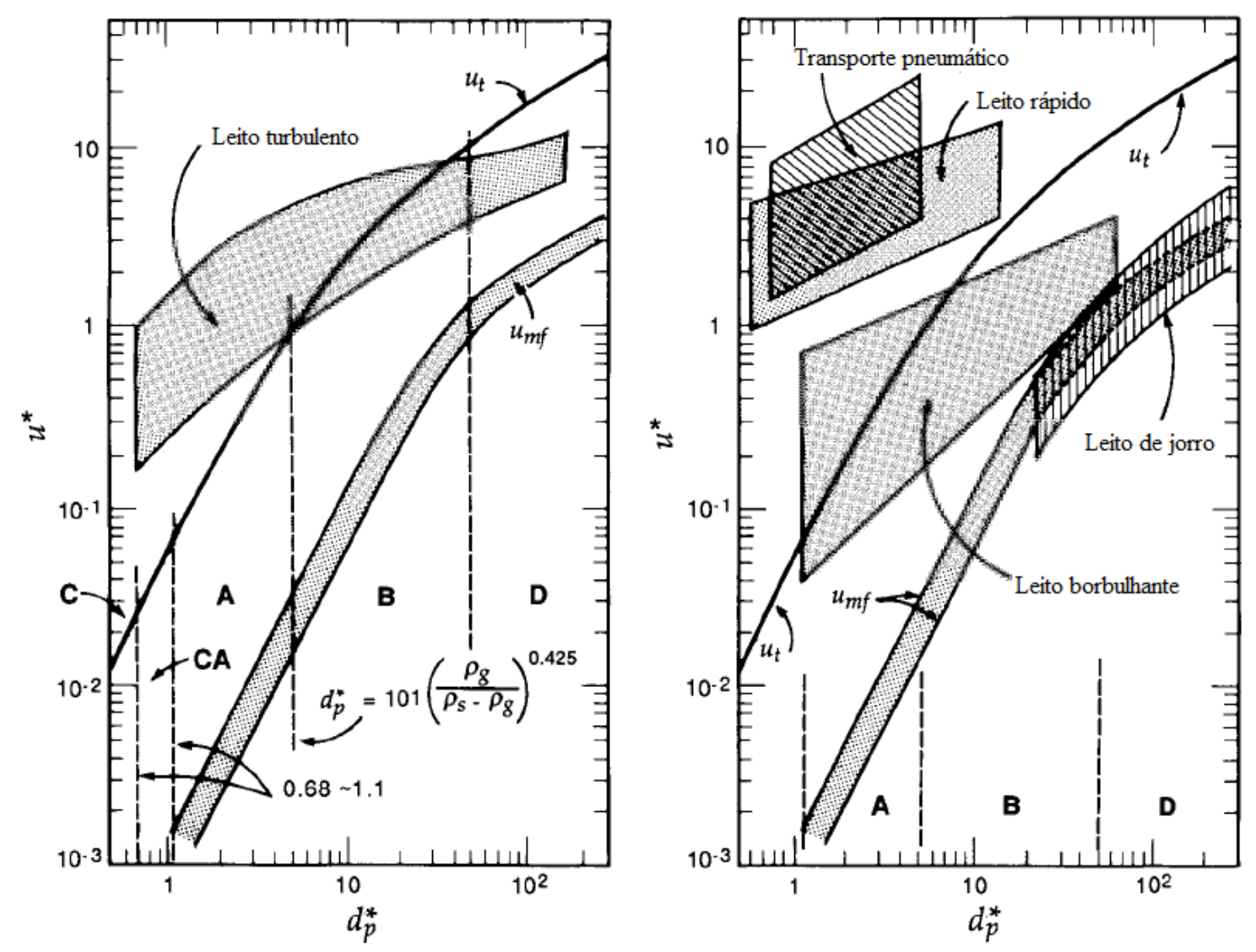

Figura 8 - Mapa de regimes de fluidização adimensionalizado de Grace. Adaptado de [20].

Com o avanço dos estudos de sistemas fluidizados, novas abordagens e teorias foram propostas para explicar a formação dos regimes de fluidização, permitindo sua quantificação. Dentre as complementações na teoria de fluidização, destaca-se a consideração da resposta caótica dos sistemas fluidizados.

\subsubsection{Abordagem moderna de sistemas fluidizados}

A existência de múltiplos padrões de regime de escoamento em sistemas de leitos fluidizado é motivação para muitos cientistas trabalharem na busca de abordagem unificada. A análise multi-escala (micro, meso e macroscópica), por enquanto aplicada em modelos numéricos, tem indicado grande potencial para estabelecer novas abordagens para previsão do comportamento heterogêneo e não-linear dos leitos fluidizados. Essa nova abordagem tem contribuído para novo mapeamento de regimes de fluidização e tem demonstrado boa concordância com dados ensaios experimentais de escala de bancada laboratorial até sistemas fluidizados de escala comercial [23].

Por outro lado, pesquisas envolvendo o comportamento caótico de sinais macroscópicas (pressão estática, diferencial, temperatura, etc.) de leitos fluidizados, tem crescido consideravelmente [29] [30] [33] [67]. Diferente da abordagem anterior, esta linha de pesquisa tem fornecido bons resultados para quantificação dos regimes de fluidização através do cálculo de invariantes do caos. 
Abordagens mais modernas para caracterização dos regimes de fluidização estão tendendo avaliar características invariantes do caos de sinais de macro-escala, como a medição de pressões estática e diferenciais, devido as suas facilidades de medição direta (compatível com sistemas comerciais), e pouca dependência da escala das colunas ensaiadas.

\subsubsection{Estrutura multi-escala}

Os sistemas complexos são caracterizados pela natureza de multi-escala que é também a principal dificuldade em analisar sistemas complexos, e está relacionada com o mecanismo real da complexidade. A estrutura multi-escala é uma das considerações mais abrangentes para modelagem intrínseca dos processos multifásicos. Conforme a Figura 9, os diferentes níveis e escalas compõe as estruturas multiescala. Os níveis são de baixo acoplamento, enquanto escalas são fortemente acoplado. Dentro de um nível, as fortes interações entre as estruturas multi-escala espaço-temporais, normalmente, dão origem a novas propriedades e funções do sistema, portanto, o reducionismo não é suficiente até mesmo para interpretar o comportamento do sistema dentro de um nível. A complexidade é, em certa medida, encapsulada dentro de cada nível abrangendo apenas uma faixa razoável de escalas, que são correlacionados com os outros níveis de forma muito menos complexa [40].

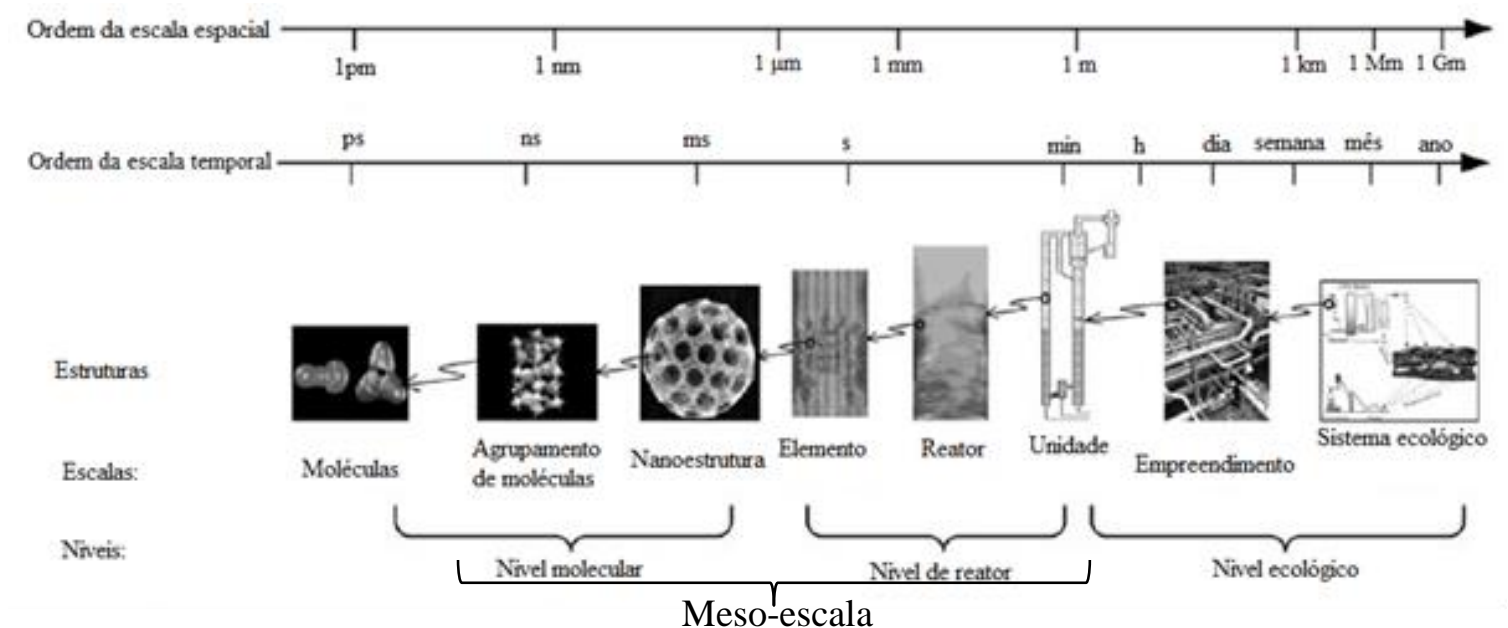

Figura 9 - Estruturas espaço-temporais multi-níveis e multi-escalas em engenharia. Adaptado de [68]

O método multi-escala considera diretamente a disparidade de comportamentos e interações em diferentes escalas, e é, portanto, uma abordagem promissora para identificar os mecanismos vigentes em sistemas complexos. De um modo geral, existem três tipos de metodologia multi-escala: descritivos, correlativos e analíticos. A metodologia multi-escala descritiva descreve a aparência de várias estruturas em diferentes escalas sem analisar os mecanismos por trás sua formação e as relações entre essas escalas. A metodologia multi-escala correlativa elucida os comportamentos em escalas maiores, analisando os mecanismos sobre as próximas escalas inferiores. A metodologia multi-escala analítica revela a relação entre escalas através da formulação de critérios de estabilidade, mecanismos dominantes e compromisso entre sub-mecanismos.

Qualitativamente, a interação de micro-escala promove o menor grau de interação entre as partículas e o fluido do sistema e corresponde ao tamanho das partículas constituintes, e predominante em ambas fase densa e fase diluída. Na meso-escala, existe a preocupação em tratar a interação entre agrupamentos 
(clusters) com a fase diluída, ou bolhas e sua emulsão. Por último, a interação de macro-escala ocorre entre o sistema fluido-partícula global e seus limites (geometria da coluna), resultando na macroheterogeneidade. A partir da análise multi-escalas pode-se resolver um sistema heterogêneo de macroescala em três subsitemas de meso e micro escala - fase densa, fase diluída e inter-fase.

Li e Kwau [22] k demonstraram que as dinâmicas complexas de um sistema de leito fluidizado pode ser reduzida a três diferentes estruturas em leitos fluidizados com base na abordagem multi-escala: macroestruturas de alta amplitude e baixa frequência, correspondendo a grande escala fenômenos como grandes bolhas e oscilações na superfície de um leito de partículas, meso-estruturas com frequências intermediárias, referentes aos clusters e pequenas bolhas, e microestruturas de altas frequências, referente as colisões de partículas no leito fluidizado e ruído medida. Métodos de análise estatística (como média, desvio padrão) e análise espectral (espectros de Fourier, energia, wavelets) tem sido empregado com êxito na quantificação de um determinado regime. Os métodos estatísticos e espectrais apresentam características variantes, o que significa que para cada geometria haverá necessidade de uma calibração do método de quantificação.

O sistema agregativo, como leito fluidizado gás-sólidos $(\mathrm{G} / \mathrm{S})$, é caracterizado não só pela chamada heterogeneidade local (denominada pelo termo meso-heterogeneidade), que descreve a coexistência localizada de duas fases; mas também pela heterogeneidade global (denominada macroheterogeneidade) que descreve a segregação em regiões diluídas e densas em diferentes partes da coluna. Com isso, há distribuição da estrutura de fase heterogênea no tempo e no espaço. A dependência do tempo da estrutura de fluxo aparece sob a forma de alternância de fase a uma posição do local, isto é, a alternada dissolução e reformação das duas fases. Isto contribui para a natureza caótica do sistema (em termos de medições temporais de pressão e de escoamento). A dependência espacial da estrutura de fluxo prevalece em ambas as direções axial e radial, que mostra a co-existência de uma região diluída na parte superior e uma região densa na parte inferior, bem como uma região diluída no centro e uma região densa, perto da parede da coluna. A distribuição espacial causa intensa retro mistura de ambos fluido e partículas, afetando assim o contato fluido-partícula no sistema, e, portanto, impactando o desempenho de um reator. A heterogeneidade em sistemas agregativos dá origem a uma característica distinta de sistemas particulados: velocidade média de deslizamento, $\mathrm{U}_{\text {slip }}$, muito maior entre o fluido e as partículas aglomeradas do que a velocidade terminal $\mathrm{U}_{\mathrm{t}}[22]$.

Quantitativamente, além dos convencionais balanços de massa, momento e energia e equações de fechamento, a avaliação multi-escala impõe complementa com mais restrições (critérios de estabilidade para dissipação de energia por unidade de massa) marcadas pela velocidade de afogamento (choking, marca a transição do fluxo mássico gás-sólido de fase densa e diluída [24]), através de equações 0-D, e capaz de ser aplicado em qualquer modelagem numérica para melhorar sua precisão [23].

Conforme a Figura 10, o método divide a região de soluções em duas partes, encontrando a linha de velocidade de afogamento. A parte direita, com fase densa livre, corresponde ao transporte diluído, que não despreza o transporte diluído da versão convencional (que despreza multi-escala). A parte esquerda, corresponde aos regimes de fluidização borbulhante, turbulento e fluidização rápida ( $\varepsilon_{c}$ é a porosidade de fase densa). Neste exemplo, mesmo que o modelo não possua condição de salto na estrutura de fluxo, capaz diferenciar os regimes, o mapa leva em consideração características geométricas de colunas, altura de leito, propriedades das partículas e do agente fluidizante. Portanto, para condição de operação e geometria de sistema fluidizado seria possível levantar o mapa de fluidização para uma dada partícula. Em termos práticos, a caracterização dos regimes rápido e de transporte, pode ser experimentada pelo brusco aumento da queda de pressão quando a velocidade do ar de entrada, cai abaixo da condição de velocidade de afogamento de um leito fluidizado. 
Um dos principais resultados das restrições minimização de energia, considerando a análise multi-escala de sistema fluidizado, reside num mecanismo capaz de definir estruturas de fluxos dominada pelo fluido, pela partícula ou pelo compromisso entre elas (capaz mapear a região azul da Figura 10). Se a velocidade do fluido é mais baixa do que $U_{m f}$, isto é, para o leito fixo, o sistema fluido-partículas é totalmente dominado pelas partículas, portanto, totalmente partícula dependente, ou partícula dominante (PD). De fato, este regime pertence ao fluxo de um único fluido através de um complicado labirinto de canais composto por partículas empacotadas pela gravidade, provocando grandes flutuações no sinal local de pressão estática. Quando a velocidade do ar de entrada, está entre $U_{m f}$ e $U_{p t}$, nem as partículas e nem o fluido podem dominar um ao outro, exibindo tendências de comprometer-se um com o outro para buscarem a mínima energia potencial das partículas e mínima resistência do fluido. Na extremidade inferior da velocidade deste intervalo, as partículas tendem a agregar-se, em uma emulsão fase contínua densa para admitir o excesso de gás fluir sob a forma de bolhas, e com o aumento da velocidade para a extremidade de velocidade superior deste intervalo, as partículas na emulsão tendem a fragmentar-se em feixes (fios), que são descontínuos e de fase densa, distribuídos em um caldo de partículas individuais escassamente dispersos. $\mathrm{O}$ fluido com a sua tendência intrínseca para escolher um caminho para cima, com resistência mínima, e as partículas com a sua tendência intrínseca de arranjarem entre si com energia potencial mínima, parecem acomodar uns aos outros para formar es regime de compromisso fluido-partícula (CFP). Em velocidades mais elevadas, para além $U_{p t}$, todas as partículas alimentadas no sistema são transportadas em fase diluída para fora do sistema sem residência prolongada e sem ser capaz de agregar-se entre si. Na medida em os arranjos de partículas são suprimidos, pela alta velocidade do fluido, este regime diluído homogêneo é fluido dominado (FD) [22]

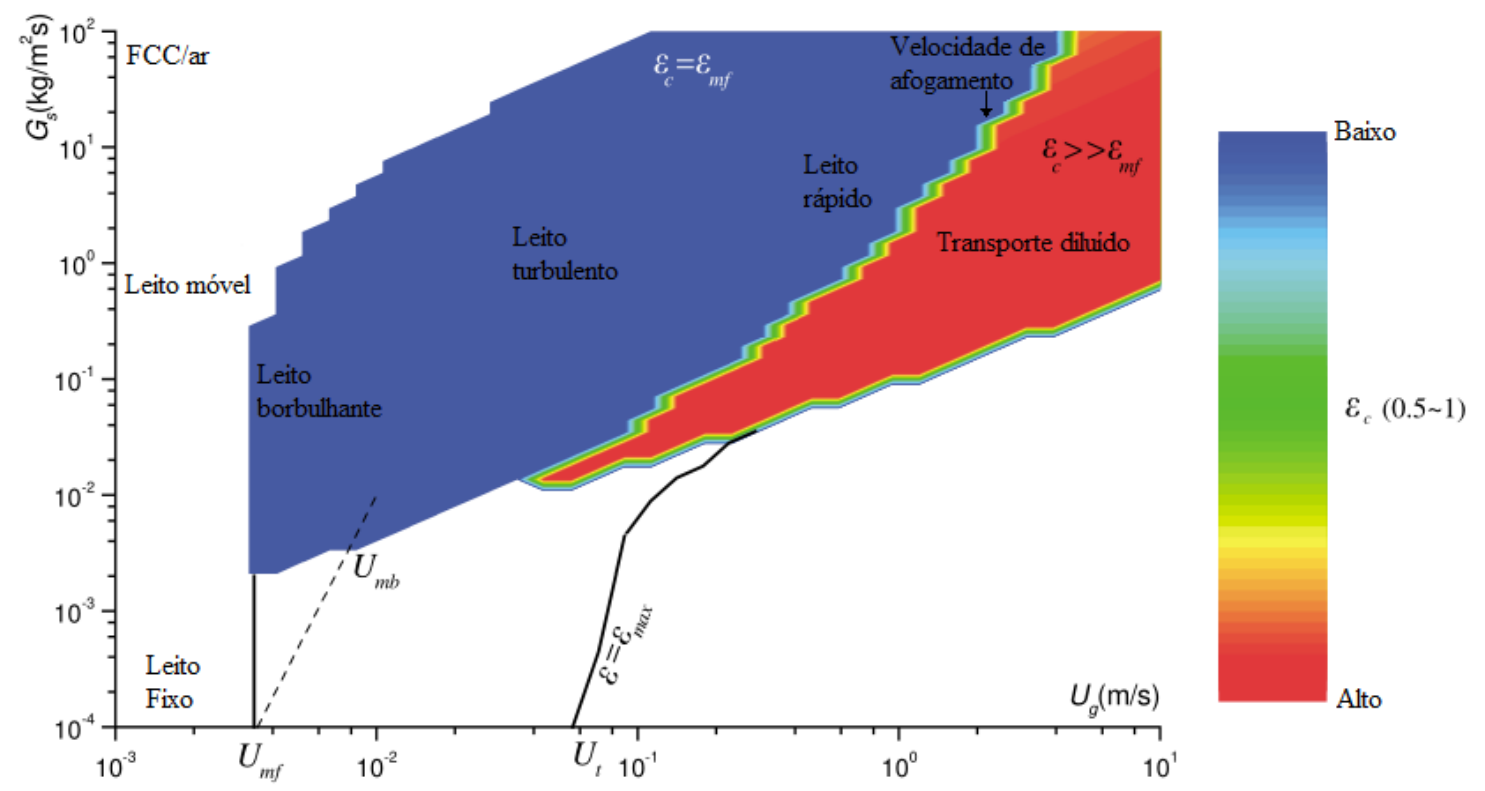

Figura 10 - Mapa de regime de fluidização para partícula FCC, a partir de simulação numérica com restrições de métodos multi-escala. Adaptado de [23].

Uma estrutura de fase pode ser confinada localmente em regiões bastante pequenas de um sistema fluido-partícula, tal como uma bolha ou de um agrupamento, ou poderia ser estendida através de regiões muito maiores nas direções radial ou axial da coluna. A heterogeneidade local é atribuída à instabilidade intrínseca de um sistema de fluido-partícula; enquanto a heterogeneidade estendida ou global resulta das 
condições de contorno sobre a coluna, por exemplo, paredes, configurações de entrada e de saída em relação à estabilidade geral [22].

Para fluidização rápida num recipiente cilíndrico, por exemplo, a macro-heterogeneidade é resolvida em duas dimensões:

- Axial: região densa no fundo suportando uma região diluído no topo.

- Radial: região de parede de baixa porosidade em torno de uma região central de alta porosidade.

Portanto, esta designação compreende as quatro seguintes categorias:

- Fase: estado de agregação das partículas (meso-heterogeneidade):

- densa como emulsão (contínua) ou agrupamentos (descontínua)

- diluída como caldo (contínuo) ou bolhas (descontínua)

- Regime: configuração de combinação de fase dependente de parâmetros de operação: borbulhante, turbulenta, rápida e transporte;

- Padrão: constituição de espectro regime depende de propriedades do material:

- borbulhante/transporte para sistemas $\mathrm{G} / \mathrm{S}$ de partículas grossas;

- particulado/borbulhante/turbulento/rápido/transporte para os sistemas catalisador FCC/ar;

- particulado, apenas para a maioria dos sistemas de líquido/sólidos (L/S);

- Região - distribuição espacial das fases dependentes de condições de contorno (macroheterogeneidade): topo e base; núcleo e de parede;

Estas definições qualitativas podem auxiliar na compreensão e identificação de regimes do fluxo bifásico fluido-partícula concomitante, indicando os relacionamentos e interdependências entre as quatro categorias (fase, regime, padrão e região) e os três fatores independentes dominantes do sistema (parâmetros de operação, propriedades do material e condições de contorno) [69].

Apesar da abordagem de minimização de energia ser bem respaldada quantitativamente, ela não foi aqui revisada, pois suas aplicações ainda estão restritas a modelos. Contudo, seus mecanismos partícula dominado, compromisso fluido-partícula e fluido dominado, serão úteis para interpretações de resultados numéricos e experimentais.

\subsubsection{Sistema de resposta caótica}

O comportamento caótico em reatores ou colunas de leito fluidizado foram relacionados para melhorar o entendimento de seu processo de escalonamento (aumento das dimensões da coluna). Não é simples escalonar reatores laboratoriais para unidades industriais e o sucesso do escalonamento não é garantido pela engenharia convencional baseada em mapas adimensionalizados [70].

O caos pode ocorrer em sistemas dinâmicos que são descritos com precisão por meio de equações nãolineares determinísticas. O comportamento caótico mostra-se através de um movimento irregular que nunca se repete exatamente. Isto significa que sua estimação futura é difícil de prever, com horizonte de previsão longo, é impossível de prever com base em observações anteriores. No entanto, em contraste com os sistemas estocásticos, sistemas caóticos determinísticos são previsíveis (pelo menos em curto prazo), porque as trajetórias dinâmicas reais visitam apenas uma pequena parte do espaço de fase completo. Uma propriedade fundamental de um sistema caótico é a sua extrema sensibilidade a pequenas perturbações e/ou condições iniciais. Para reatores de leito fluidizado, isso resulta em difícil escalonamento, ou seja, uma ligeira alteração em um dos parâmetros adimensionais que descrevem o comportamento do sistema pode causar um comportamento completamente diferente [28]. 
A teoria do caos tem sido aplicada para auxiliar para quantificar padrões de regimes de escoamento em colunas de fluidização, através de demonstrações de que flutuações de sinais possuem natureza caótica. Assim, podem ser regidos por sistemas de alta ordem [30].

Grandes contribuições para a caracterização de regimes de fluidização ocorreram quando cientistas demonstraram a presença de caos no comportamento de séries temporais de variáveis do processo de um leito fluidizado gás-sólido. Como é difícil registrar todo o conjunto de variáveis independentes de um sistema experimental, a trajetória completa de um sistema representada num espaço de fase pode ser reconstruída a partir da medida de uma única variável independente [71]. Através da teoria de Takens, Shouten et al. [72] desenvolveram um estimador para calcular a entropia de Kolmogorov de atratores a partir de séries temporais. Grassberger et al. [27] aperfeiçoaram o estimador e testaram novo algoritmo capaz de caracterizar, através do cálculo de Entropia de Kolmogorov, sinais temporais caóticos experimentais. Shouten et al. [73] mostraram uma metodologia de utilização de invariantes do caos, calculados a partir de uma série temporal do sinal de flutuação de pressão de uma coluna de leito fluidizado, para caracterização de regimes e uso de projeto para escalonamento. Entre os invariantes abordados encontram-se a dimensão de correlação e entropia de Kolmogorov. Van den Bleek et al. [29] validaram invariantes da entropia de Kolmogorov e dimensão de correlação, como novas e úteis ferramentas quantitativas para caracterizar o comportamento dinâmico não-linear de colunas de leito fluidizado.

O problema da análise global do regime de fluidização de uma coluna, pelas invariantes do caos, pode ser classificado por um sistema não-linear espaço-temporal complexo de ser modelado. Mesmo assim, muitos autores tentaram caracterizar regimes de fluidização observando poucos pontos de medição, caracterizando o comportamento local, mas não o regime de fluidização de uma coluna. Marzocchella et al. [31] caracterizaram as invariantes do caos em diversas regiões e tipos de partículas ao longo de uma coluna de fluidização fria ou alguns parâmetros do caos ao longo da coluna, mas seu estudo não especificou a evolução destes parâmetros por regime de fluidização. Os autores identificaram três regiões ao longo da coluna: a região de topo, dominada por partícula; a região do meio, dominada pelos agrupamentos (clusters); e a região da base, controlada pelos sólidos. Contudo, ainda não relacionaram o comportamento qualitativo, descrito pela literatura clássica de leito fluidizado [63] [20], com os atuais métodos de caracterização não-lineares, descritos pela literatura moderna de leito fluidizado [32] [74] [25].

Os resultados das análises não-lineares pela teoria do caos, têm apresentado bons resultados para quantificação global de regimes de leito fluidizado, com a principal contribuição de avaliar características invariantes a escala do sistema. Em teoria, as características invariantes de sistemas com resposta caótica, são preservadas, independentes da escala do sistema, e podem contribuir para solucionar problemas da gaseificação de leito fluidizado.

\subsubsection{Aplicações em leito fluidizado}

As vias para a conversão de biomassa em combustíveis líquidos ou gasosos podem ser classificadas em dois tipos principais: aqueles que se baseiam em processos termoquímicos e aqueles que utilizam meios biológicos. Processos termoquímicos usam calor, frequentemente, com catalisadores heterogêneos, para quebrar a biomassa em unidades menores que depois são transformados em moléculas úteis para geração de trabalho, como $\mathrm{H}_{2}, \mathrm{CO}$ e $\mathrm{CH}_{4}$. Os processos biológicos, em contraste, são geralmente baseados na utilização de catalisadores enzimáticos sob condições específicas, como a fermentação de açúcares em etanol [75]. A rota termoquímica apresenta características comerciais mais atrativas pela potencial capacidade de produzir grandes volumes de gás combustível limpo em pouco tempo, baixos custos e 
usando espaços relativamente pequenos. Já a rota bioquímica consome grandes áreas do reator, tempo de residência relativamente altos e baixa produção de combustíveis gasosos.

A Figura 11 apresenta uma classificação dos processos termoquímicos de conversão classificados como uma função do grau de oxidação da biomassa: no lado esquerdo, de combustão (excesso de ar) a gaseificação (menor quantidade de ar apresentado no processo) a liquefação (redução, sem ar). A mais conhecida rota de conversão termoquímica é a combustão. A combustão permite uma utilização direta de biomassa para produzir calor e trabalho, quando acoplado a processo termodinâmico. Esta rota apresenta alta emissão pela queima ineficiente de combustíveis sólidos, em leito fixo, e seu alto teor de impurezas e umidade, enquanto combustores de leitos fluidizados tem proporcionado maximização da eficiência com menores emissões [51].

A via de conversão de biomassa pela pirólise e liquefação ainda enfrentam problemas de necessitaram de grandes quantidades de energia para sua conversão e condições operacionais (pressão, temperatura e ausência de oxigênio), difíceis de controlar.

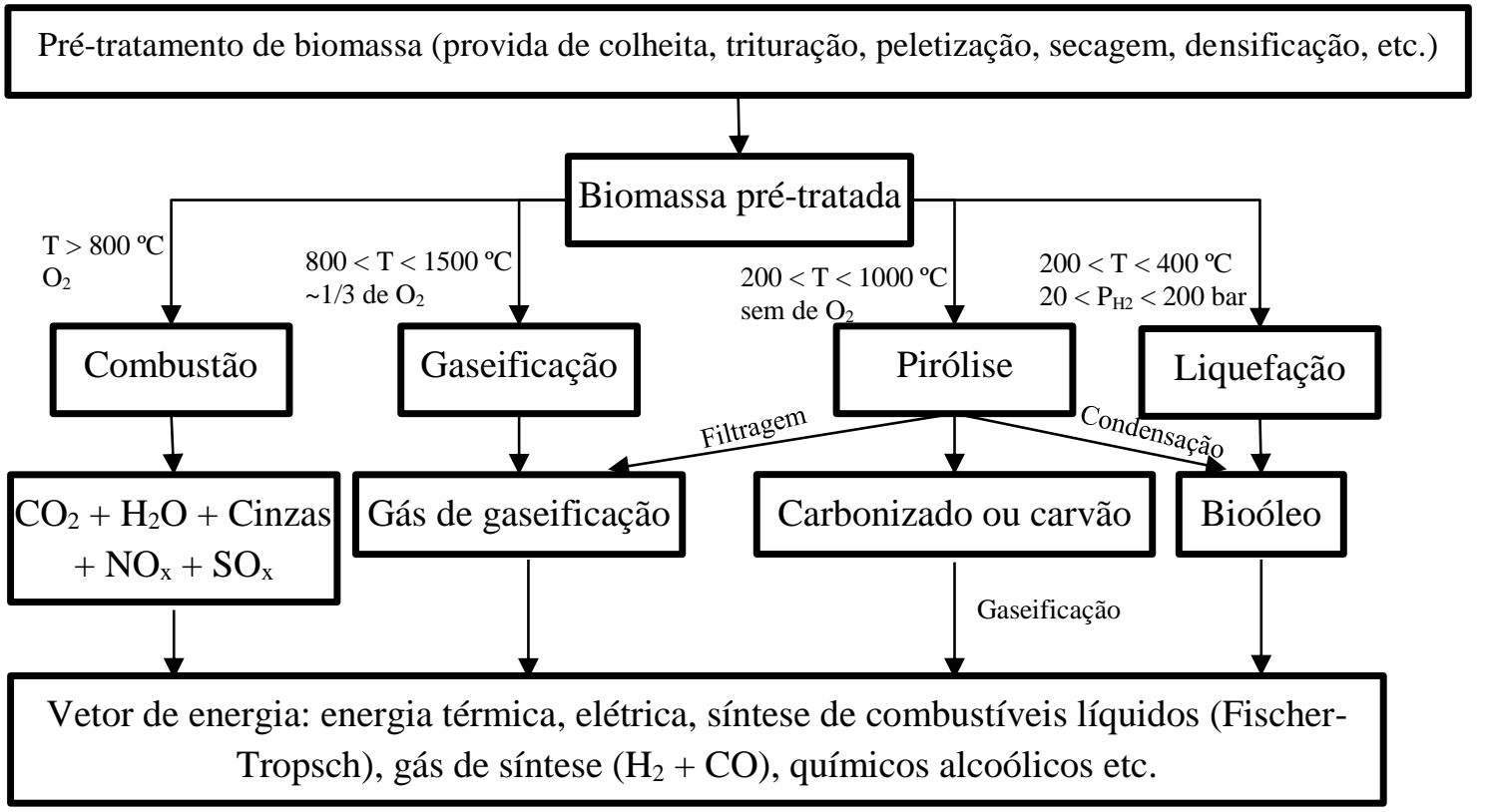

Figura 11 - Visão geral dos principais processos termoquímicos para conversão de biomassa em energia térmica ou produtos químicos. Adaptado de [51].

A gaseificação é a rota termoquímica que produz um gás de gaseificação a partir da biomassa, devido a uma entrada controlada de oxigénio, que é aproximadamente um terço da quantidade de ar necessária para a combustão estequiométrica. O gás de gaseificação contém alcatrão e outros subprodutos indesejáveis. Portanto, ele deve ser limpo (filtrado) para reduzir o seu teor de alcatrão, produzindo o gás de síntese, que pode ser utilizado para gerar calor ou em motores de combustão interna para gerar trabalho. Pode ser convertido por catalisadores para combustíveis líquidos (diesel ou metanol através do processo Fischer-Tropsch) ou aos vetores de energia gasosos ( $\mathrm{CH} 4$ ou H2) [51]. Atualmente, este processo está em grande desenvolvimento no mundo pelo potencial de converter grandes volumes e tipos de resíduos sólidos (desde fósseis a resíduos sólidos urbanos, RSU) em gás combustível limpo. Contudo, este processo ainda apresenta problemas de continuidade operacional (baixa disponibilidade) 
para ser considerado como processo de geração de energia, alta complexidade operacional e alta variabilidade na composição do gás produzido [6].

Aproximadamente $72 \%$ da energia elétrica global é gerada a partir de processos de combustão [76]. A geração de energia elétrica pela oxidação de combustíveis sólidos impuros é razoavelmente eficiente, com alta disponibilidade, baixo custo, mas altamente emissora de gases estufas. A gaseificação é um processo termoquímico que permite converter resíduos sólidos carbonáceos em combustíveis gasosos cuja combustão é mais eficiente e limpa, quando comparado a combustão direta dos resíduos sólidos brutos.

A operação contínua de processos de gaseificação com eficiência de conversão controlada, depende de muitos fatores (temperatura, fluxo de entrada, alimentação, regime de fluidização, taxa de circulação, composição da biomassa, etc). A implementação de técnicas de processamento de dados associados de instrumentação adequada pode permitir a redução da complexidade operacional e contribuir para automatização destes processos. O impacto de um processo automatizado está intimamente ligado com sua continuidade operacional. O sucesso de aplicações automatizada de combustores em leito fluidizado pode ser nos estudo de aplicações em gaseificadores.

\subsubsection{Combustores de leito fluidizado circulante}

Os leitos fluidizados circulantes foram introduzidos na indústria, a partir de combustores (geração energética térmica), no início da década de 80 [77]. A ideia de combustores de leito fluidizado evoluiu a partir de esforços para encontrar processos que permitissem o controle de emissões sem usar processos auxiliares de limpeza de gases. Esta tecnologia permite queimar combustíveis a $750-950{ }^{\circ} \mathrm{C}$, abaixo $1300^{\circ} \mathrm{C}$, onde os átomos de nitrogênio e oxigênio do ar combinam-se para formar poluentes como NOx [78].

A ação da turbulência da mistura gás-sólido, em combustores de leito fluidizado permite adição químicos como dolomita e calcário, capazes de absorver poluentes (enxofre, nitrogênio, etc), evitando o uso de processos de limpeza de gases de exaustão. Por exemplo, mais de $90 \%$ do enxofre presente no carvão pode ser capturado com uso de adsorventes [79].

A popularidade da combustão em leito fluidizado está relacionada com sua flexibilidade do processamento de diversos combustíveis (qualquer material que contenha carbono pode ser processado) e captura de poluentes, sem a necessidade de caros processos de limpeza de gases.

A tecnologia de leito fluidizado incentivou a elaboração de diversos programas de pesquisa para combustão limpa de carvão. A $1^{a}$ geração de combustores de leito fluidizado trabalharam com regimes borbulhante, consequentemente, baixas velocidades de fluidização, em condições de pressões atmosféricas ou pressurizados. A atual $2^{\mathrm{a}}$ geração de combustores de leito fluidizado trabalha com regime de fluidização rápido e efeito circulante, exigindo maior velocidade de fluidização e proporcionando maior eficiência de combustão, menor produção partículas (devido a recirculação) e melhor a captura de poluentes (devido ao aumento do grau de contato gás-sólido) [80].

Segundo a literatura [77] [81] [82], a operação de um combustor de leito fluidizado circulante (LFC ou $C F B)$, pode ser resumida nas seguintes características:

- Opera com partículas polidispersas, preferencialmente no regime rápido podendo variar seu regime entre o borbulhante e transporte pneumático.

- Opera em altas velocidades relativas entre o gás e a partícula devido ao agrupamento de partículas, normalmente, superior a velocidade terminal; 
- A manutenção do regime rápido deve assegurar uniformidade de temperatura no reator $\left(850^{\circ} \mathrm{C}\right)$ e altas taxas de circulação externa (combustível e inertes);

- A manutenção do regime também garante circulação interna e alto tempo de residência devido aos efeitos combinados com a circulação externa;

- Permite a injeção direta de diversos compostos capazes de promover a redução eficiente e controle da emissão dos gases de exaustão da combustão (redução de alcatrão, $\mathrm{CO} 2, \mathrm{NOx}$ e SOx), reduzindo a necessidade de processos de limpeza de gases;

- Alta flexibilidade em misturar combustíveis de diferentes poderes caloríficos e características granulométricas;

- Elevada eficiência de conversão de carbono, operando em regime rápido, quando comparado com a operação noutros regimes como o borbulhante e turbulento;

- Pequena área de seção transversal do reator devido as altas taxas de transferência de calor e massa quando comparado a reatores não fluidizados;

- Boa capacidade de seguimento de demanda de carga (mudanças nos valores de desejados da energia produzida) devido as altas velocidade de fluidização e a possibilidade de processar elevadas quantidades do inventário de massa

Devido as vantagens de câmaras de combustão em leito fluidizado circulante seu escalonamento tem sido amplamente aumentado, desde 84 MWth [83] [84] até 800 MWth [85] [86].

Tanto o escalonamento quanto e suas condições de controle de regime requerem conhecimentos sobre a dinâmica dos fluidos, mistura, transferência de calor e massa, etc. As estruturas multi-escala de reatores industriais e laboratoriais diferem grandemente. Por isso, é necessário o auxílio de modelagem numérica para reduzir os custos de projeto e busca de condições de controle e operação [77].

A operação de combustor circulante é realizada quando a velocidade do gás de entrada, promove um deslizamento maior do que a velocidade terminal das partículas, suficiente para arrastar as partículas e formar um padrão de escoamento núcleo-anelar, chamado de regime rápido. Neste regime, ocorre na coluna, um movimento de circulação interna das partículas, em que sobem pela parte central da coluna (núcleo) em fase diluída (perfil de alta porosidade), e descem pela borda da coluna (região anelar) em fase densa (perfil de baixa porosidade). Este padrão de escoamento garante alto grau de contato entre as partículas e maximiza a transferência de calor e massa [87] [88].

A detecção e manutenção do regime rápido, em operações industriais, ainda é ambígua quanto ao estabelecimento da faixa operacional da velocidade do gás de entrada, para manter determinado tipo de partícula neste regime [77]. Medições indiretas para detecção da velocidade de afogamento, pode auxiliar a busca e manutenção, contínua, do regime rápido em unidades industriais. Grandes companhias, como a Foster Wheeler, a GePower, a Babcock \& Wilcox, entre outras, trabalham com balanços globais de pressão (coluna, ciclone, malha circulante e selo mecânico), correlações de perfis de porosidade do tipo $S$ (conforme a Figura 6) e correlações laterais.

O perfil típico de porosidade axial do regime de fluidização rápido é caracterizado, qualitativamente, por uma região de fluxo denso, na base, coexistindo com uma região de fluxo diluído, no meio e no topo. Quantitativamente, esse comportamento pode ser caracterizado pele perfil de porosidade do tipo S. A transição gradual entre a parte inferior e superior pode ser explicado pela difusão de agrupamento de partículas ao longo da coluna. Outra característica marcante do regime de fluidização rápido, é a formação de um perfil de porosidade lateral do escoamento núcleo-anelar, onde há a coexistência de uma região central diluída ascendente e outra anelar (adjacente a parede) densa descendente. A composição do movimento ascendente central e descendente anelar é responsável pela circulação interna. Enquanto o material excedente, que é arrastado para fora da coluna, promovendo a circulação externa através da malha circulante. A associação dos movimentos de circulação interna e externa 
garantem elevado tempo de residência, altos fluxos de massas, altas taxas de transferência de calor e massa [77].

O controle da temperatura e a manutenção dos perfis são as principais referências para o controle de combustores circulantes. Contudo, esta estratégia não seria adequada caso o propósito do reator fosse alterado para geração de gás combustível, ao invés de apenas calor. A sensibilidade da cinética de reação, devido à falta de manutenção rigorosa do contato fluido-partícula, ou seu regime, poderia resultar em variações da composição molar do gás produzido.

\subsubsection{Gaseificadores de leito fluidizado circulante}

A ideia de produzir combustível gasoso limpo, através de processos termoquímicos, a partir de qualquer resíduo sólido carbonáceo é atraente, pois potencializa o fechamento de um ciclo sustentável para estes resíduos [8].

Assim como a combustão completa, o mecanismo da gaseificação (combustão parcial em atmosfera subestequiométrica, um quinto a um terço do oxigênio da combustão) obedece, basicamente, os três Ts da combustão: temperatura, a turbulência e tempo de residência. A temperatura interna do volume de um reator, sob atmosfera controlada de oxigênio, proporciona condições para acionar as reações de gaseificação. A Tabela 1, apresenta as principais reações que caracterizam a produção de combustível gasoso limpo (frações de $\mathrm{H}_{2}$ e $\mathrm{CO}$ em sua maioria) a partir do processo de gaseificação de biomassa.

Tabela 1 - Principais reações durante um processo de gaseificação de biomassa [44].

\begin{tabular}{|c|c|c|}
\hline Tipo de reação & $\begin{array}{l}\text { Reação química } \\
\end{array}$ & $\Delta \mathbf{H}[\mathrm{kJ} / \mathrm{mol}]$ \\
\hline Desvolatilização primária & Biomassa $\rightarrow \mathrm{H}_{2} \mathrm{O}, \mathrm{CO}, \mathrm{CO}_{2}, \mathrm{CH}_{4}, \mathrm{C}_{2} \mathrm{H}_{4}$ e C & + \\
\hline Craqueamento de alcatrão & $\begin{array}{l}\text { Alcatrão primário } \rightarrow \text { Alcatrão secundário }+\mathrm{H}_{2} \text {, } \\
\mathrm{CO}, \mathrm{CO}_{2}, \mathrm{CH}_{4}, \mathrm{C}_{2} \mathrm{H}_{4}\end{array}$ & + \\
\hline \multirow{7}{*}{ Homogêneas } & Alcatrão secundário $\rightarrow \mathrm{C}, \mathrm{CO}, \mathrm{H}_{2}$ & + \\
\hline & $\mathrm{H}_{2}+0,5 \mathrm{O}_{2} \rightarrow \mathrm{H}_{2} \mathrm{O}$ & -242 \\
\hline & $\mathrm{CO}+0,5 \mathrm{O}_{2} \rightarrow \mathrm{CO}_{2}$ & -283 \\
\hline & $\mathrm{CH}_{4}+0,5 \mathrm{O}_{2} \rightarrow \mathrm{CO}+2 \mathrm{H}_{2}$ & -110 \\
\hline & $\begin{array}{l}\mathrm{CH}_{4}+\mathrm{CO}_{2} \rightarrow 2 \mathrm{CO}+2 \mathrm{H}_{2} \text { (reação de } \\
\text { reformação seca) }\end{array}$ & +247 \\
\hline & $\begin{array}{l}\mathrm{CH}_{4}+\mathrm{H}_{2} \mathrm{O} \rightarrow \mathrm{CO}+3 \mathrm{H}_{2} \text { (reação de reformação } \\
\text { metano-vapor) }\end{array}$ & +206 \\
\hline & $\begin{array}{l}\mathrm{CO}+\mathrm{H}_{2} \mathrm{O} \leftrightarrow \mathrm{CO}_{2}+\mathrm{H}_{2} \text { (reação de } \\
\text { deslocamento gás-água) }\end{array}$ & -41 \\
\hline \multirow{5}{*}{ Heterogêneas } & $\mathrm{C}+\mathrm{O}_{2} \rightarrow \mathrm{CO}_{2}$ & -394 \\
\hline & $\mathrm{C}+0,5 \mathrm{O}_{2} \rightarrow \mathrm{CO}$ & -123 \\
\hline & $\mathrm{C}+\mathrm{CO}_{2} \leftrightarrow 2 \mathrm{CO}$ (reação de Boudouard) & +159 \\
\hline & $\mathrm{C}+\mathrm{H}_{2} \mathrm{O} \leftrightarrow \mathrm{CO}+\mathrm{H}_{2}$ (reação gás-água) & +119 \\
\hline & $\mathrm{C}+2 \mathrm{H}_{2} \leftrightarrow \mathrm{CH}_{4}$ (reação de metanação) & -88 \\
\hline
\end{tabular}

Diferentes tipos de gaseificadores podem promover condições para maximização da conversão termoquímica do sólido em combustível gasoso. Os gaseificadores podem se diferenciar quanto a forma de alimentação de sólidos e do agente gaseificante (contracorrente, cocorrente, etc.), o tipo de agente gaseificante (ar, $\mathrm{O}_{2}$, etc) e quanto ao movimento do leito (fixo ou fluidizado). A característica do 
movimento do leito, de fato, apresenta maior pertinência quanto ao incremento da eficiência da conversão do carbono fixo em combustível gasoso.

Em gaseificação de leito fixo existem regiões bem definidas de secagem, pirólise, combustão e gaseificação. O agente gaseificante atravessa seu leito parado, de partículas e ocorre um pequeno grau de interação fluido-partícula (turbulência), quando comparado a gaseificação de leito fluidizado. Portanto, o grau de interação fluido-partícula é um parâmetro essencial para eficiência de conversão de carbono de processos de gaseificação. Além das condições de gaseificação (temperatura, pressão, composição do material, etc) o grau de contato entre o material carbonáceos o e agente gaseificante é decisiva para aumentar a taxa da conversão de carbono. Fan et al. [13] demonstraram que taxa de conversão de carbono, a eficiência de gaseificação e o poder calorífico inferior são maiores em gaseificadores de leito fluidizado circulante do que em leitos borbulhantes.

A gaseificação de leito fluidizado tem capacidade de produzir mais energia, em forma de combustível gasoso, do que a de leito fixo, conforme mostrado na Figura 12. No leito fluidizado, a velocidade de uma ascendente atravessa o leito de partículas provocando padrões ou regimes de fluidização no escoamento multifásico fluido-partícula. A literatura atual descreve muitos regimes de fluidização, tais como, leito fixo, particulado, borbulhante, golfadas, transição turbulenta, turbulento, rápido e transporte pneumático. Esses regimes de fluidização, conforme aumentam contato fluido-partícula, aumentam a eficiência de conversão de carbono dos gaseificadores de leito fluidizado.

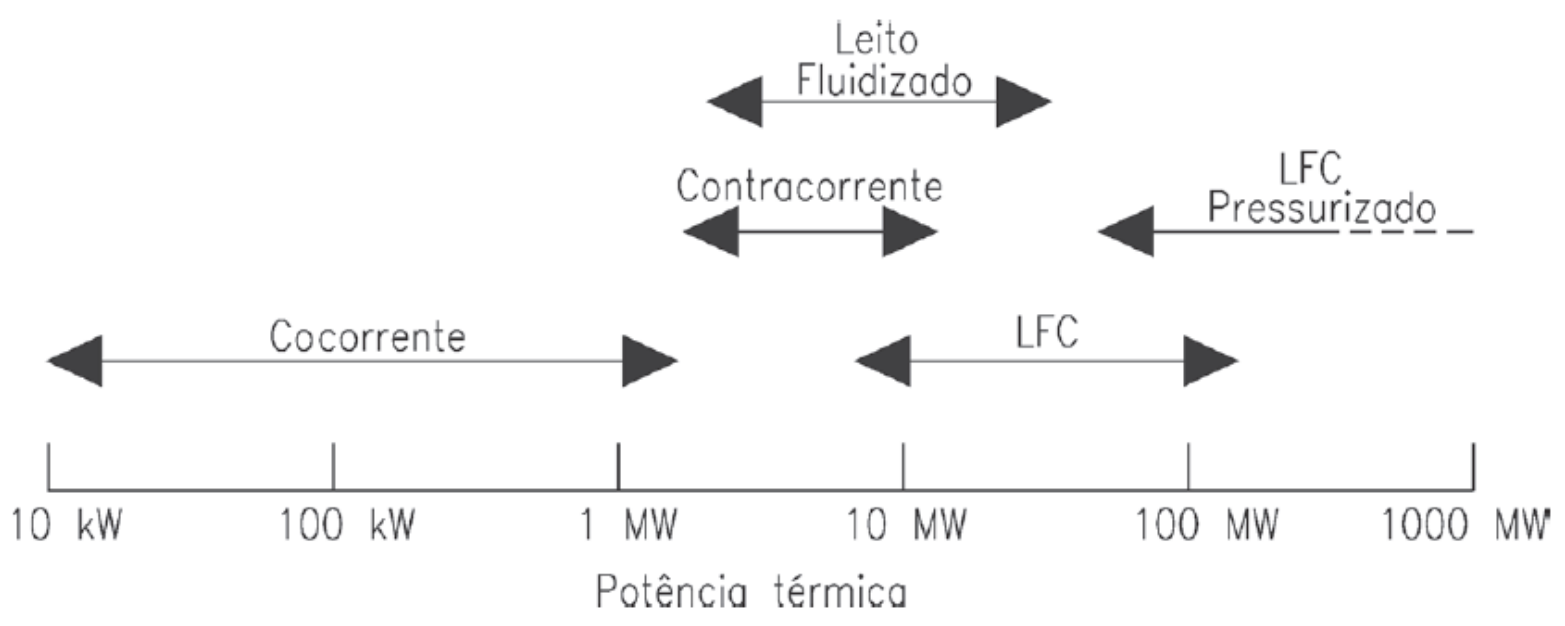

Figura 12 - Potências térmicas características para diferentes gaseificadores. Adaptado de [42]

Para que a gaseificação de leito fluidizado se consolide como fonte geradora de energia limpa, sustentável e renovável, precisa cumprir critérios mínimos de continuidade operacional e capacidade de produção energética [6]. Os critérios para que um processo se torne gerador de energia, numa região, estão cada vez mais restritos como: disponibilidade (recurso e continuidade operacional), capacidade de geração, riscos do processo (saúde e meio ambiente), emissões, terrorismo, custos (recursos, operação) [89].

Segundo Mooson [90], quando um gaseificador de leito fluidizado opera no regime de fluidização rápido, adquire as seguintes vantagens:

- Alto rendimento de conversão de carbono e tempo de retenção;

- Excelente transferência de massa e calor entre partículas e fases;

- Uniformidade de temperatura. 
Para um gaseificador operar em leito fluidizado rápido, sua malha deve ser fechada, contendo uma coluna de fluxo ascendente (riser), um separador (geralmente, ciclone), uma coluna de fluxo descendente (downer) e um selo, capaz de devolver o material sólido de volta para o riser. Esse tipo de gaseificador é chamado de leito fluidizado circulante (LFC), pois um leito de partículas fica circulando pela malha até converter todo sólido em combustível gasoso.

\subsubsection{Desafios da gaseificação de leito fluidizado}

No mundo, a distribuição de empreendimentos industriais/comerciais para gaseificação de leito fluidizado circulante de biomassa ainda é baixa, conforme a Figura 13. Conforme dados do conselho de gaseificação [12] há menos de 680 gaseificadores LFC industriais operando no mundo. Esta estatística dá indícios das dificuldades deste processo em adquirir características de processos industriais como a continuidade operacional e alta disponibilidade. A continuidade está relacionada com processos automatizados o suficiente para produzir (neste caso a produção de gás combustível), sem interrupções. Mas caso haja interrupções, estas devem raras, para garantir robustez no fornecimento de produtos.

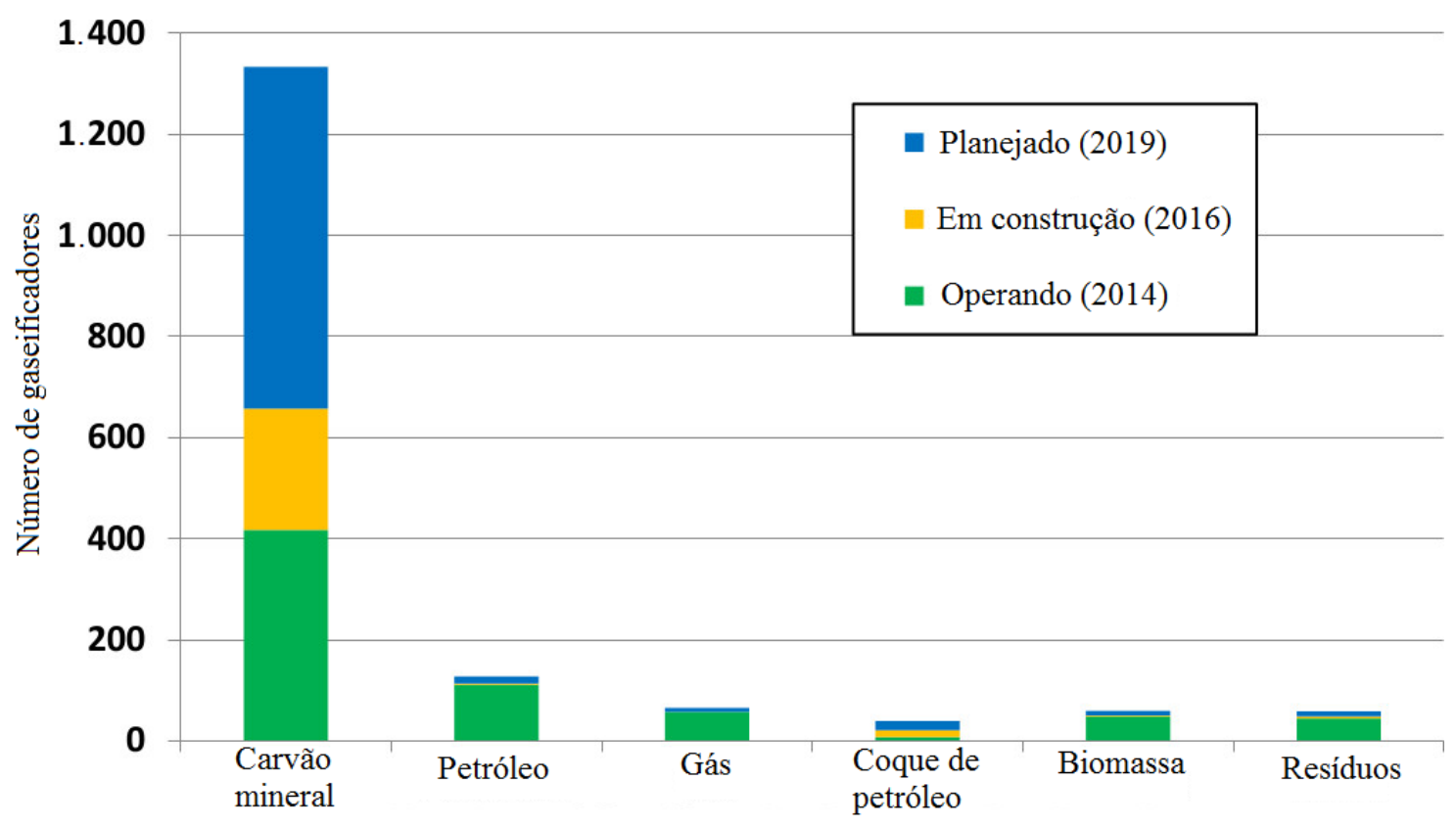

Número de gaseificadores por alimentação primária

Figura 13 - Estatística mundial do número de gaseificadores, pelo tipo de combustível. Adaptado de Gasification Council [12].

Mesmo em universidades, a quantidade de gaseificadores de leito fluidizado não é expressiva devido ao seu alto custo de projeto, execução, instrumentação e automação.

Diferente da combustão LFC, a produção e composição controlada do gás de saída de gaseificadores LFC são influenciados pela temperatura, fator de ar (F.A. ou E.R Equivalence Ratio), $F A=$ $\left(R_{A / C}\right)_{\text {real }} /\left(R_{A / C}\right)_{\text {esteq }}\left(R_{A / C}\right.$ é a razão ar/combustível), taxa de circulação e regime de fluidização. Atualmente, a gaseificação enfrenta grandes progressos para superação de desafios operacionais [91]. O controle das condições operacionais é essencial para o controle da composição final do gás de saída [92]. 
Sob o ponto de vista da cinética de reação de gaseificação Tsui e Wu [93] ensaiaram carvões com diversos diâmetros e porosidades mantendo o fluxo de sólidos circulante controlado. Contudo, fluxo de sólidos circulante não determina com precisão o regime de escoamento na coluna.

A taxa de circulação é um dos parâmetros de controle em leito fluidizados circulante. Ludlow et al. [94] propuseram um método de deslocamento de fase (atraso) entre uma aeração modulada conhecida e a resposta desta com o fluxo multifásico em diferentes regimes, para estimar a taxa de sólidos circulante $\left(\mathrm{kg} / \mathrm{s} \cdot \mathrm{m}^{2}\right)$. Contudo, este método não obteve sucesso para regime de fluidização rápido.

Experimentos realizados por $\mathrm{Ju}$ et al. [95], em colunas de gaseificação LFC de escala comercial, mostraram que a temperatura da base tende a aumentar quando comparado ao topo, quando operado fora do regime rápido. A malha circulante tem o propósito que aumentar o fluxo de massa para homogeneizar o perfil axial de temperatura da coluna. Perfis heterogêneos de temperatura, aumentam a variabilidade da composição do gás de saída. O controle de regime de fluidização poderia contribuir para redução da variabilidade da composição do gás de saída. Em geral, os perfis de temperatura e a eficiência de combustão são mais uniformes e maiores em leito fluidizados circulante (operam em regime rápido) do que em leitos borbulhantes [96].

Dentre os diversos problemas de gaseificação, destacam-se os elencados por van der Drift [97] como: redução de perda energética, aumento do poder calorífico do gás de saída, aumento da taxa de conversão de resíduos misturados, remoção de voláteis (alcatrão), redução da emissão de poluentes, redução da variabilidade da composição do gás de saída; podem ser influenciados pela falta de controle do contato gás-sólido, imposto pelo regime de fluidização. Mais especificamente, o controle do regime de fluidização em gaseificadores pode uniformizar a distribuição do campo de velocidade de partículas, a distribuição da mistura dos sólidos na coluna (sólidos em suspensão) e seu grau de contato. Uma parte dos problemas de controle da composição final do gás de saída em gaseificadores LFC possuem alguma relação com sua falta controle do regime do regime de fluidização. A fluidodinâmica de leito fluidizado, ainda não está plenamente compreendida, para solução plena do controle de regimes de fluidização. Contudo, a análise de invariantes do caos de séries temporais de pressões estática e diferencial, tem trazido luz para a quantificação de regimes de fluidização.

Os leitos fluidizados gás-sólidos (como o de gaseificadores) ainda representam a classe dos sistemas complexos hidro dinamicamente. Seus regimes de fluidização exibem características dinâmicas nãolineares e não-equilibradas com estruturas de fluxo heterogênea [98].

Através de transformadas de Fourier, Wavelets e gráficos de recorrência, Tahmasebpour et al. [99] propuseram um método para quantificação estruturas macro, meso e micro escala, até o regime o borbulhante. Apesar de trabalhar com medições em diferentes pontos da coluna, as medidas circundaram a região de base. O método não apresentou resultados para classificações de regimes de fluidização.

Análises mais modernas como as invariantes do caos, o expoente de Hurst para avaliar características multi-fractais de sinais de pressão [98]. Contudo, estas técnicas ainda não apresentaram êxito para detecção e quantificação global do regime de fluidização de uma coluna de fluidização, potencializando uso para controle processos industriais [22].

Nas aplicações de leito fluidizado, alterações dos parâmetros de fluidização, tais como tamanho de partícula (de alimentação ou devido a sinterização), velocidade de entrada de gás, temperatura e conversão do inventário de massa, devem ser detectadas rapidamente para e evitar situações indesejáveis quanto a qualidade do produto. O desafio de detecção de defluidização (perda do estado de fluidização devido a formação de aglomerado de partículas) devido ao processo de sinterização pode causar a parada da unidade. 


\subsubsection{Problema de ajuste de regime rápido em coluna LFC opaca}

Colunas de gaseificação de leito fluidizado circulante precisam ser opacas pois necessitam de material refratário para conter a alta temperatura de operação, em torno de 800 a $950{ }^{\circ} \mathrm{C}$. Para alcançar esses valores de temperatura, geralmente um queimador de partida promove a circulação de gases de exaustão da combustão estequiométrica de GLP, elevando a temperatura interna da coluna de ambiente para aproximadamente $400{ }^{\circ} \mathrm{C}$. A função do queimador de partida é pré-aquecer o refratário e um leito de partículas inertes, como areia, que tem a função de aumentar a difusividade térmica da coluna sobre o material a ser convertido.

Em laboratórios, colunas de fluidização fria e transparentes tem a função de permitir que um operador ajuste condições de alimentação de ar e partículas, para operar num determinado regime. Essa forma de operação é inviável em colunas industriais quentes. A Figura 14, apresenta em (a) a condição de uma coluna industrial pré-aquecida com leito de partículas misturados (areia e combustível). Em (b), a injeção de ar ascendente que conduzindo o leito para algum regime de fluidização. E em (c), a visão real obtida pelo operador, motivando pesquisas que auxiliem a reconstrução do estado de fluidização de um LFC quente.

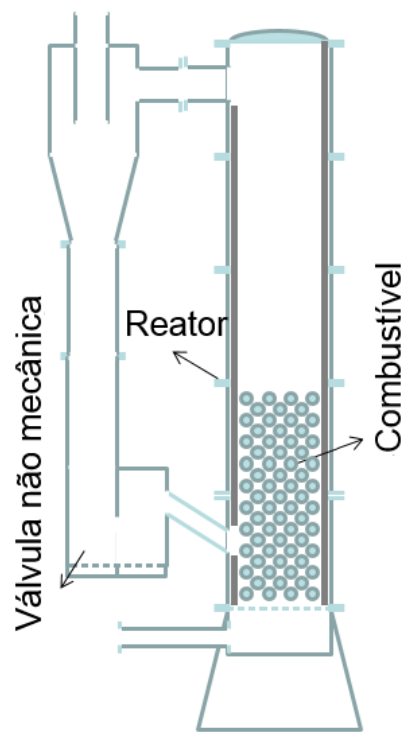

(a)

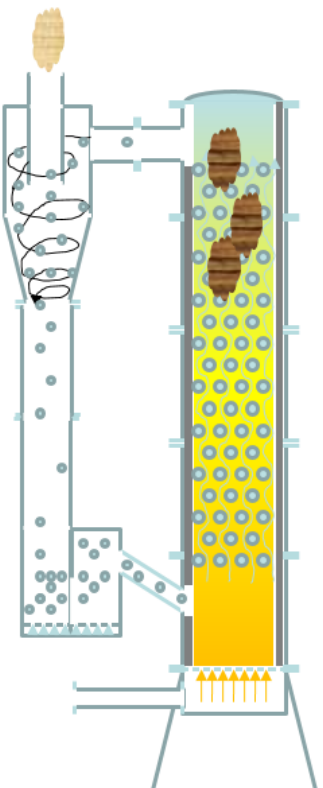

(b)

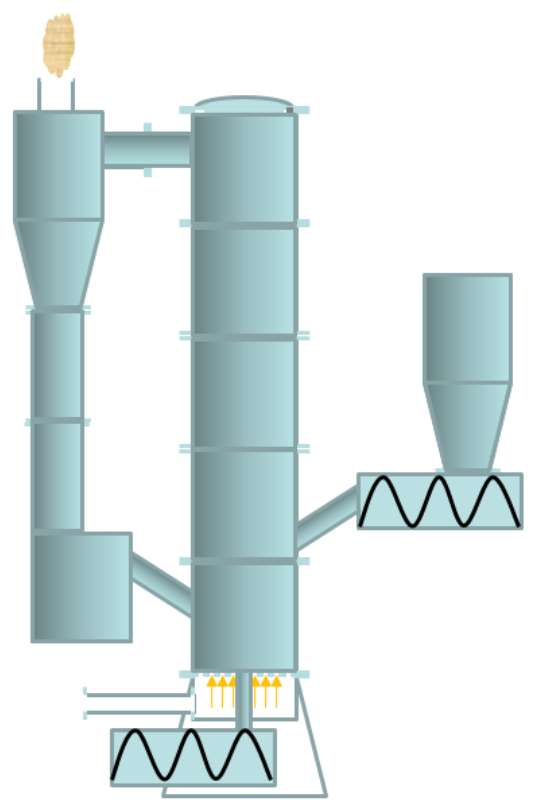

(c)

Figura 14 - Infógrafo do problema da coluna opaca de gaseificação em leito fluidizado circulante.

\subsubsection{Problema de instrumentação em gaseificação LFC}

O monitoramento e controle de arrasto de partículas em leito gás-sólido frio usando apenas um eletrodo de imersão e campos elétricos AC e DC, pode ser alcançado por Wang e Colver [100]. Contudo, necessita de calibrações e não é compatível com leitos quentes. Wang et al. [101] também mediram os perfis de velocidade de sólidos e o fluxo mássico usando sondas óticas ao longo da coluna de fluidização gás-sólido. Essa técnica é incompatível para medições em leitos quentes industriais.

Makkawi e Wright [102] mediram com precisão, num trecho de coluna fria, a fração de vazios em diversos regimes de fluidização, usando equipamento de tomografia de capacitância elétrica (ECT). Além do alto custo, o equipamento não poderia ser aplicado em leitos quentes devido a interferência do 
refratário. Já Guo et al. [103], usou o mesmo princípio de medição (capacitância) para estimar o fluxo mássico na alimentação de carvão, já que sempre está frio nas aplicações industriais.

Tebianian et al. [104]comparou diferentes técnicas como PIV, boroscopia, técnicas de emissão radioativa e de pósitrons, para medição do mesmo fluxo de sólidos em leitos gás-sólidos frios. Foi encontrado uma convergência nas medições de instrumentos mais caros com exceção do boroscópio.

Castilho et al. [33] mediram, em três pontos imersos ao leito de partículas, séries temporais de pressão diferencial para reconstrução do espaço de estado e avaliação da evolução das invariantes do caos (dimensão de correlação e entropia de Kolmogorov) para diferentes partículas e regimes de fluidização. Em sua análise, foi possível distinguir as velocidades de transição entre regimes de leito borbulhante e turbulento. Este método de quantificar os regimes baseado na análise não linear de séries de pressão, tem apresentado grande potencial para aplicações na industrial.

Como colunas de fluidização quentes geralmente operam com temperaturas altas $\left(800-950^{\circ} \mathrm{C}\right)$, a quantidade e tipos de medidores que suportem tais condições fica reduzida. A instrumentação deve ser capaz de reconstruir o estado de fluidização corrente de um sistema de leito fluidizado, atender as condições operacionais e oferecer baixo custo.

A faixa de medidores de baixo custo é restrita (sensor de pressão e termopares), porém já foram ensaiados em quase todas as funções. Apesar de diversos sensores já terem sido ensaiados em plantas de escala comercial, não foram encontrados relatos de que se tratavam de plantas de leito fluidizado circulante quente, ou seja, não se pode afirmar que soluções de alto custo foram testadas em condições de alta temperatura.

Conforme a Tabela 2, os sensores de pressão e termopares são constantemente utilizados [44] no auxílio de operações de gaseificação de leito fluidizado circulante. Os sensores de pressão conseguem suportar as condições de gaseificação porque estão conectados a uma distância da coluna através de tomadas. $\mathrm{O}$ ar, aprisionado nestas tomadas, evita a condução de calor da coluna para o sensor e a superfície lateral da tomada, por convecção natural, mantém a tomada fria. O diâmetro interno da tomada e seu prolongamento devem ser cuidadosamente projetados para evitar, respectivamente, atenuação do sinal de pressão e aquecimento do sensor. 
Tabela 2 - Técnicas de medição e parâmetros de processo de leito fluidizado aplicável para escalas de bancada (B), piloto (P) e testes em escalas comerciais (C). Adaptador de [54].

\begin{tabular}{|c|c|c|c|c|c|c|c|c|c|}
\hline & $\begin{array}{l}\text { Regime } \\
\text { de fluxo e } \\
\text { estrutura }\end{array}$ & $\begin{array}{l}\text { Caracterização } \\
\text { de partículas }\end{array}$ & Pressão & Temperatura & $\begin{array}{l}\text { Fração } \\
\text { de } \\
\text { vazios } \\
\text { (\&) }\end{array}$ & $\begin{array}{l}\text { Velocidade } \\
\text { do gás }(U)\end{array}$ & $\begin{array}{l}\text { Velocidade } \\
\text { de } \quad \text { sólidos } \\
\left(v_{\mathrm{p}}\right)\end{array}$ & $\begin{array}{l}\text { Fluxo } \\
\text { de } \\
\text { massa } \\
\text { sólida } \\
\left(\mathbf{G}_{\mathrm{s}}\right)\end{array}$ & Custo (R\$) \\
\hline $\begin{array}{ll}\begin{array}{l}\text { Sensor } \\
\text { pressão }\end{array} & \text { de } \\
\end{array}$ & $\mathrm{B}, \mathrm{P}, \mathrm{C}$ & $\mathrm{B}, \mathrm{P}, \mathrm{C}$ & $\mathrm{B}, \mathrm{P}, \mathrm{C}$ & & $\mathrm{B}, \mathrm{P}, \mathrm{C}$ & $\mathrm{B}, \mathrm{P}, \mathrm{C}$ & & & Baixo \\
\hline Termopar & & & & $\mathrm{B}, \mathrm{P}, \mathrm{C}$ & & & $\mathrm{B}, \mathrm{P}, \mathrm{C}$ & & Baixo \\
\hline Pirômetro & & & & $\mathrm{B}, \mathrm{P}, \mathrm{C}$ & & & & & Médio \\
\hline $\begin{array}{ll}\text { Tomadas } & \text { de } \\
\text { sução } & \end{array}$ & $\mathrm{B}, \mathrm{P}$ & $\mathrm{B}, \mathrm{P}, \mathrm{C}$ & & & & & $\mathrm{B}, \mathrm{P}$ & $\mathrm{B}, \mathrm{P}, \mathrm{C}$ & Médio \\
\hline $\begin{array}{l}\text { Sondas } \\
\text { capacitivas }\end{array}$ & $\mathrm{B}, \mathrm{P}$ & & & & $\mathrm{B}, \mathrm{P}$ & & $\mathrm{B}, \mathrm{P}$ & & Alto \\
\hline $\begin{array}{l}\text { Sondas de fibra } \\
\text { ótica }\end{array}$ & $\mathrm{B}, \mathrm{P}, \mathrm{C}$ & $\mathrm{B}, \mathrm{P}, \mathrm{C}$ & & & $\mathrm{B}, \mathrm{P}, \mathrm{C}$ & B, P & $\mathrm{B}, \mathrm{P}, \mathrm{C}$ & $\mathrm{B}, \mathrm{P}$ & Alto \\
\hline $\begin{array}{l}\text { Espalhamento } \\
\text { laser }\end{array}$ & B & & & & B & & B & B & Muito Alto \\
\hline LDV/PIV & $\mathrm{B}, \mathrm{P}$ & $\mathrm{B}, \mathrm{P}$ & & & $\mathrm{B}, \mathrm{P}$ & $\mathrm{B}, \mathrm{P}$ & $\mathrm{B}, \mathrm{P}$ & $\mathrm{B}, \mathrm{P}$ & Muito Alto \\
\hline Tomografia & B & & & & B & & $\mathrm{B}, \mathrm{P}$ & & Muito Alto \\
\hline $\begin{array}{l}\text { Traçador } \\
\text { gás/sólidos }\end{array}$ & B & B & & & B & $\mathrm{B}, \mathrm{P}$ & $\mathrm{B}, \mathrm{P}$ & & Alto \\
\hline $\begin{array}{l}\text { Observação } \\
\text { por câmeras }\end{array}$ & $\mathrm{B}, \mathrm{P}, \mathrm{C}$ & $\mathrm{B}, \mathrm{P}, \mathrm{C}$ & & $\mathrm{B}, \mathrm{P}, \mathrm{C}$ (IV) & $\mathrm{B}, \mathrm{P}, \mathrm{C}$ & & $\mathrm{B}, \mathrm{P}$ & & Alto \\
\hline
\end{tabular}

Nedeltchev [35] aplicou instrumentação de tomografia computadorizada usando contagem de fótons e densitometria nuclear para reconstrução precisa do sinal de porosidade. Estes métodos não são compatíveis com leitos quentes.

É comum registrar flutuações nas séries temporais de pressão estática ou diferencial durante uma operação de leito fluidizado circulante devido a interação fluido-partícula. A Figura 15 apresenta uma série de dados temporais de uma coluna semi-industrial de gaseificação LFC de $0,8 \mathrm{~m}$ de diâmetro interno e $12 \mathrm{~m}$ de altura operando em regime fluidizado. É fato que as flutuações mudam (amplitude e frequência) conforme o regime de fluidização. A taxa de amostragem precisa ser definida corretamente para alcançar quantidades de dados suficientes para a avaliação estatística. Contudo, é importante avaliar se a flutuação é fruto da interação fluido-partícula ou de ruídos espúrios.

Fica evidente no comparativo entre a Figura 15 e Figura 16 que a média do sinal pressão foi deslocada quando o regime de fluidização foi alterado do borbulhante (Figura 16) para, talvez, o turbulento (Figura 15). Um visor, localizado na base da coluna, permitiu a confirmação do regime borbulhante. Contudo, não foi tão simples distinguir, qualitativamente, entre os regimes globais turbulento, rápido e de transporte, a partir de visores locais da unidade ensaiada. Portanto, diferenciar regimes de fluidização a partir da análise de flutuações locais é um problema de engenharia. 


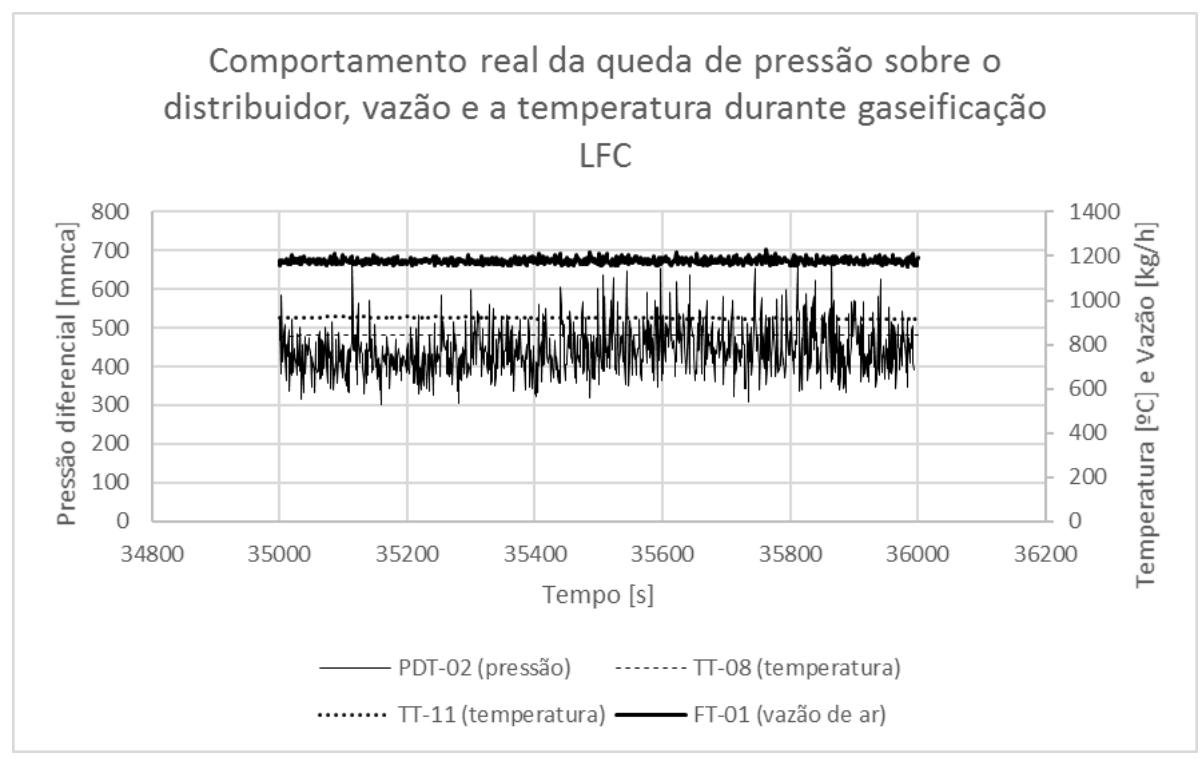

Figura 15 - Flutuações de dados de um gaseificador de leito fluidizado circulante real, com diâmetro interno de coluna de $0,8 \mathrm{~m}$ e altura de $12 \mathrm{~m}$, operando em leito fluidizado e taxa de amostragem de $1 \mathrm{~s}$.

A avaliação prévia dos dados da Figura 15 e Figura 16 indicam variações na média, desvio padrão e distribuição do espectro de frequência. A flutuação do sinal de pressão também depende da posição dos medidores na coluna. A medição do sinal de pressão estática da Figura 15 e da Figura 16 foi instalado na região de base. Diferente dos dados da base, medições preliminares nas regiões do meio e do topo indicaram amplitudes menores.

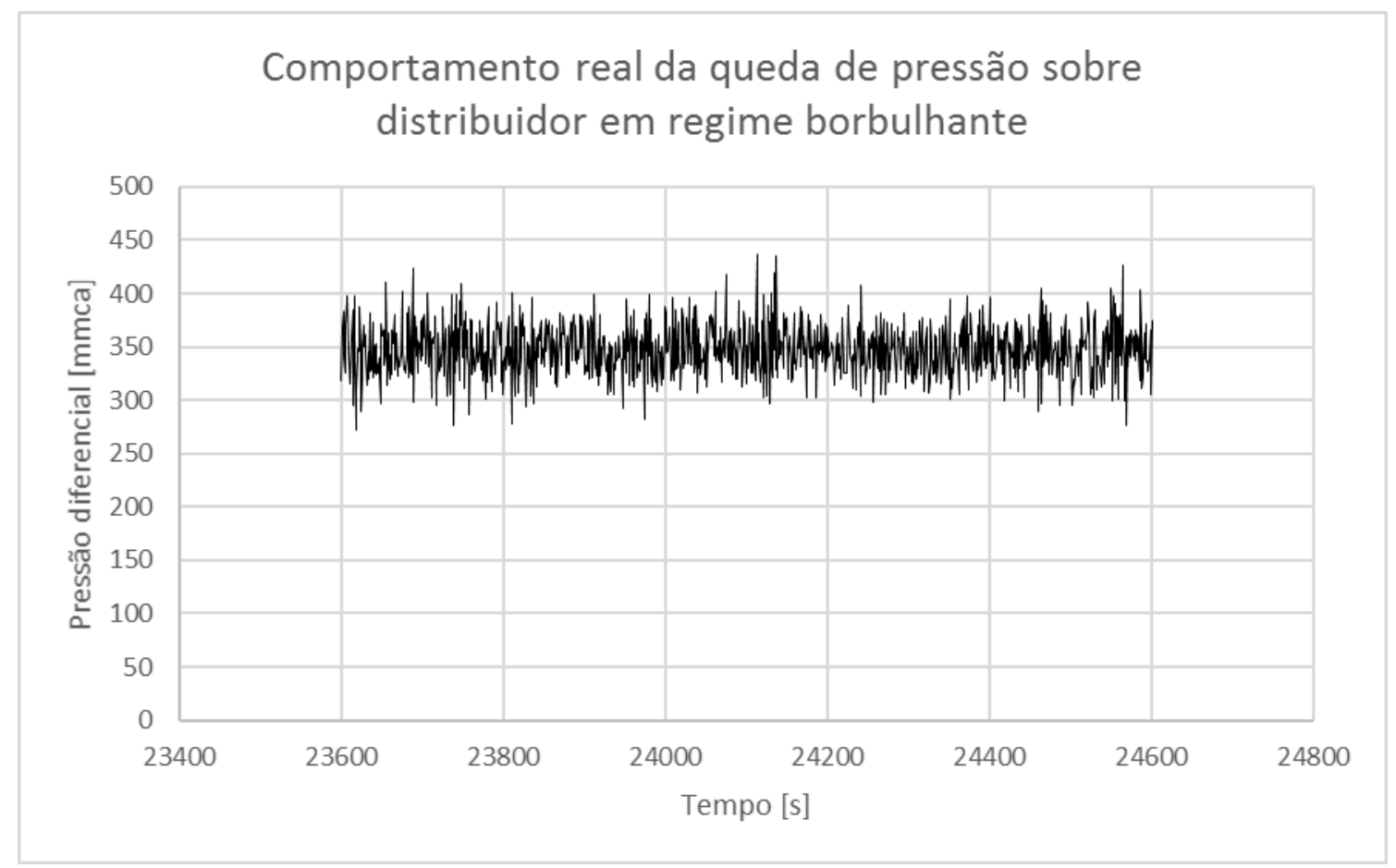

Figura 16 - Flutuações de pressão estática, na base, de um gaseificador de leito fluidizado circulante real, com diâmetro interno de coluna de $0,8 \mathrm{~m}$ e altura de $12 \mathrm{~m}$, operando em leito borbulhante e taxa de amostragem de $1 \mathrm{~s}$. 
A medição de pressão pode ajudar na inferência do regime de fluidização através das metodologias correntes. Contudo, os parâmetros avaliados por estas metodologias, não são suficientes para realizar previsões precisas quanto o regime de fluidização. A Figura 17 apresenta uma fonte de imprecisões do método baseado na queda de pressão local. Trechos muito grandes podem fazer diferentes tipos de partículas proporcionar pressões diferenciais por unidade comprimento próximas, conduzindo, erroneamente, a porosidades médias iguais. Portanto, mesmo que a porosidade média local instalada convirja para a porosidade média específica, não é condição suficiente para classificar um regime de fluidização.

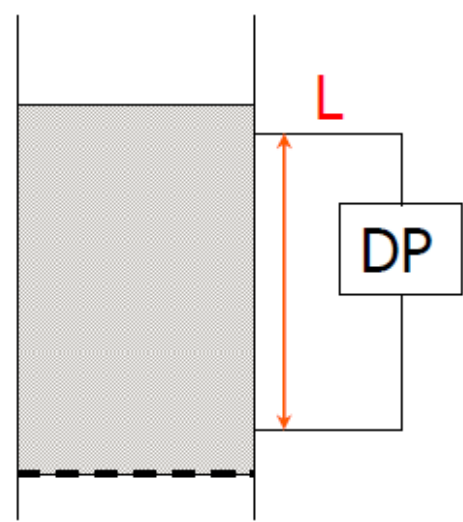

(A)

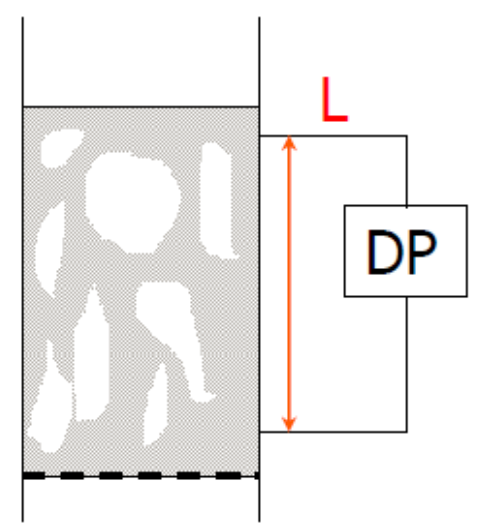

(B)

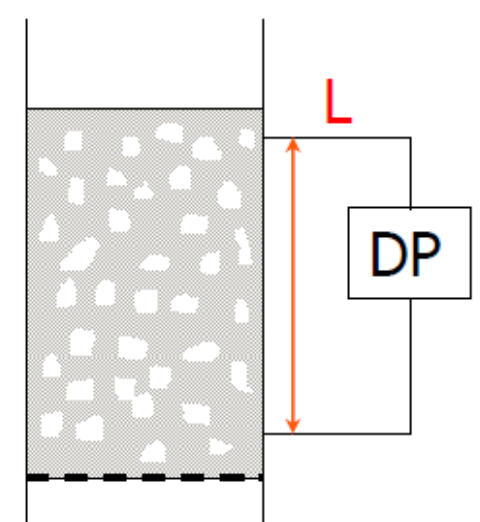

(C)

Figura 17 - Problema dos múltiplos padrões de escoamento gás-sólidos que conduzem a mesma diferença de pressão, se a distância, L, não for devidamente dimensionada.

A precisão da caracterização convencional de leito fluidizado está intimamente associada com o custo de instrumentação. Portanto, o estudo de novas abordagens, aplicados a instrumentação de baixo, tem motivado a aplicação de novas técnicas de processamento de dados capaz de extrair informações robustas e permitir a quantificação dos regimes de fluidização.

\subsubsection{Problema de quantificação de regimes em LFC}

A operação de leitos fluidizados em regime controlado é necessária quando variações ou distúrbios no inventário de massa, seja por reações químicas (secagem, combustão ou gaseificação), pelo arrasto ou pela remoção de partículas (remoção de cinzas em gaseificadores), provocam mudanças na interação fluido-partícula desejada. Contudo, para haver controle de regime é necessário quantificar os estados de fluidização para facilitar seu controle, seja por um operador humano ou por um algoritmo de controle.

Segundo Johnsson et al. [105]a interpretação dos resultados no domínio do tempo, tais como desvio padrão das flutuações de pressão, pode levar a conclusões errôneas sobre o regime de fluxo. Contudo, resultados a partir de análises de estado-espaço (dimensão de correlação e de Kolmogorov entropia, KML, em conjunto com um teste não-linearidade) de séries temporais de flutuações de pressão obtém boa sensibilidade aos regimes de fluidização. 
van Ommen et al. [106] revisou os métodos para quantificação de leitos fluidizados gás-sólidos, concluindo que a vantagem de certos métodos espaço de estado, tais como comparação de atratores, é que eles são mais sensíveis a pequenas alterações do que os métodos de domínio de frequências. Portanto, os métodos de análises não-lineares podem ser usado para o monitoramento contínuo do leito. Em geral, concluiu que, na última década, um progresso tem sido feito na compreensão da dinâmica de leito fluidizado, extraindo as informações relevantes a partir de dados de flutuação de pressão, mas a completa compreensão ainda está incompleta.

A análise dinâmica não-linear, através de invariantes do caos, tem demonstrado ser uma técnica robusta para a quantificação de regimes de fluidização a partir de séries temporais de pressão estática. Zarghami et al. [34] quantifica condições de leito fluidizado borbulhante, usando invariantes do caos de dimensão de correlação e entropia de Kolmogorov, com diferentes tipos e diâmetros de partículas.

Babei et al [67] utilizaram gráficos de recorrência, derivados da flutuação de pressão estática medida a $50 \mathrm{~mm}$ de base de uma coluna, para quantificar um determinado regime e, a partir dele, detectar a pequenas variações no regime de fluidização.

Tahmasebpoor et al. [107] quantificaram estruturas de macro, meso e microescala usando análises nãolineares de gráficos de recorrência. Eles obtiveram bons resultados para quantificação do regime borbulhante, através de invariantes, para diferentes tamanhos de partículas e diâmetros de leito.

Nedeltchev [35] aplicou técnicas do caos para reconstruir o espaço de fase, a partir de séries temporais de porosidade corrente, e identificar as transições entre regimes borbulhante e turbulento, avaliando a evolução das invariantes de entropias de Shanon e Kolmogorov. Contudo, outros regimes como o rápido não foram analisados.

Castilho et al. [33] aplicou técnicas do caos para demonstrar que a entropia de Kolmogorov da série de pressão diferencial é maior no leito borbulhante e tende a caiu no leito turbulento para todas as partículas ensaiadas. Contudo, regimes além do turbulento não foram investigados para avaliação de desempenho destas invariantes. Medições além da região de base foram desprezadas levando em conta apenas medições locais da região de imersão do leito.

Os métodos de quantificação de leito fluidizado gás-sólido pesquisados, não consideram a problema espaço-temporal dos sistemas fluidizados, e inferem a situação global de fluidização do leito através de poucas medições locais.

Além de ensaios em colunas de fluidização, outra forma que tem ganhado evidência nas investigações de técnicas de quantificação de regimes de fluidização, é a obtenção prévia de séries temporais a partir de simulações numéricas. Atualmente, os modelos numéricos indiretos, permitem considerar diversos mecanismos da interação fluido-partícula, para estudos do problema espaço-temporal em leito fluidizados, número de medidas de pressão e queda máxima de pressão ao longo da coluna.

\subsection{Fluidodinâmica computacional em colunas de fluidização}

Avanços nas técnicas de cálculos numéricos e nos fundamentos da fluidodinâmica gás-sólido tem permitido o uso de simulações numéricas para auxiliar o projeto de instalações de leito fluidizado circulante em escalas laboratorial e comercial. Atualmente, a implementação de simulações multifásicas turbulentas pode ser feita via simulações diretas ou indiretas. A simulações diretas trabalham com malhas muito refinadas (maior quantidade de células) para resolverem as equações de Navier-Stokes e a interação de forma completa, sendo necessário definir apenas as condições de contorno. Já as simulações indiretas usam malhas mais grosseiras (menor quantidade de células) e aproximações, como 
modelos de arrasto, turbulência e outras equações constitutivas para interfase fluido-partícula, reduzindo o custo computacional.

Os critérios de projeto de uma simulação multifásica para leito fluidizado, dependem fortemente das variáveis a serem investigadas. O propósito desta simulação numérica, é estudar dos perfis de queda de pressão e porosidade ao longo de uma coluna de leito fluidizado circulante, em escala laboratorial, para dimensionamento de moto-ventiladores e instrumentação de pressão (escala de medida de pressão). Apesar desta investigação almejar a quantificação da interação fluido-partícula experimentalmente através da avaliação de série temporal de flutuações do sinal de pressão estática, os atuais métodos numéricos multifásicos e multiescala, seriam capazes de estuda-los. Contudo, a investigação entre as flutuações de pressão estática numérica e experimental, em diferentes regimes de fluidização, não é escopo desta tese, podendo servir como motivação para trabalhos futuros.

Os fluxos podem ser, matematicamente, representados de duas formas. A primeira, indica um campo de velocidade em função do tempo, para cada elemento de fluido individualmente. Na teoria clássica de campos, é conhecida como especificação ou abordagem de Lagrange, representa uma maneira de olhar o movimento do fluido em que o observador segue, individualmente, cada elemento fluídico que se move através do espaço e do tempo [108]. Na prática, medidas de laboratório são difíceis de serem realizadas ao longo de trajetórias como na metodologia de Lagrange. Geralmente, o observador, está numa posição fixa em relação ao laboratório, ou seja, o instrumento está parado enquanto a corrente passa através dele.

A segunda forma, ou especificação de Euler do campo de fluxo é uma maneira de observar o movimento do fluido que se concentra em locais específicos no espaço através do qual uma corrente flui com o passar do tempo [108]. Experimentalmente, as coordenadas de Euler são mais úteis do que as de Lagrange. Mas o fato de que as leis do movimento de Newton referem-se a elementos individuais de fluido, cujas posições estão mudando as coordenadas de Euler, torna a matemática da mecânica dos fluidos significativamente mais complicada do que a de sólidos.

Atualmente, a fluidodinâmica computacional dispõe de métodos capazes de modelar o problema da interação de fluxos multifásicos aplicadas a leito fluidizado escalonados auxiliando no projeto de sistemas de injeção de ar, sólidos, instrumentação (especificação de resolução e faixa de operação de medidor) e controle de processos. A modelagem numérica tem vantagens em relação aos testes físicos: estudos paramétricos podem ser realizados com facilidade e testes de amostras não destrutivos e invasivos podem ser realizados. Portanto, a forma de modelar fluxos é essencial para produzir simulações viáveis computacionalmente e pertinentes as variáveis objeto de estudo.

\subsubsection{Tipos de simulações multifásicas}

A fluidodinâmica computacional (CFD) é capaz de produzir simulações numéricas multifásica usada em estudos de mecanismos fluidodinâmicos e auxílio em projetos, através de implementações do tipo DNS (direct numerical simulation), DEM (discret element method) e TFM (two fluid model). Os fluxos granulares diferem dos fluxos de fluidos, e são consideradas complexos porque as equações constitutivas são influenciadas por muitos parâmetros tais como coeficiente de restituição, coeficiente de friç̧ão, distribuição de tamanho de partícula, umidade, etc [109].

A simulação DNS dedica-se à solução de alta fidelidade de fluxos turbulentos. Diferente de outras abordagens numéricas, o DNS resolve a turbulência explicitamente ao invés de usar leis de fechamento e médias de Reynolds (RANS - Reynolds Averaged Navier-Stokes). A DNS também difere da simulação de grandes vórtices (LES - Large eddy simulation), pois inclui a evolução de mecanismos nas menores escalas, eliminando a necessidade de modelos submalhas (subgrid). A grande relevância do DNS é o 
fornecimento de conhecimento completo, não afetado por aproximações, por todo domínio e período da simulação. Portanto, o DNS pode ser visto como um experimento numérico que produz soluções nãoempíricas, a partir de princípios físicos fundamentais. Esta metodologia é ideal para pesquisas básicas e estudos de física da turbulência e de propostas de novas aproximações (modelos). Os benefícios científicos proporcionados pelo DNS para estudo de fluxos tem elevado preço por exigir grandes capacidades de processamento e armazenamento, devido aos cálculos dependentes do tempo dentro de domínios tridimensionais. Atualmente, a implementação do DNS está restrita a caros supercomputadores, distribuídos em poucos laboratórios no mundo e a pequenos domínios [110]. A parte sólida é tratada como partículas enquanto a parte fluida com um contínuo (vide Figura 18).

O DEM é uma abordagem lagrangiana para o fluxo granular de sistemas multifásicos, onde o comportamento de partículas são modeladas individualmente, e calculado com base nas leis do movimento de Newton [111]. A força de contato que atua sobre uma partícula é calculada usando um modelo massa-mola. Os recentes melhoramentos na capacidade de processamento dos computadores pessoais permitiram um aumento no número de partículas, domínios maiores e melhores tratamentos do acoplamento fluido-partícula a serem simulados (vide Figura 18). Apesar dos avanços, a simulação DEM ainda requer capacidade computacional (processamento, memória e armazenamento) nem sempre viável para aplicações de escala laboratorial e industrial. Quando os problemas de acoplamento fluidopartícula são calculados, a metodologia DEM é acoplada com a fluidodinâmica computacional (CFD), onde a técnica de média local de volume é usada para resolver a parte fluida [109]. O DEM modela o fluxo multifásico como uma coleção aleatória de partículas que interagem através de forças de contato. Neste método, os deslocamentos e rotações destas partículas são calculados em passos discretos de tempo. As forças e momentos que atuam em cada partícula são calculados a partir de dados inicias, leis físicas e modelos de contatos. O método é capaz de analisar múltiplas interações contínuas, descontínuas ou deformáveis, interagindo com corpos submetidos a grandes deslocamentos e rotacionais. As partículas podem ou não deformar, e o método monitora cada contato entre elas e calcula as novas posições e orientações. Além disso, o algoritmo pode modelar a propagação dinâmica de tensões de partícula para partícula [112]. O DEM pode ser adequado em aplicações de sistemas fluidizados, onde há descontinuidade por parte dos sólidos, e um meio contínuo por parte do fluido (ar), por razões que:

1. Qualquer tipo de força entre partículas pode ser incorporado,

2. Qualquer forma de partícula pode ser considerada,

3. Pode ser acoplado com outros métodos para modelar propriedades contínuas e descontínuas.

Já o TFM, aplicada para sistema multifásico, é o modelo composto de duas equações de continuidade (ambas fases), duas equações de momento em cada coordenada e duas equações de energia. Leis de fechamento adicionais são necessárias para fechar o conjunto de equações. Esta metodologia trata um sistema multifásico como se a interação das múltiplas fases se comportasse como a interação de múltiplos fluidos (vide Figura 18). Cada fase possui seu próprio conjunto de equações de equilíbrio governantes resultando em campos de velocidade, temperatura e pressão. Uma abordagem Euleriana, usa equações instantâneas locais que devem ser calculadas de forma adequada, seja no espaço, no tempo ou como um conjunto, permitindo uma malha mais grosseira e um intervalo de tempo mais longo para ser usado na simulação numérica. Como este processo introduz mais incógnitas do que o número de equações para o sistema, necessita da inclusão de expressões adicionais para fechar o conjunto de equações [113]. As leis de fechamento podem ser dos tipos topológicas, constitutivas e de transferência. As leis topológicas descrevem a distribuição espacial das quantidades específicas para cada fase. As leis constitutivas descrevem as propriedades físicas das fases, enquanto as leis de transferência descrevem diferentes interações entre as fases. No TFM, a maioria destas expressões são empíricas, sendo necessário dados experimentais e validação [114]. Por ser computacionalmente mais leves do que as simulações DNS e DEM, o TFM é, geralmente, a implementação escolhida para sistemas multifásicos. 
Como o TFM oferece uma situação aproximada da interação multifásica, deve ser corretamente especificada para atender ao estudo requerido.

Além das características de cada tipo de simulação, a Figura 18 também relaciona a viabilidade das simulações relacionando os níveis de detalhamentos dos cálculos, resolução das malhas e o tamanho do domínio. Como as simulações multifásicas, fornecidos pela DNS e DEM, ainda possuem implementações limitadas pelos altos custos computacionais, a TFM tem apresentado grandes avanços e potenciais para lidar com mecanismos multiescalas. Este trabalho apresenta uma formulação de simulação numérica tipo modelo de dois fluidos (TFM) para estudar o comportamento da queda de pressão e pressão estática local numa coluna fria de leito fluidizado circulante.

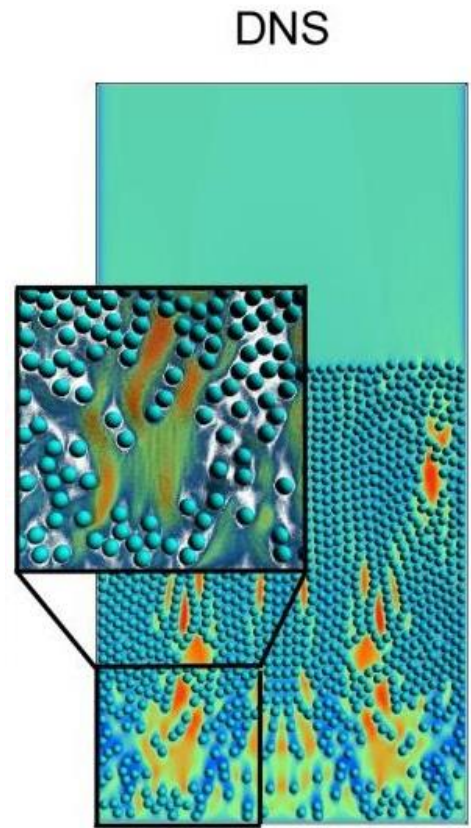

Euler-Lagrange
DEM

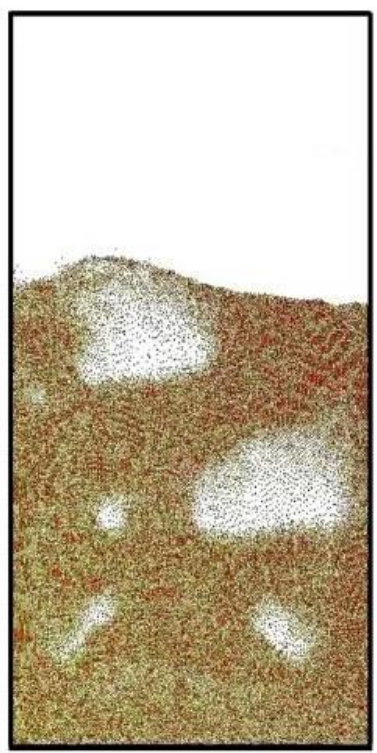

Euler-Lagrange
TFM

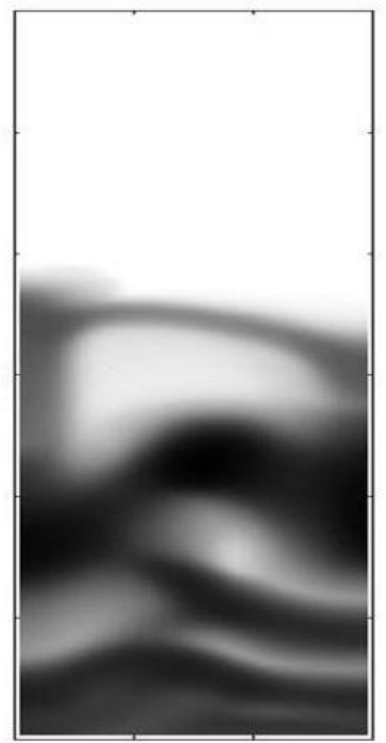

Euler-Euler

Maiores geometrias, menos detalhes

Figura 18 - Representação de simulações dos métodos numéricos de fluxo multifásico no mesmo domínio (volume de controle ou tamanho da geometria). Adaptado de [115].

A caracterização da simulação TFM pode acompanhada na seção de formulação do modelo de dois fluidos quando aplicada para leito fluidizado.

\subsubsection{Formulação do modelo de dois fluidos}

Fluxos multifásicos de dois fluidos (TFM) adotam uma abordagem Euleriana em o sistema de coordenadas é fixo a todas as células do domínio, e que equações de Navier-Stokes e balanços são resolvidas para ambas fases (sólido e gás).

Um procedimento geral para desenvolvimento de um modelo de dois fluidos iniciado pela implementação de integração de balanços de massa, momento e energia. A esses balanços são aplicados os teoremas de Leibniz e de Gauss para, respectivamente, expressar derivadas de uma integral como integrais de derivadas e, em seguida, relacionar o fluxo de um campo vetorial através de uma superfície com seu comportamento no interior da superfície de controle. Equações instantâneas locais e condições 
de salto são implementadas e definidas sobre os volumes de controle. O passo seguinte, usa procedimentos de médias sobre as equações anteriores, resultando em equações de médias. Equações de fechamento associadas as equações de médias dos balanços resultam em conjuntos fechados de equações diferenciais parciais. A definição de condições iniciais e condições de fronteiras resultam no modelo de dois fluidos ou TFM, implementado em diversos softwares como: os proprietários Abaqus, Ansys/Fluent, Comsol, Star-Ccm, Dassault Systèmes, Esteco Modefrontier, Ncode Desigh Life, FeSafe, Maxwell, Cedrat Flux, Sacs, Avl Fire, Avl Excite, Avl Cruise, Star-Cd, Simufact Welding, Simufact Forming, Esi Va One, Sysweld, Radtherm, Mpcci, Jmag; e gratuitos de código aberto OpenFOAM, MFIX, SU2, Fluidity, OpenFlower, Typhon [113].

A modelagem de dois fluidos estabelece as mudanças no momento e aceleração de parcelas fluídicas resultam de alterações de pressão e forças viscosas, originada da interação molecular. A viscosidade dinâmica da fase sólida é considerada como uma constante baseada em experimento, e a pressão de fase sólida é calculada a partir de funções envolvendo o módulo de elasticidade de colisões entre partículas e correlações empíricas [116].

\subsubsection{Equações locais}

A formulação geral do TFM pode ser representada conforme a Figura 19, em que um determinado volume de controle fixo pode compartilhar ambas fases de índice $k$. A interface com a área entre as fases $A_{i}(t)$ está movendo-se com a velocidade de $\vec{u}_{i}(t)$.

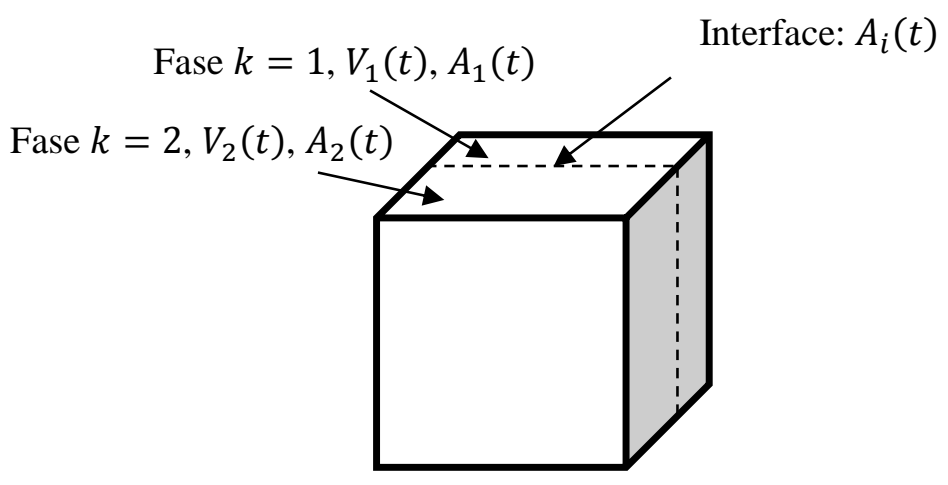

Figura 19 - Volume de controle fixado contendo duas fases. Adaptador de [113].

Supondo qualquer quantidade conservada (escalar ou vetorial), $\Psi_{k}$, pertencente à uma determinada fase $k$ a ser transportada através de um volume de controle, e usando um sistema de coordenadas fixas (abordagem Euleriana), seu balanço instantâneo local pode ser dado pela Equação 7. 


$$
\begin{aligned}
& \sum_{k=1}^{2}\left(\frac{d}{d t} \int_{V_{k}(t)} \rho_{k} \Psi_{k} d V\right) \\
&=\int_{A_{i}(t)} \phi_{i} d A \\
&+\sum_{k=1}^{2}\left(-\int_{A_{k}(t)} \rho_{k} \Psi_{k}\left(\vec{u}_{k} \cdot \vec{n}_{k}\right) d A+\int_{V_{k}(t)} \rho_{k} \phi_{k} d V\right. \\
&\left.-\int_{A_{k}(t)} J_{k} \cdot \overrightarrow{\mathrm{n}}_{k} d A\right)
\end{aligned}
$$

$\mathrm{O} \overrightarrow{\mathrm{n}}_{k}$ é o vetor normal, para fora da interface do volume ocupado pela fase $k, d / d t$ é a derivada temporal ordinária, $\vec{u}_{k}$ é a velocidade na fase $k, \rho_{k}$ é a massa específica, $\Psi_{k}$ é a quantidade conservada, $J_{k}$ é o fluxo molecular, $\phi_{k}$ é o termo fonte e $\phi_{i}$ é o termo fonte na interface. Essa formulação não inclui o termo de tensão superficial devidos aos efeitos insignificantes nos fluxos fluido-partícula [117].

A continuação da derivação da Equação 7 depende da definição velocidade num ponto da superfície geométrica do volume de controle, $\vec{u}_{i}=(\partial r / \partial t)_{\zeta, \eta=c t e}$, onde $r=(x(\zeta, \eta, t), y(\zeta, \eta, t), z(\zeta, \eta, t)) \mathrm{e}$ $(\zeta, \eta)$ são os parâmetros para localizar o ponto na superfície.

Aplicando as definições, teoremas de Leibniz e Gauss é possível reescrever a Equação 7 como uma integral de volume para os volumes ocupados pelas duas fases e uma integral de superfície que expressa as condições salto através da interface, através da Equação 8.

$$
\begin{array}{r}
\sum_{k=1}^{2} \int_{V_{k}(t)}\left(\frac{\partial}{\partial t}\left(\rho_{k} \Psi_{k}\right)+\nabla \cdot\left(\rho_{k} \Psi_{k} \vec{u}_{k}\right)+\nabla \cdot J_{k}-\rho_{k} \phi_{k}\right) d V \\
-\int_{A_{i}(t)}\left(\sum_{k=1}^{2}\left(\dot{m}_{k} \Psi_{k}+J_{k} \cdot n_{k}\right)+\phi_{i}\right) d A=0
\end{array}
$$

A segunda integral da Equação $8, \dot{m}_{k}=\rho_{k}\left(\vec{u}_{k}-\vec{u}_{i}\right) \cdot n_{k}$, representa a transferência de massa por unidade de área e tempo e deve ser satisfeita para qualquer $V_{k}(t)$ e $A_{i}(t)$. Assim a equação instantânea local é $\partial / \partial t\left(\rho_{k} \Psi_{k}\right)+\nabla \cdot\left(\rho_{k} \Psi_{k} \vec{u}_{k}\right)+\nabla \cdot J_{k}-\rho_{k} \phi_{k}$ e a condição instantânea de salto é $\sum_{k=1}^{2}\left(\dot{m}_{k} \Psi_{k}+J_{k} \cdot n_{k}\right)=-\phi_{i}$, e podem ser aplicadas ao transporte de massa, momento, energia, entropia, espécies químicas, etc. Para tais aplicações são denominadas de equações instantâneas locais e condições de salto primárias, enquanto as secundárias seriam variáveis como energia mecânica, derivada das primeiras [113].

A conservação de massa é dada pela Equação 9.

$$
\frac{\partial}{\partial t}\left(\rho_{k}\right)+\nabla \cdot\left(\rho_{k} \vec{u}_{k}\right)=0
$$




$$
\sum_{k=1}^{2} \dot{m}_{k}=0
$$

Para conservação do momento é dado pela Equação 10, em que $\bar{T}_{k}$ é o tensor e $b$ é a força do corpo.

$$
\begin{aligned}
& \frac{\partial}{\partial t}\left(\rho_{k} \vec{u}_{k}\right)+\nabla \cdot\left(\rho_{k} \vec{u}_{k}\right)-\nabla \cdot \bar{T}_{k}-\rho_{k} b=0 \\
& \sum_{k=1}^{2}\left(\dot{m}_{k} \vec{u}_{k}-\bar{T}_{k} n_{k}\right)=0
\end{aligned}
$$

A etapa seguinte, é aplicação de técnicas de médias sobre as equações instantâneas locais para estudar a evolução dos campos sobre pontos fixos no espaço do domínio.

\subsubsection{Técnicas de médias}

A modelagem de fluxos de duas fases é uma tarefa difícil dos pontos de vista matemático e físico, respectivamente, devido as complicações dos limites móveis entre duas fases individuais e devido ao estabelecimento dos mecanismos na interface (interação fluido-partícula). Para o caso do grande número de partículas suspensas num fluxo de gás, é necessário aplicar um operador de média sobre as equações instantâneas locais quando utilizado a abordagem Euleriana. Outra alternativa é usar equações diferenciais para cada partícula, como na abordagem Lagrangiana [118].

A abordagem Euleriana de um determinado parâmetro escalar, vetorial ou tensorial, trabalha com equações do tipo $f=f(r, t)$, onde estuda sua evolução (do parâmetro) num ponto fixo, $r$, no espaço, e em qualquer tempo, $t$, e qualquer uma das fases pode estar presente. Essa descrição é simplificada com a aplicação de operadores de média sobre as equações de balanço. $\mathrm{O}$ volume médio é efetuado entono de um ponto fixo, $r$, num instante, $t$, enquanto que a média de tempo é executada num ponto fixo, $r$, ao longo de um intervalo de tempo, incluindo o tempo, $t$, [119] [118]. A média conjunta pode ser vista como um média estatística do parâmetro $f_{n}$, localizado em $r$, no instante $t$, ao longo de um grande número de experimentos de mesmas condições inicias e de contorno. $\mathrm{O}$ volume médio é definido conforme a Equação 11.

$$
\langle\ldots\rangle_{v}=\frac{1}{V} \int_{V}(\ldots) d x d y d z
$$

Equação 11

As condições em que o cálculo de volume médio pode aplicado sobre dimensões características de fase, do volume médio e do sistema físico.

O operador de tempo médio é definido conforme a Equação 12.

$$
\langle\ldots\rangle_{t}=\frac{1}{T} \int_{t-T / 2}^{t+T / 2}(\ldots) d \tau
$$


As condições em que o cálculo de tempo médio pode aplicado sobre escalas de flutuações turbulentas, intervalos de tempo médio e flutuações de fluxo médio.

Para fluxos o qual não é possível distinguir entre escalas de tempo de flutuações turbulenta e escala de tempo de fluxo médio, um operador de média conjunta é definido pela Equação 13, onde $d P(\mu)$ é a probabilidade de observar o processo $\mu$, e $C$ é o conjunto de todas as realizações possíveis.

$$
\begin{array}{ll}
\langle\ldots\rangle_{c}=\int_{C}(\ldots) d P(\mu) & \text { Equação } 13
\end{array}
$$

Através deste operador mais geral (operador conjunto) não necessidade de conhecer a localização exata de cada partícula e campos de velocidade de entrada. Na prática, é a média conjunta de experimentos num leito fluidizado com mesmas distribuições de partículas e velocidades do gás de entrada. Portanto, a média conjunta é o valor médio estatístico de qualquer parâmetro de interesse numa dada posição e tempo ao longo de um número de experimentos (ergodicidade) [114] [113] [119].

O tratamento com operadores de médias conduz o modelo TFM a descrever meios contínuos interpenetrantes. O cálculo de média para fase partícula é análoga ao efetuado pela teoria cinética dos gases, quando o cálculo de média do movimento molecular descreve a fase fluida. O cálculo de média do movimento de partículas dispersas num fluxo de duas fases conduz a equações médias de movimento para a fase contínua de partículas, o que, no mesmo sentido pode ser considerada como equações instantânea locais numa escala maior. Fisicamente, o cálculo de média, para média de tempo, volume ou conjunta, pode ser importante para formulação de leis de fechamento apropriadas [114] [118] [113].

A aplicação das técnicas de médias sobre equações instantâneas locais e condições de salto conduzem para equações de balanço média e condições de salto média. Uma função degrau pode ser aplicada para indicação de fase, $X_{k}$, para fase $k$. O cálculo de média da função de indicação de fase é equivalente à ocorrência média da fase $k$, definindo a porosidade, conforme a Equação 14.

$$
\begin{aligned}
& X_{k}(r, t)= \begin{cases}1, & \text { se } r \in k \\
0, & \text { outros }\end{cases} \\
& \alpha_{k}=\left\langle X_{k}\right\rangle \\
& \sum_{k=1}^{2} \alpha_{k}=1
\end{aligned}
$$

O cálculo de média considera as propriedades da Equação 15.

$$
\begin{aligned}
& \langle f+g\rangle=\langle f\rangle+\langle g\rangle \\
& \langle f\langle g\rangle\rangle=\langle f\rangle\langle g\rangle \\
& \langle c t e\rangle=c t e \\
& \left\langle\frac{\partial f}{\partial t}\right\rangle=\frac{\partial\langle f\rangle}{\partial t}
\end{aligned}
$$




$$
\begin{aligned}
& \langle\nabla f\rangle=\nabla\langle f\rangle \\
& \langle\nabla \cdot f\rangle=\nabla \cdot\langle f\rangle
\end{aligned}
$$

A aplicação das definições de função de indicação de fase e propriedades do cálculo de média podem conduzir a relações de balanço médio conforme a Equação 16.

$$
\begin{array}{ll}
\frac{\partial\left\langle X_{k} f_{k}\right\rangle}{\partial t}=\left\langle X_{k} \frac{\partial f_{k}}{\partial t}\right\rangle+\left\langle f_{k} \frac{\partial X_{k}}{\partial t}\right\rangle & \\
\nabla\left\langle X_{k} f_{k}\right\rangle=\left\langle X_{k} \nabla f_{k}\right\rangle+\left\langle f_{k} \nabla X_{k}\right\rangle & \text { Equação } 16 \\
\nabla \cdot\left\langle X_{k} f_{k}\right\rangle=\left\langle X_{k} \nabla \cdot f_{k}\right\rangle+\left\langle f_{k} \cdot \nabla X_{k}\right\rangle & \\
\frac{\partial}{\partial t}\left\langle X_{k} \rho_{k} \psi_{k}\right\rangle=\nabla \cdot\left\langle X_{k} \rho_{k} \psi_{k} \vec{u}_{k}\right\rangle+\nabla \cdot\left\langle X_{k} J_{k}\right\rangle-\left\langle X_{k} \rho_{k} \phi_{k}\right\rangle & \\
& =\left\langle\left(\dot{m}_{k} \psi_{k}+J_{k} \cdot n_{k}\right) \frac{\partial X_{k}}{\partial n}\right\rangle
\end{array}
$$

O gradiente da função de indicador de fase é expresso como $\nabla X_{k}=\left(\partial X_{k} / \partial n\right) n_{k}$, onde $\partial X_{k} / \partial n=-\delta_{k}$. A função de Dirac, $\delta_{k}$, associado a fase $k$, é usado para separar os fluxos moleculares e de massa na interface. A propriedade da função delta de Dirac $\int_{-\infty}^{+\infty} f(\xi) \delta(\xi-a)=f(a)$, calculando a média do produto entre o valor absoluto do gradiente e os fluxos resulta num efeito de contribuição média de fluxos molecular e de massa na interface sobre todo o domínio de integração. A condição instantânea de salta pode ser transformada na condição de salto médio, conforme a Equação 17.

$$
\sum_{k=1}^{2}\left\langle\left(\dot{m}_{k} \psi_{k}+J_{k} \cdot n_{k}\right) \frac{\partial X_{k}}{\partial n}\right\rangle=-\left\langle\phi_{i} \frac{\partial X_{k}}{\partial n}\right\rangle
$$

Para transporte médio de massa e momento, e condição de salto, pode ser expresso conforme a Equação 18.

$$
\begin{aligned}
& \frac{\partial}{\partial t}\left\langle X_{k} \rho_{k}\right\rangle+\nabla \cdot\left\langle X_{k} \rho_{k} \vec{u}_{k}\right\rangle=0 \\
& \frac{\partial}{\partial t}\left\langle X_{k} \rho_{k} \vec{u}_{k}\right\rangle+\nabla \cdot\left\langle X_{k} \rho_{k} \vec{u}_{k} \vec{u}_{k}\right\rangle-\nabla \cdot\left\langle X_{k} \bar{T}_{k}\right\rangle-\left\langle X_{k} \rho_{k} g\right\rangle=\left\langle-\bar{T}_{k} \nabla X_{k}\right\rangle \\
& \left\langle-\bar{T}_{k} \nabla X_{k}\right\rangle=M_{k i} \\
& \sum_{k=1}^{2}\left\langle-\bar{T}_{k} \nabla X_{k}\right\rangle=0 \\
& \sum_{k=1}^{2} M_{k i}=0
\end{aligned}
$$




$$
M_{1 i}=-M_{2 i}
$$

A transferência de momento interfacial, $M_{k i}$, utiliza expressões empíricas para representar a interação entre fases.

As equações médias não podem ser resolvidas diretamente, pois contém médias de produtos de variáveis dependentes. Para obtenção de conjunto equações solucionáveis, é necessário utilização da decomposição de Reynolds e um processo de ponderação para as variáveis antes dos cálculos de média. O principal objetivo da decomposição e da ponderação é a de separar as médias de produtos em produtos de médias. O procedimento resulta em termos adicionais nas equações, contendo as correlações das componentes flutuantes. Aplicando a decomposição de Reynolds e o processo de ponderação para uma variável geral, $f$, resulta em $f=\langle f\rangle^{p}+f^{\prime}$, onde o primeiro representa o valor médio ponderado, $\langle f\rangle^{p}$, e o segundo, o desvio do valor médio, $f^{\prime}$. O valor médio ponderado de um dado escalar ou vetor ou um tensor $f$ pode ser definido como $\langle f\rangle^{p}=\langle p f\rangle / p$, em que o fator de ponderação, $p$, é arbitrário. As variáveis ou são ponderados com a função de indicador de fase (média fásica), $\langle f\rangle^{X_{k}}=\left\langle X_{k} f\right\rangle / X_{k}$, ou com o indicador fase vezes função da densidade (média ponderada em massa ou média de Favre), $\langle f\rangle^{X_{k} \rho_{k}}=\left\langle X_{k} \rho_{k} f\right\rangle / X_{k} \rho_{k}$. A média ponderada em massa é capaz de dividir as correlações entre flutuações de densidade e as outras flutuações de variáveis. As variáveis ponderadas como a velocidade, $\left\langle\vec{u}_{k}\right\rangle^{X_{k} \rho_{k}}$, densidade, $\left\langle\rho_{k}\right\rangle^{X_{k}}$, e o tensor de tensões, $\left\langle\bar{T}_{k}\right\rangle^{X_{k}}$, o tensor de flutuação, $\bar{T}_{k}^{R e}$, ambos para fase $k$, é ponderada utilizando a média fásica, conforme a Equação 19 [113].

$$
\begin{aligned}
& \left\langle\vec{u}_{k}\right\rangle^{X_{k} \rho_{k}}=\vec{U}_{k} \\
& \left\langle\rho_{k}\right\rangle^{X_{k}}=\left\langle\rho_{k} X_{k}\right\rangle / X_{k}=\left\langle\rho_{k} X_{k}\right\rangle / \alpha_{k}=\rho_{k}^{X_{k}} \\
& \left\langle\bar{T}_{k}\right\rangle^{X_{k}}=\bar{T}_{k}^{X_{k}} \\
& \bar{T}_{k}^{R e}=-\left\langle X_{k} \rho_{k} \vec{u}_{k}^{\prime} \vec{u}_{k}^{\prime}\right\rangle /\left\langle X_{k}\right\rangle=-\left\langle X_{k} \rho_{k} \vec{u}_{k}^{\prime} \vec{u}_{k}^{\prime}\right\rangle / \alpha_{k}
\end{aligned}
$$

Da mesma forma, a decomposição de Reynolds e o processo de ponderação pode ser aplicado sobre as equações de balanço como continuidade, momento e transferência de momento na interface, ambos para fase $k$, conforme a Equação 20.

$$
\begin{aligned}
& \frac{\partial}{\partial t}\left(\alpha_{k} \rho_{k}^{X_{k}}\right)+\nabla \cdot\left(\alpha_{k} \rho_{k}^{X_{k}} \vec{U}_{k}\right)=0 \\
& \frac{\partial}{\partial t}\left(\alpha_{k} \rho_{k}^{X_{k}} \vec{U}_{k}\right)+\nabla \cdot\left(\alpha_{k} \rho_{k}^{X_{k}} \vec{U}_{k} \vec{U}_{k}\right)=\nabla \cdot\left(\alpha_{k}\left(\bar{T}_{k}^{X_{k}}+\bar{T}_{k}^{R e}\right)\right)+\alpha_{k} \rho_{k}^{X_{k}} g+M_{k i} \\
& M_{k i}=-\left\langle\bar{T}_{k} \nabla X_{k}\right\rangle
\end{aligned}
$$

A equações de balanços são modeladas utilizando expressões empíricas conforme descrito pelas leis de fechamento, enquanto as condições de salto colocam restrições. 


\subsubsection{Leis de fechamento}

De forma geral, quatro princípios básicos são considerados para aplicação das leis de fechamento para modelo de dois fluidos [120]:

- Equipresença, quando uma função de todas as outras variáveis, a menos que a independência de qualquer um deles pode ser mostrado.

- Boa alocação, quando o conjunto de equações diferenciais tem uma solução única.

- Enquadramento indiferente, quando as leis de fechamento não dependem do referencial.

- Cumprimento da segunda lei da termodinâmica para as leis de fechamento junto com as equações de balanço originadas tanto da transferência de calor e dissipação viscosa.

Para o fechamento do problema de fluxo de duas fases de um sistema, as equações diferenciais parciais médias (balanços) necessita de equações adicionais. As leis constitutivas relacionam propriedades físicas através de axiomas e dados experimentais. Para a fase de partículas, existem duas maneiras muito diferentes de modelagem de fluxo de parâmetros tais como a viscosidade dinâmica, viscosidade granular e pressão das partículas. Modelos empíricos baseados nas propriedades das partículas e a porosidade local podem ser usados na modelagem, mas a teoria cinética de fluxo granular tem apresentado melhores resultados [121].

A Equação 21 apresenta o estresse viscoso, $\bar{\tau}_{k}$, para uma fase $k$, numa mistura de duas fases onde relaciona o termo de momento, $\nabla \cdot\left(\alpha_{k} \bar{T}_{k}^{X_{k}}\right)$, de pressão, $P_{k}$, e tensão de cisalhamento.

$$
\nabla \cdot\left(\alpha_{k} \bar{T}_{k}^{X_{k}}\right)=\nabla \cdot\left(\alpha_{k}\left(-P_{k} \bar{I}+\bar{\tau}_{k}\right)\right)=-\nabla\left(\alpha_{k} P_{k}\right)+\nabla \cdot\left(\alpha_{k} \bar{\tau}_{k}\right)
$$

Equação 21

Já o tensor, $\bar{\tau}_{k}$, de ambas as fases é muitas vezes modelado pela relação tesão/deformação de Newton, com taxa de deslocamento $\bar{S}_{k}$, viscosidade granular, $\xi_{k}$, viscosidade, $\mu_{k}$, conforme a.

$$
\begin{aligned}
& \bar{\tau}_{k}=\xi_{k}\left(\nabla \cdot \vec{U}_{k}\right) \bar{I}+2 \mu_{k}\left(\bar{S}_{k}-\frac{1}{3}\left(\left(\nabla \cdot \vec{U}_{k}\right) \bar{I}\right)\right) \\
& \bar{S}_{k}=\frac{1}{2}\left(\nabla \vec{U}_{k}+\left(\nabla \vec{U}_{k}\right)^{T}\right)
\end{aligned}
$$

Equação 22

A descrição completa da tensão em cada fase, conforme exigido para um modelo de dois fluidos, necessita de expressões para as viscosidades de fases gás e de partículas. A concentrações elevadas de partículas, a viscosidade das partículas é várias ordens de grandeza maior do que a viscosidade do gás. A viscosidade da mistura está relacionada com as viscosidades de fase, havendo diversas propostas como leito densamente empacotado, regime diluído, etc. [122] [123] [124] [125].

Os mecanismos que contribuem para viscosidades de fases são semelhantes ao explicar efeitos cinéticos e de colisões. A presença de partículas origina tensões sobre a fase partículas e estão relacionadas a teoria cinética dos gases. O efeito contributivo cinético para a viscosidade de um gás considera-o a um nível molecular. O efeito colisional é um efeito da força tangencial resultante de interações moleculares entre moléculas vizinhas, o que pode ser comparado ao atrito de deslizamento que ocorre entre as partículas durante uma colisão. Na fase gasosa, as moléculas estão a uma distância média de tal modo que o efeito de colisão é negligenciável em comparação com o efeito cinético, mas este efeito domina sobre o efeito cinético em um fluido. Na fase de partículas, o efeito de colisão é a contribuição dominante 
para a viscosidade a altas concentrações de partículas. A força normal resultante de colisões de partículas está incluída no termo pressão de partícula [126].

Considerando, para os casos de simulações em leito fluidizado circulante, a viscosidade da fase de partículas a ser consideravelmente maior do que o da fase de gás, $\mu_{G}$, a viscosidade da mistura, $\mu_{\text {mix }}$, pode ser simplificada conforme a Equação 23.

$$
\mu_{\operatorname{mix}}=\mu_{G}\left(1-\alpha_{p} / \alpha_{p, \max }\right)^{-2,5 \alpha_{p, \max }}
$$

Equação 23

$\mathrm{O}$ modelo de dois fluidos, geralmente, considera a pressão do gás igual a pressão estática, $P_{G}=P$ e $\nabla P=\alpha_{G} \rho_{G} g+\left(1-\alpha_{G}\right) \rho_{p} g$.

A pressão na fase de partículas considera a soma dos três efeitos: uma correspondente ao transporte de momento causada por correlações flutuações na velocidade de partícula, $P_{p, k i n}$, outra causada pela interação de partículas (colisões), $P_{p, c o l i}$, e a contribuição a pressão de fase gasosa, $P_{G}$, conforme a Equação 24.

$$
\nabla\left(\alpha_{p} P_{p}\right)=\nabla\left(\alpha_{p} P_{p, \text { kin }}\right)+\nabla\left(\alpha_{p} P_{p, \text { coli }}\right)+\nabla\left(\alpha_{p} P_{G}\right)
$$

Equação 24

As condições de operação de um leito influenciam fortemente na definição dos termos de pressões de partículas. O componente de colisão é o efeito dominante da pressão efetiva nas regiões densas de um leito fluidizado. Esta pressão transmite uma força tanto por impactos de curta duração resultantes de colisões, e por longa duração de contatos entre partículas. Vários modelos para o termo gradiente pressão colisional de partícula, $\nabla\left(\alpha_{p} P_{p, c o l i}\right)$, são encontrado na literatura [127] [128] entre outros, e pode ser definido conforme a Equação 25, onde $G_{0}, C$ e $\alpha^{*}$, são constantes empíricas.

$$
\begin{aligned}
& \nabla\left(\alpha_{p} P_{p, \text { coli }}\right)=-G\left(\alpha_{G}\right)+\nabla \alpha_{G} \\
& G\left(\alpha_{G}\right)=G_{0} e^{\left(C\left(\alpha_{G}-\alpha^{*}\right)\right)}
\end{aligned}
$$

Quanto a Equação 20 para $M_{k i}$, aplicando a decomposição de Reynolds, técnicas de médias na equação de momento e negligenciando o tensor de flutuações, $\bar{T}_{k}^{R e}$, pode-se obter a Equação 26. A transferência de momento interfacial, $M_{k i}^{d}$, depende do tensor de tensões, $\bar{T}_{k i}^{d}$, ambos associados a força de arrasto (vide Equação 26).

$$
\begin{aligned}
& M_{k i}=P_{i} \nabla \alpha_{k}-\bar{\tau}_{i} \nabla \alpha_{k}+M_{k i}^{d} \\
& M_{k i}^{d}=-\left\langle\bar{T}_{k i}^{d} \nabla X_{k}\right\rangle \\
& \bar{T}_{k i}^{d}=-\left(P_{k}-P_{i}\right) \bar{I}+\left(\bar{\tau}_{k}-\bar{\tau}_{i}\right)
\end{aligned}
$$

Equação 26

Para ambas fases, a condição de salto de transferência de momento interfacial, considerando o arrasto generalizado, conforme a eq. 


$$
\begin{aligned}
& \sum_{k=1}^{2} M_{k i}=P_{i} \sum_{k=1}^{2} \nabla \alpha_{k}-\bar{\tau}_{i} \sum_{k=1}^{2} \nabla \alpha_{k}+\sum_{k=1}^{2} M_{k i}^{d} \\
& \sum_{k=1}^{2} M_{k i}^{d}=0
\end{aligned}
$$

As forças correspondentes para a fase gasosa são obtidas alterando sinais nas expressões da força de fase particulada, em conformidade com a condição de salto para o arrasto generalizado.

Os modelos de arrasto estacionários são baseados em correlações para o coeficiente de arrasto para uma partícula em suspensão. A força de arrasto estacionária, $F_{a r}$, sobre uma partícula em suspensão pode ser definida quer em termos de a velocidade superficial do gás em relação ou a velocidade relativa intersticial, $U_{0}=\alpha_{G} U_{r}=\alpha_{G}\left(U_{G}-U_{p}\right)$. Em geral, a força de arrasto é influenciada pelo coeficiente de arrasto, $C_{D}$, indicadas por correlações empíricas como as fornecidas por Schiller e Naumann [129], conforme a Equação 28.

$$
\begin{aligned}
& F_{a r}=\frac{1}{2} C_{D} \rho_{G}|U| U\left(\pi d_{p}^{2} / 4\right) \\
& C_{D}=\left\{\begin{array}{r}
24\left(1+0,15(R e)^{0,687}\right) / \text { Re }, \text { se } R e<1000 \\
0,44, \text { se } R e \geq 1000
\end{array}\right. \\
& R e=\rho_{G}\left(U_{p}-U_{G}\right) d_{p} / \mu_{G} \\
& n_{p}=6\left(1-\alpha_{G}\right) / \pi d_{p}^{3} \\
& n_{p} F_{a r}=\frac{3}{4 d_{p}}\left(1-\alpha_{G}\right) C_{D} \rho_{G}|U| U
\end{aligned}
$$

O momento interfacial para fase dispersa (partícula), $M_{p i}^{d}=n_{p}\left(F_{a r}+F_{t r}+F_{a m}+F_{h i}+F_{o t}\right)$, é composto por forças de arrasto, $F_{a r}$, forças transversas, $F_{t r}$, forças de massa adicionada, $F_{a m}$, força histórica, $F_{h i}$, outras forças, $F_{o t}$ e o número de partículas por unidade de volume, $n_{p}$. Dependendo do tratamento de escala, tais forças podem ser aplicadas para uma partícula ou pela formação de agrupamentos (clusters) [113].

Uma partícula que se move num fluxo bifásico experimenta uma força transversal (ou elevação), $n_{p} F_{t r}=-C_{t r} \rho_{G}\left(1-\alpha_{G}\right)\left(U_{G}-U_{p}\right) \times\left(\nabla \times U_{G}\right)$, se o fluxo não é uniforme (gradiente de velocidade), se a partícula está em rotação ou se a partícula se move na proximidade de uma parede.

O efeito de força de massa adicionada, $n_{p} F_{a m}=C_{a m}\left(1-\alpha_{G}\right) \rho_{G}\left(\frac{D_{G} U_{G}}{D t}-\frac{D_{p} U_{p}}{D t}\right)$, ocorre quando uma fase acelera em relação a outra. A fase de aceleração deve vencer a inércia da massa que se encontra no seu caminho.

A força de histórico ou força de Basset, $n_{p} F_{h i}=\left(9 / d_{p}\right)\left(1-\alpha_{G}\right) \sqrt{\left(\rho_{G} \mu_{G} / \pi\right)} \int(a(r, t) / \sqrt{t-\tau}) d \tau$, em fluxos de duas fases é proveniente da aceleração de uma fase em relação a outra, e é um resultado da quantidade de movimento sendo difundida através da camada limite. 
Outras forças, $F_{o t}$, podem ser usadas para garantir o cumprimento da segunda lei da termodinâmica.

Modelos de turbulência não fizeram parte desta revisão bibliográfica, por não contribuírem significativamente com a análise do problema [130] [131].

A presente descrição introduz, de forma geral, as diversas implementações de dois fluidos para leitos fluidizados circulantes oferecidas em programas de código aberto ou proprietário e visa auxiliar os parâmetros de configurações de uma simulação e suas condições de contorno. O desenvolvimento apresentado não trata os mecanismos de escala micro, meso e macroscópica, mas são suficientes para realização do estudo de perda de carga e de instrumentação de pressão estática (posicionamento, resolução e tempo de resposta).

A quantificação do regime de fluidização de leitos fluidizados, necessita de revisões sobre processos de aquisição de séries temporais e suas análises.

\subsection{Aquisição de séries temporais}

A aplicação de ferramentas de análise da dinâmica de sistemas está ligada com a escolha adequada dos sensores, cabeamento (transmissão de sinais) e sistemas de aquisição dados (DAq, Data Acquisition) e aplicação computacionais para organização de dados e escrita em arquivos. Dentre inúmeras formas e estratégias para sensoriamento e transmissões de dados, as aplicações de aquisição baseadas em placas de microcomputadores completam a cadeia de medição (vide Figura 20), necessárias para o controle e estudo de variáveis de processo.

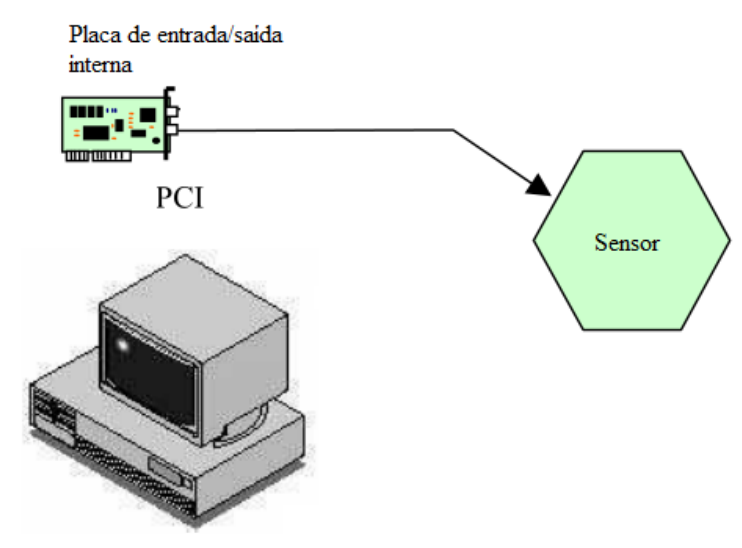

Figura 20 - Cadeia de medição e aquisição de dados baseado em microcomputador. Adaptado de [132].

Os sistemas de aquisição baseados em placas de aquisição oferecem baixo custo, altas taxas de aquisição e registro de dados quando comparados aos sistemas de aquisição que utilizam hardwares externos (altas taxas de amostragem, como VXI, FPGA) e rede de comunicação (USB) para registro de dados (baixas taxas de registro de dados), e sistemas dedicados que conferem altas taxas de amostragem, registro e custo. Os padrões de comunicação, ainda representam um gargalo na transmissão de dados, caso a aplicação necessite de altas de amostragem e registro como em estudos de leito fluidizado.

Para o correto ajuste do DAq é necessário conhecer os tipos de fontes de sinais, que podem ser fontes de sinais flutuantes ou referenciadas à terra. A referência de terra de um sinal flutuante deve ser o terra do dispositivo para estabelecimento de uma referência local, caso contrário, o sinal medido apresentará variações, se a fonte flutuar e sair da faixa de entrada do modo comum. 
Numa fonte de sinal referenciado, os terras do DAq e da instalação são interconectados. Instrumentos não isolados estão nesta categoria de conexão. Tipicamente, a diferença de potencial entre terras de instrumentos e da instalação está entre 1 a $100 \mathrm{mV}$, e pode ser maior caso estes circuitos sejam ligados incorretamente. A Tabela 3, pode auxilia a eliminação da diferença de potencial de terra com o sinal medido.

Portanto, termopares não aterrados, condicionadores de sinal com saída isolada e dispositivos a bateria são fontes de flutuação de sinal, enquanto que sensores com saída não isoladas são fonte de sinais referenciados, conforme a Tabela 3.

Tabela 3 - Fontes de sinais comuns e configurações de entrada recomendadas. Adaptado de [132] [133].

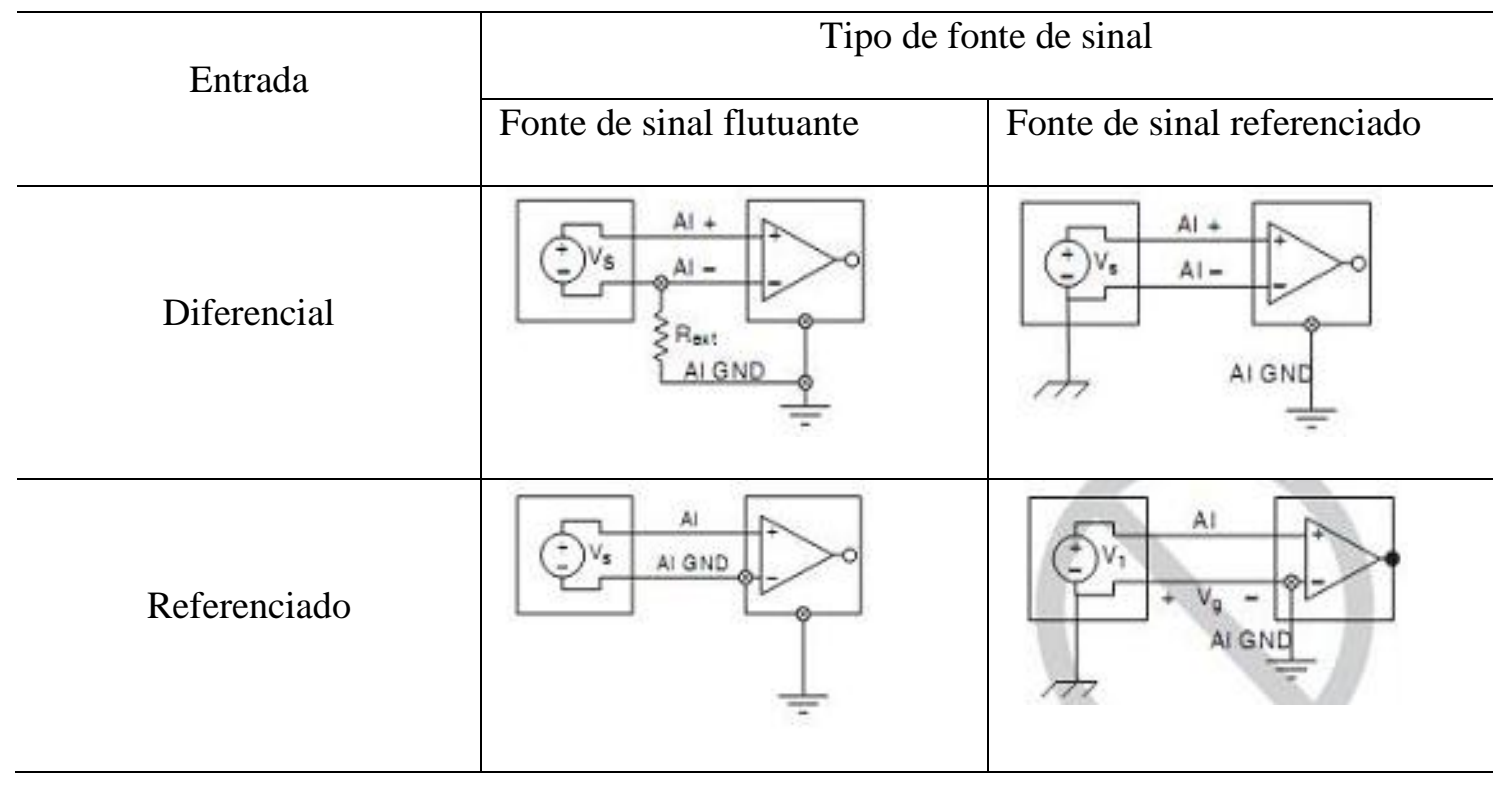

As malhas fechas de terra são a fontes de ruído em aplicações de aquisição de dados, e ocorrem quando há fluxo de corrente pelos terminais aterrados. A referência do DAq pode estar com níveis de tensão acima ou abaixo do terra da instalação, provocando induções no sinal e consequentes erros na medição. Os erros podem aparecer como sinais periódicos (rede elétrica, $60 \mathrm{~Hz}$ ) ou aperiódicos (pulsos transientes). Para evitar problemas, a malha fechada deve ser aberta e o uso de um hardware isolado elimina o caminho entre o terra da fonte de sinal e o dispositivo de medição, evitando assim qualquer fluxo de corrente entre os diversos pontos de terra [132] [133].

Uma medição diferencial ideal responde somente à diferença de potencial existente entre os seus dois terminais. A tensão diferencial é o sinal desejado, embora possa haver sinais indesejados comuns aos dois lados do par de um circuito diferencial conhecida como tensão do modo comum. Um sistema de medição diferencial ideal deve rejeitar totalmente a tensão do modo comum, sem medi-la. Contudo, os dispositivos reais são limitados, e podem ser descritos pela faixa de tensão do modo comum e a taxa de rejeição do modo comum (CMRR). A violação a máxima variação de tensão permitida em cada entrada com relação ao terra do sistema de medição (faixa de tensão de modo comum), resulta em erros de medição e danos a placa. DAqs que trabalhem com amplificadores com maiores taxas de rejeição do modo comum rejeitam melhor as tensões do modo comum [133].

Já numa medição diferencial não isolada existe um percurso elétrico entre a entrada e a saída. As características elétricas do amplificador limitam o nível do sinal do modo comum, e utilizando 
amplificadores de isolação, o percurso elétrico do condutor é eliminado, aumentando muito a taxa de rejeição do modo comum.

\subsubsection{Fontes de ruído}

Medidas corretas são cruciais para análise de experimentos. Não importa qual sensor utilizado, muitos parâmetros podem interferir, tais como a temperatura, a pressão, restrições mecânicos e ambiente eletromagnético podem contribuir para o erro de medição. Esses tipos de problema são intrínsecos aos sensores.

Dispositivos eletrônicos estão sujeitos a fontes de ruído externas (campo da compatibilidade eletromagnética estuda essas fontes) e fontes de ruído internos causados por variações de tensão e pelos próprios correntes de circuito [132].

Existem duas fontes de ruído externas:

- Uma fonte de ruído vem de distúrbios elétricos transmitidos por condução. Estes podem incluir: a influência da rede de distribuição de energia elétrica de $230 \mathrm{~V}$ a $50 \mathrm{~Hz}$; ondulações de abastecimento (por exemplo, alternando de recuperação de fase a $100 \mathrm{~Hz}$ ); sinais de energia que funcionam a frequências de comutação de cerca de $100 \mathrm{~Hz}$ a $100 \mathrm{kHz}$ (quebras no fornecimento de energia);

- Outra fonte de ruído pode ser irradiada distúrbios elétricos, incluindo transmissores de radiofrequência, campos eletromagnéticos criados por fortes variações de tensão ou corrente, por vezes, emitida por máquinas, como motores ou transformadores, ou, mais frequentemente, por conversores estáticos, como inversores.

As fontes de ruídos internos ou problema do ruído eletrônico são causadas, em sua maioria, devido as características de componentes eletrônicos (não linearidades, efeitos térmicos, ) e circuitos como os amplificadores operacionais.

\subsubsection{Instrumentação, cabeamento e calibração}

O uso de sensores pressão estática, numa coluna de fluidização, para identificação se seus regimes, é requisito para este trabalho. A instrumentação de pressão estática, converte as flutuações de pressão estática para um sinal elétrica, capaz de ser transmitido, através cabos, até um sistema de aquisição de dados.

O sensor deve ser adequadamente isolado do processo através do uso de luvas isoladoras, evitando que sinais elétricos espúrios (ruído conduzido e irradiado) sejam incorporados ao sinal elétrico de dados. Mesmo com isolamento entre sensor e processo, os cabos de transmissão de dados estão sujeitos a captura de ruídos irradiados. Uma forma de blindar os cabos contra a indução de ruídos espúrios é o uso de cabos com malha, gerando um efeito de proteção de gaiola de Faraday para o cabo. Conforme a Figura 21, as induções capturadas pela malha, são drenadas para a terra conectando apenas um dos lados da malha. 


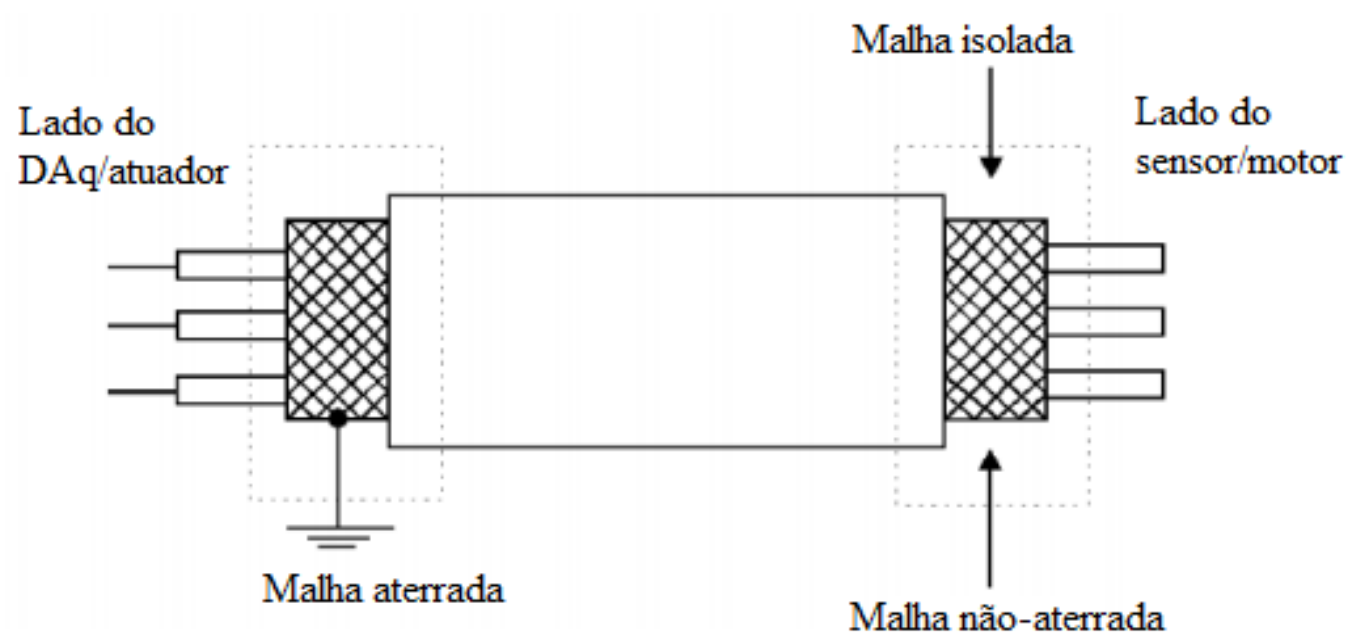

Figura 21 - Conexões de cabeamento blindado. Adaptado de [132] [134].

A maioria dos DAqs laboratoriais trabalham com a aquisição de sinal de tensão. Por outro lado, a maioria dos sensores industriais, trabalham com sinais de corrente (4 a $20 \mathrm{~mA})$. Geralmente, as aplicações laboratoriais utilizam sensores industriais, devido a sua robustez na medida. A compatibilização entre sinais de corrente e tensão deve ser realizada através de resistores de precisão, o qual, mantém suas propriedades físicas invariantes durante a faixa de corrente do sinal. O procedimento de calibração verifica se o valor da variável de processo foi corretamente convertido em sinal elétrico, transmitida sem induções e digitalizada, para posteriores análises.

\subsubsection{Filtragem de média móvel}

A média móvel é um dos filtros mais comuns, principalmente porque é o filtro digital mais simples de compreender e utilizar. Apesar de sua simplicidade, o filtro de média móvel é ideal para uma tarefa comum: reduzir o ruído aleatório, mantendo uma boa resposta ao degrau [135].

O filtro de média móvel opera com média do número de pontos do sinal de entrada para produzir cada ponto no sinal de saída conforme a Equação 29.

$$
y[i]=\frac{1}{M} \sum_{j=0}^{M-1} x[i-j]
$$

Equação 29

A quantidade de redução de ruído pode alcançar a raiz quadrada do número de pontos da média móvel [135]. Estudos de números de pontos de média móvel podem indicar a relação ótima entre a redução de ruído e o atraso do sinal reconstruído.

A filtragem digital de média móvel evidencia ainda mais a relação $S / R$ (sinal/ruído) da dinâmica de um sistema, quando associados a instrumentação, transmissão e aquisição de dados, adequadamente blindados e isolados. 


\subsection{Análise não-linear de séries temporais}

O estudo do movimento não periódico, ou comportamento caótico, tem sido objeto de investigações abstratas, experimentais até de simulações numéricas, em diversas áreas. A análise não-linear tem se tornado uma poderosa ferramenta para caracterização quantitativa de sistemas não-lineares complexos, como os fluidizados. Tais ferramentas podem auxiliar escalonamentos unidades laboratoriais e até o projeto de sistemas de controle. Dentre os diversos comportamentos caóticos de sinais observáveis em sistemas fluidizados, este trabalho analisa as flutuações de sinais de pressão estática [37].

O movimento caótico é conhecido por ocorrer como uma característica difusa de seu movimento. Para uma análise convencional desses sinais, a saída desses sistemas de comportamento caótico parece complexa no domínio do tempo e no espectro de Fourier. A banda espectral do comportamento caótico não é só larga, mas também contínua. A visão tradicional indica este comportamento semelhante a ruídos espúrios, mas este comportamento é determinístico e com um número finito de graus de liberdade (horizonte de previsão limitado). A simplicidade da análise de sinais caóticos está no estabelecimento um espaço o qual propriedades geométricas podem auxiliar o processamento destes sinais [136].

A metodologia para o processamento de sinais usando análise não-linear de série temporal conta com duas etapas. Os dados observados sempre estarão contaminados com ruídos. É necessário certificar de que a relação sinal/ruído está boa para as ferramentas de análises quantifiquem a dinâmica do processo. A análise espectral e aplicação de filtros digitais pode auxiliar na reconstrução da dinâmica do sinal [137]. Um sinal condicionado ou devidamente reconhecido que está tratando da dinâmica do sistema, está pronto para ser quantificado por invariantes do caos.

\subsubsection{Características invariantes de sistemas dinâmicos}

Classificar os sistemas dinâmicos observados é uma parte crítica da análise de séries temporais. Quando a fonte dos sinais é linear, convencionalmente, picos do espectro de Fourier em alguma frequência, são utilizados para uma caracterização. Neste tipo de sistema, o estímulo do sistema em qualquer instante com diferentes excitações de entrada, promoveriam diferentes intensidades do pico característico, no espectro de Fourier, mas na mesma frequência. Nesta análise, o espectro de Fourier fornece uma invariante ao movimento do sistema linear. A fase associada à frequência, depende das condições de medição, enquanto a magnitude o pico, depende da intensidade da excitação de entrada [37].

Nos sistemas lineares em regime permanente, as trajetórias das órbitas de seu espaço de fase se repetem, enquanto nos sistemas não-lineares com comportamento caótico, essas trajetórias nunca repetem.

Sistemas não-lineares com comportamento caótico produzem espectros contínuos de Fourier de banda larga, sendo necessário a substituição desta ferramenta por outras capazes de classificar e identificar, ou seja, invariantes ao novo tipo de sistema [138].

Sistemas não-lineares com resposta caótica possuem um atrator estranho em seu espaço de fase. Sua qualidade é estranha por apresentar detalhes, em escalas infinitesimalmente pequenas, chamados fractais. $\mathrm{O}$ atrator, é um conjunto fechado de pontos $\mathrm{A}$, no espaço de fase em que: A é um conjunto invariante, onde qualquer trajetória $X(t)$ que começa em $\mathrm{A}$, permanece em $\mathrm{A}$, por todo tempo; $\mathrm{O}$ conjunto A, atrai um conjunto aberto de condições iniciais, onde há um hipervolume $\mathrm{H}$, que contém $\mathrm{A}$, tal que para qualquer condição $X(0)$ pertencente a $\mathrm{H}$, reduzirá a distância entre a trajetória $X(t)$ e A para zero, quando $t \rightarrow \infty$. A bacia de atração é definida pelo maior conjunto de condições iniciais que satisfizer a propriedade anterior [139].

As ferramentas para quantificação de características invariantes à dinâmica das trajetórias do espaço de fase de um sistema não-linear de comportamento caótico, são conhecidas como invariantes do caos. Os 
maiores caracterizadores ou invariantes que tem emergido para classificadores de sistemas não-lineares com comportamento caótico são as famílias dimensões fractais (dimensão de correlação, entre outras), o expoente de Hurst e a entropia.

A família de dimensões fractais caracterizam a geometria (forma) e relacionam o caminho de pontos que o atrator está distribuído no espaço de fase. A entropia de Kolmogorov avalia a divergência de trajetórias para medir o grau de imprevisibilidade de uma série temporal. $\mathrm{O}$ expoente de Hurst pode quantificar a rugosidade da série temporal entre 0 e 1 , onde valores próximos de 0,5 significa que os valores são aleatórios. Essas invariantes podem quantificar mecanismos de interação fluido-partículas, quando aplicados a fluidos multifásicos.

\subsubsection{Reconstrução do espaço de fase e teorema de Takens}

Séries temporais são sequencias de escalares, que representam medições de processo, em período de amostragem fixado. A análise de séries temporais leva em conta o fato de que os pontos de tomados no tempo podem ter uma estrutura interna (como autocorrelação, tendência ou sazonalidade) que deve ser contabilizada. A análise de séries temporais possui dois objetivos principais como identificar a natureza de um fenômeno e a predição de valores futuros. Portanto, um requisito de identificar o padrão de uma série temporal observada pode ser extrapolado para prever eventos futuros [140].

O espaço de fase avalia de forma completa a caracterização da dinâmica de sistemas, pois relaciona suas variáveis de estado. Contudo, quando um experimento é observado (medido) resulta em séries temporais. Metodologias para reconstrução do espaço de fase, através das séries temporais podem auxiliar na avaliação da dinâmica do sistema investigado.

As características em estudar um sistema pelo seu espaço de estado são:

1. Representar tudo o que o sistema pode ser, portanto, todos estados possíveis, e seus formatos descrevem qualidades ou propriedades do sistema.

2. Evolução temporal através do traçado da sucessão de pontos

3. Visualização das mudanças das variáveis dinâmicas;

4. Que os estados são especificados por vetores;

5. Identificar características invariantes sob a evolução dinâmica

Como um estado pode ser especificado por um vetor, sua dinâmica m-dimensional em tempo discreto é $X_{n+1}=F\left(X_{n}\right)$, ou em tempo contínuo $d(X(t)) / d t=f(t, X(t))$. Uma sequência de pontos, passada nas equações anteriores, resultam em trajetórias do sistema dinâmico, que pode divergir para o infinito ou se estabelecer numa área limitada. A região limitada ou bacia de atração é um conjunto de condições iniciais atraídas para o mesmo comportamento assintótico. Após a evolução do sistema, considerando um tempo suficientemente longo, forma-se um subespaço de fase chamado de atrator, contendo características invariantes [32].

\subsubsection{Método de reconstrução do espaço de fase}

As razões para reconstruir um espaço de fase são:

- Para um sistema determinístico, uma vez um estado corrente fixado, os estados em todos os tempos futuros são determinados também.

- Estabelecer um espaço de fase para o sistema de tal forma que a especificação de um ponto, neste espaço, especifique o estado do sistema. Um estado específico do sistema pode ser 
representado por um ponto no espaço de fase e evolução do tempo do sistema cria uma trajetória no espaço de fase reconstruído.

Para um sistema que pode ser modelado fenomenologicamente, o espaço de fase é conhecido a partir de suas equações de movimento. Já para estudos que envolvem experimentos e ocorrência da resposta caótica, a descrição matemática é muitas vezes desconhecida. Portanto, estudar a dinâmica do sistema significa estudar a dinâmica do espaço de fase. Um espaço de fase reconstruído refere-se a métodos para inferência de informações topológicas e geométricas para reconstrução de seu atrator a partir de observações.

O teorema de imersão (incorporação) de Whitney sugere que um mapa qualquer de uma n-variedade para o espaço Euclidiano de dimensão $2 n+1$ uma imersão, ou seja, a imagem da n-variedade está completamente desdobrada no espaço maior. Com $2 n+1$ independentes sinais medidos de um sistema pode ser considerado como um mapa de conjunto de estados no espaço $2 n+1$, o teorema de Whitney implica que cada estado pode ser identificado unicamente por um vetor de $2 n+1$ medições, reconstruindo assim o espaço de fase [141]. A desvantagem da aplicação deste teorema é a necessidade de $2 n+1$ sinais genéricos para reconstrução do espaço de fase.

\subsubsection{Teorema de Takens}

A contribuição do teorema de imersão de Takens foi demonstrar que as propriedades do espaço de fase podem ser reconstruídas através da medição de um único sinal, ao invés $2 n+1$ sinais. Comparações entre aplicações do teorema de Whitney e Takens mostraram que sinais de coordenada de atraso seriam suficientes para incorporar uma variedade de dimensão n [71].

A ideia de usar coordenadas de atraso de tempo para representar um estado do sistema é resgatada da teoria das equações diferenciais ordinárias, em que os teoremas de existência afirmam que há solução única para um vetor de estados, $[y(t), \dot{y}(t), \ddot{y}(t), \ldots]$. O teorema desenvolvido por Takens e aperfeiçoado por Sauer [142] demonstrou que o uso de medidas atuais e passadas de uma variável permite a captura de boa parte das informações do sistema. O método envolve a criação de um sistema de coordenadas alternativo a partir de medidas passadas. Em outras palavras, um eixo coordenado pode representar a medida hoje $X(t)$ e outro eixo a medida minutos antes $X(t-\tau)$, e assim por diante caso envolva mais eixos. O teorema mostrou que o estado completo de um sistema caótico pode, pelo menos em teoria, estar embutido (imerso ou incorporado) em uma série temporal de uma única variável [143]. Numa reconstrução, a partir de séries temporais e coordenadas de atraso de tempo, a estrutura topológica é preservada.

Embora a teoria sugira atrasos arbitrários de coordenadas de atraso para reconstruir o atrator, a eficiência com uma quantidade limitada de dados é aumentada por boas escolhas no atraso de tempo $\tau$, conforme a Figura 22. Critérios para escolha de tempo de atraso apropriado tem rodeado os métodos de medida de auto correlação e informação mútua. O estudo de atraso para busca de coordenadas de atraso que reconstrua o atrator com a mesma topologia é apresentado na Figura 22. O item (a) da Figura 22, destacado, apresenta o atrator baseado em modelo, enquanto o restante da sequência, apresenta topologias do atrator reconstruído para diferentes configurações de atraso de tempo $\tau$. Conforme apresentado em (d), da Figura 22, o atraso $\tau=7$, apresentou a topologia mais semelhante ao atrator original, a menos de ligeira redução da faixa operacional da ordenada (-30 a 30 para -20 a 20). Os espaços de estado reconstruídos (b), (c), (e) e (f), da Figura 22, representam topologias anômalas em relação ao atrator original. 

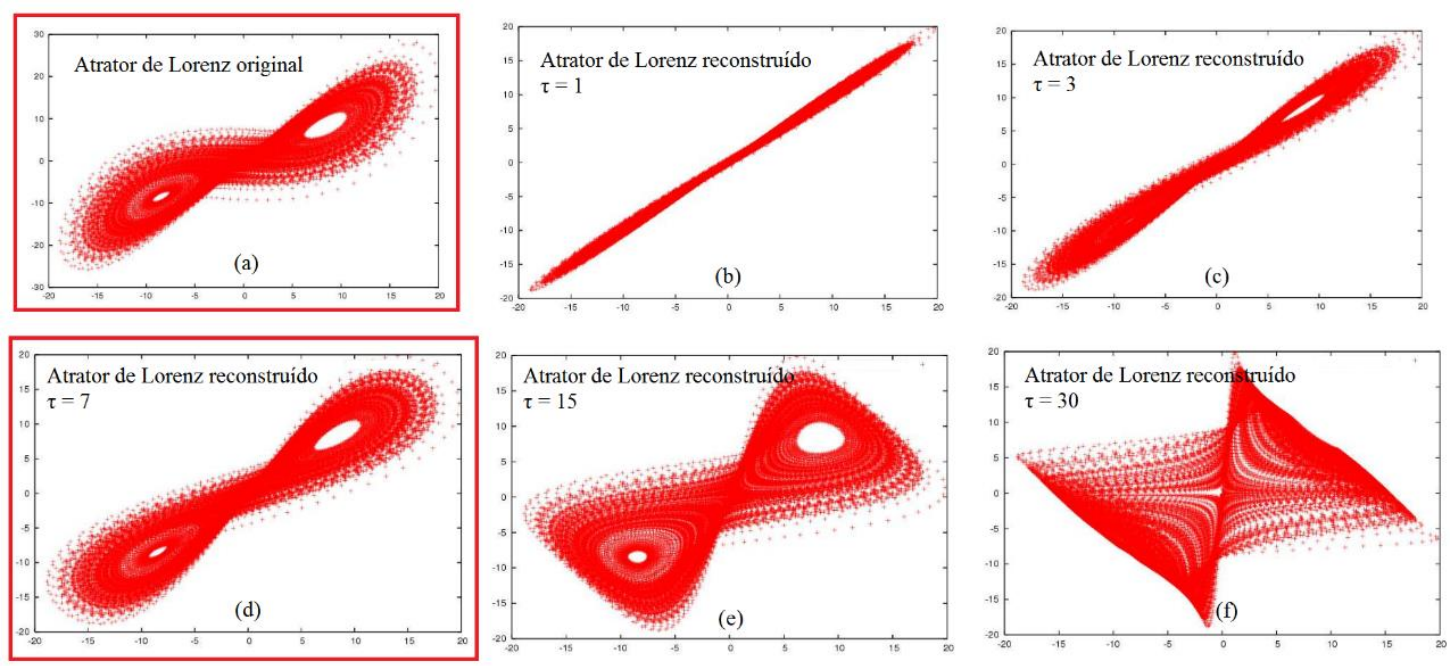

Figura 22 - Estudo de atraso para coordenadas de atraso de tempo. Adaptado de [144].

Portanto, se $\tau$ for pequeno comparado com as escalas de tempo internas do sistema, os elementos sucessivos dos vetores de atraso são fortemente correlacionados. Se $\tau$ é muito grande, os elementos sucessivos tornam-se quase independentes, e os pontos preenchem uma grande nuvem, onde as estruturas determinísticas são confinadas às escalas muito pequenas [32]. As estatísticas não-lineares dependem do comportamento de escalas do sistema e podem ser influenciadas pela escolha inadequada dos atrasos, durante a metodologia de reconstrução dos atratores a partir de séries temporais.

Muitos critérios para escolha do atraso, como o da autocorrelação, são baseados em estatísticas lineares, não levando em conta a dinâmica não-linear. Conforme sugerido por Fraser e Swinney [145], o uso do critério para escolha do atraso no primeiro mínimo da evolução da informação mútua. A informação mútua advém da Teoria da Informação, pode ser calculada através da Equação 30 e relaciona a quantidade de informação que uma variável contém sobre outra, ou ainda, a quantidade de incerteza, reduzida em uma certa variável, a partir do quanto se conhece da outra.

$$
I_{\epsilon}(\tau)=\sum_{i, j} p_{i j}(\tau)\left(\ln \left(p_{i j}(\tau)\right)\right)-2 \sum_{i} p_{i}\left(\ln \left(p_{i}\right)\right)
$$

Equação 30

Supondo reconstruções a partir de uma variável, a informação mútua é o que se sabe de $X(t+\tau)$ quando se conhece $X(t)$. Na Equação 30, é possível construir um histograma de resolução $\epsilon$ para distribuição de probabilidade dos dados. $\mathrm{O} p_{i}$ representa a probabilidade que o sinal assume o valor dentro da iésima caixa do histograma, $p_{i j}(\tau)$ é a probabilidade de $X(t)$ está na caixa i e $X(t+\tau)$ está na caixa j. Então, é possível traçar o valor de distribuição de probabilidade em função dos atrasos [32]. O primeiro mínimo de $I(\tau)$ marca o atraso de tempo em que $X(t+\tau)$ acrescenta informação máxima obtida sobre $X(t)$, ou seja, a redundância é a menor. Uma desvantagem, é que não razões teóricas para garantir que sempre haverá um mínimo. O critério do primeiro mínimos é válido apenas para imersões bidimensionais, como realizadas neste trabalho. Outros critérios para decisão do atraso de tempo, também podem ser alcançados através da correlação integral, como usado pelo software RRCHAOS [72]. 
As resoluções devem ser selecionadas de modo a ler um valor de $\tau$ estável. Para pequenos valores de $\tau$, $I_{\epsilon}(\tau)$ será grande, reduzindo rapidamente, em seguida. Para grandes valores de $\tau, X(t)$ e $X(t+\tau)$ tornam-se independente, fazendo $p_{i j}$ convergir para $p_{i} p_{j}$ e a informação mútua torna-se zero [32]. Algoritmos computacionais, como os implementados no software RRCHAOS [72] são capazes de realizar estudos de convergência de discretização numérica de caixas para reconstrução do espaço de fase, reduzindo a incerteza de estimativas de invariantes do caos como a dimensão de correlação e entropia de Kolmogorov.

\subsubsection{Dimensão de correlação}

A distinção entre diferentes comportamentos caóticos, visto também, por diferentes atratores estranhos em diagramas de fase, podem ser pode ser uma tarefa complexa, caso não haja boa métrica quantitativa para distingui-los. A caracterização quantitativa pode avaliar a dimensão, forma e evolução das órbitas dos atratores. Em sistemas com resposta caótica a característica mais básica, que é dimensão de um atrator, pode ser complexa por incorporar outras características além da geométrica, como a fração do tempo em que o atrator ocupa determinada região do espaço [139].

A dimensão de correlação faz parte de uma grande família (dimensão de soma, de imersão, etc.) de invariantes da dimensão fractal. A geometria fractal, introduzida por Benoit Mandelbrot em 1975 [146], conseguiu reconstruir formas naturais complexas (silhuetas de mapas litorâneos, formas de nuvens e folhas de plantas, etc) a partir de regras simples. Mandelbrot mostrou que estruturas simples e fundamentais como triângulos, quando regidos por regras de iteração coordenada, são capazes de reconstruir paisagens naturais, conforme a sequência (a) a (e), da Figura 23. Portanto, o que antes era chamado de irregularidade, após Mandelbrot, passa a ser representando como a natureza fractal.

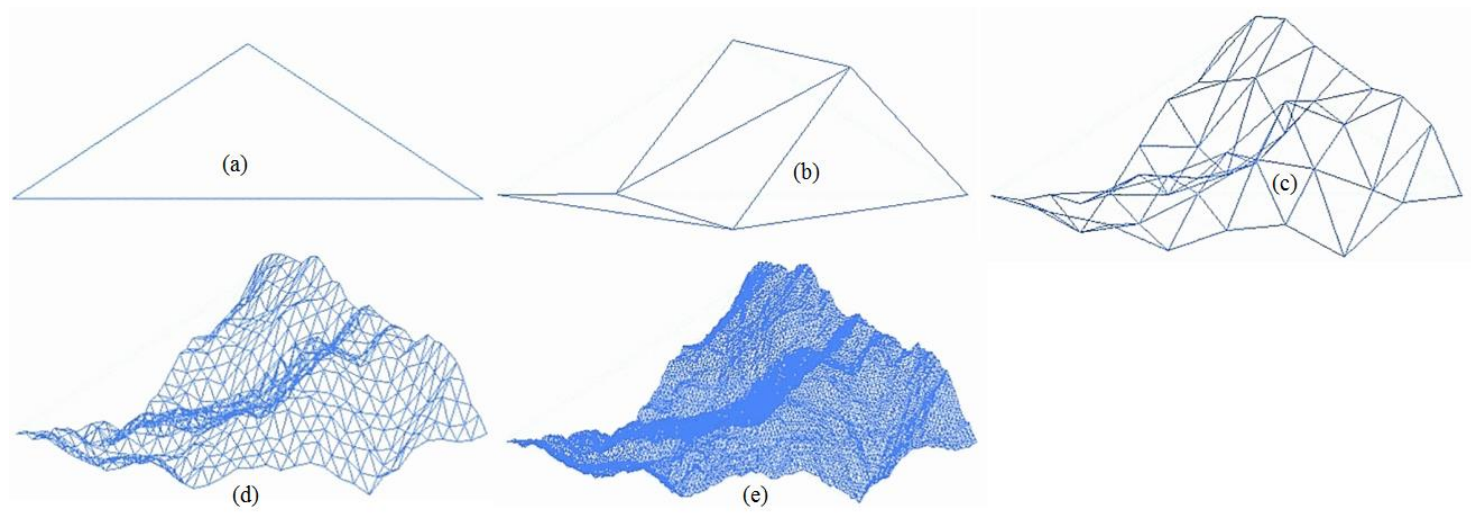

Figura 23 - Reconstrução de paisagem montanhosa a partir de iteração coordenada de triângulos. Adaptado de [147].

A natureza fractal, representa um conjunto de padrões que se repetem em todas as escalas. Se o padrão for replicado, igualmente, em todas as escalas, a natureza fractal pode ser quantificada pela autosimilaridade (como a esponja de Menger). Contudo, a natureza fractal não está limitada a padrões geométricos, podendo estender-se a padrões de sinais temporais ou sua reconstrução no plano de fase. Considerando padrões de atratores no plano de fase, diferentes graus de auto-similaridade podem ser quantificados através do método de contagem de caixas. Este método calcula o número de pequenos cubos necessários para cobrir todo o objeto fractal e comparar o resultado com o tamanho das caixas em 
uma escala logarítmica. O limite da proporção de pontos (ou trajetórias) do atrator quando o tamanho dos cubos tende para 0 define a dimensão de contagem de caixas, $D_{0}$. Algoritmos para busca da dimensão de caixas baseiam-se na: iteração dos pontos pertencentes ao atrator; discretização, da região ocupada pelo atrator em diversas caixas de dimensão $\epsilon$; contagem das caixas $N(\epsilon)$ ) contendo, pelo menos, um ponto do atrator; e repetição da contagem, considerando novos $\epsilon$. A partir da iteração deste algoritmo pode-se construir uma função $\log (N(\epsilon))$ em função de $\log (1 / \epsilon)$, onde o valor de $D_{0}$ corresponde à estabilização da inclinação [139]. Computacionalmente, o cálculo de $D_{0}$ demanda muito recurso.

Grassberger e Procaccia [27] propuseram uma nova dimensão fractal, chamada de dimensão de correlação, $D_{2}$. A definição $D_{2}$ é de particular interesse em algumas aplicações práticas, onde padrões, no espaço de fase, reconstruídos a partir de uma amostra finita de pontos de dados que têm mais probabilidade de conter ruídos. A dimensão de correlação revela a quantidade de variáveis necessárias para reconstruir o comportamento do sistema.

Conforme Grassberger e Procaccia [27], é necessário definir a correlação integrante ou função de correlação, $C(\epsilon)$, para uma coleção de pontos, $x_{n}$, em algum espaço vetorial para ser a fração de todos os possíveis pares de pontos que estão próximos de uma dada distância $\epsilon$ em uma norma particular. A fórmula básica (pode ser modificado para aplicações práticas) pode ser dada pela Equação 31.

$$
C(\epsilon)=\frac{2}{N(N-1)} \sum_{i=1}^{N} \sum_{j=i+1}^{N} \Theta\left(\epsilon-\left\|x_{i}-x_{j}\right\|\right)
$$

Onde $\Theta$ representa a função degrau de Heaviside, $\Theta(x)=0$ se $x \leq 0$ e $x=1$ para $x>0$. A soma conta apenas os pares $\left(x_{i}, x_{j}\right)$ cuja distância é menor que $\epsilon$. Para uma quantidade de dados tendendo para o infinito $(N \rightarrow \infty)$ e para pequenos $\epsilon$, Grassberger e Procaccia [27] propuseram uma lei de potência, $C(\epsilon) \propto \epsilon^{D}$, o qual a dimensão de correlação $D_{2}$, pode ser definida pela Equação 32 .

$$
\begin{aligned}
& d(N, \epsilon)=\frac{\partial \ln C(\epsilon, N)}{\partial \ln \epsilon} \\
& D_{2}=\lim _{\epsilon \rightarrow 0} \lim _{N \rightarrow \infty} d(N, \epsilon)
\end{aligned}
$$

Para estabelecer um valor de dimensão de correlação $D_{2}$, é preciso certificar-se de que este valor é robusto sobre a técnica de medição e processamento de dados. Na prática, por maiores que as séries temporais sejam, a dimensão integrante não será exata, havendo problema com os dois limites sempre que houver uma amostra finita em vez de uma distribuição completa. O número limitado pelo tamanho da amostra, $N$, e a faixa de escolhas significativas de $\epsilon$, é limitada para baixo pela precisão finita dos dados e pela inevitável falta de vizinhos mais próximos numa pequena escala de comprimento [32].

Um bom quantificador, que pode servir ao propósito de caracterização, não deve depender significativamente do procedimento de medição, coordenadas escolhidas, etc. De acordo com a sua definição, dimensões e quantificadores caóticos devem cumprir o requisito de invariância. Este requisito fundamental deve ser válido para objetos fractais apenas porque eles são menos intuitivos. Como observação conceitual, a dimensão de correlação é uma ferramenta para quantificar auto-similaridade 
quando existente numa série temporal. Em termos físicos, quando aplicado para sinais de um escoamento multifásico, como pressão estática, a dimensão de correlação representa uma medida da complexidade do atrator reconstruído a partir da série temporal em questão. Portanto, grandes valores de dimensão de correlação da série temporal de um determinado sinal indicam formas mais complexas em seu atrator. O presente trabalho usou o software RRCHAOS, desenvolvido por Shouten e coautores para calcular a dimensão de correlação [73].

\subsubsection{Entropia de Kolmogorov}

Conforme Grassberger et al. [27] a entropia de Kolmogorov ou Kolmogorov-Sinai, num sistema dinâmico com três graus de liberdade (por exemplo), repartido num espaço de fase de três dimensões em caixas de tamanho $\epsilon^{3}$ com um atrator de trajetória $X(t)$ (vide a Figura 24), pode ser definida como o somatório do produto de probabilidades conjuntas em sequências de caixas $i_{d}$, medido em intervalos de tempo, $\tau$. A probabilidade $p\left(i_{1}, i_{2}, \ldots, i_{d}\right)$ é a probabilidade conjunta que $X(t=1 \tau)$ estar na caixa $i_{1}$ (no espaço de fase), $X(t=2 \tau)$ estar na caixa $i_{2}, \ldots, X(t=d \tau)$ na caixa $i_{d}$. A entropia Kolmogorov é definida pela Equação 33 .

$$
K=-\lim _{\tau \rightarrow 0} \lim _{\epsilon \rightarrow 0} \lim _{d \rightarrow \infty} \frac{1}{d \tau} \sum_{i_{1}, \ldots, i_{d}} p\left(i_{1}, \ldots, i_{d}\right) \times \ln \left(p\left(i_{1}, \ldots, i_{d}\right)\right)
$$

A trajetória do espaço de fase pode ser baseada em equações de movimento (fenomenológica) ou obtida a partir de séries temporais escalares usando o método de atraso de tempo. Em situações experimentais, é comum no estudo de sistemas dinâmicos a aquisição de sinais unidimensionais. Metodologias, como a aplicação do teorema de Takens, permitem a reconstrução do espaço de fase baseado em séries unidimensionais. Conforme a Figura 24, uma sequência de pontos consecutivos na trajetória identifica uma sequência de caixas, associando a cada ponto a caixa que a contém.

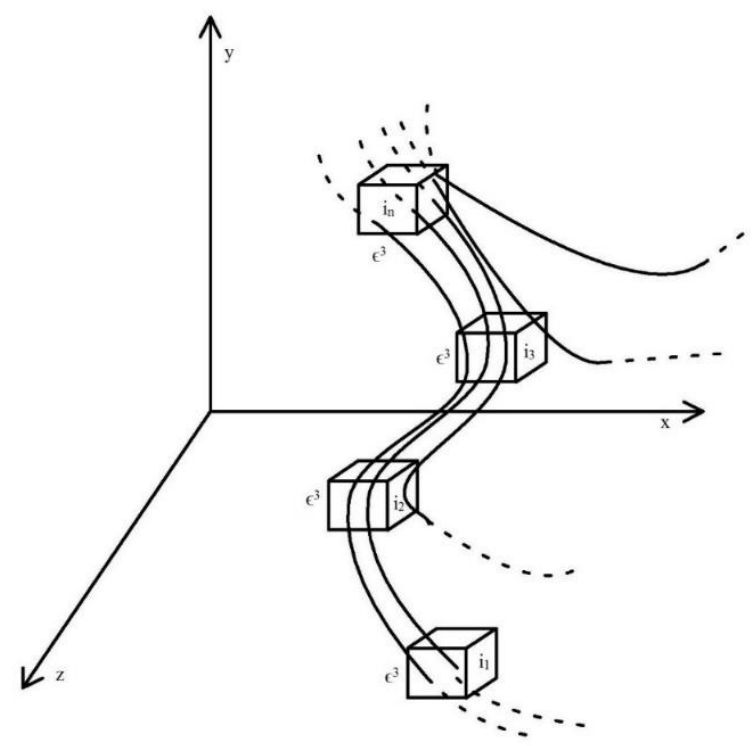

Figura 24 - Trajetórias no espaço de fase e sequências de caixas associadas. Adaptador de [148]. 
Com o auxílio da teoria da informação, a previsibilidade dos sistemas dinâmicos podem derivar de suas séries temporais. Conforme Grassberger [149], dado um intervalo de tempo $\left[t_{1}, t_{2}\right]$, as informações $I$ (em bits), necessárias para prever a evolução temporal de um sistema dinâmico, dado uma condição inicial $I_{t_{1}}$ é $I_{t_{1}, t_{2}}=I_{t_{1}}+K\left(t_{2}-t_{1}\right)$, para $t_{2}-t_{1} \rightarrow \infty$.

Quando o sistema é totalmente conhecido, $K=0$. Para $K \rightarrow \infty$, o sistema dinâmico é dito ser aleatório ou estocástico. Mas para K finito, constante e diferente de zero, o sistema dinâmico é dito ser caótico determinístico. Neste caso, o horizonte de previsão depende do valor da entropia. Para os modelos definidos analiticamente é mais simples estimar $\mathrm{K}$ a partir das equações da tangente (ou variacional) que descrevem a evolução da distância entre dois pontos (infinitesimalmente próximos). Mas é muito difícil determinar o K diretamente a partir de uma série temporal medida

A entropia é uma medida bem conhecida e utilizada para quantificar o grau de desordem num sistema dinâmico. Também tem sido associada com a perda de informação ao longo de um atrator. Quando dois pontos muito próximos, em trajetórias distintas sobre o atrator (sensibilidade, ou seja, diferentes condições iniciais) estão evoluindo em duas trajetórias diferentes, assim, dois estados distintos evoluem devido à divergência de suas trajetórias próximas. Uma interpretação de tal fato seria de que a informação inicial seria perdida depois de um certo tempo. Quando expressa em bits por segundo, a entropia indica a quantidade de informação perdida na unidade de tempo [41].

A sensibilidade é normalmente quantificada em termos dos expoentes Lyapunov e da entropia de entropia de Kolmogorov. Os expoentes de Lyapunov medem a taxa de divergência exponencial de trajetórias próximas e a entropia de Kolmogorov mede a taxa do fluxo de informação no sistema dinâmico. Longos horizontes de previsões em sistemas caóticos são praticamente impossíveis. Mesmo que a física deste sistema caótico seja conhecida por completo, erros na medição do estado inicial se propagariam de forma exponencial [150].

\subsubsection{Expoente de Hurst}

Em homenagem ao britânico H. E. Hurst [151] que desenvolveu uma metodologia capaz de distinguir sistemas aleatórios de não-aleatórios, identificando a persistência de tendências de uma série temporal. O expoente de Hurst é usado como uma medida da memória a longo prazo de uma série temporal. [74]

O trabalho de Hurst permitiu generalizar o modelo desenvolvido por Albert Einstein de que o movimento Browniano de uma partícula num fluido, é regido por colisões das moléculas deste fluido sobre a partícula. Einstein descobriu que a distância média, $r$, caminhada pela partícula, é diretamente proporcional a raiz quadrada do índice de tempo, ou seja, $r=k T^{1 / 2}$, e $k$ é função das propriedades do fluido. O movimento (trajetória em vermelho Figura 25) de uma partícula (círculo amarelo da Figura 25) num fluido é aleatório devido a inúmeras colisões entre as moléculas (pontos pretos da Figura 25) com a partícula e entre si. 


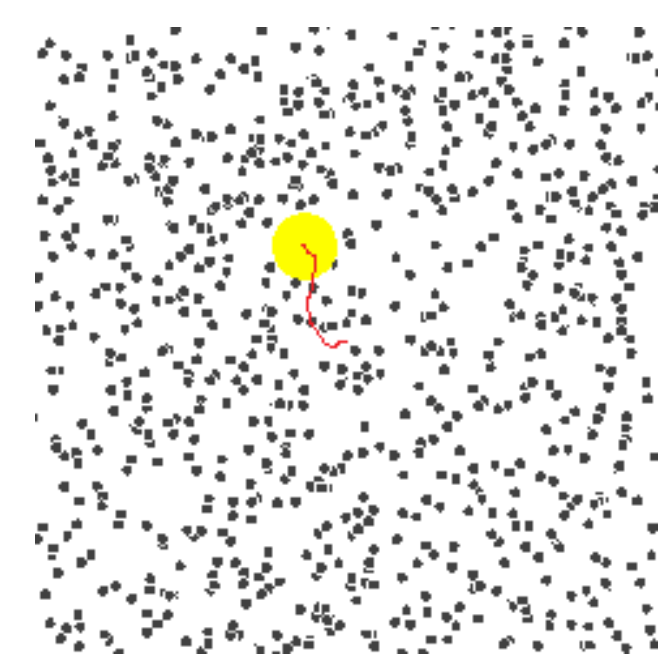

Figura 25 - As moléculas, representadas pelos pontos pretos, colidem aleatoriamente entre si e com a partícula (amarelo), tecendo uma trajetória (linha vermelha) que caracteriza o movimento Browniano. Adaptado de [152].

Para Hurst, uma série temporal pode ser fragmentada em diversos pedaços e uma métrica desses fragmentos de série (equivalente à distância média das partículas do movimento Browniano) segue uma lei similar ao movimento Browniano, em que $(R / S)=p T^{H}$, onde $R / S$ é a razão da faixa re-escalada da série (range dividido desvio padrão standard deviation), $H$ é o expoente de Hurst, $T$, é o tempo entre observações, e, $p$, é uma constante com características da série temporal. A escala da métrica $R / S$ pode ser ajustada na lei de potência pelo expoente de Hurst.

A análise de faixa re-escalonada é uma técnica para avaliar a natureza e a magnitude da variabilidade dos dados a longo prazo. Dado uma série temporal de tamanho $n$, a técnica de faixa re-escalonada divide a série em várias subséries $s$ como $s_{0}=n / 2^{0}, s_{1}=n / 2^{1}, s_{2}=n / 2^{2}, s_{3}=n / 2^{3}, \ldots, s_{\tau}=n / 2^{\tau}$, onde $\tau$ é o número de subséries e a faixa $R_{\tau}$, de cada subsérie, é a diferença entre seu valor máximo e mínimo. Para cada subsérie, calcula-se uma média $\bar{X}_{\tau}$ e seu desvio padrão $S_{\tau}$. Quando o tamanho da série é igual a subsérie, ou seja, $s_{0}=n / 2^{0}$, o valor de faixa re-escalada ou intervalo redimensionado $R_{\tau} / S_{\tau}=$ $(R / S)_{\tau}$ coincide com seu valor médio $\overline{R_{\tau} / S_{\tau}}=\overline{(R / S)_{\tau}}$ entre cada parte da subsérie. Para $\tau \geq 2$, as subséries contém partes (duas, quatro, oito, etc) onde cada parte terá seu valor $(R / S)_{\tau}$, e o um valor médio $\overline{(R / S)_{\tau}}$ entre as partes, representa a faixa re-escalada da subsérie. O logaritmo da faixa reescalada média, de cada subsérie, ou seja, $\log \left({\overline{(R / S)_{0}}}_{0}\right) \log \left({\overline{(R / S)_{1}}}_{1}\right), \ldots, \log \left(\overline{(R / S)_{\tau}}\right)$, caracteriza a magnitude das subséries. O logaritmo do tamanho de cada faixa re-escalada, ou seja, o $\log \left(n / 2^{0}\right)$, $\log \left(n / 2^{1}\right), \ldots, \log \left(n / 2^{\tau}\right)$, caracteriza a largura de cada parte das subséries. O expoente de Hurst $H$ é a inclinação formada pelo traçado dos pontos $\log \left(\overline{(R / S}_{\tau}\right)$ por $\log \left(n / 2^{\tau}\right)$.

O ponto chave para a análise de Hurst é o redimensionamento das faixas que compara o comportamento de pontos em diferentes períodos, incluindo as séries que não possuem característica fractal. Se o dado de uma série temporal de um sistema está distribuído de forma independente ou aleatória, ou ainda, por uma caminhada aleatória, o expoente de Hurst tenderia para 1/2, ou seja, similar a lei de potência de Einstein para o movimento Browniano.

Portanto, a interpretação da análise de faixa re-escalada de uma série temporal possui três possiblidades. Se o expoente de Hurst for $H=0,5$, a distribuição dos dados da série é independente e similar à de uma caminhada aleatória (ruído marrom ou movimento Browniano). Assim, a série analisada possui uma faixa re-escalada igual do que a distância equivalente à de uma caminha aleatória. 
Para valores $0 \leq H<0,5$ a série é chamada anti-persistente. Assim, a série analisada possui uma faixa re-escalada menor do que a distância equivalente à de uma caminha aleatória. Isso significa que a série tem tendências de inversão (como num sinal senoidal ou ruído rosa). Portanto, quando a série aumenta, num determinado período, tem probabilidades de diminuir no período seguinte, e vice-versa.

Para valores $0,5<H \leq 1$ a série é chamada de persistente. Assim, a série analisada possui uma faixa re-escalada maior do que a distância equivalente à de uma caminhada aleatória. Isso significa que se a série tende a aumentar em um determinado período, é mais provável que continue aumentando no período seguinte. Esse efeito é chamado de José, por que à medida em que tende a conduzir "sete anos" de fartura, seguido por "sete anos" de fome. Caso a série tenha o potencial de diminuir num determinado período e ser provável de continuar diminuindo nos períodos seguintes, ou seja, experimentar catástrofes súbitas, esse efeito é classificado como Noé [74].

O expoente Hurst pode ser calculado através de uma série temporal conforme o conjunto, representado pela Equação 34, onde $t$ é tempo entre observações e $\tau$ são os índices de subséries.

$$
\begin{aligned}
& X(t, \tau)=\sum_{i=0}^{t-1}\left(u_{i}-\langle u\rangle_{\tau}\right) \\
& R(\tau)=\max _{0 \leq t \leq \tau-1} X(t, \tau)-\min _{0 \leq t \leq \tau-1} X(t, \tau) \\
& S(\tau)=\left(\frac{1}{\tau} \sum_{t=0}^{\tau-1}\left(u_{t}-\langle u\rangle_{\tau}\right)^{2}\right)^{1 / 2} \\
& (R / S)_{\tau}=R(\tau) / S(\tau) \\
& \langle u\rangle_{\tau}=\frac{1}{\tau} \sum_{t=0}^{\tau-1} u_{t}
\end{aligned}
$$

Outra interpretação dada para o expoente de Hurst, para classificação de séries temporais, é a quantificação de sua rugosidade, em pequenas escalas. A partir de determinada série temporal, a Figura 26 mostra como a rugosidade pode variar. A presença de componentes de alta frequência, somados a série aumenta sua rugosidade, reduzindo o valor de $H$. A medida que a mesma série é suavizada, ou que suas componentes de alta frequência são removidas, a rugosidade reduz e o parâmetro $H$ aumenta.

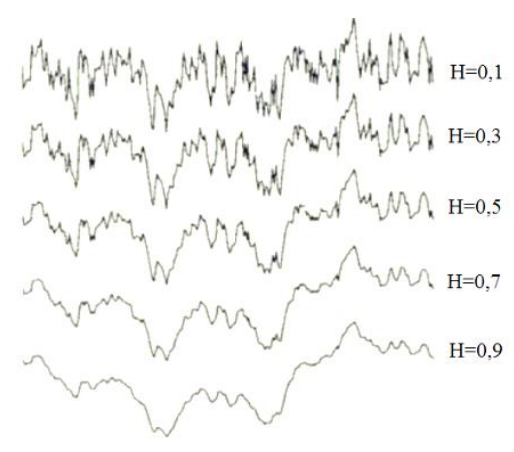

Figura 26 - Quantificação da rugosidade de série temporal a partir do expoente de Hurst. Adaptado de [153]. 


\subsection{Modelagem não-paramétrica}

A modelagem matemática do comportamento de sistemas estuda formas de desenvolver modelos matemáticos de alta fidelidade. Os modelos matemáticos podem ser classificados quanto a linearidade ou não-linearidade, variante ou invariante no tempo e de parâmetros concentrados ou distribuídos. Os tipos de modelos são estáticos ou dinâmicos, discretos ou contínuos, autônomos ou não-autônomos, mono ou multivariáveis, determinísticos ou estocásticos, paramétricas ou não-paramétricas [154].

As formas conhecidas de modelagem são:

- Caixa branca, fenomenológico ou conceitual em que toda física do problema, balanços de energia, momento, continuidade e relações constitutivas são conhecidas e viáveis de serem aplicadas.

- Caixa preta, onde um pouco ou nenhum conhecimento prévio sobre o sistema exige o uso de técnicas de identificação de sistemas.

Em sistemas fluidizados, uma modelagem caixa branca, pode ser inviável até mesmo usando simulação numérica. Caso a modelagem caixa branca seja por simulação numérica direta (DNS), mesmo situações de escala piloto já a torna inviável. Para o caso da modelagem caixa branca usar simulação numérica indireta trabalhar com modelos do tipo TFM ( two fluid model), PIC (particle in cell) e DEM (discret element method), terem conjuntos de equações de balanços e constitutivas capazes de fechar seus modelos, dependendo do tamanho do problema (número de malhas) e das variáveis de processos a serem avaliadas, a investigação pode ser inviável computacionalmente. Outro problema a ser avaliado, é que nem sempre a simulação numérica indireta resulta em fidelidade de determinada variável de processo, já que usa aproximações para tratar algumas escalas espaço-temporais.

O caso da modelagem caixa preta, requer algum tipo de metodologia de identificação capaz de excitar um sistema e a partir da observação de sua resposta, propor a estrutura e parâmetros para ajuste do modelo.

Estruturas de modelos não-lineares aplicados a sistemas fluidizados ainda são incomuns nos acervos técnicos disponíveis. Para auxiliar no controle de processos, é escopo desta pesquisa investigar estrutura de modelos não-paramétricos como tabelas ou gráficos capazes de relacionar um índice de quantificação do regime de fluidização (adimensional) pela velocidade de entrada de $\operatorname{ar}(\mathrm{m} / \mathrm{s})$ [155].

Nesta pesquisa, está incluído a proposta de modelos não-paramétricos baseados em invariantes do caos, capazes de ajustarem-se as diferentes escalas de unidades de variáveis de entrada como velocidade do ar de entrada, rotação do alimentador, etc. 


\section{PROPOSTA E PROJETO DE BANCADA}

Este capítulo apresenta a proposta de projeto de banca de estudo de quantificação de regimes de fluidização. Esta proposta implementa uma simulação numérica multifásica 3D usando modelo de dois fluidos para estudos de perda de carga e faixa de operação em medidores de pressão estática numa coluna fria de leito fluidizado circulante.

Para alcançar uma especificação técnica de bancada experimental para estudos de quantificação de leito fluidizado, este capítulo dedica-se a caracterização de uma simulação numérica multifásica capaz reconstruir comportamentos similares aos experimentais para dimensionamento de ventiladores (propulsores de ar) e especificação de instrumentação apropriada.

Esta metodologia é dividia em quatro etapas. Na primeira, são levantados os principais critérios para seleção das dimensões de uma coluna como diâmetro, altura, posições e diâmetros das entradas/saídas. Em seguida, são levantadas informações para definir dimensões de domínios e características simulações estacionária e transiente capazes de cumprir os requisitos inicias.

A segunda etapa conta a implementação e discussão de simulação TFM das especificações da etapa anterior. É discutido a implementação do efeito circulante da coluna LFC, especificações de discretização e condições de contorno, capazes de executar ensaios numéricos em diferentes regimes de fluidização.

A terceira etapa trata das definições do processo de classificação de regimes de fluidização, do procedimento de análise linear da evolução das pressões estática e diferencial e do procedimento de análise não-lineares para avaliar seu comportamento caótico.

O último passo apresenta os resultados do modelo numérico e informações para montagem e descrição de nova metodologia experimental para quantificação de regimes de fluidização.

\subsection{Parâmetros de coluna LFC fria}

O propósito de especificar parâmetros para simulação de uma coluna de fluidização circulante fria, é relacionar critérios suficientes a reprodução de fenômenos fluidodinâmicos esboçados nas variáveis estudadas. Portanto, é importante estudar da simulação, quedas de pressão na coluna sob diferentes regimes de fluidização, auxiliando na especificação do sistema de injeção de ar de entrada, e as taxas de variação de pressão e amplitudes, para especificação de instrumentação adequada. O modelo TFM/MFIX foi escolhido por ser capaz reproduzir problemas numéricos de escala laboratorial (precisão de $0,1 \mathrm{~m}$ ) e fluxos densos/diluídos em leito fluidizado circulante. $\mathrm{O}$ modelo de dois fluidos trata ambas fases (gás e sólida) com abordagem euleriana e usa correlações de arrasto fluido-partícula como leis de fechamento para o acoplamento [156]. A metodologia para especificação de simulação para coluna LFC fria foi dividida em três etapas.

A primeira etapa, um levantamento bibliográfico auxilia e verifica dimensões preliminares. Através de um banco de correlações do software Ergun 6.2 foi possível verificar parâmetros como a classificação da partícula e altura do bordo livre a partir da estimação da elutriação. 
Na segunda etapa, é discutida a razão pela qual a dimensão 3D para esta simulação foi escolhida. O estudo com precisão satisfatória, da evolução da pressão estática/diferencial ao longo de uma coluna fria, operando em diversos regimes, exige condições mínimas para atender seu propósito.

Por fim, é discutida uma implementação para malha circulante sem onerar, computacionalmente, o tempo de simulação.

\subsubsection{Seleção de coluna LFC}

Não há na literatura, critérios bem estabelecidos para seleção de uma coluna fria de seção transversal circular, em escala laboratorial, com propósito de estudos dos regimes de fluidização. A seleção desta, conforme referido na literatura [157], é baseado em dados experimentais (diâmetro e altura da coluna), observações científicas (quantitativa e qualitativa), características de partículas e efeitos de componentes mecânicos (distribuidor, posição de tomadas de saídas e entradas, selo mecânico LFC).

Devido as facilidades construtivas e documentação, as colunas de seção transversais circulares são as mais usadas. Outra consideração é o uso de materiais lisos e transparentes (resina) na parede da coluna, para evitar problemas de borda e confirmação visual dos regimes [36].

De forma geral, uma coluna de fluidização fria de escala laboratorial, não inclui critério de tempo de residência com as que realizam reações químicas. Como seu principal propósito é o estudo de regimes de fluidização, a coluna deve ter espaço adequado para o desenvolvimento dos regimes borbulhantes, turbulento, rápido e de transporte. A Figura 27 apresenta a sequência de etapas utilizadas para verificação da coluna. A composição desta proposta foi baseada na literatura e no uso do software proprietário Ergun 6.2. A faixa de operação das características de partículas foram 0,4 a 2,0 mm de diâmetro e massa específica de 1600,0 a $2700,0 \mathrm{~kg} / \mathrm{m}^{3}$ (partículas de areia e vidro). A posição da entrada circulante é de $10,0 \mathrm{~cm}$ a partir da base, a saída é do tipo T, posição de saída é de $10,0 \mathrm{~cm}$ a partir do topo e diâmetro de entrada/saída de $3,0 \mathrm{~cm}$.

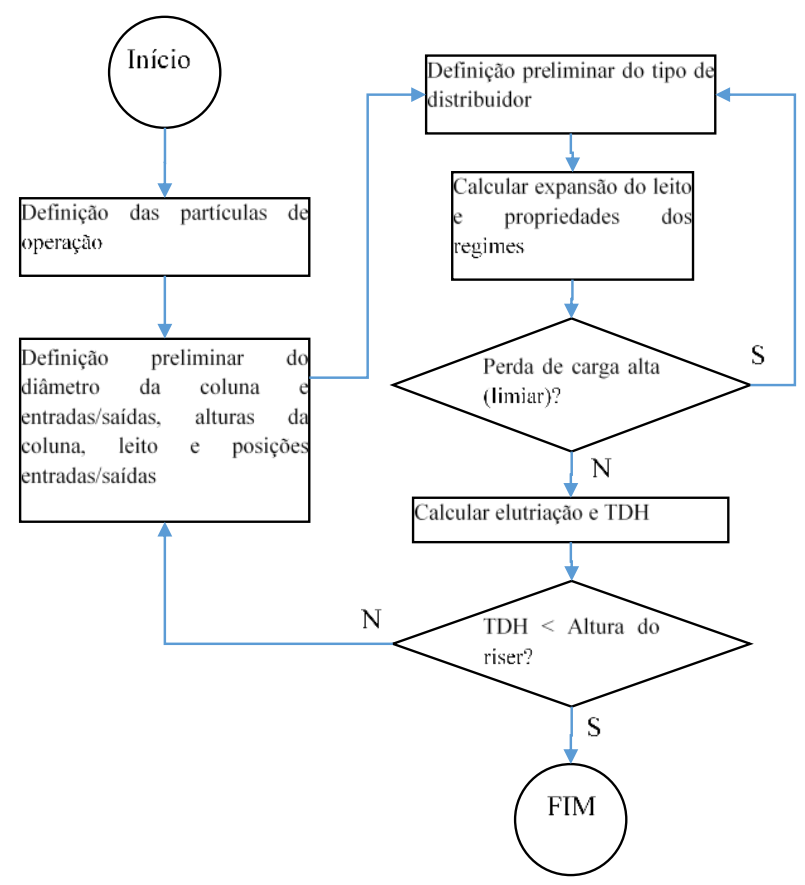

Figura 27 - Fluxograma para seleção de coluna de fluidização LFC fria em escala laboratorial. 
Com as especificações de partículas, o software classifica as partículas nos grupos de Geldart (B e D, neste caso e conforme a Figura 28) e calcula coeficientes de arrasto, velocidades terminal e de mínima fluidização e Reynolds da partícula. A definição preliminar do diâmetro e altura da coluna foram, respectivamente, $0,11 \mathrm{~m}$ e $1,1 \mathrm{~m}$. A consideração do distribuidor foi de perda desprezível, o que na prática representa usar uma trama (ou peneira de arame) de mesh, ou dimensões de furos inferior a menor diâmetro de partícula ensaiada $(<0,4 \mathrm{~mm})$. Essa consideração implica que o distribuidor tem a função apenas reter o leito quando empacotado e que o escoamento do gás de entrada de fluidização já está plenamente desenvolvido. O software Ergun aplica um banco de dados de correlações [158] para estimar a perda de carga (equação de Ergun), faixas de velocidade para desempenhar os regimes de fluidização (banco de dados experimental e levantamento de literatura) e o TDH (transport disengagement height). O TDH (vide Figura 28) é um parâmetro que estima a altura da coluna (baseado no método de Zenz), acima da altura de leito, em que o fluxo de sólidos arrastados fica próximo de zero, no regime borbulhante [54] [159] [160] [161]. A altura operacional do leito foi definida em $8 \mathrm{~cm}$, baseado nas alturas operacionais usadas em gaseificadores de leito fluidizado circulante reais (6 a $8 \%$ da altura da coluna) presenciadas pelo autor. Como o maior TDH estimado para faixa de partículas operacionais foi de $0,68 \mathrm{~m}$, menor do que a altura da coluna, a altura definida da coluna está conforme ao critério de projeto.
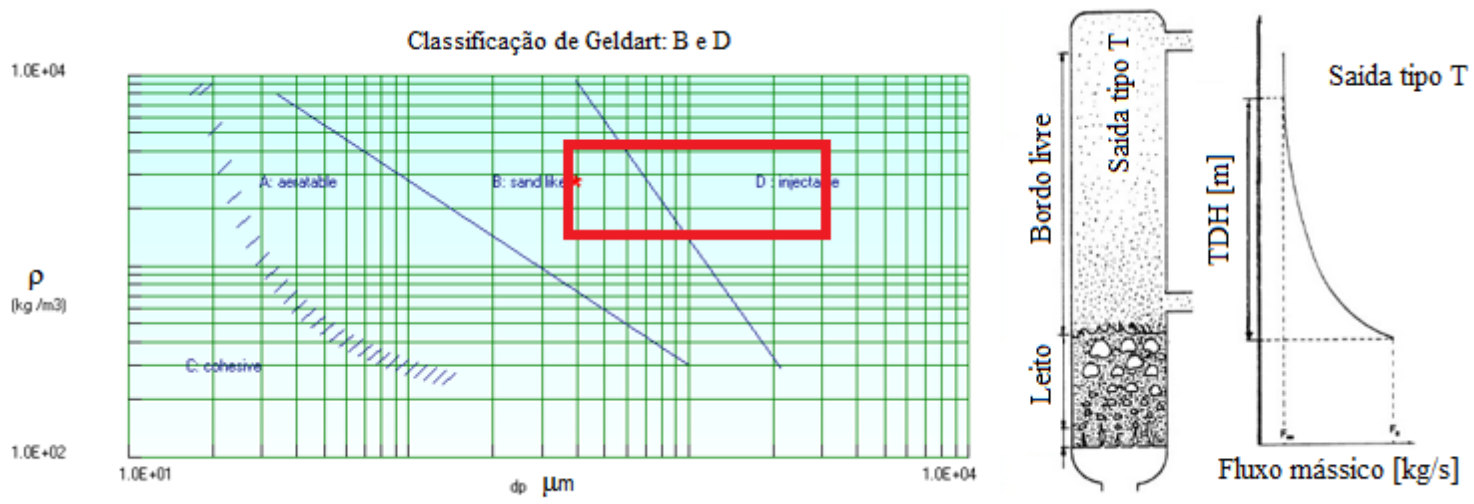

Figura 28 - Classificação de partículas e aplicação de correlações para estimativa do TDH.

Para o desenvolvimento de outros regimes como o turbulento, rápido e transporte, não há critérios me estabelecidos na literatura [54]. As dimensões de diâmetro da coluna de $0,11 \mathrm{~m}$ e altura $1,1 \mathrm{~m}$ foram consideradas satisfatórias, pois corroboram com dimensões usadas em outros trabalhos [162] [163] [164] [165] [166] [167], que investigaram experimentalmente os regimes de fluidização em colunas LFC frias.

\subsubsection{Dimensão do domínio}

A definição do número de dimensões do domínio de uma simulação multifásica depende, basicamente, do propósito da investigação. Uma grande quantidade de trabalhos [168] [169] [170], implementa simulações multifásicas em duas dimensões devido redução de custo computacional, de implementação (simplificações) para investigações de mecanismos de formação do escoamento. Considerando o propósito de especificação de propulsores de ar (pressão e vazão) para desempenhar regimes de 
fluidização numa coluna LFC fria e para estudo de instrumentação, a simulação numérica deve ser de três dimensões e transiente. O estudo de instrumentação considera as taxas de variações de pressão e suas amplitudes.

A Figura 29 apresenta um comparativo de gradientes de pressão ao longo de uma coluna fria LFC, entre um modelo TFM 2D, 3D e experimental de mesmas medidas [131]. O trabalho mostra o quanto superdimensionado a previsão do gradiente de pressão, ao longo da coluna e regime, permanece quando comparados com modelos 3D e dados experimentais. Segundo Li et al. [131], como a simulação 2D não considera distribuições de fluxos e interações radiais, o gradiente de pressão axial é superdimensionado.

A comparação entre o modelo 3D e experimental, mostra que em certas regiões da coluna, houve discrepâncias na previsão do gradiente para partículas do Grupo A e B. As partículas do grupo A são mais leves do que os do grupo $\mathrm{B}$, provocando estimativas discrepantes do modelo em relação ao experimento. Para as partículas do grupo B, houve boa concordância entre os dados experimentais e do modelo 3D, conforme mostrado na Figura 29.
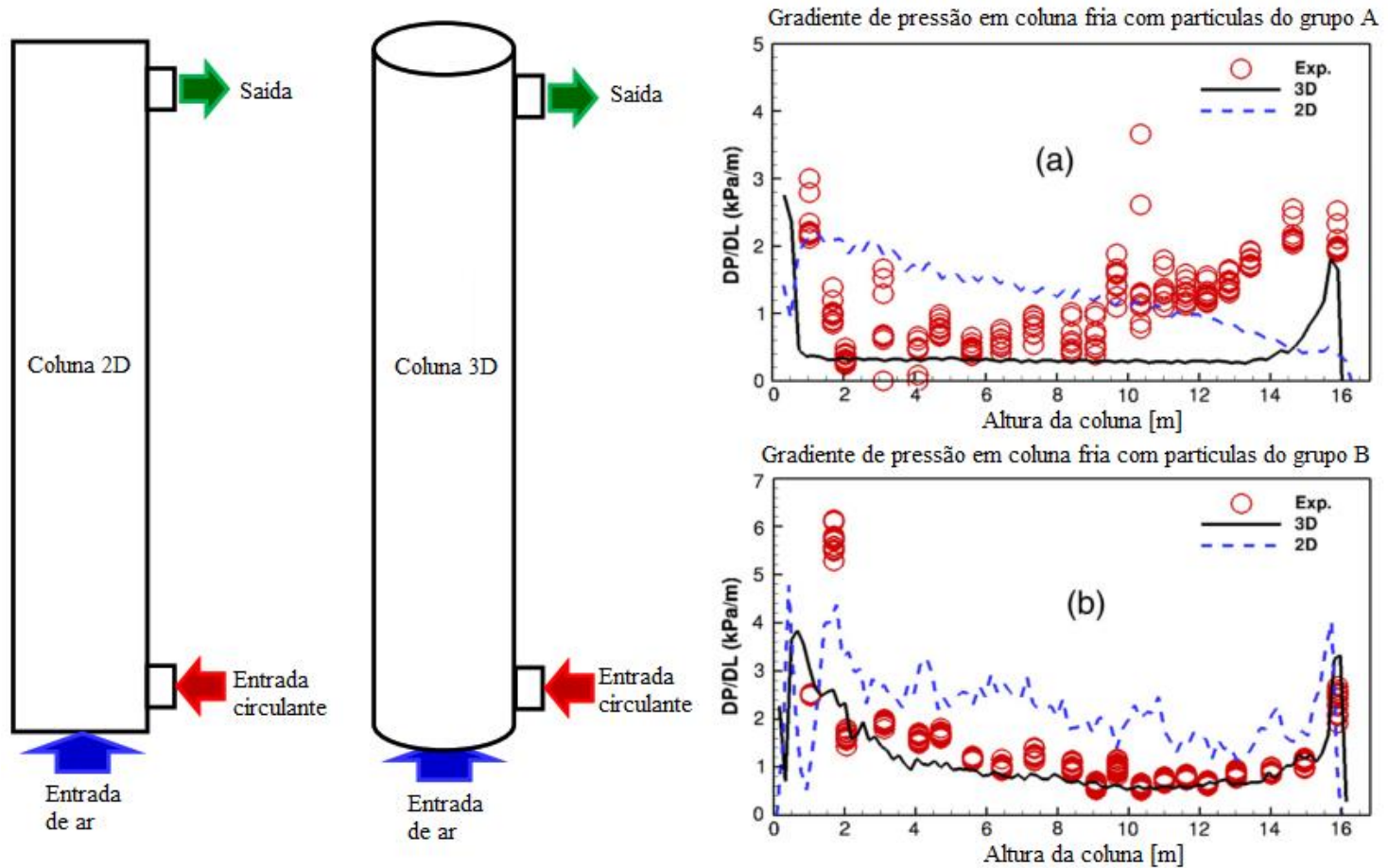

Figura 29 - Comparativo entre simulações TFM 2D, 3D e experimental para coluna LFC fria de mesmas dimensões. Adaptado de [131].

Além das características geométricas, este tópico incrementa a especificação da simulação com considerações de simular partículas maiores do que a do grupo A, como os grupos B e D, o domínio ter três dimensões transiente.

\subsubsection{Efeito circulante}

Sistemas fluidizados que operam com regimes que provocam altos índices de arrasto necessitam de malha circulante para preservar seu regime. Segundo Basu et al. [6], dentre os regimes de alto índice de arrasto como turbulento, rápido e transporte pneumático, o regime rápido provoca as maiores taxas de 
troca de calor e massa (turbulência), e maiores tempos de residência, que favorecem a maximização da produção de gás em gaseificadores LFC, conforme a Figura 30. Como grau de turbulência e tempo de residência variam conforme o regime de fluidização, o estudo para manter tais variáveis controladas, durante operações unitárias é imprescindível.

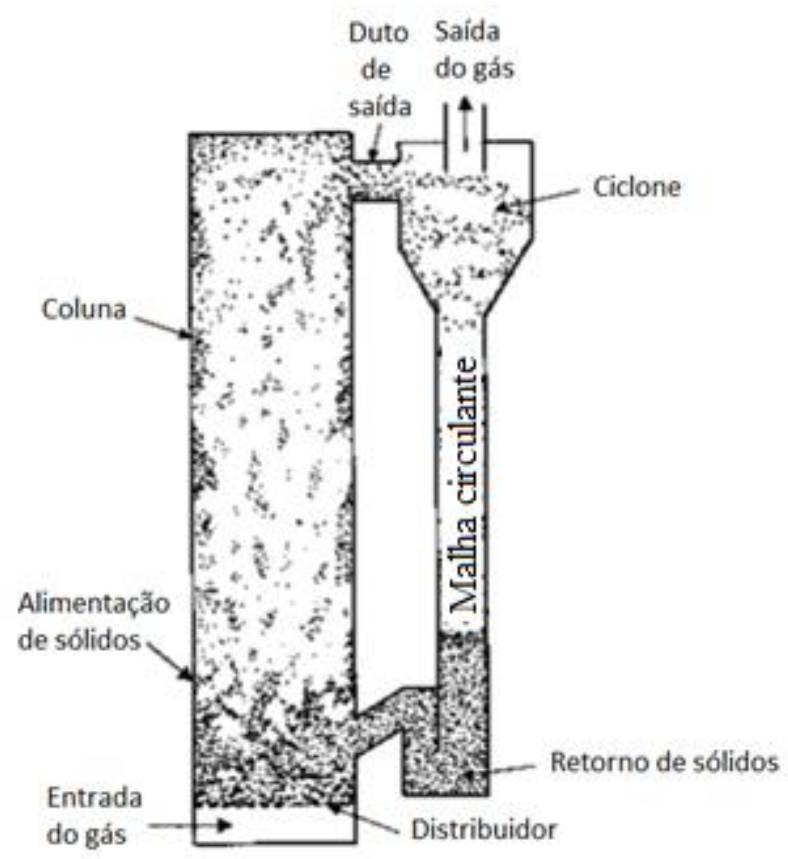

Figura 30 - Sistema de leito fluidizado circulante operando em regime rápido. Adaptador de [54].

Numericamente, seria pouco viável implementar uma malha circulante usufruindo dos efeitos fluidodinâmicos do ciclone. Portanto, o código de simulação LFC deve suportar funções definidas por usuários, capazes de substituir um ciclone numérico por um algoritmo que contabiliza determinadas o material sólido, que deixa a coluna, e o devolve para o leito. Essa equivalência permite reproduzir o efeito circulante de manter o inventário de massa constante. De forma geral, o usuário deve selecionar as células computacionais que caracterizam a superfície de saída e de retorno da coluna, integrando o fluxo de sólidos de saída e re-injetando na entrada, em cada instante de tempo.

\subsection{Simulação de coluna fria LFC}

O problema aqui modelado refere-se à construção de um domínio computacional, com coluna de paredes cilíndrica, tomadas de entrada/saída para malha circulante e entrada de ar na base. O projeto de colunas de fluidização ou reatores tradicionalmente se baseia em dados de laboratório ou em unidades de escala piloto. Apesar de processos terem sido escalonados com êxito, há relatos de ocorrência de grandes falhas [65] [171] [172]. Trabalhos como Pedroso et al. [173] usam simulações numéricas do escoamento de dois fluidos para verificação e desenvolvimento de leis de escalonamento para sistemas fluidizados. A escolha do código de implementação foi baseada em infraestrutura de documentação, fóruns, experimento, o código ser aberto (bibliotecas abertas), ter aplicações voltados para sistemas de leito fluidizado e permitir funções personalizadas capazes implementar malhas circulantes. O software pesquisado que cumpre tais requisitos é o MFIX (Multiphase Flow with Interphase eXchanges) desenvolvido pela NETL (National Energy Technology Laboratory). O processo de modelagem foi dividido em quatro etapas. 
Na primeira etapa, são abordados as equações e correlações implementadas pelas bibliotecas do MFIX como conservação de massa, momento, energia interna e energia granular. Em seguida, é discutida a implementação da malha circulante, o processo de discretização e as condições de contorno.

Na segunda etapa, são descritos os métodos de ensaios realizados na simulação capazes de classificar, numericamente, os regimes de fluidização, a análise de pressões estática e diferencial e análise nãolinear de invariantes do caos aplicadas nos sinais de pressão.

A terceira etapa, conta com a apresentação dos resultados para especificação do sistema de propulsão de ar, instrumentação de pressão e análises não-lineares de séries temporais dos sinais de pressão.

\subsubsection{Coluna LFC no MFIX}

A modelagem fluidodinâmica baseada nas leis de conservação de massa, momento, energia e espécies são ferramentas com grande potencial para projetos de escalonamento de reatores de leito fluidizado circulante [174].

A implementação das bibliotecas MFIX contam com equações governantes e correlações para parametrização de modelo TFM. Os modelos fluidodinâmicos de duas fases tratam as partes fluidas e sólidas como dois contínuos interpenetrantes. As partículas são consideradas idênticas, caracterizadas por geometrias e propriedades idênticas. Mesmo assim, o código permite descrever os fenômenos de segregação e elutriação de partículas, através de especificação de múltiplos componentes sólidos. O código tem sido utilizado para prever os fluxos transientes, não-isotérmicos, tridimensionais das fases fluida e sólida dentro de um leito fluidizado circulante, e validadas com dados experimentais [174].

As principais características do código MFIX são:

- Equações de equilíbrio de massa e momento para fases de gás e sólidos múltiplos;

- Uma fase gasosa e duas equações de energia de fase sólida;

- Um número arbitrário de equações de equilíbrio de espécies para cada uma das fases;

- Equações de tensão granular baseadas na teoria cinética e na teoria do fluxo;

- Uma sub-rotina química definida pelo usuário;

- Sistemas de coordenadas cartesianas ou cilíndricas tridimensionais;

- Malha não uniforme;

- Superfícies internas impermeáveis e semipermeáveis;

- Arquivo de dados de entrada do usuário amigável;

- Arquivos de saída múltiplos, de precisão única, binários, de acesso direto, que minimizam o armazenamento em disco e aceleram a recuperação de dados;

- E relatórios de erros extensivos.

- O formato dos arquivos de saída são compatíveis com inúmeros software de pós-processamento.

A escolha do modelo TFM/MFIX atende a escala laboratorial do domínio computacional proposto $(0,1$ $\mathrm{m})$. O modelo de dois fluidos aplica uma abordagem euleriana para resolver equações para ambas fases (gás e sólida) e usa correlações de arrasto gás-sólido como leis de fechamento para o acoplamento entre as fases [156].

O MFIX é compatível com as plataformas Windows e Linux, mas a segunda que é recomendada. As instruções de instalação são claras e estão disponíveis em https://mfix.netl.doe.gov/. O MFIX não é uma linguagem, mas uma biblioteca desenvolvida em Fortran. O usuário pode modelar escoamento de propósito geral para descrever reações químicas e transferência de calor em fluxos densos ou diluídos de fluidos e sólidos, os quais ocorrem tipicamente em reatores de conversão de energia e processamento 
químico. Possui capacidade de modelar escoamento com múltiplos tipos de partículas, em sistemas de coordenadas cartesianas ou cilíndricas tridimensionais, com malhas uniformes ou não, considerando balanços de energia e de espécies de gás/sólidos. Seus cálculos fornecem informações dependentes do tempo sobre a pressão, temperatura, composição e distribuições de velocidade nos reatores. Essas informações, podem auxiliar o no conhecimento das condições no reator, realizar estudos paramétricos e experimentais e obter informações para o projeto de escalonamento de reatores multifásicos.

Para iniciar uma simulação, o usuário deve escrever um de entrada chamado mfix.dat, contendo palavras-chave para configurar a simulação. Para rodá-la, o usuário deve compilar a simulação com as diretivas do arquivo de entrada. As diretivas incluem: especificação de modelos (TFM, DEM, PIC), domínio, malha computacional, condições de inicias/fronteiras e o uso de processamento paralelo, permitindo a redução do tempo de simulação [175].

Como cada código de simulação numérica aplica equações governantes para construção de seus modelos, formula suas relações constitutivas e as condições iniciais e de fronteiras, é importante descrevê-las.

\subsubsection{Conservação de massa}

A aplicação de técnicas de médias para derivar as equações que descrevem contínuos interpenetrantes resultam em variáveis pontuais que representam médias sobre uma grande região, quando comparado com o espaço ocupado pelas partículas, mas ao mesmo tempo, muito menor do que o domínio do escoamento. Essa consideração torna a simulação TFM viável para tratar escalar de porte industrial.

Variáveis de campo e frações de volume de cada fase, são implementadas no código TFM/MFIX para rastrear a fração do volume de média ocupado por várias fases. Estes são designados por $\varepsilon_{g}$ para a fase fluida (também conhecida como a fração de vazio) e $\varepsilon_{s m}$ para a m-ésima fase de sólidos $(M)$. Essas frações de volume são consideradas como funções contínuas de espaço e tempo. Por definição, quando somadas, as frações de volume de todas as fases devem alcançar a unidade, conforme a Equação 35. A densidade efetiva (macroscópica) das fases gás e sólido são respectivamente, $\rho_{g}$, e $\rho_{s m}$, conforme descrito pela Equação 35.

$$
\begin{aligned}
& \varepsilon_{g}+\sum_{m=1}^{M} \varepsilon_{s m}=1 \\
& \rho_{g^{\prime}}=\varepsilon_{g} \rho_{g} \\
& \rho_{s m^{\prime}}=\varepsilon_{s m} \rho_{s m}
\end{aligned}
$$

$\mathrm{Na}$ Equação 36, é apresentada a lei de continuidade para fases sólida e gás, onde o primeiro termo explica a taxa de acumulação de massa por unidade de volume, o segundo termo é a taxa líquida de fluxo de massa convectiva, e o termo à direita é transferência de massa interfásica, devido aos processos físicos. A massa específica da fase fluida, $\rho_{g}$ pode ser modelada pela lei do gás ideal

$$
\frac{\partial}{\partial t}\left(\varepsilon_{g} \rho_{g}\right)+\nabla \cdot\left(\varepsilon_{g} \rho_{g} \vec{v}_{g}\right)=\sum_{n=1}^{N_{g}} R_{g n}
$$




$$
\begin{aligned}
& \frac{\partial}{\partial t}\left(\varepsilon_{s m} \rho_{s m}\right)+\nabla \cdot\left(\varepsilon_{s m} \rho_{s m} \vec{v}_{s m}\right)=\sum_{n=1}^{N_{s m}} R_{s m n} \\
& \rho_{g}=\frac{P_{g} M w}{R T_{g}}
\end{aligned}
$$

\subsubsection{Balanço da quantidade de momento}

A Equação 37 fornece a conservação de momento para ambas fases, onde $\overline{\bar{S}}_{g}$ é o tensor de tensão de fase gasosa, $\vec{I}_{g m}$ é uma força de interação de transferência entre as fases gasosa e m-ésima fase sólida, e $\vec{f}_{g}$ é a resistência ao escoamento oferecida pelas superfícies internas porosas. O mesmo é válido para fase sólida. O termo $\vec{I}_{m l}$ é a força de interação entre as fases sólidas m-ésima e l-ésima. O termo $\frac{\partial}{\partial \mathrm{t}}\left(\rho_{\mathrm{sm}} \varepsilon_{\mathrm{sm}} \vec{v}_{\mathrm{sm}}\right)$ representa a taxa líquida de aumento de momento, em seguida, $\nabla \cdot\left(\rho_{\mathrm{sm}} \varepsilon_{\mathrm{sm}} \vec{v}_{\mathrm{sm}} \vec{v}_{\mathrm{sm}}\right)$, representa a taxa líquida de transferência de momento por convecção. Já os termos $\nabla \cdot \overline{\bar{S}}_{s m}$, representa forças de superfície normal e de cisalhamento, enquanto o segundo, $\varepsilon_{\mathrm{sm}} \rho_{\mathrm{sm}} g$, representa as forças do corpo.

$$
\begin{array}{ll}
\frac{\partial}{\partial \mathrm{t}}\left(\rho_{\mathrm{g}} \varepsilon_{\mathrm{g}} \vec{v}_{\mathrm{g}}\right)+\nabla \cdot\left(\rho_{\mathrm{g}} \varepsilon_{\mathrm{g}} \vec{v}_{\mathrm{g}} \vec{v}_{\mathrm{g}}\right)=\nabla \cdot \overline{\bar{S}}_{g}+\varepsilon_{\mathrm{g}} \rho_{\mathrm{g}} g-\sum_{m=1}^{M} \vec{I}_{g m}+\vec{f}_{g} & \text { Equação } 37 \\
\frac{\partial}{\partial \mathrm{t}}\left(\rho_{\mathrm{sm}} \varepsilon_{\mathrm{sm}} \vec{v}_{\mathrm{sm}}\right)+\nabla \cdot\left(\rho_{\mathrm{sm}} \varepsilon_{\mathrm{sm}} \vec{v}_{\mathrm{sm}} \vec{v}_{\mathrm{sm}}\right)=\nabla \cdot \overline{\bar{S}}_{s m}+\varepsilon_{\mathrm{sm}} \rho_{\mathrm{sm}} g+\vec{I}_{g m}-\sum_{\substack{l=1 \\
l \neq m}}^{M} \vec{I}_{m l} &
\end{array}
$$

Para implementação do modelo TFM/MFIX, os mecanismos e formulação das forças de interação ou transferência de momento fluido-sólidos, estão inclusos: força de arrasto, causada por diferenças de velocidade entre as fases; empuxo, causada pelo gradiente de pressão do fluido; Efeito de massa virtual, causado pela aceleração relativa entre fases; Força de elevação de Saffman, causada por gradientes de velocidade de fluido; força de Magnus, causada por spin de partículas; força de Basset, que depende da história do movimento da partícula através do fluido; força de Faxen, que é uma correção aplicada ao efeito de massa virtual e força de Basset para considerar gradientes de velocidade de fluido; e forças causadas por gradientes de temperatura e densidade, conforme a Equação 38.

A generalização das fórmulas usadas para sistemas com uma partícula para multiparticulares incluem:

- O efeito da aproximação entre partículas. Esta consideração, implica que a força de arrasto é uma função da fração de volume de sólidos, número de Reynolds de partículas, e são deduzidas a partir de correlações experimentais;

- A força de interação de uma partícula é corrigida considerando a transferência entre massas das fases, para o caso de reações químicas;

- A transferência de impulso faz parte da força de interação;

- A formulação do arrasto fluido-partícula considera partículas uniformes, lisas, esféricas, enquanto interações reais lidam com partículas ásperas, não-esféricas e de diferentes tamanhos;

- As interações fluido-partícula e partícula-partícula são tratadas de forma separada. A técnicas de média usadas para aproximar as partículas como um contínuo granular torna as equações 
incapazes de tratar a micro-hidrodinâmica próxima as partículas, que sob condições adequadas, favoreçam a formação de agrupamentos (clusters) [175] [174].

Assim, a interação fluido-partícula do modelo TFM/MFIX considera apenas forças mais significativas como empuxo, arrasto e transferência de momento devido a transferência de massa, conforme Equação 38 .

$$
\begin{gathered}
\vec{I}_{g m}=-\varepsilon_{\mathrm{sm}} \nabla P_{g}-F_{\mathrm{gm}}\left(\vec{v}_{\mathrm{sm}}-\vec{v}_{\mathrm{g}}\right)+R_{0 m}\left[\xi_{0 \mathrm{~m}} \vec{v}_{\mathrm{sm}}+\bar{\xi}_{0 \mathrm{~m}} \vec{v}_{\mathrm{g}}\right] \\
\xi_{0 \mathrm{~m}}=\left\{\begin{array}{l}
1, \text { para } R_{0 m}<0 \\
0, \text { para } R_{0 m} \geq 0
\end{array}, \bar{\xi}_{0 \mathrm{~m}}=1-\xi_{0 \mathrm{~m}}\right. \\
F_{\mathrm{gm}}=\frac{3 \varepsilon_{\mathrm{sm}} \varepsilon_{\mathrm{g}} \rho_{\mathrm{g}}}{4 V_{r m}^{2} d_{p m}} C_{D s}\left(\frac{R e_{m}}{V_{r m}}\right)\left|\vec{v}_{\mathrm{sm}}-\vec{v}_{\mathrm{g}}\right| \\
V_{r m}=0,5\left(A-0,06 R e_{m}+\sqrt{\left(0,06 R e_{m}\right)^{2}+0,12 R e_{m}(2 B-A)+A^{2}}\right) \\
A=\varepsilon_{g}^{4,14}, B=\left\{\begin{array}{c}
0,8 \varepsilon_{g}^{1,28}, \text { se } \varepsilon_{\mathrm{g}} \leq 0,85 \\
\varepsilon_{g}^{2,65}, \text { se } \varepsilon_{\mathrm{g}}>0,85
\end{array}, R e_{m}=\frac{d_{p m}\left|\vec{v}_{\mathrm{sm}}-\vec{v}_{\mathrm{g}}\right| \rho_{\mathrm{g}}}{\mu_{\mathrm{g}}}\right. \\
C_{D s}(R e)=\left(0,63+\frac{4,8}{\sqrt{R e}}\right)^{2}
\end{gathered}
$$

Apesar do conhecimento da transferência de momento partícula-partícula ser menor, quando comparado a transferência fluido-partícula, segundo Syamlal et al. [174] é seguro considerar que o efeito principal é o arrasto entre as fases por causa das diferenças de velocidade. As formulas para descrever as interações partícula-partícula é dado pela Equação 39.

$$
\begin{aligned}
& \vec{I}_{m l}=-F_{\mathrm{sml}}\left(\vec{v}_{\mathrm{sl}}-\vec{v}_{s m}\right)+R_{m l}\left[\xi_{\mathrm{ml}} \vec{v}_{\mathrm{sl}}+\bar{\xi}_{\mathrm{ml}} \vec{v}_{s m}\right] \\
& \xi_{\mathrm{ml}}=\left\{\begin{array}{l}
1, \text { para } R_{m l}<0 \\
0, \text { para } R_{m l} \geq 0
\end{array}, \bar{\xi}_{\mathrm{ml}}=1-\xi_{\mathrm{ml}}\right. \\
& F_{\mathrm{sml}}=\frac{3}{2 \pi} \frac{\left(1+e_{l m}\right)\left((\pi / 2)+C_{f l m}\left(\pi^{2} / 8\right)\right)}{\left(\rho_{\mathrm{sl}} d_{p l}^{3}+\rho_{\mathrm{sm}} d_{p m}^{3}\right)}\left(\varepsilon_{s l} \rho_{\mathrm{sl}} \varepsilon_{\mathrm{sm}} \rho_{\mathrm{sm}}\right)\left(d_{p l}\right. \\
& \left.+d_{p m}\right)^{2}\left(g_{0 l m}\left|\vec{v}_{\mathrm{sl}}-\vec{v}_{s m}\right|\right) \\
& g_{0 l m}=\frac{1}{\varepsilon_{g}}+\frac{3 d_{p l} d_{p m}}{\varepsilon_{g}^{2}\left(d_{p l}+d_{p m}\right)} \sum_{\lambda=1}^{M} \frac{\varepsilon_{s \lambda}}{d_{p \lambda}}
\end{aligned}
$$

Equação 39

Para o tensor de fase fluida, segue a descrição pela Equação 40.

$$
\begin{aligned}
& \overline{\bar{S}}_{g}=-P_{\mathrm{g}} \overline{\bar{I}}+\overline{\bar{\tau}}_{g} \\
& \overline{\bar{\tau}}_{g}=2 \varepsilon_{g} \mu_{g} \overline{\bar{D}}_{g}+\varepsilon_{g} \lambda_{g} \operatorname{tr}\left(\overline{\bar{D}}_{g}\right) \overline{\bar{I}}
\end{aligned}
$$

Equação 40 


$$
\overline{\bar{D}}_{g}=\frac{1}{2}\left[\nabla \vec{v}_{\mathrm{g}}+\left(\nabla \vec{v}_{\mathrm{g}}\right)^{T}\right]
$$

A fase sólida é considerada invíscido, se o leito é totalmente fluidizado. Um termo de pressão de sólidos é usado para evitar que a fração de vazio não seja menor do que a de leito empacotado. Esta pressão torna-se zero quando a fração de vazio se torna maior do que a fração vazia do leito empacotado. Os fluxos granulares podem ser classificados em dois regimes de fluxo distintos: um regime viscoso ou de cisalhamento rápido, em que as tensões surgem devido à transferência de momento colisional ou translacional, e a um regime plástico ou de cisalhamento lento, em que as tensões surgem devido ao atrito de Coulomb entre grãos, num contato de maior período, conforme a Figura 31.

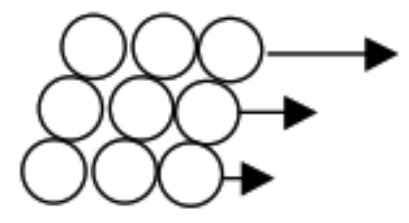

Fluxo plástico

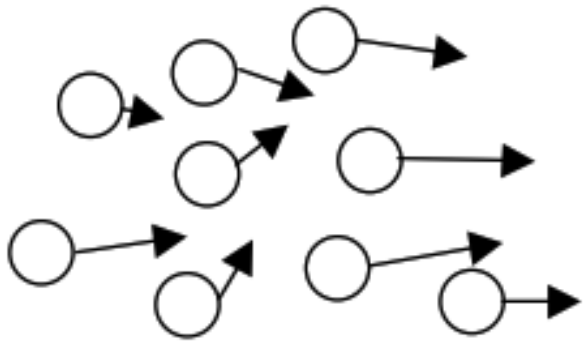

Fluxo viscoso

Figura 31 - Fluxos granulares de cisalhamento lento e rápido. Adaptado de [174].

O modelo TFM/MIFX implementa um modelo para descrever fluxos granulares de cisalhamento, combinando as teorias de regimes de fluxo viscoso e plástico. As teorias são comutadas através pelo empacotamento crítico, $\varepsilon_{g}^{*}$, o qual considera a ocorrência da transição do regime de fluxo granular, conforme a Equação 41. O algoritmo introduz métodos rigorosos da teoria cinética dos gases para descrever a transferência colisional de momento e, assim, derivar expressões para o tensor de tensão. Nos fluxos granulares rápidos, a energia cinética do fluxo médio primeiro se degrada na energia cinética de flutuações de partículas aleatórias e depois se dissipa como calor por causa de colisões inelásticas. A energia cinética das flutuações pode ser explicada na teoria por uma temperatura granular, $\Theta_{m}$, que é diferente da temperatura da partícula (uma medida da energia cinética das vibrações moleculares dentro da partícula). As fórmulas para tensões em fluxos granulares rápidos foram incluídas em vários modelos de fluxo de duas fases de leitos fluidizados, conforme a Equação 41. As tensões no regime de fluxo plástico são, geralmente, descritas adotando teorias do estudo da mecânica do solo. As tensões surgem devido ao atrito das partículas e são descritas por modelos fenomenológicos ao invés de modelos mecanicistas, como no caso do regime de fluxo rápido. No MFIX, as tensões são calculadas apenas para sólidos de fase 1, mesmo quando são especificadas várias fases de sólidos, conforme a Equação 41. Os cálculos de tensão implícita requerem uma quantidade considerável de tempo computacional. Ajustando o ângulo de atrito interno ( $\phi$, vide Equação 41) para zero, os cálculos de tensão plástica podem ser desligadas (para leitos empacotados).

$$
\overline{\bar{S}}_{s m}=\left\{\begin{array}{l}
-P_{s m}^{p} \overline{\bar{I}}+\overline{\bar{\tau}}_{s m}^{p}, \text { se } \varepsilon_{g} \leq \varepsilon_{g}^{*} \\
-P_{s m}^{v} \overline{\bar{I}}+\overline{\bar{\tau}}_{s m}^{v}, \text { se } \varepsilon_{g}>\varepsilon_{g}^{*}
\end{array}\right.
$$

Equação 41 


$$
\begin{aligned}
& P_{s m}^{v}=K_{1 m} \varepsilon_{s m}^{2} \Theta_{m}, K_{1 m}=2\left(1+e_{m m}\right) \rho_{s m} g_{0 m m} \\
& \overline{\bar{\tau}}_{s m}^{v}=2 \mu_{s m}^{v} \overline{\bar{D}}_{s m}+\lambda_{s m}^{v} \operatorname{tr}\left(\overline{\bar{D}}_{s m}\right) \overline{\bar{I}}, \lambda_{s m}^{v}=K_{2 m} \varepsilon_{s m} \sqrt{\Theta_{m}} \\
& K_{2 m}=\frac{4 d_{p m} \rho_{s m}\left(1+e_{m m}\right) \varepsilon_{s m} g_{0 m m}}{3 \sqrt{\pi}}-\frac{2}{3} K_{3 m} \\
& K_{3 m}=\frac{d_{p m} \rho_{s m}}{2}\left\{\frac{\sqrt{\pi}}{3\left(3-e_{m m}\right)}\left[1+0,4\left(1+e_{m m}\right)\left(3 e_{m m}-1\right) \varepsilon_{s m} g_{0 m m}\right]\right. \\
& \left.+\frac{8 \varepsilon_{s m} g_{0 m m}\left(1+e_{m m}\right)}{5 \sqrt{\pi}}\right\} \\
& \mu_{s m}^{v}=K_{3 m} \varepsilon_{s m} \sqrt{\Theta_{m}}, \overline{\bar{D}}_{s m}=\frac{1}{2}\left[\nabla \vec{v}_{s m}+\left(\nabla \vec{v}_{s m}\right)^{T}\right], P_{s m}^{p}=\varepsilon_{s m} P^{*} \\
& P^{*}=A\left(\varepsilon_{g}^{*}-\varepsilon_{g}\right)^{n}, n=10, \overline{\bar{\tau}}_{s 1}^{p}=2 \mu_{s 1}^{p} \overline{\bar{D}}_{s 1}, \mu_{s 1}^{p}=\frac{P^{*} \sin \phi}{2 \sqrt{I_{2 D}}} \\
& I_{2 D}=\frac{1}{6}\left[\left(D_{s 11}-D_{s 22}\right)^{2}+\left(D_{s 22}-D_{s 33}\right)^{2}+\left(D_{s 33}-D_{s 11}\right)^{2}+D_{s 12}^{2}+D_{s 23}^{2}\right. \\
& \left.+D_{s 31}^{2}\right]
\end{aligned}
$$

Quanto a conservação da energia interna, as equações foram desligadas para cumprir o propósito desta simulação, uma vez que a coluna foi considerada fria e que as trocas de calor e massa não importam.

\subsubsection{Conservação de energia granular}

A teoria cinética que descreve o fluxo de partículas lisas, ligeiramente inelásticas, esféricas foi usada na derivação da relação constitutiva que descreve o tensor de tensão para m-ésima fase sólida, $\overline{\bar{S}}_{S m}$, conforme Equação 41. As relações constitutivas resultantes contêm a m-ésima temperatura granula $\Theta_{m}$. A temperatura granular é proporcional à energia granular do contínuo, onde é definida como a energia cinética específica da componente flutuante aleatória da velocidade da partícula, conforme Equação 42.

$$
\begin{aligned}
& \frac{3}{2} \Theta_{m}=\frac{1}{2}\left\langle C_{m}^{2}\right\rangle, \vec{c}_{m}=\vec{v}_{s m}+\vec{C}_{m} \\
& \begin{aligned}
\frac{3}{2}\left(\frac{\partial}{\partial \mathrm{t}}\left(\varepsilon_{\mathrm{sm}} \rho_{\mathrm{sm}} \Theta_{m}\right)+\nabla \cdot\left(\varepsilon_{\mathrm{sm}} \rho_{\mathrm{sm}} \Theta_{m} \vec{v}_{\mathrm{sm}}\right)\right) \\
=\overline{\bar{S}}_{s m} \nabla \vec{v}_{\mathrm{sm}}-\nabla \cdot \vec{q}_{\Theta_{m}}-\vec{\gamma}_{\Theta_{m}}+\phi_{g m}+\sum_{\substack{l=1 \\
l \neq m}}^{M} \phi_{l m}
\end{aligned}
\end{aligned}
$$

$$
\begin{aligned}
\frac{3}{2} \frac{\partial}{\partial \mathrm{t}} \sum_{m=1}^{M}\left(\varepsilon_{\mathrm{sm}} \rho_{\mathrm{sm}} \Theta_{m}\right)+\frac{3}{2} \nabla \cdot \sum_{m=1}^{M}\left(\varepsilon_{\mathrm{sm}} \rho_{\mathrm{sm}} \Theta_{m} \vec{v}_{\mathrm{sm}}\right) \\
=\sum_{m=1}^{M}\left[\overline{\bar{S}}_{s m} \nabla \vec{v}_{\mathrm{sm}}-\nabla \cdot \vec{q}_{\Theta_{m}}-\vec{\gamma}_{\Theta_{m}}+\phi_{g m}+\sum_{\substack{l=1 \\
l \neq m}}^{M} \phi_{l m}\right]
\end{aligned}
$$




$$
\begin{gathered}
\Theta=\frac{\sum_{m=1}^{M}\left(\varepsilon_{\mathrm{sm}} \rho_{\mathrm{sm}} \Theta_{m}\right)}{\sum_{m=1}^{M}\left(\varepsilon_{\mathrm{sm}} \rho_{\mathrm{sm}}\right)}, \rho_{s}=\sum_{m=1}^{M}\left(\varepsilon_{\mathrm{sm}} \rho_{\mathrm{sm}}\right), \sum_{m=1}^{M}\left(\varepsilon_{\mathrm{sm}} \rho_{\mathrm{sm}} \Theta_{m}\right)=\rho_{s} \Theta \\
\mathrm{m}_{\mathrm{pm}} \Theta_{m}=\mathrm{m}_{\mathrm{pl}} \Theta_{l}, \rho_{\mathrm{sm}} \Theta_{m}=\frac{\rho_{s} \Theta}{d_{p m}^{3} \sum_{l=1}^{M}\left(\varepsilon_{\mathrm{sl}} / d_{p l}^{3}\right)} \\
\quad \sum_{m=1}^{M}\left(\varepsilon_{\mathrm{sm}} \rho_{\mathrm{sm}} \Theta_{m} \vec{v}_{\mathrm{sm}}\right)=\frac{\rho_{s} \Theta}{d_{p m}^{3} \sum_{l=1}^{M}\left(\varepsilon_{\mathrm{sl}} / d_{p l}^{3}\right)} \sum_{m=1}^{M}\left(\varepsilon_{\mathrm{sm}} \vec{v}_{\mathrm{sm}} / d_{p m}^{3}\right) \\
\vec{v}_{\mathrm{s}}=\frac{\sum_{m=1}^{M}\left(\varepsilon_{\mathrm{sm}} \vec{v}_{\mathrm{sm}} / d_{p m}^{3}\right)}{\sum_{l=1}^{M}\left(\varepsilon_{\mathrm{sl}} / d_{p l}^{3}\right)}, \sum_{m=1}^{M}\left(\varepsilon_{\mathrm{sm}} \rho_{\mathrm{sm}} \Theta_{m} \vec{v}_{\mathrm{sm}}\right)=\rho_{s} \Theta \vec{v}_{\mathrm{s}}
\end{gathered}
$$

Portanto, a equação de energia granular média torna-se a Equação 43.

$$
\begin{aligned}
& \frac{3}{2}\left(\frac{\partial}{\partial \mathrm{t}}\left(\rho_{s} \Theta\right)+\nabla \cdot\left(\rho_{s} \Theta \vec{v}_{\mathrm{s}}\right)\right) \\
& =\sum\left[\overline{\bar{S}}_{s m} \nabla \vec{v}_{\mathrm{sm}}-\nabla \cdot \vec{q}_{\Theta_{m}}-\vec{\gamma}_{\Theta_{m}}+\phi_{g m}+\sum_{\substack{l=1 \\
l \neq m}}^{M} \phi_{l m}\right] \\
& \Theta_{m}=\frac{\rho_{s} \Theta}{\rho_{\mathrm{sm}} d_{p m}^{3} \sum_{l=1}^{M}\left(\varepsilon_{\mathrm{sl}} / d_{p l}^{3}\right)}
\end{aligned}
$$

A implementação do MFIX assume que a energia granular é dissipada localmente, negligenciando as contribuições de convecção e difusão, e mantendo apenas os termos de geração e dissipação. Desta forma, a equação de energia granular algébrica resultante é conforme a Equação 44.

$$
\begin{aligned}
& \frac{3}{2}\left(\frac{\partial}{\partial \mathrm{t}}\left(\rho_{s} \Theta\right)+\nabla \cdot\left(\rho_{s} \Theta \vec{v}_{\mathrm{s}}\right)\right) \\
& =\sum\left[\overline{\bar{S}}_{s m} \nabla \vec{v}_{\mathrm{sm}}-\nabla \cdot \vec{q}_{\Theta_{m}}-\vec{\gamma}_{\Theta_{m}}+\phi_{g m}+\sum_{\substack{l=1 \\
l \neq m}}^{M} \phi_{l m}\right] \\
& \Theta_{m}=\frac{\rho_{s} \Theta}{\rho_{\mathrm{sm}} d_{p m}^{3} \sum_{l=1}^{M}\left(\varepsilon_{\mathrm{sl}} / d_{p l}^{3}\right)} \\
& \Theta_{m} \\
& =\left[\frac{-K_{1 m} \varepsilon_{s m} t r\left(\overline{\bar{D}}_{s m}\right)}{2 \varepsilon_{s m} K_{4 m}}\right. \\
& \left.+\frac{\sqrt{K_{1 m}^{2} \operatorname{tr}^{2}\left(\overline{\bar{D}}_{s m}\right) \varepsilon_{s m}^{2}+4 K_{4 m} \varepsilon_{s m}\left(K_{2 m} t r^{2}\left(\overline{\bar{D}}_{s m}\right)+2 K_{3 m} t r\left(\overline{\bar{D}}_{s m}^{2}\right)\right)}}{2 \varepsilon_{s m} K_{4 m}}\right]^{2}
\end{aligned}
$$




$$
K_{4 m}=\frac{12\left(1+e_{m m}^{2}\right) \rho_{\mathrm{sm}} g_{0 m m}}{d_{p m} \sqrt{\pi}}
$$

A equação de energia granular para a m-ésima fase sólida, contém o termo q descrevendo o fluxo difusivo da energia granular, conforme a e.

$$
\begin{aligned}
& \vec{q}_{\Theta_{m}}=-k_{\Theta_{m}} \nabla \Theta_{m} \\
& \begin{array}{c}
k_{\Theta_{m}}=\frac{15 d_{p m} \varepsilon_{\mathrm{sm}} \rho_{\mathrm{sm}} \sqrt{\pi \Theta_{m}}}{4(41-33 \eta)}\left[1+\frac{12}{5} \eta^{2}(4 \eta-3) \varepsilon_{\mathrm{sm}} g_{0 m m}\right. \\
\left.\quad+\frac{16}{15 \pi}(41-33 \eta) \eta \varepsilon_{\mathrm{sm}} g_{0 \mathrm{~mm}}\right]
\end{array} \\
& \eta=\frac{1}{2}\left(1+e_{m m}\right)
\end{aligned}
$$

O termo $\gamma_{\Theta_{m}}$ representa a taxa de dissipação de energia granular dentro da fase m-ésima de sólidos devido a colisões entre as partículas que constituem o contínuo, representado conforme a Equação 46. $\mathrm{O}$ termo $\phi_{g m}$ representa a transferência de energia granular entre a fase fluida e a fase sólida. Fisicamente, isto representa a transferência para a fase fluida da energia cinética de flutuações aleatórias na velocidade da partícula, conforme a Equação 46.

$$
\begin{aligned}
& \gamma_{\Theta_{m}}=K_{4 m} \varepsilon_{s m}^{2} \Theta_{m}^{\frac{3}{2}} \\
& \phi_{g m}=-3 F_{g m} \Theta_{m} \\
& \phi_{1 m}=0
\end{aligned}
$$

\subsubsection{Planejamento e especificação de modelo}

A especificação da simulação no MFIX segue, de forma geral, a seguinte sequência de parametrização:

- Controle da execução: Especifica nome da execução, descrição, sistema de unidade, o tipo de execução, tempo de simulação, passo de tempo, equações governantes, modelo de turbulência e modelo de arrasto.

- Físicos: Pressão de referência no domínio, valor da aceleração da gravidade e componente da aceleração gravitacional, coeficiente de elasticidade.

- Numéricos: Definem os tipos de solvers, o tipo de discretização para cada tipo de variável, número de iterações e limites para resíduos.

- Geométricos: Definem o tipo de coordenada, a relação dimensão e quantidade de células, métodos para representação geométrica do domínio, tolerâncias entre interseções de células.

- Fase gás: Especifica propriedades da fase gás.

- Fase de sólidos: Especifica propriedades da fase sólida.

- Condições iniciais/fronteira: Estabelece as condições iniciais e fronteiras para o domínio, parede, etc. 
- Funções definidas pelo usuário: Estabelece uma via para que o usuário implemente correções nos modelos ou novas funções não implementadas pela biblioteca nativa do MFIX.

- Controle de processamento paralelo: especifica como o problema de soluções das equações podem ser decompostas para reduzir o tempo da solução.

O tipo de execução é uma parâmetro importante para informar ao compilador se a simulação está começando (desconsiderando dados históricos) ou se está continuando (deve iniciar a partir de dados históricos), permitindo a fragmentação da simulação. O passo de tempo e especificações máximas e mínimas são importantes parâmetros para a convergência dos cálculos. Como esta coluna LFC é fria, as equações de energia e espécie são desligadas. Para a formulação da tensão granular é aplicado a formulação de energia granular algébrica e fluxo granular viscoso. Um modelo de arrasto de Wen Yu é especificado para tratar a interface fluido-partícula, conforme a Figura 32. Esta seção também especifica as chamadas para sub-rotinas (CALL_USR), conforme será comentada posteriormente.

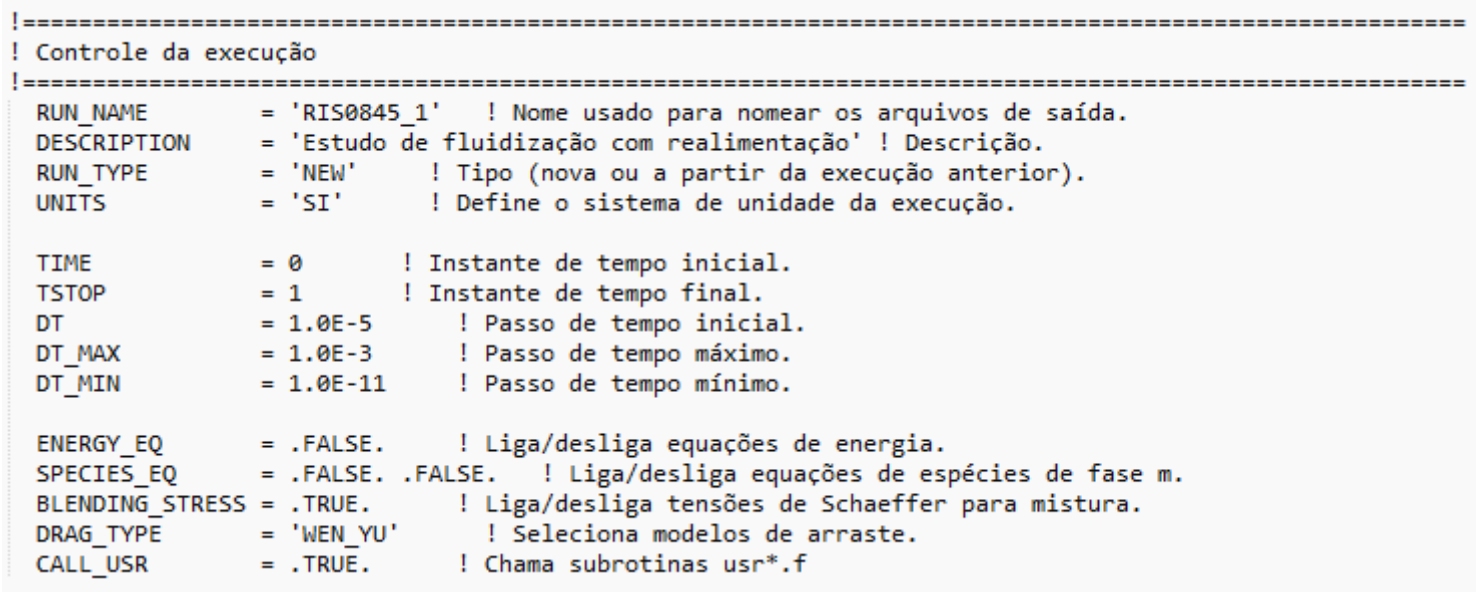

Figura 32 - Trecho do código com o controle de parâmetros de execução aplicados na simulação de coluna LFC fria.

Dentre os parâmetros físicos estão as especificações dos coeficientes de restituição para colisões partícula-partícula, o coeficiente de especularidade entre partícula-parede usado no cálculo de escorregamento parcial e aceleração da gravidade, conforme a Figura 33.

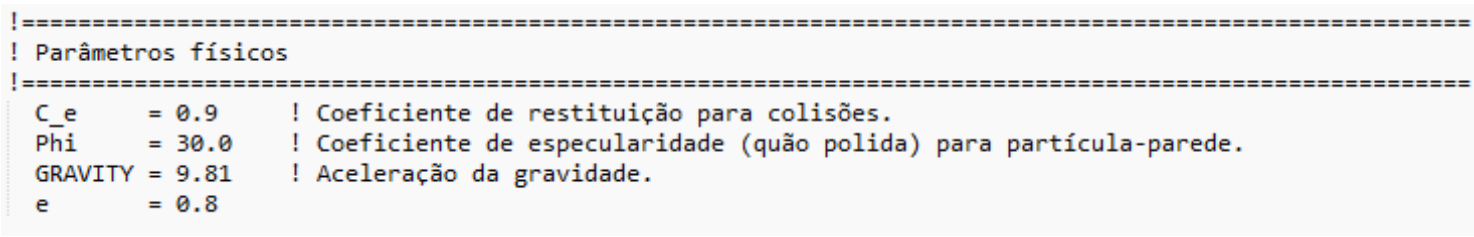

Figura 33 - Trecho do código com os parâmetros físicos da simulação de coluna LFC fria.

Um dos parâmetros geométricos comumente especificados em simulações numéricas multifásicas é o formato da malha e sua quantidade. O MFIX trabalha apenas com malhas ortogonais cartesianas ou cilíndricas. Com base nos resultados de Li et al. [130], o critérios adotados para a dimensão da malha 
considerada fina, foi de, no mínimo, 10 vezes o diâmetro da partícula (partícula considerada é de 400 $\mu \mathrm{m}$, portanto, $4 \mathrm{~mm}$ ) e passos de tempo de $0,1 \mathrm{~ms}$, conforme a Figura 34. Os estudos de Li et al. [130] mostraram que o critério apresentou boa concordância com dados experimentais no que tange a queda de pressão, fluxos de sólidos axiais e radiais.

Outro ensaio, também verificado por Li et al. [130], em colunas LFC fria, 3D, transiente, com malha circulante, foi a diminuta contribuição do modelo de turbulência na simulação, para o estudo da flutuação de pressão estática. A razão deste último, é que para o fluxo gás-sólido denso considerado, a turbulência da fase gasosa não é a preocupação principal quando as colisões entre partículas dominam o fluxo e, portanto, nenhum modelo de turbulência é usado [130].

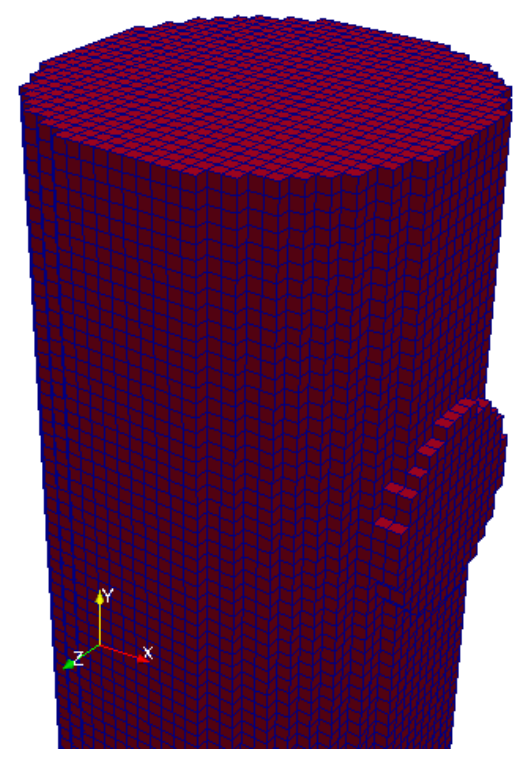

Figura 34 - Malha ortogonal cartesiana de $4 \mathrm{~mm}$ aplicada em domínio de coluna LFC. Perspectiva da saída da coluna.

Para especificar a quantidade de malha cartesiana de um domínio no MFIX, deve-se especificar a relação entre a dimensão física e a quantidade de partições em determinada direção. Portanto, se a direção y possuir 1,1 m (YLENGTH=1,1) particionadas em 275 partes (JMAX=275), nessa direção cada célula terá $4 \mathrm{~mm}(1,1 \mathrm{~m} \div 275$ partes). Este procedimento é definido para as direções restantes gerando a presente malha cúbica de $4 \mathrm{~mm}$ de lado, conforme a Figura 35.

Outra importante definição nos parâmetros geométricos do domínio é a especificação das fronteiras ora parede, ora superfícies de entrada ou saída. A construção geométrica desta coluna utiliza superfícies quádricas para delimitar as fronteiras do domínio. Portanto, foram especificadas três formas cilíndricas (QUADRIC_FORM) para representar o corpo da coluna, a entrada circulante e a saída (vide Figura 35). As quádricas precisam ser indexadas (GROUP_Q), ter suas origens posicionadas (T_X, T_Y e T_Z) e suas dimensões especificadas (raio e altura), conforme as palavras-chave indicadas na Figura 35. O relacionamento entre as quádricas precisa der definido através do comando GROUP_RELATION para formação de uma única peça. Alguns parâmetros de tolerância garantem a conformidade dos limiares estarem fechados. Por fim, o parâmetro FLUID_IN_CLIPPED_REGION é destinado para informar se as células internas as superfícies fechadas, representarão os fluidos interpenetrantes (vede Figura 35). 


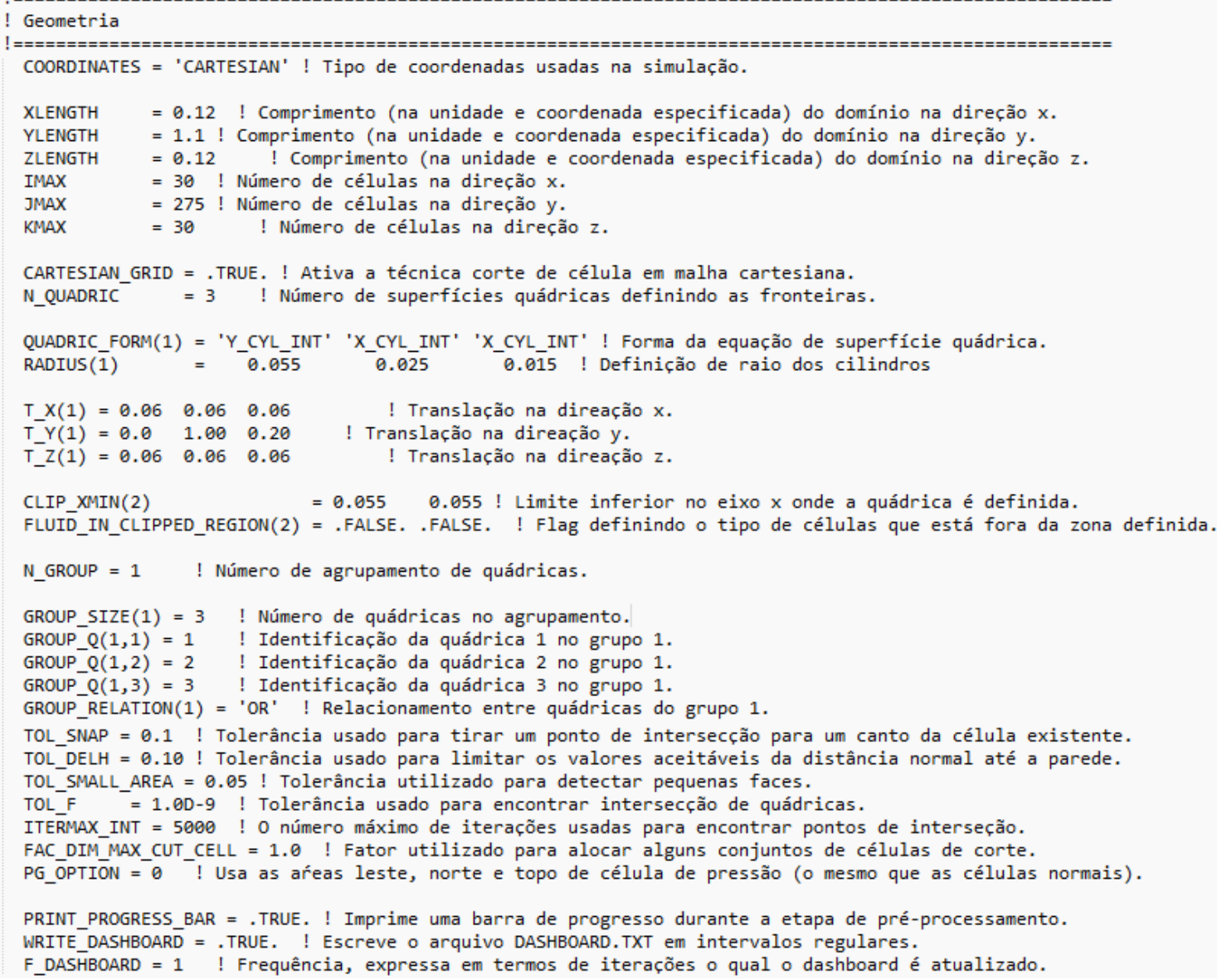

Figura 35 - Trecho do código com os parâmetros geométricos para simulação de coluna LFC fria.

A Figura 36 trata das especificações da fase fluida definindo a viscosidade específica do gás, condutividade térmica, calor específico e peso molar do ar $\left(21 \%\right.$ de $\mathrm{O}_{2}$ e $79 \%$ de $\left.\mathrm{N}_{2}\right)$, no sistema internacional.

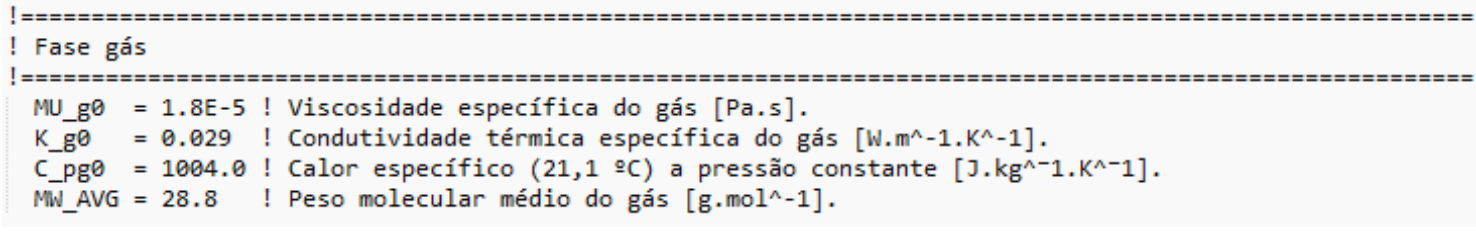

Figura 36 - Trecho do código com as especificação de parâmetros da fase gás da simulação multifásica.

A Figura 37 trata das especificações da fase sólida definindo o número de fases sólidas, o diâmetro das partículas, a massa específica de cada partícula, condutividade térmica, calor específico e fração de vazios, considerando o sistema internacional. 


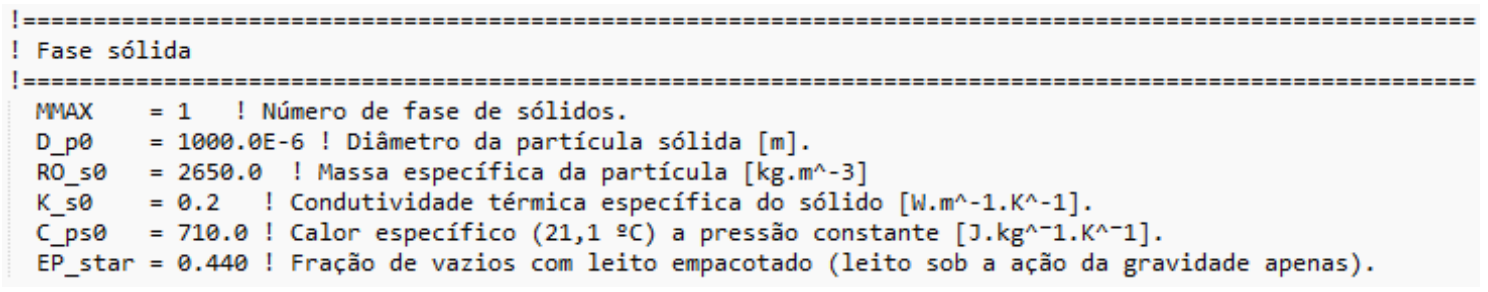

Figura 37 - Trecho do código com as especificações de parâmetros da fase sólida da simulação multifásica.

\subsubsection{Técnicas numéricas e discretização}

Para acelerar o código, sua técnica numérica aplica um esquema semi-implícito que usa o ajuste automático do tempo-passo. O MFIX usa o método SIMPLE (SemiImplicit Method for Pressure Linked Equations) com modificações para melhorar a estabilidade e a velocidade dos cálculos. Uma destas melhorias é o uso de equação de correção de fração de volume de sólidos (em vez de uma equação de correção de pressão de sólidos), ajudando na convergência quando os sólidos estão ligeiramente comprimidos. Essa equação também incrementa efeitos na pressão de sólidos, ajudando a estabilizar os cálculos em regiões densamente compactadas. Outra melhoria é o ajuste automático do tempo-passo para assegurar que o funcionamento progrida com a velocidade de execução a mais elevada.

O MFIX trabalha com nove tipos de discretização de equações independente, ou seja, cada tipo de equação pode ter sua própria discretização, conforme abaixo:

- $\quad$ First-order upwinding [0];

- First-order upwinding (usando fatores down-wind) [1];

- Smart [2];

- Superbee [3];

- QUICKEST [4];

- ULTRA-QUICK [5];

- $\quad$ van Leer [6];

- MUSCL [7];

- $\operatorname{minmod}[8]$;

A característica de cada método não será discutida, pois exaustivos trabalhos [174] [175] [176] já o fizeram. O método Smart [2] foi utilizado e validado, atendo a requisitos de estabilidade numérica, precisão, nas condições de leito fluidizado.

O MFIX trabalha com dez tipos de equações indexadas. As equações de pressão de gás trabalha com o índice 1, enquanto o sequencia restante são: as equações de fração de volume de sólidos [2], equações de momento orientadas em $\mathrm{U}$ para fases fluidas e sólidas [3], equações de momento orientadas em $\mathrm{V}$ para fases fluidas e sólidas [4], equações de momento orientadas em W para fases fluidas e sólidas [5], equações de energia (temperatura) para fases fluidas e sólida [6], frações de massa para espécies sólidas fluidas e sólidas [7], temperatura granular [8], funções definidas pelo usuário [9] e equações de difusão [10].

A Figura 38 apresenta os parâmetros numéricos usados nesta implementação de coluna LFC fria. O parâmetro DISCRETIZE $=9 * 2$ informa que entre os dez tipos de equação citadas, nove são discretizadas usando o método Smart [2]. O tipo de solver utilizado para solucionar os nove tipos de equação é o gradiente conjugado [5]. Os parâmetros restantes foram sintonizados nos informações recomendadas pelo suporte MFIX. 


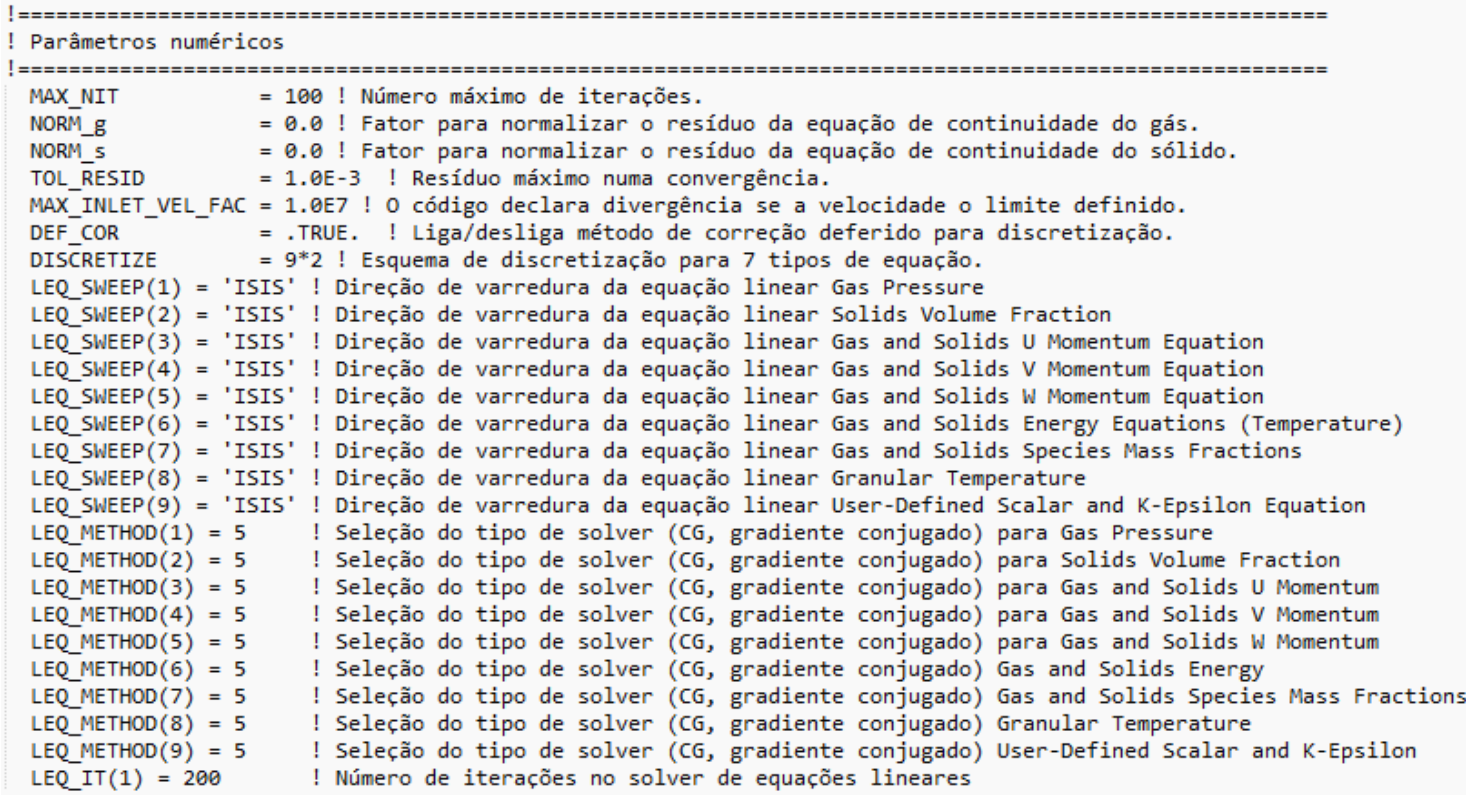

Figura 38 - Trecho do código com os parâmetros numéricos para simulação de coluna LFC fria.

\subsubsection{Condições iniciais e de fronteira}

As variáveis de campo $\left(P_{g, s}, T_{g, s}, \vec{v}_{g, s}\right.$, etc. $)$ necessitam de definição de valores inicias em todo o domínio computacional. Para que haja convergência, os valores das condições iniciais devem ser estabelecidos com alguma precisão.

A Figura 39, apresenta a especificação das condições iniciais de leito. O nível de leito foi de $8 \mathrm{~cm}$ (IC_Y_N(1)=0,08), com porosidade inicial de leito empacotado de 0,44 , temperatura inicial de $19{ }^{\circ} \mathrm{C}$ (293,0 K), velocidade inicial das fases fluida e sólida no leito são de $0,0 \mathrm{~m} / \mathrm{s}$ e pressão estática atmosférica (101.325 Pa). A especificação de condições iniciais é indexada e atribuída a uma região delimitada pela faixa estabelecida em cada direção. Assim, na direção x, a região de condição inicial 1 é delimitada pela face oeste posicionada em 0,0 (IC_X_W=0,0) até a face leste posicionada em $0,12 \mathrm{~m}$ (IC_X_E=0,12). A especificação em cada direção, define a condição inicial de uma determinada região, conforme a Figura 39. 


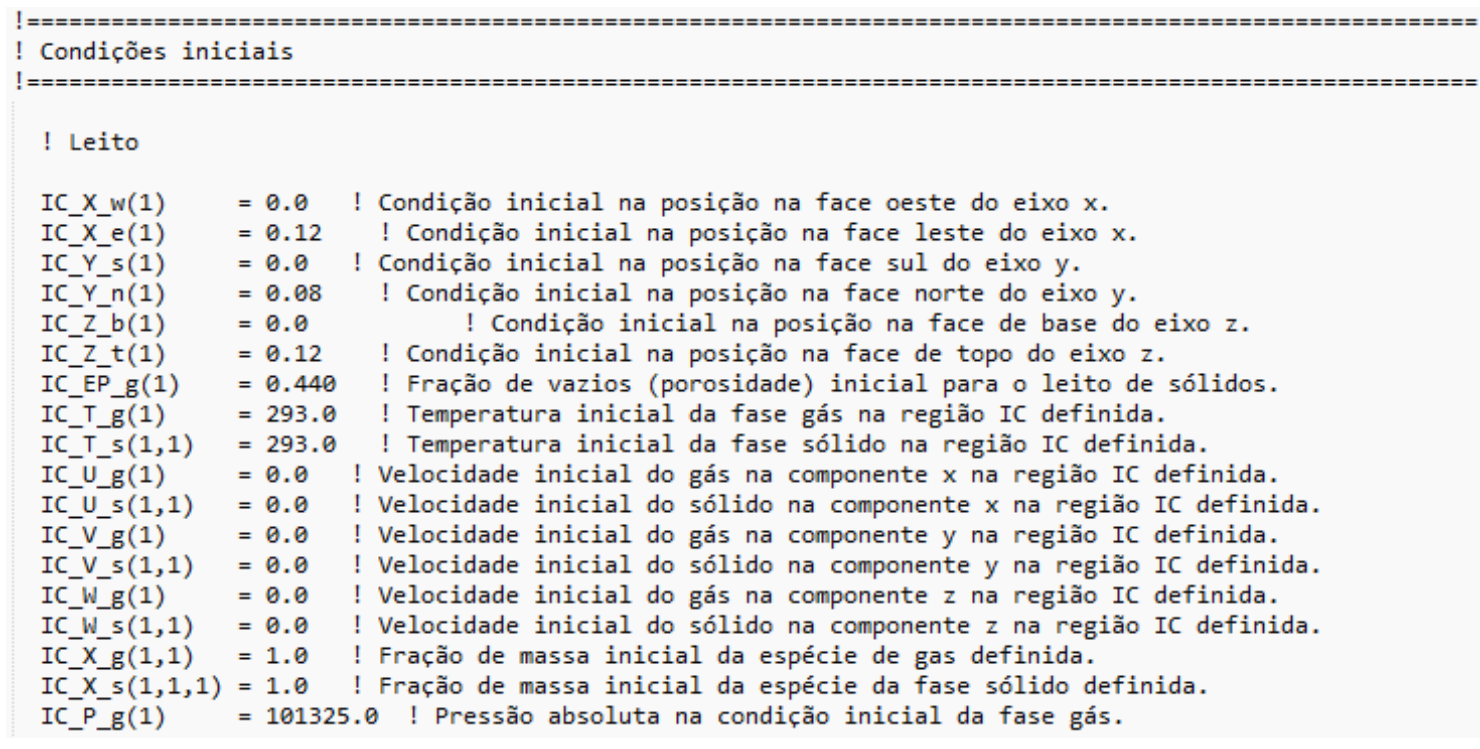

Figura 39 - Trecho do código com as condições iniciais de leito para a coluna LFC.

As mesmas definições aplicadas na Figura 39 são válidas para Figura 45. Contudo, as regiões de condições iniciais não podem interceder entre si. Portanto, o limiar de altura de nível de leito é utilizado para definir o começo do bordo livre. A região de bordo livre (região 2) contém apenas ar parado, a pressão e temperaturas atmosféricas, conforme indicado pelas palavras-chave da Figura 40.

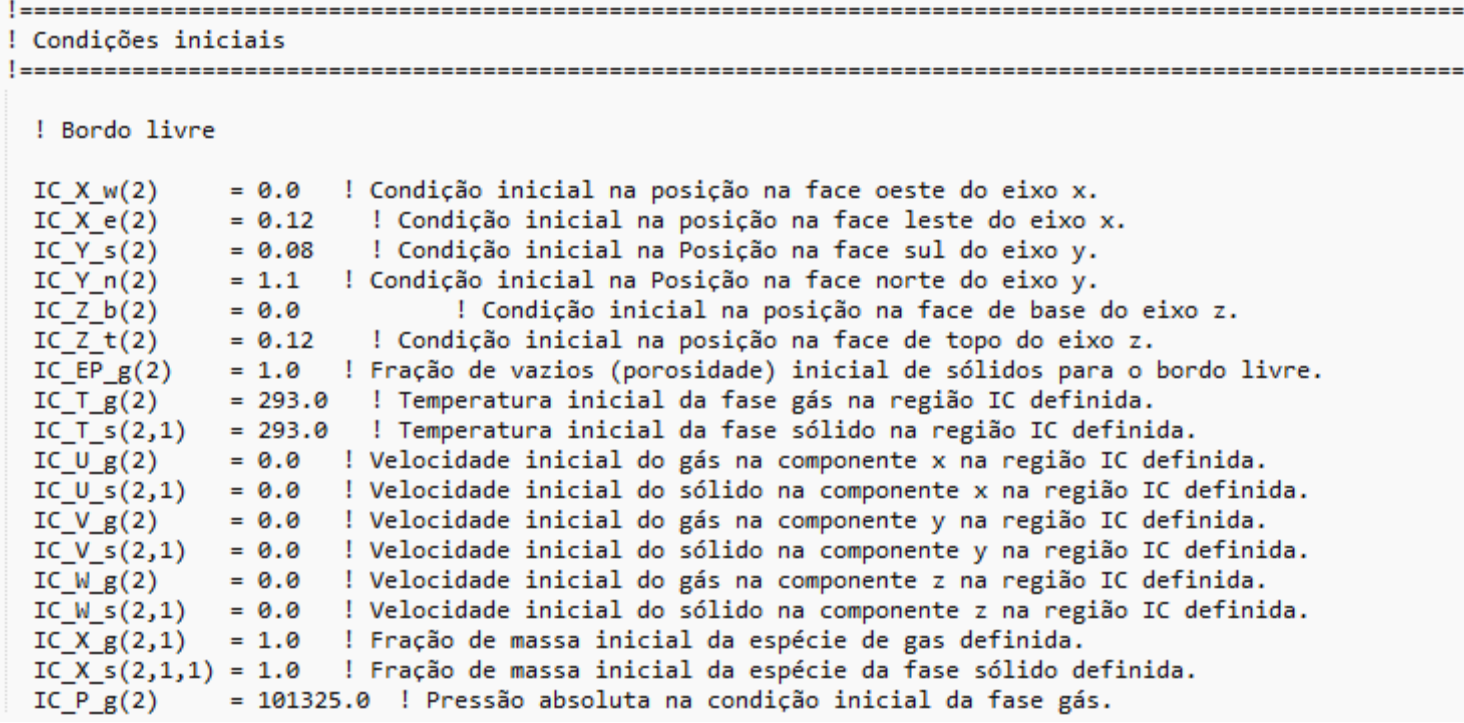

Figura 40 - Trecho do código com as condições iniciais de bordo livre para a coluna LFC.

Geralmente, as definições de uma simulação multifásica convencional encerram-se com as especificações das condições de fronteira ou de contorno. Como esta simulação trabalha com funções definidas pelo usuário, discutida no item posterior, excede, portanto, as definições convencionais. A Figura 41 apresenta as palavras-chave utilizadas para definir uma superfície, na base da coluna LFC, por onde o ar entra (BC_TYPE(1)='MI', mass inflow) na coluna com uma velocidade inicial. A superfície é definida a partir dos limiares das direções x e z (BC_X_W, BC_X_E, BC_Y_S e BC_Y_N) 
direção y nula (BC_Z_B e BC_Z_T), conforme a Figura 41. Uma consideração que vale ser mencionada é que a superfície de distribuição do campo de velocidade do ar de entrada é uniforme. Como só existe ar no bordo livre a fração de vazios é unitária $\left(B C \_E P \_g(1)=1,0\right)$. A velocidade inicial da fase gás (BC_V_G(1)) é um parâmetro que pode mudar para investigar diferentes regimes de fluidização desenvolvidos em cada tipo de leito.

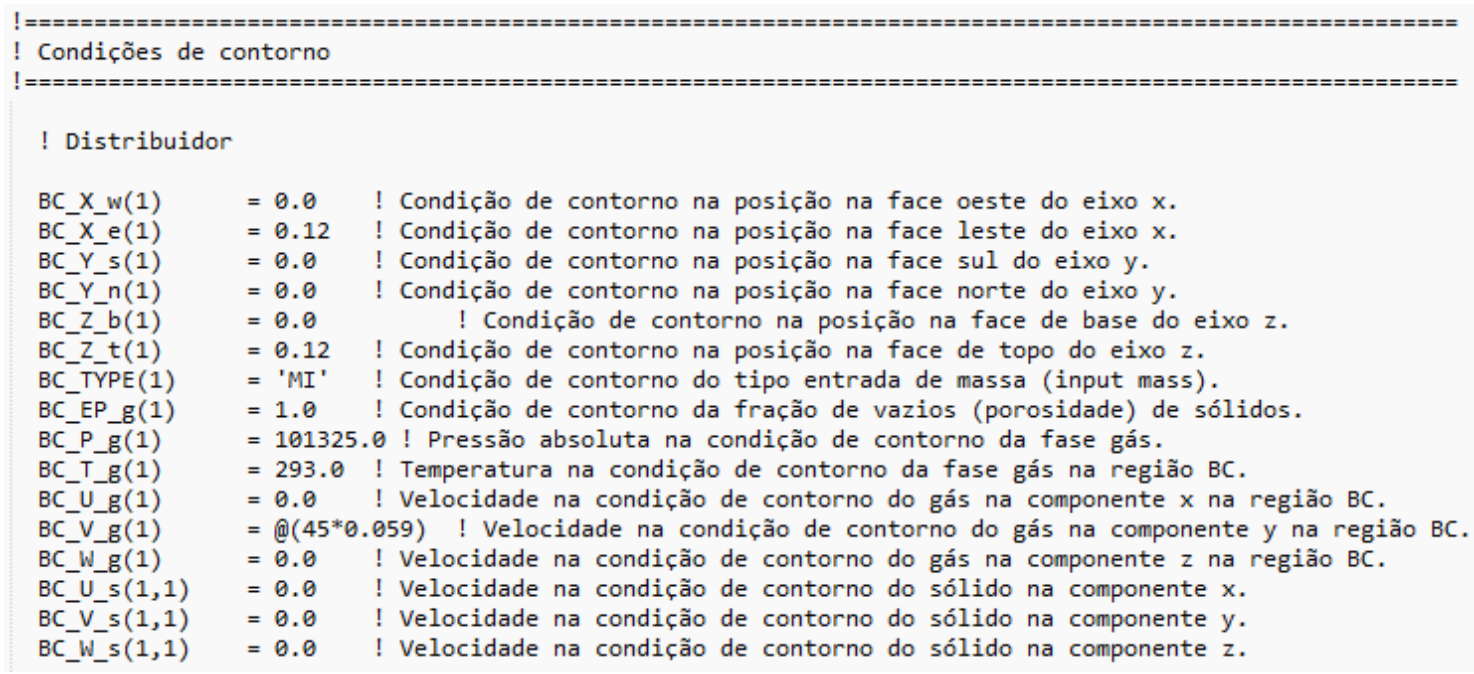

Figura 41 - Trecho do código com as condições de contorno para o distribuidor da coluna LFC fria.

Para definir a saída da coluna (conforme mostrado na Figura 34), uma superfície de saída deve ser posicionada sobre a superfície de saída do domínio. Esta superfície de saída (superfície 2) é classificada como do tipo PO (pressure output), onde a pressão externa é definida como a atmosférica (BC_P_G), conforme indicado pela Figura 42.

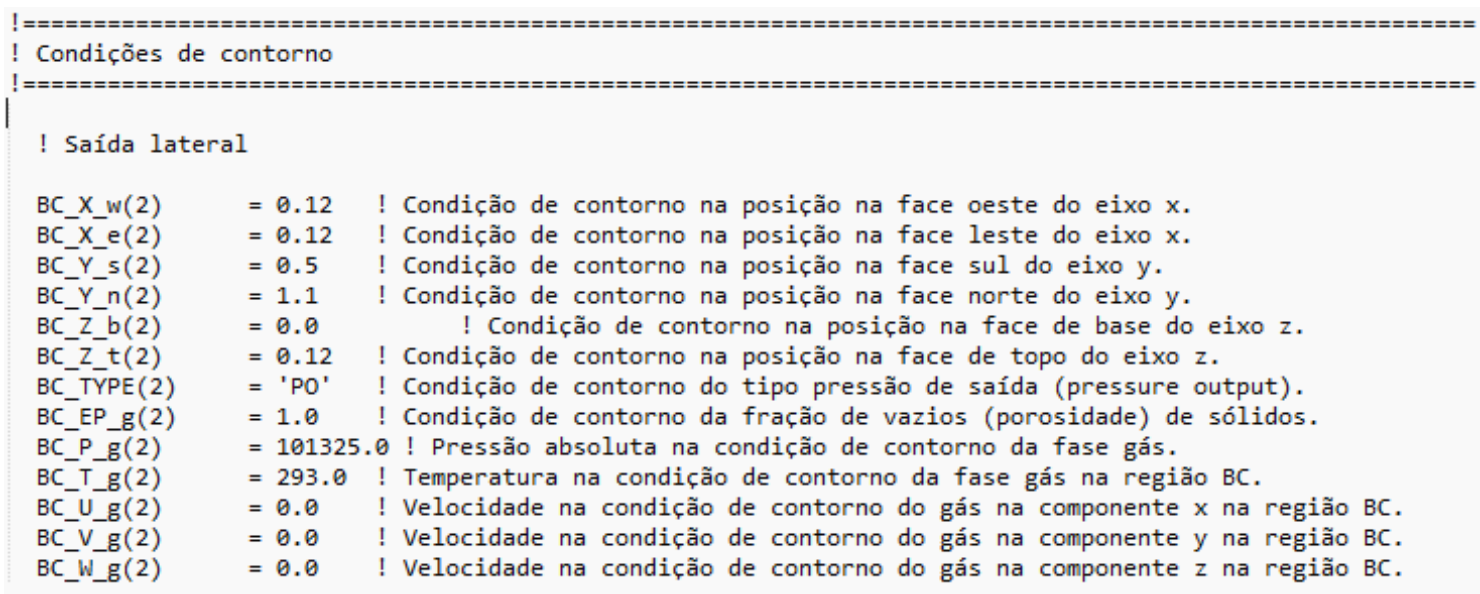

Figura 42 - Trecho do código com as condições de contorno para a saída lateral da coluna LFC fria.

Outra importante superfície definida é a de entrada lateral, responsável pelo retorno do material que foi arrastado para fora da coluna. Esta superfície, indexada como 3, é classificada como do tipo MI (mass 
inflow) e, preliminarmente, é definida condições de entrada de velocidade nula e fração de vazios iniciais de 0,440 , pois uma função definida pelo usuário será responsável em compensar, dinamicamente, os sólidos arrastados para fora da coluna, conforme indicado no trecho do código da Figura 43.

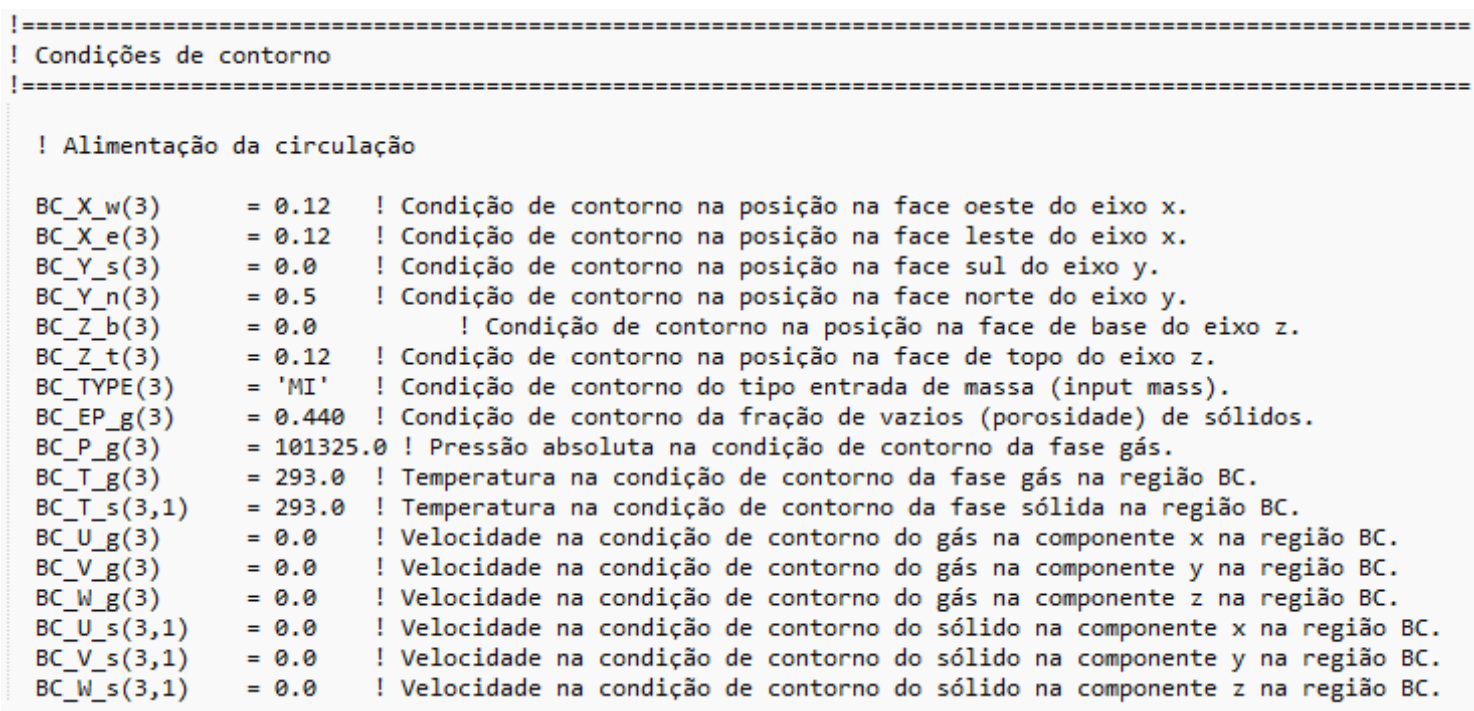

Figura 43 - Trecho do código com as condições de contorno para a entrada lateral da coluna LFC fria.

Para encerrar as definições de parede no domínio, a Figura 44 apresenta um trecho de código em que uma nova superfície 4 é criada, estabelecendo o topo da coluna LFC como um tipo parede com escorregamento parcial (BC_TYPE(4)='PSW'). Para definir o comportamento do escorregamento para cada fase, para essa parede, foi estabelecido o livre escorregamento para a fase sólida (BC_UW_S, BC_VW_S e BC_WW_S iguais a 0) e nenhum escorregamento para a fase gasosa (BC_UW_G, BC_VW_G e BC_WW_G iguais a 0), conforme indicado na Figura 44.

Até agora as superfícies laterais dos três cilindros usados para compor a coluna LFC não foram definidas como parede. Como são quádricas, foram definidas do tipo parede com escorregamento parcial para fases através do parâmetro BC_TYPE(10) = 'CG_PSW' 'CG_PSW' 'CG_PSW'. Para definir o comportamento do escorregamento para cada fase, para as superfícies laterais das quádricas, foi estabelecido o livre escorregamento para a fase sólida (BC_UW_S, BC_VW_S e BC_WW_S iguais a 0,0 0,0 0,0) e nenhum escorregamento para a fase gasosa (BC_UW_G, BC_VW_G e BC_WW_G iguais a 0,0 0,0 0,0), conforme indicado na Figura 44. 


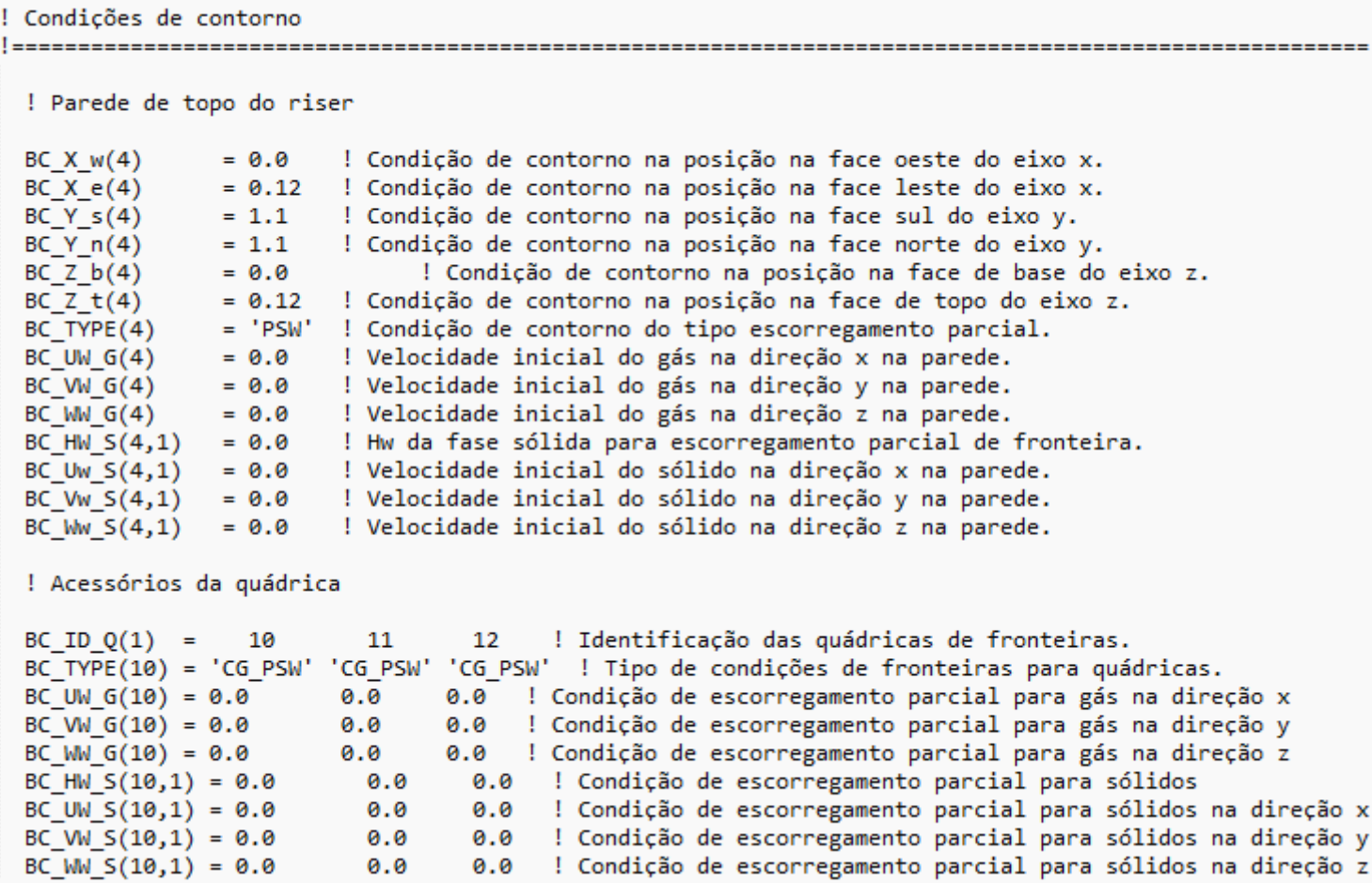

Figura 44 - Trecho do código com as condições de contorno no topo da coluna LFC fria e condições de escorregamento para as fases gás e partícula.

\subsubsection{Malha circulante}

Considerando leitos frios (sem reações químicas), os fluidizados circulante distinguem-se dos fluidizados por permitir a conservação do inventário de massa e consequente sustentação dos regimes turbulento, rápido e transporte. A particularidade desta simulação multifásica é a aproximação considerada para o efeito circulante e preservação do inventário de massa. Para simular uma coluna circulante deve haver um separador da mistura gás-sólido e um sistema de injeção de sólidos de volta para a coluna (vide Figura 45). Geralmente, um ciclone é usado como separador, enquanto válvulas não mecânicas como as válvulas $\mathrm{J}$ e $\mathrm{L}$, cumprem o propósito de selar e reinjetar os sólidos de volta para a coluna. Uma simulação do sistema de leito fluidizado circulante com ciclone e válvula $\mathrm{L}$, por exemplo, aumentaria, consideravelmente, o número de células do domínio, onerando o tempo de simulação. Uma proposta alternativa e simplificadora, aqui proposta, visa implementar o efeito de circulação auxiliada pelo algoritmo, conforme a Figura 45. A cada instante de tempo, um algoritmo deve contabilizar a quantidade de sólidos arrastados para fora da coluna por unidade de área. Em seguida, o fluxo contabilizado de saída é usado como fluxo da superfície lateral de entrada, garantindo a preservação do inventário de massa. Essa aproximação distingue-se de uma malha circulante real em dois pontos: o atraso de tempo entre a saída e retorno do inventário de massa é negligenciado e a eficiência da separação da mistura gás-sólido é $100 \%$. Mesmo assim, a aproximação foi considerada satisfatória para estudos de queda de pressão uma vez que o atraso para unidade de escala laboratoriais são desprezíveis e que a eficiência de separação de um ciclone é maior do que $80 \%$. 


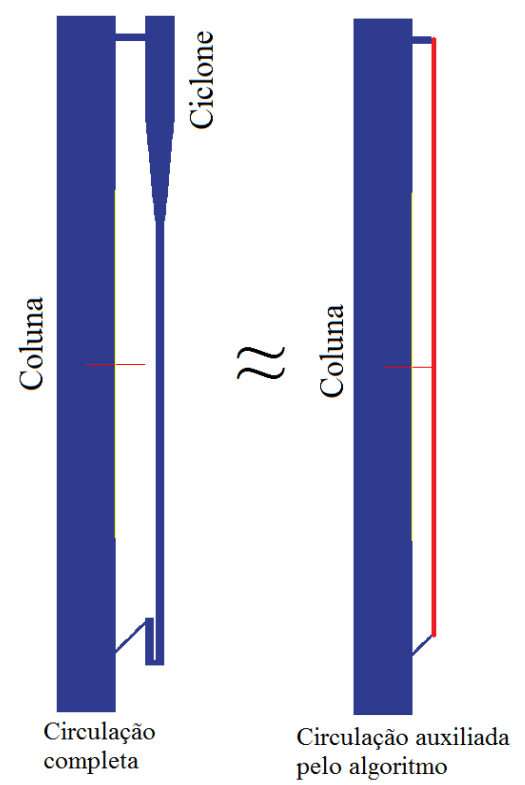

Figura 45 - Aproximação numérica implementada para o efeito circulante.

\subsubsection{Circulação auxiliada por algoritmo}

A implementação de uma função definida pelo usuário está prevista pelos desenvolvedores da biblioteca MFIX. Portanto, existem arquivos com nomes pré-determinados para serem usados para implementações personalizadas. A Figura 46 apresenta um fluxograma de execução de simulação no MFIX, evidenciado a sequência de chamada aos arquivos e se as funções são executadas por tempo ou iteração da simulação. A cada instante de tempo muitas iterações podem ocorrer. Portanto, a chamada usr.f foi usada por atender aos requisitos de compensação temporal, e não a cada iteração.

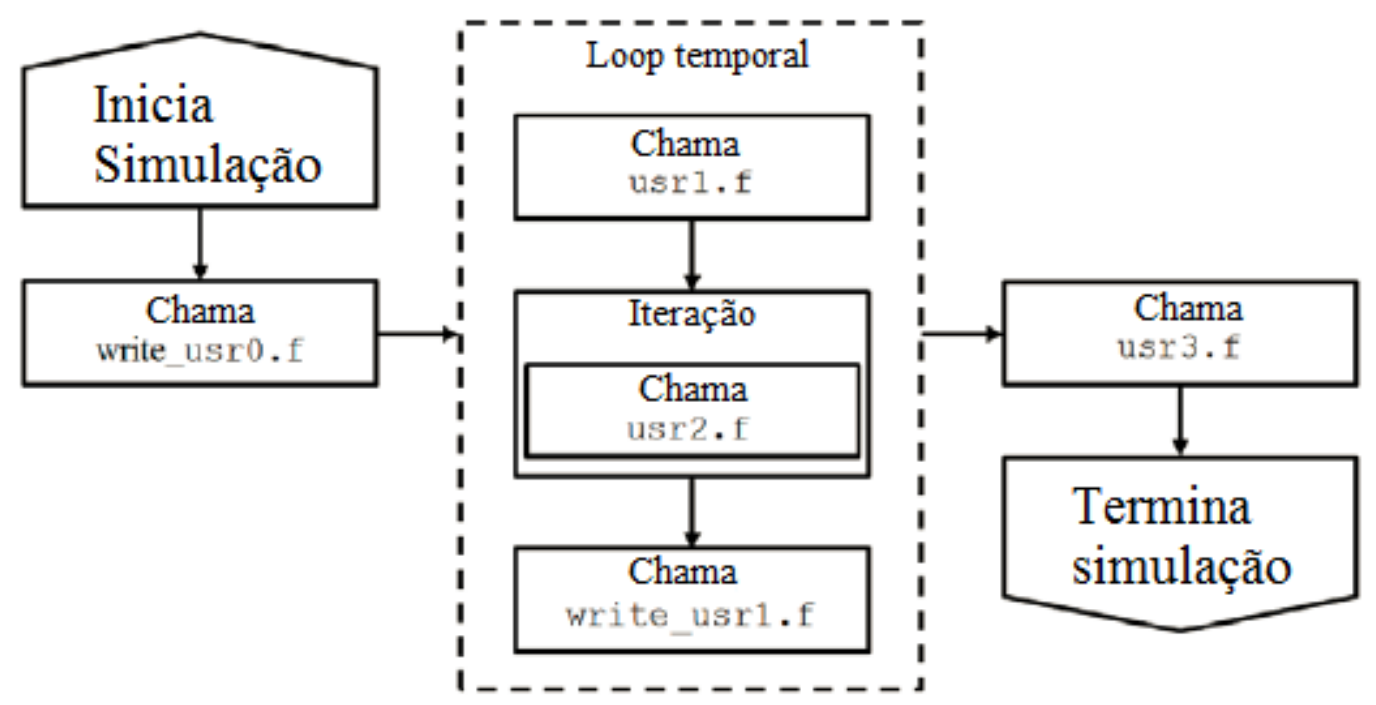

Figura 46 - Fluxograma de execução da simulação para uso de funções definidas pelo usuário. Adaptado de [175] 
A biblioteca também possui diversas variáveis prontas, como a massa instantânea do inventário, facilmente acessada pela função CALL get_smass. Quando a simulação MFIX inicia, o inventário de massa de referência é guardado numa variável INV_I. A cada instante, o trecho do código apresentado pela Figura 47, compara o inventário de massa instantâneo com o inventário de referência. Quando o inventário corrente for menor do que a referência (menor do que zero), a variável que ajusta a velocidade de sólidos na direção x, BC_U_S, divide a massa residual instantânea pela área da superfície de entrada lateral 3, reinjetando os sólidos de volta para a coluna. Para evitar que a velocidade dos sólidos ultrapasse limites físicos ou alcance valores não realizáveis uma condicionante limita a velocidade dos sólidos em $10 \mathrm{~m} / \mathrm{s}$. Para que os ajustes sejam efetuados a função set_bc0 é invocada, conforme apresentado na Figura 47.

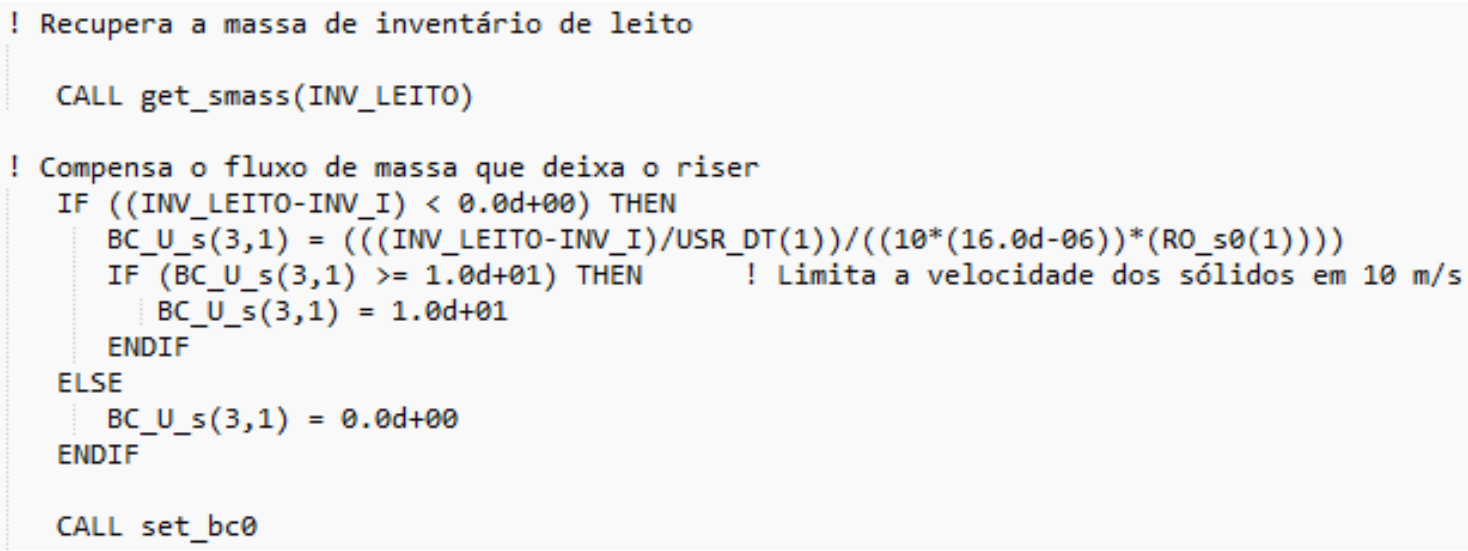

Figura 47 - Função definida pelo usuário para devolver o material arrastado para fora, de volta para a coluna.

Como resultado, a Figura 48 apresenta a comparação entre duas simulações. O gráfico da esquerda da Figura 48 apresenta o valor instantâneo de massa de uma coluna LFC fria, operando com leito turbulento. Esse regime promove arrasto suficiente para reduzir o inventário de massa com passar do tempo. Considerando um nível de 10\% $(11 \mathrm{~cm})$, e velocidade de entrada de ar constante para o desenvolvimento do regime turbulento, uma pequena taxa de arrasto é imposta à coluna (linha contínua quase horizontal do gráfico da esquerda da Figura 48), e após atingir um certo nível de perda, torna-se leve o suficiente para ser completamente arrastado. Portanto, o inventário de massa variável pode alterar o regime de fluidização, para uma mesma velocidade de entrada de ar. O efeito circulante é desejável, pois mantém o inventário constante, tornando o regime apenas função das propriedades do leito, geometria da coluna e da velocidade do ar de entrada. Este ensaio foi realizado para diferentes alturas de leito (20, 30, 40 e 50\% da altura de coluna), mantendo velocidade turbulenta constante, mostrando que o ponto em que um drástico arrasto modifica consideravelmente o inventário é deslocado para instante mais próximos do início da simulação (gráfico da esquerda da Figura 48).

Através da implementação da malha circulante, auxiliada pelo algoritmo (gráfico da direita da Figura 48), cessa-se a perda do inventário de massa. Pequenas flutuações foram detectadas, devido talvez, a compensação temporal perder informações em cada iteração. Contudo, essas flutuações são desprezíveis para estudo. A partir da implementação do efeito circulante é possível a realização de estudos de perdas de carga e flutuações dos sinais de pressão para instrumentação. 

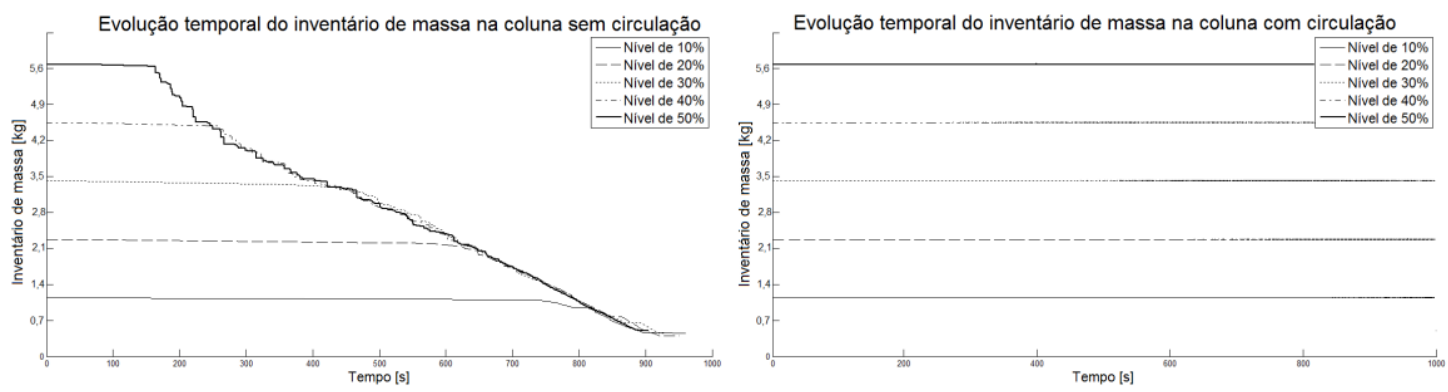

Figura 48 - Efeito circulante auxiliado por algoritmo mantém o inventário de massa constante.

A partir da implementação da simulação de coluna LFC fria é possível efetuar um planejamento definido: quantidade de simulações, condições operacionais e o pós-processamento das informações pertinentes ao projeto.

\subsubsection{Planejamento de armazenamento da simulação}

Uma simulação numérica, realizada por programa de código aberto, requer planejamento de armazenamento (storage) para gerenciar o pós-processamento. O tamanho do domínio, discretização, taxa de amostragem e a modelagem escolhida, definem o tamanho do arquivo de saída. Quando o código é comercial, a forma de gerenciamento dos arquivos já está embutida na solução. No TFM/MFIX, os arquivos de saída possuem a extensão .RES, e são fragmentados em diversos outros arquivos (.SPx) contendo suas respectivas variáveis de campo. O problema é quando a simulação gera arquivos de resultados maiores do que $4 \mathrm{~GB}$ e os softwares de pós-processamento não conseguem fazer sua leitura. Um dos propósitos desta simulação é a avaliação de perda de carga e avaliação da série temporal do sinal de pressão estático escolha de instrumentação adequados. Contudo, estas mesmas séries serão usadas para avaliação quantitativa do regime de fluidização através do cálculo de algumas invariantes do caos (entropia de Kolmogorov, coeficiente de Hurst, dimensão de correlação). Os cálculos destas variáveis, exigem um número mínimo do tamanho de amostras (> 15.000 amostras) para que seus estimadores mantenha a incerteza do cálculo abaixo de 1\%. Para garantir a precisão dos cálculos das invariantes foram usadas amostras de 17.000 dados. Como numericamente, a coluna LFC atingiu a estabilidade a partir dos três primeiros segundos (através de procedimentos de suavização e derivação), os dados a partir do tempo restante foram usados para avaliação. Então, o tempo de simulação numérica foi definido como $20 \mathrm{~s}$ e amostragem de $1 \mathrm{~ms}$. Contudo, o arquivo de resultado, para as condições apresentadas foram de 193 GB gerando problemas de pós-processamento devido a ultrapassagem do limite de 4 GB.

O atual estágio de desenvolvimento do MFIX só permite que o usuário fracione o tempo total de simulação em diversas simulações mais curtas. Para esta implementação, o MFIX trabalha com Flags que permitem reiniciar as simulações a partir de um histórico já simulado. Um script foi desenvolvido para fracionar o tempo máximo de simulação em pequenas simulações de curta duração, executando-a em sequência.

Conforme a Figura 49, o período de escrita das variáveis (amostragem) foi de $1 \mathrm{~ms}(0,001 \mathrm{~s})$. Para cada 20 s de simulação, numa determinada velocidade de entrada de ar, diversos arquivos de saída são gerados (incluindo as séries temporais em três regiões da coluna) totalizando 193 GB de dados fracionados por velocidade (ou regime). O tempo real para conclusão dos $20 \mathrm{~s}$ de simulação é foi de 16 dias, trabalhando com processamento paralelo de 8 threads. Os parâmetros RES_DT determina a taxa de amostragem que 
o arquivo de resultado é atualizado, conforme a Figura 49. O vetor de parâmetros SPX_DT guardam determinadas variáveis, conforme definidas no guia do usuário que acompanha as bibliotecas [175].

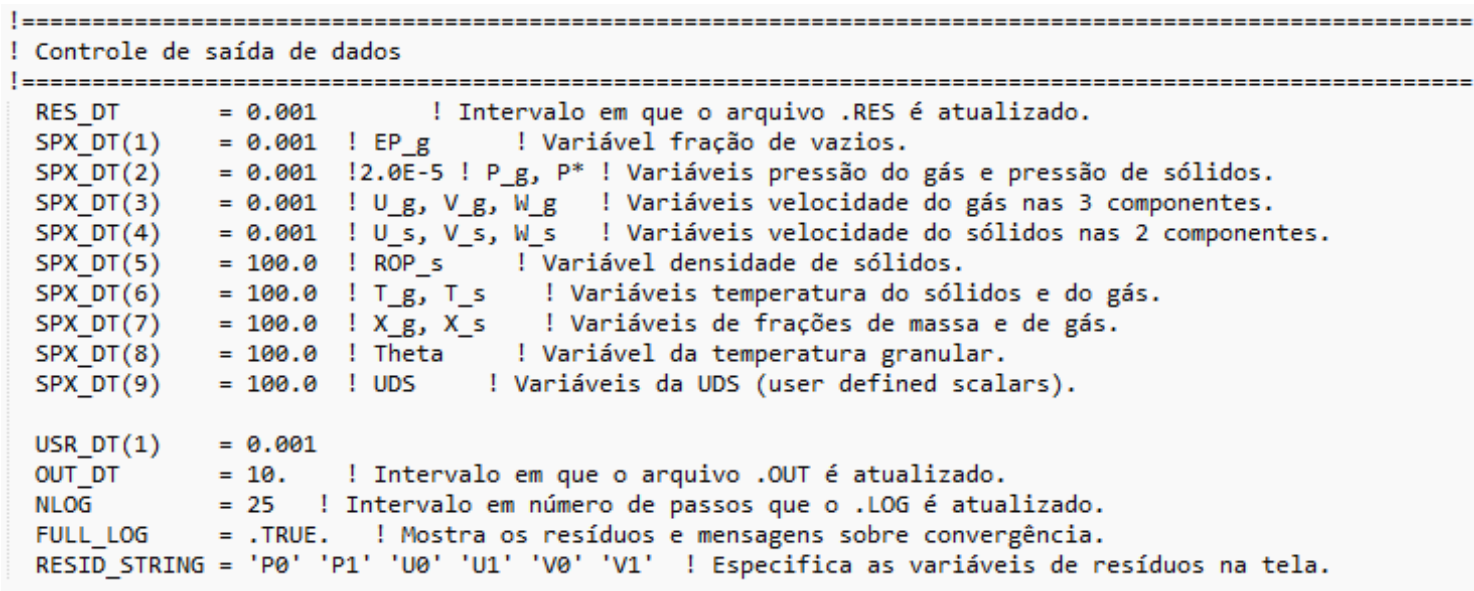

Figura 49 - Parâmetros de controle de saída de dados.

Um dos critérios para escolha do modelo TFM é o de seu solver suportar o cálculo paralelo. Uma vez que a decomposição (da direção de um acoplamento de malha) em todas as direções reduz a área de superfície da malha do processador ao volume, o custo de comunicação é reduzido para a mesma malha computacional. O desempenho paralelo é muito dependente do julgamento da correta combinação da direção de decomposição e a escolha de pré-condicionadores. O produto entre os parâmetros NODESI * NODESJ * NODESK, deve ser igual ao número de processadores especificados ou threads da CPU, conforme a Figura 50. A direção vertical foi escolhida para aplicação da decomposição nos cálculos.

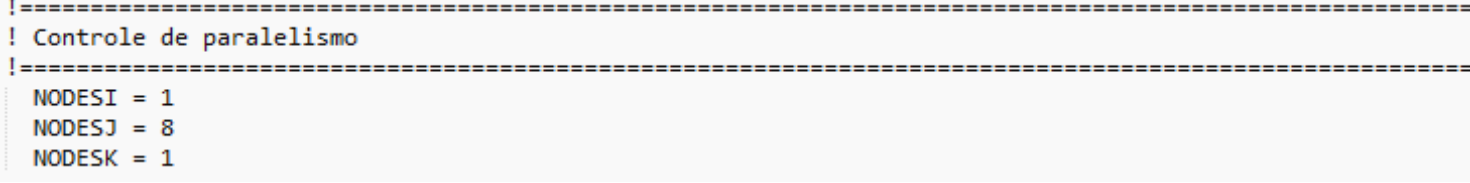

Figura 50 - Parâmetros de controle de paralelismo de soluções das equações.

\subsection{Ensaio em simulação}

O item anterior tratou da caracterização completa de simulação TFM gás-sólido para uma coluna LFC fria. A etapa seguinte, faz jus a definição de ensaios capazes de auxiliar no estudo de queda de pressão e levantamento das flutuações dos sinais de pressão estática, nos diversos regimes de fluidização.

O propósito desta simulação reside em avaliar o comportamento de variáveis como os perfis axiais de queda de pressão estática. O conhecimento prévio dos perfis de queda de pressão pode auxiliar na especificação do sistema de injeção de ar (especificando sua pressão e vazão) e os perfis de pressão estática pode auxiliar na especificação de instrumentação adequada a realizada da medida.

Numericamente, o leito foi excitado por diferentes condições iniciais de velocidade de entrada de ar num período de simulação de curta duração $(6 \mathrm{~s})$, para obtenção de resultados mais rápidos 
(aproximadamente 4 dias em processamento paralelo). As características numéricas das partículas que fizeram parte do ensaio foram as de 1,0 mm de diâmetro, semelhante a areia do grupo B de Geldart. Com base nos parâmetros de velocidade de mínima fluidização e velocidade terminal foi estabelecido uma faixa de velocidades iniciando por um quarto do valor de mínima fluidização (para haver resolução entre os regimes expandido até borbulhante/turbulento), variando de um quarto a um quarto da mínima fluidização até $20 \%$ da velocidade terminal. A partir de $20 \%$ da velocidade terminal, varia-se de $10 \mathrm{em}$ $10 \%$ da velocidade terminal até 1,4 vezes da velocidade terminal. Esta proposta para excitar a coluna LFC evita perder resolução durante a exploração das faixas de velocidades em que os regimes se desenvolvem. A sequência de excitação da coluna é executada e seu dados armazenados, conforme indicado na Figura 51.

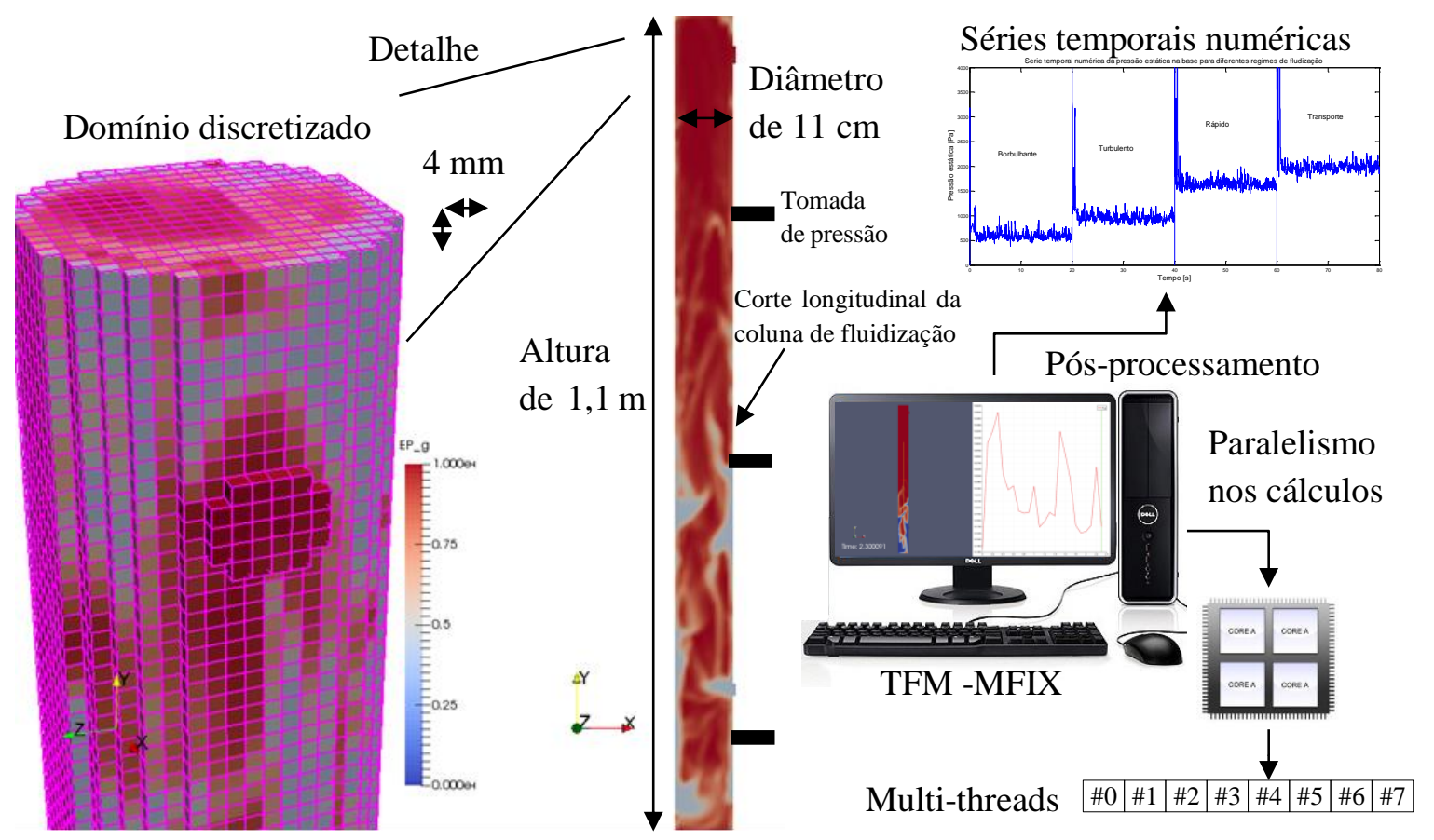

Figura 51 - Metodologia de ensaios de simulação 3D em coluna fria de leito fluidizado circulante.

O domínio foi discretizado usando malhas ortogonais cúbicas de $4 \mathrm{~mm}$ de lado, totalizando 168.338 células computacionais. O tamanho de malha escolhido permite simulações com diâmetros de partículas acima de $400 \mu \mathrm{m}$ sem subespecificar o tamanho da malha. Os parâmetros físicos da fase fluida foram o do ar, enquanto a da fase sólida foram a da areia de diâmetro de 1,0 mm, conforme a Tabela 4.

As condições inicias foram de $0,08 \mathrm{~m}$ de leito (sólidos) empacotado parado e fase fluida também parada, em relação a coluna. Após diversas tentativas de velocidade inicial do fluxo de entrada de ar, foram identificadas quatro velocidades referentes aos quatro regimes de fluidização investigados (borbulhante, turbulento, rápido e transporte), conforme a Tabela 4. Os regimes foram identificados a partir de diferentes condições iniciais, ou seja, para cada nova velocidade de entrada de ar, o leito iniciou parado (empacotado). Para velocidades iniciais próximas a velocidade terminal, uma grande quantidade de massa foi ejetada da coluna. Contudo, o algoritmo de compensação manteve o inventário de massa constante. $\mathrm{O}$ transiente entre a primeira ejeção de massa e a estabilização da circulação dura aproximadamente $1,5 \mathrm{~s}$. 
Tabela 4 - Parâmetros físicos e condições iniciais para o modelo TFM de leito fluidizado circulante.

\begin{tabular}{l|l}
\hline Propriedades & Valores \\
\hline Massa específica do gás, $\mathrm{kg} / \mathrm{m}^{3}$ & 1,2 \\
\hline Viscosidade do gás, Pa.s & $1,8 \mathrm{E}-5$ \\
\hline Diâmetro da partícula, $\mu \mathrm{m}$ & 1000 \\
\hline Massa específica da partícula, $\mathrm{kg} / \mathrm{m}^{3}$ & 2573 \\
\hline Velocidade terminal da partícula, $\mathrm{m} / \mathrm{s}$ & 5,51 \\
\hline Velocidades superficiais do gás, $\mathrm{m} / \mathrm{s}$ & 2,$655 ; 3,835 ; 5,015 ; 6,018 ; 6,785$ \\
\hline Porosidade de leito empacotado, [-] & 0,436 \\
\hline Diâmetro da coluna, [m] & 0,11 \\
\hline Altura da coluna, $[\mathrm{m}]$ & 1,1 \\
\hline Altura inicial de leito, $[\mathrm{m}]$ & 0,08 \\
\hline Modelo de turbulência & Não aplicado \\
\hline Condição de parede para fase gás & Sem escorregamento \\
\hline Condição de parede para fase sólida & Livre escorregamento \\
\hline
\end{tabular}

Através do pós-processamento dos dados de simulação é possível gerar animações do escoamento, permitindo o julgamento dos regimes com base na descrição qualitativa da literatura. Contudo, através da aplicação de recursos computacionais, é possível realizar estudos de médias para estabelecer critérios mais precisos ao estabelecidos qualitativamente.

\subsubsection{Classificação de regimes}

Os recursos de pós-processamento para identificação dos regimes de fluidização médios, foram desenvolvidos no programa aberto Paraview (www.paraview.org). Ao longo dos 3 segundos finais dos 6 segundos de simulação preliminar foram efetuadas médias temporais dos campos de velocidade dos sólidos de diversas velocidades do ar de entrada. As escolhas de 4 faixas de velocidades resultaram em campos médios de 4 regimes de fluidização, conforme a Figura 52. Para partículas esféricas de 1,0 mm de diâmetro e com massa específica de $2600 \mathrm{~kg} / \mathrm{m}^{3}$ efetuou-se a média temporal em cada velocidade entre 1,1 a $2,7 \mathrm{~m} / \mathrm{s}$ resultando num campo médio de velocidade de sólidos semelhante a coluna borbulhante da Figura 52. O regime borbulhante, em geral, é caracterizado pela identificação de leito bem definido e presença de bolhas.

O mesmo procedimento de médias entre as velocidades do ar de 2,8 a $5,6 \mathrm{~m} / \mathrm{s}$ foi utilizado para identificação do regime turbulento da Figura 52. O regime turbulento é caracterizado pela indefinição do leito e presença de golfadas (quantitativamente caracterizada por abruptas mudanças nos valores médios do campo de velocidade de sólidos).

Os valores médios entre as velocidades do ar de 5,7 a $6,6 \mathrm{~m} / \mathrm{s}$ definiram o regime rápido, indicado na Figura 52. O regime rápido é caracterizado pela formação do escoamento núcleo-anelar onde uma fração de sólidos sobe pela parte central (vetores ascendentes na parte central da Figura 52 que apresenta o regime rápido), e outra, desce pela parte lateral da coluna (setas descendentes).

Por fim, os valores médios de velocidade de entrada de ar acima de $6,7 \mathrm{~m} / \mathrm{s}$ convergiram para o regime de transporte pneumático, conforma Figura 52. Este regime é caracterizado por todo o campo vetorial de velocidade de sólidos ser ascendente ao longo da coluna, e possuir o mais alto índice de arrasto, quando compadrado aos regimes anteriores. 


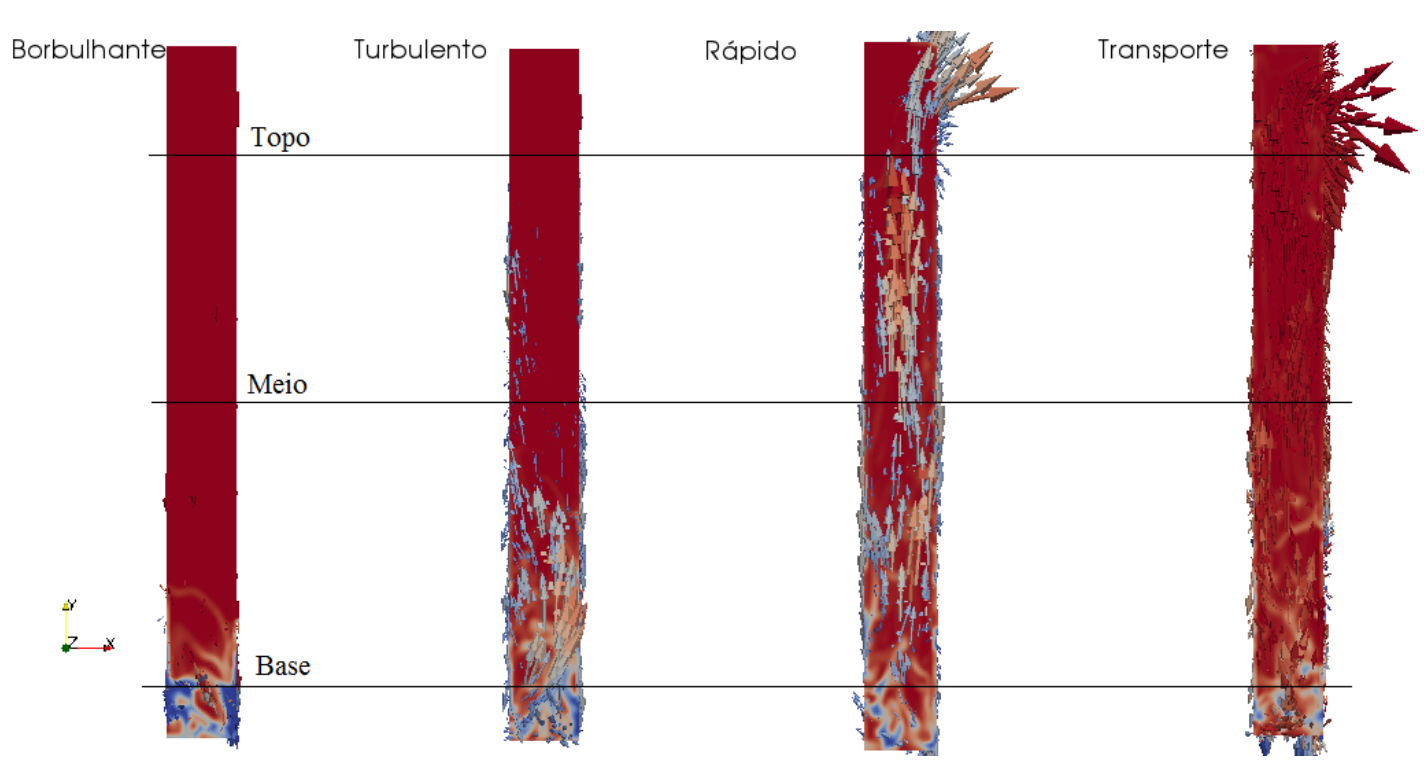

Figura 52 - Comparativo entre reconstruções de valores médios temporais dos campos de velocidade de sólidos na coluna LFC fria.

Uma avaliação ainda mais detalhada pode ser efetuada através da análise dos perfis radiais em três regiões (vide Figura 52) da coluna LFC. A classificação destas três regiões será discutida no item posterior. Conforme Saayman et al. [25], usaram equipamentos de raio $\mathrm{X}$ rápido para reconstruir escoamentos experimentais, descobrindo que a evolução da formação dos regimes de fluidização está ligado a formação de vazios. Em regimes borbulhantes, são produzidos vazios descontínuos no volume do leito. O regime turbulento, é uma transição de formação de vazios descontínuos e contínuos, sem leito definido, enquanto do regime rápido em diante, os vazios tornam-se contínuos. Esta avaliação pode ser realizada através do levantamento dos perfis axiais de porosidade central e lateral.

Quantitativamente, o regime borbulhante poderia ser avaliada, para qualquer nível de leito, pela clara formação de duas regiões bem definidas, uma densa de base e outra diluída de bordo livre, conforme a o perfil de porosidade da Figura 53. No volume de controle do leito, os perfis axiais de porosidade central e lateral, respectivamente, apresentam a formação de bolhas (região diluída central) no núcleo, e zona densa na região anelar. Os perfis axiais médios de porosidade central e lateral indicam um leito bem consolidado. A diferença de porosidades axiais médias entre as partes centrais e laterais são fortes evidências para caracterização deste regime. As velocidades dos sólidos, em três regiões $(8,50$ e $90 \mathrm{~cm}$ de altura da base) reiteram a dinâmica na base, partícula dominado, e a velocidade nula no bordo livre, fluido dominado. O caso extremo do leito completamente preenchido e operando no regime borbulhante poderia ser identificado através desta metodologia, indicando um perfil de porosidade denso, na lateral, mais diluído na parte central e baixas velocidades dos sólidos nas três regiões. 

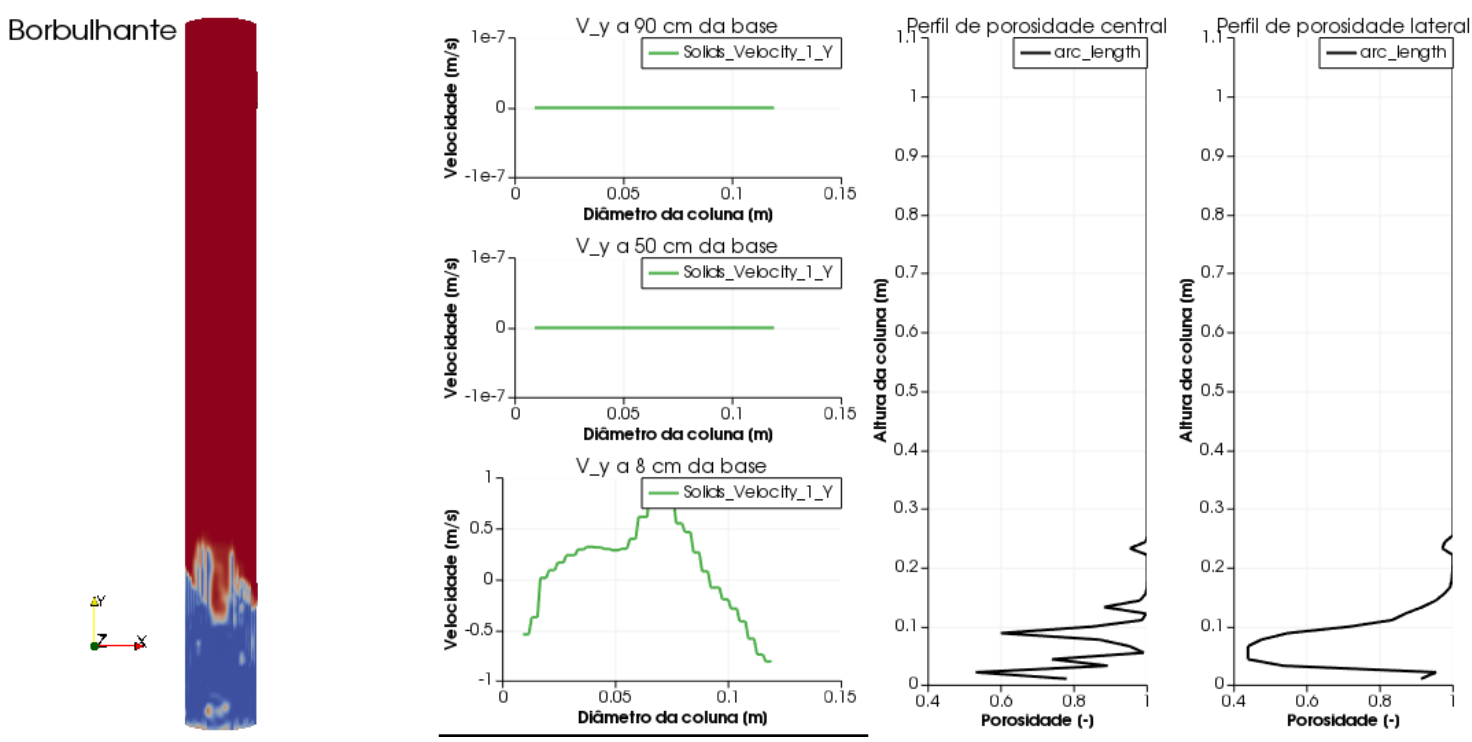

Figura 53 - Perfis radiais em três regiões (base, meio e topo) do regime borbulhante.

Conforme previsto por Saayman et al. [25], o regime turbulento é caracterizado pela instabilidade entre a descontinuidade e continuidade de formação de vazios. Numericamente, observa-se uma convergência entre os perfis axiais médios de porosidade central e lateral, conforme indicado na Figura 54. As velocidades dos sólidos nas regiões podem auxiliar na distinção deste regime, uma vez que a velocidade média dos sólidos do topo estar próxima de zero.
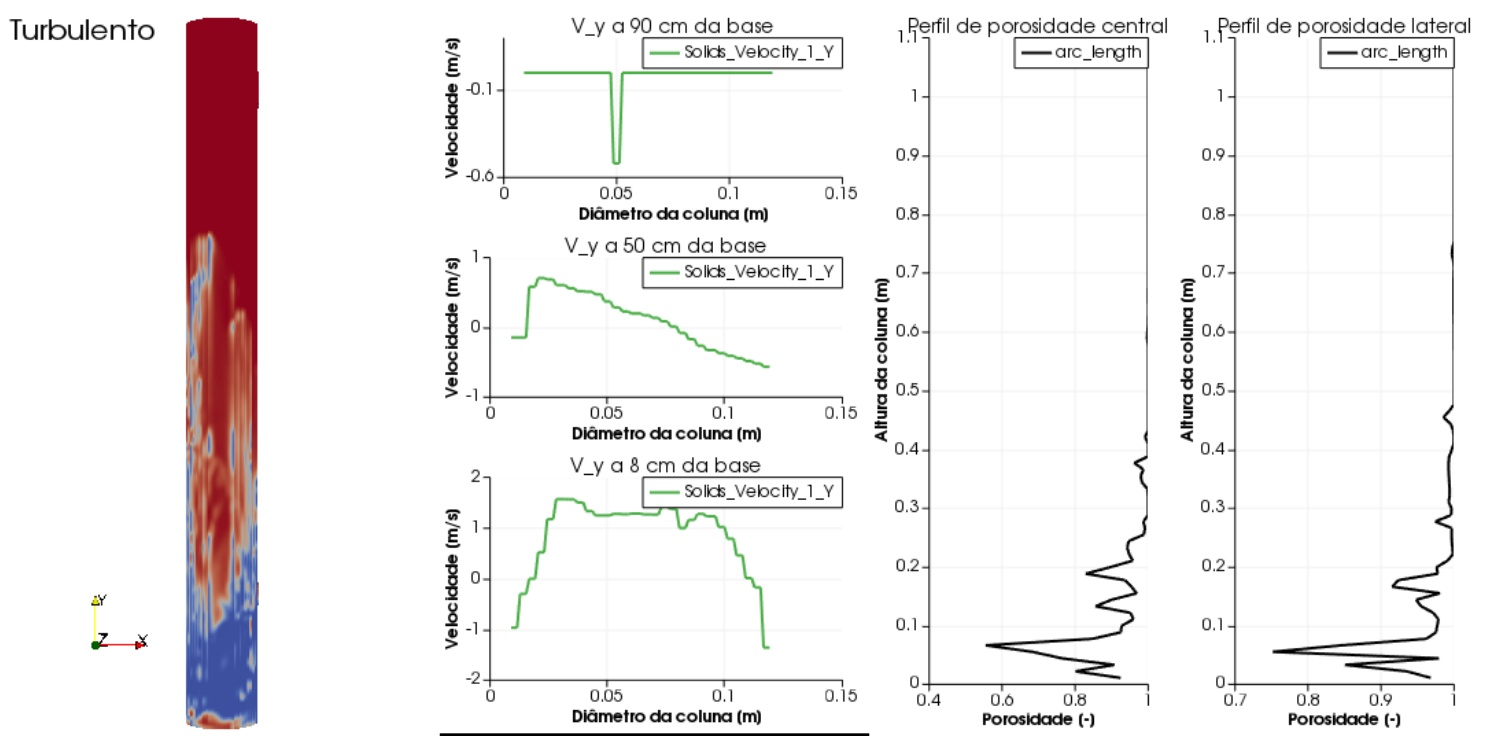

Figura 54 - Perfis radiais em três regiões (base, meio e topo) do regime turbulento.

No regime rápido, a convergência entre perfis de porosidade prevalece. A distinção com o regime anterior, ocorre pela distribuição de velocidade no topo, onde forma-se o fluxo núcleo-anelar em que sólidos de fase diluída são arrastados ascendentemente pela região central (núcleo), enquanto sólidos de fase densa caem descendentemente pela lateral (zona anelar). A distribuição de velocidades dos sólidos, indicada pela Figura 55, apresenta uma leve desaceleração do entre as regiões do meio e do topo, caracterizando a circulação interna. 


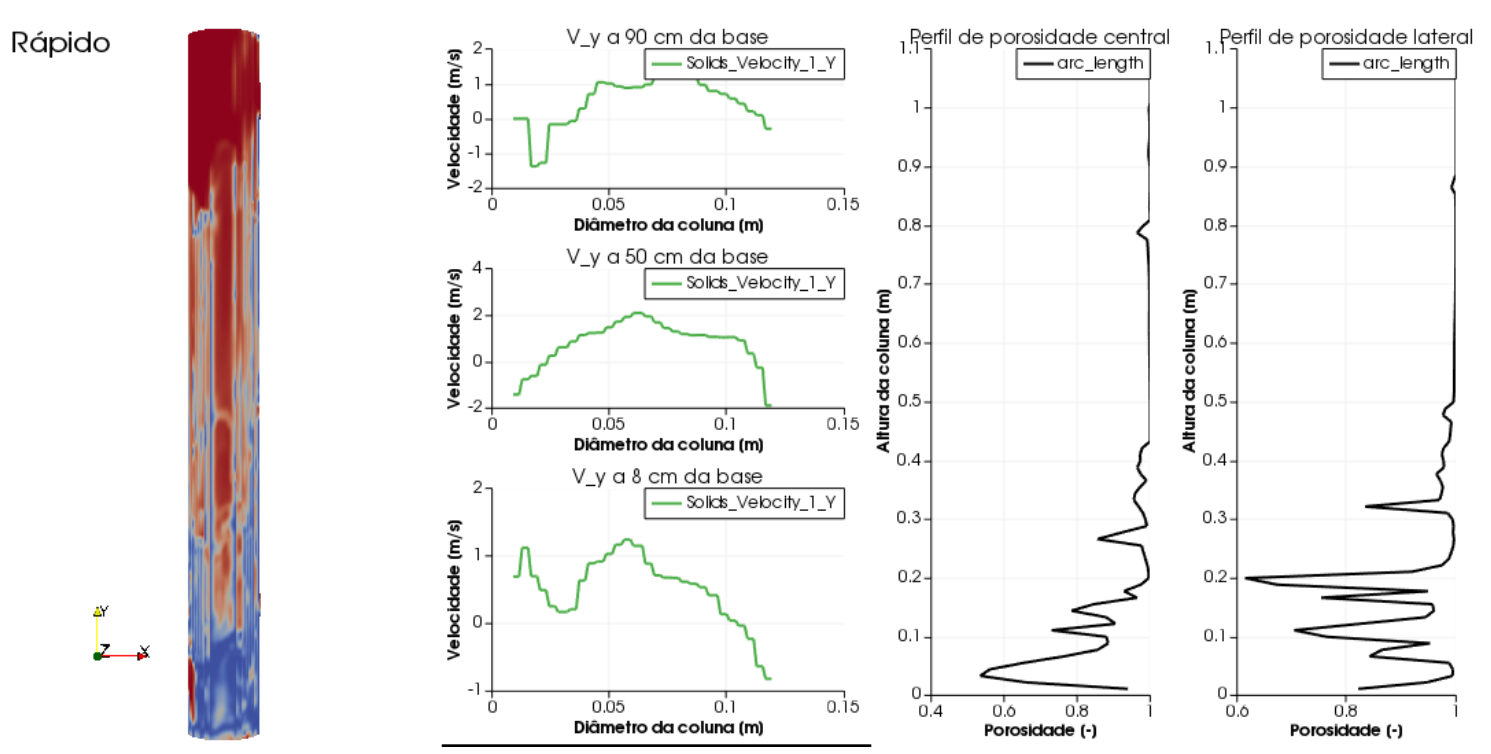

Figura 55 - Perfis radiais em três regiões (base, meio e topo) do regime rápido.

No transporte pneumático, conforme a Figura 56, há a preservação entre os perfis de porosidade central e lateral e certa permanência da velocidade dos sólidos, entre as regiões de meio e do topo. A permanência da velocidade indica drástica redução da circulação interna e aumento do arrasto de material para fora da coluna.
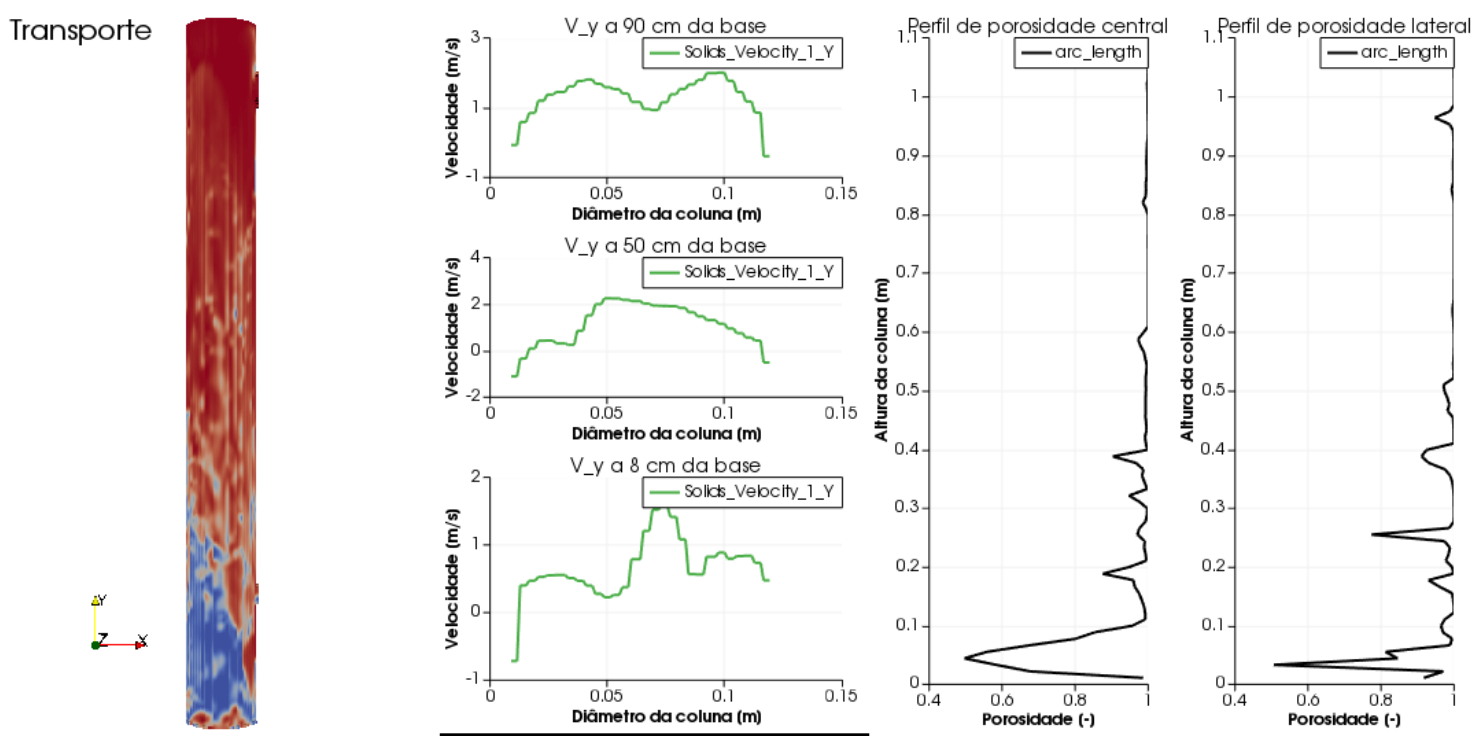

Figura 56 - Perfis radiais em três regiões (base, meio e topo) do regime transporte.

Através deste estudo, foi possível reunir informações da literatura e ensaios numéricos capazes de definir quantitativamente características dos regimes de fluidização. Foi possível verificar duas regiões características: a região de base densa, devido a incansável força gravitacional tentar mantê-lo coeso durante todos os regimes; e a região do meio ou do bordo livre diluída, devido a contribuição de frações 
de sólidos serem pela ação do arrasto do leito. Mas haveriam regiões, ao longo de uma coluna de leito fluidizado circulante capazes de fornecer informações mensuráveis para auxiliar um operador na identificação ou classificação dos regimes?

\subsubsection{Regiões características}

O estudo para responder ao questionamento anterior foi desenvolvido em duas etapas: uma análise numérica, a partir deste item, e uma análise experimental, discutida no capítulo posterior.

Apesar da simulação numérica auxiliar na identificação/classificação das velocidades de transição entre os regimes, através de seu pós-processamento, sua precisão está condicionada a especificação de uma boa simulação (realista), capaz de considerar ao máximo os mecanismos fluidodinâmicos nas diferentes escalas. Portanto, a avaliação numérica deve estar associada a avaliação experimental de mesma escala.

A literatura moderna sobre a leitos fluidizados explica o desenvolvimento dos regimes de fluidização como um fenômeno distribuído [46]. Portanto, medições pontuais, ao longo da coluna poderiam gerar indicadores capazes de auxiliar a identificação dos regimes. Essa mesma literatura explica os regimes de fluidização através de três mecanismos locais: o escoamento dominado pelo fluido (diluído), o escoamento dominado pela partícula (denso) e o compromisso fluido-partícula, quando nem um nem outro dominam [46].

Apesar da literatura moderna explicar os regimes de forma satisfatória por meios numéricos, a identificação experimental fica à mercê de medições precisas de perfis de porosidade central, lateral e velocidade de partículas. De forma prática, a instrumentação mais acessível para leitos fluidizados comerciais, ainda são os medidores de pressão estática, diferencial e termopares. Portanto, este estudo está tendenciado a buscar regiões características de uma coluna LFC fria numérica, baseado no sinal de pressão estático.

A Figura 57 apresenta um comparativo entre os perfis axiais de pressão estática da coluna LFC fria indicando pouco sobre características dos regimes de fluidização. Mesmo que houvesse alguma característica linear (frequência ou amplitude), estaria condicionada a escala da coluna, isto é, haveria diferentes características lineares nas diferentes escalas. Portanto, considerando um regime de fluidização em estado estacionário, o presente estudo considerou a avaliação de características nãolineares ao longo da coluna LFC, através das séries temporais (flutuações) do sinal de pressão estática, conforme indicado nas três regiões de cada perfil axial pressão da Figura 57. 

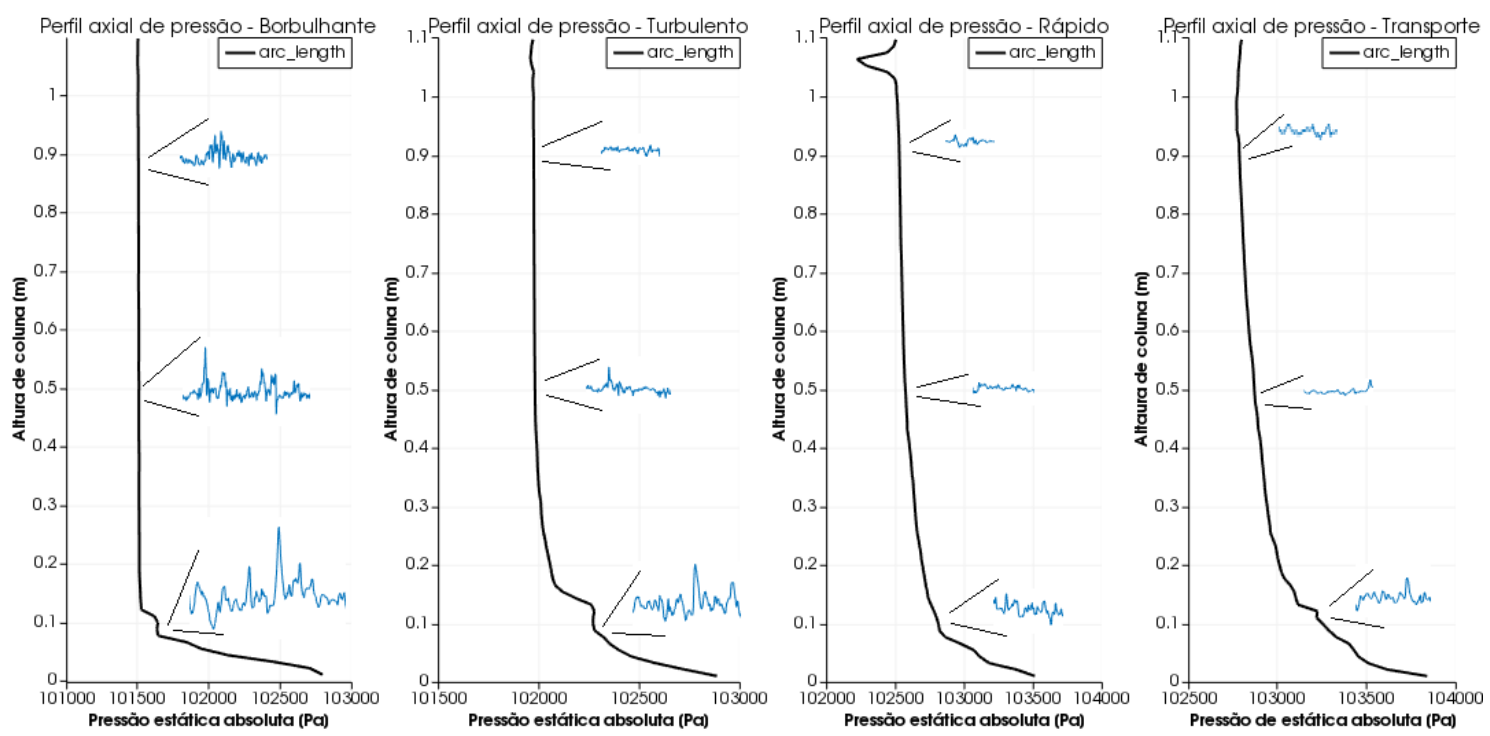

Figura 57 - Estudo de flutuações de pressão estáticas características ao longo da coluna LFC.

Numericamente, as flutuações de pressão estão isentas de ruídos de medição. Pela Figura 57 é possível observar a discrepância entre amplitudes dos sinais da base com os sinais do bordo livre (meio e topo), o qual corrobora com as previsões da literatura de quem fases densas (típicas na base) aumentam a dispersão da flutuação do sinal de pressão. A medida em que os regimes se tornam mais energéticos (do borbulhante para o transporte) o leito se distribui melhor na coluna, tornando-se mais homogêneo e diluído, reduzindo a dispersão da flutuação do sinal de pressão estática na base (vide Figura 57). Como a dispersão é uma característica estatística variante com a escala do processo não deve contribuir para caracterização das regiões da coluna.

A vantagem da caracterização não-linear é que sistemas de leito fluidizado são problemas espaçotemporais não-lineares de comportamento caótico. Esta caracterização é capaz de quantificar propriedades não-lineares, pouco dependentes da escala do problema, através de séries temporais. As características não-lineares de comportamento caótico que avaliam séries temporais são conhecidas como invariantes do caos. Cada tipo de invariante avalia determinada propriedade do comportamento não-linear caótico da série. As séries temporais estudadas são de sinais de flutuação de pressão estática.

Para o cálculo da invariante do expoente de Hurst foi utilizado a implementação de Aste [177]. Já as invariantes da dimensão de correlação e entropia de Kolmogorov foi utilizado o software RRCHAOS desenvolvido por Schouten et al. [178] [72].

A Figura 58 avalia o perfil axial do expoente de Hurst da simulação da coluna LFC fria nos regimes de fluidização aqui definidos. O expoente de Hurst entre 0,5 a 1,0 avalia o grau de rugosidade da série temporal em 0,5 é muito rugosa (ou série aleatória), e 1,0 representa uma série suave. A avaliação do expoente de Hurst, na base e para todos os regimes, pode ser interpretada como se a rugosidade da série de pressão, nesta região, dependesse pouco do regime de operação. Apesar do escoamento partícula dominado predominante na base, ser responsável pelo aumento da dispersão da flutuação, a rugosidade da série permaneceu (vide altura de base de $8 \mathrm{~cm}$ no gráfico da Figura 58). A medida em que a tomada de pressão tende ao meio da coluna, o escoamento torna-se mais diluído, implicando em diferentes comportamentos do expoente de Hurst face aos diferentes regimes. Para os regimes borbulhante e turbulento no meio da coluna, o expoente avalia a flutuação como rugosa face aos regimes rápido e de transporte. Entre os regimes rápido e transporte, o expoente de Hurst avalia no topo, o regime rápido com flutuações mais suaves do que o de transporte, conforme a tomada do meio do gráfico Figura 58. 
Em relação ao expoente é possível distinguir duas regiões características: a de base e a de bordo livre (meio e topo).

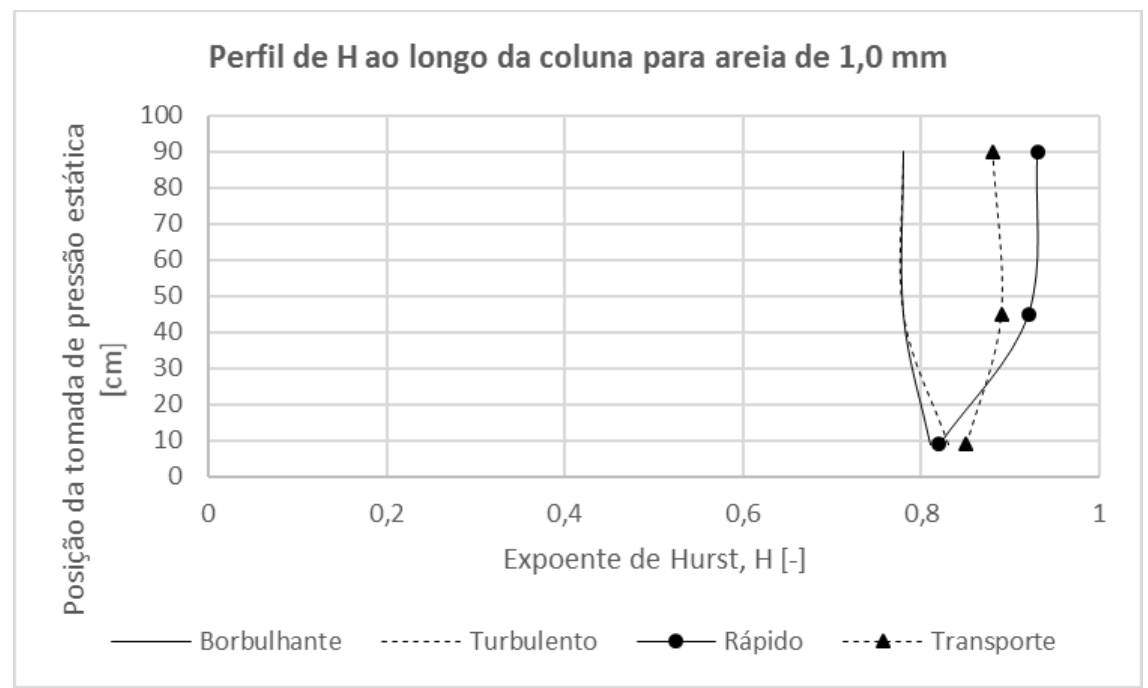

Figura 58 - Perfil do expoente de Hurst ao longo da coluna LFC para diferentes regimes de fluidização.

A Figura 59 avalia o perfil axial da dimensão de correlação dos resultados da simulação da coluna LFC fria nos regimes de fluidização. A dimensão de correção, usada para avaliação da série temporal de flutuação de pressão estática, mede o grau de complexidade que o escoamento local provoca nas flutuações de pressão estática ao longo do leito. Para essa invariante do comportamento caótico, a simulação nenhuma mudança axial foi observada para todos os regimes. Contudo, o regime turbulento foi o único que apresentou maior grau de complexidade (vide deslocamento da curva tracejada da Figura 59), mas de forma axialmente uniforme. Uma razão para este aumento da complexidade das flutuações no regime turbulento para esta simulação numérica pode estar associada ao mecanismo de compromisso fluido-partícula característicos deste regime, onde nem o fluido e nem a partícula dominam.

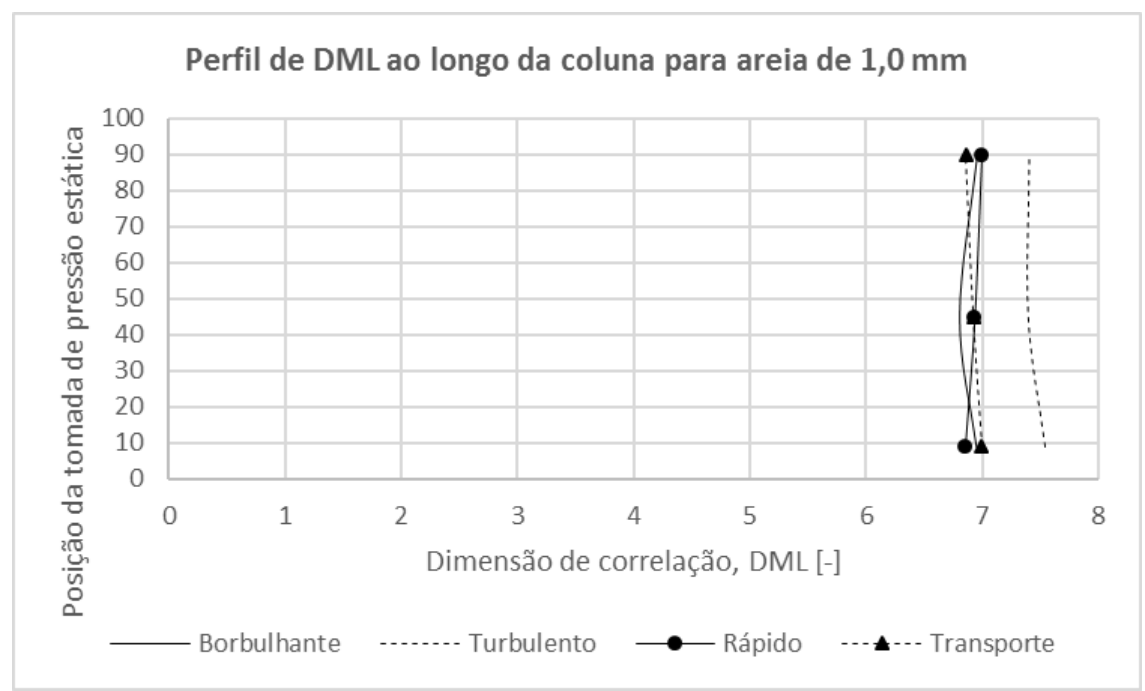

Figura 59 - Perfil da dimensão de correlação ao longo da coluna LFC para diferentes regimes de fluidização. 
A Figura 60 avalia o perfil axial da entropia de Kolmogorov das séries temporais do sinal de flutuação da pressão estática ao longo da coluna LFC. A entropia é invariante do comportamento caótico capaz de medir o grau de desordem num sistema dinâmico. Levando em conta a série temporal do sinal de flutuação de pressão estática, esta invariante é capaz de quantificar o grau de desordem das flutuações de pressão estática face aos diferentes regimes de fluidização. A invariante foi capaz de detectar diferentes comportamentos locais, ao longo da coluna LFC. A partir dos dados numéricos, o regime borbulhante apresenta baixo grau de desordem nas flutuações de pressão estática na base, e desordem mais alta e uniforme no bordo livre. No regime turbulento, essa invariante apresentou uniformidade ao longo da coluna, apesar do aumento em relação ao regime borbulhante. O grau de desordem das flutuações de pressão, regime turbulento é maior do que no regime borbulhante, conforme tracejada da Figura 60.

No regime rápido, essa invariante apresenta uma interessante distribuição axial. Primeiro, a entropia de base, meio e topo, foi a maior entre todos os regimes. Segundo, o grau de desordem na base, é o maior entre o meio e topo. No meio da coluna, o perfil axial apresenta o menor valor, enquanto no topo o valor tende a aumentar. No regime rápido, o escoamento núcleo-anelar apresentar três comportamentos em três regiões distintas: na base, o qual a gravidade tentar deixar o leito coeso com escoamento partícula dominado; no meio, o qual uma fase diluída sobre pela parte central e uma fase densa desce pela lateral; e no topo, o qual parte dos sólidos retornam para promover a circulação interna e parte arrastada para fora da coluna sofre o efeito do topo. Os efeitos de topo poderiam contribuir com o aumento da desordem do sinal de pressão estático no topo, conforme indicado na Figura 60.

No regime de transporte, o comportamento da entropia foi similar ao do regime turbulento, indicado pela redução do grau de desordem e por sua uniformidade axial, conforme indicado na Figura 60. A redução da desordem e sua uniformidade pode ser explicada por que no regime de transporte todo leito é distribuído ao longo da coluna, impondo um escoamento fluido dominado por toda sua extensão.

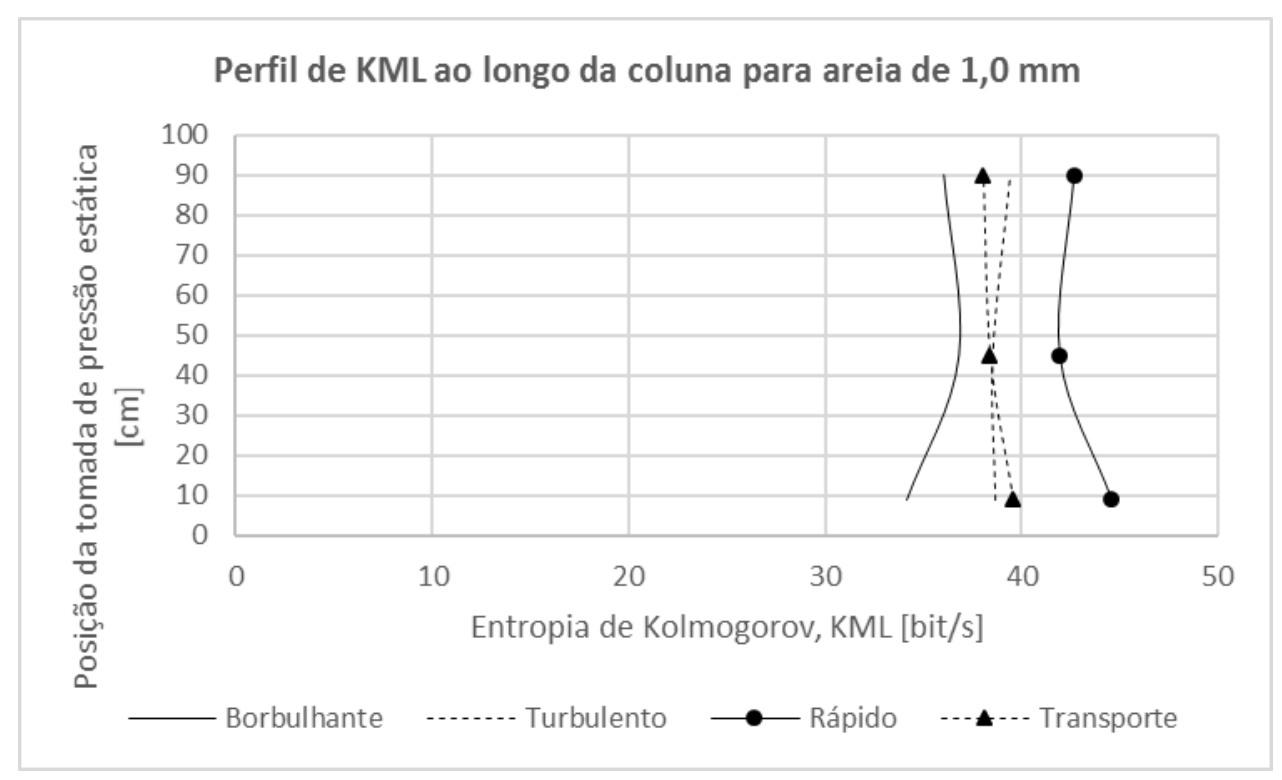

Figura 60 - Perfil da entropia de Kolmogorov ao longo da coluna LFC para diferentes regimes de fluidização. 
A análise dos perfis de invariantes ao longo da coluna LFC fria simulada evidenciou três regiões características: a base, o meio e o topo. A simulação apresentou indícios em que cada uma das regiões apresentou peculiaridades nas invariantes avaliadas.

\subsection{Avaliação da simulação numéricas}

Uma avaliação nos dados de simulação numérica apresenta resultados preliminares para auxiliar na previsão de perda de carga máxima, faixa de operação dos medidos de pressão estática e regiões características para posicionamento de tomadas de pressão numa coluna LFC fria.

\subsubsection{Queda de pressão}

O estudo numérico da queda de pressão numa coluna LFC permite avaliar os patamares médios da perda de carga face as velocidades de entradas do ar necessárias para o desenvolvimento dos regimes de fluidização.

A Figura 61 apresenta resultados indicando o comportamento da perda de carga aos diferentes regimes de fluidização. O comportamento numérico defere ligeiramente com o descrito na literatura, pois após a velocidade de mínima fluidização a queda esperada deveria ser constante e não ascendente, como indicado na Figura 61. Uma razão tal comportamento pode estar relacionado com a parametrização do modelo TFM ou até a escolha de outros como o DEM, PIC, etc. Os principais resultados deste estudo são a estimativa da queda de pressão média máxima de aproximadamente 700,0 $\mathrm{Pa}$ (72 mmca), pressão estática máxima de 2.350,0 Pa (240 mmca) e vazão máxima de $350 \mathrm{~m} 3 / \mathrm{h}$ de ar (relação entre a área da coluna e a velocidade máxima simulada). Os resultados estimados, permitirão dimensionar e especificar uma planta, em escala laboratorial, para ensaios de quantificação de leito fluidizado circulante.

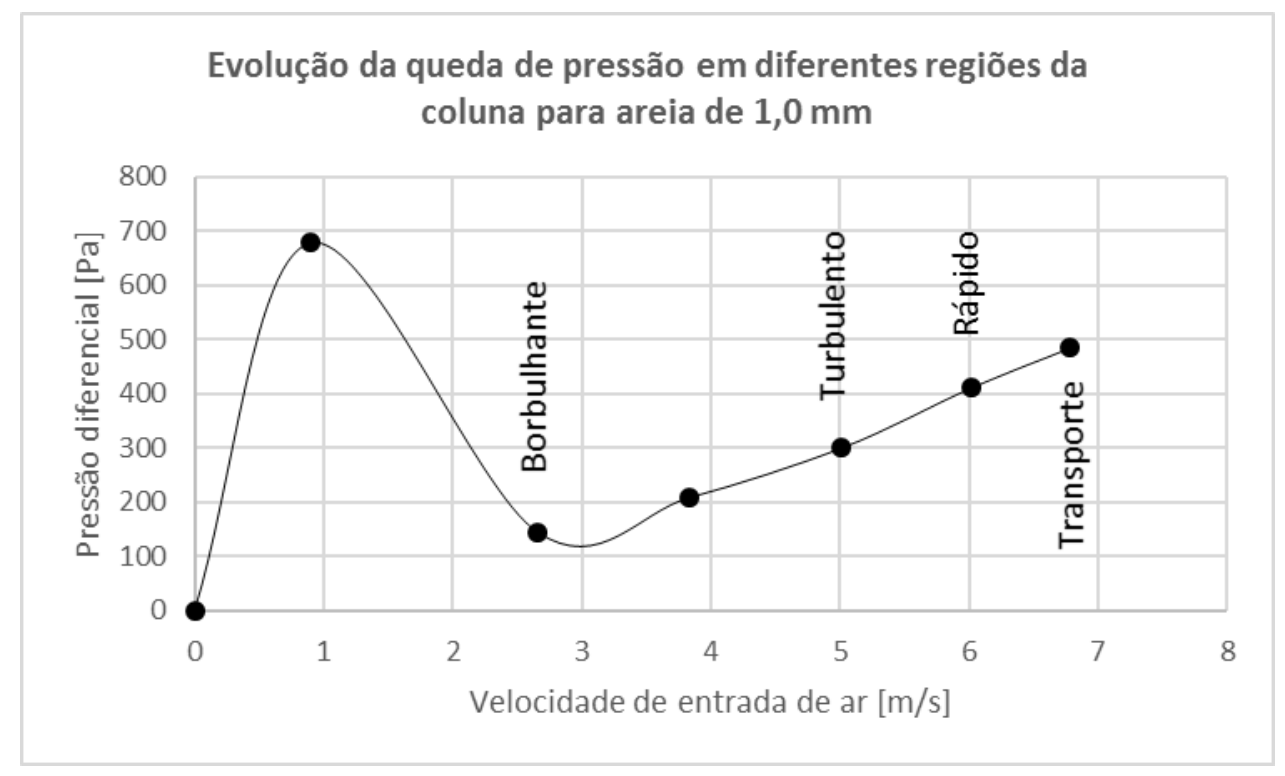

Figura 61 - Pressão diferencial na coluna LFC face as velocidades de entrada do ar que desenvolveram os regimes de fluidização estudados. 


\subsubsection{Instrumentação}

Para avaliação da instrumentação de pressão, os dados numéricos podem auxiliar na especificação de faixa de operação, resolução e tempo de resposta.

A Figura 62 apresenta o resultado da dispersão das flutuações de pressão estática na base, onde ocorrem as maiores flutuações na simulação numérica. $\mathrm{O}$ regime borbulhante apresentou as maiores dispersões quando comparado com os outros regimes, o qual corroboram com a avaliação experimental de Saayman et al. [25]. Contudo, os valores absolutos da dispersão apresentada pela simulação numérica ( $70 \mathrm{~Pa})$ foi menor do que os valores reais (250 Pa), apresentados por Saayman et al. [25].

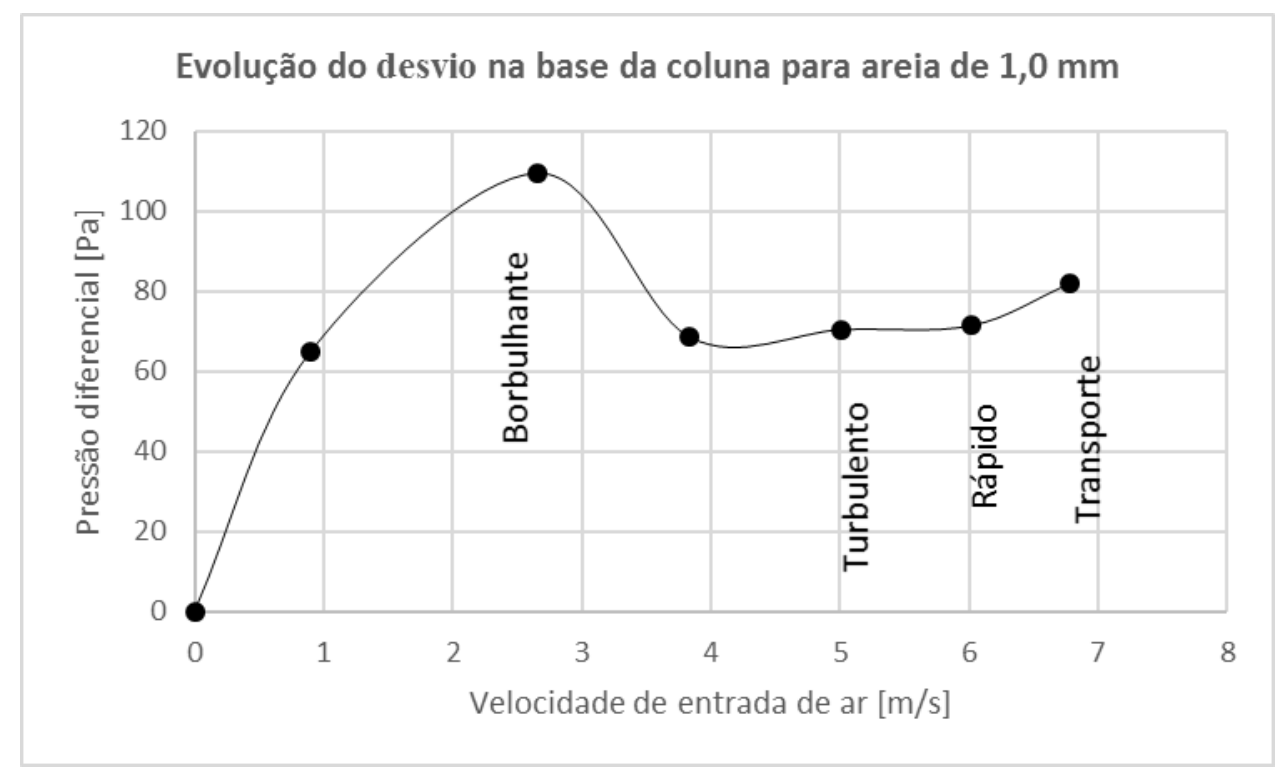

Figura 62 - Desvio padrão do sinal de pressão estática na base da coluna LFC, face as velocidades de entradas de ar que desenvolveram os regimes de fluidização estudados.

A Figura 63 indica a amplitude das flutuações do sinal de pressão estática na base, durante o regime de transporte. Esse resultado pode auxiliar na especificação da resolução do medidor de pressão, com a aplicação de filtros quantizadores.

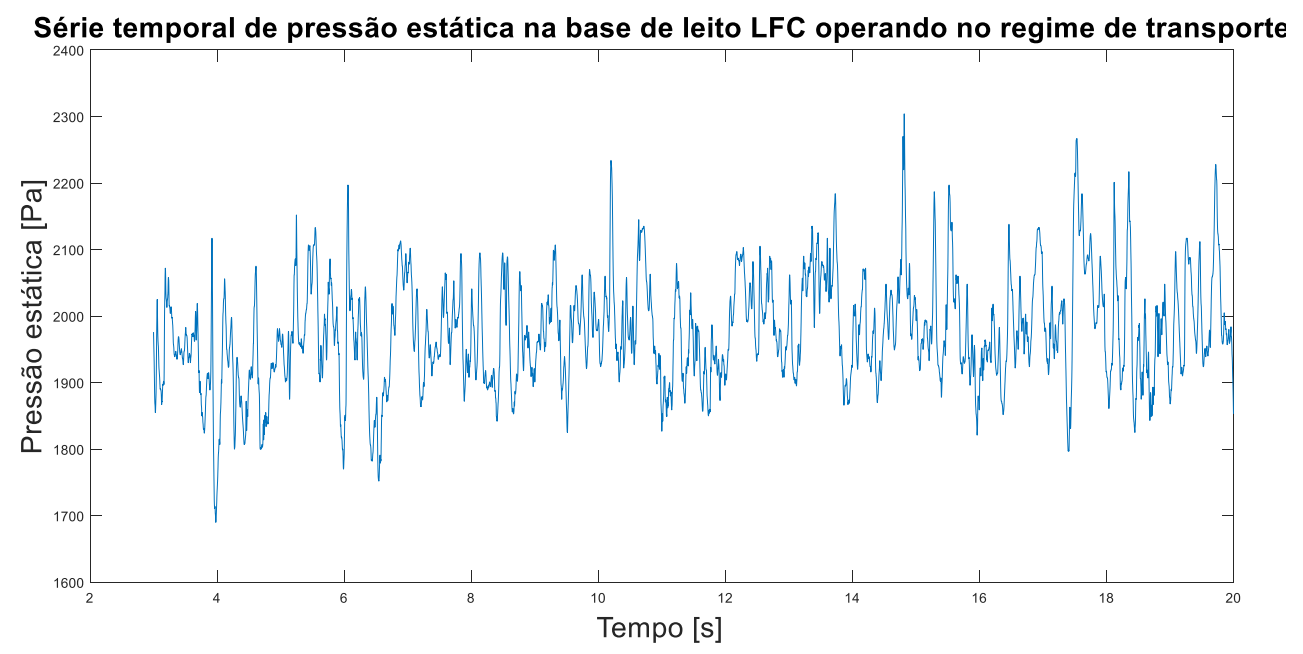

Figura 63 - Série temporal do sinal de pressão estática na base de uma coluna LFC numérica. 
Portanto, o estudo numérico conduz ao posicionamento de três medidores na base, meio e topo de uma coluna LFC. Considerando apenas colunas com seção circular, a base, pode ser definida como região entre 6-8\% da altura da coluna, enquanto o meio, como a região de altura entre $49-51 \%$ da altura da coluna. A região do topo, pode ser definida como uma região entre $89-90 \%$ da altura da coluna, caso esta faixa percentual esteja abaixo da tomada de saída. Caso contrário, a sugestão aqui apresentada para região do topo, deve ser desconsiderada.

O instrumento de pressão deve ter um tempo de resposta de $1 \mathrm{~ms}$, resolução de $50 \mathrm{~Pa}(0,5 \mathrm{mbar})$ e faixa operacional 0-5000 $\mathrm{Pa}(0-55 \mathrm{mbar})$. 


\section{MÉTODO DE QUANTIFICAÇÃO DE REGIMES DE FLUIDIZAÇÃO}

Este capítulo apresenta uma proposta experimental para quantificação dos regimes de fluidização em coluna LFC. $O$ projeto da coluna, em escala laboratorial, é baseado na metodologia do capítulo anterior. $O$ presente capitulo, apresenta detalhes da construção de uma bancada de leito fluidizado circulante para ensaios de quantificação de regimes de fluidização. Uma nova abordagem para quantificação de regimes de leito fluidizado é proposta com base na avaliação de invariantes do caos. As invariantes são calculadas a partir de séries temporais do sinal de flutuação de pressão estática, ao longo de regiões características das colunas.

A metodologia aqui proposta, contribui para a quantificação de sistemas de leito fluidizado. Seu diferencial, em relação a outros trabalhos [23] [40] [41] [33] [42] [43] [44] [45] [25] [46] [47] [48] [49] [50] [51] [52], é a consideração do problema espaço-temporal (distribuído), não-linear de comportamento caótico. Tal consideração implica numa proposta de quantificação para leito fluidizado com medidas distribuídas (mais de uma tomada de medição) ao longo da coluna e avaliação de invariantes do caos (e não mais variantes estatísticas).

Para que a análise distribuída não inviabilize o processo de quantificação de um sistema fluidizado, o estudo de regiões características do capítulo anterior, foi utilizado como critério par ao posicionamento dos medidores de pressão estática. Através da análise do comportamento das invariantes do caos, a partir das séries temporais de pressão estática observadas, localmente, nas regiões de base, meio e topo (segundo definições do capítulo anterior), é possível inferir sobre o regime de fluidização desempenhado naquela coluna.

A vantagem da avaliação de um sistema dinâmico, como os leitos fluidizados, a partir das invariantes do caos, está em sua capacidade de extrair características dinâmicas que pouco depende da escala do sistema [37] [30] [39] [28] [38]. Supondo que uma coluna de escala laboratorial ( 0,11 de diâmetro e 1,1 $\mathrm{m}$ de altura), operando com $8 \%$ de nível de leito de areia 1,0 $\mathrm{mm}$ (diâmetro de partícula) e em regime borbulhante, apresentasse na base um valor de entropia maior do que o topo, em teoria, esse comportamento deve ser preservado, caso o mesmo ensaio (condição de regime, diâmetro e densidade de partícula, altura inicial, etc.) fosse realizado numa coluna escalonada (por exemplo, 0,2 $\mathrm{m}$ de diâmetro e $6,8 \mathrm{~m}$ de altura).

A metodologia de quantificação experimental é dividida em três. Na primeira, são discutidas as características para o projeto da coluna levando em conta os tipos de partícula, a construção da coluna e malha circulante/válvula L. A segunda etapa trata dos cuidados de instrumentação para atenuação de ruído e captura de dados. Na terceira etapa, são descritos os tipos de partículas, os regimes experimentais definidos e os ensaios para quantificação de regimes experimentais, calculando as invariantes locais, a partir da séries temporais do sinal de pressão estática.

\subsection{Projeto de coluna LFC experimental}

Para o projeto de coluna LFC experimental, há necessidade de complemento da metodologia utilizada, na etapa anterior, levando em conta parâmetros construtivos e limitações dos equipamentos. A primeira complementação, cruza a queda de pressão do sistema com a curva de carga de sopradores comerciais. 
O cálculo de perda de carga total é baseado nas características dos tipos de partículas ensaiados e altura de nível de leito.

A segunda etapa, envolve cuidados com a parte construtiva de forma que fique fiel a simulação realizada no capítulo anterior. O material especificado para a coluna foi resina, para que um operador possa certificar os regimes desenvolvidos. Para controlar o regime de fluidização, um variador de frequência foi instalado no motor do soprador, permitindo corrigir a injeção de ar na coluna.

A terceira etapa, zela pela conservação do inventário de massa através da malha circulante. A circulação dos sólidos conta com um ciclone e um selo mecânico. A selagem é realizada através de uma válvula não-mecânica chamada válvula L. Se formato do tipo L, permite que as partículas se acomodem no joelho do L, selando a parte circulante e priorizando o escoamento de ar pela coluna. Após a separação da mistura ar-sólidos, o material é empacotado na parte vertical da válvula L. Para evitar que o material acumule na válvula $\mathrm{L}$, injetores laterais de ar empurram o material assentado no joelho de volta para a coluna.

\subsubsection{Caracterização de partículas}

As partículas selecionadas para os ensaios de quantificação de regimes de fluidização são classificadas nos grupos B e D de Geldart. Esta classificação possui baixa força de coesão entre partículas e pode ser facilmente fluidizável nos regimes borbulhante, turbulento, rápido e o transporte pneumático. O critério de escolha foi baseado na semelhança com partículas de carvão, sob o ponto de vista da facilidade de fluidização.

A Tabela 5 apresenta resultados de medições laboratoriais para três tipos de partículas. A intenção de usar três diferentes tipos de partículas é de avaliar a capacidade dos quantificadores de regimes, baseado nas invariantes do caos de séries temporais de flutuação de pressão, de serem influenciados pelas propriedades físicas das partículas. A esfericidade das partículas foi negligenciada como parâmetro significativo na interação fluido-partícula.

Tabela 5 - Medições da massa específica e porosidade de leito empacotado para o vidro $355 \mu \mathrm{m}$, areia $1,0 \mathrm{~mm}$ e areia $1,2 \mathrm{~mm}$.

\begin{tabular}{c|c|c}
\hline & Massa específica $\left[\mathrm{kg} / \mathrm{m}^{3}\right]$ & Porosidade de leito empacotado \\
\hline Vidro $355 \mu \mathrm{m}$ & $2440 \pm 30$ & $0,416 \pm 0,003$ \\
\hline Areia $1,0 \mathrm{~mm}$ & $2570 \pm 20$ & $0,436 \pm 0,004$ \\
\hline Areia $1,2 \mathrm{~mm}$ & $2600 \pm 40$ & $0,481 \pm 0,005$ \\
\hline
\end{tabular}

\subsubsection{Perda de carga total}

Para contabilizar a perda de carga total da bancada experimental, foram calculadas as perdas de carga nos trechos reto, curva, coluna de fluidização com $8 \mathrm{~cm}$ de leito e ciclone, na faixa de velocidades suficientes para desempenhar os regimes de fluidização.

A perda de carga (em mmca) do trecho reto é estimada aplicando o método de Moody-Rouse e o diagrama de Moody, através da Equação 47, onde, $\gamma$ é o peso específico do ar $\left(11,77 \mathrm{~N} / \mathrm{m}^{3}\right), f=0,038$ é o fator de atrito, $L$ é o comprimento da tubulação, $D$ é o diâmetro da tubulação e $\bar{v}$ é a velocidade média do ar de entrada ( 0 a $6,59 \mathrm{~m} / \mathrm{s})$. 


$$
\begin{aligned}
& R e=\frac{\rho \bar{v} D}{\mu} \\
& \Delta P_{\text {trecho }}=\gamma \cdot f \cdot \frac{L}{D} \cdot \frac{\bar{v}^{2}}{2 g} \cdot 0,102
\end{aligned}
$$

A perda de carga (em mmca) da curva pode ser estimada de forma semelhante ao trecho reto, usando a Equação 48 , onde $f=0,03$ e $L_{e q}$ é o comprimento equivalente da curva $90^{\circ}$.

$$
\begin{aligned}
& R e=\frac{\rho \bar{v} D}{\mu} \\
& \Delta P_{\text {curva }}=\gamma \cdot f \cdot \frac{L_{e q}}{D} \cdot \frac{\bar{v}^{2}}{2 g} \cdot 0,102
\end{aligned}
$$

Para a previsão de perda de carga na coluna, foi estabelecida por simulação numérica considerando 8 $\mathrm{cm}$ de altura de leito e diâmetro de partícula de 1,2 $\mathrm{mm}$ (maior partícula ensaiada). Através de ensaios, numa faixa de velocidade de entrada de ar capaz de desenvolver os regimes de fluidização, uma correlação analítica $5^{\text {a }}$ ordem pode ser ajustada $\left(R^{2}=0,98\right)$ e representada conforme a Equação 49 , onde a queda de pressão (mmca) foi relacionada com a vazão do ar de entrada $\left(\mathrm{m}^{3} / \mathrm{min}\right)$.

$$
\begin{gathered}
\Delta P_{\text {coluna }}=9,0426 q^{5}-103,01 q^{4}+430,18 q^{3}-786,53 q^{2}+572,22 q \quad \text { Equação } 49 \\
+0,2927
\end{gathered}
$$

Por fim, a estimativa da perda de carga de um ciclone de geometria padrão ( $a=0,095, b=0,03, s=$ $0,13, h=0,17, D=0,11, D e=0,05, H=0,3$ e $D b=0,05$ ), sugerido por Maurício et al. [179], pode ser dado, conforme Equação 50. O procedimento adotado calcula a perda de carga (em mmca) em função da vazão $\left(\mathrm{m}^{3} / \mathrm{min}\right)$ para uma faixa de velocidade de entrada do ar que desenvolvem os regimes de fluidização $(0$ a $6,59 \mathrm{~m} / \mathrm{s})$

$$
\Delta P_{\text {ciclone }}=36,16 q^{2}-3,5578 q+6,5901
$$

Equação 50

A Figura 64 apresenta o resultado do estudo de perda total numa bancada de leito fluidizado circulante, considerando um leito de $8 \mathrm{~cm}$ e partículas de $1,2 \mathrm{~mm}$ de diâmetro. A figura apresenta a contribuição de perda de carga de cada trecho (reto, curva, coluna e ciclone), destacando o ciclone como acessório de maior consumidor de energia de pressão (linha com marcador triangular do gráfico superior da Figura 64). O gráfico inferior, apresenta a relação entre as curvas de carga do soprador e a perda de carga total do sistema, no qual se cruza na vazão que o regime de transporte é desempenhado. Assim, a faixa de operacional de pressão e vazão, é suficiente para realização de estudos de quantificação regimes de fluidização numa coluna LFC. 

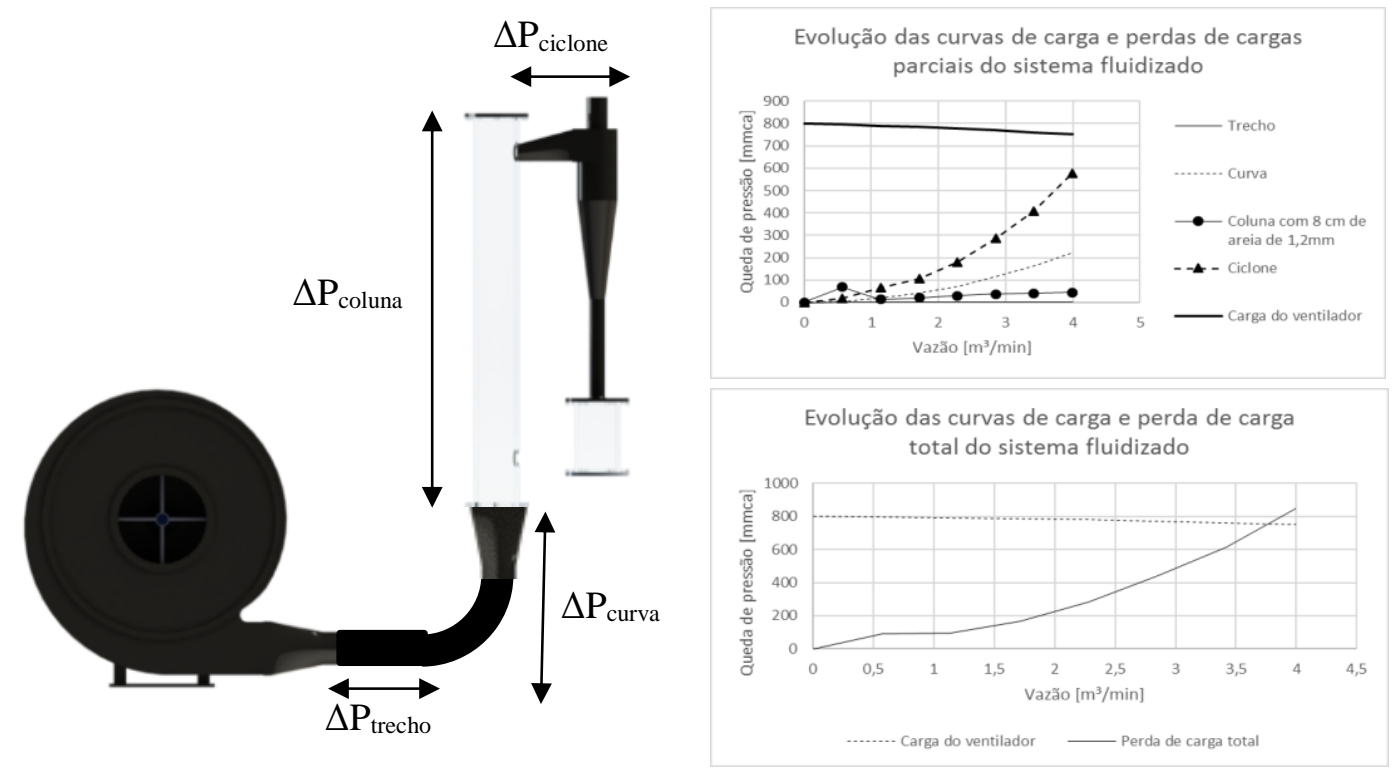

Figura 64 - Metodologia adotada para o cálculo de perda de carga total de coluna LFC experimental.

Portanto, um soprador comercial com pressão máxima de $800 \mathrm{mmca}$ e vazões até $5 \mathrm{~m} / \mathrm{min}$ foi utilizado para injeção de ar de entrada na coluna LFC experimental. Para alturas de leito acima de $12 \mathrm{~cm}$, o ponto de equilíbrio entre a carga do soprador e a perda de carga total do sistema reduz para velocidades em que apenas os regimes borbulhantes e turbulento podem ser desenvolvidos.

\subsubsection{Construção de coluna}

A construção da coluna foi baseada, fielmente, na simulação numérica. Assim como na simulação numérica é possível avaliar qualitativamente, através do pós-processamento (animações), um regime de fluidização, a coluna experimental foi especificada com material transparente de resina, $0,11 \mathrm{~m}$ de diâmetro interno, $1,1 \mathrm{~m}$ de altura e $50 \mathrm{~mm}$ de parede.

Um soprador injeta ar o no sistema através de um trecho reto, uma curva, um tela de retenção de leito, a coluna e um ciclone. Nesta banca, o distribuidor de ar da coluna é uma fina tela $(1,0 \mathrm{~mm})$ com orifícios de $150 \mu \mathrm{m}$ (menor do que a menor partícula $355 \mu \mathrm{m}$ ) com única função de sustentar o leito. A distância de trecho reto e suavidade da curva $90^{\circ}$ são considerados satisfatórios para manter o escoamento do completamente desenvolvido (distribuído) quando entra em contato com o leito.

O gradiente de pressão imposto pelo soprador é controlador por um variador de frequência (inversor, conforme indicado na Figura 68) capaz de controlar a velocidade do soprador, e consequentemente, o gradiente sobre o sistema.

Além do material transparente, a coluna é reforçada com um trecho de aço para melhorar a rigidez com os acoplamentos mecânicos como o ciclone, conforme a Figura 65. O topo coluna possui uma tampa para limpeza da parede e acesso para remoção de leito através de aspiradores de pó.

As tomadas de pressão são espaçadas em $9 \mathrm{~cm}$, distribuídas ao longo até $10 \mathrm{~cm}$ abaixo (para desprezar os efeitos de saída em T da coluna, vide Figura 65) do ponto de saída, no topo da coluna. O volume de posicionamento das tomadas representa a região de interesse de medição, onde são desempenhados os regimes de fluidização. 
A malha circulante experimental inicia com um pescoço, ciclone, trecho reto vertical (downer) e selo mecânico (válvula L) para o retorno do material sólido a coluna (vide Figura 65). A mistura gás-partícula que deixa a coluna pelo topo é separada no ciclone, fazendo com que a fase gasosa saia pela saída superior, enquanto a fase sólida desce para o downer, até o joelho da válvula $\mathrm{L}$.

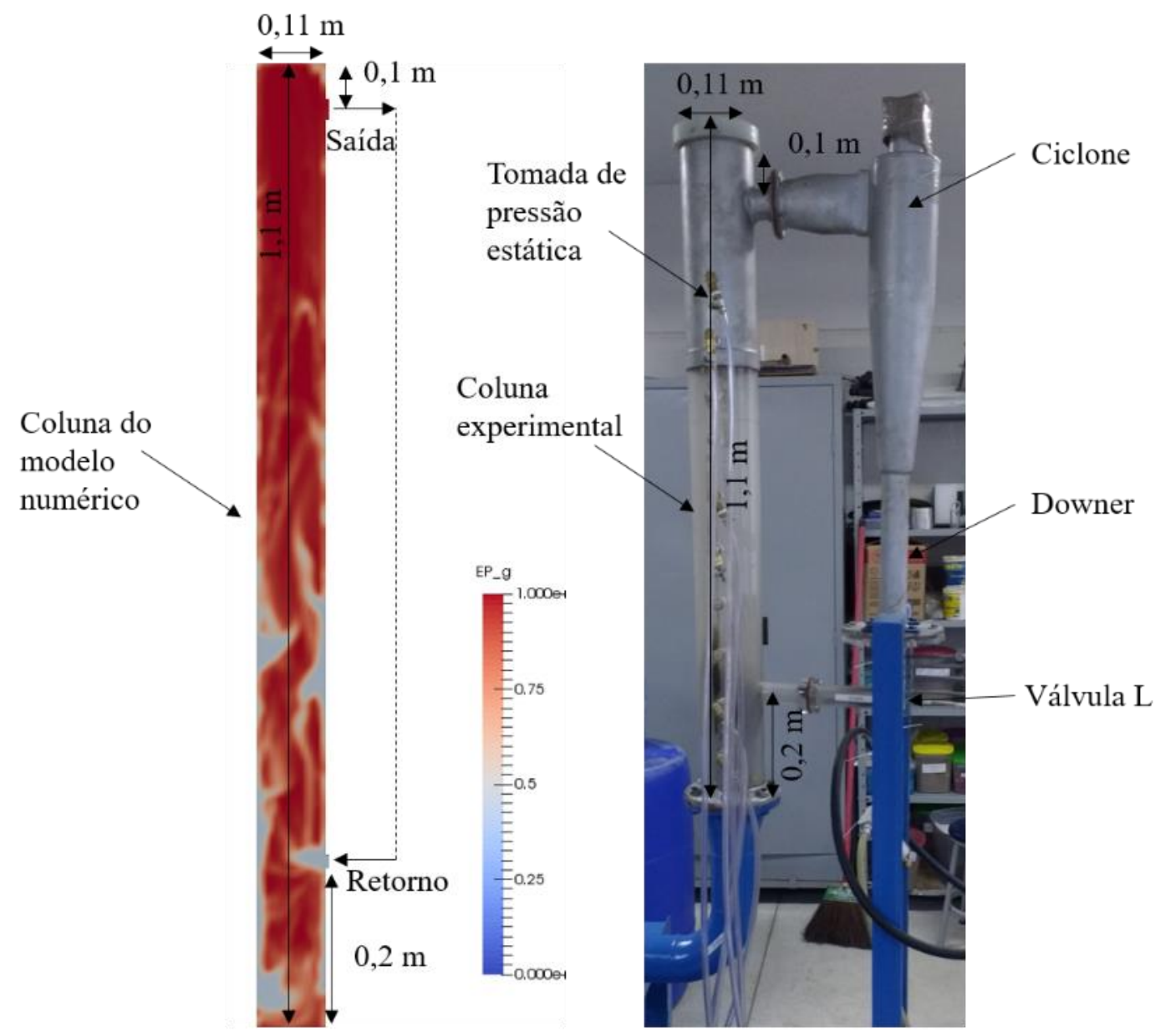

Figura 65 - Comparativo entre coluna LFC numérica e bancada experimental de leito fluidizado circulante.

Existem vários tipos de selagem mecânica para leitos fluidizados através de válvulas não-mecânicas. A válvula L é uma destas válvulas não mecânicas por que sem partes móveis pode controlar o fluxo de sólidos.

\subsubsection{Válvula L}

A válvula $L$ é o componente que fecha a malha circulante, encerrando o arranjo para a conservação do inventário de massa, conforma a Figura 66. No joelho da válvula L o material sólido se assenta e através de um fluxo lateral de ar (vide Figura 66), o material sólido é arrastado de volta para coluna.

O posicionamento da aeração ou fluidização lateral de uma válvula $\mathrm{L}$ é forte dependente de sua geometria e das características das partículas [180] [181]. O assentamento do material no joelho sela a 
coluna e a malha circulante. $O$ arrasto lateral deve ser capaz de vencer a contrapressão da coluna e drenar todo material assentado na parte vertical da válvula $\mathrm{L}$.

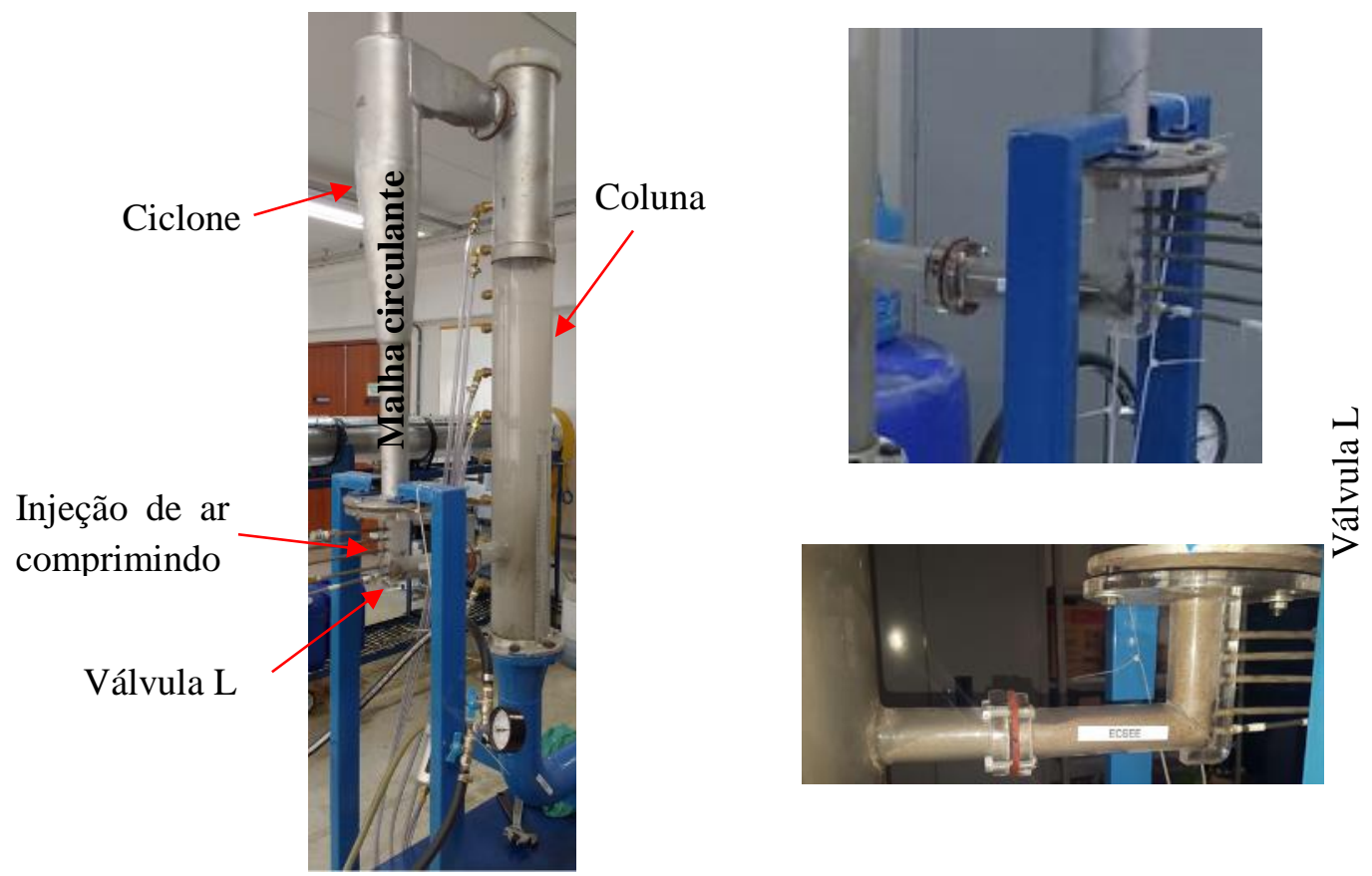

Figura 66 - Montagem de malha circulante, destacando a selagem mecânica a partir da válvula L.

Um ensaio preliminar, preenchendo a parte vertical da válvula L com areia, mostrou que o pescoço de interligação com a coluna ficou grande, exigindo fluxo de ar lateral com alta energia de pressão para devolver o material assentado para a coluna. Dentre as diversas injeções laterais, a primeira, de baixo para cima, foi utilizada (vide Figura 66) conectado a um compressor. A unidade compressora associado a filtros de remoção umidade e válvula agulha, permitiram um ajuste de arrasto suficiente para promover uma circulação contínua do material (conservação do inventário de massa).

\subsection{Aquisição de dados}

Diferente da simulação, a única forma de observar dados numa bancada experimental é através de instrumentação. Como toda medição pode ser influenciada por ruídos espúrios do ambiente, este tópico trata dos cuidados usados para redução deste.

A Figura 67 apresenta a coluna LFC experimental com as tomadas de pressão estática e o posicionamento dos medidores. As tomadas foram construídas para validar o estudo numérico do perfil axial das invariantes do caos. 


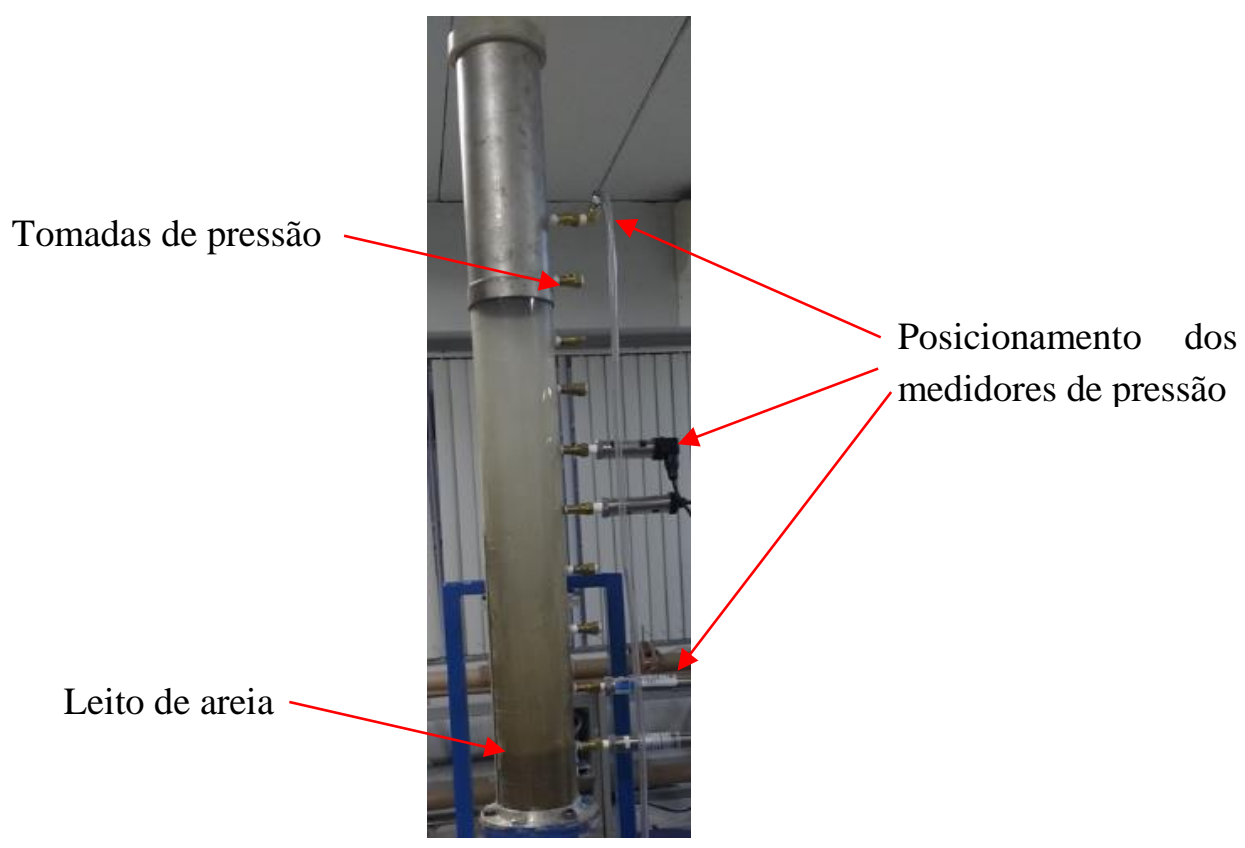

Figura 67 - Tomadas de pressão e posicionamento dos medidores de pressão estática da coluna LFC experimental.

A informação de flutuação de pressão estática é convertida num sinal de tensão elétrica, conduzido por fios até um sistema de aquisição de dados. Desde de a conversão do sinal, passando por sua condução até a placa de aquisição de dados, estão sujeitos a interferência de ruídos eletromagnéticas irradiados e conduzidos.

As proteções utilizadas nesta bancada envolvem o uso de blindagem em cabos, gaiolas de Faraday nas placas de aquisição de dados e isolamento das fontes de alimentação dos motores (potência) e do sistema de instrumentação e aquisição.

\subsubsection{Proteção contra ruído}

A instrumentação e aquisição de dados baseada em sinais de tensão possui custos acessíveis, porém é extremamente sensível a ruídos. O ambiente laboratorial não costuma ser um ambiente favorável para qualquer aquisição de dados visto que possui muitas cargas especiais como motores, inversores de frequência, contribuindo para o ruído conduzido, e roteadores sem fio, antenas, contribuindo para o ruído irradiado. Outra consideração importante é a falta de cuidado com o solo da estaca de aterramento (como solo seco com baixa condutividade) ou junção dos aterramentos de instrumentação e potência.

Os cuidados no tratamento de ruído para instrumentação deste trabalho são baseados na criação de aterramento próprio para instrumentação, blindagem em cabos de potência, instrumentação e sistemas de aquisição dados, e isolação da rede elétrica do sistema de aquisição de dados.

\subsubsection{Cabos blindados}

O ruído de natureza eletromagnética, irradiado ou conduzido como interferência eletromagnética (EMI), pode atrapalhar o bom funcionamento de instrumentos e equipamentos. Em transmissão de sinais analógicos, os cabos podem ser as principais fontes de transferência para EMI, funcionando tanto como 
fonte como receptor. Como fonte, o cabo pode conduzir o ruído para outros equipamentos e atuar como uma antena que irradia o ruído. Como receptor, o cabo também atua como uma antena receptor de captura EMI irradiada de outras fontes. A malha de blindagem de um cabo atua como um escudo, evitando que um cabo-fonte irradie, e reflete a EMI para um cabo-receptor (vide Figura 68). Em ambos os casos a energia pode atravessar o escudo, mas será altamente atenuada. Além da adoção de cabos blindados, boas práticas como colocar os cabos de sinal longe dos cabos de alimentação também pode evitar que o ruído da linha de alimentação seja acoplado às linhas de sinal.

A blindagem de um cabo pode oferecer cobertura total (100\%), através de folhas, e parcial (70 ou 95\%), através de malhas trançadas. As malhas trançadas são mais baratas e foram as escolhidas (95\%) pelo ambiente laboratorial ser classificado com um nível moderado de ruído.

Além da blindagem dos cabos, o sistema de aquisição deve ser protegido para evitar induções diretas.

\subsubsection{Isolamento e blindagem do DAq}

O sistema de aquisição de dados $(D A q)$ é um equipamento sensível a EMI e deve ser protegido de forma adequada. Este aplica duas técnicas de proteção contra ruído no DAq.

A primeira é a blindagem através de uma gaiola de Faraday em que uma caixa de papelão é recoberta com papel alumínio e os instrumentos e o DAq são posicionados no centro da caixa, onde o campo elétrico é constante e nulo, conforme representado pela Figura 68. Caixa não possui vedação eletromagnética total, devido a entrada dos cabos e tomada de pressão. Cada instrumento inserido na gaiola de Faraday é isolado de forma que suas carcaças não experimentem diferenças de potências. A blindagem protege o DAq do ruído irradiado. Contudo, comparando as magnitudes entre os ruídos irradiados e conduzidos, o segundo representa o maior problema.

A segunda técnica para proteção de EMI utilizada é o isolamento do DAq da rede elétrica, através de no-break complementados de banco de baterias auxiliares, conforme indicado pela Figura 68. A maior fonte emissora de ruído conduzido é o inversor de frequência. Uma das razões da geração do ruído é o chaveamento de componente semicondutores que produzem distorções harmônicas que se propagam pela rede elétrica. A rede de alimentação, já ruidosa, soma-se ao ruído produzido, podendo levar os níveis a magnitudes perigosas para instrumentação sensível e de baixa potência. A ligação isolada, permite abrir o circuito da rede elétrica ruidosa, fazendo com que um banco de baterias com autonomia de 1,5 h seja capaz de coletar e armazenar dados experimentais. 


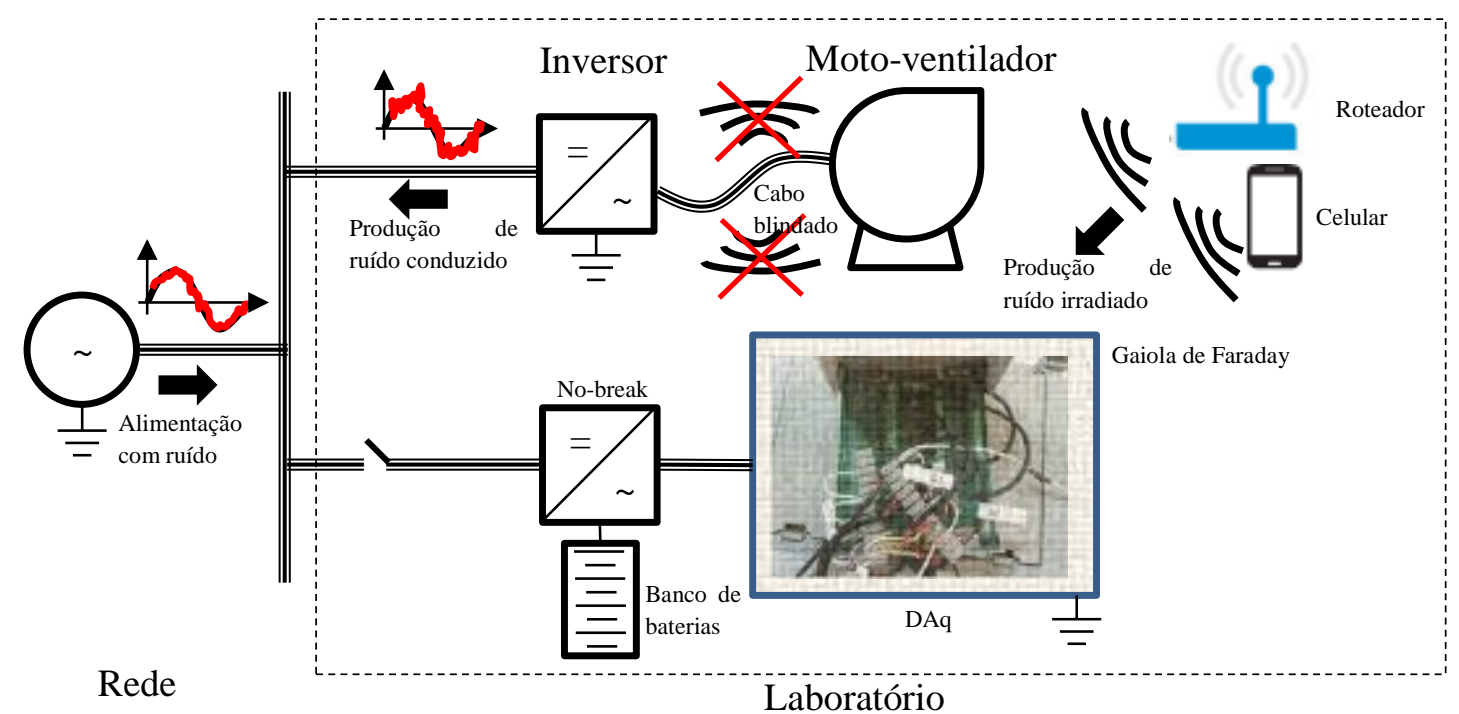

Figura 68 - Esquema de ligações elétricas completo, destacando as fontes de ruído irradiada e conduzida.

Um estudo do desempenho da medição deve ser conduzido para averiguar a eficácia dos cuidados na atenuação do ruído, durante a aquisição dos dados. Um comparativo entre a aquisição bruta e a protegida pode indicar qualitativamente e quantitativamente a influência do ruído no sinal de flutuação de pressão estática.

\subsubsection{Desempenho da medição}

O estudo de desempenho da medição tem o objetivo ressaltar as contribuições dos cuidados aplicados para imunizar o DAq e os instrumentos nele conectados. Neste ensaio, os geradores de ruído (inversores, roteadores, celulares, switch, flutuações nativas da rede) e os meios de atenuação (blindagem de cabos, blindagem por gaiola de Faraday e isolamento da rede elétrica) são colocados à prova.

O ensaio de desempenho de medição, utiliza uma coluna de com $8 \mathrm{~cm}$ de leito das partículas mais pesadas (1,2 mm de diâmetro), para geração de ruídos proporcionais a carga real, maximizando a produção de ruídos. Com a carga mencionada, o ventilador foi submetido a rotações de até 3400 RPM, capazes de provocar grandes níveis de distorções harmônicas conduzidas, na rede elétrica, devido aos chaveamentos dos componentes eletrônicos, e pulsos eletromagnéticos irradiados. A soma destes sinais conduzidos e irradiados são considerados os ruídos que alcançam os sistemas de instrumentação e DAq.

A Figura 69 apresenta três séries temporais da pressão estática da base, para a mesma condição de leito ( $8 \mathrm{~cm}$ de leito e submetido a uma rotação de ventilador de até 3400 RPM), com diferentes proteções.

O primeiro caso da Figura 69, sem qualquer proteção de blindagem ou isolamento o sinal adquirido é bruto, contendo todas as induções possíveis, desfavorecendo a relação sinal/ruído e mascarando o sinal característico das flutuações reais na pressão estática.

O segundo caso da Figura 69, trata da aquisição de um sinal cuja proteção utilizada é apenas a blindagem nos cabos e no DAq (gaiola de Faraday). É possível verificar a forte atenuação das induções irradiadas, mas a insistente presença do ruído conduzido. 
No terceiro caso da Figura 69, mantendo as condições experimentais dos dois primeiros, um sinal totalmente protegido (blindagem dos cabos e DAq, e isolamento) do ruído é aquisitado. Comparado ao primeiro caso, a relação sinal/ruído favorecida, permitindo a identificação dos degraus no sinal devido a mudanças de rotações no ventilador. O retângulo do sinal filtrado com blindagem e isolamento da Figura 69, destaca o momento em que a proteção do isolamento é desacionada, através do religamento do no-break à rede elétrica, e o ruído conduzido volta a interferir no sinal aquisitado.

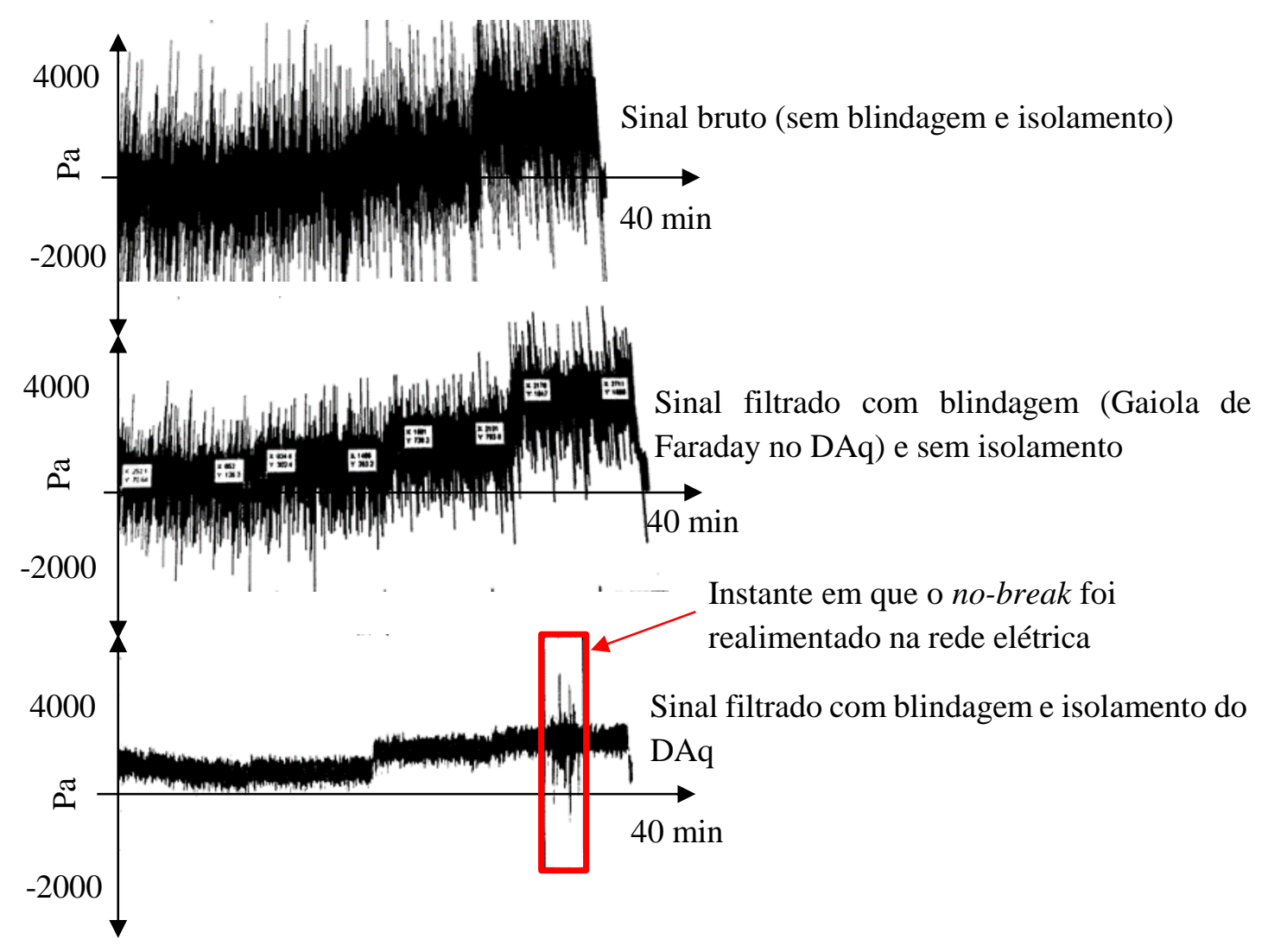

Figura 69 - Desempenho da imunidade de uma aquisição de dados experimental.

Apesar da grande atenuação dos métodos de blindagem utilizados, uma pequena parcela de flutuações espúrias pode induzir a instrumentação e o DAq. Métodos digitais podem ser aplicados para melhorar a visibilidade das flutuações face a interação fluido-partícula e não aos ruídos espúrios remanescentes.

\subsubsection{Filtragem digital}

Uma visão ainda mais minuciosa das flutuações do sinal de pressão estática no sinal protegido (blindado e isolado) indicam que ruídos residuais poderiam dificultar a percepção do comportamento da variabilidade nos diferentes regimes de fluidização.

A Figura 70 apresenta um comparativo entre o sinal protegido (azul) pelos cuidados em blindar e isolar o sistema de instrumentação e DAq, e o mesmo sinal filtrado digitalmente (vermelho) por média móvel de 11 atrasos. 
O sinal azul da Figura 70 indica que o esquema experimental para proteção contra ruído foi capaz evidenciar os diferentes patamares (regimes de fluidização) de pressão estática, mas não foi possível evidenciar as diferentes dispersões oferecidas por cada um desses patamares. Saayman et al. [25] usaram técnicas robustas de reconstrução de imagem por raio $\mathrm{X}$ rápido demonstrando que a dispersão (desvio padrão amostral do sinal de pressão estática) das flutuações de pressão diferencial pode ser maior no regime turbulento.

O sinal vermelho da Figura 70 é o mesmo sinal azul, mas filtrado digitalmente pela aplicação de média móvel de 11 atrasos, reduzindo em mais de 3 vezes a magnitude do sinal. Para atrasos menores do que 11, a magnitude dos picos não sofreu redução suficiente para evidenciar diferentes dispersões em cada regime de fluidização (ver no sinal vermelho da Figura 70 as diferentes dispersões em cada patamar). Para atrasos maiores do que 11 atrasos, o sinal vermelho perdeu a sincronia medida nas transições entre patamares de pressão (destaque da elipse no instante $1250 \mathrm{~s}$ da Figura 70, evidenciando que os sinais protegido e filtrado permanecem em fase). O sinal vermelho filtrado também foi capaz de evidenciar peculiaridades como pequenos surtos de pressão (destaque da elipse no instante $700 \mathrm{~s}$ do sinal vermelho da Figura 70), comuns em leitos na fluidizados na iminência de iniciar o borbulhamento.

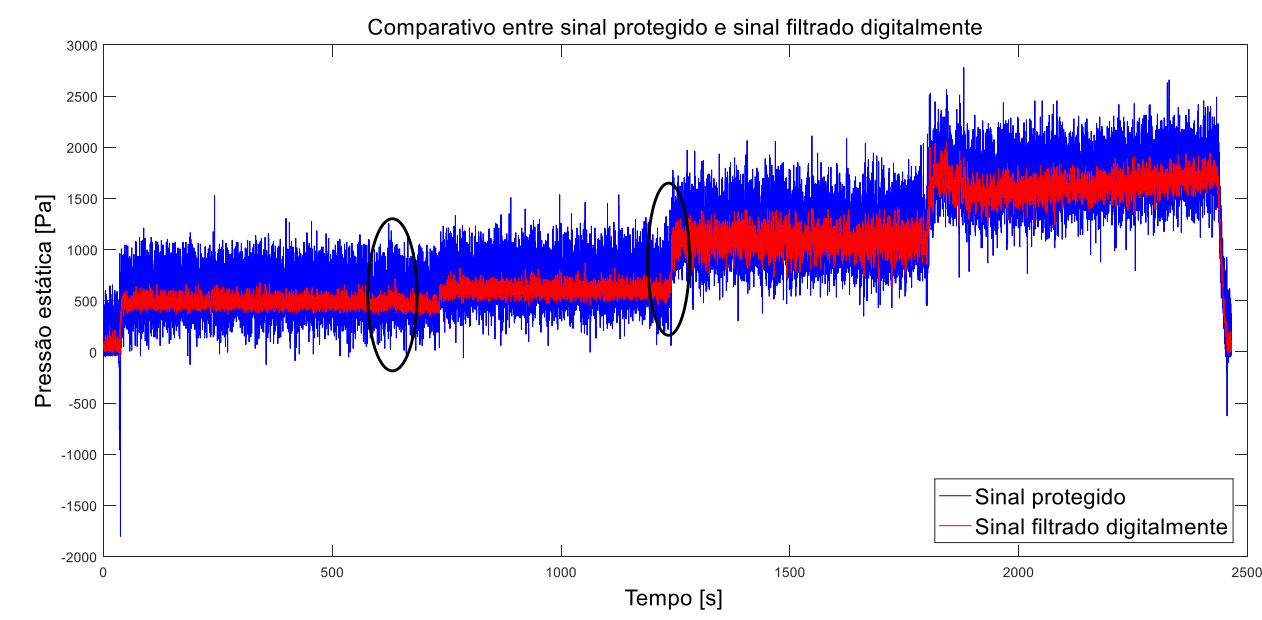

Figura 70 - O sinal protegido e filtrado digitalmente permite evidenciar flutuações da interação fluidopartícula.

A medição local do sinal filtrado (média móvel) resultante foi considerado satisfatório para medição por estar em fase com o sinal protegido, elevada relação sinal/ruído e apresentar comportamento da evolução da dispersão, em cada regime, semelhante aos resultados encontrados na literatura [25] [45]. Diferente de outros estudos que tentam classificar um regime de fluidização de uma coluna baseado numa única medição local, o presente trabalho propõe múltiplas medições. Como a fluidização em coluna, é um problema espaço-temporal, uma única medição pode não garantir unicidade na quantificação das séries temporais para um determinado regime. Como a presença de sólidos em suspensão influencia uma observação local (série temporal), e com base no estudo capítulo anterior, uma coluna possui, no mínimo, três regiões características, sob o ponto de vista das invariantes do caos, relevantes para o aparato experimental de quantificação dos regimes. 


\subsubsection{Regiões características}

Num escoamento bifásico (gás-sólido), há presença de sólidos provoca alterações mensuráveis na flutuação (amplitude e frequência) de pressão estática conforme o regime local [25]. O desenvolvimento dos regimes de fluidização ao longo de uma coluna, implicam na formação de regiões com porosidades características e consequentes flutuações.

O capítulo anterior apresentou um estudo numérico capaz de evidenciar regiões com diferentes porosidades e flutuações locais, mesmo com as considerações de um modelo de fluidos interpenetrantes.

A Figura 71, apresenta destaque (retângulos) de três regiões características para as observações locais: a região de base (R1, a $9 \mathrm{~cm}$ da base), a região do meio (R3, a 45 da base) e a região de topo (R5, a 90 $\mathrm{cm}$ da base). O critério de caracterização destas regiões é baseado nos perfis axiais de porosidade e flutuação de pressão estática, quando um leito de $8 \mathrm{~cm}$ foi submetido aos diferentes regimes de fluidização (borbulhante, turbulento, rápido e transporte).

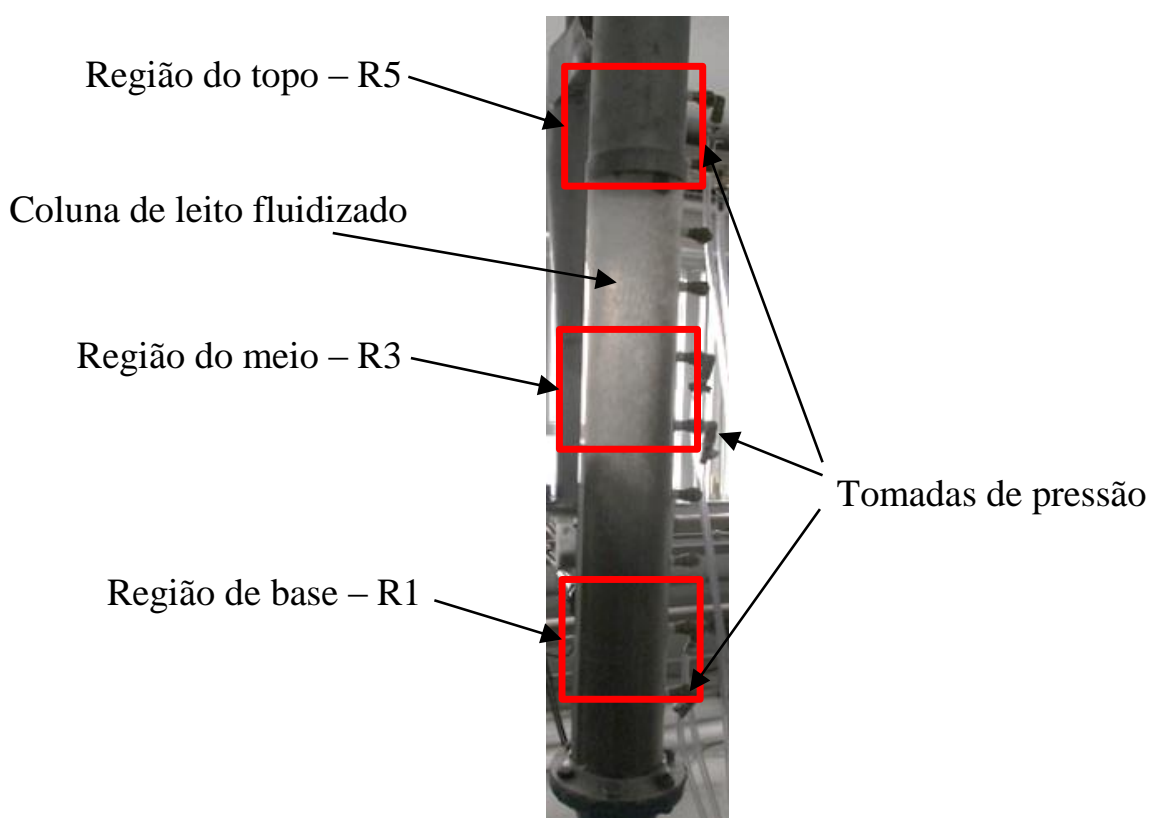

Figura 71 - Regiões características para observação local da flutuação pressão estática ao longo de uma coluna LFC.

O comportamento experimental qualitativo, na base, corrobora com o pós-processamento do modelo numérico (capítulo anterior), onde a gravidade tenta manter o leito de partículas coeso, indicando região com as maiores flutuações de pressão e fração de sólidos da coluna. Na região do meio, qualitativamente, houve um disparate entre as flutuações de pressão estática experimental e numérica, onde a primeira apresentou amplitudes maiores. E na região do topo, qualitativamente, os efeitos experimentais da saída da coluna apresentaram amplitudes maiores nas flutuações do que na simulação numérica.

Quantitativamente, ensaios experimentais preliminares apresentaram boa concordância entre a pressão estática ao longo do leito numérico (vide Figura 72) e simulado. A dispersão do sinal de pressão diferencial de base apresentou maior valor no regime turbulento conforme previsto por Saayman et al. [25]. Nas regiões do meio e no topo, onde o escoamento foi mais diluído os dados preliminares numéricos e experimentais divergiram. 

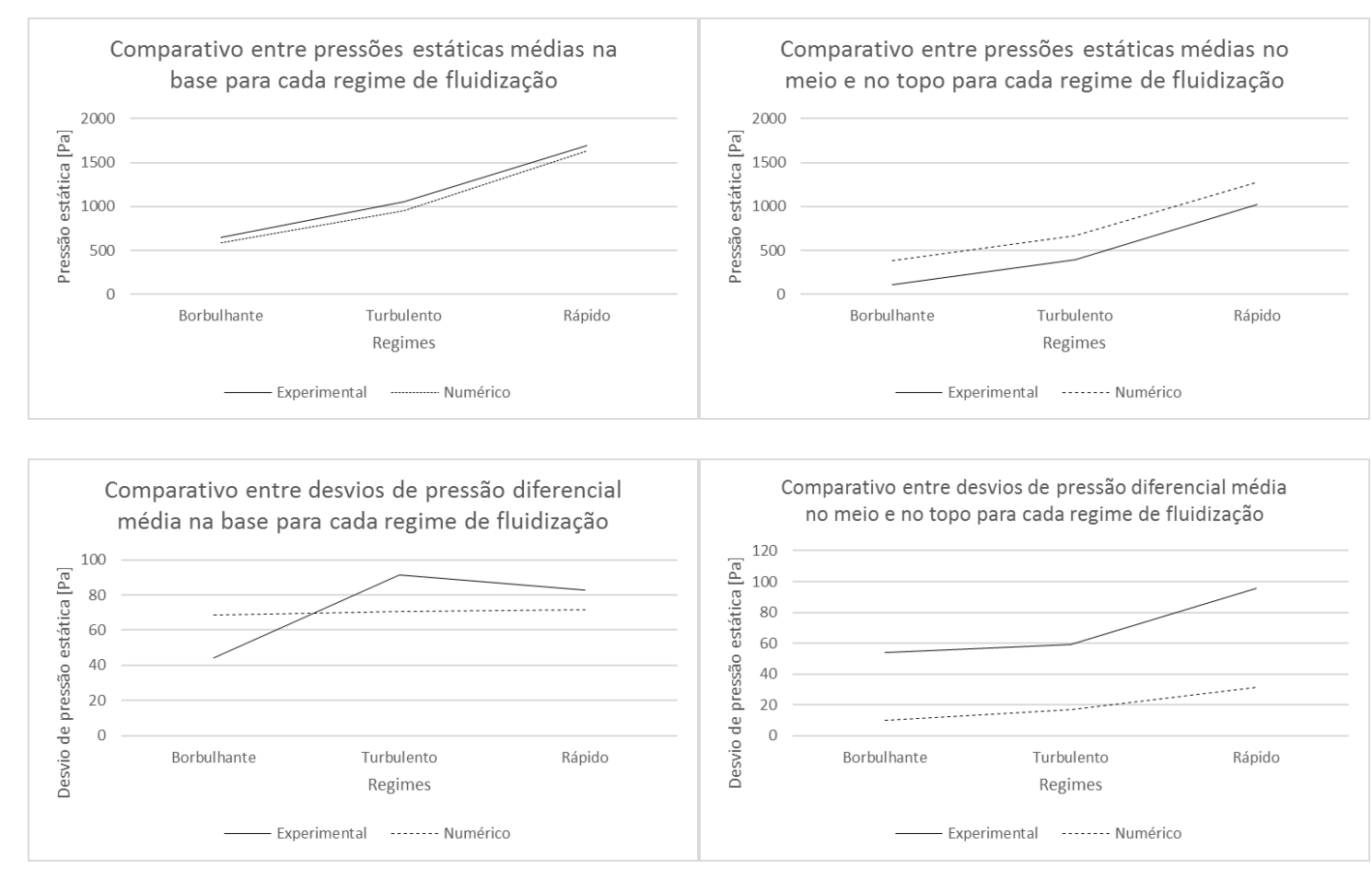

Figura 72 - Comparativo dos comportamentos das pressões estáticas médias e desvios padrão de pressão diferencial entre colunas LFC experimental e simulada.

Para encerrar o processo de aquisição de dados, é preciso conhecer a quantidade de amostra, que cada série temporal deve conter, para que as incertezas de estimação de invariantes do caos permaneçam abaixo de $1 \%$. Este estudo deve levar em conta a velocidade de aquisição do DAq e o tempo de resposta dos medidores de pressão (atraso que o medidor possui em converter a pressão mecânica em sinal condicionado), conforme o próximo item.

\subsubsection{Captura de dados}

A captura de dados refere-se ao processo que trata a taxa de aquisição dos sinais de flutuações de pressão estática, nas três regiões, simultaneamente. Os dados de pressão são coletados quase simultaneamente, nas três regiões da coluna, separados por vírgula, e com precisão de seis dígitos. A coleta de dados conta com uma aplicação desenvolvida no software proprietário Labview (National Instruments) e hardware NI PCI-6251, o qual permite o monitoramento, a captura e apresentação os dados da série temporal pressão estática em gráficos. A captura pode ser habilitada ou não através de um botão, conforme a Figura 73. 

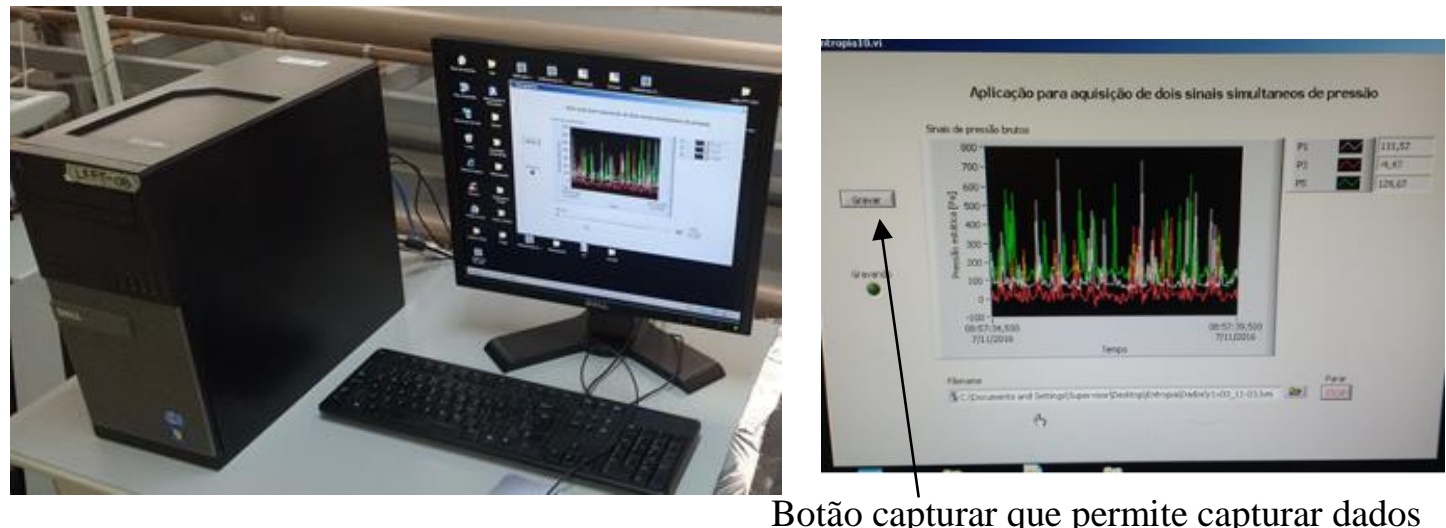

Figura 73 - Aplicação para aquisição de dados desenvolvida em Labveiw para observação de flutuação de pressão estática em três regiões (base, meio e topo) ao longo da coluna LFC.

Com as medições bem condicionadas (faixas operacionais, blindagem e isolamento), corretamente posicionadas e com aplicação para permitir o correto armazenamento das séries temporais, o sistema de aquisição foi considerado satisfatório para efetuar os ensaios experimentais.

\subsection{Ensaios experimentais}

O planejamento dos ensaios experimentais foi baseado em estudos teóricos da fluidodinâmica de leito fluidizado. Há dois principais fatos que suportam a proposta deste trabalho. O primeiro, é a presença dos sólidos num escoamento multifásico, modificar o padrão de flutuações na pressão estática. A segunda, é que numa coluna de seção cilíndrica, os regimes de fluidização formados modificam o padrão de flutuação axial da pressão estática, conforme o movimento local dos sólidos naquela região. Este movimento local pode ser caracterizado pelos perfis de porosidade locais radial e axial de uma dada região. A realização desta medição pode ser fisicamente não realizável, longe das condições laboratoriais. Na prática, a tecnologia de leito fluidizado pode ser aplicada em diversas condições de pressão ( 0 a 40 bar) e temperatura (ambiente a $1100{ }^{\circ} \mathrm{C}$ ), sendo impraticável o uso de instrumentos diferentes dos medidores de pressão (estática ou diferencial) e temperatura.

Os primeiros estudos de quantificação de regimes de fluidização a partir de séries temporais de sinais de flutuação, avaliaram a amplitude e frequência do sinal resultante, para tentar reconstruir o comportamento da coluna LFC. Seus resultados confirmaram que a presença de diferentes características de sólidos, pode ser quantificada proporcionalmente ao padrão de escoamento desempenhado. Contudo, a escala da coluna (laboratorial a industrial) e a quantificação convencional, a partir de um único ponto de medida, pode resultar algumas inconsistências.

A primeira inconsistência da quantificação convencional dos regimes de fluidização, encontra-se em avaliar o regime global de uma coluna com apenas uma medição. O problema de fluidização numa coluna LFC trata de um problema não-linear espaço-temporal, onde diversas medidas são necessárias para caracterizar os estados ou regimes de fluidização.

A segunda inconsistência da quantificação convencional dos regimes de fluidização, encontra-se na escolha de parâmetros estatísticos, ou variantes a escala a escala do processo. Quando uma determinada amplitude e frequência se destaca, num espectro de Fourier, em determinado regime de fluidização, estes valores (amplitude e frequência) não se preservam se a mesmo tipo de partícula e regime de fluidização for realizado numa coluna LFC com escala maior. Portanto, a quantificação de sistema 
dinâmico através de parâmetros variantes à sua escala, necessitará de um procedimento de calibração para cada tipo de coluna, identificando os mínimos e máximos.

Esta proposta de quantificação visa contribuir para solução das inconsistências apresentadas realizando mais de uma medida e avaliação do sinal de pressão por invariantes do caos. Em termos de evolução axial de algumas invariantes do caos, foram identificadas três regiões características: a base, o meio e o topo. Quanto aos tipos de invariantes do caos, foram testadas a entropia de Kolmogorov, a dimensão de correlação e o expoente de Hurst.

A Figura 74, apresenta a nova metodologia experimental para quantificação de regimes de fluidização em coluna LFC. A coluna LFC é preenchida com $8 \mathrm{~cm}$ de leito com diferentes tipos de sólidos: areia $1,0 \mathrm{~mm}$, areia $1,2 \mathrm{~mm}$ e partículas de vidro $0,355 \mathrm{~mm}$. Com leito na coluna, um ventilador sopra ar com diversos fluxos, através do leito de partículas, desempenhando os regimes de fluidização. Para estudar um determinado regime, a rotação do ventilador é fixada e controlada através de um inversor de frequência. $\mathrm{O}$ regime de fluidização deve ser desempenhado por um determinado período, para que o sistema de aquisição de dados registre a série temporal no tamanho adequado. A quantidade de amostras da série temporal permite avaliar a incerteza das estimativas das invariantes do caos.

Para garantir o dinamismo de operações reais de leito fluidizado, os experimentos consideram transições ascendente de regimes de fluidização. Portanto, dado a investigação de regimes borbulhantes e turbulentos, por exemplo, o ventilador é colocado na rotação que desempenha o regime borbulhante por um período determinado, e em seguida, alterna para a rotação que eleva o leito para o regime turbulento, permanecendo no período determinado. Contudo, o inverso não é testado, regimes descendentes como a transição entre turbulento para o borbulhante, conforme o gráfico da Figura 74 . A série temporal do ensaio, deve sofrer tratamento para cortar as partes transitórias e manter as flutuações em regime estacionário de cada tipo de regime, conforme pode ser visto nas linhas paralelas verticais do gráfico da Figura 74.

A medida que os regimes de fluidização são desempenhados, diferentes fluxos de materiais arrastados são impostos a coluna, influenciando consideravelmente na redução do inventário de massa. Quando o arrasto começa a reduzir, significativamente, o inventário, a malha de circulação deve ser acionada através da injeção de ar lateral da válvula L (vide detalhe na Figura 74), para empurrar os sólidos de volta para coluna. 


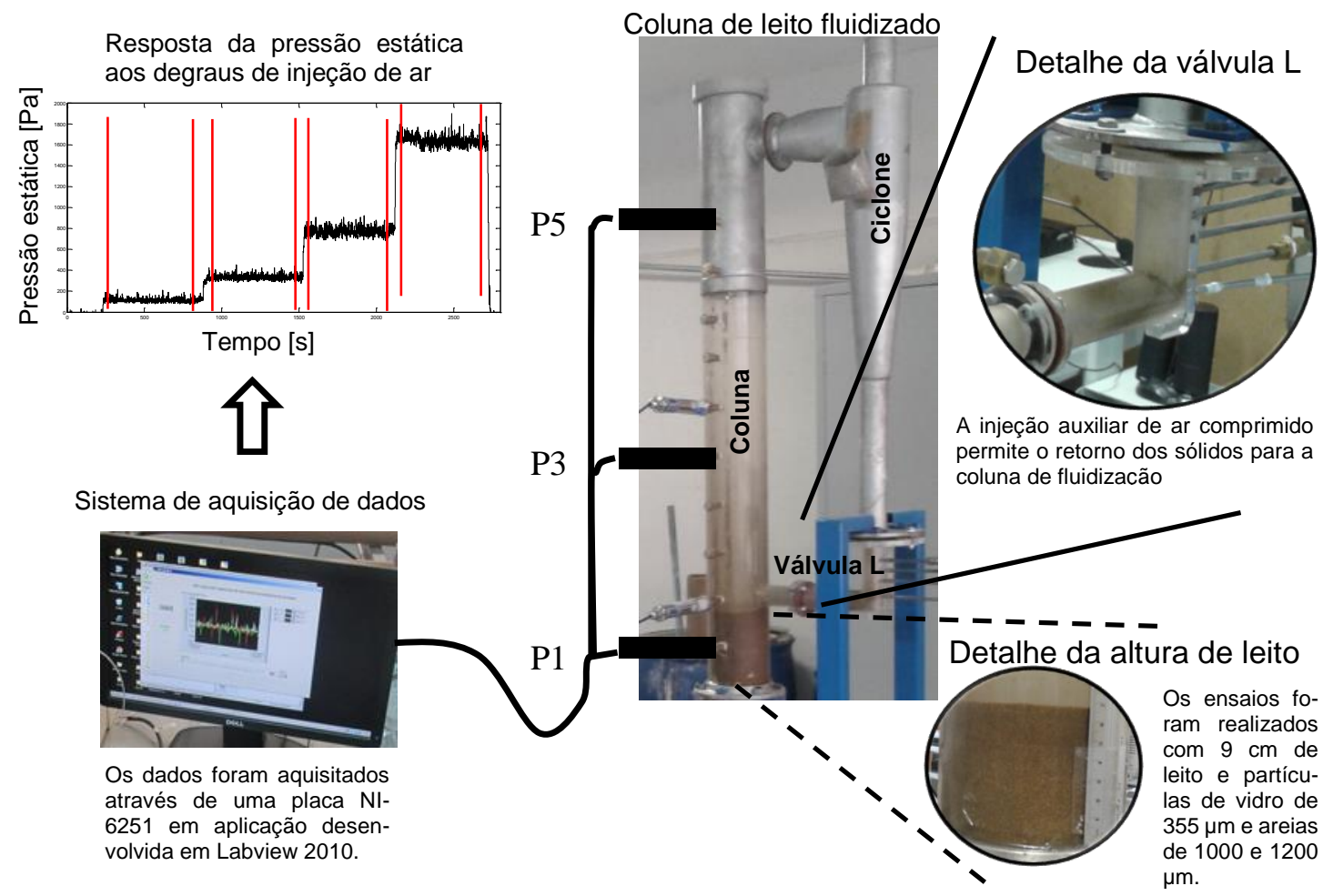

Figura 74 - Proposta de metodologia experimental para quantificação de regimes de fluidização em coluna LFC.

Para garantir que cada tipo de partícula desenvolva o mesmo tipo de escoamento, cada regime de fluidização experimental deve ser fixado com base nas descrições qualitativas da literatura [54]. A definição do estado de fluidização é importante para garantir que quantificação proposta retrate o regime a ser controlado.

\subsubsection{Regimes experimentais}

O mesmo procedimento utilizado para identificar os regimes de fluidização na coluna numérica, foi utilizado para a coluna experimental. Com parede transparente, um operador pode desenvolver diversos regimes de fluidização modificando o fluxo de ar, através da mudança da rotação do ventilador. Os regimes experimentais desempenhados foram: expandido, borbulhante, turbulento e rápido. Contudo, apenas os regimes borbulhante, turbulento e rápido foram investigados, pois a modelagem numérica usada não previu satisfatoriamente a expansão do leito.

O primeiro regime experimental alcançado foi o expandido, conforme a Figura 75. Nele, uma pequena expansão pode ser visualmente verificada e uma flutuação da superfície do leito. Nesse regime, o ar atravessa o leito sem deformá-lo, distanciando as partículas, mas mantendo o leito coeso. Contudo, esse regime não será investigado devido ao seu baixo uso em aplicações industriais, e as dificuldades de evidenciar o efeito de expansão do leito através de simulação numérica, usando modelo TFM.

Conforme a Figura 75, o regime borbulhante foi identificado variando a rotação do ventilador até a confirmação visual de formação de bolhas através do leito de partículas. Nesse regime, bolhas são formadas e atravessam o leito em grande velocidade, promovendo seu movimento, mas o leito continua coeso. As bolhas provocam flutuações características na medição de pressão de base. 
Aumentando a rotação do ventilador, a partir do regime borbulhante, percebe-se que as bolhas discretas se transformam numa passagem de ar mais contínua, pela parte central do leito, tornando-se o regime turbulento. $\mathrm{O}$ ar na parte central, promove arrasto nas partículas, e a medida que caminham pelo bordo livre (freeboard), dissipam a energia de transporte, provocando um movimento de sobe e desce no leito, conforme indicado na Figura 75.

A partir do regime turbulento, e aumentando a rotação do ventilador até que a passagem de ar, pela parte central, torne-se plenamente contínua e seja possível identificar uma circulação interna, o escoamento alcança o regime rápido. A Figura 75, apresenta um instantâneo do escoamento núcleo-anelar, característico do regime rápido, onde a porção central diluída é arrastada para topo da coluna, enquanto a porção anelar densa cai para a base da coluna.

O regime de transporte pneumático não foi investigado devido ao subdimensionamento do diâmetro de descarga inferior de sólidos do ciclone da planta proposta. Quando ocorrera o transporte pneumático, na coluna, todo o material acumulava no ciclone e o inventário de massa reduzira a zero.

Borbulhante

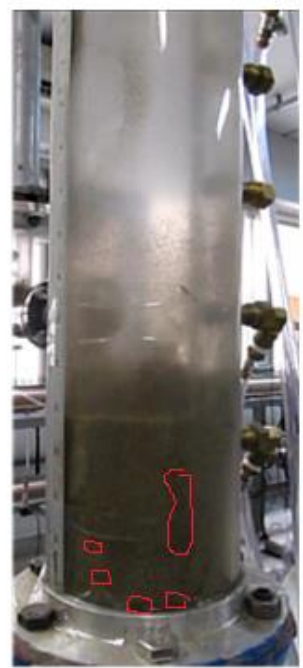

Turbulento

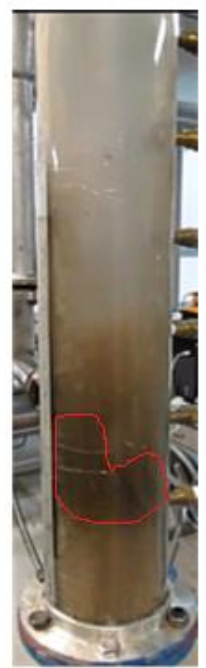

Rápido

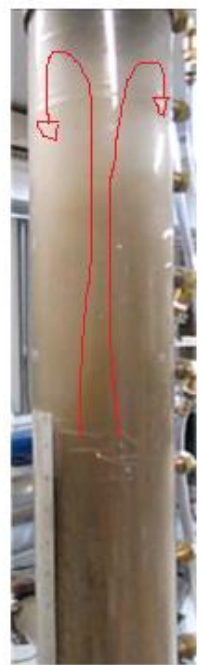

Figura 75 - Definição dos regimes de fluidização experimental usados para nova proposta de quantificação.

Através de uma coluna LFC transparente, um operador treinado consegue facilmente controlar um regime de fluidização. A necessidade de colunas LFC opacas, reside no uso de materiais refratário para conservação de calor, em aplicações de secagem, pirólise, gaseificação e combustão.

A Tabela 6 apresenta as rotações em que desempenharam regimes de fluidização para cada tipo de partícula, em leito de $8 \mathrm{~cm}$. Cada tipo de partícula impõe distintas faixas e distribuições de rotações. 
Tabela 6 - Rotação do ventilador que desempenha cada regime de fluidização para cada tipo de partícula com $8 \mathrm{~cm}$ de leito.

\begin{tabular}{c|l|c}
\hline \multicolumn{1}{c|}{ Partículas } & \multicolumn{1}{|c|}{ Regimes } & Rotações [RPM] \\
\hline \multirow{4}{*}{ Vidro 0,355 mm } & Expandido & 1548 \\
\cline { 2 - 3 } & Borbulhante & 1791 \\
\cline { 2 - 3 } & Turbulento & 2174 \\
\cline { 2 - 3 } & Rápido & 2431 \\
\hline \multirow{4}{*}{ Areia 1,0 mm } & Expandido & 1792 \\
\cline { 2 - 3 } & Borbulhante & 1948 \\
\cline { 2 - 3 } & Turbulento & 2308 \\
\cline { 2 - 3 } & Rápido & 3046 \\
\hline \multirow{4}{*}{ Areia 1,2 mm } & Expandido & 1699 \\
\cline { 2 - 3 } & Borbulhante & 1900 \\
\cline { 2 - 3 } & Turbulento & 2411 \\
\cline { 2 - 3 } & Rápido & 2960 \\
\hline
\end{tabular}

O conhecimento prévio da distribuição de rotações para cada tipo de partícula, com mesmo nível de leito, permite realizar ensaios capazes de produzir séries temporais dos sinais de flutuação de pressão estática, em três regiões da coluna LFC, e com tamanho adequado. Cada série observada pode ser submetida a um processo para quantificação de suas flutuações e evolução ao longo de diferentes posições da coluna e condições operacionais (regimes) submetidos. O procedimento experimental descreve como os ensaios são planejados para alcançar a proposta de quantificação global do regime de desenvolvido numa coluna LFC.

\subsubsection{Procedimento experimental}

O planejamento do experimento é dividido em três partes: a confirmação influência dos sólidos sob o aspecto das flutuações de pressão estática ao longo da coluna LFC; a quantificação dos regimes, promovida por diferentes gradientes, mas mantendo o nível e inventário de leito constante; e a quantificação dos regimes mantendo o gradiente de pressão constante e promovendo diferentes regimes de fluidização pela redução do nível do leito (o inventário permanece constante para cada escolha de nível de leito).

\subsubsection{Ensaio de coluna vazia}

O ensaio de coluna vazia tem o objetivo de observar o comportamento de invariantes do caos numa coluna sem leito. A importância deste ensaio reside em testar a influência do escoamento multifásico (gás-sólido) nas flutuações de pressão estática e na quantificação local, através das invariantes.

Com uma coluna vazia, a rotação do ventilador foi submetida a diferentes rotações e, portanto, diferentes fluxos de ar. O escoamento monofásico, em diferentes fluxos, pode produzir diferentes flutuações detectável na pressão estática, permitindo a quantificação da coluna vazia.

A Tabela 7 apresenta lista de eventos para o ensaio de coluna vazia, evidenciando a transição entre as rotações (fluxos). Para a primeira repetição, a rotação é nula e a gravação de dados é habilitada por alguns minutos, onde toda gravação é sempre realizada de forma isolada da rede. Em seguida, a rotação é alterada para 500 RPM, permanecendo ali por $10 \mathrm{~min}$. O passo seguinte, eleva a rotação para 1000 
RPM e permanece por 10 min. Em seguida, a rotação é novamente elevada para 2000 RPM, permanecendo por $10 \mathrm{~min}$. O passo seguinte, a rotação é elevada para $3000 \mathrm{RPM}$, permanecendo por 10 min. Após os patamares de rotações mencionados, permanecendo ao 10 min em cada nível, o ventilador é então desligado. Este processo é repetido por cinco vezes par garantir repetibilidade.

Tabela 7 - Lista de eventos de ensaio de coluna LFC vazia, identificando os instantes de mudança de rotação.

\begin{tabular}{|c|c|c|c|}
\hline Repetição & Data e hora & Descrição de eventos & Rotação [RPM] \\
\hline \multirow{6}{*}{1} & 19/01/2016 08:13 & Gravação de dados (vazio1.lvm) & 0 \\
\hline & $19 / 01 / 201608: 13$ & Partida do ventilador & 500 \\
\hline & $19 / 01 / 201608: 23$ & Mudança de rotação & 1000 \\
\hline & $19 / 01 / 201608: 33$ & Mudança de rotação & 2000 \\
\hline & $19 / 01 / 201608: 43$ & Mudança de rotação & 3000 \\
\hline & $19 / 01 / 201608: 43$ & Parada do ventilador & 0 \\
\hline \multirow{6}{*}{2} & 20/01/2016 09:08 & Gravação de dados (vazio2.lvm) & 0 \\
\hline & 20/01/2016 09:08 & Partida do ventilador & 500 \\
\hline & $20 / 01 / 201609: 18$ & Mudança de rotação & 1000 \\
\hline & $20 / 01 / 201609: 28$ & Mudança de rotação & 2000 \\
\hline & $20 / 01 / 201609: 38$ & Mudança de rotação & 3000 \\
\hline & $20 / 01 / 201609: 38$ & Parada do ventilador & 0 \\
\hline \multirow{6}{*}{3} & $20 / 01 / 201610: 05$ & Gravação de dados (vazio3.lvm) & 0 \\
\hline & $20 / 01 / 201610: 05$ & Partida do ventilador & 500 \\
\hline & $20 / 01 / 201610: 15$ & Mudança de rotação & 1000 \\
\hline & $20 / 01 / 201610: 25$ & Mudança de rotação & 2000 \\
\hline & $20 / 01 / 201610: 35$ & Mudança de rotação & 3000 \\
\hline & $20 / 01 / 201610: 35$ & Parada do ventilador & 0 \\
\hline \multirow{6}{*}{4} & $20 / 01 / 201611: 05$ & Gravação de dados (vazio4.lvm) & 0 \\
\hline & 20/01/2016 11:05 & Partida do ventilador & 500 \\
\hline & $20 / 01 / 201611: 15$ & Mudança de rotação & 1000 \\
\hline & $20 / 01 / 201611: 25$ & Mudança de rotação & 2000 \\
\hline & $20 / 01 / 201611: 35$ & Mudança de rotação & 3000 \\
\hline & $20 / 01 / 201611: 35$ & Parada do ventilador & 0 \\
\hline \multirow{6}{*}{5} & $20 / 01 / 201612: 01$ & Gravação de dados (vazio5.lvm) & 0 \\
\hline & 20/01/2016 12:01 & Partida do ventilador & 500 \\
\hline & $20 / 01 / 201612: 11$ & Mudança de rotação & 1000 \\
\hline & $20 / 01 / 201612: 21$ & Mudança de rotação & 2000 \\
\hline & $20 / 01 / 201612: 31$ & Mudança de rotação & 3000 \\
\hline & $20 / 01 / 201612: 31$ & Parada do ventilador & 0 \\
\hline
\end{tabular}

Como uma coluna LFC possui tomadas de saída e entrada (malha circulante) as flutuações de pressão estática pode sofrer diferentes mudanças devido a rotação do ventilador.

\subsubsection{Ensaio a nível constante}

O ensaio a nível constante, estabelece um leito de $8 \mathrm{~cm}$ de nível (proporção de operação de 7-8\% da altura da coluna, geralmente, utilizadas em gaseificadores LFC), de diferentes tipos de partícula (vidro e areia), operando com inventário constante (efeito circulante), onde diferentes gradientes de pressão provocam os regimes de fluidização.

A Tabela 8 descreve os eventos ocorridos durante as cinco repetições de ensaio a nível constante para as partículas de vidro $0,355 \mathrm{~mm}$. Na primeira repetição, a gravação dos dados é iniciada por alguns minutos e com o leito empacotado. Em seguida, a rotação do ventilador é conduzida para 1548 RPM (conforme identificação da Tabela 6), mantendo o leito em regime expandido por $10 \mathrm{~min}$. O passo seguinte, incrementou uma nova rampa na rotação do ventilador para 1791 RPM, provocando o regime borbulhante, permanecendo neste regime por $10 \mathrm{~min}$. Como o regime borbulhante impõe um pequeno arrasto, o ar lateral da válvula L é acionado e ajustado para promover o transporte proporcional de volta para a coluna LFC. Em seguida, a rotação é elevada para 1791 RPM, alcançando o regime turbulento e 
permanecendo por $10 \mathrm{~min}$, impondo um novo arrasto, sendo necessário um novo ajuste da válvula L, para reposição de partícula e manutenção do inventário de massa. Por fim, a rotação do ventilador é elevada para 2431 RPM, conduzindo o leito para novo estado, o regime rápido, em que é necessário um novo ajuste na válvula $\mathrm{L}$, para manutenção do inventário de massa.

Tabela 8 - Lista de eventos de ensaio a nível constante, identificando os momentos e tipos de ajustes para manter o inventário constante.

\begin{tabular}{|c|c|c|c|c|}
\hline \multicolumn{5}{|c|}{ Partícula de vidro dp $=355 \mu \mathrm{m}$} \\
\hline Repetição & Data e hora & Descrição de eventos & Rotação [RPM] & Regime \\
\hline \multirow{6}{*}{1} & 20/01/2016 16:09 & Gravação de dados (ensaio1.lvm) & 0 & Leito empacotado \\
\hline & 20/01/2016 16:09 & Partida do ventilador & 1548 & Leito expandido \\
\hline & 20/01/2016 16:19 & Mudança de rotação e ajuste na válvula L & 1791 & Leito borbulhante \\
\hline & 20/01/2016 16:29 & Mudança de rotação e ajuste na válvula $\mathrm{L}$ & 2174 & Leito turbulento \\
\hline & 20/01/2016 16:39 & Mudança de rotação e ajuste na válvula $L$ & 2431 & Leito rápido \\
\hline & 20/01/2016 16:49 & Parada do ventilador & 0 & Leito empacotado \\
\hline \multirow{6}{*}{2} & 20/01/2016 16:50 & Gravação de dados (ensaio2.lvm) & 0 & Leito empacotado \\
\hline & 20/01/2016 16:50 & Partida do ventilador & 1548 & Leito expandido \\
\hline & 20/01/2016 17:00 & Mudança de rotação e ajuste na válvula L & 1791 & Leito borbulhante \\
\hline & 20/01/2016 17:10 & Mudança de rotação e ajuste na válvula L & 2174 & Leito turbulento \\
\hline & 20/01/2016 17:20 & Mudança de rotação e ajuste na válvula $L$ & 2431 & Leito rápido \\
\hline & 20/01/2016 17:30 & Parada do ventilador & 0 & Leito empacotado \\
\hline \multirow{6}{*}{3} & $20 / 01 / 201617: 35$ & Gravação de dados (ensaio3.lvm) & 0 & Leito empacotado \\
\hline & 20/01/2016 17:35 & Partida do ventilador & 1548 & Leito expandido \\
\hline & 20/01/2016 17:45 & Mudança de rotação e ajuste na válvula $L$ & 1791 & Leito borbulhante \\
\hline & 20/01/2016 17:55 & Mudança de rotação e ajuste na válvula L & 2174 & Leito turbulento \\
\hline & 20/01/2016 18:05 & Mudança de rotação e ajuste na válvula $\mathrm{L}$ & 2431 & Leito rápido \\
\hline & 20/01/2016 18:15 & Parada do ventilador & 0 & Leito empacotado \\
\hline \multirow{6}{*}{4} & 20/01/2016 18:22 & Gravação de dados (ensaio4.lvm) & 0 & Leito empacotado \\
\hline & 20/01/2016 18:22 & Partida do ventilador & 1548 & Leito expandido \\
\hline & 20/01/2016 18:32 & Mudança de rotação e ajuste na válvula L & 1791 & Leito borbulhante \\
\hline & 20/01/2016 18:43 & Mudança de rotação e ajuste na válvula $L$ & 2174 & Leito turbulento \\
\hline & $20 / 01 / 201618: 53$ & Mudança de rotação e ajuste na válvula $\mathrm{L}$ & 2431 & Leito rápido \\
\hline & 20/01/2016 19:04 & Parada do ventilador & 0 & Leito empacotado \\
\hline \multirow{6}{*}{5} & 20/01/2016 19:10 & Gravação de dados (ensaio5.lvm) & 0 & Leito empacotado \\
\hline & 20/01/2016 19:10 & Partida do ventilador & 1548 & Leito expandido \\
\hline & 20/01/2016 19:20 & Mudança de rotação e ajuste na válvula $L$ & 1791 & Leito borbulhante \\
\hline & 20/01/2016 19:30 & Mudança de rotação e ajuste na válvula $L$ & 2174 & Leito turbulento \\
\hline & 20/01/2016 19:40 & Mudança de rotação e ajuste na válvula $L$ & 2431 & Leito rápido \\
\hline & 20/01/2016 19:50 & Parada do ventilador & 0 & Leito empacotado \\
\hline
\end{tabular}

Em cada patamar de rotação ou regime de fluidização, os dados são gravados durante 10 min e de forma protegida (blindado e isolado da rede) e o ensaio é repetido por cinco vezes para o mesmo tipo de partícula. Em cada repetição três séries temporais (base, meio e topo) são geradas com aproximadamente 18.000 dados cada (já desprezando as partes transientes da série ou cotes mencionados na Figura 74).

Uma Tabela 8 também foi gerada para as partículas de área $1,0 \mathrm{~mm}$ e areia $1,2 \mathrm{~mm}$, para manter o rastreamento do ensaio das análises.

\subsubsection{Ensaio a gradiente constante}

Um gradiente fixo de pressão pode provocar diferentes regimes de fluidização, alterando a massa de leito, alterando seu nível. Para cada altura de leito fixada o inventário de massa permanece constante. $\mathrm{O}$ propósito deste ensaio é de confirmar a robustez da quantificação pelas invariantes, face aos regimes de fluidização, em diferentes níveis de leito.

A Tabela 8 descreve os eventos ocorridos na realização dos ensaios com o gradiente constante de pressão (220 Pa) sobre um leito de areia 1,0 mm de diferentes níveis. O gradiente é fixado entre a tomadas P1 ( $9 \mathrm{~cm}$ da base) e P3 (45 cm da base) pela rotação do ventilador, enquanto a altura do nível do leito é 
modificada até que um regime de fluidização se desenvolva. Na primeira repetição, a gravação de dados é iniciada a rotação nula, por alguns minutos, Em seguida, com um nível de $10 \mathrm{~cm}$ de leito de areia 1,0 m e uma rotação do ventilador de 1707 RPM o regime expandido manteve-se por 10 min. Em seguida, reduzindo o nível para $9 \mathrm{~cm}$ de leito e elevando a rotação para 17085 RPM, foi possível desenvolver o regime de fluidização borbulhante, com duração de $10 \mathrm{~min}$. $\mathrm{O}$ regime turbulento pode ser alcançado, reduzindo o nível para $7 \mathrm{~cm}$ e aumentando a rotação para 2039 RPM e permanecendo por $10 \mathrm{~min}$. Por fim, com a redução do nível para $6 \mathrm{~cm}$, aumento da rotação para 2769 RPM e permanecendo por 10 min, foi possível investigar o regime rápido.

Tabela 9 - Lista de eventos de ensaio de gradiente de pressão constante, identificando os momentos, configurações do nível de leito e ajustes para manter o inventário constante.

\begin{tabular}{|c|c|c|c|c|}
\hline \multicolumn{5}{|c|}{ Partícula de areia dp = 1,0 mm, pressão diferencial 220 Pa (P1 - P3) } \\
\hline Repetição & Data e hora & Descrição de eventos & Rotação [RPM] & Regime \\
\hline \multirow{6}{*}{1} & 14/12/2016 10:00 & Gravação de dados (diferencial1.lvm) & 0 & Leito empacotado \\
\hline & 14/12/2016 10:00 & Nível de $10 \mathrm{~cm}$ de leito e ajuste de rotação & 1707 & Leito expandido \\
\hline & 14/12/2016 10:10 & Nível de 9 cm de leito, ajuste de rotação e válvula $\mathrm{L}$ & 1785 & Leito borbulhante \\
\hline & $14 / 12 / 201610: 20$ & Nível de $7 \mathrm{~cm}$ de leito, ajuste de rotação e válvula $\mathrm{L}$ & 2039 & Leito turbulento \\
\hline & 14/12/2016 10:30 & Nível de $6 \mathrm{~cm}$ de leito, ajuste de rotação e válvula L & 2769 & Leito rápido \\
\hline & $14 / 12 / 201610: 39$ & Parada do ventilador & 0 & Leito empacotado \\
\hline \multirow{6}{*}{2} & 14/12/2016 11:02 & Gravação de dados (diferencial2.lvm) & 0 & Leito empacotado \\
\hline & 14/12/2016 11:02 & Nível de $10 \mathrm{~cm}$ de leito e ajuste de rotação & 1707 & Leito expandido \\
\hline & $14 / 12 / 201611: 12$ & Nível de 9 cm de leito, ajuste de rotação e válvula L & 1785 & Leito borbulhante \\
\hline & $14 / 12 / 201611: 22$ & Nível de $7 \mathrm{~cm}$ de leito, ajuste de rotação e válvula L & 2039 & Leito turbulento \\
\hline & $14 / 12 / 201611: 32$ & Nível de $6 \mathrm{~cm}$ de leito, ajuste de rotação e válvula $\mathrm{L}$ & 2769 & Leito rápido \\
\hline & $14 / 12 / 201611: 32$ & Parada do ventilador & 0 & Leito empacotado \\
\hline \multirow{6}{*}{3} & 14/12/2016 15:04 & Gravação de dados (diferencial3.lvm) & 0 & Leito empacotado \\
\hline & $14 / 12 / 2016$ 15:04 & Nível de $10 \mathrm{~cm}$ de leito e ajuste de rotação & 1707 & Leito expandido \\
\hline & 14/12/2016 15:14 & Nível de $9 \mathrm{~cm}$ de leito, ajuste de rotação e válvula L & 1785 & Leito borbulhante \\
\hline & $14 / 12 / 201615: 24$ & Nível de 7 cm de leito, ajuste de rotação e válvula L & 2039 & Leito turbulento \\
\hline & $14 / 12 / 201615: 34$ & Nível de $6 \mathrm{~cm}$ de leito, ajuste de rotação e válvula $\mathrm{L}$ & 2769 & Leito rápido \\
\hline & $14 / 12 / 201615: 34$ & Parada do ventilador & 0 & Leito empacotado \\
\hline \multirow{6}{*}{4} & $14 / 12 / 201616: 22$ & Gravação de dados (diferencial4.lvm) & 0 & Leito empacotado \\
\hline & $14 / 12 / 201616: 22$ & Nível de $10 \mathrm{~cm}$ de leito e ajuste de rotação & 1707 & Leito expandido \\
\hline & $14 / 12 / 201616: 32$ & Nível de $9 \mathrm{~cm}$ de leito, ajuste de rotação e válvula $\mathrm{L}$ & 1785 & Leito borbulhante \\
\hline & $14 / 12 / 201616: 43$ & Nível de $7 \mathrm{~cm}$ de leito, ajuste de rotação e válvula L & 2039 & Leito turbulento \\
\hline & $14 / 12 / 201616: 53$ & Nível de $6 \mathrm{~cm}$ de leito, ajuste de rotação e válvula L & 2769 & Leito rápido \\
\hline & 14/12/2016 16:04 & Parada do ventilador & 0 & Leito empacotado \\
\hline \multirow{6}{*}{5} & $14 / 12 / 201617: 12$ & Gravação de dados (diferencial5.lvm) & 0 & Leito empacotado \\
\hline & $14 / 12 / 201617: 12$ & Nível de $10 \mathrm{~cm}$ de leito e ajuste de rotação & 1707 & Leito expandido \\
\hline & $14 / 12 / 201617: 22$ & Nível de 9 cm de leito, ajuste de rotação e válvula L & 1785 & Leito borbulhante \\
\hline & $14 / 12 / 201617: 32$ & Nível de 7 cm de leito, ajuste de rotação e válvula L & 2039 & Leito turbulento \\
\hline & $14 / 12 / 201617: 43$ & Nível de $6 \mathrm{~cm}$ de leito, ajuste de rotação e válvula L & 2769 & Leito rápido \\
\hline & $14 / 12 / 201617: 44$ & Parada do ventilador & 0 & Leito empacotado \\
\hline
\end{tabular}

O ensaio com gradiente constante foi repetido cinco vezes e apenas para areia 1,0 $\mathrm{mm}$. Cada regime de fluidização teve duração de 10 min de para coleta de dados, o qual produz séries temporais adequadas (em tamanho e taxa amostral) para realização de análises não-lineares.

\subsubsection{Análise não-linear}

Os ensaios produziram séries temporais, ao longo de três regiões da coluna LFC experimental, em diversos estados de fluidização. Na avaliação clássica de Fourier, os sinais experimentais de flutuação de pressão estática produzem, em sua maioria, espectros distribuídos, a avaliação não-linear passa a contribuir para a quantificação local. A análise não-linear, aqui proposta, resgata das séries temporais características invariantes, comuns aos sistemas dinâmicos de comportamento caótico. As invariantes permitem quantificar comportamentos dinâmicos, a partir de séries observáveis (comuns ao controle de processos industriais), que pode ser conservado para sistema em escala piloto ou escalonado. Portanto, 
a reconstrução de mapas de fluidização a partir de invariantes do caos poderia contribuir para solucionar o problema que os atuais mapas adimensionalizados [18] [20] enfrentam, devido ao subdimensionamento dos regimes de fluidização, durante o escalonamento de unidades.

A análise não-linear foi dividida em três etapas. Na primeira etapa, um estudo da informação mútua de cada série (em cada região e regime específico) foi realizado para reconstrução do espaço de fase a partir de coordenadas de atraso. Na etapa seguinte, as séries foram avaliadas sobre a dimensão de correlação, quantificando a complexidade da flutuação de pressão, e a entropia de Kolmogorov, para avaliar a o grau de desordem destes sinais. A terceira e última etapa, as séries foram avaliadas por algoritmo de estimativa do expoente de Hurst, capaz de quantificar a rugosidade da série, onde zero, é totalmente rugosa, e um, é classificada como suave.

\subsubsection{Reconstrução do espaço de fase}

Para realização do estudo de informação mútua, foi utilizado o pacote aberto TISEAN [182] de softwares para análises não-lineares, de fácil acesso e instalação, compilado em C++ e executado sob a plataforma Windows. Sua parametrização, permite a integração com outros softwares de análise, como o Matlab, agilizando a geração de resultados.

Uma série temporal, em arquivo texto, por exemplo b1p5.txt, pode ser submetida ao estudo de informação mútua através do comando mutual.exe b1p5.txt -D100 -ob1p5_k.txt. Em poucos segundos, um novo arquivo b1p5_k.txt é gerado relacionando a informação mútua normalizada com atrasos de tempo da série em análise.

A Figura 76 apresenta o resultado do estudo de informação mútua de uma série temporal de flutuação de pressão estática, localizada na tomada P5 (90 cm da base da coluna LFC), indicando trabalhar com 11 períodos de atraso para a reconstrução do espaço de estado, usando coordenadas de atraso. Conforme Fraser e Swinney que estabeleceram o critério do primeiro de forma contabilizar a dinâmica não-linear [145].

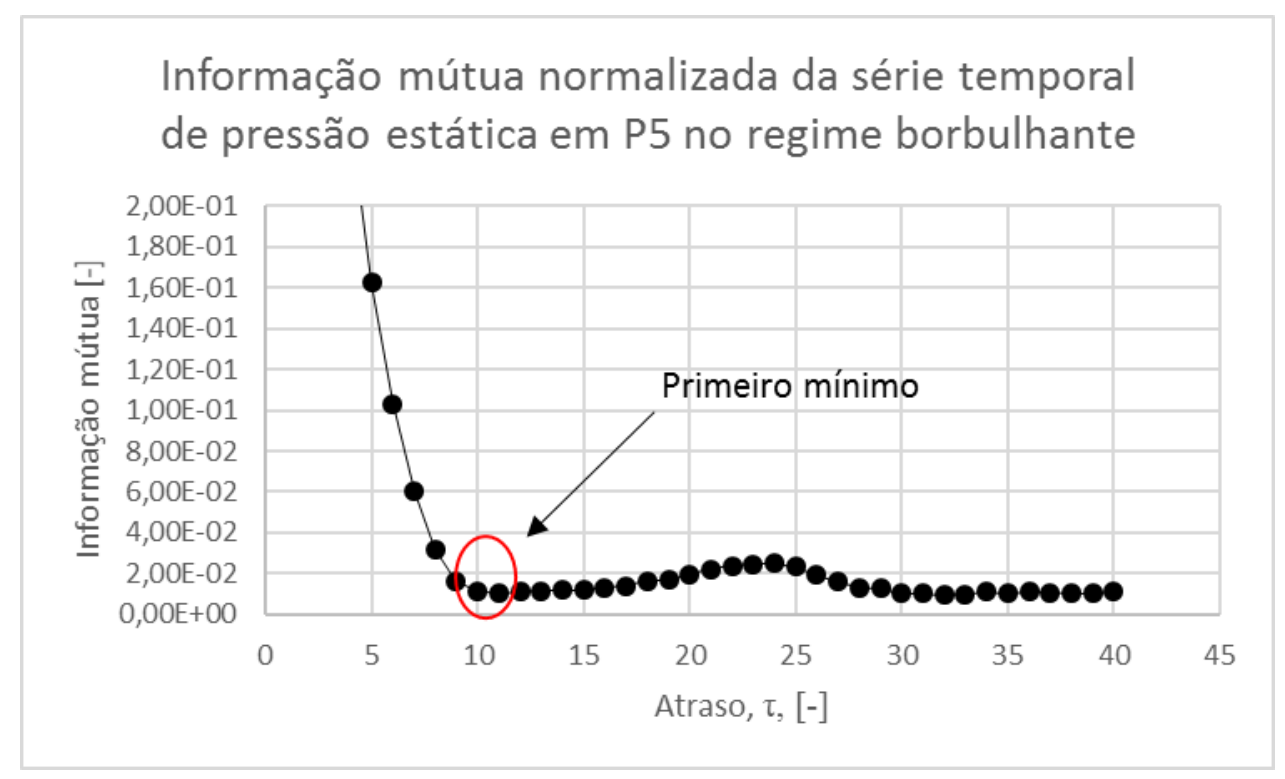

Figura 76 - Estudo de informação mútua de série temporal de flutuação de pressão estática na tomada P5 (90 cm da base), indicando um atraso de 11 períodos, considerando o critério do primeiro mínimo. 
Um script no Matlab pode automatizar o processo, de forma a chamar o comando para análise do arquivo da série, carregar seu resultado e busca o primeiro mínimo, analisando a inversão de sinal. De posse do atraso indicado pela aplicação do método, pode-se reconstruir o espaço de estado, para cada região da coluna e em cada regime, permitindo investigações quanto ao seu comportamento.

\subsubsection{Dimensão de correlação e entropia de Kolmogorov}

Diferente do software mencionado no item anterior, o RRCHAOS [73], trabalha com uma interface específica para entrada de séries temporais, dificultando a automação plena de análises. O principal critério para sua escolha reside em suas implementações trabalharem com séries ruidosas para estimativa das invariantes do caos.

Conforme a Figura 77, configura-se a lista de análises desejadas para ser aplicada a cada série de entrada. Neste caso, a dimensão de correlação e a entropia de Kolmogorov (ver Figura 77). Um operador deve entrar com os arquivos das séries (um a um), fazendo com que o software gere, internamente, uma lista de paths para executar os cálculos em sequência, de cada arquivo entrada. Em seguida, no menu Calculate (vide Figura 77), o programa inicia a sequência de cálculos, produzindo um arquivo de saída para cada série, ou seja, as estimativas de dimensão de correlação e entropia de Kolmogorov de cada série estarão no mesmo arquivo. Os estimadores, implementados no RRCHAOS, estimam a incerteza de suas invariantes selecionadas.

Para automatizar a organização dos resultados, um script, no Matlab, pode varrer o conteúdo de cada arquivo de saída, buscando palavras-chave e evitando erros de manipulação de dados. Este processo de quantificação foi efetuado em todas as séries produzidas com incertezas menores ou iguais a $1 \%$.

As informações observadas e sintonizadas, através da classificação visual dos regimes de fluidização, são organizadas junto as informações processadas para estimar as invariantes do caos, para promover estudos de quantificação de regimes de fluidização da coluna LFC experimental.

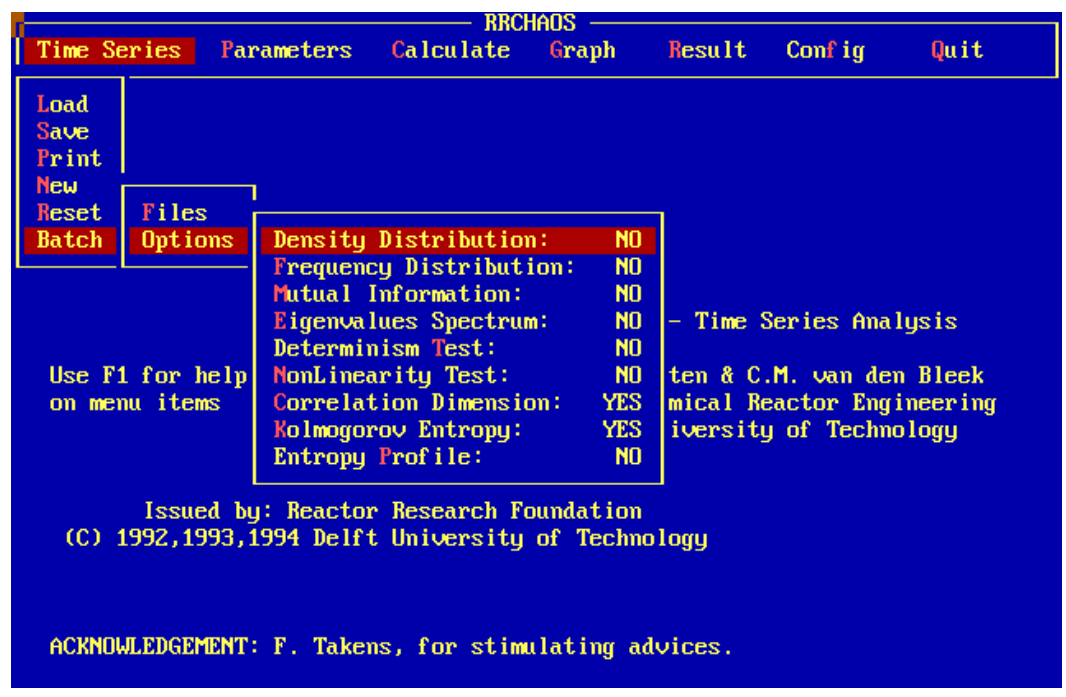

Figura 77 - Tela de configuração do software RRCHAOS para estimativa das invariantes dimensão de correlação e entropia de Kolmogorov. 


\subsubsection{Expoente de Hurst}

Para estimar o expoente de Hurst de séries temporais de sinais de flutuação de pressão estática foi utilizado a implementação de Bill Davison [183], também comparada com a implementação de Tomaso Aste [184]. Ambas implementações estão em conformidade com Steeb [74]. Como os resultados entre as implementações foram muitos próximos, para as séries experimentais, e as funções são implementadas no Matlab, o processo de automação de quantificação da rugosidade das séries foi completo.

A quantificação local de cada série temporal pela invariante do expoente de Hurst, pode ser comparada com os regimes de fluidização classificados visualmente. A análise conjunta, da quantificação de cada região, pode auxiliar no julgamento da classificação do regime de fluidização de uma coluna LFC.

A Tabela 10 apresenta um resumo da organização dos dados rastreando a classificação visual, a rotação do ventilador, o tipo de partícula, parâmetros locais variantes (pressão média e desvio padrão) e invariantes (expoente de Hurst, entropia de Kolmogorov e dimensão de correlação). Para cada tipo de partícula, foram organizados dados médios conforme a Tabela 10.

Tabela 10 - Caracterização local média dos regimes de fluidização através das invariantes do caos como expoente de Hurst, entropia de Kolmogorov e dimensão de correlação, para areia de 1,0 mm.

\begin{tabular}{|c|c|c|c|c|c|c|c|c|}
\hline Tomadas & Posição & Regimes & Rotação [RPM] & $\mathrm{P} 1[\mathrm{~Pa}]$ & $\sigma 1[\mathrm{~Pa}]$ & H1 & KML1 [bit/s] & DML1 \\
\hline \multirow{4}{*}{$\mathrm{P} 1$} & \multirow{4}{*}{$\begin{array}{l}9 \mathrm{~cm} \\
\text { (base) }\end{array}$} & Expandido & 1792 & 266,72 & 46,88 & 0,74 & 10,58 & 2,65 \\
\hline & & Borbulhante & 1948 & 412,06 & 54,31 & 0,64 & 10,73 & 3,93 \\
\hline & & Turbulento & 2308 & 911,73 & 86,19 & 0,65 & 8,96 & 4,94 \\
\hline & & Rápido & 3046 & 1630 & 102,7 & 0,90 & 6,62 & 5,06 \\
\hline \multirow{5}{*}{ P3 } & \multirow{5}{*}{$\begin{array}{l}45 \mathrm{~cm} \\
\text { (meio) }\end{array}$} & Regimes & Rotação [RPM] & $\mathrm{P} 3[\mathrm{~Pa}]$ & $\sigma 3[\mathrm{~Pa}]$ & $\mathrm{H} 3$ & KML3 [bit/s] & DML3 \\
\hline & & Expandido & 1792 & 79,34 & 52,84 & 0,42 & 11,04 & 2,96 \\
\hline & & Borbulhante & 1948 & 139,43 & 53,92 & 0,66 & 11,32 & 2,93 \\
\hline & & Turbulento & 2308 & 517,73 & 59,18 & 0,67 & 12,30 & 4,31 \\
\hline & & Rápido & 3046 & 1130,1 & 95,65 & 0,89 & 11,93 & 4,43 \\
\hline \multirow{5}{*}{ P5 } & \multirow{5}{*}{$\begin{array}{l}90 \mathrm{~cm} \\
\text { (topo) }\end{array}$} & Regimes & Rotação [RPM] & P5 [Pa] & $\sigma 5[\mathrm{~Pa}]$ & H5 & $\mathrm{K} 5[\mathrm{bit} / \mathrm{s}]$ & DML5 \\
\hline & & Expandido & 1792 & 88,81 & 52,71 & 0,49 & 11,18 & 3,36 \\
\hline & & Borbulhante & 1948 & 144,44 & 54,72 & 0,68 & 11,09 & 3,73 \\
\hline & & Turbulento & 2308 & 513,51 & 59,46 & 0,67 & 12,17 & 5,19 \\
\hline & & Rápido & 3046 & 1078,3 & 92,57 & 0,88 & 12,18 & 5,11 \\
\hline
\end{tabular}

Esta metodologia de quantificação permite avaliar a evolução das características invariantes locais para composição de um índice capaz de classificar os regimes de fluidização de uma coluna LFC. 


\section{RESULTADOS E DISCUSSÃO}

Este capítulo apresenta os resultados alcançados pela metodologia proposta no capítulo anterior. A quantificação clássica, baseada na pressão diferencial, é reconstruída para evidenciar sua insuficiência na classificação de regimes de fluidização. A quantificação, baseada nas invariantes do caos, permite caracterizar, localmente, o escoamento gás-sólido numa coluna LFC. O comportamento local de algumas invariantes, é conservado face ao tipo de regime de fluidização imposto na coluna. As invariantes, ao longo da coluna, podem ser associadas para elaboração de um índice de quantificação global de uma coluna LFC. $O$ índice proposto pode ser ensaiado para avaliação de desempenho em aplicação de controle de regimes de fluidização em processos industriais.

Estes resultados são descritos em quatro etapas para consolidar um índice para quantificação de regimes de fluidização em colunas LFC.

$\mathrm{Na}$ primeira etapa, a quantificação clássica remonta as primeiras propostas de metodologias de quantificação, válidas apenas para as condições específicas (operacionais e tipos de partículas) da escala do problema. Portanto, o comportamento da evolução do desvio padrão na base de uma coluna LFC, por exemplo, para um mesmo regime de fluidização, pode apresentar diferentes comportamentos. Essas variáveis, apresentam características de comportamentos o qual não se preservam quando o regime de fluidização é mantido e diferentes partículas são ensaiadas.

Na segunda etapa, a quantificação não-linear baseada nas invariantes do caos, permite classificar os regimes de fluidização independentemente do tipo de partícula. Ou seja, as invariantes do caos são sensíveis ao regime de fluidização. A análise não-linear é baseada na avaliação das flutuações das séries temporais de pressão estática, ao longo da coluna LFC, através das invariantes do caos.

Na terceira etapa, as invariantes locais são associadas para construir um índice de divergência de características caóticas entre regiões da coluna LFC. O comportamento deste índice se preservou para todas as partículas aqui ensaiadas. Portanto, a hipótese aqui proposta, é que o comportamento deste índice, pode se preservar para as colunas LFC em qualquer escala.

Na quarta etapa, apresenta maneiras para controlar regimes de fluidização em colunas opacas de forma manual e automatizada. Também são discutidos os impactos desta nova proposta, se aplicada a gaseificação LFC.

\subsection{Quantificação clássica}

A quantificação clássica é, geralmente, baseada em variáveis como: pressão estática, diferencial, desviopadrão das pressões, velocidade ou vazão do agente fluidizante e características de partículas. Os itens seguintes, apresentam análises do comportamento das variáveis envolvidas na quantificação clássica, evidenciando sua dependência com as características das partículas (diâmetro, massa específica, classificação de Geldart) e com a escala que uma coluna LFC se encontra. 


\subsubsection{Vidro $355 \mu \mathrm{m}$}

A Figura 78 apresenta a evolução do comportamento do desvio padrão, pressão estática e diferencial, base da coluna LFC, para diferentes regimes de fluidização. Os dados experimentais do desvio padrão da pressão estática de base, para o vidro $355 \mu \mathrm{m}$, não corroboram com os dados de Saayman [25], pois o comportamento observado é de uma função monotonicamente crescente (vide linha contínua sem marcado da Figura 78). Contudo, como será apresentado adiante, essa concordância depende das características da partícula (diâmetro, massa específica e classificação de Geldart). Uma explicação para tal fato, reside que partículas mais leves, como o vidro, não influenciam tanto as flutuações de pressão estática, ou seja, um escoamento dominado pelo fluido. Para o comportamento da pressão estática, é esperado uma função crescente monotonicamente (vide linha tracejada da Figura 78), enquanto o para pressão diferencial, entre a base ( $9 \mathrm{~cm}$ da base) e o meio ( $45 \mathrm{~cm}$ da base), manteve-se a estrutura curva clássica de queda de pressão em leito fluidizado (vide linha contínua com marcado da Figura 78).

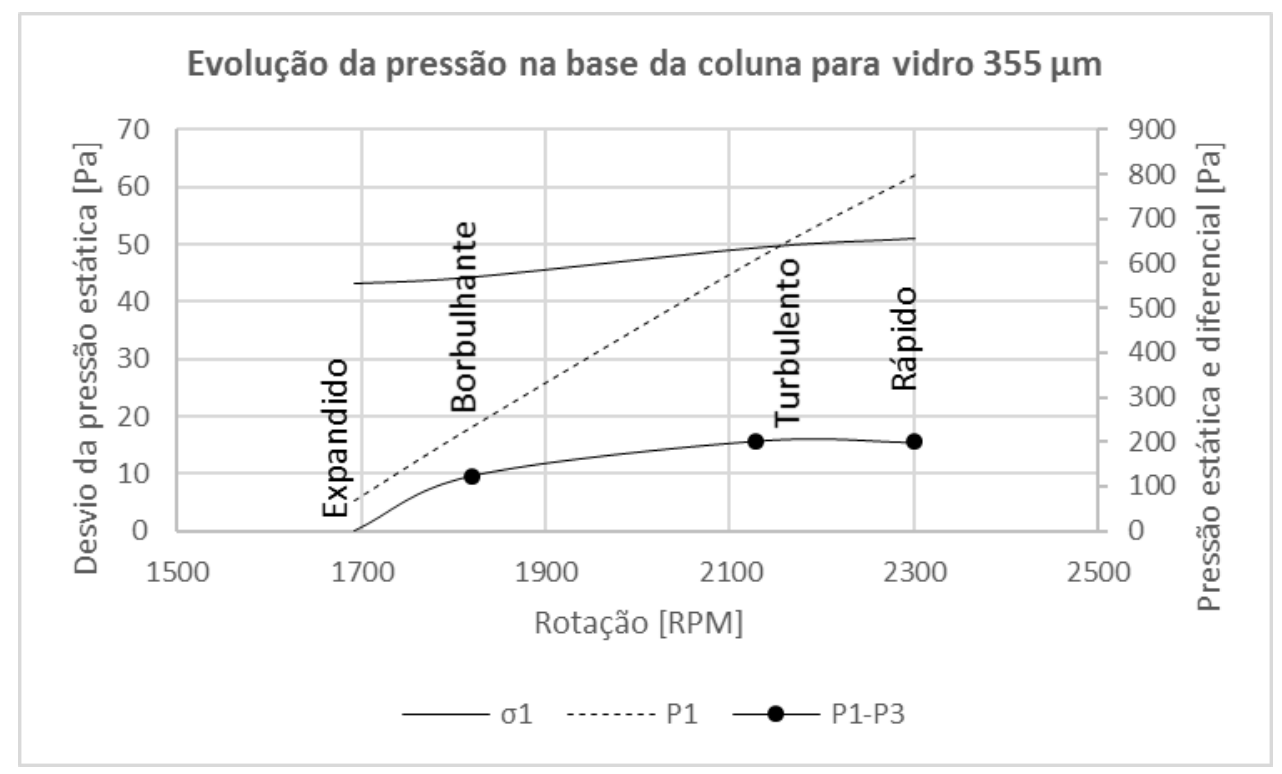

Figura 78 - Comportamento na base ( $9 \mathrm{~cm}$ da base) dos sinais de desvio padrão $(\sigma 1)$, pressão estática (P1) e diferencial (P1-P3) numa coluna LFC com leito de partículas de vidro $355 \mu \mathrm{m}$, submetidos a diferentes regimes de fluidização.

O comportamento do desvio padrão no meio (linha contínua sem marcador na Figura 79), para uma coluna LFC de partículas de vidro $355 \mu \mathrm{m}$, apresenta o mesmo comportamento da base (vide Figura 78), a menos de um deslocamento positivo, conforme indicado pela Figura 79. O deslocamento é provocado pelo aumento da turbulência do agente fluidizante, após permear o leito. Uma razão que explica a pequena diferença de pressão estática entre os regimes expandido e borbulhante (linha tracejada na Figura 79), no meio, é o fato do leito estar completamente formado nesses regimes, provocarem fortes quedas de pressão. Quanto a curva de queda de pressão entre o meio e o topo (P3-P5, linha contínua com marcador na Figura 79) se mantem constante devido ao fato de não haver quedas de pressão de significativas nesta região, durante o desenvolvimento de cada regime de fluidização. 


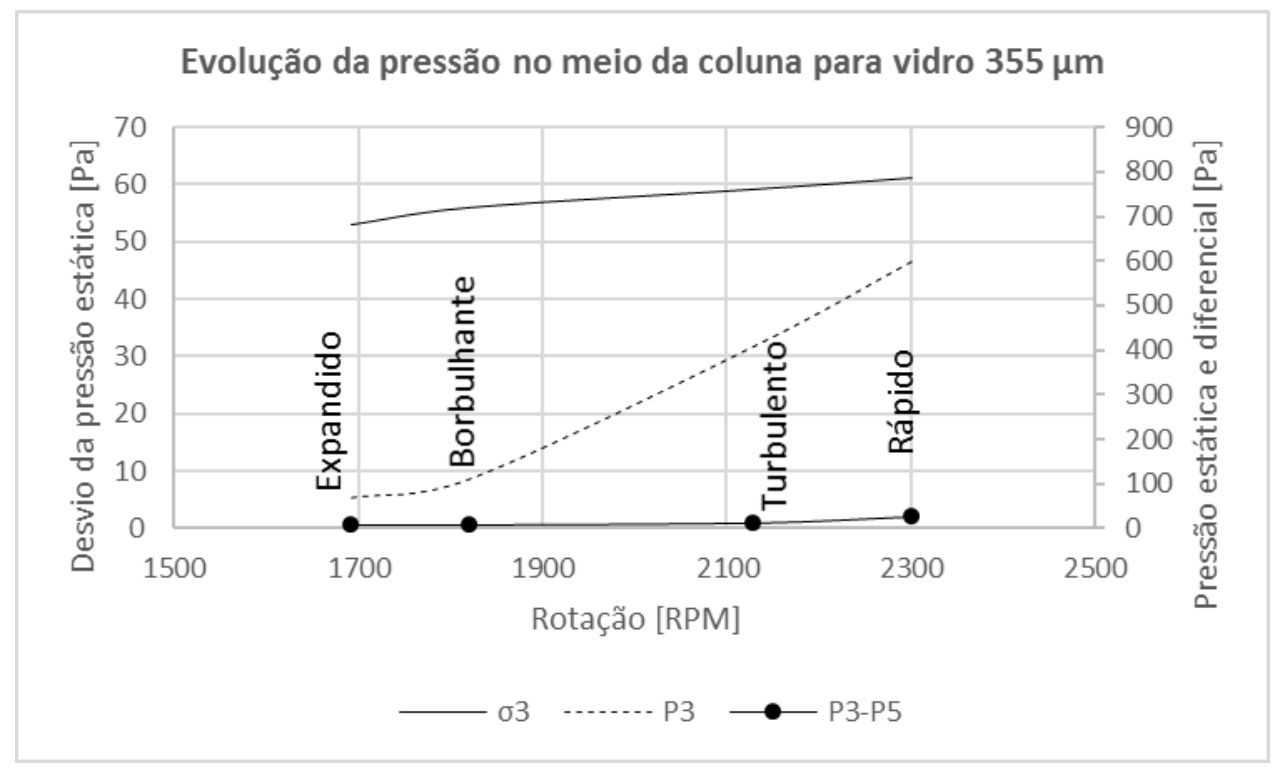

Figura 79 - Comportamento no meio ( $45 \mathrm{~cm}$ da base) dos sinais de desvio padrão $(\sigma 3)$, pressão estática (P3) e diferencial (P3-P5) numa coluna LFC com leito de partículas de vidro $355 \mu \mathrm{m}$, submetidos a diferentes regimes de fluidização.

Já o comportamento do desvio padrão e da pressão estática (ver linhas contínua sem marcador e tracejada da Figura 80) do topo são semelhantes ao do meio (ver linhas contínua sem marcador e tracejada da Figura 79), enquanto o comportamento da pressão diferencial P1-P5 (ver linha contínua com marcado da Figura 80) é semelhante ao da pressão diferencial P1-P3 (ver linha contínua com marcado da Figura 78).

Outras variáveis como sondas capacitivas, sondas de fibra ótica, espalhamento laser e LDV/PIV (Laser Doppler Velocimetry/Particle Imaging Velocimetry) podem ser utilizadas para auxiliar na quantificação dos regimes de fluidização ou operação em colunas opacas. Contudo, estas tecnologias ainda possuem um elevado custo e não podem ser aplicadas a condições reais como na gaseificação de leito fluidizado circulante $\left(\sim 800^{\circ} \mathrm{C}\right)$.

O vidro $355 \mu \mathrm{m}$ foi escolhido para ensaios por possuir características (diâmetro, massa específica e classificação de Geldart) semelhantes a partículas de carvão e outros materiais gaseificáveis em reatores LFC.

Outra forma de quantificação clássica de quantificação é através do mapa adimensionalizado de Grace [16] [20] [87] . Contudo, não foi possível compara-la, pois, as variáveis experimentais observadas neste trabalho não dispõe da medição direta de vazão/velocidade do agente fluidizante. 


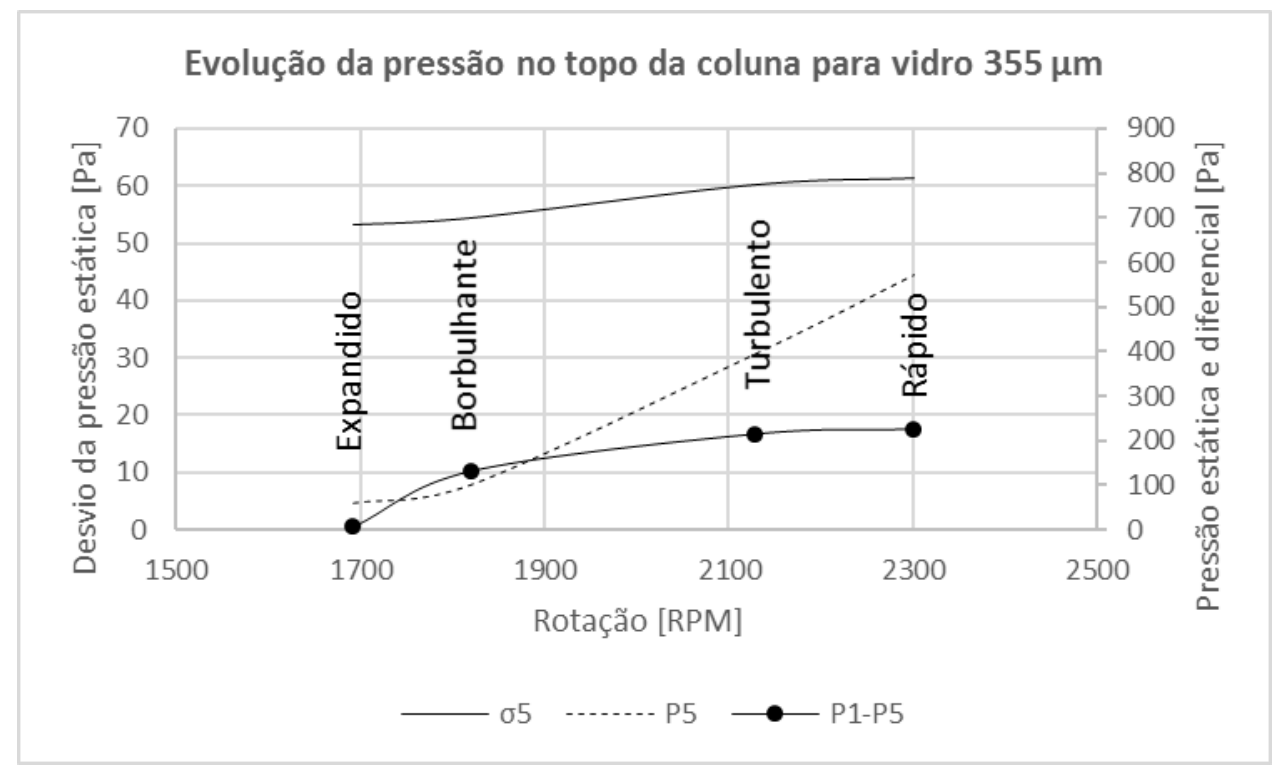

Figura 80 - Comportamento no topo (90 cm da base) dos sinais de desvio padrão $(\sigma 5)$, pressão estática (P5) e diferencial (P1-P5) numa coluna LFC com leito de partículas de vidro $355 \mu \mathrm{m}$, submetidos a diferentes regimes de fluidização.

A análise de outros tipos de partículas é necessária para investigação dos comportamentos que são preservados face ao regime a um determinado regime de fluidização desenvolvido.

\subsubsection{Areia $1,0 \mathrm{~mm}$}

A Figura 81, apresenta dados experimentais do desvio padrão da pressão estática de base, para a areia 1,0 mm. Apesar de reduzir sua inclinação do desvio (linha contínua sem marcador da Figura 81), quando comparado com o comportamento do desvio do vidro $355 \mu \mathrm{m}$ (linha contínua sem marcador da Figura 78), não corroboram com os dados de Saayman [25], pois o comportamento observado é de uma função monotonicamente crescente. Contudo, é possível perceber a mudança do comportamento do desvio face ao aumento da massa específica, diâmetros da partícula. Uma explicação para a redução da inclinação do desvio, reside que partículas mais pesadas, começam a impor flutuações na base da coluna LFC, quando operado nos regimes turbulento e rápido. Para o comportamento da pressão estática, é esperado uma função crescente monotonicamente (vide linha tracejada da Figura 81), enquanto o para pressão diferencial, entre a base ( $9 \mathrm{~cm}$ da base) e o meio ( $45 \mathrm{~cm}$ da base), manteve-se a estrutura curva clássica de queda de pressão em leito fluidizado (vide linha contínua com marcado da Figura 81). Devido ao aumento do diâmetro e massa específica as faixas de desvio, pressão estática e diferencial são deslocadas para cima, quando comparados com as partículas de vidro $355 \mu \mathrm{m}$. 


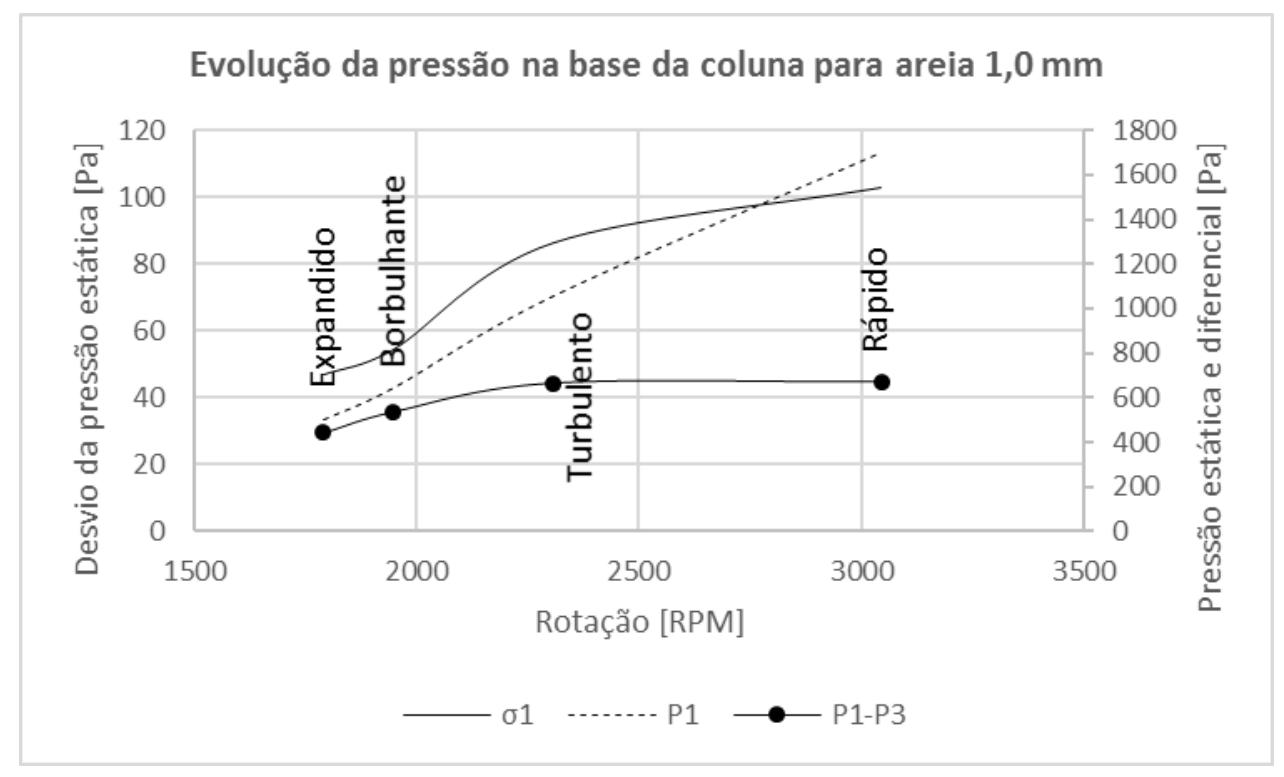

Figura 81 - Comportamento na base $(9 \mathrm{~cm}$ da base) dos sinais de desvio padrão $(\sigma 1)$, pressão estática (P1) e diferencial (P1-P3) numa coluna LFC com leito de partículas de areia 1,0 mm, submetidos a diferentes regimes de fluidização.

Conforme a Figura 82, o comportamento do desvio padrão (linha tracejada da Figura 82) e pressão estática (linha contínua sem marcador da Figura 82) no meio da coluna LFC, para as partículas de areia $1,0 \mathrm{~mm}$, são de uma função crescente monotonicamente. A pressão diferencial (linha contínua com marcador da Figura 82) entre o meio e o topo, assim como no vidro $355 \mu \mathrm{m}$, permanece constante, a menos do descolamento positivo para areia $1,0 \mathrm{~mm}$.

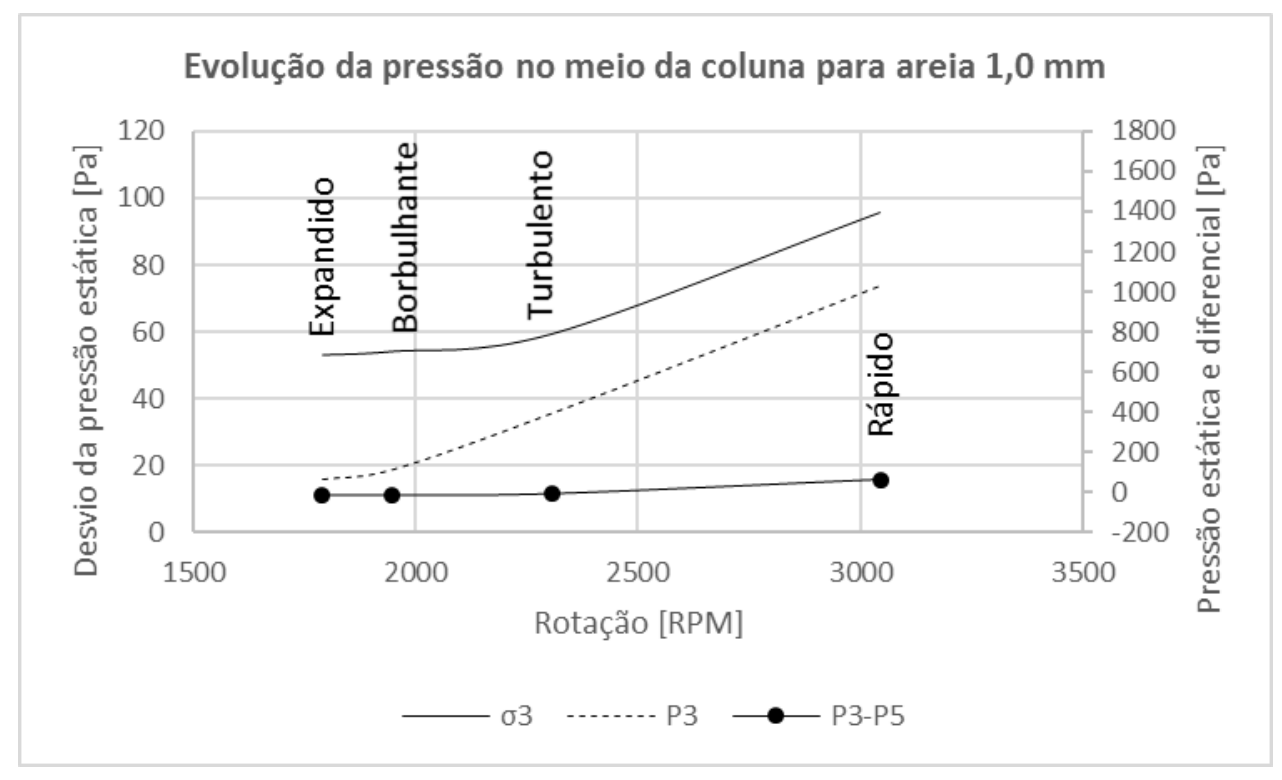

Figura 82 - Comportamento no meio (45 $\mathrm{cm}$ da base) dos sinais de desvio padrão $(\sigma 3)$, pressão estática (P3) e diferencial (P3-P5) numa coluna LFC com leito de partículas de areia 1,0 mm, submetidos a diferentes regimes de fluidização. 
A Figura 83, apresenta o comportamento do desvio padrão no topo (linha contínua sem marcador da Figura 83) semelhante ao desvio padrão do meio da coluna LFC (linha contínua sem marcador da Figura 83), indicando que esta variante estatística (desvio padrão) não consegue avaliar as diferenças ocorridas em cada uma destas regiões (meio e topo). A pressão estática (linha tracejada da Figura 83) permanece com seu comportamento de função monotonicamente crescente, não contribuindo para detecção/classificação de regimes de fluidização.

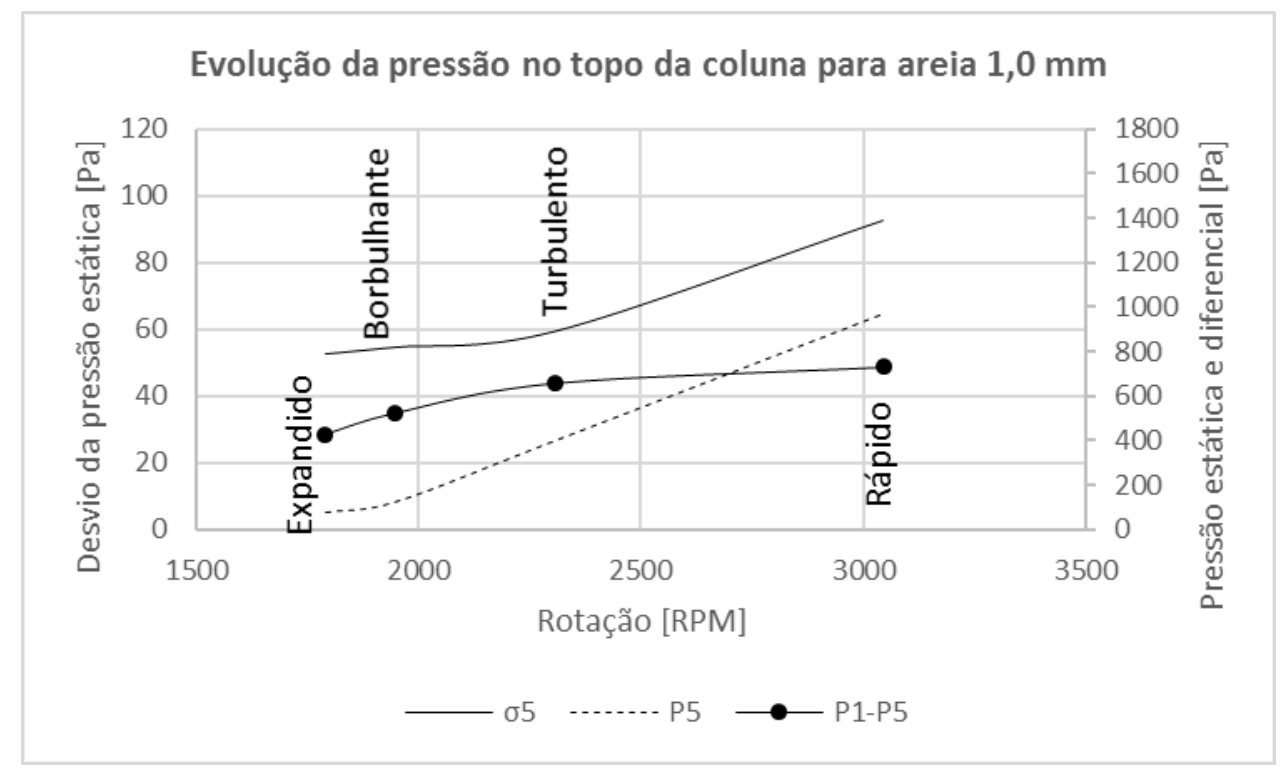

Figura 83 - Comportamento no topo ( $90 \mathrm{~cm}$ da base) dos sinais de desvio padrão $(\sigma 5)$, pressão estática (P5) e diferencial (P1-P5) numa coluna LFC com leito de partículas de areia 1,0 mm, submetidos a diferentes regimes de fluidização.

Através da análise local do desvio padrão da areia 1,0 mm (linhas contínuas sem marcador da Figura 81, Figura 82 e Figura 83), é possível observar o comportamento distinto entre as zonas de base e os locais restante. Pela ação da gravidade, tentar manter o leito coeso, durante todos os instantes em que os regimes de fluidização são desempenhados, faz desta (a base da coluna LFC) uma região importante para observações e caracterizações do regime.

\subsubsection{Areia $1,2 \mathrm{~mm}$}

Os dados experimentais da Figura 84, apresenta o comportamento do desvio padrão (linha contínua sem marcador da Figura 84) do sinal de pressão estática na base da coluna LFC, para areia 1,2 mm. É possível perceber uma queda do desvio padrão após o regime turbulento, o qual esse comportamento corrobora com o apresentado por Saayman [25]. No regime rápido, a dispersão das flutuações de pressão estática caiu em relação ao regime turbulento, podendo indicar certo ordenamento do escoamento. A faixa de dispersão da areia 1,2 mm (linha contínua sem marcador da Figura 84) reduziu em relação a areia 1,0 mm (linha contínua sem marcador da Figura 81). Novamente, a pressão estática apresenta o comportamento de uma função crescente monotonicamente (ver linha tracejada da Figura 84), enquanto a pressão diferencial apresenta a estrutura clássica da queda de pressão em leito fluidizado de coluna LFC, conforme a linha contínua com marcador da Figura 84. O incremento do diâmetro da areia 1,2 $\mathrm{mm}$, em relação a areia 1,0 mm não modificou a faixa da pressão estática. 


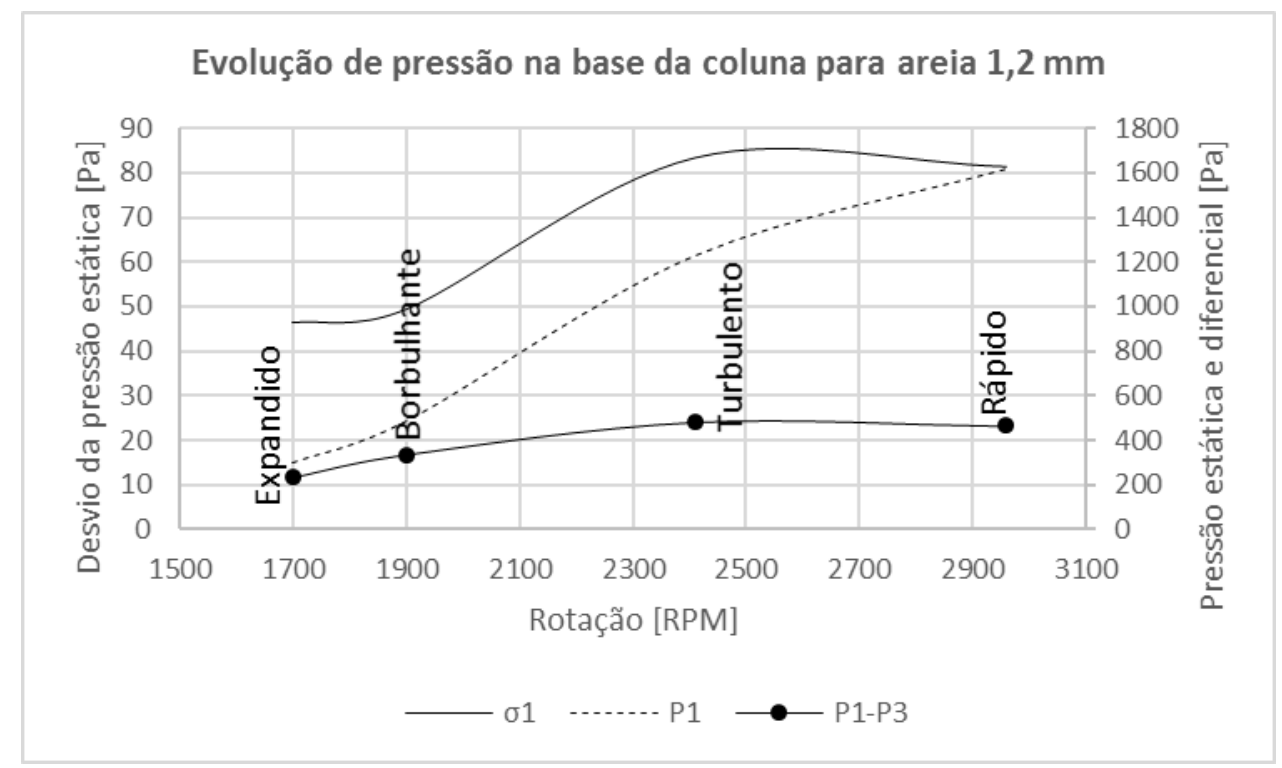

Figura 84 - Comportamento na base ( $9 \mathrm{~cm}$ da base) dos sinais de desvio padrão $(\sigma 1)$, pressão estática (P1) e diferencial (P1-P3) numa coluna LFC com leito de partículas de areia 1,2 mm, submetidos a diferentes regimes de fluidização.

A Figura 85 apresenta o comportamento do meio da coluna LFC do desvio padrão (linha contínua sem marcador da Figura 85), o qual manteve a mesma estrutura da base (linha contínua sem marcador da Figura 84), a menos de sua amplitude, que foi menor no meio. A pressão estática (linha tracejada da Figura 85) manteve o comportamento de função crescente monotonicamente, enquanto a pressão diferencial (linha contínua com marcador da Figura 85) permanece constante.

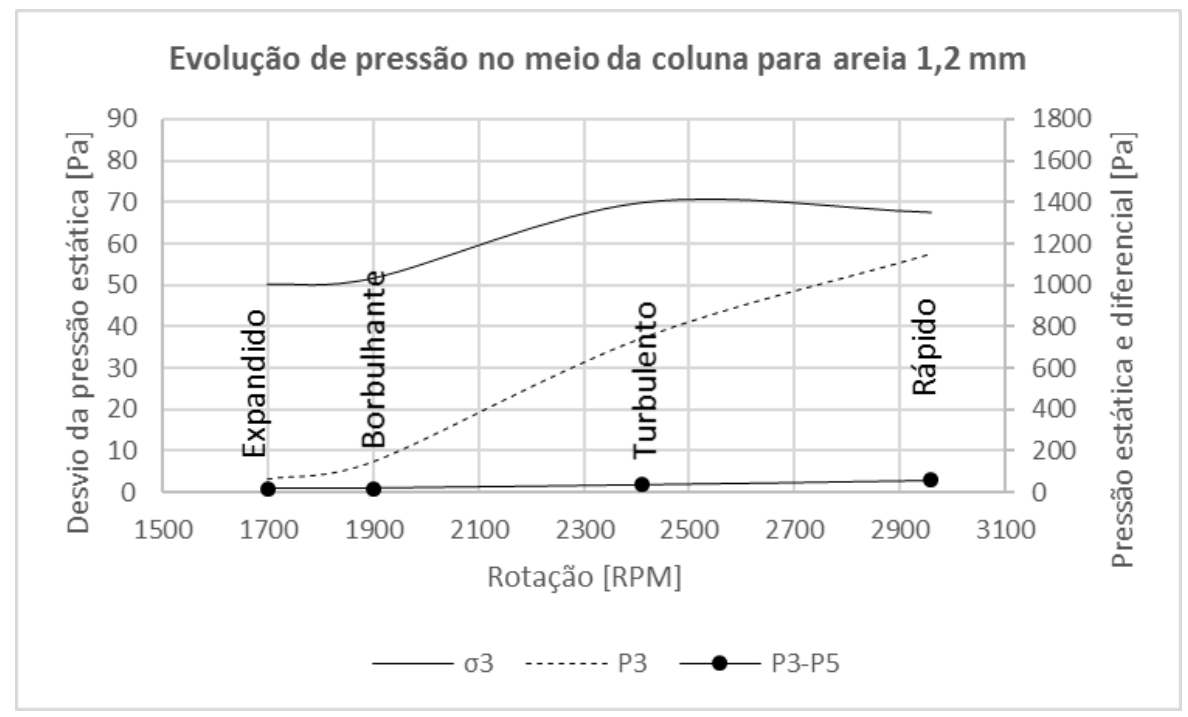

Figura 85 - Comportamento no meio ( $45 \mathrm{~cm}$ da base) dos sinais de desvio padrão $(\sigma 3)$, pressão estática (P3) e diferencial (P3-P5) numa coluna LFC com leito de partículas de areia 1,2 mm, submetidos a diferentes regimes de fluidização. 
Por fim, conforme a Figura 86, o comportamento do desvio no topo da coluna LFC (linha contínua sem marcador da Figura 86) foi semelhante (em forma e amplitude) ao do meio (linha contínua sem marcador da Figura 85), indicando certa similaridade estatística do escoamento em ambas regiões. A pressão estática (linha tracejada da Figura 86) manteve o comportamento de função crescente monotonicamente, enquanto o comportamento da pressão diferencial P1-P5 (linha contínua com marcador da Figura 86) foi similar a pressão diferencial P1-P3 (linha contínua com marcador da Figura 84).

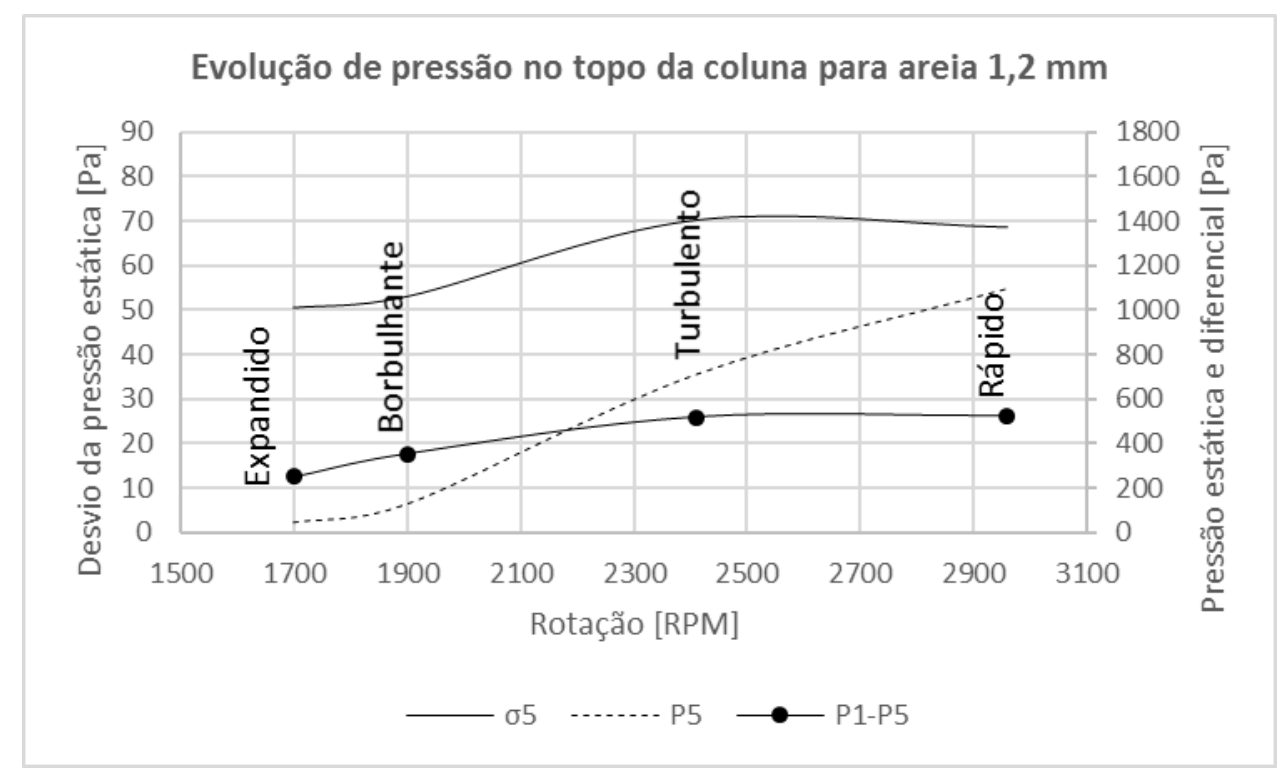

Figura 86 - Comportamento no topo ( $90 \mathrm{~cm}$ da base) dos sinais de desvio padrão $(\sigma 5)$, pressão estática (P5) e diferencial (P1-P5) numa coluna LFC com leito de partículas de areia 1,2 mm, submetidos a diferentes regimes de fluidização.

Como estes experimentos de fluidização não contaram com medições de vazão/velocidade do ar de entrada, não foi possível a aplicação de mapas de fluidização. Contudo, o modelo numérico permite recuperar os dados necessários para a montagem deste mapa.

\subsubsection{Mapa de fluidização}

O mapa de regime de fluidização foi testado com os dados das simulações. No mapa da Figura 87, as regiões limitadas e hachuradas, delimitam e classificam os regimes de fluidização. Essa avaliação clássica, superestima os regimes de fluidização alcançados pela modelagem TFM 3D (vide Figura 87). As quatro linhas horizontais, são resultados do parâmetro $V^{*}=U^{*}$, calculado em função de cada velocidade inicial da simulação. Já a linha vertical, é calculada em função dos parâmetros da partícula, principalmente, pelo seu diâmetro. O mapa sugere que os regimes borbulhante, turbulento, rápido e transporte, previamente classificados qualitativamente pela simulação, sejam classificados, inconsistentemente, como regimes turbulento e rápido (cruzamento entre linhas horizontais e verticais dentro das regiões de regime turbulento e rápido).

A avaliação de regimes de fluidização por mapas já apresenta inconsistência para sistemas reais, o estudo realizado mostra que as inconsistências são ainda maiores considerando análise numérica de modelos matemáticos. Como uma simulação numérica apresenta todos os requisitos para efetuar os cálculos adimensionais $V^{*}$ e $A r$, pode-se verificar a classificação dos regimes através do mapa da Figura 87. 


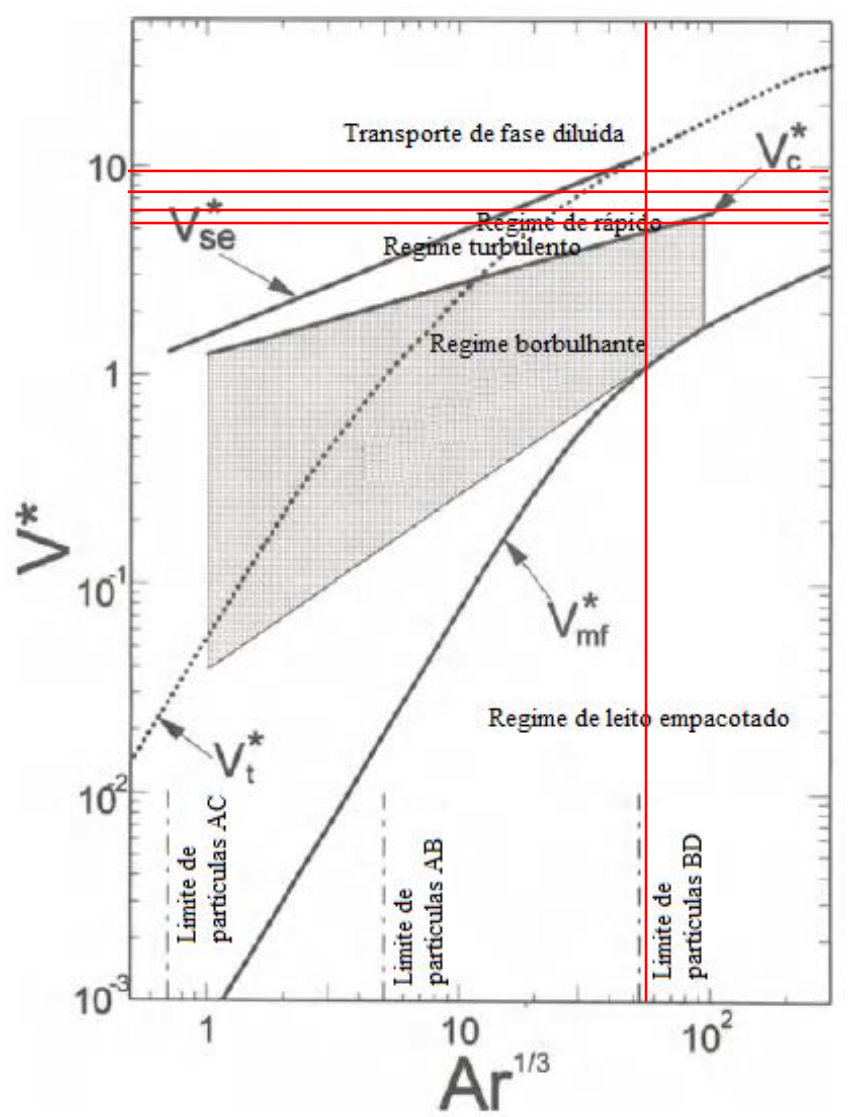

Figura 87 - Quantificação clássica de regimes de fluidização através do uso de mapa de regimes de Grace.

Infelizmente, o âmbito da avaliação/quantificação clássica de séries temporais, para classificação de regimes de fluidização em colunas LFC, não permite investigar outros critérios além das variantes estatísticas. Portanto, os sinais experimentais aqui observados devem ser avaliados sob uma nova ótica, permitindo recuperar informações invariantes no tempo para caracterizações mais robustas, conforme os itens posteriores.

\subsection{Quantificação não-linear}

A quantificação não-linear permite observar num sistema dinâmico, características invariantes no tempo. O problema espaço-temporal, como o que ocorre na fluidização de coluna LFC pode ser investigada através da observação de sinais e estudos através da teoria do caos. Os sinais aqui observados, são as flutuações de pressão estática a partir de séries temporais. O processo de quantificação não-linear foi divido em quatro etapas.

A primeira etapa, apresenta a reconstrução do espaço de fase local, através das coordenadas de atraso, para investigação de geometrias características em cada regime de fluidização.

A segunda etapa, apresenta uma demonstração da robustez do perfil de uma invariante do caos na coluna LFC, para distinguir quando o escoamento é desenvolvido numa coluna vazia ou cheia. 
Considerando uma coluna cheia de leito, a terceira etapa, apresenta como as invariantes são capazes de quantificar cada regime de fluidização para cada tipo de partícula.

Por fim, a quarta etapa, apresenta uma observação de que relações entre quantificações locais da coluna LFC, baseadas nas invariantes do caos, são preservadas devido ao tipo de regime desempenhado e não ao tipo de partícula. Essas relações são denominadas de similaridade caótica entre regiões da coluna LFC.

\subsubsection{Diagrama de fase}

Os diagramas de fase são ferramentas importantes para caracterização de sistemas dinâmicos por permitir estuda-lo em termos de convergência/divergência de trajetórias e de seu formato/tamanho. $\mathrm{O}$ presenta trabalho avalia apenas o formato e o tamanho formado por essas trajetórias, em cada regime desempenhado. Estudos mais aprofundados sobre a dinâmica das trajetórias podem ser apontados como investigações futuras.

Os diagramas de fase são reconstruídos através das coordenadas de atrasos, a partir séries temporais locais de flutuações de pressão estática, ao longo da coluna LFC. Portanto para cada tipo de leito de partículas (vidro $355 \mu \mathrm{m}$, areia 1,0 $\mathrm{mm}$ e areia 1,2 $\mathrm{mm}$ ) e do cada regime desenvolvido, os estados locais são reconstruídos e apresentados num único gráfico. A distribuição de condições de pressão estática, imposta pela natureza de cada tipo de partícula, pode ser investigada.

\subsubsection{Estados reconstruídos para o vidro $355 \mu \mathrm{m}$}

A Figura 88 apresenta o resultado da reconstrução do diagrama de fase usando coordenadas de atrasos, a partir da série temporal de flutuação de pressão estática na base, para partículas de vidro $355 \mu \mathrm{m}$. Cada estado de fluidização (linhas ou trajetórias azul, verde, vermelho e preto na Figura 88) possui uma localização no diagrama em torno da pressão média daquele regime. No regime expandido (linha azul na Figura 88) na base da coluna LFC, o formato elíptico e certa rugosidade radial poder ser observada na associação das trajetórias deste estado. No regime borbulhante (linha vermelha na Figura 88) na base da coluna LFC, o centro da figura é deslocado e uma ligeira deformação no formato elíptico, em relação ao regime expandido (linha azul na Figura 88), é observado. No regime turbulento (linha verde na Figura 88) na base da coluna LFC, além do centro deslocado, o tamanho da figura sofre um considerável aumento e deformação formação, são observados. No regime rápido (linha preta da Figura 88), o centro da figura é deslocado e a deformação do estado desaparece, retomando o formato elíptico do regime expandido (linha azul da Figura 88). A deformação pode ser explicada como um indicador de viés no escoamento, que é transferido para as flutuações de pressão. Como o regime borbulhante e turbulento são marcados, respectivamente, pelas formações espúrias de bolhas e golfadas, poderiam originar as deformações medidas na base. 


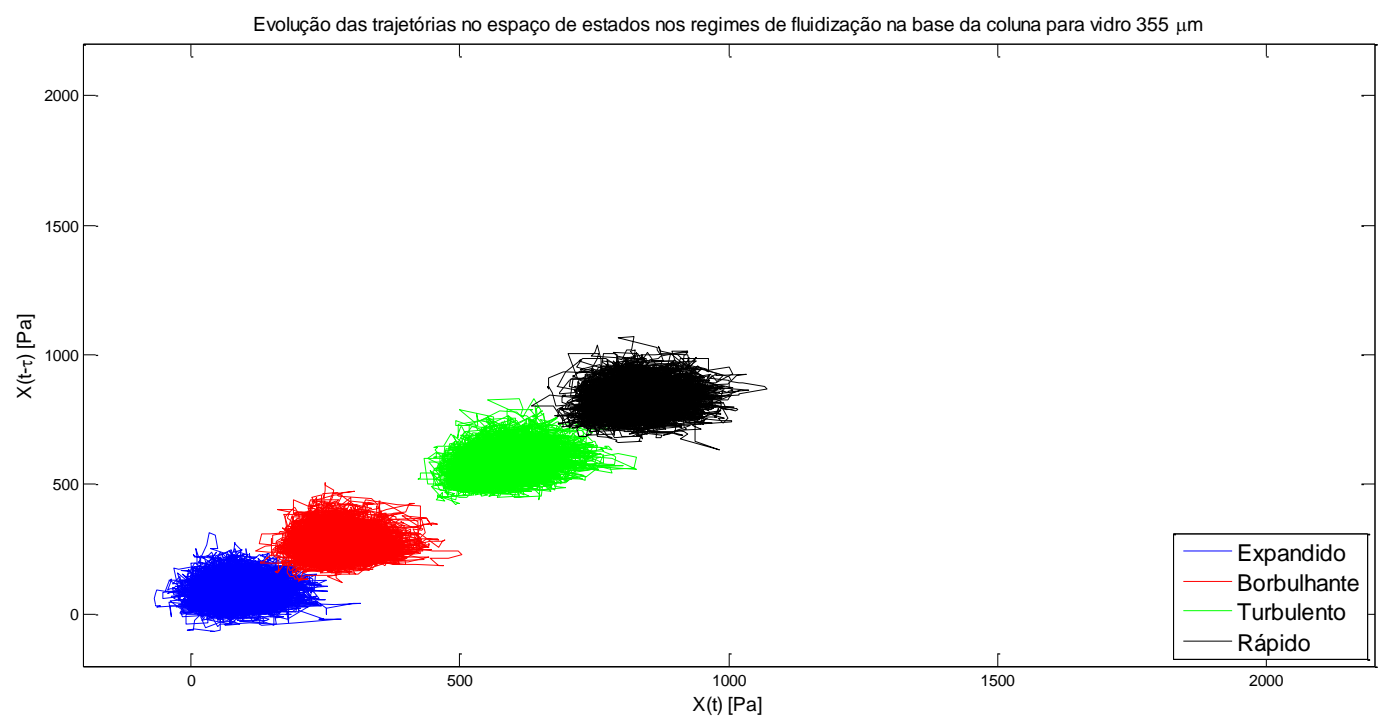

Figura 88 - Evolução das trajetórias dos estados de fluidização na base da coluna LFC para o vidro 355 $\mu \mathrm{m}$.

No meio da coluna LFC, as partículas de vidro $355 \mu \mathrm{m}$ apresentam um comportamento característico, conforme indicado na Figura 89. Os quatro estados (linhas azul, vermelha, verde e presta da Figura 89) possuem aproximadamente o mesmo formato elíptico. O tamanho e rugosidade radial das elipses são aproximadamente os mesmos, a menos do regime turbulento (linha verde na Figura 89), pois destaca-se por ser o maior.

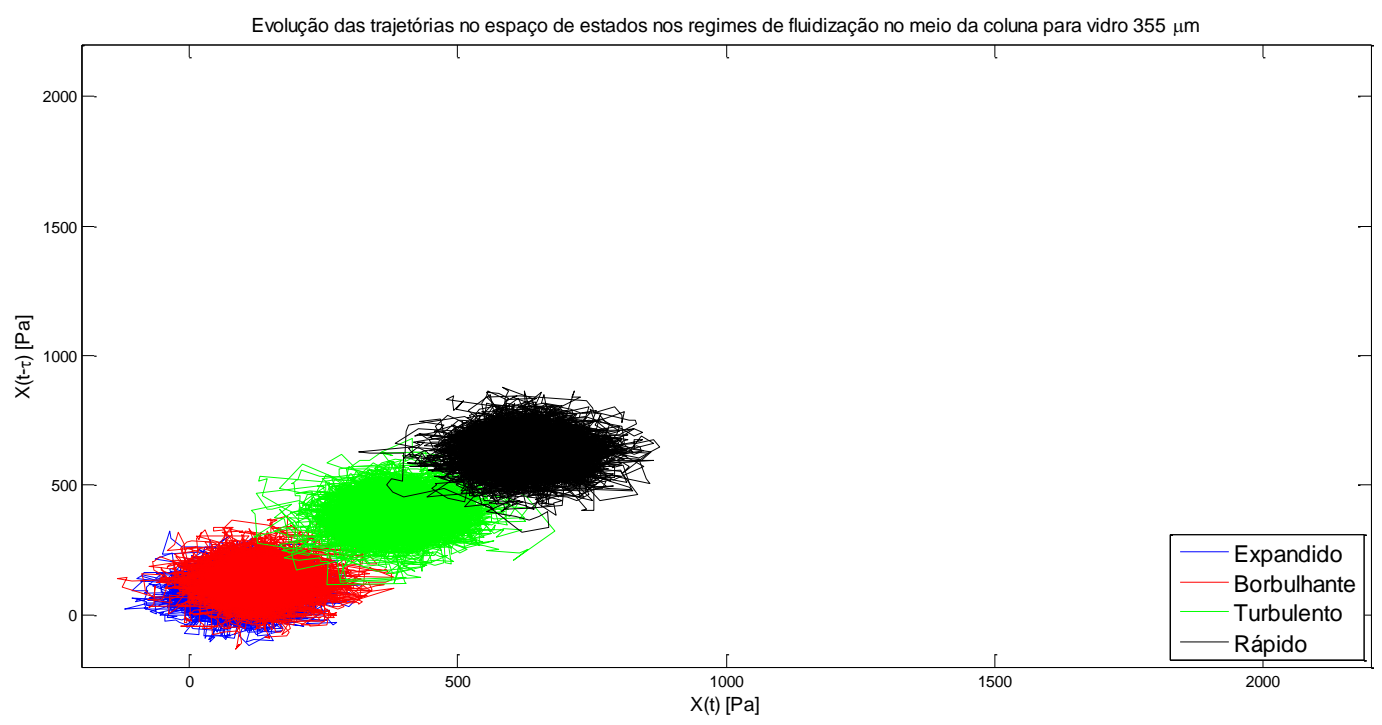

Figura 89 - Evolução das trajetórias dos estados de fluidização no meio da coluna LFC para o vidro 355 $\mu \mathrm{m}$. 
No topo da coluna LFC, as partículas de vidro $355 \mu \mathrm{m}$ apresentam um comportamento característico, conforme indicado na Figura 90. O comportamento no topo é semelhante ao comportamento do meio da coluna LFC, para vidro $355 \mu \mathrm{m}$, indicando grau de similaridade entre as flutuações de pressão estática, a menos da posição do centro de cada figura.

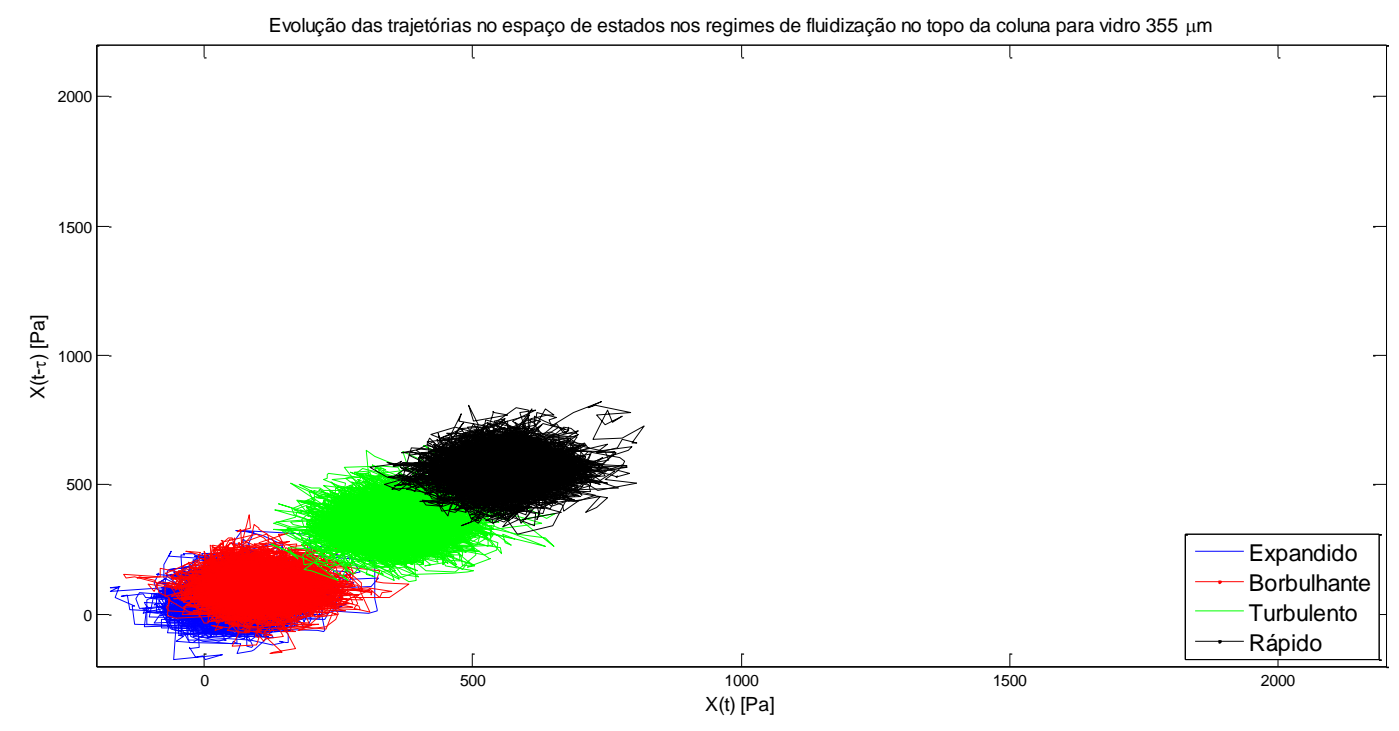

Figura 90 - Evolução das trajetórias dos estados de fluidização no topo da coluna LFC para o vidro 355 $\mu \mathrm{m}$.

O estudo local de órbitas/trajetórias relativo aos estados de fluidização das partículas de vidro $355 \mu \mathrm{m}$ corrobora com a existência de duas regiões características, uma de base e o restante da coluna (freeboard). Outros tipos de partículas devem ser investigados para verificação da preservação da existência de apenas duas regiões características.

\subsubsection{Estados reconstruídos para a areia 1,0 mm}

A Figura 91 apresenta o resultado da reconstrução do diagrama de fase usando coordenadas de atrasos, a partir da série temporal de flutuação de pressão estática na base, para partículas de areia 1,0 mm. Cada estado de fluidização (linhas ou trajetórias azul, verde, vermelho e preto na Figura 91) possui uma localização no diagrama em torno da pressão média daquele regime. No regime expandido (linha azul na Figura 91) na base da coluna LFC, o formato elíptico e certa rugosidade radial poder ser observada na associação das trajetórias deste estado. No regime borbulhante (linha vermelha na Figura 91) na base da coluna LFC, o centro da figura é deslocado e uma ligeira deformação no formato elíptico da figura, em relação ao regime expandido (linha azul na Figura 91), é observado. No regime turbulento (linha verde na Figura 91) na base da coluna LFC, além do centro deslocado e formato elíptico se manter, o tamanho da figura e sua rugosidade sofrem um considerável aumento. Contudo, para a areia 1,0 mm, não foi identificado deformação da figura no regime turbulento (linha verde da Figura 91), quando comparado com o vidro $355 \mu \mathrm{m}$, mesmo regime (linha verde da Figura 88). Uma explicação para tal diferença de comportamento, reside no fato que as partículas são pesadas impondo flutuações mais ordenadas. No regime rápido (linha preta da Figura 91Figura 88), o centro da figura é deslocado e uma rugosidade (linha azul da Figura 91), é observada. 


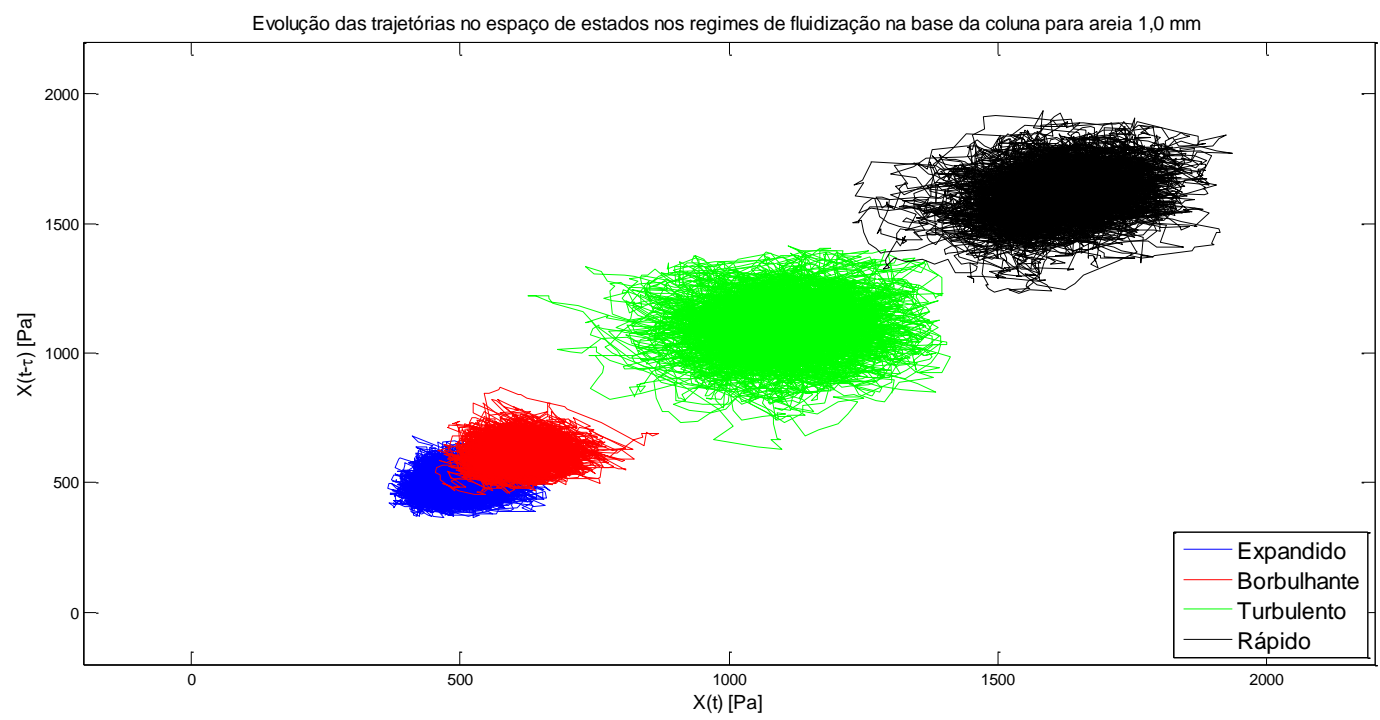

Figura 91 - Evolução das trajetórias dos estados de fluidização na base da coluna LFC para a areia 1,0 $\mathrm{mm}$.

No meio da coluna LFC, as partículas de areia 1,0 apresentam um comportamento característico, conforme indicado na Figura 92. Os quatro estados (linhas azul, vermelha, verde e presta da Figura 92) possuem aproximadamente o mesmo formato elíptico. O tamanho e rugosidade radial das elipses são aproximadamente os mesmos, a menos do regime rápido (linha preta na Figura 92) que se destaca por uma rugosidade maior. A alta rugosidade do sinal de flutuação de pressão no regime rápido pode estar associada ao expoente de Hurst baixo (discutido posteriormente).

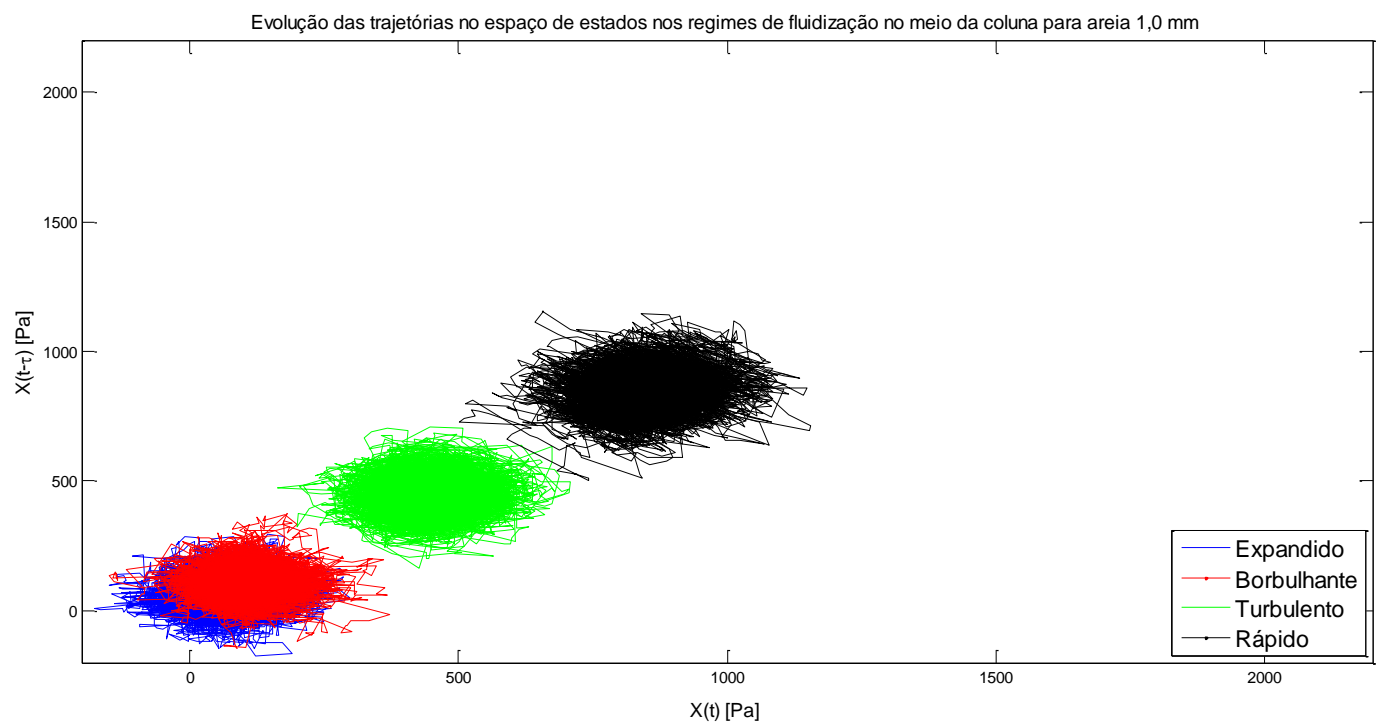

Figura 92 - Evolução das trajetórias dos estados de fluidização no meio da coluna LFC para a areia 1,0 $\mathrm{mm}$. 
No topo da coluna LFC, as partículas da areia 1,0 $\mathrm{mm}$ apresentam um comportamento característico, conforme indicado na Figura 93. O comportamento no topo é semelhante ao comportamento do meio da coluna LFC, para areia 1,0 mm, indicando grau de similaridade entre as flutuações de pressão estática, a menos da posição do centro de cada figura.

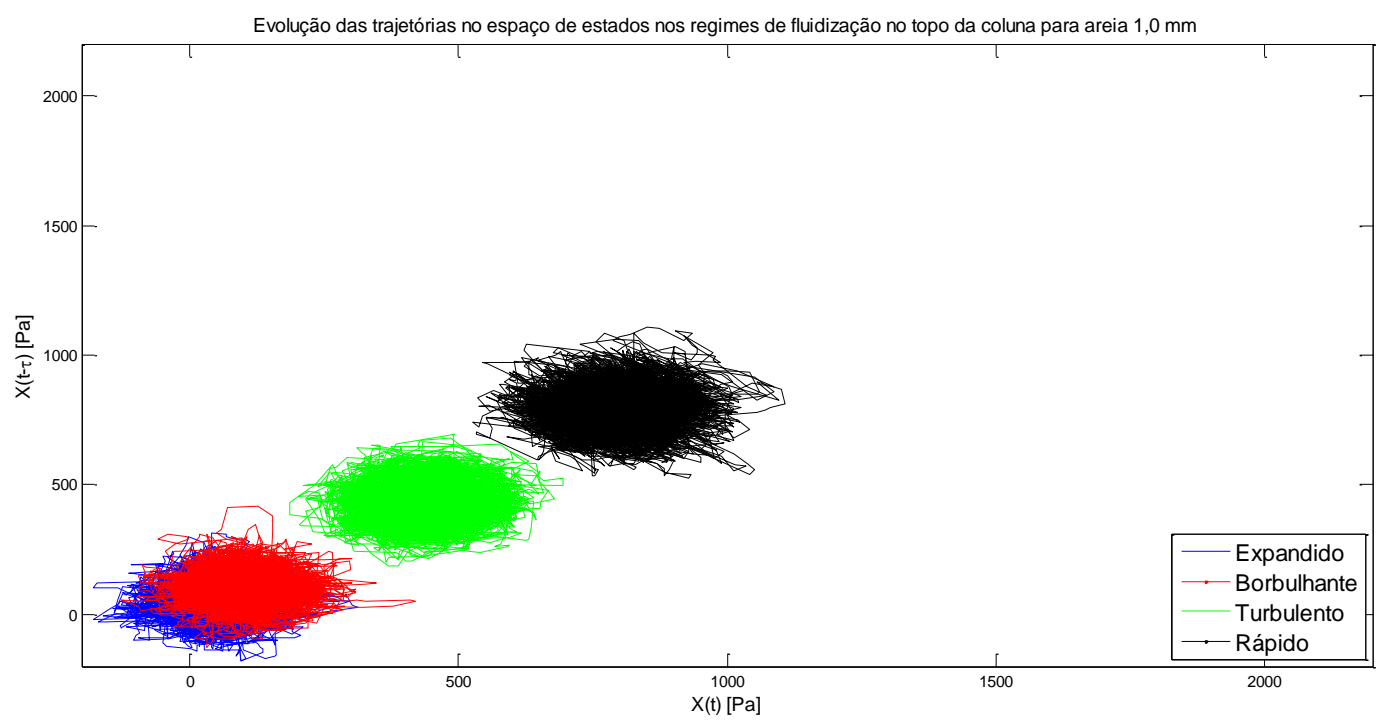

Figura 93 - Evolução das trajetórias dos estados de fluidização no topo da coluna LFC para a areia 1,0 $\mathrm{mm}$.

O estudo local de órbitas/trajetórias relativo aos estados de fluidização das partículas de areia 1,0 mm também corrobora com a existência de duas regiões características, uma de base e o restante da coluna (freeboard). Contudo, comparativamente, o estudo da reconstrução do diagrama de fase entre o vidro $355 \mu \mathrm{m}$ e a areia $1,0 \mathrm{~mm}$ ainda não indicam características marcantes em comum para uso na quantificação de regimes. Mais um tipo de partícula deve ser investigado para composição do estudo e investigação do comportamento característico.

\subsubsection{Estados reconstruídos para a areia 1,2 mm}

A Figura 94 apresenta o resultado da reconstrução do diagrama de fase usando coordenadas de atrasos, a partir da série temporal de flutuação de pressão estática na base, para partículas de areia 1,2 mm. Cada estado de fluidização (linhas ou trajetórias azul, verde, vermelho e preto na Figura 94) possui uma localização no diagrama em torno da pressão média daquele regime. No regime expandido (linha azul na Figura 94) na base da coluna LFC, o formato elíptico e rugosidade radial poder ser observada na associação das trajetórias deste estado. No regime borbulhante (linha vermelha na Figura 94) na base da coluna LFC, o centro da figura é deslocado e uma ligeira deformação no formato elíptico da figura, em relação ao regime expandido (linha azul na Figura 94), é observado. No regime turbulento (linha verde na Figura 94) na base da coluna LFC, além do centro deslocado e formato elíptico se manter, o tamanho da figura sofre um considerável aumento. Contudo, para a areia $1,2 \mathrm{~mm}$, não foi identificado deformação da figura no regime turbulento (linha verde da Figura 94), quando comparado com o vidro $355 \mu \mathrm{m}$, mesmo regime (linha verde da Figura 88). Uma explicação para tal diferença de comportamento, reside 
no fato que as partículas são ainda mais pesadas, impondo flutuações mais ordenadas. No regime rápido (linha preta da Figura 94Figura 88), o centro da figura é deslocado e uma rugosidade (linha azul da Figura 94), é observada.

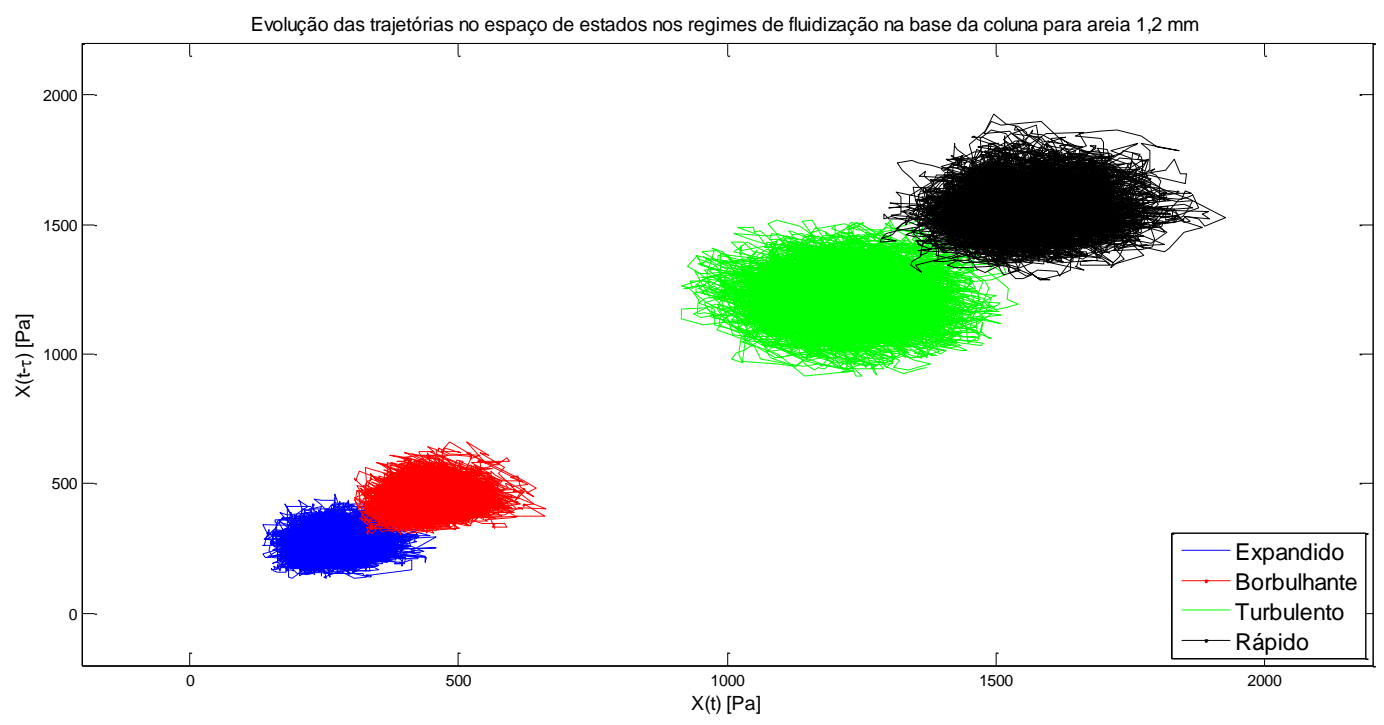

Figura 94 - Evolução das trajetórias dos estados de fluidização na base da coluna LFC para a areia 1,2 $\mathrm{mm}$.

No meio da coluna LFC, as partículas de areia 1,2 apresentam um comportamento característico, conforme indicado na Figura 95. Os quatro estados (linhas azul, vermelha, verde e presta da Figura 95) possuem aproximadamente o mesmo formato elíptico. O tamanho e rugosidade radial das elipses são aproximadamente os mesmos, a menos do regime rápido (linha preta na Figura 95) que se destaca por uma rugosidade maior. A alta rugosidade do sinal de flutuação de pressão no regime rápido pode estar associada ao expoente de Hurst baixo (discutido posteriormente).

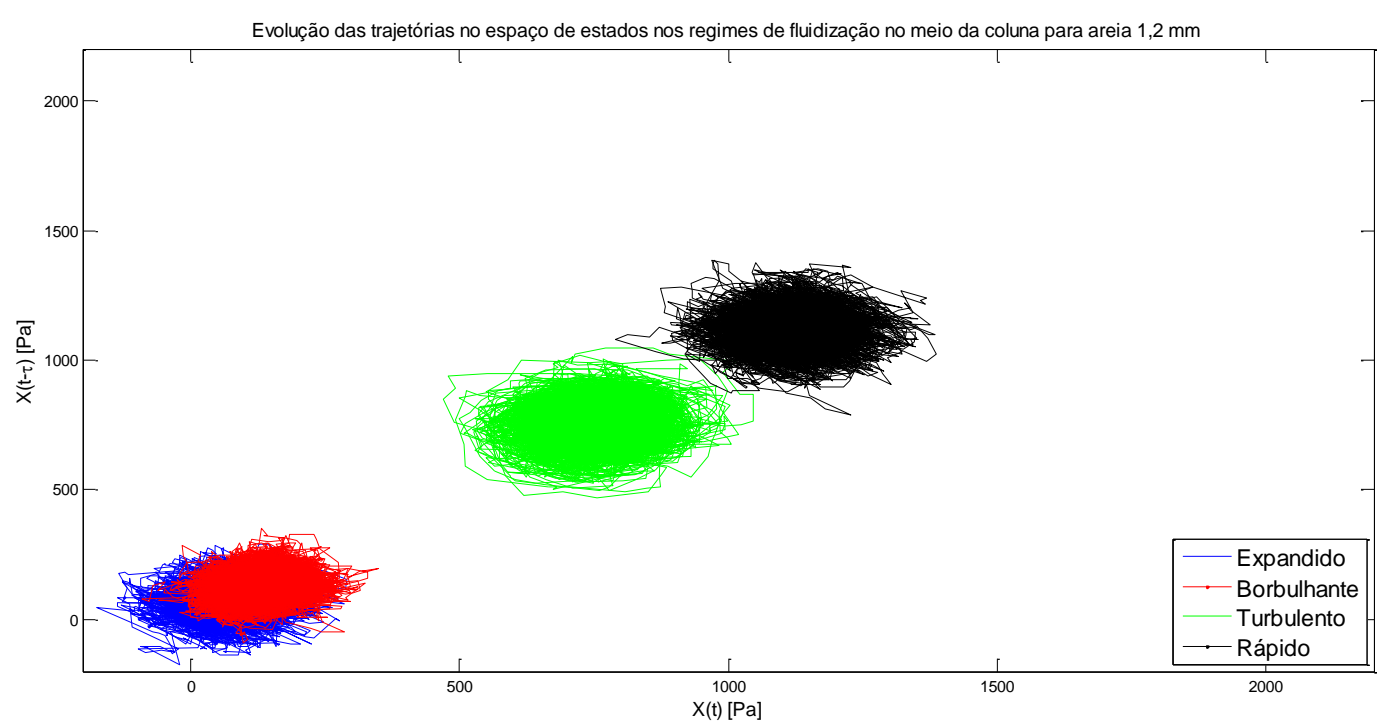

Figura 95 - Evolução das trajetórias dos estados de fluidização no meio da coluna LFC para a areia 1,2 $\mathrm{mm}$. 
No topo da coluna LFC, as partículas da areia 1,2 $\mathrm{mm}$ apresentam um comportamento característico, conforme indicado na Figura 96. O comportamento no topo é semelhante ao comportamento do meio da coluna LFC, para areia 1,2 mm, indicando grau de similaridade entre as flutuações de pressão estática, a menos da posição do centro de cada figura.

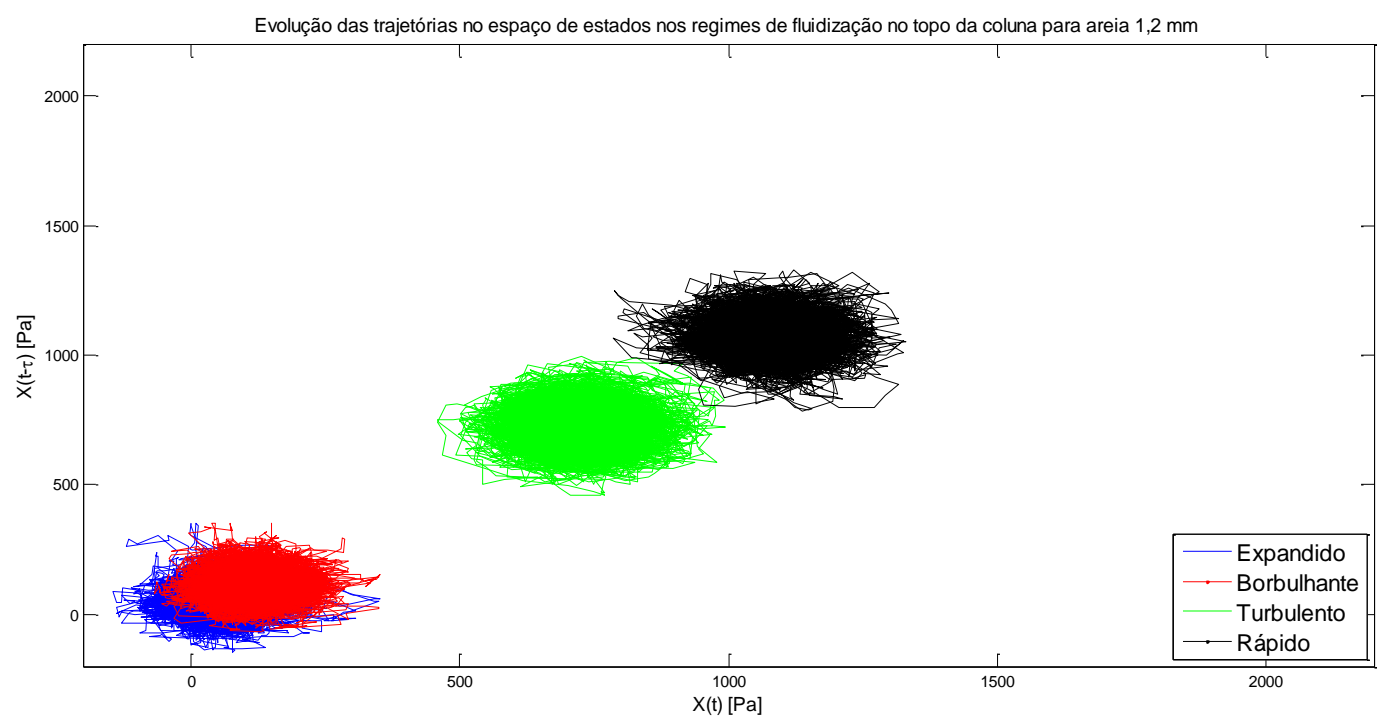

Figura 96 - Evolução das trajetórias dos estados de fluidização no topo da coluna LFC para a areia 1,2 $\mathrm{mm}$.

Uma comparativo entre os diagramas de fase, mostra o quão dinâmico é a distribuição de condições operacionais de pressão estática para desenvolvimento dos mesmos regimes, considerando as características (diâmetro, massa específica e classificação de Geldart) de cada tipo de partícula. Esta metodologia de reconstrução do diagrama de fase a partir das coordenadas de atraso, através das séries temporais ao longo da coluna LFC, não foi suficiente para distinguir regimes de fluidização.

\subsubsection{Ensaio de coluna com e sem leito}

Este ensaio de quantificação visa avaliar a capacidade de uma invariante distinguir flutuações entre coluna vazia e cheia de leito de partículas. A sensibilidade de um invariante em quantificar e detectar flutuações características entre um fluxo monofásico (gás) e bifásico (gás-sólido) pode ter grande utilidade no controle de regimes de fluidização.

A Figura 97 apresenta os perfis de entropia, ao longo de uma coluna LFC, comparando o leito vazio, em diversos fluxos de ar, e um leito com partículas de vidro $355 \mu \mathrm{m}$, em diversos regimes de fluidização.

As linhas contínuas da Figura 97, representam os perfis de entropia, variando fluxos do ar de entrada com a coluna vazia. Para o fluxo imposto pela rotação de 1000 RPM (perfil Vazia1000, linha contínua e sem marcado da Figura 97) gera uma entropia maior no meio e igual, na base e no topo. As flutuações espúrias são maiores no centro da coluna do que na base e no topo, que são maios ordenados. Para o fluxo imposto pela rotação de 2000 RPM (perfil Vazia2000, linha contínua e com marcador circular da 
Figura 97), a estrutura se mantém, porém, deslocada positivamente. Contudo, para um fluxo imposto pela rotação de 3000 RPM (perfil Vazia3000, linha contínua e com marcador quadrático da Figura 97), a estrutura se mantém, porém, deslocada negativamente em relação a rotação de 1000 RPM. O aumento da rotação impõe fluxos com baixos níveis de flutuações espúrias, reduzindo o valor da entropia.

Ao preencher a coluna com um nível de $8 \mathrm{~cm}$ de leito de partículas de vidro $355 \mu \mathrm{m}$ e definir rotações ao ventilador para desempenhar os regimes de fluidização (linhas tracejadas da Figura 97) é possível verificar o impacto do escoamento gás-sólido no sobre a métrica do perfil de entropia. No regime expandido (perfil vidro_ex ou linha tracejada sem marcador da Figura 97), o leito se mantém coeso, e a passagem do fluxo (ar) pelos interstícios do leito, na base, impõe flutuações que permanecem iguais pelo meio e topo da coluna LFC. No regime borbulhante (linha tracejada com marcador circular da Figura 97), o escoamento gás-sólido na base começa a apresentar uma tendência de ordenamento, através da redução da entropia de base, enquanto no meio e no topo, um aumento da imprevisibilidade e do valor da entropia. No regime turbulento (linha tracejada com marcador quadrático da Figura 97), a tendência de redução da imprevisibilidade, na base, e aumento do grau de desordem, no meio e topo, são ainda maiores do que o regime borbulhante anterior. E no regime rápido (linha tracejada com marcador triangular da Figura 97), o comportamento do perfil de entropia do vidro $355 \mu \mathrm{m}$ na base, é semelhante ao desta partícula no regime turbulento (linha tracejada com marcador quadrático da Figura 97), enquanto no meio e no topo, devido a formação do escoamento núcleo-anelar, a entropia aumentou.

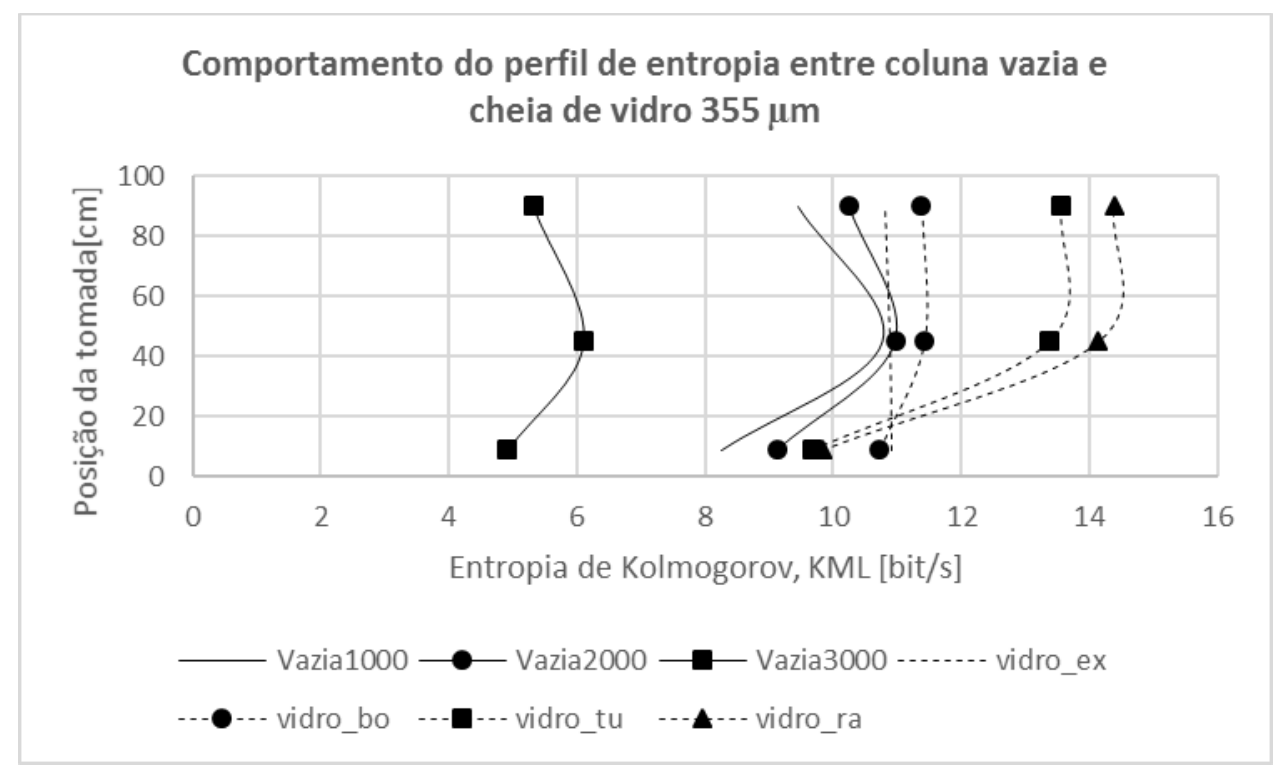

Figura 97 - Comparativo entre os perfis de entropia de coluna vazia e cheia de leito de partícula de vidro $355 \mu \mathrm{m}$.

As linhas contínuas da Figura 98, representam os perfis de entropia, variando fluxos do ar de entrada com a coluna vazia. Para o fluxo imposto pela rotação de 1000 RPM (perfil Vazia1000, linha contínua e sem marcado da Figura 98) gera uma entropia maior no meio e igual, na base e no topo. As flutuações espúrias são maiores no centro da coluna do que na base e no topo, que são maios ordenados. Para o fluxo imposto pela rotação de 2000 RPM (perfil Vazia2000, linha contínua e com marcador circular da Figura 98), a estrutura se mantém, porém, deslocada positivamente. Contudo, para um fluxo imposto pela rotação de 3000 RPM (perfil Vazia3000, linha contínua e com marcador quadrático da Figura 98), 
a estrutura se mantém, porém, deslocada negativamente em relação a rotação de 1000 RPM. O aumento da rotação impõe fluxos com baixos níveis de flutuações espúrias, reduzindo o valor da entropia.

Ao preencher a coluna com um nível de $8 \mathrm{~cm}$ de leito de partículas de areia 1,0 $\mathrm{mm}$ e definir rotações ao ventilador para desempenhar os regimes de fluidização (linhas tracejadas da Figura 98) é possível verificar o impacto do escoamento gás-sólido no sobre a métrica do perfil de entropia. No regime expandido (perfil areia1_ex ou linha tracejada sem marcador da Figura 98), o leito se mantém coeso, e a passagem do fluxo (ar) pelos interstícios do leito, na base, impõe flutuações que permanecem aproximadamente iguais pelo meio e topo da coluna LFC. No regime borbulhante (linha tracejada com marcador circular da Figura 98), o escoamento gás-sólido na base, no meio e no topo, apresenta uma tendência semelhante ao regime expandido (linha tracejada sem marcador da Figura 98). O motivo desta semelhança reside na característica intrínseca da areia de não borbulhar com tanta facilidade quanto as partículas de vidro. No regime turbulento (linha tracejada com marcador quadrático da Figura 98), a tendência de redução da imprevisibilidade, na base, e aumento do grau de desordem, no meio e topo, são ainda maiores do que o regime borbulhante anterior. E no regime rápido (linha tracejada com marcador triangular da Figura 98), o comportamento do perfil de entropia da areia 1,0 mm na base, é maior do que no regime turbulento (linha tracejada com marcador quadrático da Figura 98), enquanto no meio e no topo, devido a formação do escoamento núcleo-anelar, a entropia reduziu ligeiramente.

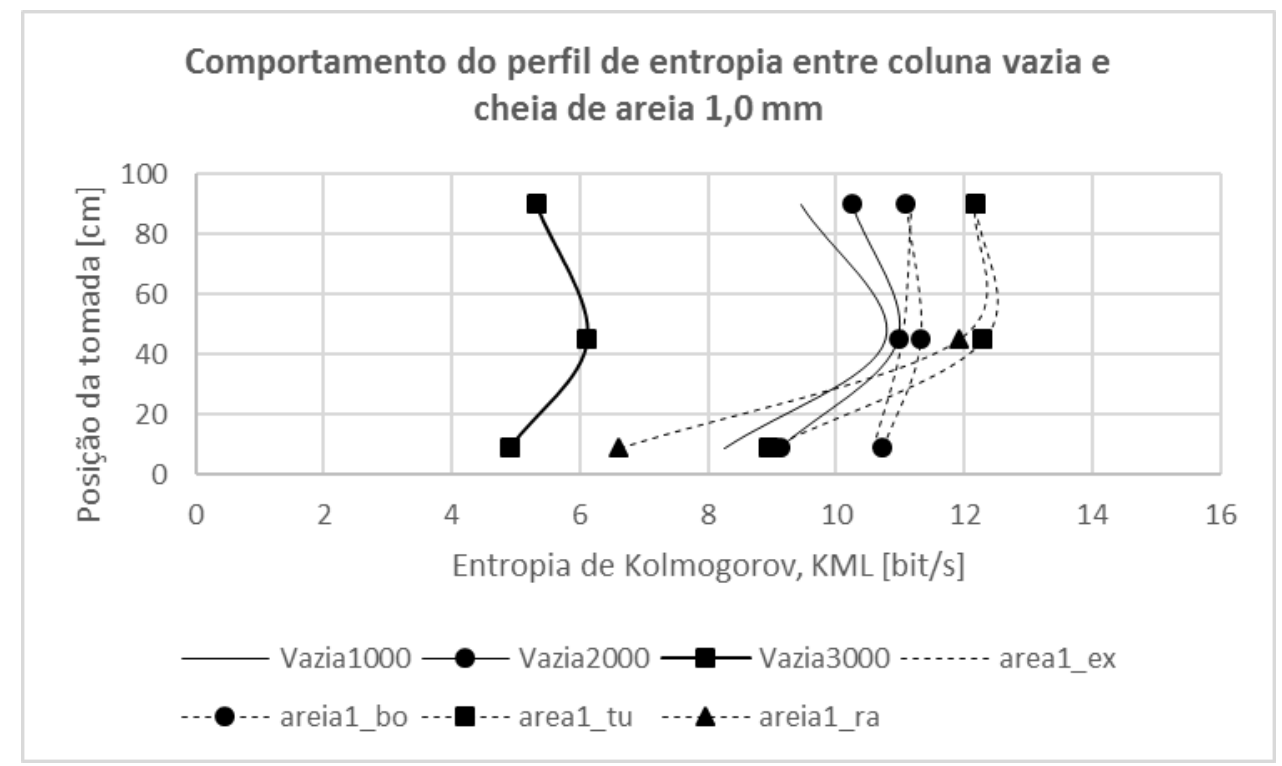

Figura 98 - Comparativo entre os perfis de entropia de coluna vazia e cheia de leito de partícula de areia $1,0 \mathrm{~mm}$.

As linhas contínuas da Figura 99, representam os perfis de entropia, variando fluxos do ar de entrada com a coluna vazia. Para o fluxo imposto pela rotação de 1000 RPM (perfil Vazia1000, linha contínua e sem marcado da Figura 99) gera uma entropia maior no meio e igual, na base e no topo. As flutuações espúrias são maiores no centro da coluna do que na base e no topo, que são maios ordenados. Para o fluxo imposto pela rotação de 2000 RPM (perfil Vazia2000, linha contínua e com marcador circular da Figura 99), a estrutura se mantém, porém, deslocada positivamente. Contudo, para um fluxo imposto pela rotação de 3000 RPM (perfil Vazia3000, linha contínua e com marcador quadrático da Figura 99), a estrutura se mantém, porém, deslocada negativamente em relação a rotação de 1000 RPM. O aumento da rotação impõe fluxos com baixos níveis de flutuações espúrias, reduzindo o valor da entropia. 
Ao preencher a coluna com um nível de $8 \mathrm{~cm}$ de leito de partículas de areia 1,2 $\mathrm{mm}$ e definir rotações ao ventilador para desempenhar os regimes de fluidização (linhas tracejadas da Figura 99) é possível verificar o impacto do escoamento gás-sólido no sobre a métrica do perfil de entropia. No regime expandido (perfil areia12_ex ou linha tracejada sem marcador da Figura 99), o leito se mantém coeso, e a passagem do fluxo (ar) pelos interstícios do leito, na base, impõe flutuações que permanecem aproximadamente iguais pelo meio e topo da coluna LFC. No regime borbulhante (linha tracejada com marcador circular da Figura 99), o escoamento gás-sólido na base, no meio e no topo, apresenta uma tendência semelhante ao regime expandido (linha tracejada sem marcador da Figura 99). O motivo desta semelhança reside na característica intrínseca da areia de não borbulhar com tanta facilidade quanto as partículas de vidro. No regime turbulento (linha tracejada com marcador quadrático da Figura 99), a tendência de redução da imprevisibilidade, na base, e aumento do grau de desordem, no meio e topo, são ainda maiores do que o regime borbulhante anterior. E no regime rápido (linha tracejada com marcador triangular da Figura 99), o comportamento do perfil de entropia da areia 1,0 $\mathrm{mm}$ na base, é maior do que no regime turbulento (linha tracejada com marcador quadrático da Figura 99), enquanto no meio e no topo, devido a formação do escoamento núcleo-anelar, a entropia reduziu ligeiramente.

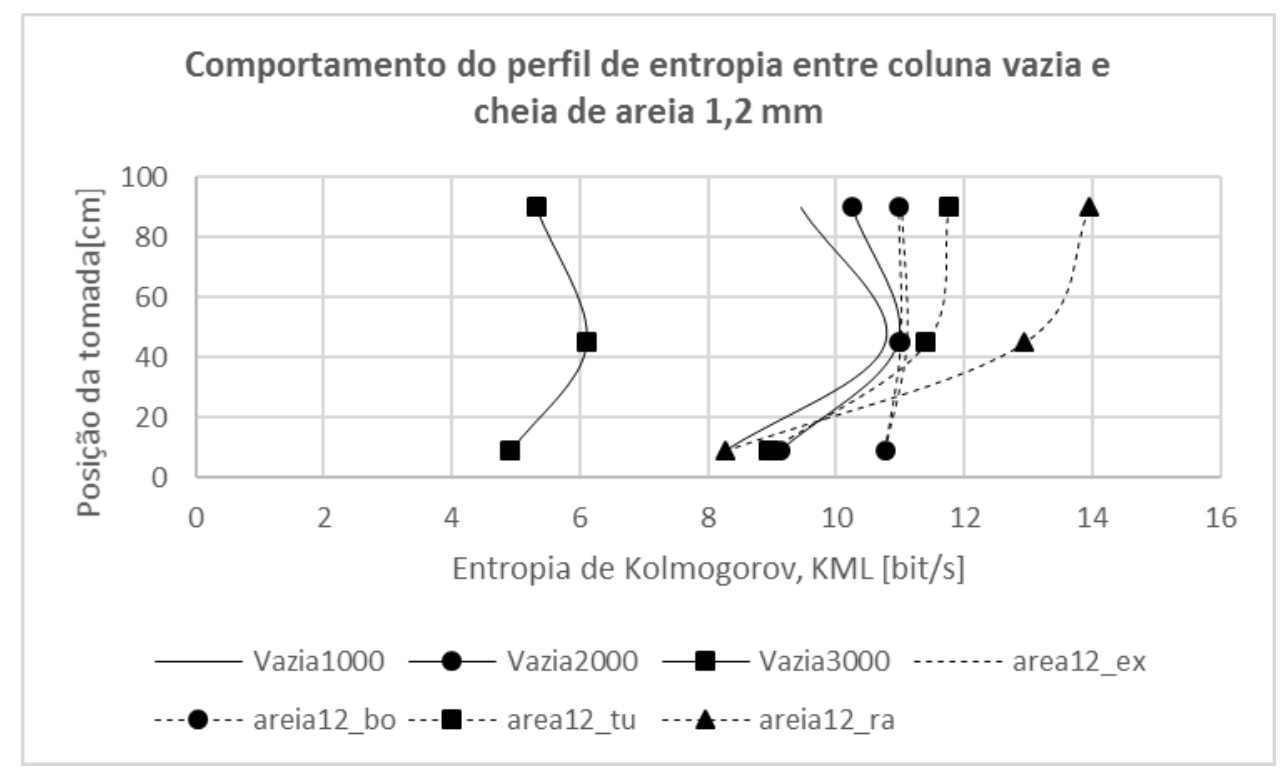

Figura 99 - Comparativo entre os perfis de entropia de coluna vazia e cheia de leito de partícula de areia $1,2 \mathrm{~mm}$.

A presença de sólidos aumenta a entropia, quando comparado a um escoamento na mesma sem sólidos, o que corrobora com trabalhos da literatura [28] [41] [33].

Neste ensaio de avaliação entre quantificador, considerando uma coluna vazia e cheia é possível demonstrar que uma invariante do caos, como a entropia de Kolmogorov, pode distinguir, através da flutuação de pressão estática entre a presença ou não de sólidos no escoamento. A próxima etapa reside na investigação de outras invariantes capazes de auxiliar na quantificação dos diversos regimes de fluidização, mas que seja pouco sensível ao tipo de partícula aqui investigada (vidro $355 \mu \mathrm{m}$, areia 1,0 $\mathrm{mm}$ e areia $1,2 \mathrm{~mm}$ ). 


\subsubsection{Evolução de invariantes do caos}

Este ensaio visa apresentar os resultados da investigação sobre a evolução de invariantes (entropia de Kolmogorov, dimensão de correlação e expoente de Hurst) em diferentes escoamentos gás-sólidos e tipos de partículas, para a quantificação de regimes de fluidização em colunas LFC. Os ensaios são apresentados em duas etapas: em nível de leito constante, onde diferentes gradientes de pressão são aplicados para o desenvolvimento dos regimes de fluidização; e os ensaios com gradiente constante, onde o nível de leito é alterado para o desenvolvimento dos regimes de fluidização.

\subsubsection{Nível constante}

A partir de um nível de leito de partículas de $8 \mathrm{~cm}$ de vidro $355 \mu \mathrm{m}$, diferentes gradientes de pressão são aplicados a coluna LFC para desempenhar os regimes de fluidização investigados (expandido, borbulhante, turbulento e rápido).

A Figura 100 apresenta um comportamento da evolução das invariantes do caos investigadas, na base, em diversos regimes de fluidização, para o vidro $355 \mu \mathrm{m}$. No regime expandido, o expoente de Hurst apresenta rugosidade de $\sim 72 \%$ (linha contínua da Figura 100), dimensão de correlação $\sim 7$ (linha contínua com marcador da Figura 100) e entropia de Kolmogorov 11 bit/s (linha tracejada da Figura 100). O regime borbulhante, apresenta uma rugosidade de $\sim 68 \%$, dimensão de correlação $\sim 7$ e entropia de Kolmogorov de $\sim 10$. Entre o regime expandido e o borbulhante na base, para o vidro $355 \mu \mathrm{m}$, a série tornou-se mais rugosa (devido à queda do expoente de Hurst) e o grau de imprevisibilidade reduziu (devido a redução da entropia de Kolmogorov), enquanto a dimensão de correlação permaneceu a mesma. No regime turbulento, a rugosidade cai (com o aumento do expoente de Hurst, linha contínua da Figura 100), a entropia de Kolmogorov cai para $~ 9$ bit/s (linha tracejada da Figura 100), enquanto a dimensão de correlação aumenta (linha contínua com marcador da Figura 100), em relação ao regime borbulhante. No regime rápido, a rugosidade aumenta ligeiramente (com a queda do expoente de Hurst, linha contínua da Figura 100), a imprevisibilidade continua a cair (linha tracejada da Figura 100) e a complexidade da flutuação aumenta (linha contínua com marcador na Figura 100), em relação ao regime turbulento.

Na base, o padrão de flutuação da pressão estática torna-se mais suave (aumento do expoente de Hurst), menos imprevisível e mais complexo, para partículas de vidro $355 \mu \mathrm{m}$, à medida que o fluxo de ar de entrada aumenta, conforme a Figura 100.

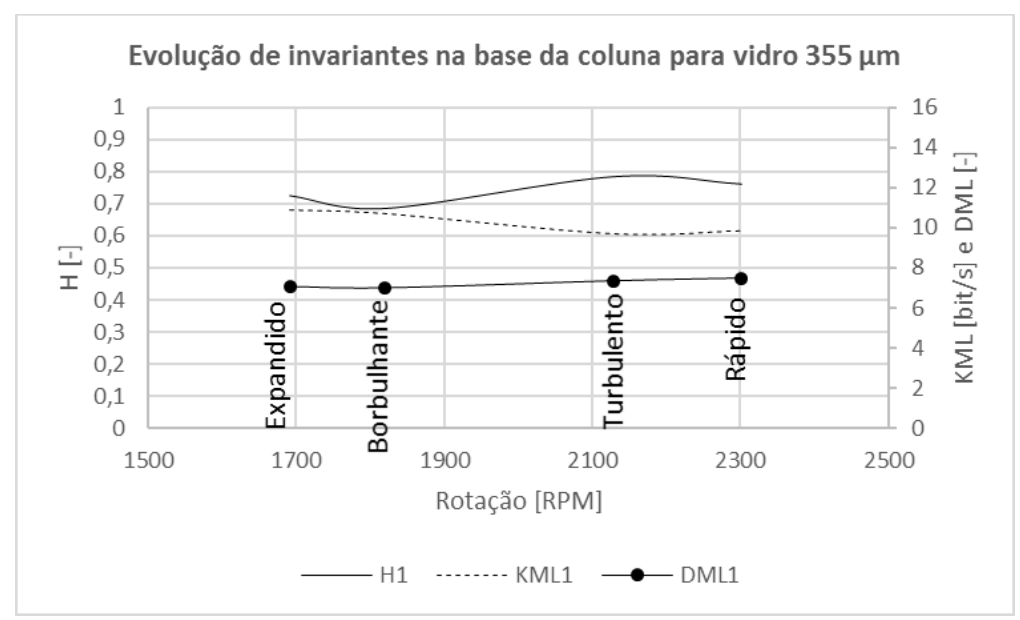

Figura 100 - Comportamento da evolução do expoente de Hurst, dimensão de correlação e entropia de Kolmogorov, na base, em diferentes regimes, para leito de $8 \mathrm{~cm}$ de partículas de vidro $355 \mu \mathrm{m}$. 
A Figura 101 apresenta um comportamento da evolução das invariantes do caos investigadas, no meio, em diversos regimes de fluidização, para o vidro $355 \mu \mathrm{m}$. No regime expandido, o expoente de Hurst apresenta rugosidade de $\sim 63 \%$ (linha contínua da Figura 101), dimensão de correlação 6 (linha contínua com marcador da Figura 101) e entropia de Kolmogorov 10 bit/s (linha tracejada da Figura 101). O regime borbulhante, apresenta uma rugosidade de $\sim 59 \%$, dimensão de correlação $\sim 6$ e entropia de Kolmogorov de $\sim 11$. Entre o regime expandido e o borbulhante na base, para o vidro $355 \mu$ m, a série tornou-se mais rugosa (devido à queda do expoente de Hurst) e o grau de imprevisibilidade aumentou (devido ao aumento da entropia de Kolmogorov), enquanto a dimensão de correlação permaneceu aproximadamente a mesma. No regime turbulento, a rugosidade cai (com o aumento do expoente de Hurst, linha contínua da Figura 101), a entropia de Kolmogorov aumenta para $~ 13$ bit/s (linha tracejada da Figura 101), enquanto a dimensão de correlação aumenta (linha contínua com marcador da Figura 101), em relação ao regime borbulhante. No regime rápido, a rugosidade aumenta ligeiramente (com a queda do expoente de Hurst, linha contínua da Figura 101), a imprevisibilidade continua a aumentar (linha tracejada da Figura 101) e a complexidade da flutuação aumenta (linha contínua com marcador na Figura 101), em relação ao regime turbulento.

No meio, o padrão de flutuação da pressão estática torna-se mais suave (aumento do expoente de Hurst), mais imprevisível e mais complexo, para partículas de vidro $355 \mu \mathrm{m}$, à medida que o fluxo de ar de entrada aumenta, conforme a Figura 101.

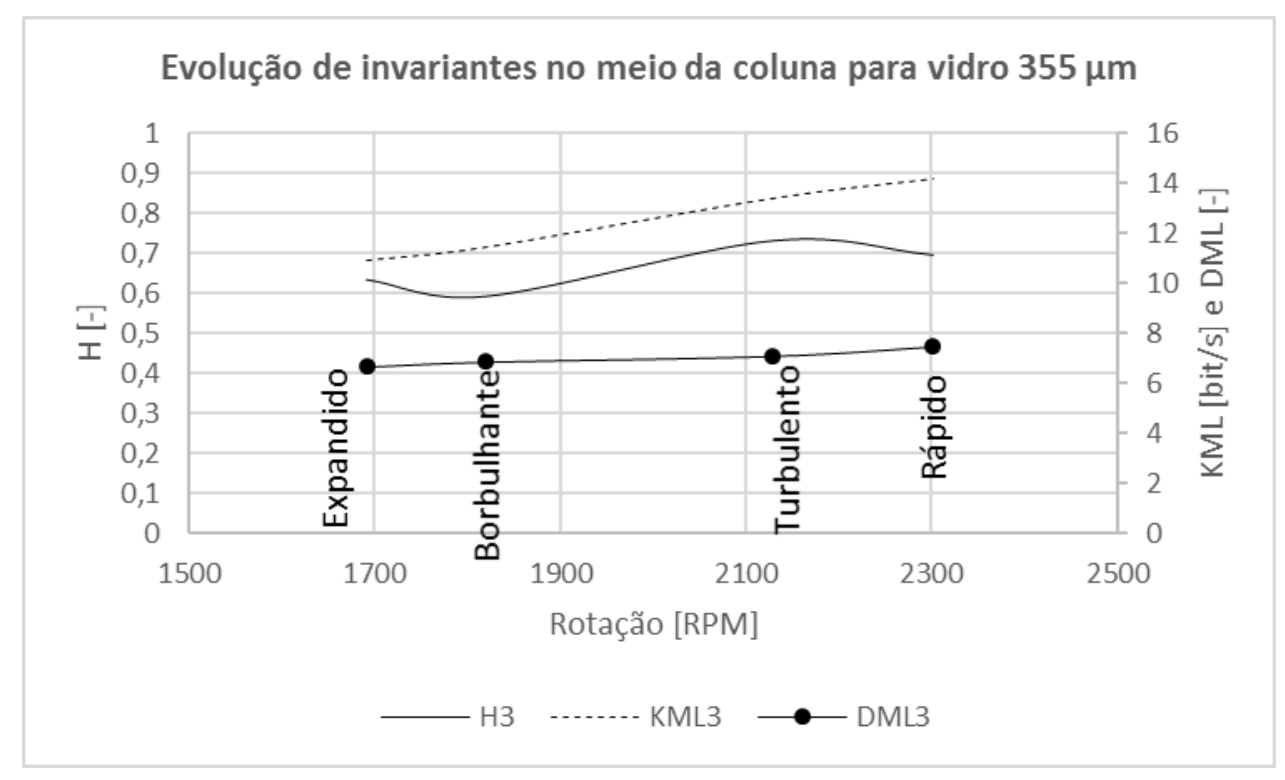

Figura 101 - Comportamento da evolução do expoente de Hurst, dimensão de correlação e entropia de Kolmogorov, no meio, em diferentes regimes, para leito de $8 \mathrm{~cm}$ de partículas de vidro $355 \mu \mathrm{m}$.

A Figura 102 apresenta um comportamento da evolução das invariantes do caos investigadas, no topo, em diversos regimes de fluidização, para o vidro $355 \mu \mathrm{m}$. No regime expandido, o expoente de Hurst apresenta rugosidade de $\sim 63 \%$ (linha contínua da Figura 102), dimensão de correlação 6 (linha contínua com marcador da Figura 102) e entropia de Kolmogorov 10 bit/s (linha tracejada da Figura 102). O regime borbulhante, apresenta uma rugosidade de $\sim 63 \%$, dimensão de correlação $\sim 6$ e entropia de Kolmogorov de $\sim 11$. Entre o regime expandido e o borbulhante na base, para o vidro $355 \mu \mathrm{m}$, a série permaneceu com mais rugosidade e o grau de imprevisibilidade aumentou (devido ao aumento da 
entropia de Kolmogorov), enquanto a dimensão de correlação permaneceu aproximadamente a mesma. No regime turbulento, a rugosidade cai (com o aumento do expoente de Hurst, linha contínua da Figura 102), a entropia de Kolmogorov aumenta para $~ 13$ bit/s (linha tracejada da Figura 102), enquanto a dimensão de correlação aumenta (linha contínua com marcador da Figura 102), em relação ao regime borbulhante. No regime rápido, a rugosidade aumenta ligeiramente (com a queda do expoente de Hurst, linha contínua da Figura 102), a imprevisibilidade continua a aumentar (linha tracejada da Figura 102) e a complexidade da flutuação aumenta (linha contínua com marcador na Figura 102), em relação ao regime turbulento.

No topo, o padrão de flutuação da pressão estática torna-se mais suave (aumento do expoente de Hurst), mais imprevisível e mais complexo, para partículas de vidro $355 \mu \mathrm{m}$, à medida que o fluxo de ar de entrada aumenta, conforme a Figura 102.

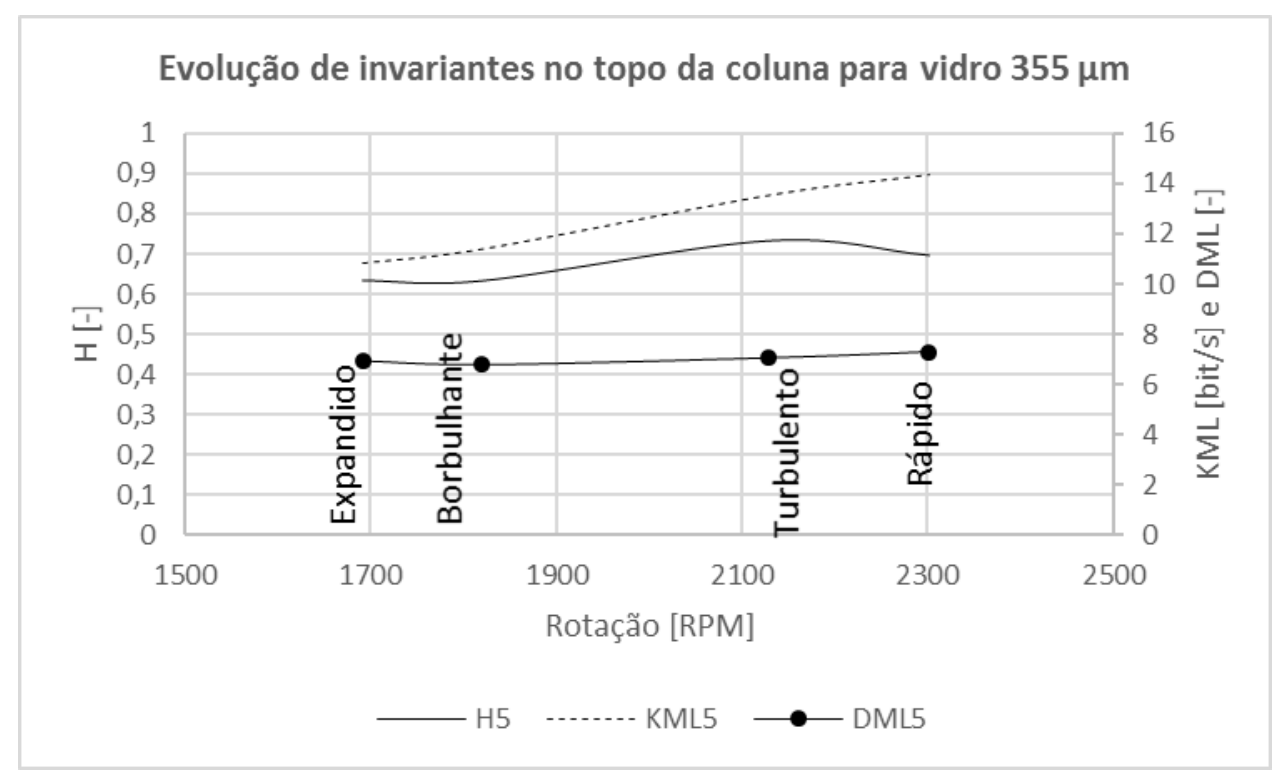

Figura 102 - Comportamento da evolução do expoente de Hurst, dimensão de correlação e entropia de Kolmogorov, no topo, em diferentes regimes, para leito de $8 \mathrm{~cm}$ de partículas de vidro $355 \mu \mathrm{m}$.

A partir de um nível de leito de partículas de $8 \mathrm{~cm}$ de areia $1,0 \mathrm{~mm}$, diferentes gradientes de pressão são aplicados a coluna LFC para desempenhar os regimes de fluidização investigados (expandido, borbulhante, turbulento e rápido).

A Figura 103 apresenta um comportamento da evolução das invariantes do caos investigadas, na base, em diversos regimes de fluidização, para areia 1,0 mm. No regime expandido, o expoente de Hurst apresenta rugosidade de $\sim 80 \%$ (linha contínua da Figura 103), dimensão de correlação $~ 7$ (linha contínua com marcador da Figura 103) e entropia de Kolmogorov 10 bit/s (linha tracejada da Figura 103). O regime borbulhante, apresenta uma rugosidade de $\sim 66 \%$, dimensão de correlação $\sim 7$ e entropia de Kolmogorov de $\sim 10$. Entre o regime expandido e o borbulhante na base, para a areia 1,0 $\mathrm{mm}$, a série tornou-se mais rugosa (devido à queda do expoente de Hurst) e o grau de imprevisibilidade permaneceu, enquanto a dimensão de correlação permaneceu a mesma. No regime turbulento, a rugosidade cai (com o aumento do expoente de Hurst, linha contínua da Figura 103), a entropia de Kolmogorov cai para $~ 8$ bit/s (linha tracejada da Figura 103), enquanto a dimensão de correlação aumenta (linha contínua com marcador da Figura 103), em relação ao regime borbulhante. No regime rápido, a rugosidade aumenta ligeiramente (com a queda do expoente de Hurst, linha contínua da Figura 103), a imprevisibilidade 
continua a cair (linha tracejada da Figura 103) e a complexidade da flutuação aumenta (linha contínua com marcador na Figura 103), em relação ao regime turbulento.

Na base, o padrão de flutuação da pressão estática torna-se mais suave (aumento do expoente de Hurst), menos imprevisível e mais complexo, para partículas de areia $1,0 \mathrm{~mm}$, à medida que o fluxo de ar de entrada aumenta, conforme a Figura 103.

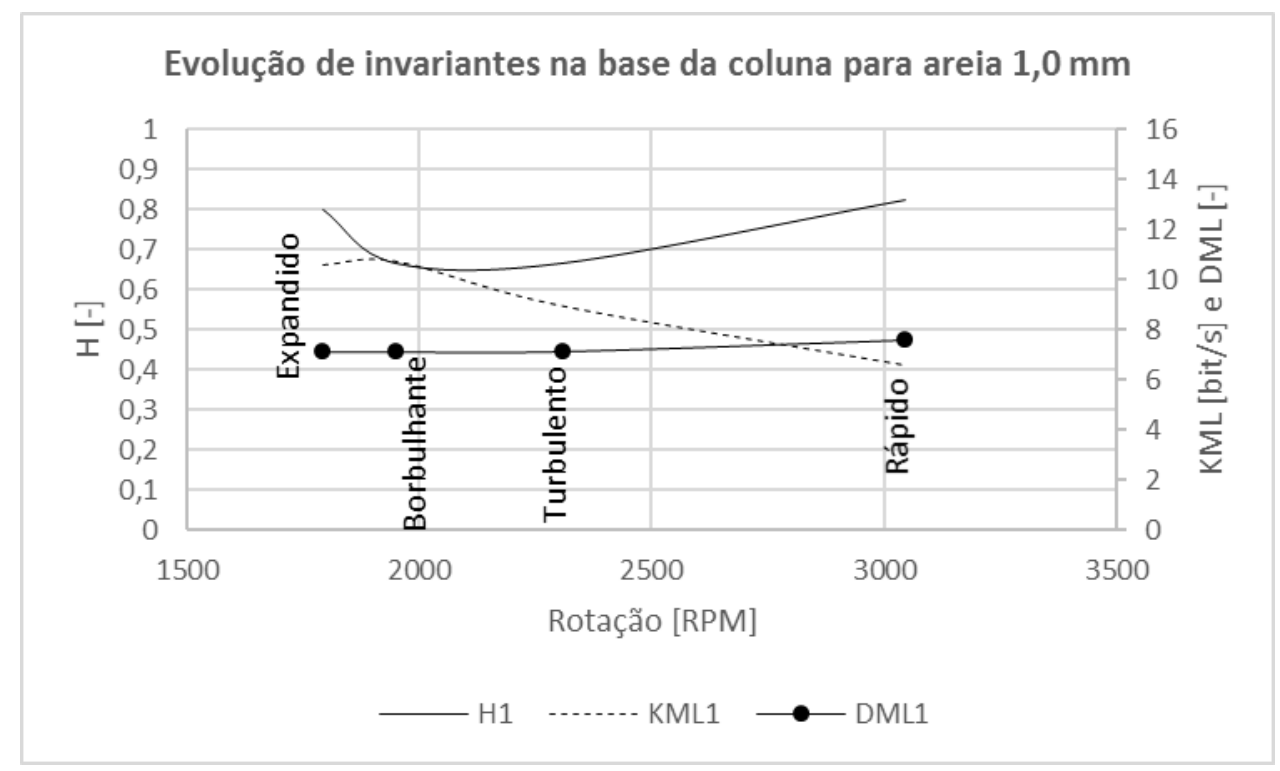

Figura 103 - Comportamento da evolução do expoente de Hurst, dimensão de correlação e entropia de Kolmogorov, na base, em diferentes regimes, para leito de $8 \mathrm{~cm}$ de partículas de areia 1,0 $\mathrm{mm}$.

A Figura 104 apresenta um comportamento da evolução das invariantes do caos investigadas, no meio, em diversos regimes de fluidização, para a areia 1,0 mm. No regime expandido, o expoente de Hurst apresenta rugosidade de $\sim 65 \%$ (linha contínua da Figura 104), dimensão de correlação $\sim 7$ (linha contínua com marcador da Figura 104) e entropia de Kolmogorov 11 bit/s (linha tracejada da Figura 104). O regime borbulhante, apresenta uma rugosidade de $\sim 70 \%$, dimensão de correlação $\sim 7$ e entropia de Kolmogorov de $\sim 11$. Entre o regime expandido e o borbulhante na base, para a areia 1,0 mm, a série tornou-se mais suave (devido ao aumento do expoente de Hurst) e o grau de imprevisibilidade aumentou (devido ao aumento da entropia de Kolmogorov), enquanto a dimensão de correlação permaneceu aproximadamente a mesma. No regime turbulento, a rugosidade cai (com o aumento do expoente de Hurst, linha contínua da Figura 104), a entropia de Kolmogorov aumenta para 12 bit/s (linha tracejada da Figura 104), enquanto a dimensão de correlação aumenta (linha contínua com marcador da Figura 104), em relação ao regime borbulhante. No regime rápido, a suavidade da série aumenta ligeiramente (com o aumento do expoente de Hurst, linha contínua da Figura 104), a imprevisibilidade permanece alta (linha tracejada da Figura 104) e a complexidade da flutuação aumenta (linha contínua com marcador na Figura 104), em relação ao regime turbulento.

No meio, o padrão de flutuação da pressão estática torna-se mais suave (aumento do expoente de Hurst), mais imprevisível e mais complexo, para partículas de areia $1,0 \mathrm{~mm}$, à medida que o fluxo de ar de entrada aumenta, conforme a Figura 104. 


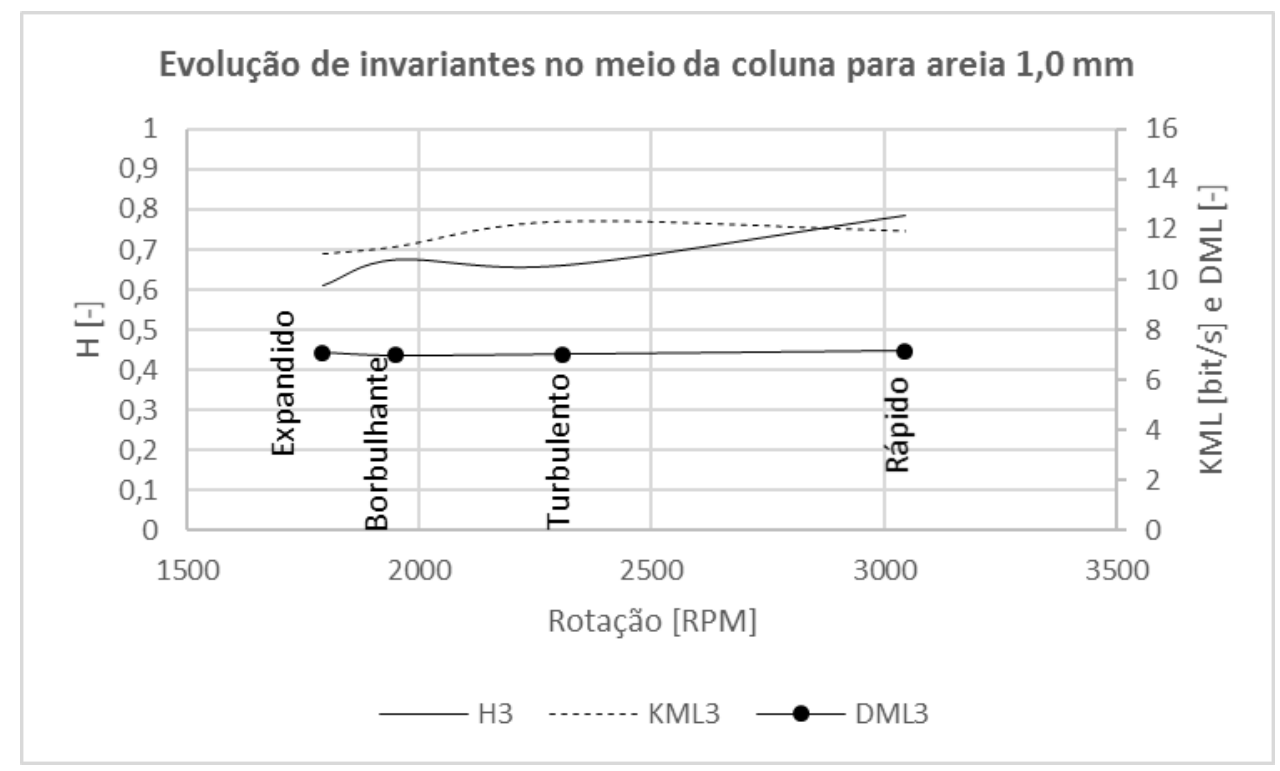

Figura 104 - Comportamento da evolução do expoente de Hurst, dimensão de correlação e entropia de Kolmogorov, no meio, em diferentes regimes, para leito de $8 \mathrm{~cm}$ de partículas de areia 1,0 $\mathrm{mm}$.

A Figura 105 apresenta um comportamento da evolução das invariantes do caos investigadas, no topo, em diversos regimes de fluidização, para a areia 1,0 mm. No regime expandido, o expoente de Hurst apresenta rugosidade de $\sim 63 \%$ (linha contínua da Figura 105), dimensão de correlação $\sim 7$ (linha contínua com marcador da Figura 105) e entropia de Kolmogorov 11 bit/s (linha tracejada da Figura 105). O regime borbulhante, apresenta uma rugosidade de $\sim 70 \%$, dimensão de correlação $\sim 7$ e entropia de Kolmogorov de $\sim 11$. Entre o regime expandido e o borbulhante na base, para a areia 1,0 $\mathrm{mm}$, a série tornou-se mais suave (devido ao aumento do expoente de Hurst) e o grau de imprevisibilidade aumentou (devido ao aumento da entropia de Kolmogorov), enquanto a dimensão de correlação permaneceu aproximadamente a mesma. No regime turbulento, a rugosidade cai (com o aumento do expoente de Hurst, linha contínua da Figura 105), a entropia de Kolmogorov aumenta para 12 bit/s (linha tracejada da Figura 105), enquanto a dimensão de correlação aumenta (linha contínua com marcador da Figura 105), em relação ao regime borbulhante. No regime rápido, a suavidade da série aumenta ligeiramente (com o aumento do expoente de Hurst, linha contínua da Figura 105), a imprevisibilidade aumenta (linha tracejada da Figura 105) e a complexidade da flutuação aumenta (linha contínua com marcador na Figura 105), em relação ao regime turbulento.

No topo, o padrão de flutuação da pressão estática torna-se mais suave (aumento do expoente de Hurst), mais imprevisível e mais complexo, para partículas de areia $1,0 \mathrm{~mm}$, à medida que o fluxo de ar de entrada aumenta, conforme a Figura 105. 


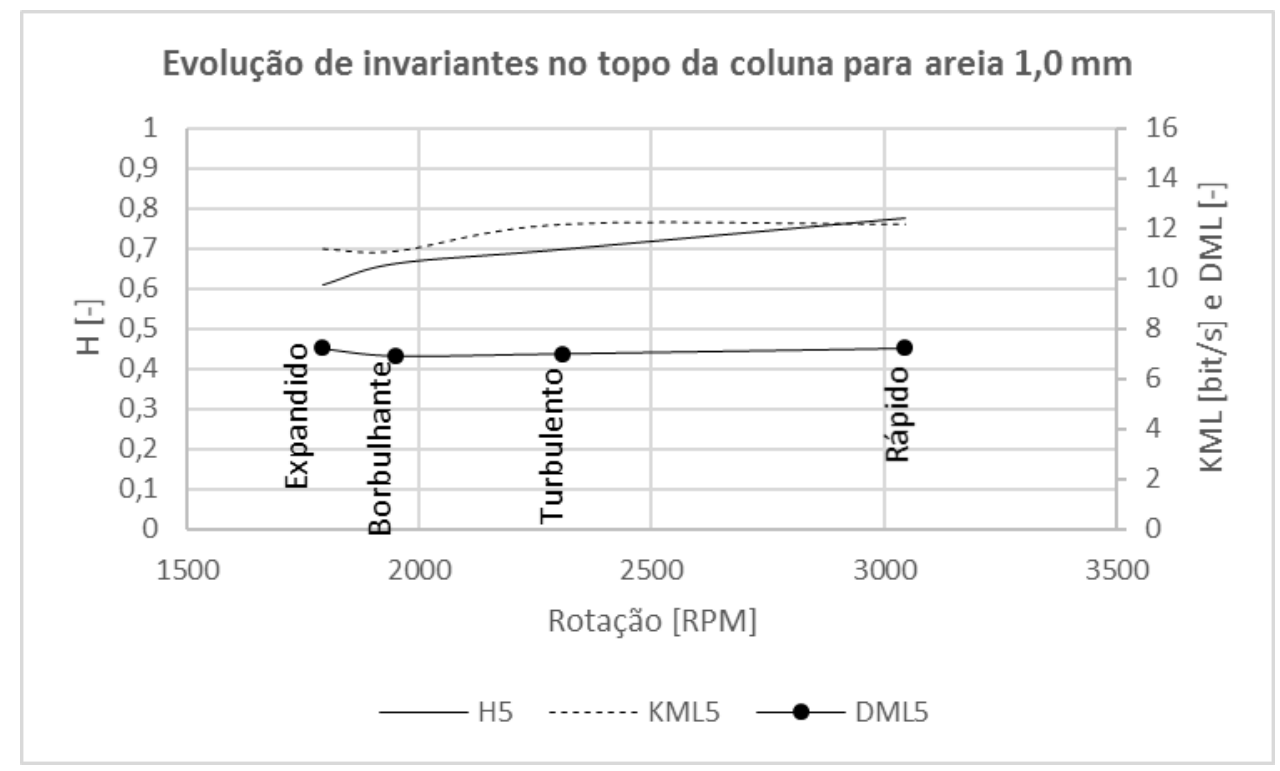

Figura 105 - Comportamento da evolução do expoente de Hurst, dimensão de correlação e entropia de Kolmogorov, no topo, em diferentes regimes, para leito de $8 \mathrm{~cm}$ de partículas de areia 1,0 $\mathrm{mm}$.

A partir de um nível de leito de partículas de $8 \mathrm{~cm}$ de areia 1,2 $\mathrm{mm}$, diferentes gradientes de pressão são aplicados a coluna LFC para desempenhar os regimes de fluidização investigados (expandido, borbulhante, turbulento e rápido).

A Figura 106 apresenta um comportamento da evolução das invariantes do caos investigadas, na base, em diversos regimes de fluidização, para areia 1,2 mm. No regime expandido, o expoente de Hurst apresenta rugosidade de $\sim 80 \%$ (linha contínua da Figura 106), dimensão de correlação 7 (linha contínua com marcador da Figura 106) e entropia de Kolmogorov 10 bit/s (linha tracejada da Figura 106). O regime borbulhante, apresenta uma rugosidade de $\sim 72 \%$, dimensão de correlação $\sim 7$ e entropia de Kolmogorov de $\sim 10$. Entre o regime expandido e o borbulhante na base, para a areia 1,0 mm, a série tornou-se mais rugosa (devido à queda do expoente de Hurst) e o grau de imprevisibilidade permaneceu, enquanto a dimensão de correlação permaneceu a mesma. No regime turbulento, a rugosidade cai (com o aumento do expoente de Hurst, linha contínua da Figura 106), a entropia de Kolmogorov cai para $~ 8$ bit/s (linha tracejada da Figura 106), enquanto a dimensão de correlação aumenta (linha contínua com marcador da Figura 106), em relação ao regime borbulhante. No regime rápido, a suavidade aumenta (com o aumento do expoente de Hurst, linha contínua da Figura 106), a imprevisibilidade continua a cair (linha tracejada da Figura 106) e a complexidade da flutuação aumenta (linha contínua com marcador na Figura 106), em relação ao regime turbulento.

Na base, o padrão de flutuação da pressão estática torna-se mais suave (aumento do expoente de Hurst), menos imprevisível e mais complexo, para partículas de areia $1,2 \mathrm{~mm}$, à medida que o fluxo de ar de entrada aumenta, conforme a Figura 106. 


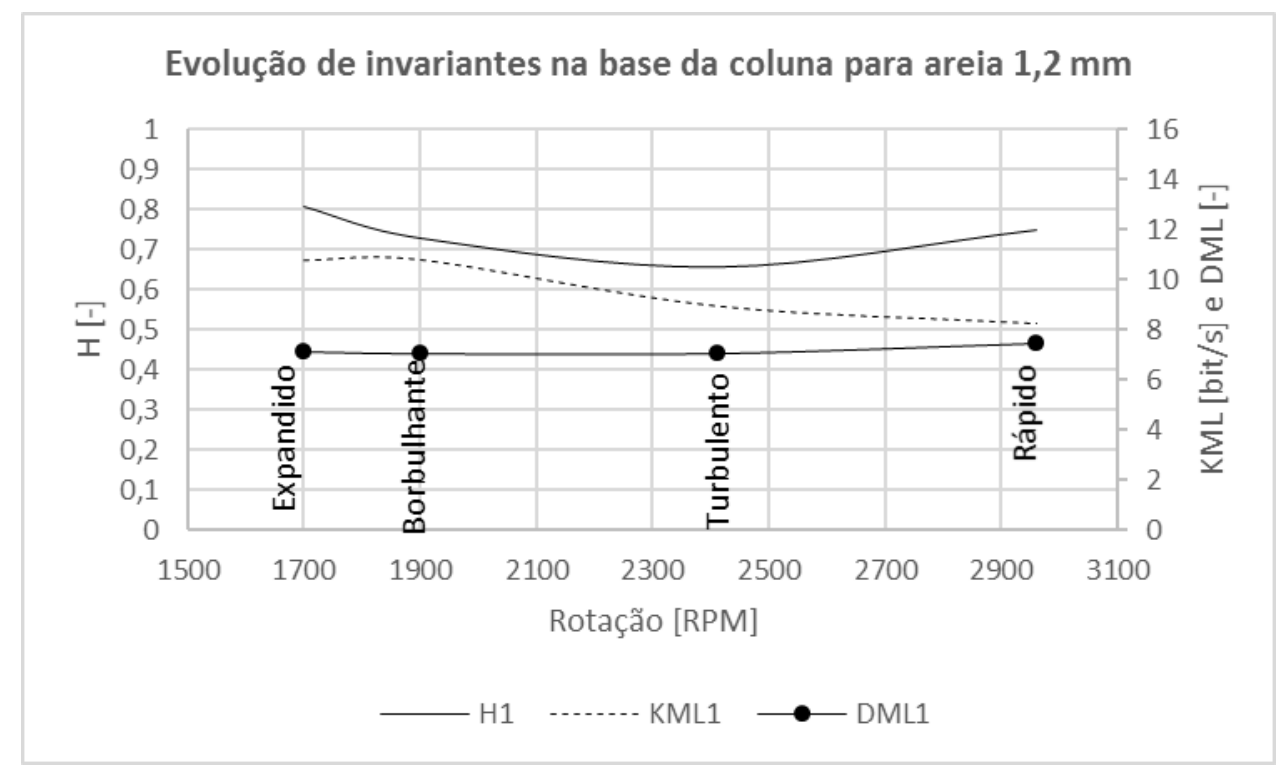

Figura 106 - Comportamento da evolução do expoente de Hurst, dimensão de correlação e entropia de Kolmogorov, na base, em diferentes regimes, para leito de $8 \mathrm{~cm}$ de partículas de areia 1,2 $\mathrm{mm}$.

A Figura 107 apresenta um comportamento da evolução das invariantes do caos investigadas, no meio, em diversos regimes de fluidização, para a areia 1,2 mm. No regime expandido, o expoente de Hurst apresenta rugosidade de $\sim 65 \%$ (linha contínua da Figura 107), dimensão de correlação 7 (linha contínua com marcador da Figura 107) e entropia de Kolmogorov 11 bit/s (linha tracejada da Figura 107). O regime borbulhante, apresenta uma rugosidade de $\sim 70 \%$, dimensão de correlação $\sim 7$ e entropia de Kolmogorov de $\sim 11$. Entre o regime expandido e o borbulhante na base, para a areia 1,2 $\mathrm{mm}$, a série tornou-se mais suave (devido ao aumento do expoente de Hurst) e o grau de imprevisibilidade aumentou (devido ao aumento da entropia de Kolmogorov), enquanto a dimensão de correlação permaneceu aproximadamente a mesma. No regime turbulento, a rugosidade cai (com o aumento do expoente de Hurst, linha contínua da Figura 107), a entropia de Kolmogorov aumenta para 12 bit/s (linha tracejada da Figura 107), enquanto a dimensão de correlação aumenta (linha contínua com marcador da Figura 107), em relação ao regime borbulhante. No regime rápido, a suavidade da série aumenta ligeiramente (com o aumento do expoente de Hurst, linha contínua da Figura 107), a imprevisibilidade permanece alta (linha tracejada da Figura 107) e a complexidade da flutuação aumenta (linha contínua com marcador na Figura 107), em relação ao regime turbulento.

No meio, o padrão de flutuação da pressão estática torna-se mais suave (aumento do expoente de Hurst), mais imprevisível e mais complexo, para partículas de areia $1,2 \mathrm{~mm}$, à medida que o fluxo de ar de entrada aumenta, conforme a Figura 107. 


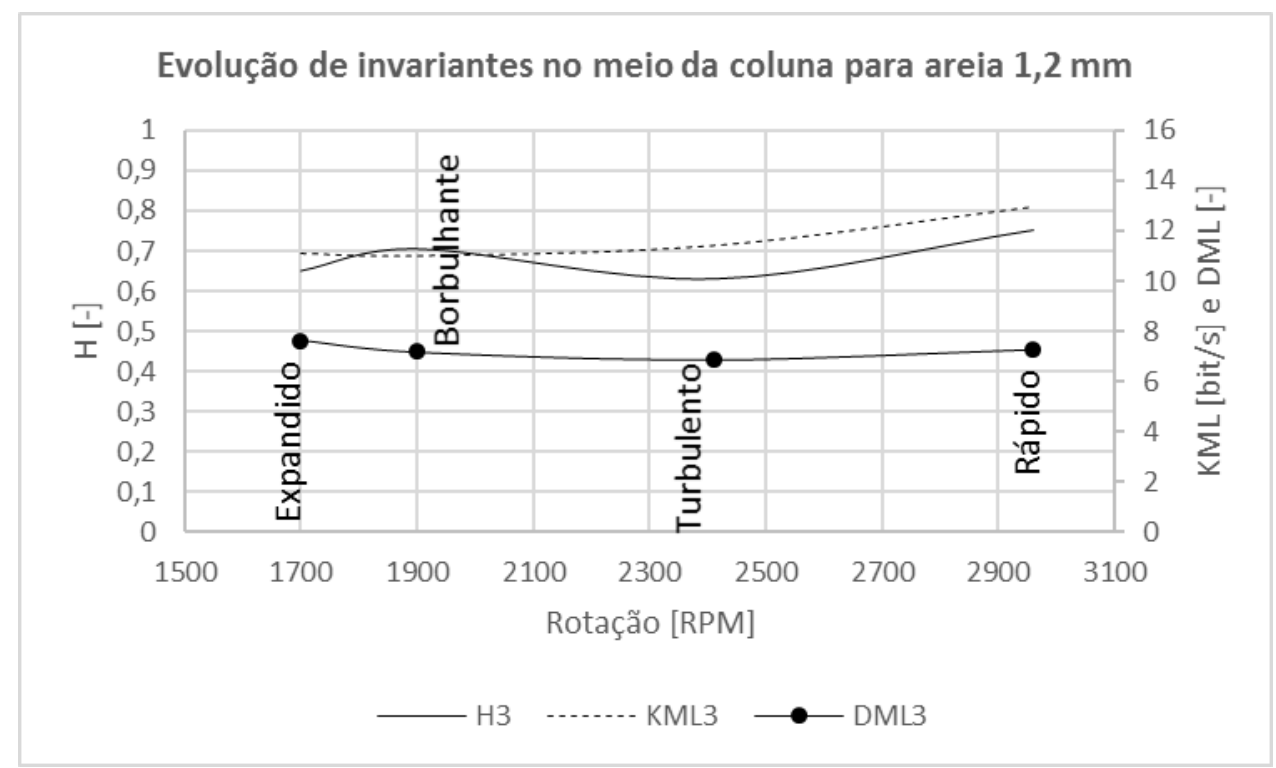

Figura 107 - Comportamento da evolução do expoente de Hurst, dimensão de correlação e entropia de Kolmogorov, no meio, em diferentes regimes, para leito de $8 \mathrm{~cm}$ de partículas de areia 1,2 $\mathrm{mm}$.

A Figura 108 apresenta um comportamento da evolução das invariantes do caos investigadas, no topo, em diversos regimes de fluidização, para a areia 1,2 $\mathrm{mm}$. No regime expandido, o expoente de Hurst apresenta rugosidade de $\sim 63 \%$ (linha contínua da Figura 108), dimensão de correlação $~ 7$ (linha contínua com marcador da Figura 108) e entropia de Kolmogorov 11 bit/s (linha tracejada da Figura 108). O regime borbulhante, apresenta uma rugosidade de $\sim 70 \%$, dimensão de correlação $\sim 7$ e entropia de Kolmogorov de $\sim 11$. Entre o regime expandido e o borbulhante na base, para a areia 1,2 $\mathrm{mm}$, a série tornou-se mais suave (devido ao aumento do expoente de Hurst) e o grau de imprevisibilidade aumentou (devido ao aumento da entropia de Kolmogorov), enquanto a dimensão de correlação permaneceu aproximadamente a mesma. No regime turbulento, a rugosidade aumenta (com o queda do expoente de Hurst, linha contínua da Figura 108), a entropia de Kolmogorov aumenta para 12 bit/s (linha tracejada da Figura 108), enquanto a dimensão de correlação aumenta (linha contínua com marcador da Figura 108), em relação ao regime borbulhante. No regime rápido, a suavidade da série aumenta ligeiramente (com o aumento do expoente de Hurst, linha contínua da Figura 108), a imprevisibilidade aumenta (linha tracejada da Figura 108) e a complexidade da flutuação aumenta (linha contínua com marcador na Figura 108), em relação ao regime turbulento.

No topo, o padrão de flutuação da pressão estática torna-se mais suave (aumento do expoente de Hurst), mais imprevisível e mais complexo, para partículas de areia $1,2 \mathrm{~mm}$, à medida que o fluxo de ar de entrada aumenta, conforme a Figura 108. 


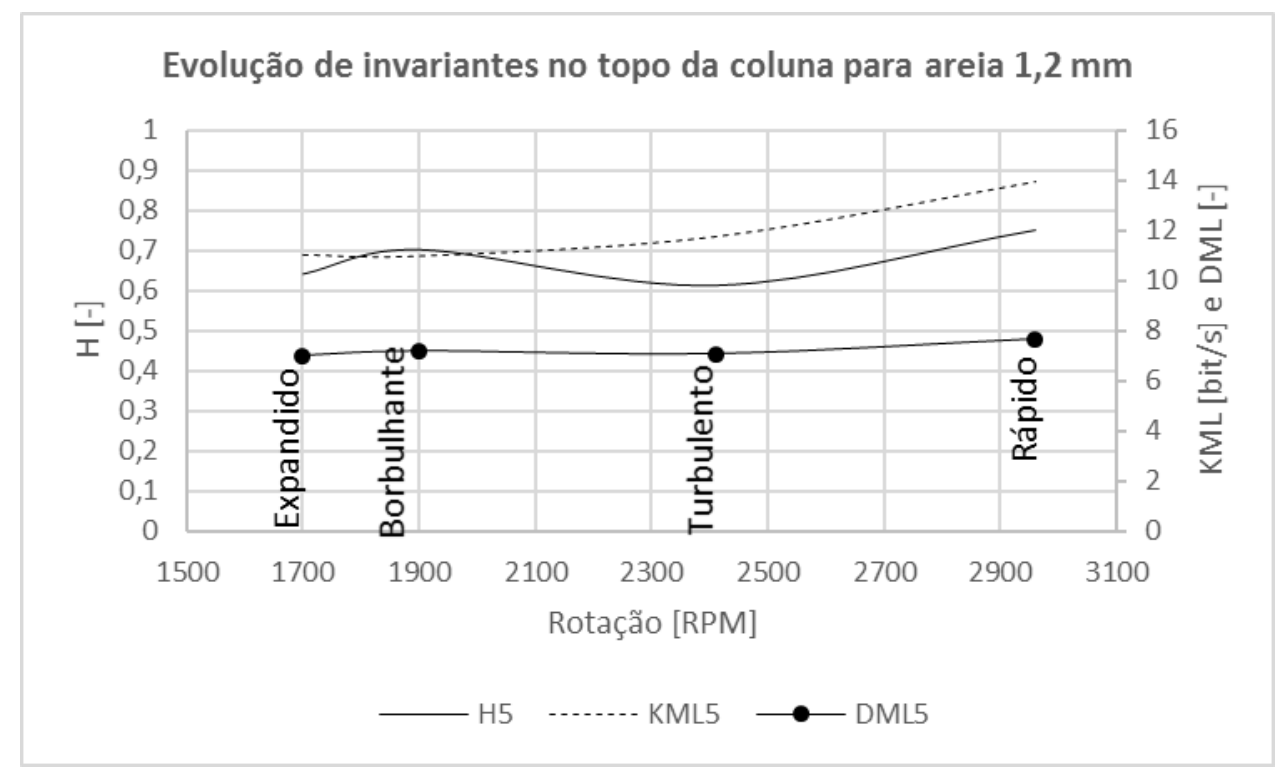

Figura 108 - Comportamento da evolução do expoente de Hurst, dimensão de correlação e entropia de Kolmogorov, no topo, em diferentes regimes, para leito de $8 \mathrm{~cm}$ de partículas de areia 1,2 $\mathrm{mm}$.

Por fim, a Figura 109 resume os perfis axiais da entropia de Kolmogorov de cada tipo de partícula e para cada tipo de regime de fluidização. No regime expandido (linhas contínuas sem marcador da Figura 109) é possível observar a semelhança axial entre os tipos de partículas (vidro e areias). No regime borbulhante (linhas tracejadas sem marcador da Figura 109), também foi possível identificar a classe de perfis comuns. No regime turbulento (linhas contínuas com marcador circular), é possível identificar uma estrutura de perfis próximos, mas em todos os casos, a entropia de base (linhas com marcadores circulares preto, vermelho e verde da Figura 109) é menor do que os valores de entropia do meio e topo. No regime rápido (linhas tracejadas com marcador triangular), indicam uma estrutura de perfis próximos, mas em todos os casos, a entropia de base (linhas com marcadores triangulares preto, vermelho e verde da Figura 109) é menor do que os valores de entropia do meio e topo.

Através da avaliação dos perfis de entropia de Kolmogorov, os regimes expandido e borbulhante são facilmente distinguíveis dos regimes turbulento e rápido. O expoente de Hurst, pode ser associado a entropia de Kolmogorov para distinguir os quatro estados de fluidização. Contudo, os perfis de entropia indicam que as regiões do meio e do topo podem apresentar uma ligeira diferença. Uma das razões que explica a diferença entre essas regiões pode estar associada ao efeito de topo do escoamento que geram flutuações distintas da região do meio da coluna LFC. Um estudo para quantificar o grau de similaridade, em termos de uma invariante do caos, deve ser extraído dos ensaios aqui realizados, conforme os itens seguintes. 


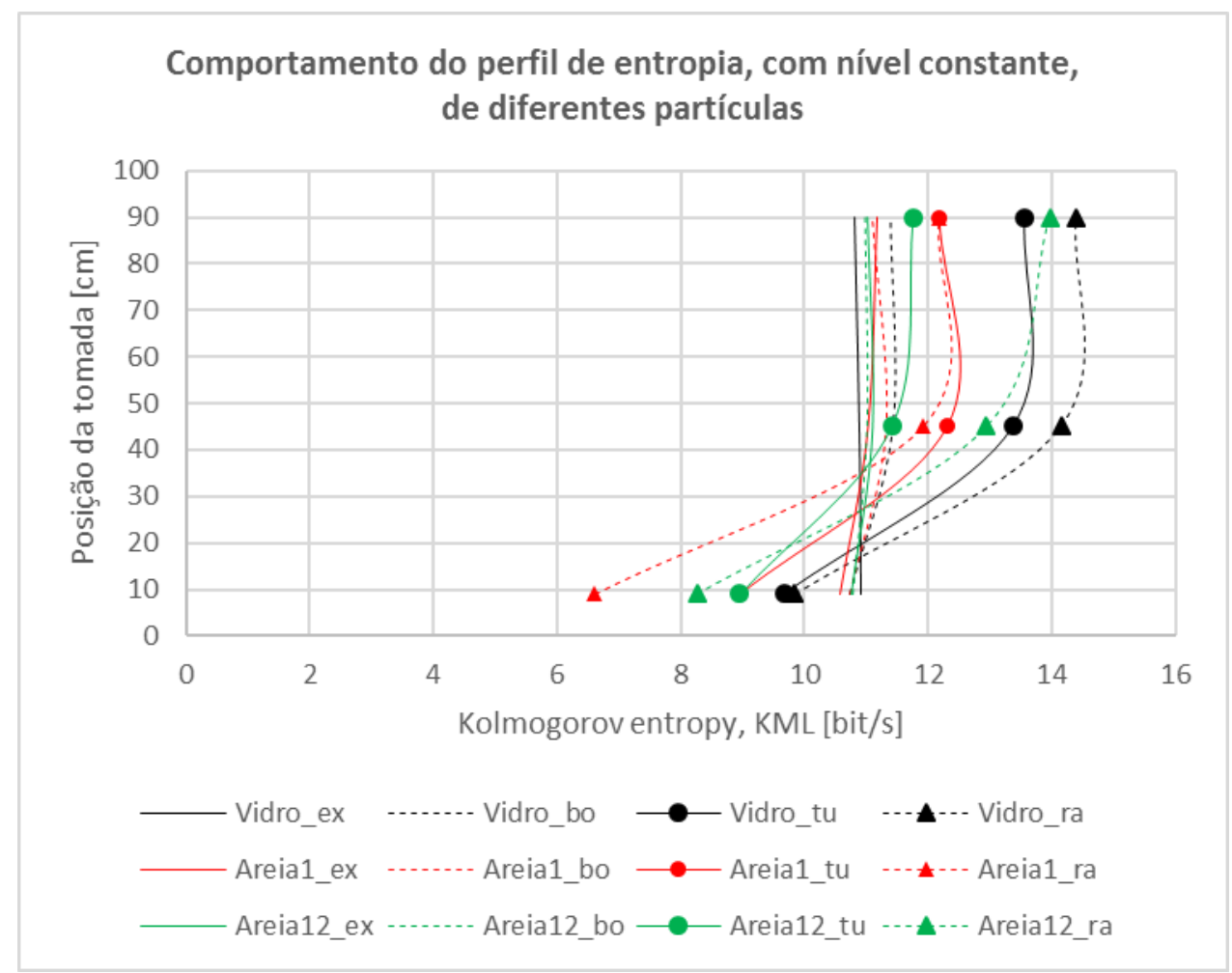

Figura 109 - Perfis axiais do comportamento da entropia de Kolmogorov para as partículas investigadas, na coluna LFC.

Como o desenvolvimento dos regimes de fluidização numa coluna LFC, também pode ser realizado mantendo-se um gradiente constante, enquanto altera-se o nível de leito, ensaios com inventários distintos devem ser realizados para comparação dos resultados.

\subsubsection{Gradiente constante}

$\mathrm{O}$ ensaio de gradiente constante fixa uma pressão diferencial entre as tomadas 1 e 3 manipulando a rotação do ventilador e a altura do nível do leito de areia 1,0 $\mathrm{mm}$ para alcançar o regime de fluidização de interesse. A entropia de Kolmogorov foi a única invariante apresentada devido as outras não apresentarem resultado significativos.

A Figura 110 apresenta a evolução da entropia de Kolmogorov variando-se a altura de leito e a rotação do ventilador. Para o regime expandido, um leito de $10 \mathrm{~cm}$ de areia $1,0 \mathrm{~mm}$ e uma rotação de aproximadamente 1700 RPM alcançaram uma pressão diferencial P1-P3 igual $170 \mathrm{~Pa}$, produzindo uma entropia de base, meio e topo aproximadamente igual (linhas contínua sem marcador, tracejada e contínua com marcador circular da Figura 110). No regime borbulhante, um leito de $9 \mathrm{~cm}$ de areia 1,0 mm e uma rotação de 1785 RPM alcançaram uma pressão diferencial P1-P3 igual $170 \mathrm{~Pa}$, produzindo uma tendência de redução da entropia de base, e uma tendência de crescimento das entropias de meio e topo (linhas contínua sem marcador, tracejada e contínua com marcador circular da Figura 110). No regime turbulento, um leito de $7 \mathrm{~cm}$ de areia $1,0 \mathrm{~mm}$ e uma rotação de 2039 RPM alcançaram uma pressão diferencial P1-P3 igual 170 Pa, produzindo uma tendência de redução da entropia de base, e uma tendência de crescimento das entropias de meio e topo (linhas contínua sem marcador, tracejada e contínua com marcador circular da Figura 110). E por fim, no regime rápido, um leito de $6 \mathrm{~cm}$ de areia 1,0 mm e uma rotação de 2769 RPM alcançaram uma pressão diferencial P1-P3 igual 170 Pa, 
produzindo uma tendência de redução da entropia de base, e uma tendência de crescimento das entropias de meio e topo (linhas contínua sem marcador, tracejada e contínua com marcador circular da Figura $110)$.

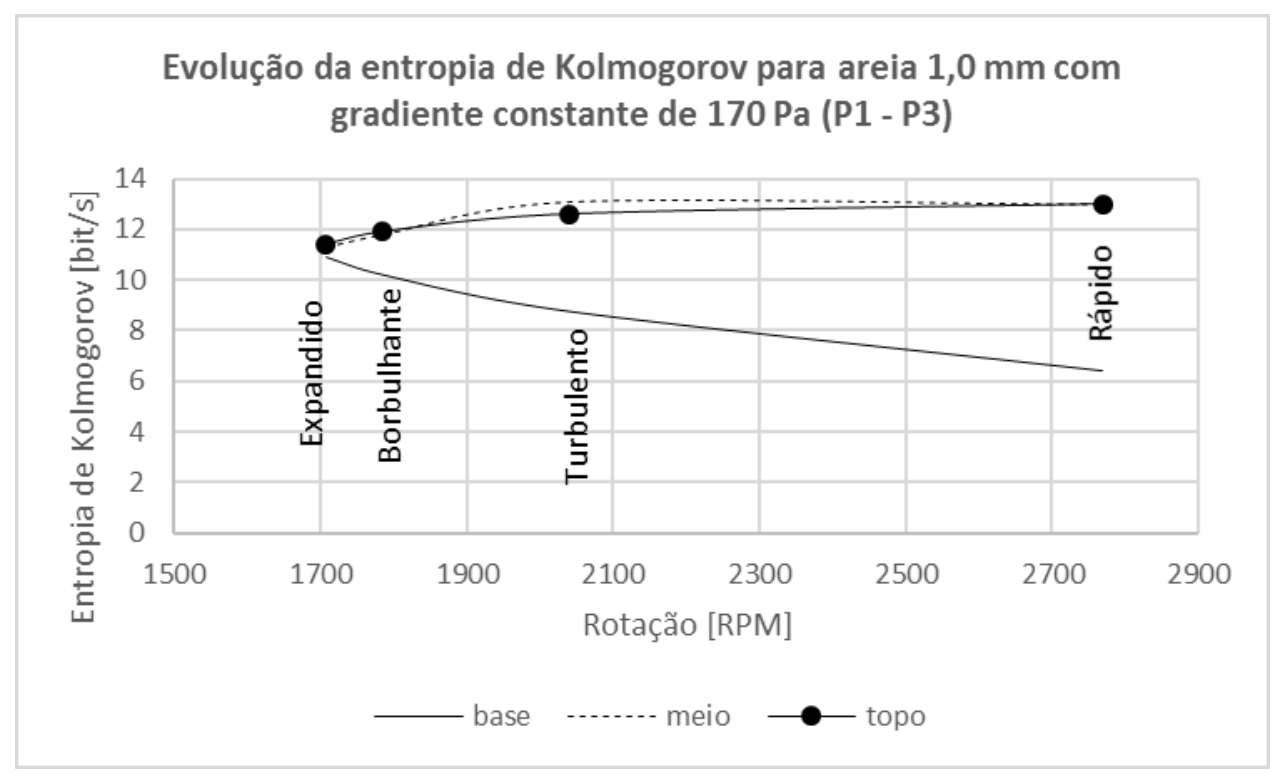

Figura 110 - Comportamento da evolução da entropia de Kolmogorov na coluna LFC, em diferentes regimes, para leito de $8 \mathrm{~cm}$ de partículas de areia $1,0 \mathrm{~mm}$.

Conforme a Figura 111, os perfis de entropia concordam com os perfis apresentados na Figura 109, indicando novamente a robustez do método em extrair das séries temporais, o comportamento pertinente aos regimes de fluidização.

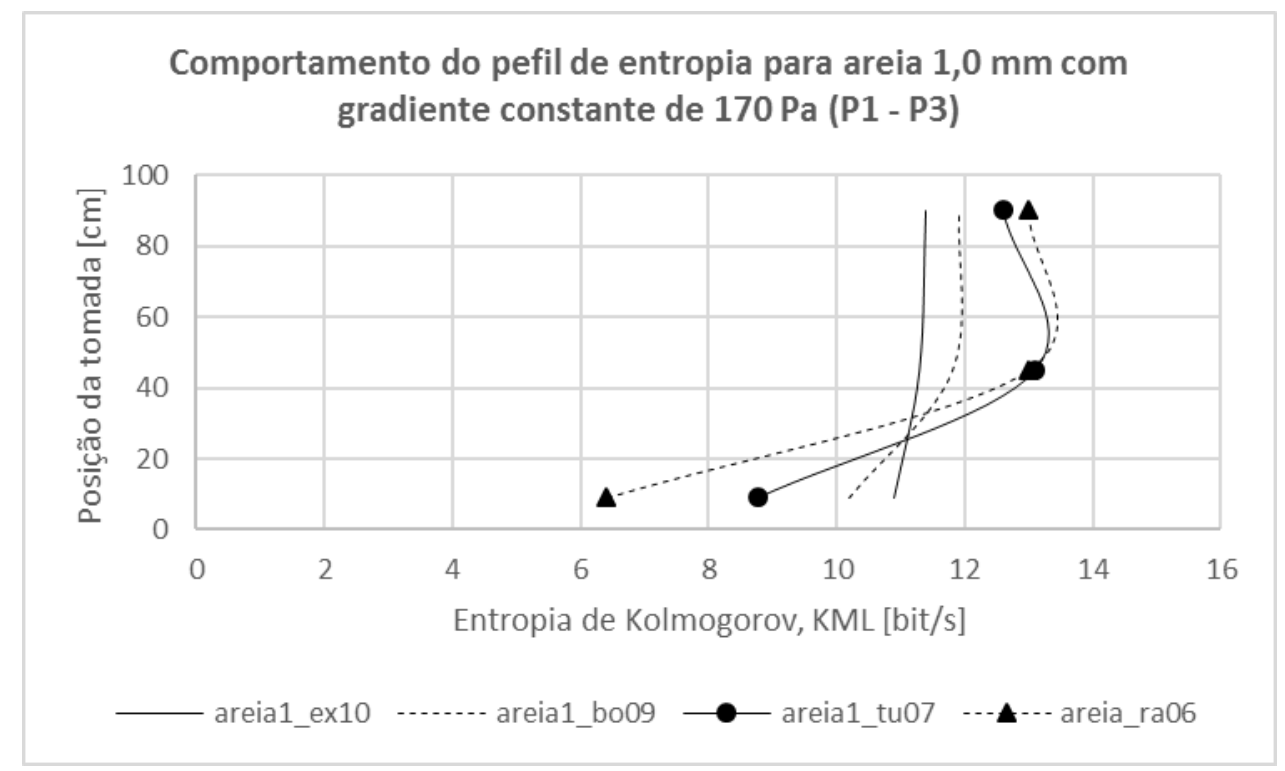

Figura 111 - Perfis axiais do comportamento da entropia de Kolmogorov para as partículas de areia 1,0 $\mathrm{mm}$, na coluna LFC. 
Os resultados entre ensaios com nível e gradiente constante, indicam grande sensibilidade do método aos regimes de fluidização, através da utilização a entropia de Kolmogorov como quantificador local, ao longo da coluna LFC. Para ser possível lançar hipóteses quanto ao uso de invariantes para o controle de regimes, uma verificação do grau de semelhança, em termos de propriedades do caos, entre as regiões de uma coluna LFC, é realizado.

\subsubsection{Similaridade caótica}

A similaridade caótica é o termo designado para avaliar a semelhança entre duas ou mais quantidades, em termos da mesma propriedade do caos [185]. O quociente entre mesmos tipos de invariantes, avaliadas em diferentes posições da coluna LFC, poderiam quantificar a similaridade. Um índice, baseado na razão de características entre regiões, pode ser definido conforme a Equação 51, relacionando as razões de entropias de Kolmogorov entre diferentes regiões i e j da coluna LFC.

$$
I K_{i j}=\frac{K_{i}}{K_{j}} \mid i \neq j \text { e } i, j=\{1,3,5\}
$$

Equação 51

A razão $P_{i} / P_{j}$ relaciona pressões estáticas média entre regiões i e j, mas não é considerado como índice invariante devido a influência do peso das diferentes partículas. O mesmo vale $\sigma_{i} / \sigma_{j}$.

A Tabela 11 apresenta os índices utilizados para análise. Considerando a mesma ordenação de dados para as três partículas o expoente de Hurst, $H$, e razão de entropias de Kolmogorov entre regiões, $I K_{i j}$, apresentaram a maior pertinência para caracterizar os estados de fluidização, pois permaneceram sensíveis aos regimes e não aos parâmetros geométricos das partículas como massa específica e seu diâmetro.

O índice $I K_{i j}$ avalia o grau de semelhança entre essas regiões e quanto mais próximo da unidade, mais similares, em termos entrópicos, serão. No caso do expoente de Hurst, apenas seu valor absoluto foi avaliado para medir a evolução da rugosidade local da série de pressão estática face aos diferentes regimes de fluidização.

No regime expandido, a similaridade entre as três regiões (base, meio e topo) máxima para as três partículas (vidro $355 \mu \mathrm{m}$, areia 1,0 $\mathrm{mm}$ e areia $1,2 \mathrm{~mm}$ ), conforme indicado na Tabela 11. No regime borbulhante, a similaridade entre as regiões começa a reduzir (vide Tabela 11). No regime turbulento, a similaridade entras regiões do meio e topo máxima, enquanto a similaridade entre as regiões de base e meio são baixas (vide Tabela 11). No regime rápido, a similaridade entras regiões do meio e topo máxima, enquanto a similaridade entre as regiões de base e meio são ainda mais baixas (vide Tabela 11 ), em relação ao regime turbulento. Este comportamento para o índice $I K_{i j}$, é preservado para os três tipos de partículas ensaiadas. Portanto, a região de topo torna-se essencial para quantificação da similaridade caótica e análises na avaliação de regimes de fluidização em coluna LFC. 
Tabela 11 - Caracterização local média usando o expoente de Hurst e índice do caos para as partículas de vidro e areia em cada regime.

\begin{tabular}{|c|c|c|c|c|c|c|c|c|}
\hline Partículas & Regimes & Rotação [RPM] & H1 [-] & $\mathrm{H} 3[-]$ & H5 [-] & $I K_{13}[-]$ & $I K_{53}[-]$ & $I K_{15}[-]$ \\
\hline \multirow{4}{*}{ Vidro } & Expandido & 1692 & 0,72 & 0,63 & 0,63 & 1,00 & 0,99 & 1,01 \\
\hline & Borbulhante & 1820 & 0,68 & 0,59 & 0,63 & 0,94 & 0,99 & 0,94 \\
\hline & Turbulento & 2129 & 0,78 & 0,73 & 0,73 & 0,72 & 1,01 & 0,71 \\
\hline & Rápido & 2301 & 0,76 & 0,69 & 0,69 & 0,69 & 1,02 & 0,68 \\
\hline \multirow{4}{*}{ Areia $1,0 \mathrm{~mm}$} & Expandido & 1792 & 0,80 & 0,61 & 0,61 & 0,96 & 1,01 & 1,02 \\
\hline & Borbulhante & 1948 & 0,67 & 0,68 & 0,66 & 0,95 & 0,98 & 0,99 \\
\hline & Turbulento & 2308 & 0,67 & 0,66 & 0,70 & 0,72 & 0,99 & 1,00 \\
\hline & Rápido & 3046 & 0,82 & 0,78 & 0,77 & 0,58 & 1,01 & 1,01 \\
\hline \multirow{4}{*}{ Areia $1,2 \mathrm{~mm}$} & Expandido & 1699 & 0,80 & 0,65 & 0,63 & 0,97 & 0,99 & 0,97 \\
\hline & Borbulhante & 1900 & 0,72 & 0,70 & 0,70 & 0,98 & 0,99 & 0,98 \\
\hline & Turbulento & 2411 & 0,65 & 0,63 & 0,61 & 0,78 & 1,03 & 0,76 \\
\hline & Rápido & 2960 & 0,74 & 0,75 & 0,75 & 0,64 & 1,08 & 0,59 \\
\hline
\end{tabular}

A Figura 112 apresenta o comportamento geral do índice de similaridade caótica, baseado na entropia de Kolmogorov. Quando a distâncias (d1, d2 e d3, vide Figura 112) entre $I K_{53}$ e $I K_{13}$ é nula o regime pode ser expandido ou borbulhante. Quando a distância é máxima, encontra-se o regime rápido. E por hipótese e dados simulados, no regime de transporte, existe uma tendência de uniformidade do escoamento, ao longo da coluna LFC, gerando uma similaridade caótica entre todas as regiões e consequente redução entre as linhas contínuas e tracejada da Figura 112.

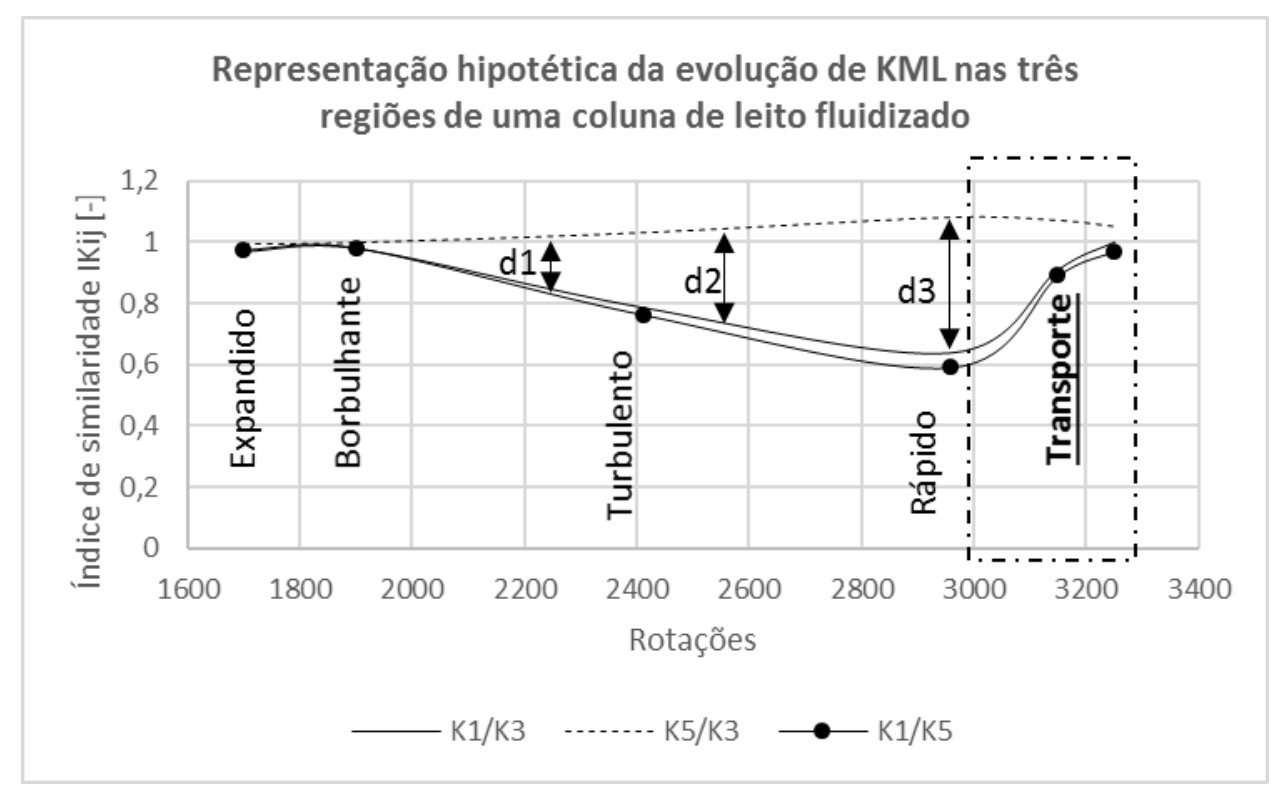

Figura 112 - Comportamento do índice de similaridade caótica, considerando a hipótese do regime de transporte. 


\subsection{Modelo não-paramétrica}

O processo de identificação para controle de processos, visa busca de modelos capazes de representar o comportamento/características de processos reais. A identificação, aqui proposta, é dividida em duas etapas: a quantificação de regimes através da definição de variável para representar o comportamento modelado e a proposta de um modelo baseado em parâmetros.

\subsubsection{Quantificação de regimes}

Finalmente, a quantificação dos regimes de fluidização pode ser definida em duas etapas.

Na primeira etapa, um índice de divergência avalia a falta de similaridade entre as três regiões para quantificar um determinado regime, independentemente do tipo de partícula.

Na segunda etapa, o expoente de Hurst é utilizado para complementar a quantificação, contribuindo para uma avaliação mais precisa.

\subsubsection{1 Índice de divergência}

Em termos absolutos, a análise quantitativa de interfaces permite a distinção dos regimes de fluidização antes e depois da divergência entre similaridades de regiões.

$\mathrm{O}$ índice de caos $I K_{13}$ mede a similaridade entre as regiões 1 e 3 (interface 1-3). Quanto mais próximo da unidade, mais similar, em termos caóticos, é a interface analisada. O mesmo é válido para a interface 3-5. A divergência, $d=I K_{53}-I K_{13}$, é a diferença do índice de caos entre duas interfaces. Os regimes expandido e borbulhante são caracterizados por divergências nulas, enquanto os regimes turbulento e rápido por divergências não nulas.

A Figura 113 apresenta o resultado do índice de divergência para cada amostra do ensaio com partículas de vidro $355 \mu \mathrm{m}$. O regime rápido está localizado nos maiores valores de divergência, enquanto os regimes expandido e borbulhante são nulos.

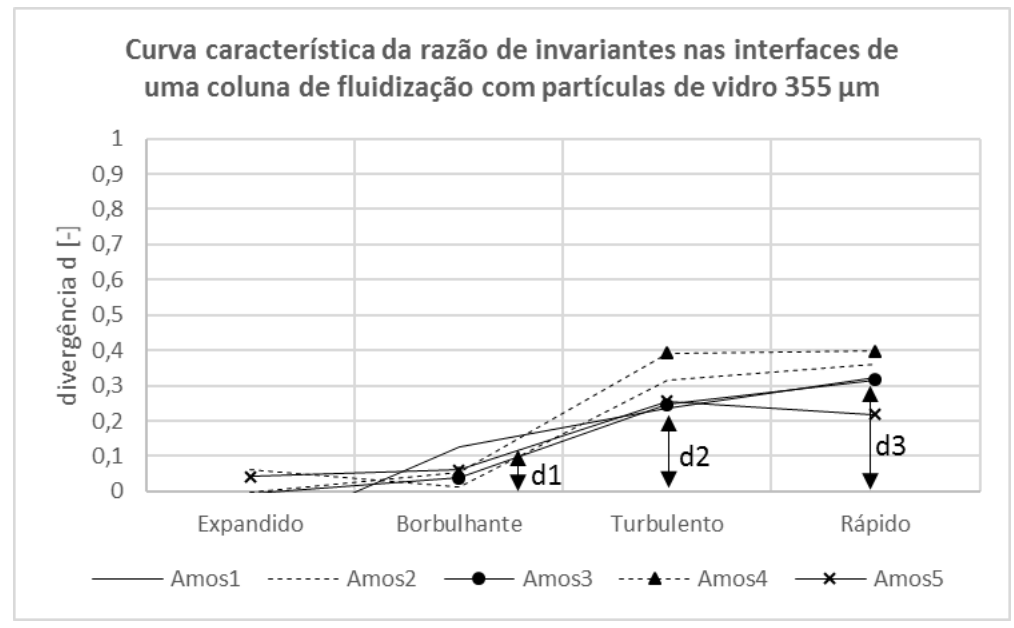

Figura 113 - Curvas características do sinal de divergência de cada ensaio para partículas de vidro 355 $\mu \mathrm{m}$. 
A Figura 114 apresenta o resultado do índice de divergência para cada amostra do ensaio com partículas de areia $1,0 \mathrm{~mm}$. O regime rápido está localizado nos maiores valores de divergência, enquanto os regimes expandido e borbulhante são nulos.

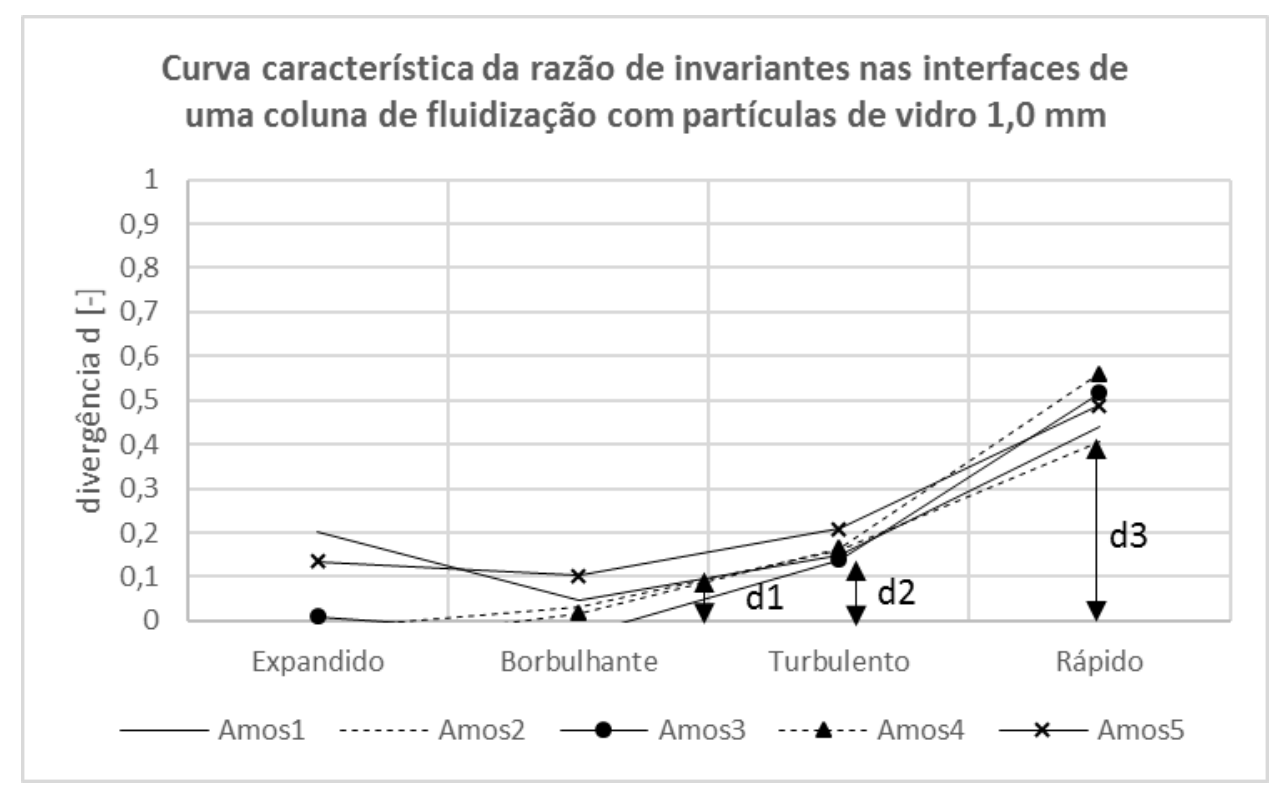

Figura 114 - Curvas características do sinal de divergência de cada ensaio para partículas de areia 1,0 $\mathrm{mm}$.

A Figura 115 apresenta o resultado do índice de divergência para cada amostra do ensaio com partículas de areia 1,2 $\mathrm{mm}$. O regime rápido está localizado nos maiores valores de divergência, enquanto os regimes expandido e borbulhante são nulos.

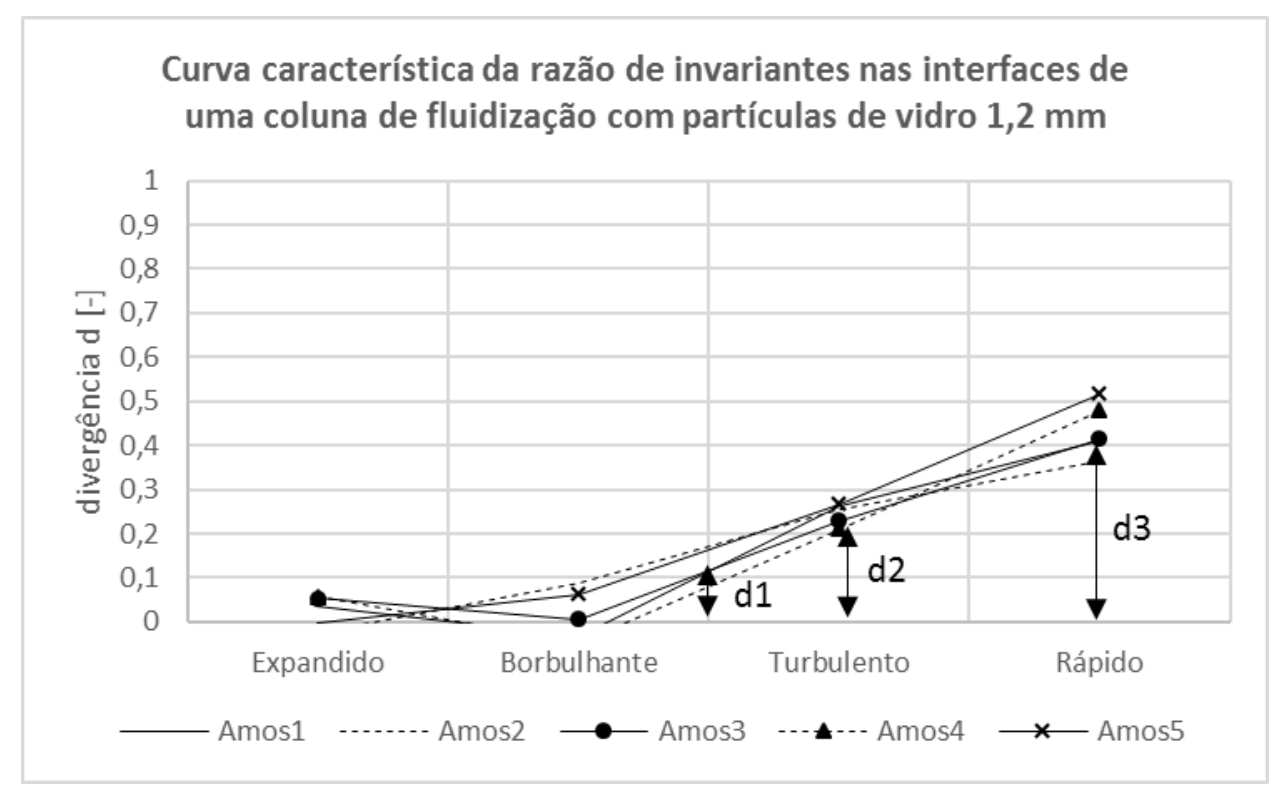

Figura 115 - Curvas características do sinal de divergência de cada ensaio para partículas de areia 1,0 $\mathrm{mm}$. 
O estudo indica uma sensibilidade dos índices aos regimes de fluidização, ou seja, a interação fluidopartícula local. É esperado que este comportamento característico seja conservado mesmo para colunas de leito fluidizado circulante escalonadas.

\subsubsection{Precisão na quantificação}

Para incrementar a precisão do índice, principalmente, onde a divergência é nula (regimes expandido e borbulhante), o expoente de Hurst pode auxiliar em distingui-los.

A Figura 116, Figura 117 e Figura 118 apresentam perfis axiais comuns para o regime expandido e borbulhante, o qual podem ser usados auxiliar seu julgamento.

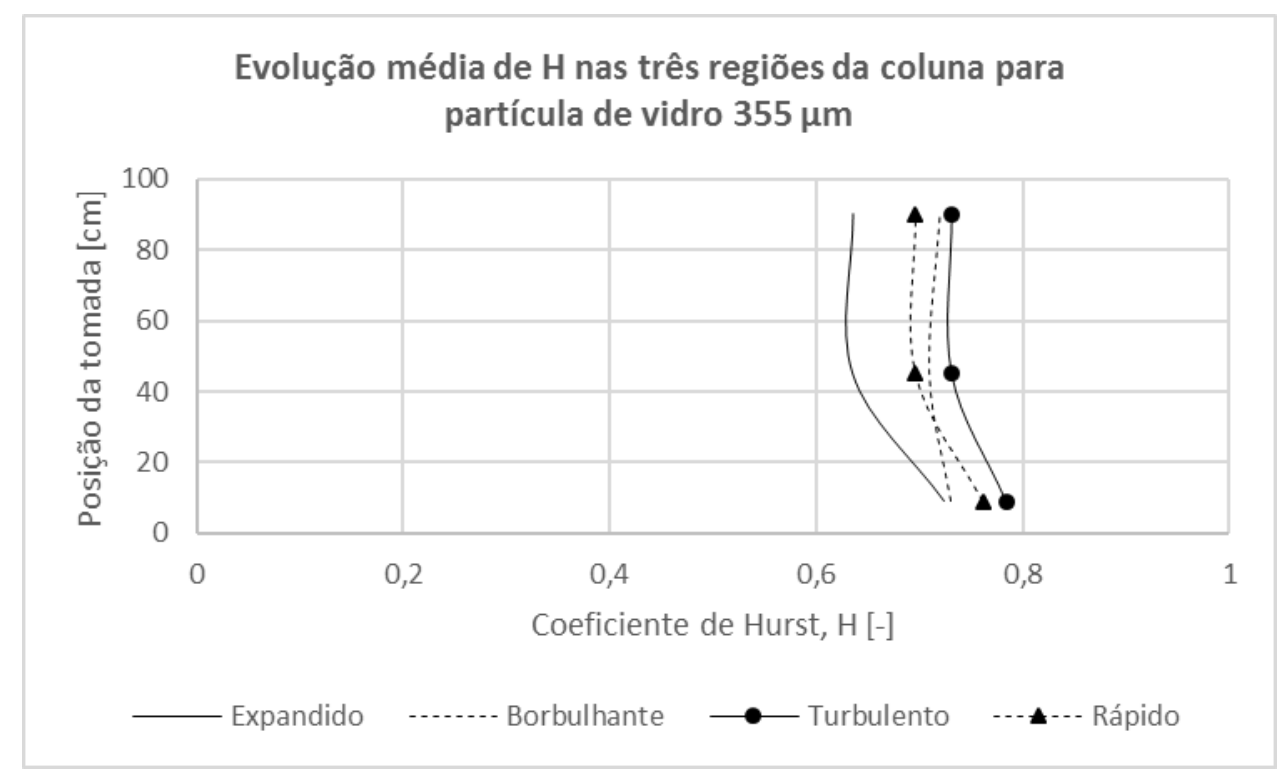

Figura 116 - Perfil axial do expoente de Hurst para um leito de vidro $355 \mu \mathrm{m}$ em coluna LFC.

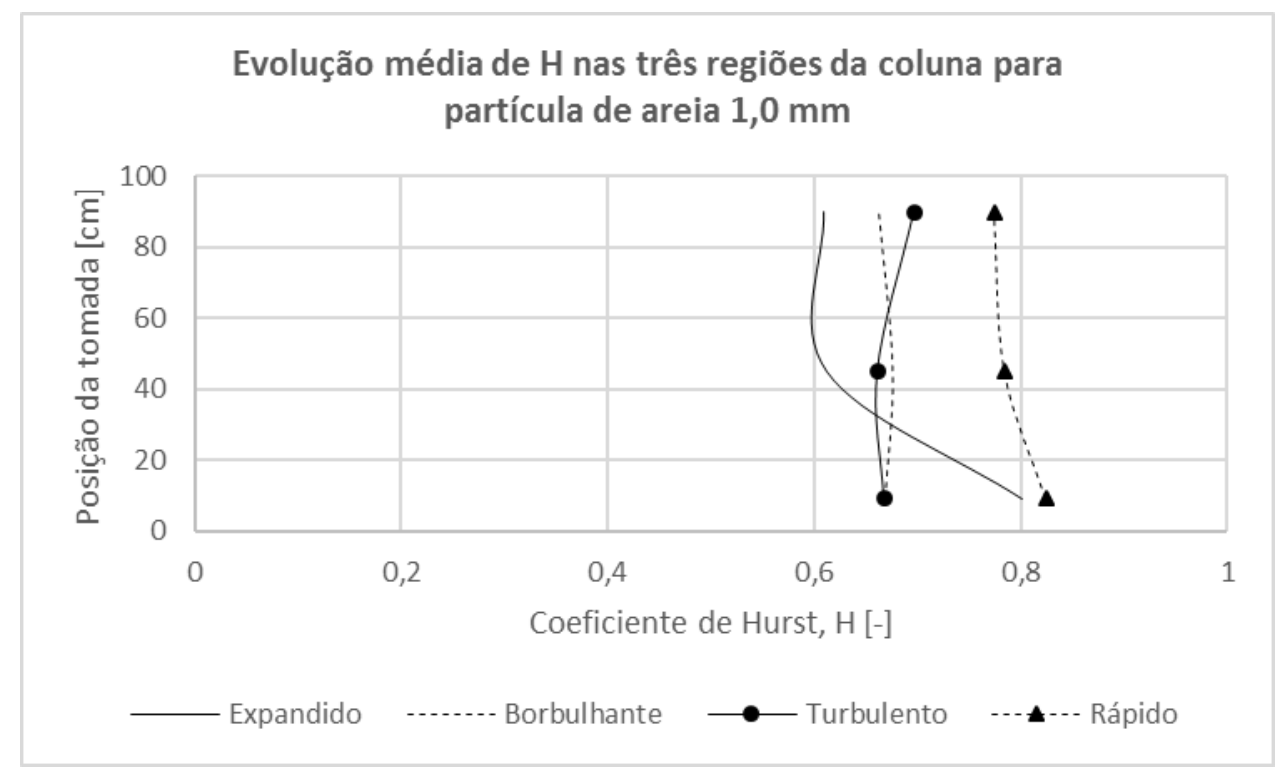

Figura 117 - Perfil axial do expoente de Hurst para um leito de areia 1,0 mm em coluna LFC. 


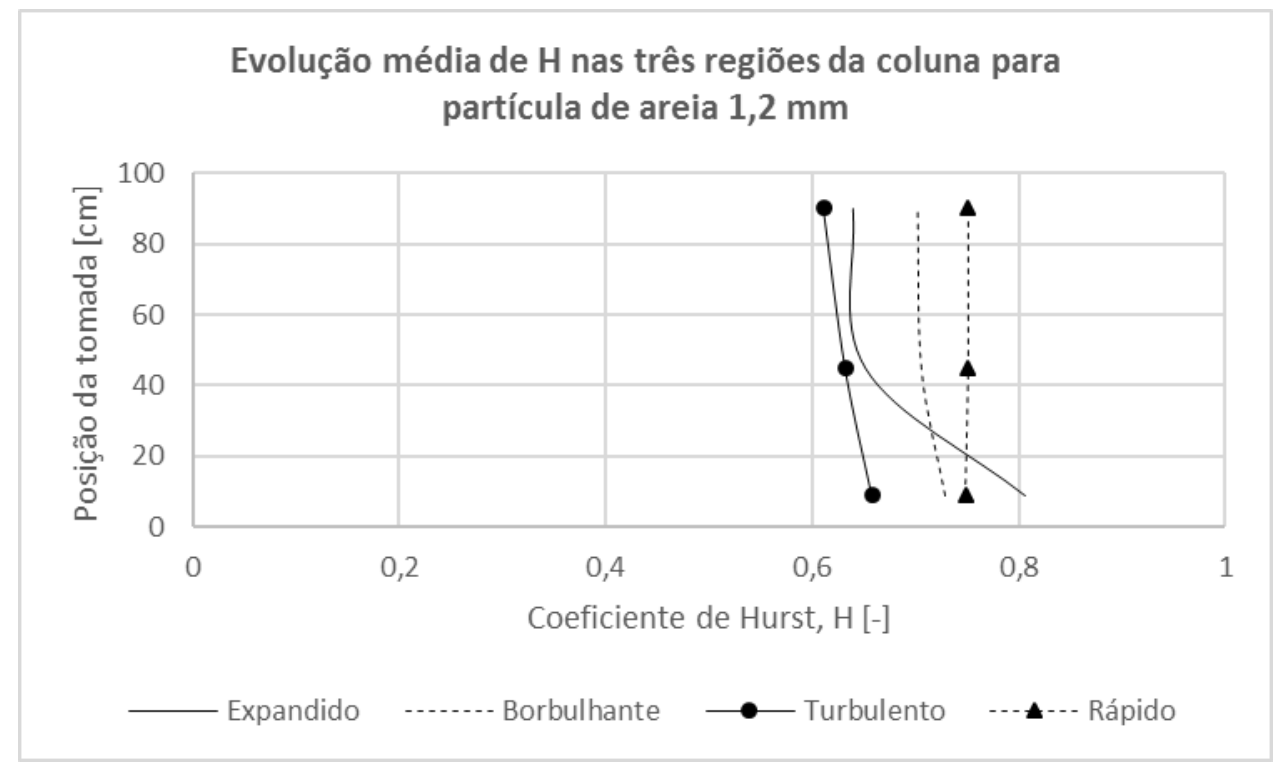

Figura 118 - Perfil axial do expoente de Hurst para um leito de areia 1,2 mm em coluna LFC.

A metodologia aqui desenvolvida demonstrou que o comportamento dinâmico de uma coluna de fluidização deve ser tratado como um problema espaço-temporal entre regiões da coluna. Além disso, mostrou-se que as invariantes do caos podem quantificar a interação fluido-partícula de acordo com os regimes de fluidização corrente. Neste contexto, o índice de divergência, a partir da razão entre entropias de uma região, podem identificar e quantificar o regime de uma coluna de fluidização. A Tabela 12 resume as condições quantitativas para classificação dos regimes de fluidização.

Tabela 12 - Modelo não-paramétrico para classificação dos regimes de fluidização a partir dos índices do caos.

\begin{tabular}{l|c}
\hline \multicolumn{1}{c|}{ Regimes } & Condições \\
\hline Expandido & $H_{1}>0,7, H_{3} \approx H_{5}$ e $d \approx 0$ \\
\hline Borbulhante & $H_{1}<0,7, \mathrm{e} d \approx 0$ \\
\hline Turbulento & $0<d<\max (d)$ \\
\hline Rápido & $\max (d)$ \\
\hline Transporte (hipótese) & $H_{1} \approx H_{3} \approx H_{5}$ e $d \approx 0$ \\
\hline
\end{tabular}

Este estudo indica a seguinte classificação de regimes:

- Expandido: As razões nas interfaces são iguais (antes da divergência) e coeficientes de Hurst de base maiores do que 0,7. Devido ao escoamento ordenado do leito fixo expandido, a série temporal na base da coluna LFC é suave.

- Borbulhante: As razões nas interfaces são iguais (antes da divergência) e coeficientes de Hurst de base menores do que 0,7 . O movimento borbulhante provoca flutuações espúrias na série de pressão estática da base.

- Turbulento: As razões nas interfaces são diferentes (após a divergência) e quantificadas pela divergência $d=I K_{53}-I K_{13}$. Diferentes valores de $d$ correspondem a diferentes níveis do regime turbulento. Quando $d$ assume seu valor máximo, o regime não é mais turbulento.

- Rápido: A divergência $d=I K_{53}-I K_{13}$ é máxima. 
- Transporte (hipótese): As razões, $I K_{i j}$, nas interfaces são iguais (suposta convergência).

\subsection{Controle de regimes}

A Figura 119 apresenta um fluxograma do funcionamento do algoritmo de controle proposto para gaseificadores de leito fluidizado circulante (LFC). Os destaques, em vermelho, representam o que será complementado em relação aos algoritmos convencionais. O propósito é manter o regime fluidização controlado, face a diversas razões de equivalência ou fator de ar. Numa operação real, o fator de ar pode variar entre $0<F A<+\infty$, onde próximo de zero é quando a razão ar/combustível real é muito menor do que a estequiométrica, e $+\infty$, quando a alimentação é nula. No controle convencional, regula-se o fator de ar entre 0,2 a 1,0, desprezando o regime desenvolvido, avaliando apenas as taxas de ar e combustíveis, para comutar o reator para os modos combustor e gaseificador. O modo combustor é necessário para regular a temperatura do reator usando a energia das reações exotérmicas, enquanto o modo gaseificação, há reações em que ora consome ora fornece energia (vide Tabela 1).

Um reator de leito fluidizado circulante, geralmente, trabalha com partículas inertes como a própria cinza (residual da gaseificação) ou areia como forma de distribuir o calor por todo o volume da coluna. Para os experimentos realizados na unidade Gaslin, em Linhas - ES, usa-se aproximadamente 3\% do volume da coluna como inerte de areia. Um pré-aquecedor, usa a energia térmica do gás de exaustão da queima de um combustível (Butano, GPL, etc.) para elevar a temperatura ambiente do reator para aproximadamente $400{ }^{\circ} \mathrm{C}$. Para que o pré-aquecimento do leito ocorra de forma eficaz, recomenda-se ajustar trabalhar no regime borbulhante, visto que os regimes mais energéticos promovem um arrasto demasiado. $\mathrm{O}$ modo de controle de regime borbulhante é iniciado, considerando que há leito na coluna e sem conhecer o inventário corrente, efetua variações na velocidade do ar de entrada até encontrar a condição de fluidização borbulhante.

Seguindo o fluxograma da Figura 119, a etapa seguinte, é a operação de aquecimento através do ajuste do modo combustor. Contudo, propõe-se para esta etapa, que além do ajuste de $F A=1$, a manutenção do regime rápido seja mantida, escolhendo adequadas razões ar/combustível. Para cumprir duas restrições o operador deve dosar uma quantidade de leito (inventário de massa) que alcance o regime rápido na quantidade estequiométrica de ar. Estas duas restrições simultâneas, conduzirão a um fluxo mássico de circulação $\left(\mathrm{kg} / \mathrm{m}^{2} \mathrm{~s}\right)$, ou a uma capacidade de carreamento de partículas $K^{*}$. A medida que a conversão termoquímica ocorrer o inventário de sólidos será convertido em gases de gaseificação, ocorrendo redução desse inventário. Se não houver compensações no inventário de sólidos, através da remoção de cinzas e reposição de sólidos, o fator de ar e o regime não estarão controlados.

A etapa final, conforme a Figura 119, com a coluna na temperatura desejada, o fator de ar deve descer para 0,2 , mantendo o regime rápido. Para alcançar o novo estado de equilíbrio, deve-se reduzir a relação ar/combustível real em relação a estequiométrica, implicando no aumento do fluxo de combustível e consequente aumente de $K^{*}$ e do fluxo mássico circulante $\left(\mathrm{kg} / \mathrm{m}^{2} \mathrm{~s}\right)$. Este algoritmo pode contribuir com melhorias na conversão contínua e manter composição do gás de saída controlado. 


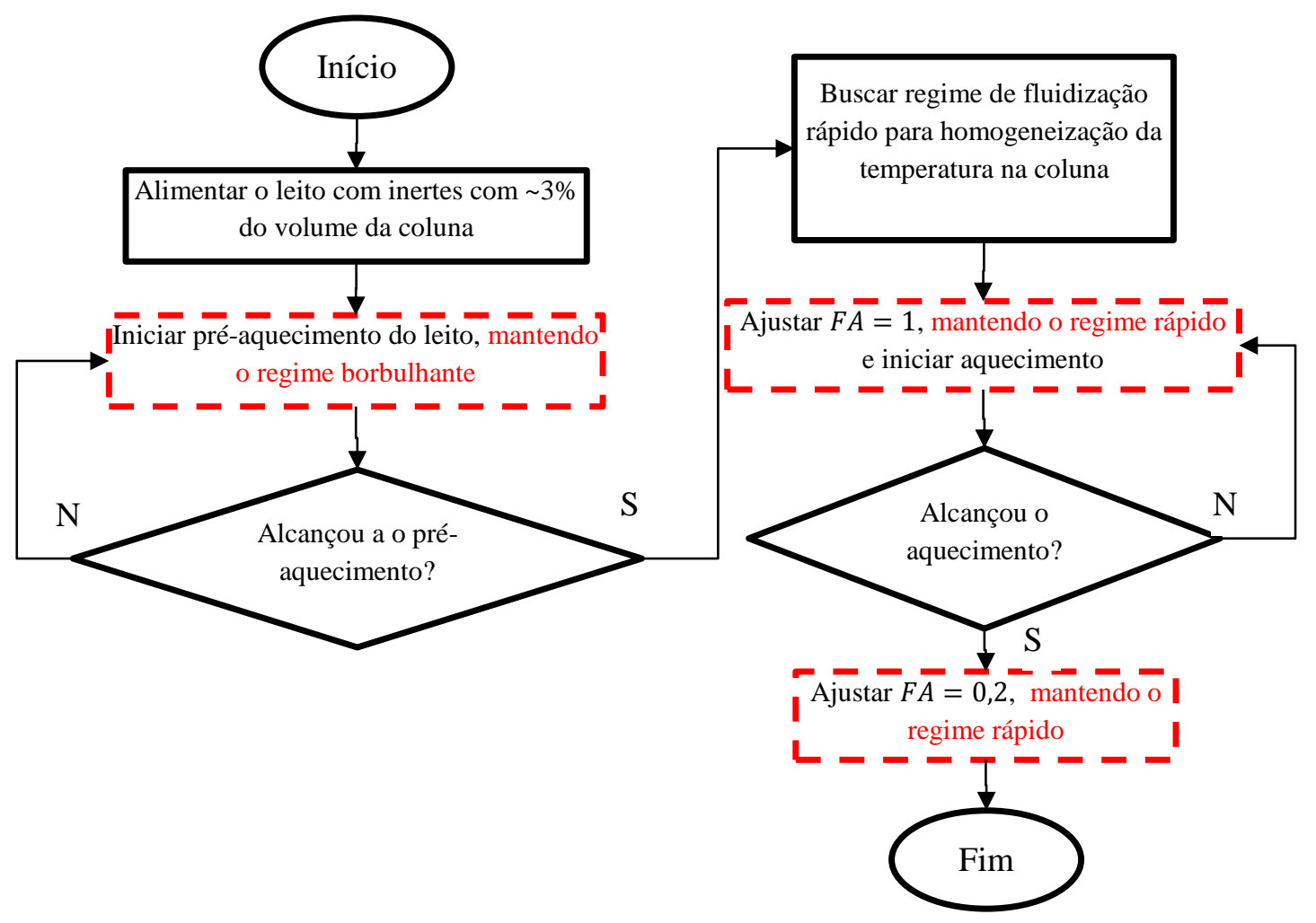

Figura 119 - Fluxograma de proposta para controle de regime de fluidização aplicado a gaseificadores.

A metodologia permite a realização de um controle automático de regimes de fluidização podendo ser implementado em qualquer sistema de controle de processos.

\subsubsection{Controlador automático de regimes de fluidização}

A Figura 120 sugere uma estratégia de controle cascata, facilmente implementada no âmbito do controle digital. Sensores de pressão, preferencialmente os mais rápidos (maior tempo de resposta), ou uma matriz deles deve ser instalada, dentro da região de interesse (vide Figura 120), pelo menos um na base, um no meio e outro no topo. A malha de controle tomou como referência a norma ISA 5.1 para sua representação, indicando os sensores de pressão estática da coluna, PT (pressure transmissor), o bloco de quantificação do regime do leito, XT, um bloco de controle de regime, XC, um bloco de controle de vazão, FC (flow control), e um bloco de medição de vazão, FT (flow transmissor).

Os sensores de pressões estática, coletam informações e as entregam para o bloco XT, responsável pela quantificação do regime de fluidização corrente. O bloco organiza as informações em vetores de informações de aproximadamente 15.000 dados. Portanto, quanto mais rápida a velocidade de resposta dos sensores, menor será o tempo em que uma nova quantificação será informada para o controlador. Os medidores usados nesta tese possuíam tempo de resposta de $30 \mathrm{~ms}$, demorando aproximadamente 8 minutos para gerar uma nova quantificação. Se o tempo de resposta do medidor fosse de $1 \mathrm{~ms}$, o tempo de resposta do bloco cairia para aproximadamente $1 \mathrm{~min}$. O bloco XT entrega para o bloco do controlar o sinal de divergência corrente, $d$.

O bloco do controlador de regime, $\mathrm{XC}$, compara um sinal d desejado ( $\mathrm{d}_{\max }$ para regime rápido) com o sinal d corrente, gerando um sinal de erro através da diferença entre eles. $\mathrm{O}$ sinal de erro alimenta um algoritmo de controle, como um simples controle proporcional-integral (PI), produzindo um sinal que 
pode ser usado diretamente para compensar o fluxo de ar de entrada ou, como apresentado na Figura 120, servir de referência para o bloco FC. Portanto, nos regimes expandido e borbulhante a divergência desejada é nula e as invariantes pode ser usada para distingui-los. Para o regime turbulento, um sinal desejado de divergência deve ser informado. Para o regime rápido, a malha buscará o valor máximo de divergência.

A estratégia de controle em cascata foi sugerida por atender a consideração mais importante desta, de que a malha interna (variável secundária ou vazão) deve responder mais rapidamente a variações no distúrbio e na variável manipulada do que a malha externa (variável primária ou divergência do leito) [186]. De fato, quando um ventilador mudar a rotação, quase instantaneamente o fluxo mudará. Contudo, esta mesma mudança demorará, no mínimo $60 \mathrm{~s}$ (sensores rápidos) para o bloco XT perceber que a nova vazão mudou o regime de fluidização. Caso os sensores sejam lentos (30 ms), o bloco XT vai demorar pelo menos 8 min para perceber a mudança. Portanto, os requisitos deste sistema fluidizado satisfaz a solução de controle cascata.

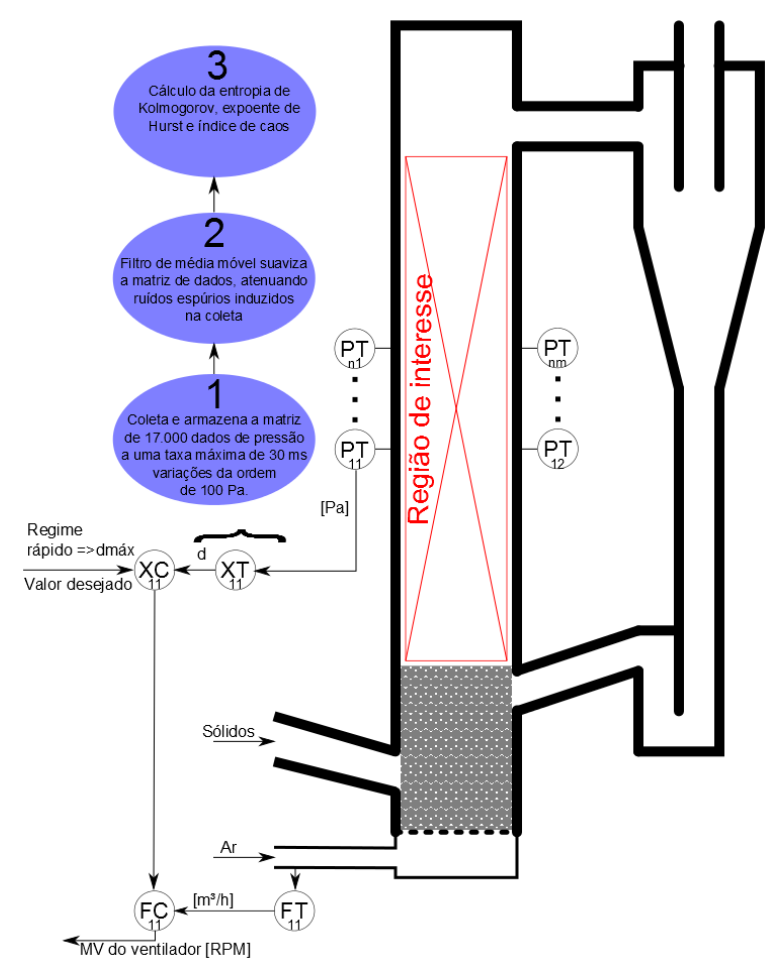

Figura 120 - Estratégia de controle cascata para implementação de controle de regime de leito fluidizado circulante.

A implementação do controlador não foi realizada e pode ser tema para trabalhos futuros. 


\section{CONCLUSÃO}

Este capítulo resume as conclusões do estudo numérico e experimental da quantificação do estado de um leito fluidizado circulante através das invariantes do caos.

Uma coluna de leito fluidizado é um problema não-linear espaço-temporal e, portanto, apresenta comportamentos mensuráveis diferenciados de pressão estática, ao longo de seu eixo axial. O escoamento bifásico $\mathrm{G} / \mathrm{S}$ (gás/sólido) pode ser dominado ora pelo fluido, ora pela partícula ou pelo compromisso fluido-partícula, provocando flutuações características mensuráveis nos sinais de pressão estáticas locais.

Através da modelagem numérica, foi possível iniciar o estudo não-linear espaço-temporal de escoamento multifásico aplicado a leito fluidizado circulante. O estudo da fluidodinâmica computacional permite quantificar mecanismos de interação e auxilia na explicação dos resultados. $\mathrm{O}$ modelo TFM permite distinguir o fluxo denso e diluído, através da avaliação não-linear de séries temporais nestas regiões em função da posição da tomada. Processos de média para resolver equações NS e a considerações de uniformidade (parâmetros concentrados) em cada célula, reduzem a representativa da interação fluido-partícula. Neste trabalho, a simulação permitiu definir um esquema de ensaios e análises não-lineares, conduzindo para a confirmação experimental.

As conclusões preliminares levam em conta um comparativo entre as simulações numéricas propostas neste trabalho e os dados experimentais. Esse processo de validação foi considerado satisfatório para fluxos densos, no uso de séries temporais de pressões estática e diferencial para caracterização de regimes de fluidização borbulhante.

A simulações numéricas podem contribuir para estudos de controle processos desde que levem em conta os mecanismos de interação fluido-partícula em micro, meso e macra-escala.

O uso do medidor de pressão estática, para instrumentar uma coluna de fluidização fria, foi escolhido devido ao seu baixo custo e insensibilidade a alta temperatura, quando aplicado para instrumentar uma coluna de fluidização quente. Como o ar é um péssimo condutor de calor, o aumento do comprimento tomada de pressão é a principal alteração a ser realizada para migrar uma coluna de leito fluidizado circulante fria para quente, para aplicações industriais.

A teoria do caos, quando aplicada em séries temporais de pressão estática, ao longo de uma coluna de leito fluidizado circulante, foi capaz de medir a interação fluido-partícula local através de suas invariantes como o coeficiente de Hurst, a entropia de Kolmogorov e a dimensão de correlação. O caos determinístico, presentes nos sistemas dinâmicos bifásicos G/S (gás-sólido), se distribui numa coluna de fluidização, de forma a permitir sua caracterização local, usando séries temporais de pressão estática em diferentes regimes.

Para a aplicação da análise não linear no problema de caracterização de um leito fluidizado circulante, enfatizando o controle de processos, foi necessário a construção de uma malha de leito fluidizado circulante capaz de manter os regimes de fluidização, por longo período, capaz de produzir quantidades de informações suficientes para os indicadores. A circulação foi mantida e o inventário de massa, através de uma válvula L com injeção de ar seco, trabalhando com pressões de 4 a 6 bar. Como cada regime produz diferentes arrastos, a cada mudança do regime, realizou-se ajustes na pressão de injeção lateral capaz de arrastar o material ejetado do riser de volta para a coluna. Os ensaios experimentais contaram com partículas de vidro $355 \mu \mathrm{m}$, areia $1,0 \mathrm{~mm}$ e areia $1,2 \mathrm{~mm}$, e leito empacotado de $8 \mathrm{~cm}$ de altura, o qual foram submetidas aos regimes expandido, borbulhante, turbulento, rápido e transporte (curto 
período) ajustando-se os fluxos do ar de entrada que produziam esses regimes, tendo auxílio as modernas descrições qualitativas dos regimes da literatura. Conhecida a faixa operacional que produziu cada regime para cada tipo de partícula, o experimento foi repetido cinco vezes para cada partícula, gravando as informações pertinentes. O método aqui proposto, trabalhou com medições de flutuações da pressão estática, considerando estas produzidas pela interação fluido-partícula local, e não por ruídos eletromagnéticos irradiados ou conduzidos. Portanto, sensores, fio e placa de aquisição, transferiram sinais cuidadosamente isolados, blindados e filtrados para entregar flutuações fluido-partículas reais do processo de fluidização em leito fluidizado. Os sensores aqui usados eram limitados ao tempo de resposta de $30 \mathrm{~ms}$, sendo necessários aproximadamente $10 \mathrm{~min}$ de aquisição de dados para a análise não linear quantificar o estado do leito. Instrumentos mais rápidos $(\leq 1 \mathrm{~ms})$ seriam capazes de reduzir o período de avaliação de leito para $20 \mathrm{~s}$, contribuindo para atuações mais rápidas e estabilidade do regime de fluidização.

Quando submetido a um regime de fluidização, um leito fixo ou em movimento, promoveu distribuições de pressão estática e flutuações associadas ao padrão de escoamento local. $\mathrm{O}$ experimento tratou de investigar o comportamento destas flutuações em três regiões, na base (tomada a $9 \mathrm{~cm}$ de altura, em relação a base), no meio (tomada a $45 \mathrm{~cm}$ ) e no topo (tomada a $90 \mathrm{~cm}$ ), quanto ao nível de caos, quantificado pelas invariantes. Para cada regime de fluidização, foram encontradas similaridades, em termos de invariantes do caos, entre as regiões do meio e do topo, e discrepâncias dessas duas regiões com a região de base. Após diversas repetições, foram observados dois comportamentos: o comportamento característico da base, entropia inversamente proporcional ao aumento do fluxo do ar de entrada, e os comportamentos característicos do meio e do topo, entropia diretamente proporcional ao aumento do fluxo do ar de entrada. O experimento apontou que numa coluna de leito empacotado, se houver três medições de pressão estática, sendo uma molhada (tomada banha pelo leito) e duas secas (tomadas acima da lâmina de leito), haverá diferença entre as tomadas secadas das molhas, mas pouca diferença entre as secas (deslocadas espacialmente), quando fluxo do ar de entrada aumentar. Ou seja, na base a mistura fluido-partícula inicia-se densa, tornando-se diluída, à medida que o fluxo do ar de entrada aumenta; enquanto nas regiões do meio e do topo, ocorre o inverso da base, a mistura fluidopartícula inicia-se completamente fluida (diluída), tornando-se densa à medida que o fluxo do ar de entrada aumenta. Foram, então, identificados dois mecanismos chamado de diluição de tomada molhada e densificação de tomada seca. O experimento também indicou, em termos de entropia, que o sinal de pressão estática, na base, tendeu a se ordenar (redução de KML) à medida que o fluxo do ar de entrada aumentava, enquanto nas regiões do meio e do topo, tendeu a desordem (aumento de KML) à medida que o fluxo do ar de entrada aumentava.

A identificação dos mecanismos de diluição da tomada molhada e densificação da tomada seca foi possível comparando a convergência das variantes estatísticas (média e desvio padrão) e invariantes caóticas (H, KML e DML), nas regiões do meio e do topo, em cada regime de fluidização, e a distinção destas regiões com a base. Na dinâmica de um leito fluidizado, a gravidade tenta manter o leito coeso (concentrado) fazendo com que a dissipação da energia do fluxo do ar de entrada seja distinto do processo de dissipação do fluxo de ar quando as partículas adquirem movimento. A região de base concentrada, impõe até o regime rápido, a passagem de frações de vazios, em forma de bolhas descontínuas (regime borbulhante), em formas de golfos descontínuos (regime turbulento), ou de forma contínua (regime rápido) gerando o escoamento núcleo-anelar pela coluna de fluidização. Após o regime rápido, o leito da região de base é completamente descaracterizado, dando lugar a uma coluna homogênea operando no regime de transporte pneumático diluído.

As séries temporais de pressão estática locais foram digitalmente filtradas com média móvel de 10 atrasos, para remoção do ruído de fundo proveniente dos amplificadores operacionais da eletrônica dos sensores, e cortes para remoção do regime transiente e mudanças entre regimes. Para uma determinada 
partícula foram geradas 3 séries temporais de pressão estática (base, meio e topo) em cada regime de fluidização. Como cada partícula experimentou 4 regimes, totalizaram-se 12 séries de pressão estática, encerrando uma amostra. Cada amostragem sofreu 5 repetições por tipo partícula para garantir estatística nas análises. Os 3 tipos de partículas totalizaram 180 séries temporais de pressão estática, o qual o processamento de cada série gerou 12 índices para serem analisados. Este de vetor de índices contém informações da pressão média, desvio padrão, coeficiente de Hurst, entropia de Kolmogorov e dimensão de correlação. Para a invariantes do caos, o coeficiente de Hurst foi estimado sem incerteza, a partir de uma função baseada em implementações da MathWorks, enquanto, a entropia de Kolmogorov e a dimensão de correlação foram estimadas com incertezas menores que $1 \%$ pelo software RRCHAOS. Os outros 7, dos 12 indicadores do vetor, foram criados a partir da combinação entre as 5 características fundamentais citadas, como a pressão diferencial e razões entre invariantes. Portanto, o processo de caracterização local foi considerado satisfatório para investigação da quantificação global da coluna de fluidização.

As características variantes como a média, desvio padrão e pressão diferencial, foram usadas para validação (incluindo a comparação com outros trabalhos), enquanto as características invariantes foram utilizadas com propósitos, além validação, para a quantificação de cada regime por tipo de partícula. A análise não linear demonstrou, para todas as partículas, que a entropia de Kolmogorov (em bit/s) na região de base decresce à medida que o fluxo do ar de entrada aumenta até o início do transporte pneumático. Quando o regime de transporte pneumático é iniciado, a entropia da base assume o mesmo valor das entropias das outras regiões. Já nas regiões do meio e do topo, para todas as partículas, a entropia de Kolmogorov foi similar, entre elas, e diretamente proporcional ao aumento do fluxo do ar de entrada. O coeficiente de Hurst na base, quantificou a série temporal de pressão estática, com suavidade de $70-80 \%$, considerando todas as partículas no regime expandido, caindo para $60 \%$, nos regimes borbulhante e turbulento, retornando novamente para $70-80 \%$ no regime rápido, e aumentando para $80-100 \%$ no regime de transporte pneumático. A evolução, concomitante das regiões, do comportamento absoluto das invariantes do caos sugeriu verificar o comportamento da razão instantânea entre elas. Portanto, a avaliação da razão de entropias, entre duas regiões de uma coluna, indica uma divergência entre indicadores (bifurcação), marcando o início do regime turbulento. O regime rápido, em todos os casos, foi caracterizado quando a divergência, da razão entre entropias, foi máxima. Por fim, no transporte pneumático, os dados geraram indícios de convergência das razões do caos, entre estas regiões.

A similaridade caótica, conceito desenvolvido neste trabalho, que avalia o regime de fluidização através da razão entre invariantes do caos de tomadas espacialmente distribuídas. Este índice, foi associado a regiões de base-meio, $I K_{13}$, e topo-meio, $I K_{53}$. A diferença destes índices, produz o sinal de divergência, $d$, entre as interfaces (regiões). Para divergências nulas ou próximos de zero, permanecem os regimes expandido e borbulhante. Para divergência maior do que zero e menor do que seu valor máximo, permanece o regime turbulento. $\mathrm{O}$ regime rápido foi encontrado quando o sinal de divergência foi o máximo. Com base em observações experimentais lança-se a hipótese que a divergência volta a cair, após um máximo, quando o regime de transporte estiver presente. Além disso, os ensaios mostram que o sinal de divergência é sensível ao regime e não diferente as características das partículas (diâmetro e massa específica).

Este trabalho lançou uma nova abordagem na caracterização de regimes de fluidização de um leito fluidizado, a partir da curva característica da razão invariante de interfaces de uma coluna. $O$ traçado do índice normalizado sugerido (razão invariante de interfaces), foi baseado na medição da interação fluidopartícula de três regiões distintas de uma coluna de fluidização, a partir das entropias de Kolmogorov locais do sinal temporal de pressão estática. A partir dos ensaios, foi encontrada uma característica comum a todas as partículas, quanto a divergência entre as interfaces base-meio e meio-topo ou entre as 
interfaces base-topo e meio-topo. Essa métrica avaliou simultaneamente a discrepância das regiões de base-meio, e a semelhança das regiões do meio e do topo. Este comportamento, comum para leitos fluidizados que operam com partículas aproximadamente esféricas, seria capaz, de auxiliar a regulação de um gaseificador de leito fluidizado, mantendo um determinado regime controlado. O controle é necessário devido à perda de massa ou conversão para gás (caso quente), diminuindo a complexidade operacional e variabilidade da composição final do gás, além de contribuir para continuidade operacional.

Este estudo concluiu que as invariantes do caos foram sensíveis aos regimes de fluidização e pouco dependeram das características das partículas. Apesar desta técnica não ter sido testada em colunas escalonadas, teoricamente, é possível inferir que as invariantes permanecerão sensíveis aos regimes de fluidização e pouco sensível a mudança geométrica de uma coluna escalonada.

O método proposto demonstrou potencial para ser aplicado em controle de processos contínuos de leito fluidizado como limpeza, mistura, recobrimento, granulação, secagem, pirólise, gaseificação e combustão, para manutenção dos regimes de fluidização desejados face as mudanças de inventário de massa. O conceito aqui proposto, associado a instrumentação rápida de medição de pressão estática, poderia ser usado para controlar sistemas fluidizados, em tempo real, de conversão de sólidos, como gaseificadores de leito fluidizado circulante, continuamente. Os principais impactos são redução da complexidade operacional, facilitada por uma malha de controle, grau de turbulência global da coluna, controlado pela manutenção de um determinado regime, redução da variabilidade do gás de gaseificação, devido ao controle do regime, e incremento da repetibilidade do processo.

Este trabalho abre precedentes para diversos níveis de estudo, como iniciação científica, trabalhos de conclusões de curso, dissertações e teses. De forma a contribuir com a continuidade do estudo foram listados possíveis trabalhos futuros.

\subsection{Contribuições}

Segue as contribuições:

1. É possível quantificar regimes de fluidização através da avaliação de flutuações de sinais de pressão estática na coluna LFC;

2. O sistema de medição ao longo da coluna LFC deve conter, no mínimo, três tomadas de medição: na base, no meio e no topo.

3. Um índice de divergência da similaridade caótica pode auxiliar no controle automatizado de regimes de fluidização para melhoria de processos industriais.

\subsection{Trabalhos futuros}

Segue os trabalhos que ainda podem ser excutados:

1. Avaliar abrangência da medição de pressão estática local: Qual seria o volume de controle que uma tomada de pressão estática pode caracterizar?

2. Aumentar a resolução da curva característica do índice de caos, reduzindo o intervalo entre velocidades.

3. Validar desempenho do modelo EMMS em simulação TFM para avaliação de índice de caos.

4. Usar invariantes do caos para estimar fluxo de sólidos e controle de circulação na válvula L.

5. Usar medidores de pressão mais rápidos (menores tempos de respostas), reduzindo o período de um sistema avaliar o regime corrente. 
6. Da teoria da informação, investigar novas invariantes, a partir da elevação da ordem, q (maior do que 2), da entropia de Rényi, sensíveis aos regimes de fluidização.

7. Investigar a quantidade mínima de medições axiais e invariantes capazes de identificar os regimes de fluidização.

8. Investigar medições radiais para identificação de regimes de fluidização.

9. Investigar o comportamento do desvio padrão, coeficiente de Hurst, KML e dimensão de correlação do sinal de pressão diferencial.

10. Implementar algoritmos de estimação de invariantes do caos para controladores.

11. Implementar malha de controle clássico PI para o controle de regimes em leito fluidizado circulante.

12. Estudo matemático de órbitas não periódicas de diagramas de fase de sinais de pressão estática de sistemas dinâmicos de leito fluidizado.

13. Simulações e experimentos em diferentes geometrias de coluna LFC 


\section{REFERÊNCIAS BIBLIOGRÁFICAS}

1. HINRICHS, R. A.; KLEINBACH, M. Energia e Meio Ambiente. [S.1.]: Thomson, 2003.

2. IEA, I. E. A. Key world energy statistics: Also available on smartphones and tablets. [S.1.]. 2016.

3. GLERSE, M.; B., L. Operation control of circulating fluidized bed boilers. International Journal of Energy Research, 20, 1996. 839-85.

4. CORTEZ, L. A. B.; LORA, E. E. S.; GÓMEZ, E. O. Biomassa para energia. [S.1.]: Editora Unicamp, 2011.

5. LIU, Z.; PENG, T.; LIN, C. Impact of $\mathrm{CaO}$ and $\mathrm{CaCO} 3$ addition on agglomeration/defluidization and heavy metal emission during waste combustion in fluidized-bed. Fuel Processing Technology, 118, n. 171-179, 2014.

6. BASU, P.; ACHARYA, B.; DUTRA, A. . Gasification in fluidized beds: present status \& design. Proceedings of the 20th International Conference on Fluidized Bed Combustion, 2010. 97103.

7. SÁNCHEZ, C. G. Tecnologia da gaseificação de biomassa. Campinas, SP: Editora Átomo, 2010.

8. SIDDIQUI, S. Opportunities and Obstacles in Large-Scale Biomass Utilization: The Role of the Chemical Sciences and Engineering Communities: A Workshop Summary (2013). Washington. 2012.

9. BOARD, N.; NCPS, C. \&. E. The Complete Book on Biomass Based Products (Biochemicals, Biofuels, Activated Carbon). [S.1.]: Asia Pacific Business Press Inc., 2015.

10. ASADULLAH, M. Barriers of commercial power generation using biomass gasification gas: A review. Renewable and Sustainable Energy Reviews, 29, 2013. 201-215.

11. PEREZ, R.; PEREZ, M. . A fundamental look at energy reserves for the planet. IEA/SHC SOLAR UPDATE, 2009.

12. GSTC. The Gasification Industry. The Gasification and Syngas Technologies Council, Janeiro 2013. Disponivel em: <http://www.gasification-syngas.org/resources/the-gasification-industry/>. Acesso em: Janeiro 2016.

13. FAN, X. et al. Comparison of bubbling fluidized bed and circulating fluidized bed in gasification of biomass. Nongye Jixie Xuebao/Transactions of the Chinese Society of Agricultural Machinery 42, China, 4, April 2011. 96-99.

14. ZENZ, F. A. Two-phase fluidized-solid flow. Ind. Eng. Chern., 41, 1949. 2801-2806. 
15. REH, L. Fluid bed processing. Chem. Eng. Progr., 67, 1971. 58-63.

16. YERUSHALMI, J.; CANKURT, N. T. . Further Studies of the Regimes of Fluidization. Powder Technology, 24, 1979. 187-205.

17. BROEDERMANN, P. Calcining of Fine-Grained Materials in the Circulating Fluid Bed. Lurgi Express Information, 1981. 1-29.

18. AVIDAN, A. A.; YERUSHALMI, J. Bed expansion in high velocity fluidization. Powder Technology, 32, 1982. 223-232.

19. KWAUK, M. et al. Circulating Fluidized Bed Technology. Pergamon Press, 1985. 33-62.

20. GRACE, J. R. Contacting modes and behaviour classification of gas-solid and other two-phase suspensions. The Canadian Journal of Chemical Engineering, 64, n. 3, Junho 1986. 353-528.

21. MOUSA, M. B. M.; FATEEN, S. K.; IBRAHIM, E. A. Hydrodynamics of a Novel Design Circulating Fluidized Bed Steam Reformer Operating in the Dense Suspension Upflow Regime. ISRN Chemical Engineering, 2014, 2014. 13.

22. LI, J.; KWAUK, M. Particle-flow two-phase flow: The energy-minimization multi-scale method. Beijing: Academia Sinica, 1994.

23. GE, W.; LI, J. Physical mapping of fluidization regimes-the EMMS approach. Chemical Engineering Science, 57, 2002. 3993-4004.

24. NASCIMENTO, R.; TRIGUEROS, D. E. G.; MÓDENES, A. N. Determinação do ponto de colapso em leitos fluidizados circulantes. Varia Scientia, 7, 2009. 135-146.

25. SAAYMAN, J. et al. Fluidization Regimes Characterized Using a Fast X-Ray Tomography Setup. The 14th International Conference on Fluidization, 2013.

26. TAKENS, F. . Dynamical systems and turbulence. Proceedings of a symposium held at the university of warwick, 898, 1980. 366-381.

27. GRASSBERGER, P. . P. I. . Estimation of the Kolmogorov entropy from a chaotic signal. Physical review A, 28, n. 4, October 1983.

28. SCHOUTEN, J. C.; VANDER STAPPEN, M. L. M.; VAN DEN BLEEK, C. M. Deterministic chaos analysis of gas-solids fluidization. Fluidization VII, Engen Foundation, New York, 1992. 103-111.

29. VAN DEN BLEEK, C. M. . S. J. C. . Deterministic chaos: a new tool in fluidized bed design and operation. The Chemical Engineering Journal 53, 1993. 75-37.

30. CAI, Y.; WAMBSGANSS, M. W.; JENDRZEJCZYK, J. A. Application of Chaos Theory in Identification of Two-Phase Flow Patterns and Transitions in a Small, Horizontal, Rectangular Channel. Journal of Fluids Engineering, 118, 1996. 383-390. 
31. MARZOCCHELlA, A. . Z. R. C. . S. J. C. . V. D. B. C. M. . Chaotic Behavior of Gas-Solids Flow in the Riser of a Laboratory-Scale Circulating Fluidized Bed. Particle Technolow and Fluidization, June 1997.

32. KANTZ, H. . S. T. . Nonlinear time series analysis. Cambridge: Cambridge University Press, 2003.

33. CASTILHO, G. J. et al. Experimental Fluid Dynamics Study in a Fluidized Bed by Deterministic Chaos Analysis. Particulate Science and Technology 29, 2011. 179-196.

34. ZARGHAMI, R. et al. Nonlinear Dynamic Characteristics of Bubbling Fluidization. In: L., C.; D., M. Advances in Multiphase Flow and Heat Transfer. [S.1.]: Bentham e-books, v. 3, 2012. p. 300-331.

35. NEDELTCHEV, S. New methods for flow regime identification in bubble columns and fluidized beds. Chemical Engineering Science, 137, 2015. 436-446.

36. GRACE, J. R.; AVIDAN, A. A.; KNOWLTON, T. M. Circulating Fluidized Beds. New York: Blackie academic \& professional, 1997.

37. GURAN, A.; INMAN, D. J. Smart Structures, Nonlinear Dynamics, and Control. [S.1.]: Prentice Hall, 1995. 368 p.

38. STRINGER, J. Is a fluidized bed a chaotic dynamic system? Proc. 10 Int. Conf on Fluid. Bed Combustion, San Fransisco, CA, 1, 1989. 265-272.

39. DAW, C. S.; HALOW, J. S. Characterization of voidage and pressure signals from fluidized beds using deterministic chaos theory. Proc. 11 Int. Conf on Fluid. Bed Combustion, Montral, Ed. E.J. Anthony, 1, 1991. 777-786.

40. LI, J. et al. Multi-scale compromise and multi-level correlation in complex systems. Chemical Engineering Research and Design, 83, 2005. 574-582.

41. ZARGHAMI, R.; MOSTOUFI, N.; SOTUDEH-GHAREBAGH, R. Nonlinear Characterization of Pressure Fluctuations in Fluidized Beds. Ind. Eng. Chem. Res., 47, 2008. 9497-9507.

42. LORA, E. E. S.; VENTURINI, O. J. Biocombustíveis. [S.1.]: Interciência, 2012.

43. MANSUKHANI, S. Predictability of Time Series. Analytics: driving better business secisions, July/August 2012. 29-31.

44. MIKULANDRIć, R. et al. Biomass gasification process modelling approaches. 8th Conference on Sustainable Development of Energy, Water and Environment Systems - SDEWES Conference, 2013.

45. PRIETO, W. H. . C. G. J. . C. M. A. . Aplicação da análise de caos na caracterização de regimes fluidizados para partículas dos grupos A e D na classificação de geldart: estudo experimental. XXXVI Congresso Brasileiro de Sistemas Particulados - ENEMP, 2013. 
46. LI, J. et al. From Multiscale Modeling to Meso-Science: A Chemical Engineering Perspective Principles, Modeling, Simulation, and Application. London: Springer, 2013.

47. SOLIMENE, R. et al. Hydrodynamic Characterization of "GULF STREAM" Circulation in a Pilot Scale Fluidized Bed Combustor. The 14th International Conference on Fluidization - From Fundamentals to Products, Eds, ECI Symposium Series, 2013.

48. CHEN, X.; WANG, J. A comparison of two-fluid model, dense discrete particle model and CFDDEM method for modeling impinging gas-solid flows. Powder Technology, 2014. 94-102.

49. DEEN, N. G. et al. Review of direct numerical simulation of fluid-particle mass, momentum and heat transfer in dense gas-solid flows. Chemical Engineering Science 116, 2014. 710-724.

50. LIU, M.; HU, Z. . Nonlinear Analysis and Prediction of Time Series in Multiphase Reactors. [S.1.]: Springer, 2014.

51. DUFOUR, A. Thermochemical Conversion of Biomass for the Production of Energy and Chemicals. [S.1.]: ISTE, 2016.

52. TANG, Y. et al. Direct numerical simulations and experiments of a pseudo-2D gas-fluidized bed. Chemical Engineering Science 143, 2016. 166-180.

53. HATMAN, M.; TRNKA, O.; SVOBODA, K. Use of pressure fluctuations to determine online the regime of gas-solids suspensions from incipient fluidization to transport. Ind. Eng. Chem., 48, 2009. 6830-6835.

54. YANG, W. Handbook of fluidization and fluid-particle systems. [S.1.]: Taylor \& Francis Group LLC, 2003.

55. WADELL, H. Sphericity and Roundness of Rock Particles. The Journal of Geology, 41, May 1933. 310-331.

56. BRUSEWITZ, G. H. Density of rewetted high moisture grains. Transactions of the ASAE, St. Joseph, 18, 1975. 935-938.

57. HAIDER, A.; LEVENSPIEL, O. Drag Coefficient and Terminal Velocity of Spherical and Nonspherical Particles. Powder Technology, 58, 1989. 63-70.

58. ERGUN, S. Fluid flow through packed columns. Chem Eng Prog, 48, February 1952. 89-94.

59. GIBILARO, L. et al. Generalized friction factor and drag coefficient correlations for fluid-particle interactions. Chem Eng Sci, 40, 1985. 1817-1823.

60. YERUSHALMI, J.; TURNER, D. H.; SQUIRES, A. M. The fast fluidized bed. Ind. Eng. Chern. Process Des. Dev., 15, 15, 1976. 47-51.

61. ROCHA, M. S.; SIMÕES-MOREIRA, J. R. Void Fraction Measurement and Signal Analysis from Multiple-Electrode Impedance Sensors. Heat Transfer Engineering, 29, 2008. 924-935.

62. GELDART, D. Characterization of fluidized powders. Gas fluidization, 1986. 33-51. 
63. KUNII, D.; LEVENSPIEL, O. Fluidization engineering. Stoneham: Butterworth-Heinemann, 1991.

64. MIYAUCHI, T. et al. Transport phenomena and reaction in fluidized catalyst beds. Adv. Chem. Eng., 11, 1981. 275-448.

65. SQUIRES, A. M.; KWAUK, M.; AVIDAN, A. A. Fluid beds: at last, challenging two entrenched practices. Science 230, 1985. 1329-1337.

66. KIM, S. W. et al. Flow behavior and regime transition in a high-density circulating fluidized bed riser. Chemical Engineering Science, 59, 2004. 3955-3963.

67. BABAEI, B.; ZARGHAMI, R.; SOTUDEH-GHAREBAGH, R. Monitoring of fluidized beds hydrodynamics using recurrence quantification analysis. AIChE Journal: Particle Technology and Fluidization, 59, n. 2, 2013. 399-406.

68. GE, W. et al. Chemical engineeering and chemical process technology - Vol. V - Multi-Scale Modeling. [S.1.]: Encyclopedia of Life Support Systems , 2010.

69. LI, Y.; KWAUK, M. The dynamics of fast fluidization. in Fluidization, 1980. 537-544.

70. GLICKSMAN, L. R. Scaling relationships for fluidized beds. Chem. Engng Sci., 43, 1988. 14191421.

71. TAKENS, F. Detecting strange attractors in turbulence. Springer Lecture Notes in Mathematics 898, 898, 1981. 366-381.

72. SCHOUTEN, J. C. . T. F. . V. D. B. C. M. . Maximum-likelihood estimation of the entropy of an attractor. Physical review E, January 1994.

73. SCHOUTEN, J. C. . T. F. . V. D. B. C. M. . Estimation of the dimension of a noisy attractor. Physical review E, 50, n. 3, September 1994.

74. STEEB, W.-H. The nonlinear workbook. [S.1.]: Third, 2005.

75. CROCKER, M. Thermochemical Conversion of Biomass to Liquid Fuels and Chemicals. [S.1.]: RSC Energy and Environment Series, 2010.

76. IEA, I. E. A. Key World Energy Statistics. [S.1.]. 2014.

77. WANG, W.; LI, J. Modeling of Circulating Fluidized Bed Combustion. In: LACKNER, M.; WINTER, F.; AGARWAL, A. K. Handbook of Combustion. [S.1.]: Wiley-VCH, v. Volume 4: Solid fuels, 2010. Cap. 12, p. 3168.

78. ENGSTROM, F. Development of commercial operation of a circulating fluidized bed combustion system. Proceedings of the 6th International Conference on Fluidized Bed Combustion, Washington D.C., 1980.

79. SYRED, N.; KHALATOV, A. Advanced Combustion and Aerothermal Technologies: Environmental Protection and Pollution Reductions. [S.1.]: Springer, 2007. 
80. OSKARSSON, K. et al. A Planner's Guide for Selecting Clean-coal Technologies for Power Plants. Washington D.C. 1997.

81. LI, Y.; ZHANG, X. Circulating fluidized bed combustion, in Fast Fluidization. In: WEI, J.; KWAUK, M. Advances in Chemical Engineering Series. [S.1.]: Elsevier Science and Technology Books, v. 20, 1994. p. 331-388.

82. BASU, P.; FRASER, S. A. Circulating Fluidized Bed Boilers: Design and Operations. Boston: Butterworth-Heinemann, 1991.

83. MILES, T. R. et al. Alkali deposits found in biomass power plants, a preliminary investigation of their extent and nature. [S.l.]. 1995.

84. REH, L. Development potentials and research needs in circulating fluidized bed combustion. China Particuology, 1, 2003. 185-200.

85. FAN, Z.; ROBERSON, A.; GOIDICH, S. 800 MWe circulating fluidized bed boiler with $1300^{\circ} \mathrm{F}$ supercritical steam. Proceedings of the 33rd International Technical Conference on Coal Utilization and Fuel Systems, Clearwater, Florida, 2008.

86. ZEVENHOVEN, M. et al. The Abo Akademi database-fuel characterization. Toronto, Ontario. 2005.

87. BI, H. T.; GRACE, J. R.; ZHU, J. Types of choking in vertical pneumatic systems. International Journal of Multiphase Flow, 19, 1993. 1077-1092.

88. YANG, W. C. Choking revisited. Industrial and Engineering Chemistry Research, 43, 2004. 5496-5506.

89. REGÓS, G. Comparison of power plants' risks with multi criteria decision models. Central European Journal of Operations Research, 21, December 2013. 845-865.

90. MOOSON, K. Advances in chemical engineering: Fast Fluidization. California: Academic Press, Inc, v. 20, 1994. 94 p.

91. BASU, P. Combustion and Gasification in Fluidized Beds. [S.1.]: Taylor \& Francis Group, 2006.

92. FANG, Y. et al. Experiment and mathematical modeling of a bench-scale circulating fluidized bed gasifier. Fuel Processing Technology, 69, 2001. 29-44.

93. TSUI, H.; WU, C. Operating concept of circulating fluidized bed gasifier from the kinetic point of view. Powder Technology, 132, 2007. 167-183.

94. LUDLOW, J. C.; PANDAY, R.; SHADLE, L. J. Phase-Shift Method to Estimate Solids Circulation Rate in Circulating Fluidized Beds. Ind. Eng. Chem. Res. 52, 2013. 1958-1969.

95. JU, F. et al. Experimental study of a commercial circulated fluidized bed coal gasifier. Gasification: Fundamentals and application, 91, 2010. 818-822. 
96. LEE, G. S.; HAN, G. Y.; KIM, S. D. Coal combustion characteristics in a circulating fast fluidized bed. Korean Journal of Chemical Engineering, 1, n. 1, 1984. 71-76.

97. VAN DER DRIFT, B. Challenges in Biomass Gasification. ECN. Barcelona. 2015.

98. ZHAO, G. B.; YANG, Y. R. Multiscale resolution of fluidized-bed pressure fluctuations. AIChE Journal, 49, 2003. 869-882.

99. TAHMASEBPOUR, M. et al. Characterization of various structures in gas-solid fluidized beds by recurrence quantification analysis. Particuology, 2013. 647-656.

100. WANG, J. S.; COLVER, G. M. Elutriation control and charge measurement of fines in a gas fluidized bed with ac and dc electric fields. Powder Technology, 2003, 135-136, 2003. 169-180.

101. WANG, C. et al. Detailed measurements of particle velocity and solids flux in a high density circulating fluidized bed riser. Chemical Engineering Science, 114, 2014. 9-20.

102. MAKKAWI, Y. T.; WRIGHT, P. C. Fluidization regimes in a conventional fluidized bed characterized by means of electrical capacitance tomography. Chemical Engineering Science, 57, 2002. 2411-2437.

103. GUO, X. et al. Application of a Capacitance Solid Mass Flow Meter in a Dense Phase Pneumatic Conveying System of Pulverized Coal. AIP Conf. Proc., 914, 2007. 320-327.

104. TEBIANIAN, S. et al. Solids flux measurements via alternate techniques in a gas-fluidized bed. Chemical Engineering Journal, 306, 2016. 306-321.

105. JOHNSSON, F. et al. Characterization of fluidization regimes by time-series analysis of pressure fluctuations. International Journal of Multiphase Flow, 26, 2000. 663-715.

106. VAN OMMEN, R. J. et al. Time-series analysis of pressure fluctuations in gas-solid fluidized beds - A review. International Journal of Multiphase Flow, 37, 2011. 403-428.

107. TAHMASEBPOOR, M. et al. Characterization of fluidized beds hydrodynamics by recurrence quantification analysis and wavelet transform. International Journal of Multiphase Flow, 69, 2015. 31-41.

108. BATCHELOR, G. K. An Introduction to Fluid Dynamics. [S.1.]: Cambridge University Press, 2002.

109. SAKAI, M. How Should the Discrete Element Method Be Applied in Industrial Systems?: A Review. KONA Powder and Particle Journal, 33, 2016. 169-178.

110. COLEMAN, G. N.; SANDBERG, R. D. A primer on direct numerical simulation of turbulence - methods, procedures and guidelines. University of Southampton. Southampton, p. 21. 2010.

111. CUNDALL, P. A.; STRACK, O. D. L. A discrete numerical model for granular assemblies. Geotechnique, 29, 1979. 47-65. 
112. MAHMOOD, A. A.; ELEKTOROWICZ, M. A Review of Discrete Element Method Research on Particulate Systems. IOP Conference Series: Materials Science and Engineering, 136, n. 1, 2016. 012034. Disponivel em: <http://stacks.iop.org/1757-899X/136/i=1/a=012034>.

113. ENWALD, H.; PEIRANO, E.; ALMSTEDT, A. Eulerian two-phase flow theory applied to fluidization. International Journal of Multiphase Flow, 22, December 1996. 21-66.

114. ANDERSON, T.; JACKSON, R. Fluid mechanical description of fluidized beds, 6, 1967. 527 539.

115. KUIPERS, J. A. M. et al. Numerical Simulation of Dense Gas-Solid Fluidized Beds: A Multiscale Modeling Strategy. Annu. Rev. Fluid Mech. 40, 2008. 47-70.

116. CABEZAS-GÓMEZ, L.; SILVA, R. C.; MILIOLI, F. E. Some modeling and numerical aspects of the two-fluid simulation of the gas-solids flow in a CFB riser, São Paulo, 23, n. 4, Oct 2006. 487-496.

117. DELHAYE, J. M. Jump conditions and entropy sources in two-phase systems. Local, 1, 1974. 395-409.

118. ISHII, M.; HIBIKI, T. Thermo-Fluid Dynamics of Two-Phase Flow. Second Edition. ed. New York: Springer, 2011.

119. DelhaYe, J. M.; GOIT, M.; RIETHMUlleR, M. L. Thermohydraulics of Two-phase Systems for Industrial Design and Nuclear. New York: McGraw Hill, 1981.

120. DREW, D. A.; LAHEY, R. T. Analytical modeling of multiphase flow. In: ROCO, M. C. Particulate Two-phase Flow. Boston: Butterworth-Heinemann, 1993. Cap. 16.

121. SAVAGE, S. B.; JEFFREY, D. J. The stress tensor in a granular flow at high shear rates, 110, 1981. 255-272.

122. HWANG, G. J.; SHEN, H. H. Modelling the solids phase stress in a fluid-solid mixture, 15, 1989. 257-268.

123. FRANKEL, N. A.; ACRIVOS, A. On the viscosity of a concentrated suspension of solid spheres, 1967, 22. 847-853.

124. BRINKMAN, H. C. The viscosity of concentrated suspensions and solutions, 20, 1952. 571-573.

125. ROSCOE, R. The viscosity of suspensions of rigid spheres, 3, 1952. 267-269.

126. PANTON, R. L. Incompressible Flow. New York: Wiley, 1984.

127. CAMPBELL, C. S.; WANG, D. G. Particle pressure in gas-fluidized beds, 227, 1991. 495-598.

128. MASSOUDI, M. et al. Remarks on the modelling of fluidized systems, 38, 1992. 471-472.

129. SCHILLER, L.; NAUMANN, A. A drag coefficient correlation, 77, 1935. 318-320. 
130. LI, T. et al. CFD simulations of circulating fluidized bed risers, part I: Grid study. Powder Technology, 254, Março 2014. 170-180.

131. LI, T.; PANNALA, S.; SHAHNAM, M. CFD simulations of circulating fluidized bed risers, part II, evaluation of differences between 2D and 3D simulations. Powder Technology, 254, 2014. $115-124$.

132. PLACKO, D. Fundamentals of Instrumentation and Measurement. Newport Beach: ISTE, 2007.

133. NI, N. I. M Series User Manual: NI 622x, NI 625x, and NI 628x Devices. National Instruments, 2 Fevereiro 2016. Disponivel em: 〈http://www.ni.com/pdf/manuals/371022k.pdf>.

134. WEG, W. M. Inversor de Frequência. manual do usuário CFW-08, 2012. Disponivel em: $<$ http://ecatalog.weg.net/files/wegnet/WEG-cfw-08-inversor-de-frequencia-wash-10000154548guia-rapido-portugues-br.pdf $>$. Acesso em: 2016.

135. SMITH, S. W. The Scientist and Engineer's Guide to Digital Signal Processing. Second. ed. San Diego: California Technical Publishing, 1999.

136. LI, W. et al. Flow regime identification in a three-phase bubble column based os statistical, Hurst, Hilbert-Huang transform and Shannon entropy analysis. Chemical Engineering Science, 102, 2013. 474-485.

137. SASIC, S.; LECKNER, B.; JOHNSSON, F. Characterization of fluid dynamics of fluidized beds by analysis of pressure fluctuations. Progress in energy and combustion science, 33, 2007. 453496.

138. BI, H. T. A critical review of the complex pressure fluctuation phenomenon in gas-solids fluidized beds. Chemical engineering science, 62, 2007. 3473-3493.

139. MONTEIRO, L. H. A. Sistemas dinâmicos. $2^{a}$ Edição. ed. São Paulo: Editora Livraria da Física, 2006.

140. HOLDEN, A. V. Chaos. New Jersey: Princeton University Press, 1986.

141. WHITNEY, H. Differentiable Manifolds. Annals of Mathematics, Second Series, 37, July 1936. 645-680.

142. SAUER, T. Chaotic itinerancy based on attractors of one-dimensional maps. Chaos: an interdisciplinary Journal of Nonlinear Science - AIP, 13, 2003. 947-952.

143. HAMILTON, F.; BERRY, T.; SAUER, T. Predicting chaotic time series with a partial model. PHYSICAL REVIEW E, 92, 2015.

144. KIEN, N. S. State space reconstruction. Seminar Takens, 2013. Disponivel em: <http://eceresearch.unm.edu/chaouki/PAPERS/Journals/CSM-Delay-NIculescu/References/Takensresults/seminar-takens.pdf>. Acesso em: 11 Setembro 2016. 
145. FRASER, A. M.; SWINNEY, H. L. Independent coordinates for strange attractors from mutual information. Phys Rev A Gen Phys., 33, 1986. 1134-1140.

146. MANDELBROT, B. B. The fractal geometry of nature. New York: W. H. Freeman and Copany, 1982.

147. CAMPOS, A. C. Animated fractal mountain. Wikimedia Commons, 2006. Disponivel em: <https://commons.wikimedia.org/wiki/File:Animated_fractal_mountain.gif>. Acesso em: 2016.

148. CORANA, A.; ROLANDO, C. An optimized direct algorithm to estimate the Kolmogorov entropy from a time series. Physics Letters A, 207, 1995. 77-82.

149. GRASSBERGER, P. Estimating the fractal dimensions and entropies of strange attractors. In: HOLDEN, A. V. Chaos, nonlinear science: Theory and applications. Princeton: Princeton U. Press, 1986. Cap. 14, p. 291-311.

150. THEILER, J. Estimating the Fractal Dimension of Chaotic Time Series. The Lincoln Laboratory Journal, Volume 3, Number 1, 1990.

151. HURST, H. E. The Long-Term Storage Capacity of Reservoirs. Transactions of the American Society of Civil Engineers vol. 116, 1951. 770-799.

152. ESQUEMBRE, F. Brownian motion large.gif. Wikipédia, 2012. Disponivel em: <https://pt.wikipedia.org/wiki/Ficheiro:Brownian_motion_large.gif >. Acesso em: Outubro 2016.

153. PEITGEN, H. O.; SAUPE, D. The Science of Fractal Images. New York: Springer-Verlag, 1988.

154. AGUIRRE, L. A. Introdução à identificação de sistemas - técnicas lineares e não lineares: Teoria e aplicação. 4a . ed. Belo Horizonte: Editora UFMG, 2015.

155. GARCIA, C. Modelagem e simulação. São Paulo: Edusp, 2005.

156. VAN DER HOEF, M. A. et al. Numerical simulation of dense gas-solid fluidized beds: a multiscale modeling strategy. Annual Review of Fluid Mechanics, 40, Janeiro 2008. 47-70.

157. FIORILLO, D. A. et al. Projeto de fluidizador em escala laboratorial, 2015.

158. SHAKOURZADEH, P. Ergun 6.2: User's Manual. Revised November. ed. [S.l.]: [s.n.], 2006.

159. ZENZ, F. A.; WEIL, N. A. A Theoretical-Empirical Approach to the Mechanism of Particle Entrainment from Fluidized Beds. AIChE Journal, 4, 1958. 472.

160. VAN DER MEER, E. H.; THORPE, R. B.; DAVIDSON, J. F. The Influence of Exit Geometry for a Circulating Fluidized Bed With a Square Cross-Sectional Riser. Circulating Fluidized Bed Technology, V, 1997. 575-580.

161. WEN, C. Y.; CHEN, L. H. Fluidized Bed Freeboard Phenomena: Entrainment and Elutriation. AIChE Journal, 28, 1982. 
162. BAI, D. et al. Characterization of Gas Fluidization Regimes Using Pressure Fluctuations. Powder Technology, Canadá, Agosto 1995.

163. ELLIS, N. et al. Characterization of dynamic behaviour in gas-solid turbulent fluidized bed using chaos and wavelet analyses. Chemical Engineering Journal, Canadá, 2003.

164. ALBERTO, C.; FELIPE, S.; ROCHA, S. C. S. Time Series Analysis of Pressure Fluctuation in Gas-Solid Fluidized Beds. Brazilian Journal of Chemical Engineering, São Paulo, 21, Junho 2004.

165. LETZEL, H. M. et al. Characterization of Regimes and Regime Transitions in Bubble Columns by Chaos Analysis of Pressure Signals. Chemical Engineering Science, Holanda, 1997.

166. LLAURÓ, F. X.; LLOP, M. F. Characterization and classification of fluidization regimes by nonlinear analysis of pressure fluctuations. International Journal of Multiphase Flow, Girona, Junho 2006.

167. AZIZPOUR, H. et al. Characterization of Regime Transition in Fluidized Beds at High Velocities by Analysis of Vibration Signals. Industrial \& Engineering Chemistry Research, Irã, 2012.

168. SUTKAR, V. S. et al. Experimental investigations of a pseudo-2D spout fluidized bed with draft plates. Chemical engineering science, 102, 2013. 524-543.

169. MA, J.; LIU, D.; CHEN, X. Bubble Behaviors of Large Cohesive Particles in a 2D Fluidized Bed. Industrial and Engineering Chemistry Research, 55, Janeiro 2016. 624-634.

170. HAMZEHEI, M.; RAHIMZADEH, H.; AHMADI, G. Computational and experimental study of heat transfer and hydrodynamics in a $2 \mathrm{D}$ gas-solid fluidized bed reactor. Industrial and Engineering Chemistry Research, 49, n. 11, Junho 2010. 5110-5121.

171. KRAMBECK, F. J. et al. Predicting Fluid-Bed Reactor Efficiency Using Adsorbing Gas Tracers. AIChE J., 33, 1987. 1727-1734.

172. PANDAY, R. et al. Challenge problem: 1 . Model validation of circulating fluidized beds. Powder Technology, 258, 2014. 370-391.

173. PEDROSO, F. A.; ZINANI, F.; INDRUSIAK, M. L. S. Numerical study of circulating fluidized beds built using Glicksman's simplified and full sets of scaling parameters. The Brazilian Society of Mechanical Sciences and Engineering, Fevereiro 2016. 14.

174. SYAMLAL, M.; ROGERS, W.; O'BRIEN, T. J. MFIX Documentation: Theory Guide. NETL. [S.1.], p. 57. 1993.

175. NETL, N. E. T. L. MFIX 2015-1 User Guide: Open source multiphase flow modeling for realworld applications. National Energy Technology Laboratory. [S.1.], p. 123. 2015.

176. GASKELL, P. H.; LAU, A. K. C. Curvature-compensated convective transport: SMART, a new boundedness-preserving transport algorithm. Int. J. Numer. Methods in Fluids, 8, 1988. 617641. 
177. ASTE, T. Generalized Hurst exponent. Mathworks, 2011. Disponivel em: <https://www.mathworks.com/matlabcentral/fileexchange/30076-generalized-hurst-exponent $>$. Acesso em: Janeiro 2016.

178. SCHOUTEN, J. C.; VAN DEN BLEEK, C. M. RRCHAOS, a software package for analysis of (experimental) chaotic times series. Reactor Research Foundations, Netherland, 1994.

179. MAURÍCIO, P. et al. Um algoritmo para dimensionamento de ciclones. Revista da Faculdade de Ciência e Tecnologia, Porto, 3, 2006. 40-51. Disponivel em: <http://bdigital.ufp.pt/handle/10284/539>. Acesso em: 2016.

180. TONG, H. et al. Hydrodynamic modeling of the L-valve. Powder Technology, 129, 2003. 8-14.

181. ARENA, U.; LANGELI, C. B.; A., C. L-valve behaviour with solids of different size and density. Powder Technology, 98, 1998. 231-240.

182. HEGGER, R.; KANTZ, H.; SCHREIBER, T. Nonlinear Time Series Analysis. TISEAN 3.0.1, 1999. Disponivel em: <http://www.mpipks-dresden.mpg.de/ tisean/Tisean_3.0.1/index.html>. Acesso em: Janeiro 2016.

183. DAVISON, B. Mathworks. Community, 1994. Disponivel em: <https://www.mathworks.com/matlabcentral/fileexchange/9842-hurst-exponent>. Acesso em: Janeiro 2016.

184. ASTE, T. Mathworks. Community, 1994. Disponivel em: <https://www.mathworks.com/matlabcentral/fileexchange/30076-generalized-hurst-exponent $>$. Acesso em: Janeiro 2016.

185. MORI, H.; KURAMOTO, Y. Dissipative Structures and Chaos. Tokyo: Springer, 1997.

186. SMITH, C. A.; CORRIPIO, A. B. Princípios e Prática do Controle Automático do Processo. [S.1.]: LTC, 2008. 